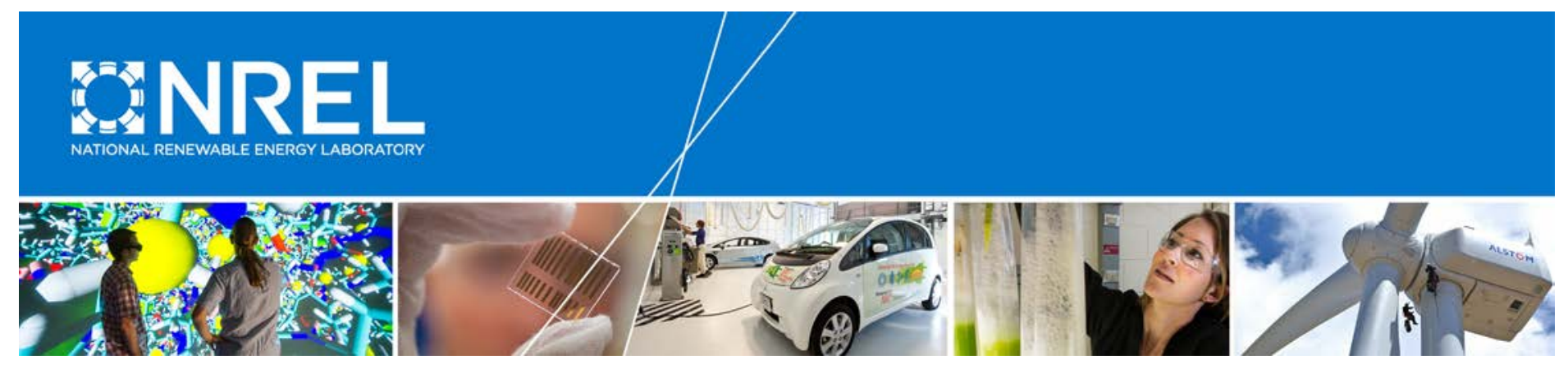

\title{
Electricity Generation Baseline Report
}

Jeffrey Logan, Cara Marcy, James McCall, Francisco Flores-Espino, Aaron Bloom, Jørn Aabakken, Wesley Cole, Thomas Jenkin, Gian Porro, and Chang Liu National Renewable Energy Laboratory

Francesco Ganda Argonne National Laboratory

Richard Boardman Idaho National Laboratory

Thomas Tarka, John Brewer, and Travis Schultz National Energy Technology Laboratory

NREL is a national laboratory of the U.S. Department of Energy Office of Energy Efficiency \& Renewable Energy Operated by the Alliance for Sustainable Energy, LLC

This report is available at no cost from the National Renewable Energy Laboratory (NREL) at www.nrel.gov/publications.

Technical Report

NREL/TP-6A20-67645

January 2017

Contract No. DE-AC36-08G028308 


\section{Electricity Generation Baseline Report}

Jeffrey Logan, Cara Marcy, James McCall, Francisco Flores-Espino, Aaron Bloom, Jørn Aabakken, Wesley Cole, Thomas Jenkin, Gian Porro, and Chang Liu National Renewable Energy Laboratory

Francesco Ganda

Argonne National Laboratory

Richard Boardman Idaho National Laboratory

Thomas Tarka, John Brewer, and Travis Schultz National Energy Technology Laboratory

Prepared under Task No. EP42.0401

NREL is a national laboratory of the U.S. Department of Energy Office of Energy Efficiency \& Renewable Energy Operated by the Alliance for Sustainable Energy, LLC

This report is available at no cost from the National Renewable Energy Laboratory (NREL) at www.nrel.gov/publications.

National Renewable Energy Laboratory 15013 Denver West Parkway Golden, CO 80401 303-275-3000 • www.nrel.gov
Technical Report

NREL/TP-6A20-67645

January 2017

Contract No. DE-AC36-08G028308 


\section{NOTICE}

This report was prepared as an account of work sponsored by an agency of the United States government. Neither the United States government nor any agency thereof, nor any of their employees, makes any warranty, express or implied, or assumes any legal liability or responsibility for the accuracy, completeness, or usefulness of any information, apparatus, product, or process disclosed, or represents that its use would not infringe privately owned rights. Reference herein to any specific commercial product, process, or service by trade name, trademark, manufacturer, or otherwise does not necessarily constitute or imply its endorsement, recommendation, or favoring by the United States government or any agency thereof. The views and opinions of authors expressed herein do not necessarily state or reflect those of the United States government or any agency thereof.

This report is available at no cost from the National Renewable Energy Laboratory (NREL) at www.nrel.gov/publications.

Available electronically at SciTech Connect http:/www.osti.gov/scitech

Available for a processing fee to U.S. Department of Energy and its contractors, in paper, from:

U.S. Department of Energy

Office of Scientific and Technical Information

P.O. Box 62

Oak Ridge, TN 37831-0062

OSTI http://www.osti.gov

Phone: 865.576.8401

Fax: 865.576.5728

Email: reports@osti.gov

Available for sale to the public, in paper, from:

U.S. Department of Commerce

National Technical Information Service

5301 Shawnee Road

Alexandria, VA 22312

NTIS http://www.ntis.gov

Phone: 800.553 .6847 or 703.605 .6000

Fax: 703.605.6900

Email: orders@ntis.gov 


\section{Acknowledgments}

The authors wish to thank the Baseline Generation Team at the Office of Energy Policy and System Analysis (EPSA) in the U.S. Department of Energy (DOE) for the sponsorship and guidance on this work. Rob Anderson, Carol Battershell, Aaron Bergman, Erin Boyd, Alex Breckel, Hugh Chen, Christina Cody, Carla Frisch, Liz Hartman, Eric Hsieh, Emily Lewis, Larry Mansueti, Josh Olazabal, Jeanette Pablo (team lead), Lara Pierpoint, John Richards, and Robert Schmitt provided helpful feedback and advice during the process of producing this report. We also thank Michelle Dallafior (Office of Electricity Delivery and Energy Reliability), Paul Donohoo-Vallet (Office of Energy Efficiency and Renewable Energy), Sarah Forbes (Office of Fossil Energy), Michael Goff (Office of Nuclear Energy), Lindsey Griffith (EPSA), Elke Hodson (EPSA), Jordan Kislear (Office of Fossil Energy), Steve Lindenberg (Office of Energy Efficiency and Renewable Energy), Timothy Reinhardt (Office of Energy Efficiency and Renewable Energy), Margaret Schaus (Office of Fossil Energy), and Bradley Williams (Office of Nuclear Energy) for interim feedback and review.

We also appreciate the critical reviews by the following individuals and organizations, which improved and informed the analysis contained herein: Michelle Melton (Center for Strategic and International Studies), Karl Hausker (World Resources Institute), Manuel Baritaud (International Energy Agency), Doug Smith and Sue Sheridan (Van Ness Feldman), and many individuals from the Electric Power Research Institute.

Any remaining errors, omissions, or mischaracterizations are the responsibility of the authors. 


\section{Scope and Organization}

This report was developed by a team of national laboratory analysts over the period October 2015 to May 2016 and is part of a series of studies that provide background material to inform development of the second installment of the Quadrennial Energy Review (QER 1.2). The report focuses specifically on U.S. power sector generation. The report limits itself to the generation sector and does not address in detail parallel issues in electricity end use, transmission and distribution, markets and policy design, and other important segments.

Chapter 1 provides a brief introduction to the report.

Chapter 2 of the report focuses on the main drivers of change, as well as future uncertainties, in the U.S. generation sector. These include the impact of low natural gas prices; the rise of renewable and distributed generation; recent Federal and State policies impacting generation; the decoupling of gross domestic product (GDP), electricity demand, and greenhouse gas (GHG) emissions; and the electrification of the transportation sector.

Chapter 3 discusses crosscutting metrics and trends in the U.S. generation sector. These attributes include generation roles, capacity factors and heat rates, costs, sustainability characteristics, ownership types, and Federal policy.

Chapter 4 describes recent trends in power generation, focusing on the national and regional levels at the North American Electric Reliability Corporation (NERC) boundaries.

Chapters 5 through 13 focus on individual generation technologies and provide information on technology cost and performance trends, fuel supply, environmental impacts, constraints, existing deployment metrics, and policy and regulatory drivers that have impacted deployment and could affect future development.

Appendix A contains additional information about each generation technology. Appendix B contains details on the levelized cost of electricity (LCOE) methodology used in chapter 3 and throughout. 


\section{Abbreviations}

$\mathrm{AC}$

AEO2015

AMD

Btu

BWR

$\mathrm{CC}$

$\mathrm{CCS}$

$\mathrm{CO}_{2}$

CPP

CSP

CT

CWIP

DC

DOE

EGS

EIA

EOR

EPA

EPRI

EPSA

ERCOT

EV

FERC

FORGE

FRCC

GDP

GHG

GW

GWd/MTU

GWe

GWh

HOGR

IEA

IGCC

IGCC-CCS

IOU

ITC

$\mathrm{kW}$

$\mathrm{kWh}$

LACE

LBNL

LCOE alternating current

Annual Energy Outlook 2015

acid mine drainage

British thermal unit

boiling water reactors

combined cycle

carbon capture and storage

carbon dioxide

Clean Power Plan

concentrating solar power

combustion turbine

construction work in progress

direct current

U.S. Department of Energy

enhanced geothermal systems

U.S. Energy Information Administration (DOE)

enhanced oil recovery

U.S. Environmental Protection Agency

Electric Power Research Institute

Office of Energy Policy and Systems Analysis

(DOE)

Electric Reliability Council of Texas

electric vehicle

U.S. Federal Energy Regulatory Commission

Frontier Observatory for Research in Geothermal Energy

Florida Reliability Coordinating Council

gross domestic product

greenhouse gas

gigawatt

gigawatt-days per metric ton uranium

gigawatt electrical

gigawatt-hour

High Oil and Gas Resource

International Energy Agency

integrated gasification combined cycle

integrated gasification combined cycle-carbon

capture and storage

investor-owned utility

investment tax credit

kilowatt

kilowatt-hour

levelized avoided cost of electricity

Lawrence Berkeley National Laboratory

levelized cost of electricity 
LFG

LWR

MHK

MISO

MMBtu

MRO

MSW

MW

MWe

MWh

NERC

NGCC

NGCT

NMVOC

$\mathrm{NO}_{\mathrm{x}}$

NREL

NPCC

NYISO

O\&M

ORNL

PC

PEV

PJM

PMA

PPA

$\mathrm{PSH}$

PTC

PURPA

PV

PWR

QER

R\&D

RFC

RDD\&D

RPS

RTO/ISO

SERC

SMR

$\mathrm{SO}_{\mathrm{x}}$

SPP

ST

Syngas

TRE landfill gas

light water reactor

marine and hydrokinetic

Mid-Continent Independent System Operator

million British thermal unit

Midwest Reliability Organization

municipal solid waste

megawatt

megawatt electrical

megawatt-hour

North American Electric Reliability Corporation

natural gas combined cycle

natural gas combustion turbine

non-methane volatile organic compound

nitrogen oxides

National Renewable Energy Laboratory

Northeast Power Coordinating Council

New York Independent System Operator

operation and maintenance

Oak Ridge National Laboratory

pulverized coal

plug-in electric vehicle

Pennsylvania, New Jersey, Maryland

Interconnection

Power Marketing Administration

power purchase agreement

pumped storage hydroelectric

production tax credit

Public Utilities Regulatory Policy Act of 1978

photovoltaics

pressurized water reactor

Quadrennial Energy Review

research and development

ReliabilityFirst Corporation

research, development, demonstration, and

deployment

renewable portfolio standards

Regional Transmission Organization/Independent

System Operator

SERC Reliability Corporation

small modular reactor

sulfur oxides

Southwest Power Pool

steam turbine

synthesis gas

Texas Reliability Entity 
TVA

TWh

VER

WECC

WEO

WWTP
Tennessee Valley Authority

terawatt-hour

variable energy resource

Western Electricity Coordinating Council

World Energy Outlook

waste water treatment plant 


\section{Executive Summary}

The share of electricity generation in the United States from different sources has arguably changed more rapidly since 2007 than at any time since 1950. At least three trends are catalyzing these changes: (1) the low price of natural gas; (2) the rise in renewable and distributed generation due to falling costs; and (3) recent Federal and State policies impacting generation. Understanding these trends and phenomena in the context of the history of generation, potential for additional generation, constraints, and comparative characteristics that drive generation investment is essential to identifying policies and measures that will facilitate the development of a generation fleet that meets U.S. objectives for the $21^{\text {st }}$ century. These objectives include reliability, resiliency, affordability, cleanliness, and climate goals as articulated by various stakeholders including business as well as state and local governments.

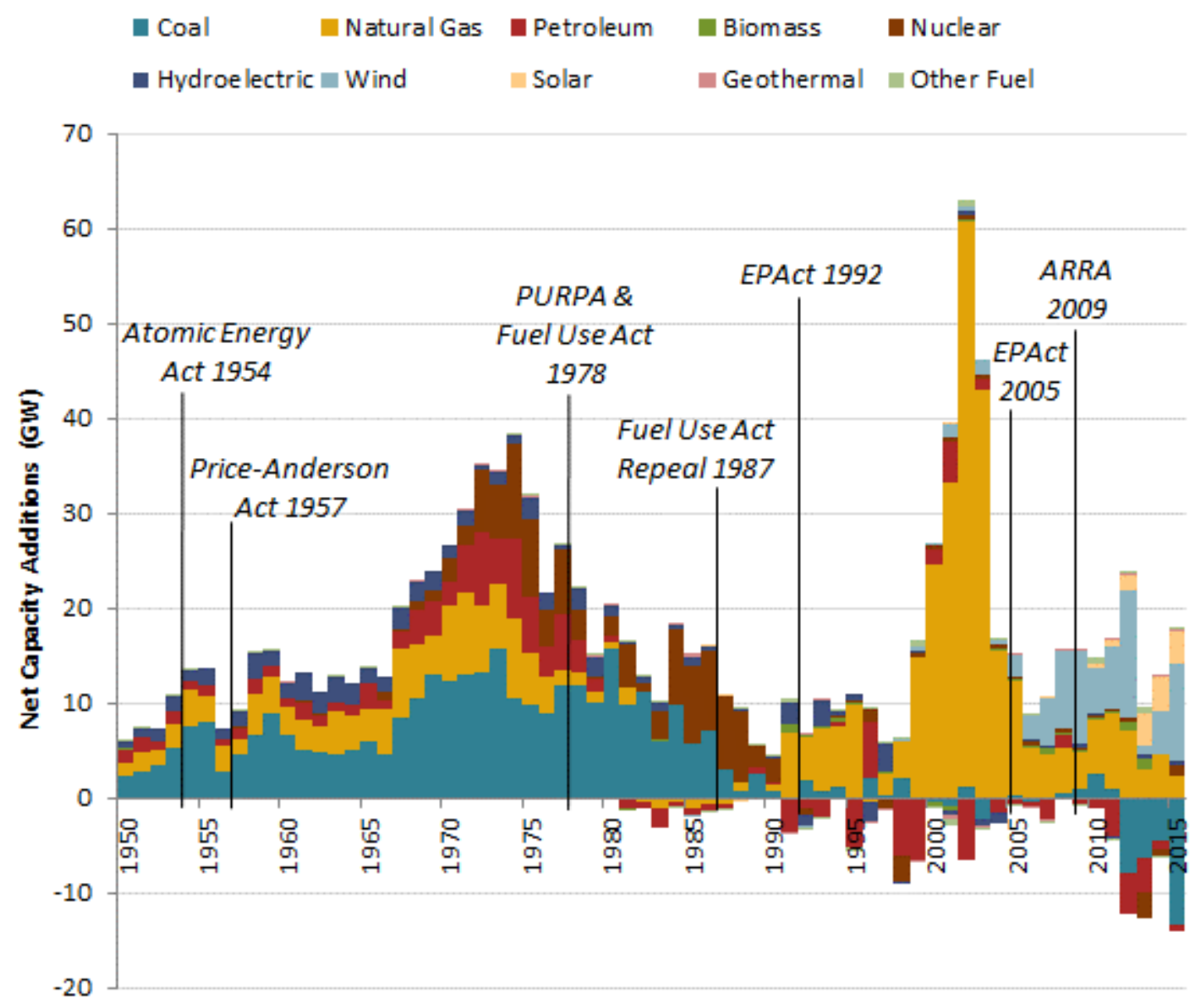

Figure ES-1. Net capacity additions (GW) by fuel type, 1950-2015

Capacity additions came in waves that were largely influenced by policy and technology. The 1930s and 1940s fostered the development of hydropower; nuclear power boomed in the 1960s and 1970s; natural gas additions peaked in the 2000s; and non-hydro renewables have grown since 2005. Sources: EIA 1990 and EIA $2016^{1}$.

Set forth below are 15 key findings and supporting information derived from this report. 
1. Diversity is a key attribute of electricity generation in the United States, but rather than being the result of a deliberative, long-term national initiative, this diversity has developed through growth spurts of specific generation technologies at different times, often due to a confluence of policies, historic events, capital cost, fuel cost, and technological advancements ${ }^{2}$.

A. As shown in Figure ES-1, most generation sources have experienced eras of significant capacity growth: hydro (1930-1950, not shown); coal (1950-1985); nuclear (1960-1980); natural gas (1990-2010); and renewables (2005-present).

2. The national generation mix has transitioned over the past few decades, and continuing significant changes are projected. The U.S. generation fleet is transitioning from one dominated by centralized generators with high inertia and dispatchability to one that is more hybridized, relying on a mixture of traditional, centralized generation and variable utility-scale and distributed renewable generation ${ }^{3}$.

A. From 2005 to 2015 , the generation mix has changed significantly. In 2005, the top six generation sources in descending order were coal, nuclear, gas, hydro, petroleum, and non-hydro renewables. By 2015, gas and coal were tied at the top, followed by nuclear, non-hydro renewables, hydro, and petroleum (Figure ES-2 and Figure ES-3).

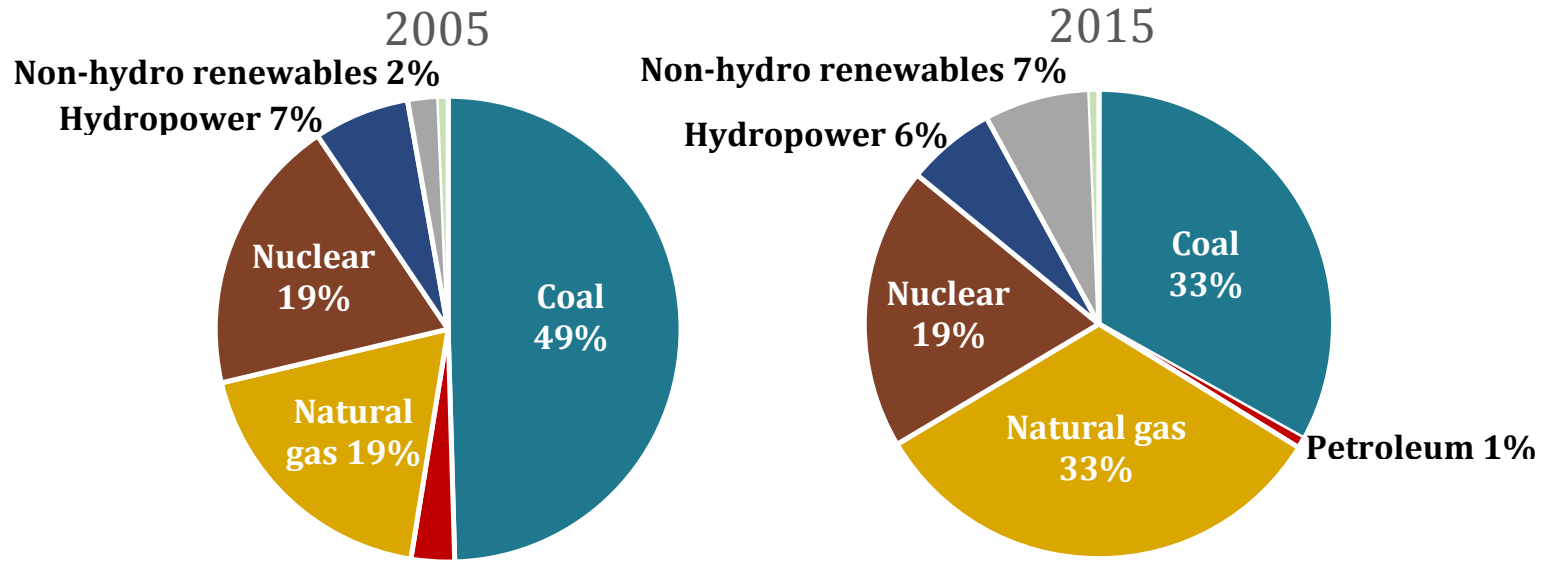

Petroleum 3\%

Figure ES-2. Annual net generation from all sectors

Natural gas and non-hydro renewable generation grew from 2005 to 2015, while coal and petroleum generation decline. Source: EIA $2016^{4}$ 


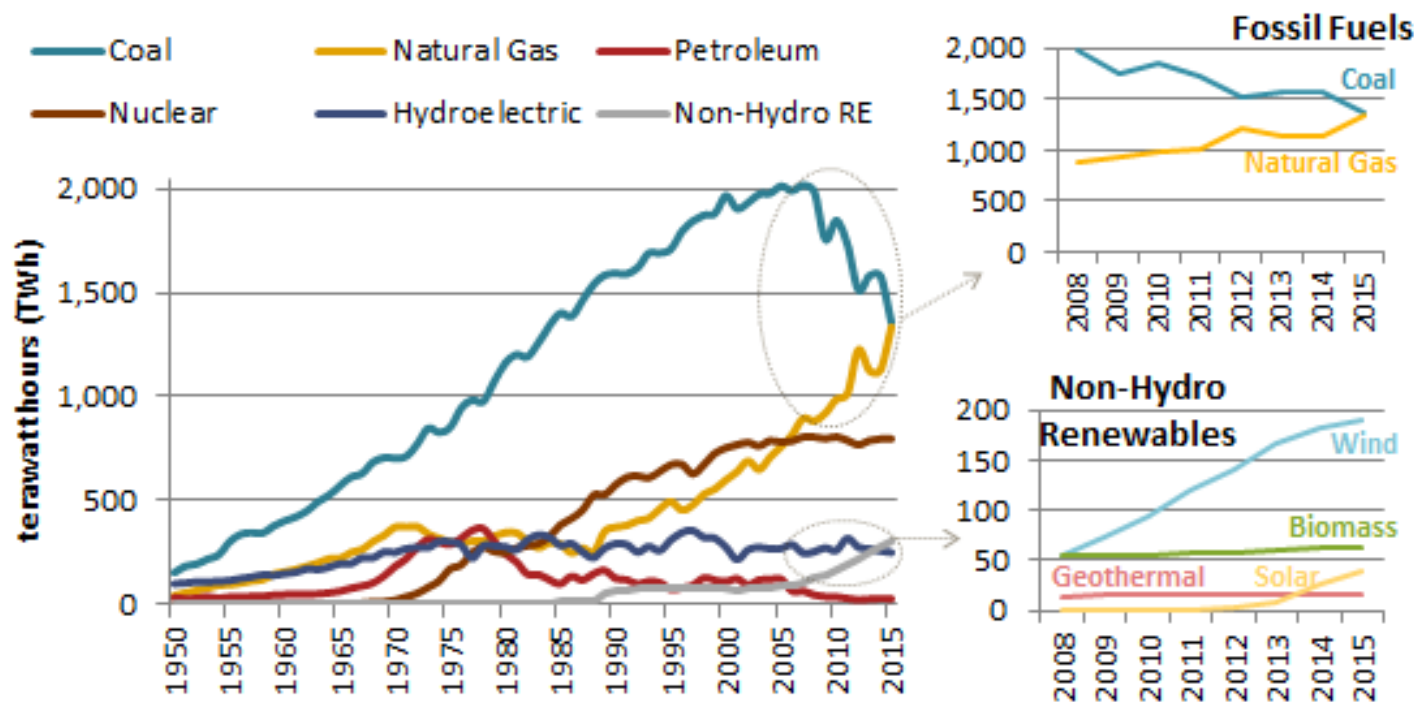

Figure ES-3. Annual generation from select technologies in the United States, 1950-2015 (left), and generation from coal and natural gas (right-top) and non-hydro renewables (right-bottom), 2008-2015.

Coal generation began to decline in 2007, and has largely been replaced by natural gas. Although solar ${ }^{\mathrm{i}}$ and wind make up a much smaller portion of total generation, these technologies have also seen significant growth since 2008 . Sources: EIA $2016^{5}$.

3. Retail electricity prices have risen over time but have grown more slowly than prices for other essentials for quality of life (Figure ES-4). The costs of production, however, can vary significantly among generation sources.

\footnotetext{
${ }^{\mathrm{i}}$ Note that solar data started including generation from distributed PV resources in 2014.
} 


\section{Comparison of Electricity and Other Consumer Price Trends}

(1970 to 2015)

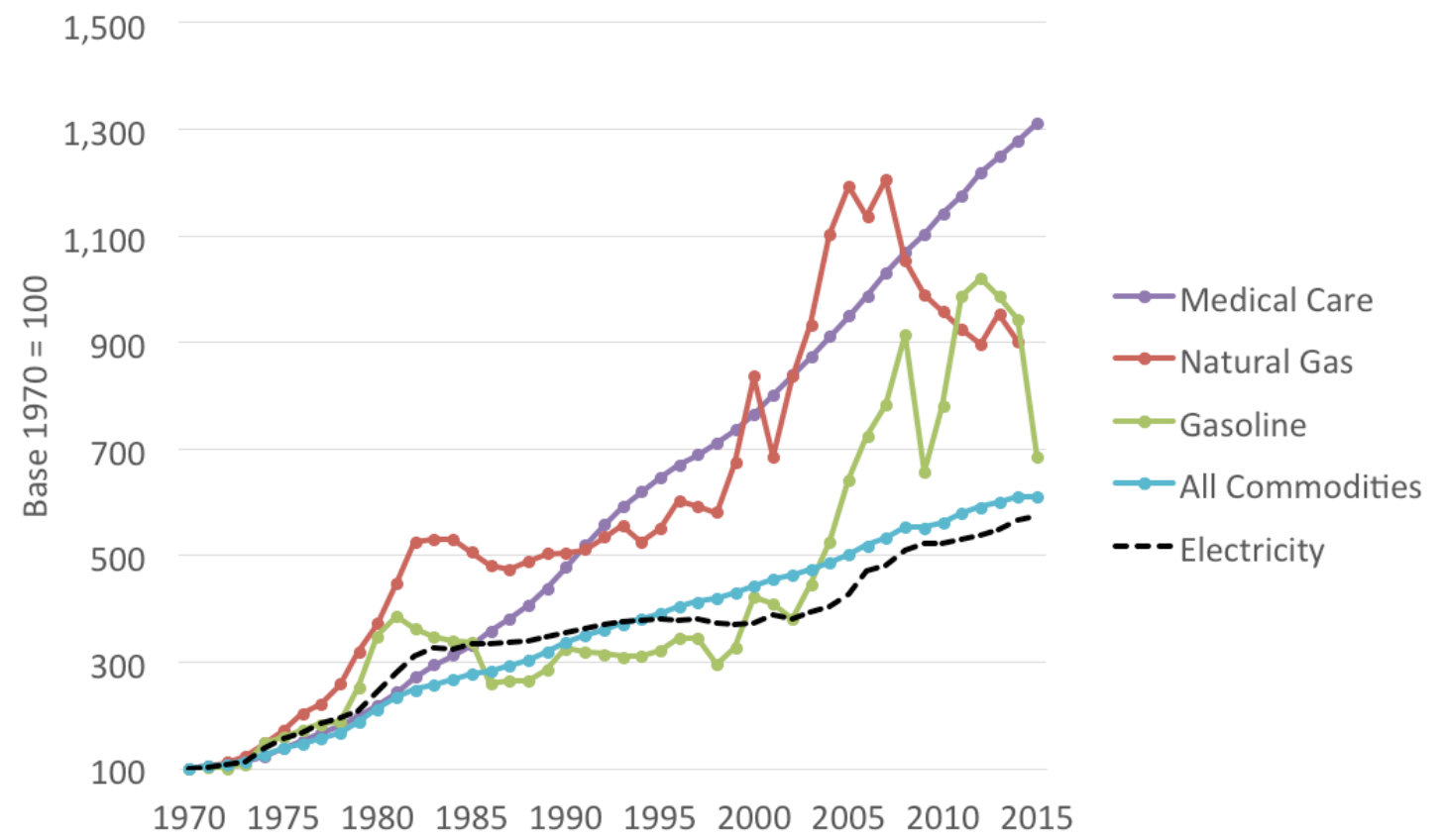

Figure ES-4. Comparison of electricity, natural gas, gasoline, medical care, and all commodities prices, $1970-2015(1970 \$)$

Electricity prices have risen over time, but less in comparison to other commodities. Source: EIA 2016 and BLS $2016^{6}$

4. Ownership can be a factor in whether Federal and State policies drive capacity additions because incentives and regulatory treatment vary depending on the type of ownership. It should be noted, however, that ownership itself is impacted by federal policy.

A. Federal utilities are not subject to State law; municipally and cooperative-owned utilities often receive different treatment than investor-owned utilities (IOUs) in Federal and State regulations, including eligibility for tax credits for solar and wind. As a result, these entities often use different financing mechanisms as well.

B. Ownership impacts management, rate setting, financing, and tax status.

C. The Federal Government owns $49 \%$ of hydropower capacity, but many of the hydropower dams are multipurpose.

D. Examples of ownership created by Federal policy include The Tennessee Valley Authority Act of 1933 and the Public Utility Regulatory Policies Act.

5. Regional generation mixes vary significantly from the national mix. Based on announced additions and retirements, there appears to be no trend toward declining regional variation $^{7}$.

A. The Florida Reliability Coordinating Council (FRCC) and the Midwest Reliability Organization (MRO) vary greatly from the national generation portfolio, with significant differences between them (Figure ES-5). In FRCC, 60\% of generation 
came from natural gas, $24 \%$ from coal, and $12 \%$ from nuclear in 2014 . That same year, the MRO generated $60 \%$ of electricity from coal, $15 \%$ from wind, and $13 \%$ from nuclear. Nationally, the greatest contribution to the generation portfolio in 2015 was from coal at $33 \%$, a proportion significantly less than the largest source in these regions (Figure ES-2).

B. The Western Electricity Coordinating Council (WECC) has the highest share of renewable capacity and generation among NERC regions. WECC has some of the highest shares of hydro generation, at 22\% (Figure ES-6). The region's primary fuel source is natural gas, which represented $30 \%$ of generation in 2014 . WECC has the most diverse portfolio (measured by HH Index ${ }^{i i}$ ) at 0.22 , with eight generation sources contributing $2 \%$ or greater to the portfolio. Nationally, the $\mathrm{HH}$ Index of the generation portfolio is 0.26 , where a lower number indicates a more diverse portfolio.

C. The SERC Reliability Corporation (SERC) is the only region with new nuclear capacity expected to come online in the near term (2016-2020), with over 5 gigawatts (GW) expected by roughly 2020 (Figure ES-7).
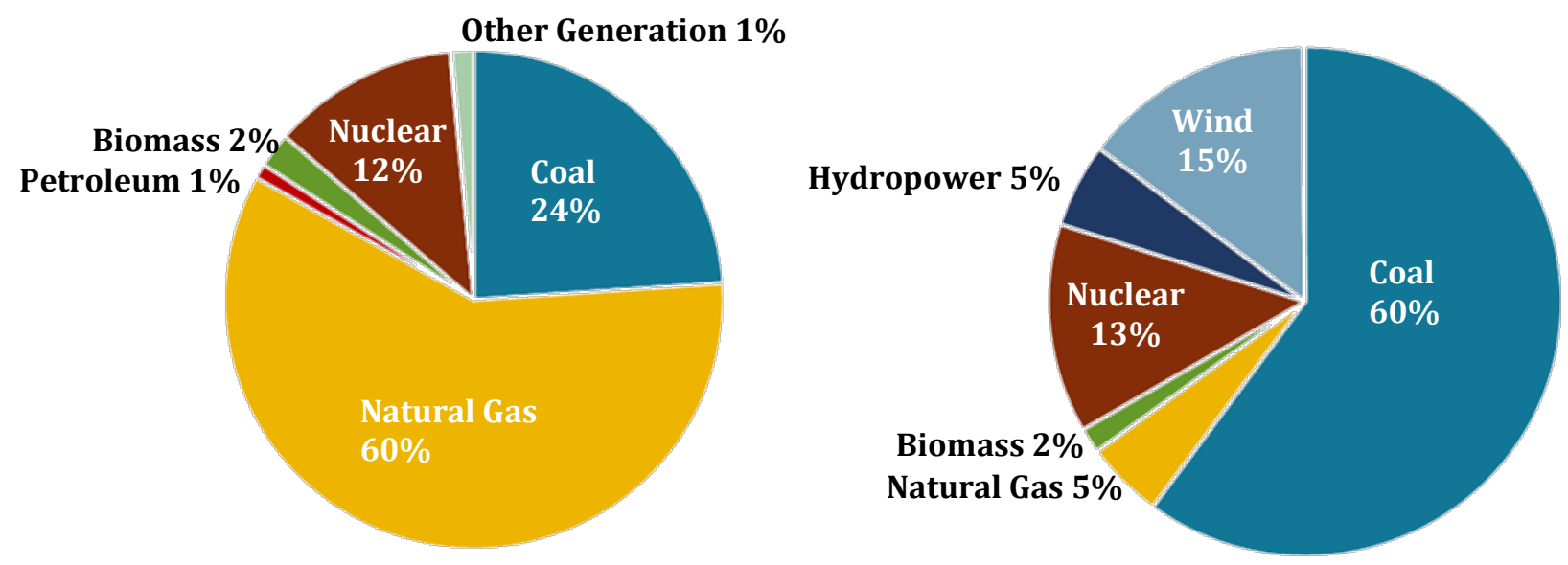

Figure ES-5. Percentage of generation by fuel, 2014: FRCC (left); MRO (right)

In FRCC, $60 \%$ of generation came from natural gas, while MRO generated $60 \%$ of electricity from coal. Nationally, the greatest contribution in 2014 was from coal at 39\%, significantly less than the largest source in these regions. Source: SNL $2015^{8}$.

\footnotetext{
${ }^{i i} \mathrm{HH}$ Index is a market concentration measure used by regulators such as the U.S. Department of Justice to determine whether individual companies have a large enough market share to exert control over prices. It is calculated as the sum of the squares of all of the markets shares of each company within a market.
} 


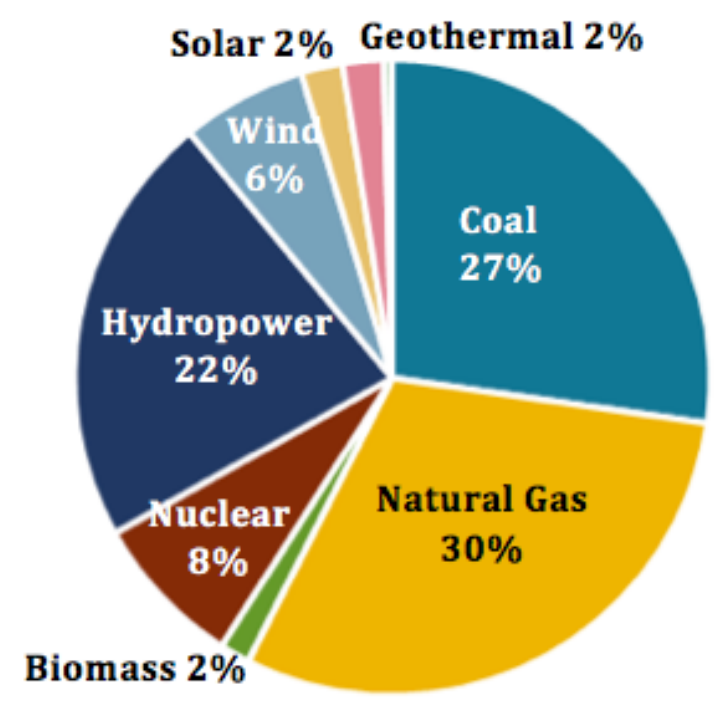

Figure ES-6. Percentage of generation by fuel in 2014 in the WECC region

In 2014, WECC had the most diverse generation portfolio, with eight generation sources contributing $2 \%$ or greater to the portfolio. Source: SNL $2015^{9}$.

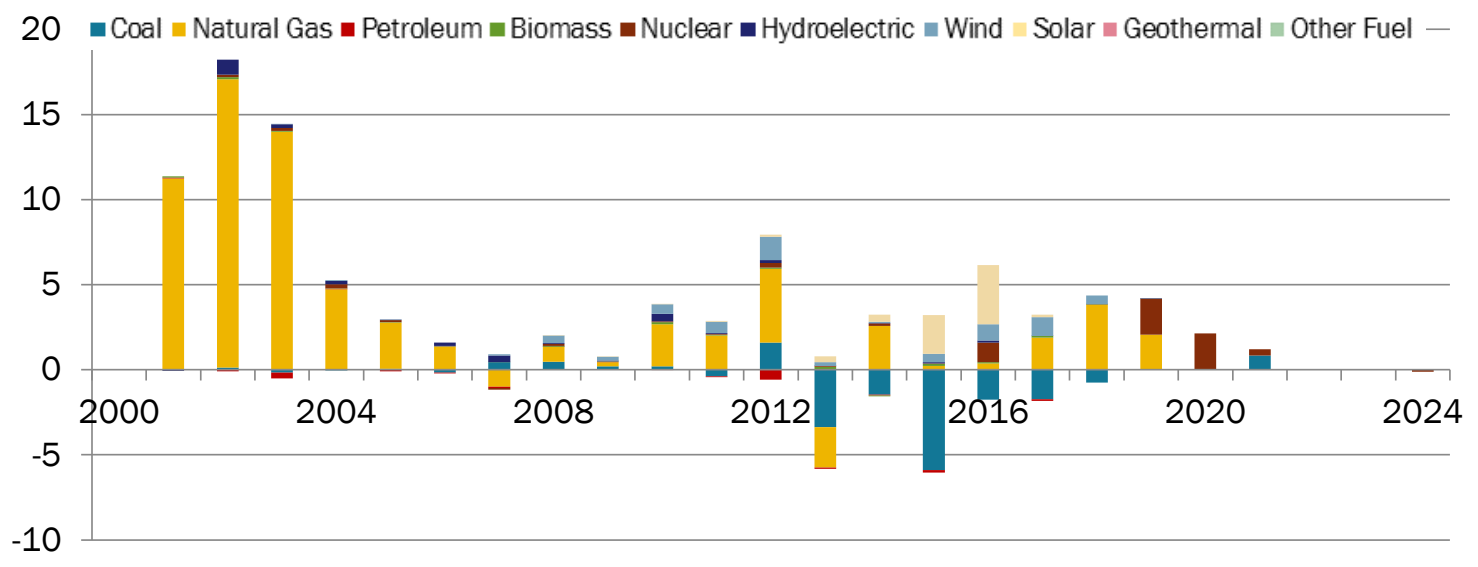

Figure ES-7. SERC net capacity additions or retirements (GW) by fuel, 2000-2024

SERC is the only region the United States that has planned nuclear capacity additions. Historical additions/retirements as of 2014 are reported; future additions/retirements are announced. Source: SNL $2015^{10}$.

6. The forecasted shift in generation has positive and negative implications for greenhouse gas (GHG) emissions because there are large variations in growth trends and GHG emissions among the generation sources ${ }^{11}$.

A. Nuclear power currently provides the largest share of GHG emission-free electricity in the United States. In 2015, nuclear was providing 20\% of U.S. electricity and $59 \%$ of its carbon-free electricity. However, more nuclear plants are retiring than being constructed due to low prices in electricity markets and high capital costs.

B. Hydroelectric power, another GHG emission-free source of electricity, contributed $6 \%$ of electricity generated in the United States in 2015 and is projected to have relatively flat growth, despite significant potential for expansion. 
C. Wind and solar generation — both GHG emission-free sources — are growing rapidly but still represented only about $6 \%$ of total generation as of 2015 .

D. Coal generation currently is responsible for the largest share of carbon dioxide $\left(\mathrm{CO}_{2}\right)$ emissions from the electric power sector. Coal-fired capacity saw its last notable additions in 2010 as plants planned before the financial crisis of 2008 came online. There were roughly $25 \mathrm{GW}$ of coal retirements from 2012-2014, and there were $13 \mathrm{GW}$ of coal retirements in 2015 . The coal units that were retired in 2015 tended to be smaller and older (average age is 54 years, and the rest of fleet that continues to operate has an average age of 38 years $)^{12}$.

E. Natural gas generation has less than $50 \%$ of the burner-tip carbon emissions compared to conventional coal generation. This has GHG implications for replacing coal in the short run. Over the longer term, all emissions from natural gas production and generation will become more important to consider given carbon mitigation goals as articulated by various stakeholders, including businesses as well as state and local governments.

F. Natural gas and coal would need carbon capture and storage (CCS) to achieve significantly lower GHG emissions, and the combined technologies needed to achieve CCS are in the first-of-its-kind deployment phase in the United States.

7. There is significant variation among the states with regard to electricity imports and exports. Where sales to end users exceed generation, the state runs an electricity deficit and must import energy. Several states stand out as large net importers (measured in gigawatt-hours [GWh]): California, Virginia, Massachusetts, Tennessee, and Ohio. Massachusetts is particularly notable for its small size but large quantity of net imports. Proportional to its total end-use sales, Massachusetts exceeds any other state in percentage of net imports. Idaho and Delaware, while not large net importers in terms of total energy, import high percentages of their total sales (Section 4.1).

8. Changes in electricity markets, fleet composition, and usage patterns in recent years have seen power plant operators and engineering, permitting, and construction vendors adapt both coal and nuclear plants for more flexible operation. However, flexible operation can come at a cost: reduced efficiency, higher marginal emissions, and increased wear and tear on the equipment, which increases maintenance costs ${ }^{13}$.

9. The national average capacity factor for the fleet of natural gas combined cycle (NGCC) plants has increased from approximately $40 \%$ in 2008 to over $55 \%$ in 2015 , illustrating the greater utilization of existing generation assets. The national average heat rate for natural gas plants shows a significant decline (i.e., improved efficiency) since 2003; however, analysis shows the average heat rate for the fleet of NGCC plants has remained steady since 2007. For gas-fired combustion turbines (CTs), heat rate has declined modestly, and the overall decline is due to the increased deployment of NGCC plants, which are inherently more efficient than $\mathrm{CTs}^{14}$.

10. Wind and solar generation have recently been experiencing rapid growth due to technological advances and reductions in cost, but their national market generation share totaled only $5.6 \%$ in 2015 , and much of their projected growth is due to recently enacted tax credit extensions ${ }^{15}$. 
11. Although distributed solar accounted for less than $0.3 \%$ of the national generation mix in 2015 , it accounted for $31 \%$ of total photovoltaic (PV) generation, and in some states, such as California and Hawaii, deployment has been growing rapidly due to favorable market conditions and policies (see Figure ES-8).

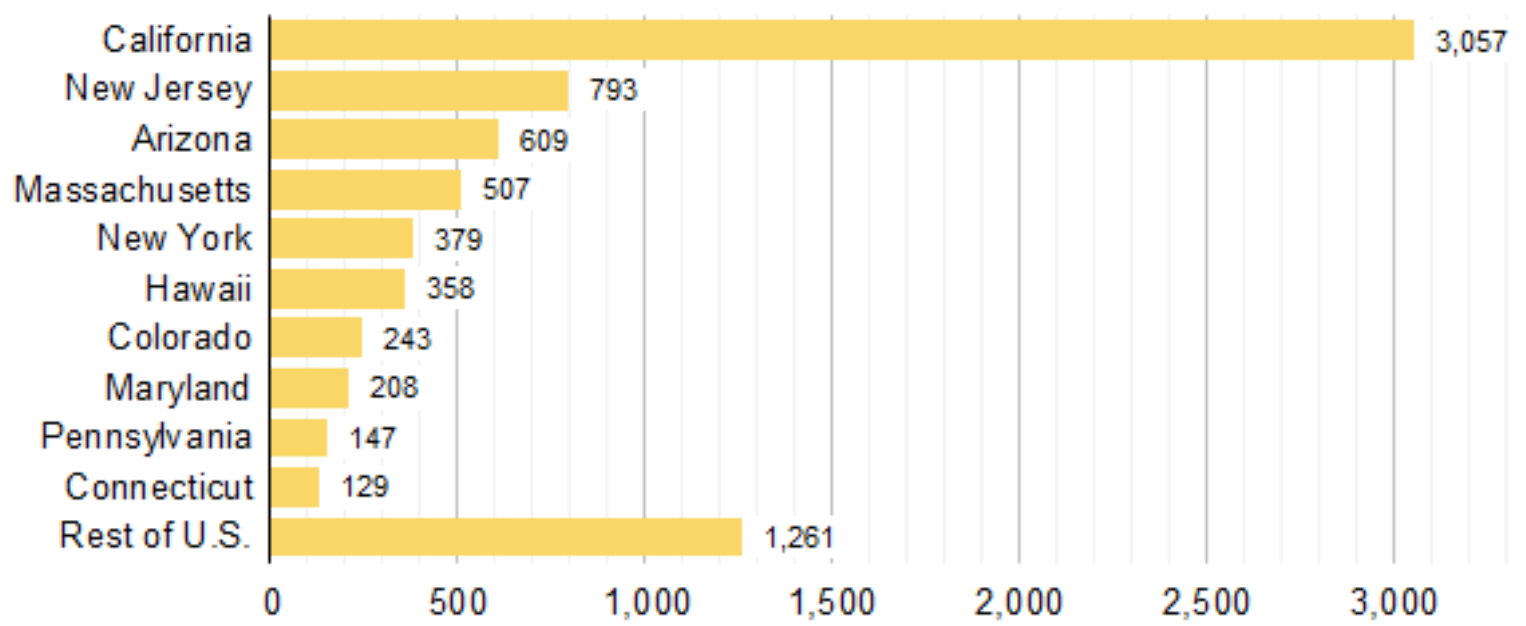

Figure ES-8. Distributed solar PV installed capacity (MW), top 10 states, as of September 2015

California had more installed distributed PV capacity than the next six largest states as of September 2015.

Source: EIA $2015^{\mathbf{1 6}}$.

12. Wind generation represents the highest percentage of non-hydro renewables in the national generation mix, and utility-scale wind represents the highest percentage compared to utility-scale solar, distributed solar, and distributed wind ${ }^{17}$.

A. Wind generation increased from 18 terawatt-hours (TWh) in 2005 to $191 \mathrm{TWh}$ in 2015, a more than tenfold increase, but still only accounted for approximately $4.7 \%$ of total net generation at the national level. At the end of 2015, wind generation exceeded $15 \%$ of total in-state generation in eight states: Iowa, South Dakota, Oklahoma, Kansas, North Dakota, Minnesota, Idaho, and Vermont. The extension of the production tax credit (PTC), passed in December 2015, is expected to further expand the deployment of wind energy in the United States.

B. Distributed wind capacity (i.e., turbines of no more than 1 megawatt [MW]) reached a cumulative capacity of almost $1 \mathrm{GW}$ in 2015.

13. Utility-scale solar and wind are experiencing substantial cost improvements and making inroads against other utility-scale generation. While there are emerging opportunities to address variability, it can remain a significant challenge when shares of variable generation exceed a certain level ${ }^{18}$.

A. Utility-scale solar PV cost reductions have been significant, with organizations like Lazard reporting a decline in levelized cost of electricity (LCOE) for utilityscale PV projects of 85\% between 2009 and 2016 (right side of Figure ES-9). Wind generators have enjoyed similar cost reductions and technology improvements (left side of Figure ES-9), with Lazard estimating a 66\% reduction in LCOE over the same time frame. 

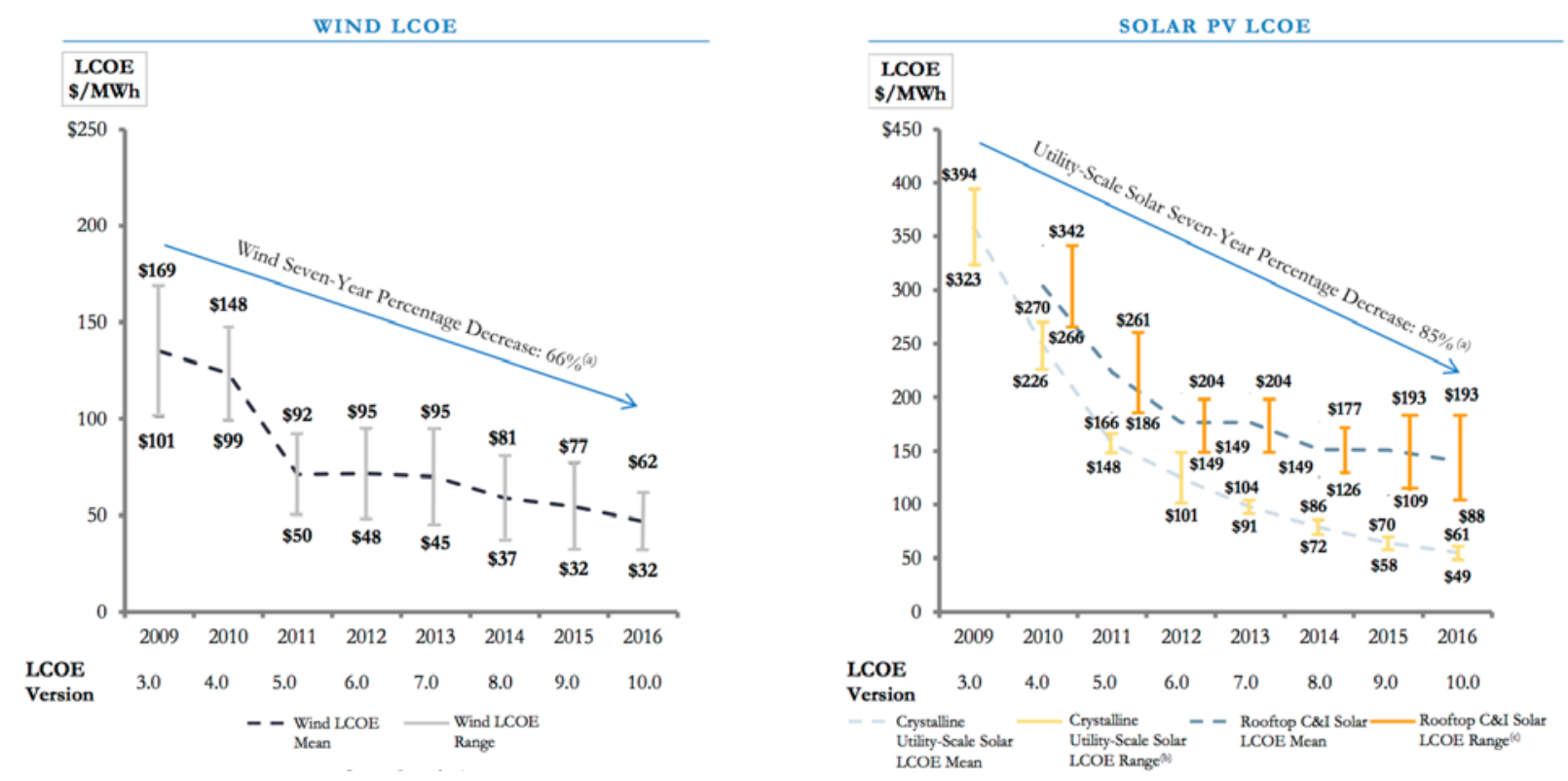

Figure ES-9. Change in U.S. LCOE for wind and PV, 2009-2016

LCOE for wind and solar have decreased dramatically since 2009, which has increased their deployment across the United States. Source: Lazard $2016^{19}$.

14. While several low-GHG generation technologies have potential to contribute to the future generation mix, barriers currently exist that could result in untapped resource potential, early closures, or unvalued grid services:

A. As of May 2016, five new nuclear plants were under construction, while four plants had retired before the end of their scheduled permitting lifetime and an additional nine have announced that they will retire by 2020 .

B. Geothermal generators are dispatchable plants capable of providing valuable services to the grid, such as generation flexibility. As more variable energy resources (VERs) are integrated to the electric system, the flexibility of dispatchable capacity will grow in importance. The services a geothermal plant can provide include regulation reserves, load following, spinning reserves, nonspinning reserves, and replacement or supplemental reserves. Current ancillary service compensation models in areas with the most geothermal development do not provide sufficient revenue to warrant the increased operational and control retrofitting expenses.

C. Prior to 1980, geothermal generation remained below 5 TWh annually. Then, between 1980 and 1989, generation tripled to 15 TWh as new facilities came online. Much of the early growth in geothermal power was driven by Public Utilities Regulatory Policy Act of 1978 (PURPA) incentives, although the influence of this policy has declined over time as the avoided costs of utility generation have fallen (see Section 12, Figure 12-6). Challenges in exploring new 'blind' hydrothermal resources and long drilling times for production wells have led to increased uncertainty for investors in large geothermal projects. Additionally, expiration of tax credit horizons that do not allow enough time for 
project development (e.g., commence construction clauses that do not take into account the long lead time of geothermal project development), scarcity of power purchase agreement (PPA) opportunities, the need for transmission infrastructure, and low natural gas prices have likely contributed to modest growth in recent years.

D. Because the majority of hydropower facilities support multiple purposes such as recreation, flood management, irrigation, navigation, and water supply, requirements for uses other than power generation - such as reservoir elevation rules upstream or dissolved oxygen or flow requirements downstream - can impact when the plant is able to release or store water.

E. An Oak Ridge National Laboratory (ORNL) report found that the technical resource potential for new hydropower development was $65.5 \mathrm{GW}$ of capacity, when excluding federally protected lands (see Section 8, Figure 8-5). Another ORNL report found a technical resource potential of over $12 \mathrm{GW}$ capacity at the more than 50,000 existing nonpowered dams in the United States (see Section 8, Figure 8-6).

F. Hydropower provides a variety of ancillary services that are beneficial to the electricity system. One example is output regulation and frequency response (including inertia), in which hydropower generators can quickly respond to sudden changes in system frequency. Other ancillary services include spinning and supplemental reserves enabled by high ramping capability, reactive power and voltage support, and black start capability. There has been a renewed interest in the flexibility benefits that many hydropower projects can offer the grid given the growth in variable renewable sources like wind and solar. A recent report notes that about half of all installed hydropower capacity $(39 \mathrm{GW})$ has high flexibility potential, and could play an important role in low-cost integration of variable renewable generators ${ }^{20}$. Pumped storage hydroelectric (PSH) can also be used in peaking and balancing applications to maintain grid reliability in areas with high penetrations of VERs.

G. Over the next 10 years, existing U.S. Federal Energy Regulatory Commission (FERC) licenses will expire for nearly 250 hydropower plants, totaling more than $16,000 \mathrm{MW}$ of installed capacity. On average, it takes 8 to 10 years to relicense an existing hydro project, with at least 5 years of pre-filing activity and then at least another 3 years after the application is filed. However, only 2,198 dams are currently used for hydroelectricity-3\% of the nation's total dams. (Other uses for dams include navigation, flood control, irrigation, and recreation.) Adding hydroelectricity to these preexisting dams may not face as many siting constraints because some of the environmental impacts from dam construction have already been incurred; this, combined with the ability to leverage existing infrastructure at nonpowered dams, can reduce costs (see Section 8). 
15. While the generation mix is expected to continue changing, fossil fuels are projected to make up around $50 \%$ of both U.S. and world generation in 2040. Research, development, demonstration, and deployment (RDD\&D) initiatives that lower costs for clean generation technologies are potential opportunities to both provide technology export benefits and assist the United States in meeting its carbon mitigation goals.

A. Both the U.S. generation mix and the global generation mix are projected to include over 50\% of fossil generation in 2040 in some scenarios (Figure ES-10).

B. Penetration of renewable energy in the United States as a percentage of generation is projected to lag the rest of the world.

C. Commercial low-GHG generation technologies or commercial technologies to control GHG emissions from fossil generation are needed to meet domestic and international emission and climate objectives.

D. If U.S. commercial technologies are developed, they could provide competitive advantage and export opportunities, in addition to supplying a robust domestic market.
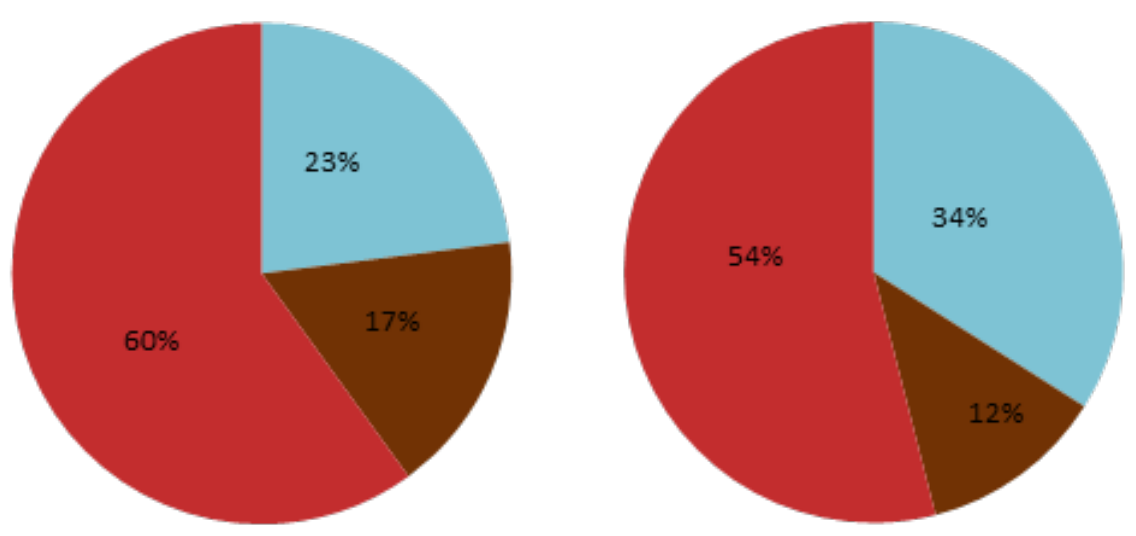

\footnotetext{
Figur-10. Projiented Robles Nuclear Power
}

Figure ES-10. Projected generation mix of the United States (left) and world (right) in 2040 from the QER 1.2 Base Case and the International Energy Agency's (IEA's) World Energy Outlook (WEO) New Policies Scenario

While renewables are projected to gain a significant share of generation in these scenarios, fossil fuels are projected to continue to make up 55\%-60\% of both U.S. and world generation. Sources: EPSA 2016 \& IEA $2015^{21}$. 


\section{Table of Contents}

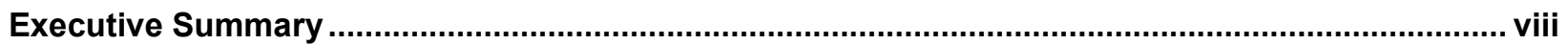

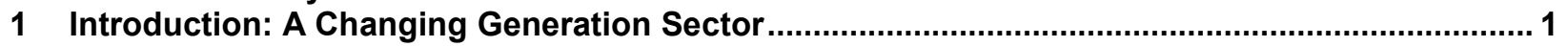

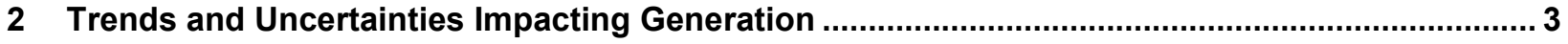

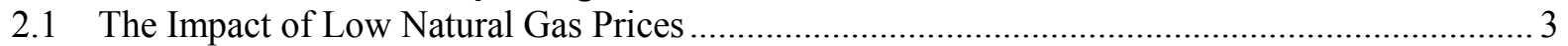

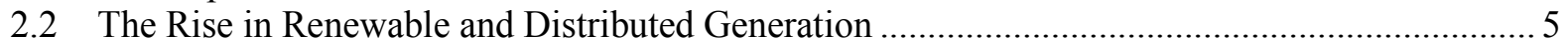

2.3 Recent Federal and State Policies Impacting Generation......................................................... 9

2.3.1 EPSA QER 1.2 Outlook for Generation Through 2040 …......................................... 9

2.4 Changing Relationship Among GDP, Electricity Demand, and GHG Emissions ..................... 12

2.5 Future Uncertainty: Electrification of the Transportation Sector ............................................ 13

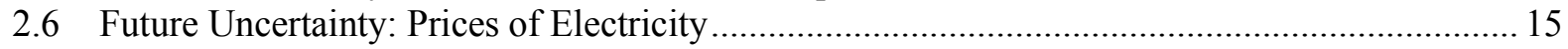

3 Crosscutting Attributes of the U.S. Power Generation Sector ................................................ 16

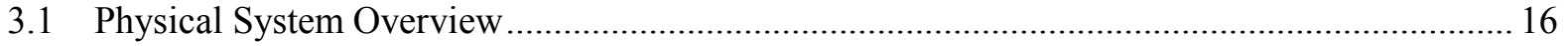

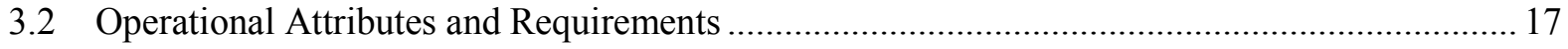

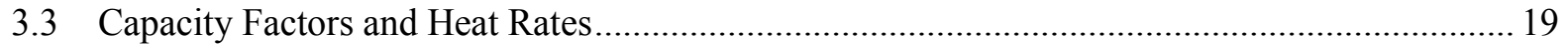

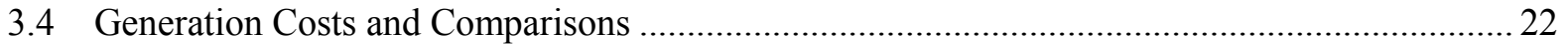

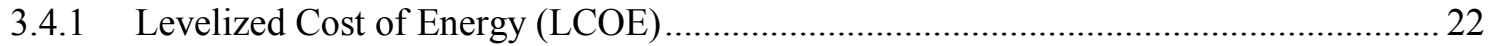

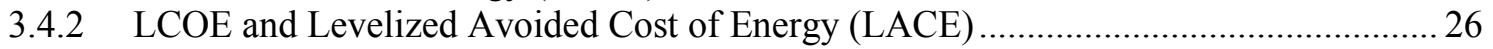

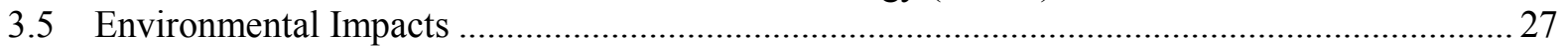

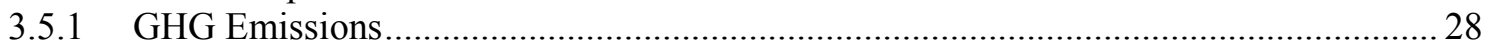

3.5.2 Life-Cycle Emissions: Criteria Pollutants and Particulates.......................................... 30

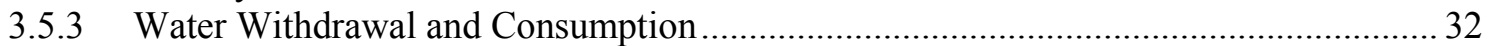

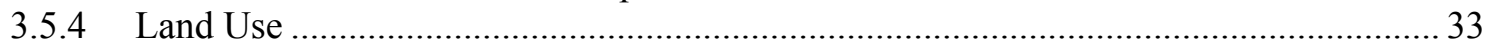

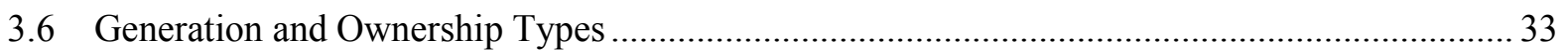

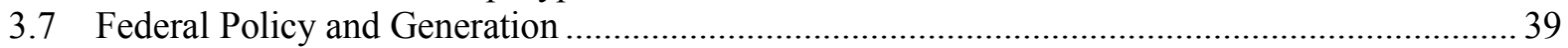

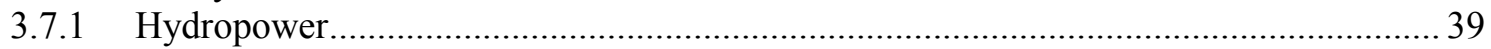

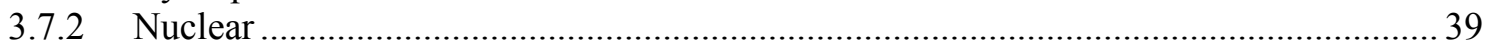

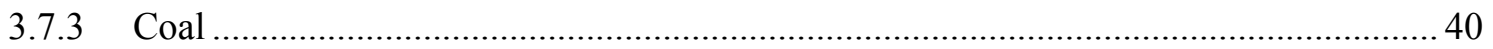

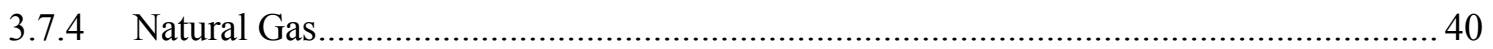

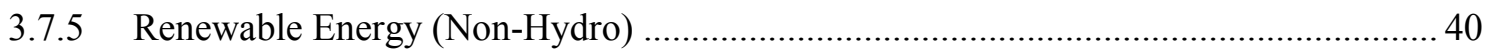

4 National and Regional Generation Data

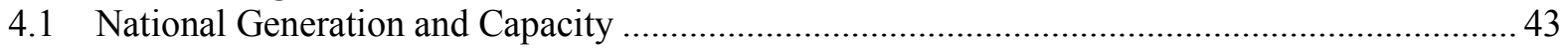

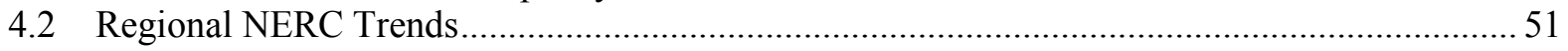

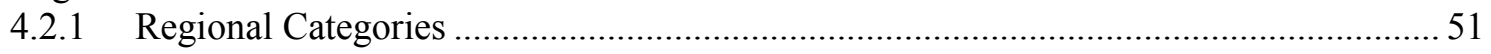

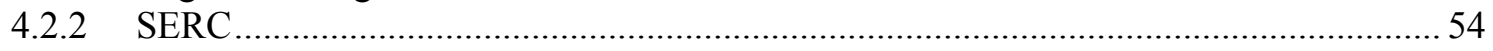

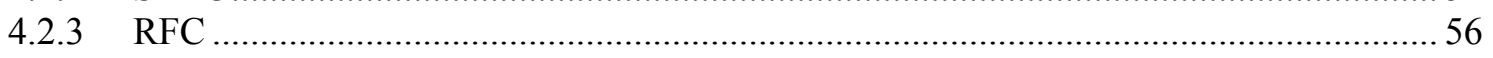

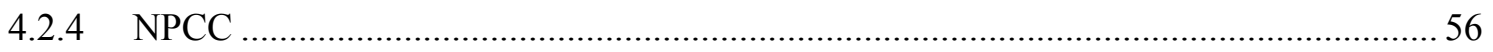

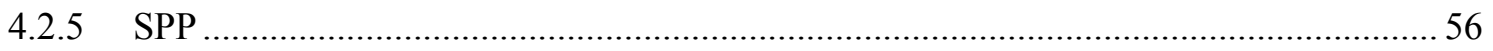

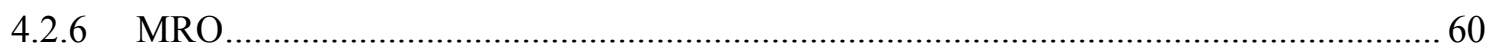

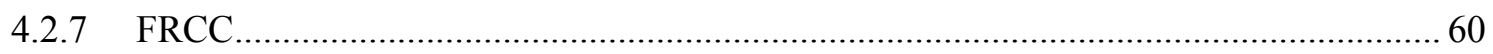

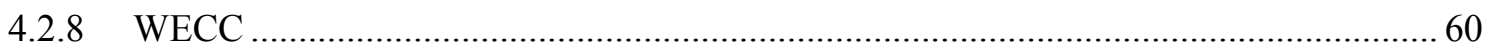

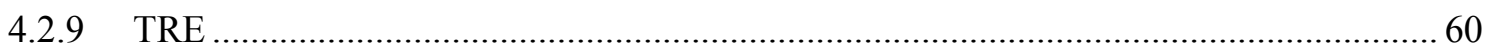

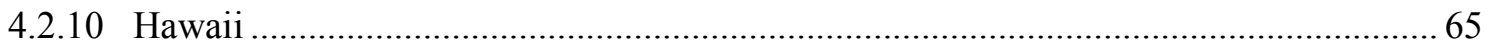

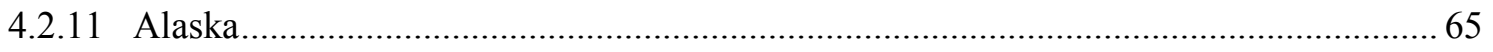

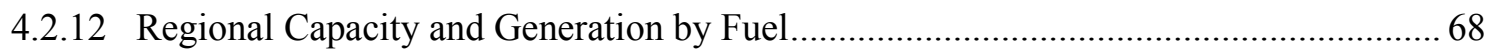

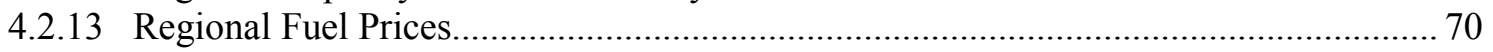

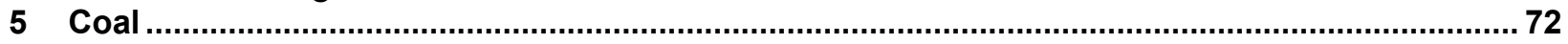

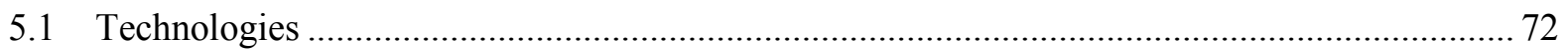

5.2 Operational Attributes and Fleet Characteristics............................................................. 73

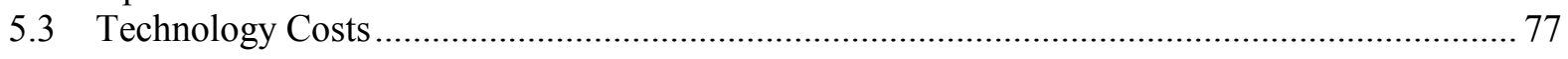




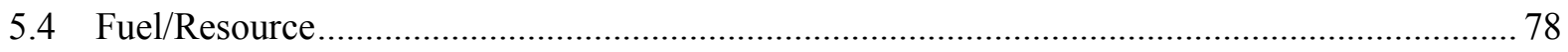

5.4.1 Coal Price History …………………………………......................................... 78

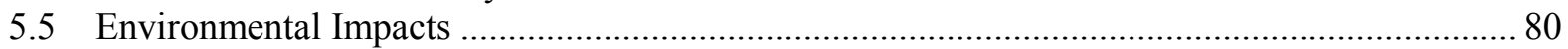

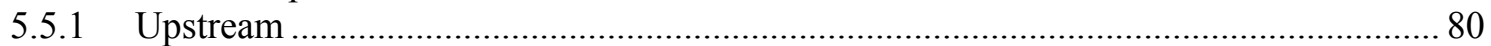

5.5.2 Emissions and Environmental Impact...……………………………………..... 81

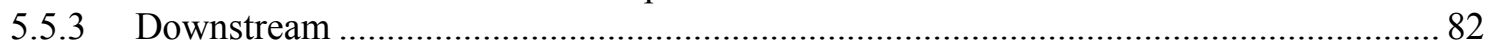

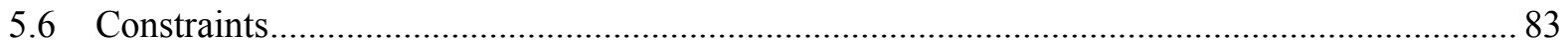

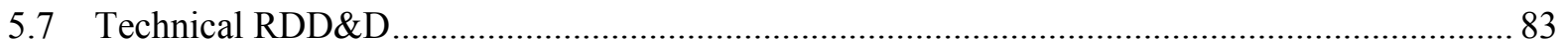

5.8 Development and Projected Future Deployment ……………………………………………..... 84

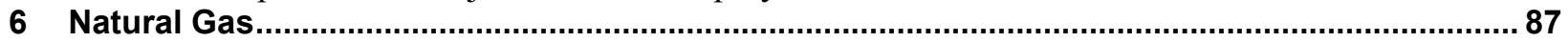

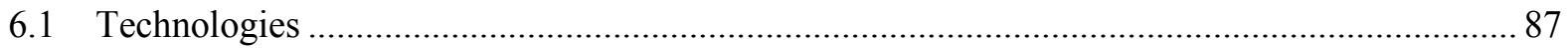

6.2 Operational Attributes and Fleet Characteristics...................................................................... 88

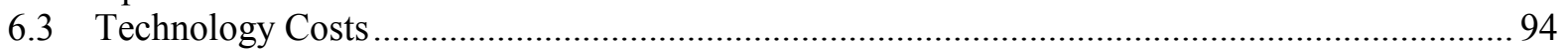

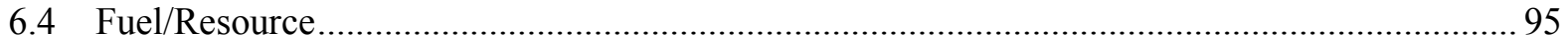

6.4.1 Natural Gas Price History …………………………………………………..... 95

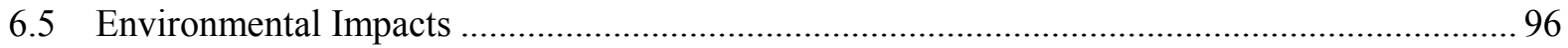

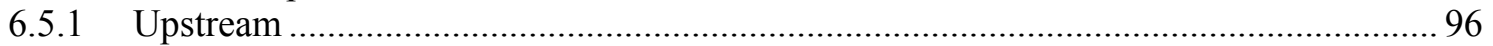

6.5.2 Emissions and Environmental .......................................................................... 97

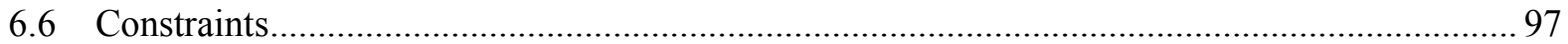

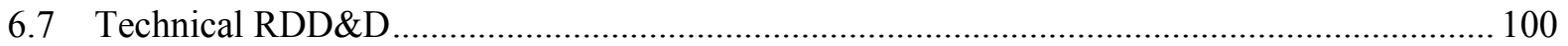

6.8 Development and Projected Future Deployment …………..................................................... 100

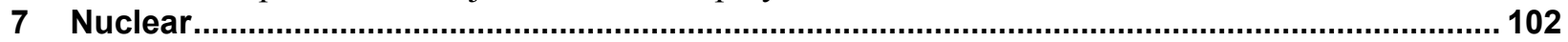

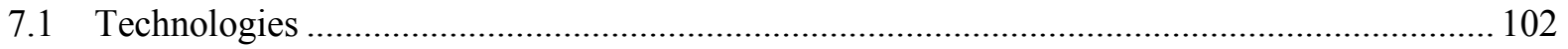

7.2 Operational Attributes and Fleet Characteristics................................................................. 102

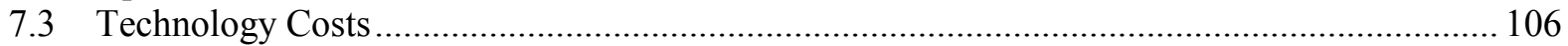

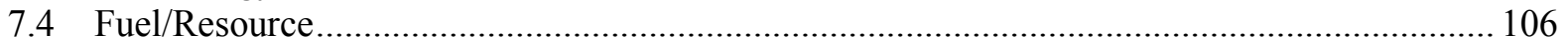

7.4.1 Uranium Price History ......................................................................................... 108

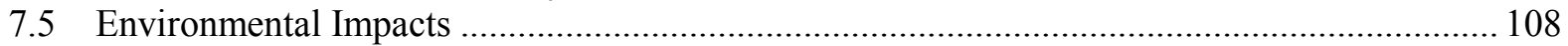

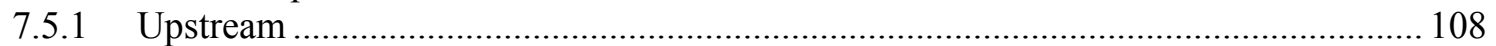

7.5.2 Emissions and Environmental Impacts .................................................................... 109

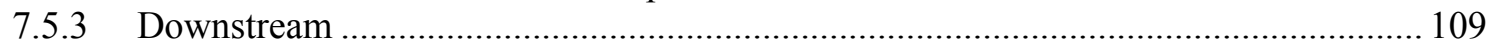

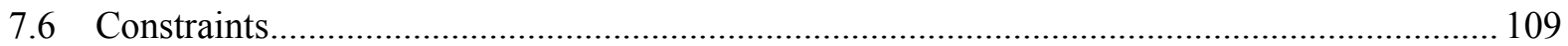

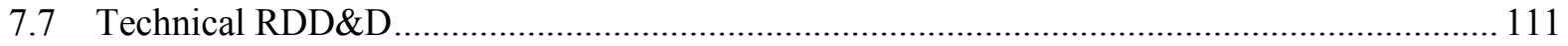

7.8 Development and Projected Future Deployment ………………………………………...... 112

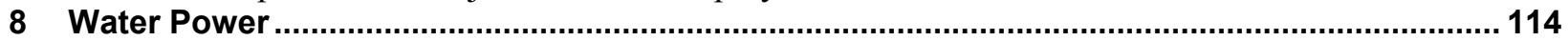

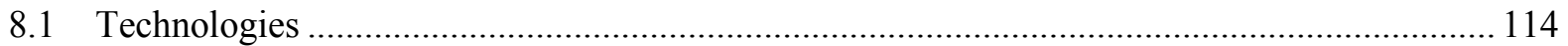

8.2 Operational Attributes and Fleet Characteristics................................................................. 114

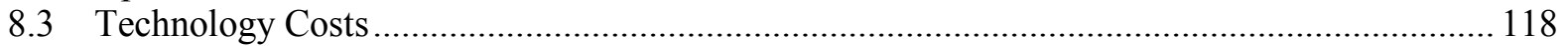

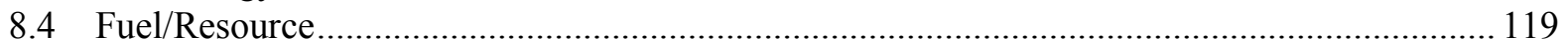

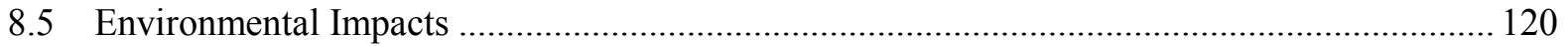

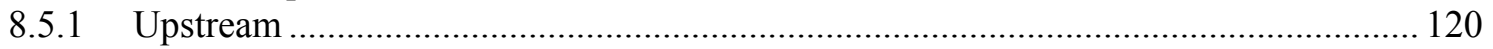

8.5.2 Emissions and Environmental Impact...………………………………………. 121

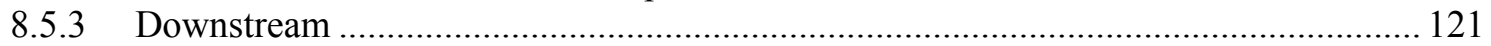

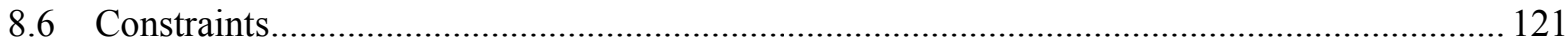

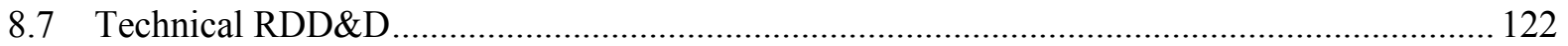

8.8 Development and Projected Future Deployment ……………………………………......... 125

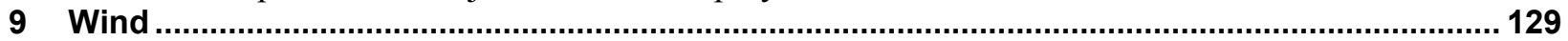

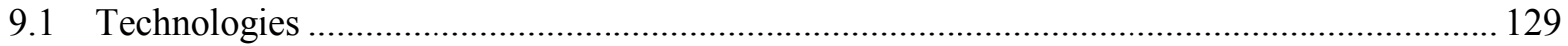

9.2 Operational Attributes and Fleet Characteristics................................................................ 130

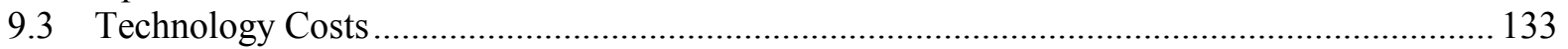

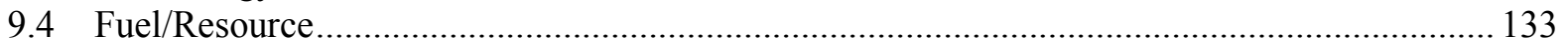




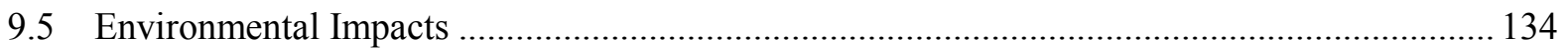

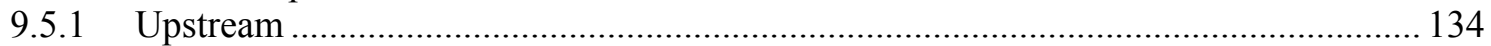

9.5.2 Emissions and Environmental Impact................................................................... 135

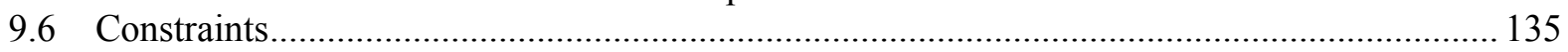

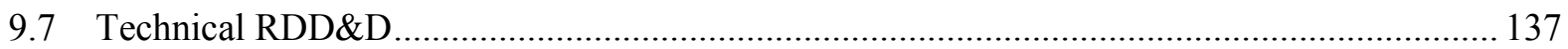

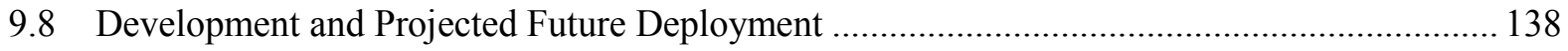

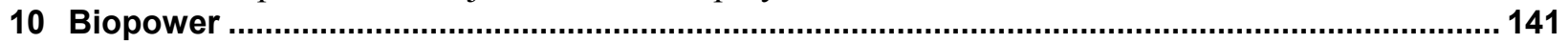

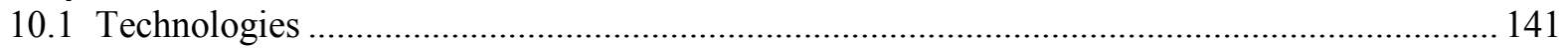

10.2 Operational Attributes and Fleet Characteristics................................................................... 141

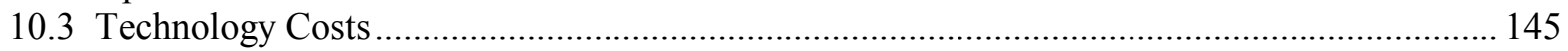

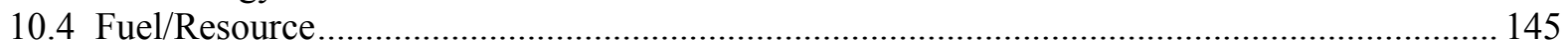

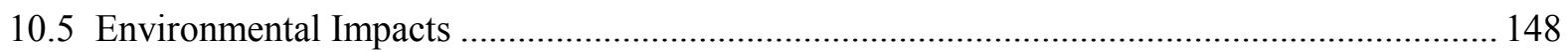

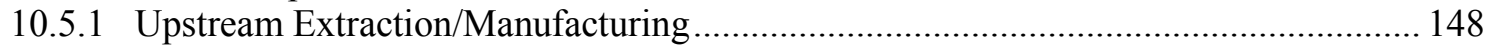

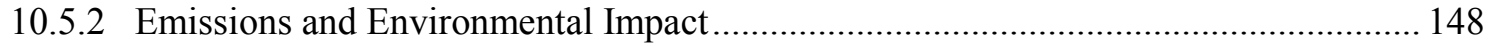

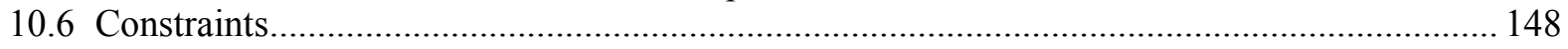

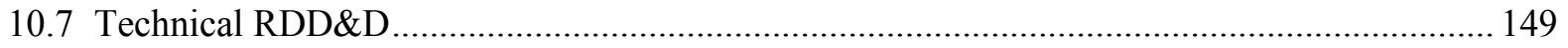

10.8 Development and Projected Future Deployment ………………………………………….... 149

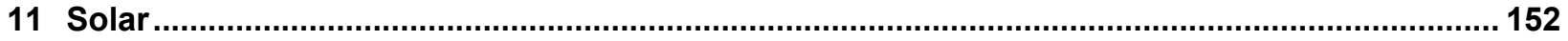

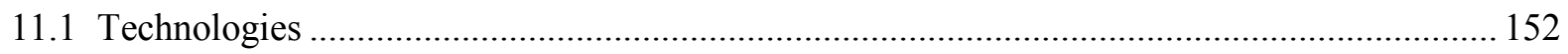

11.2 Operational Attributes and Fleet Characteristics.................................................................. 152

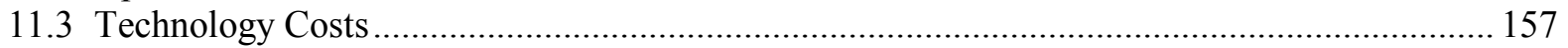

11.4 Fuel/Resource

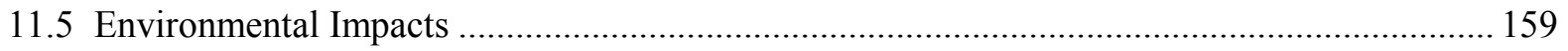

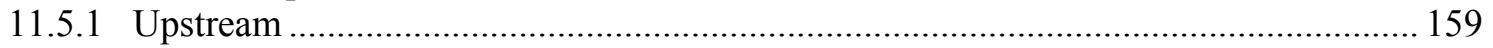

11.5.2 Emissions and Environmental Impact.................................................................. 159

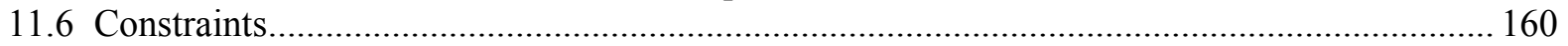

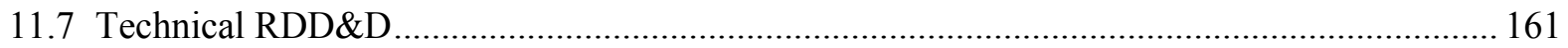

11.8 Development and Projected Future Deployment ………......................................................... 162

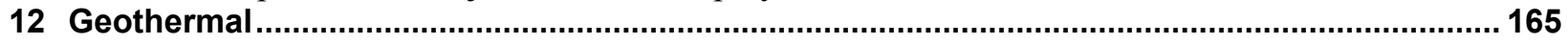

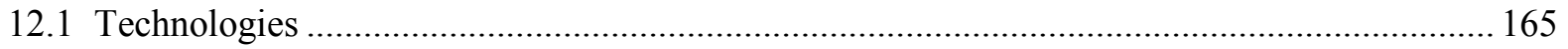

12.2 Operational Attributes and Fleet Characteristics.................................................................. 165

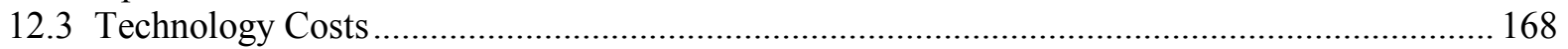

12.4 Fuel/Resource

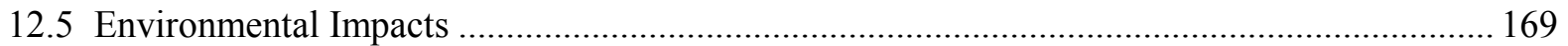

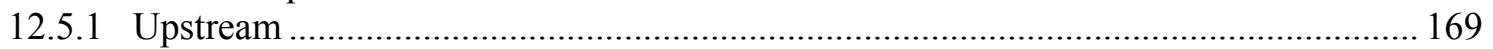

12.5.2 Emissions and Environmental Impact................................................................ 169

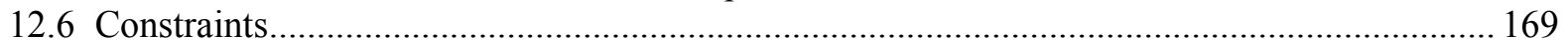

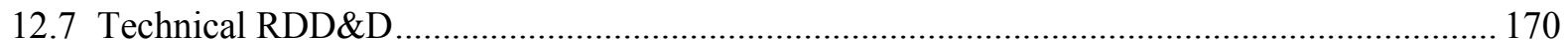

12.8 Development and Projected Future Deployment ………….................................................. 171

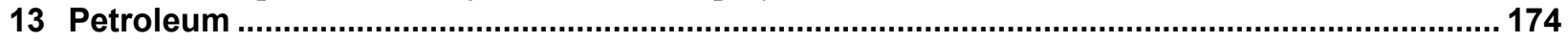

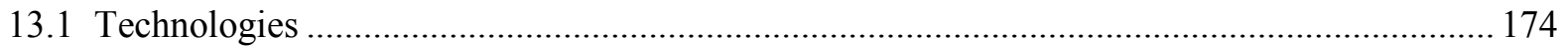

13.2 Operational Attributes and Fleet Characteristics.................................................................... 174

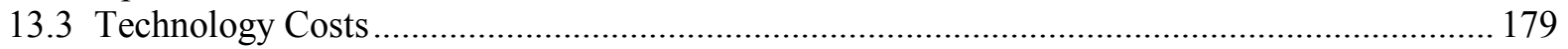

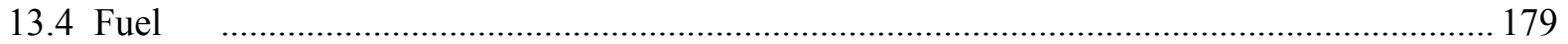

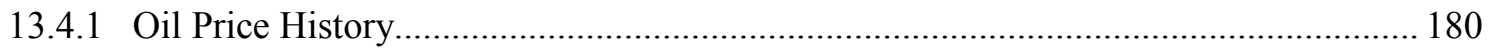

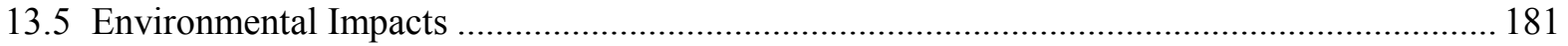

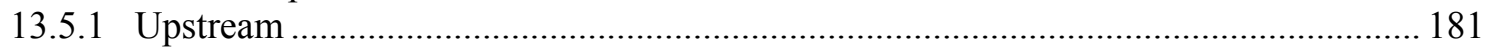

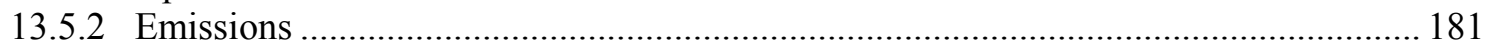

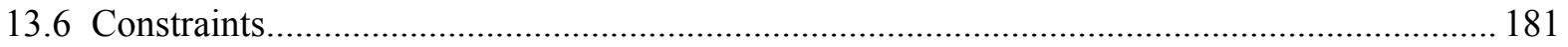

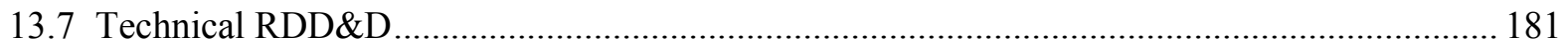

13.8 Development and Projected Future Deployment ………………………………………...... 181 


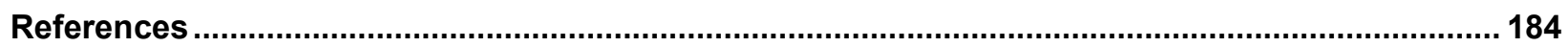

Appendix A: Supplementary Detail on Generating Technologies ............................................. 212

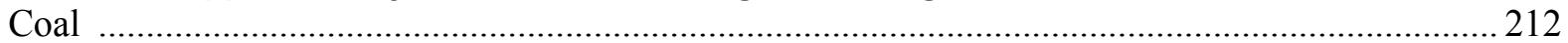

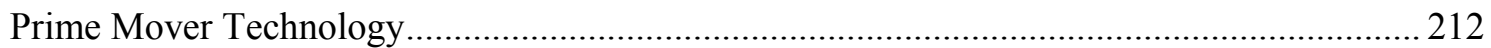

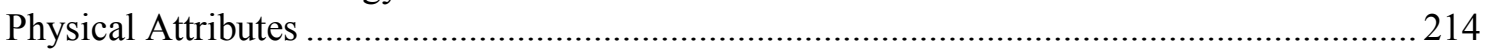

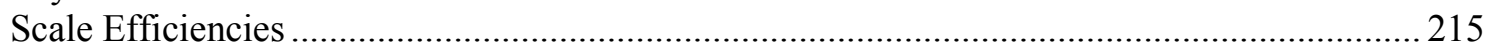

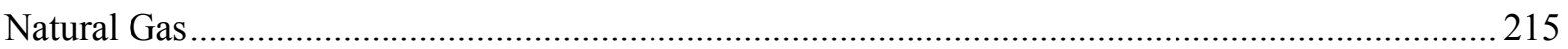

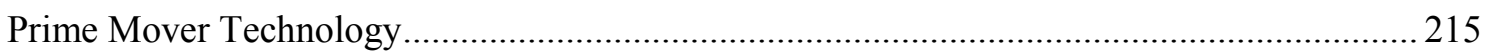

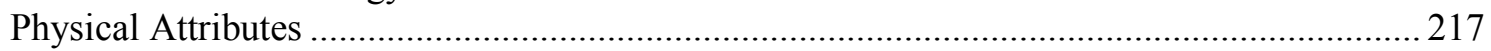

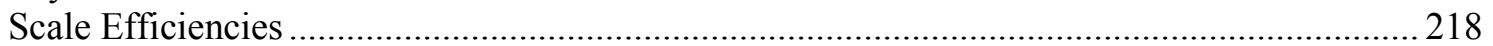

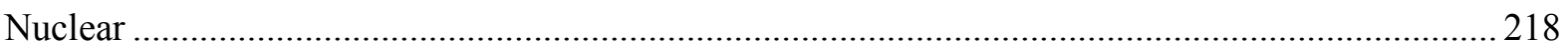

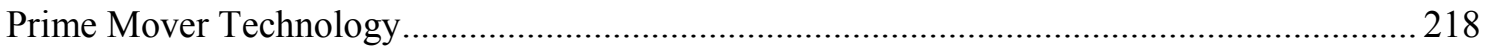

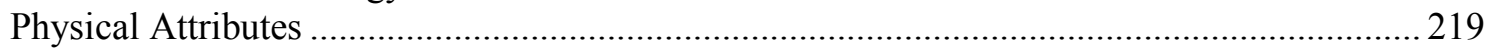

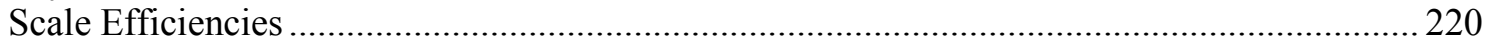

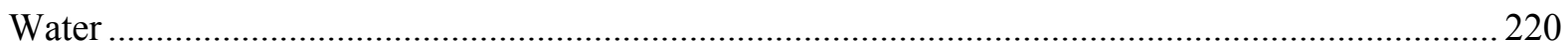

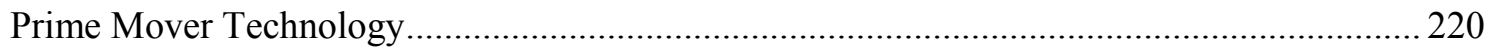

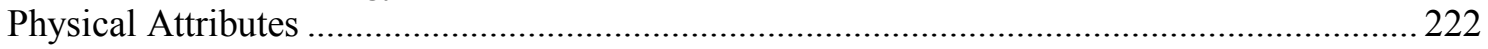

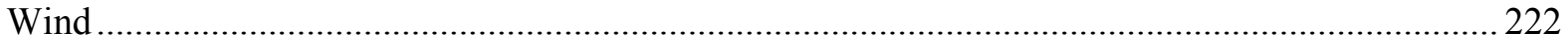

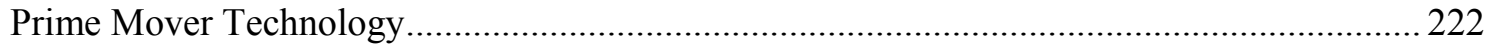

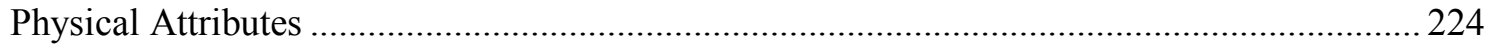

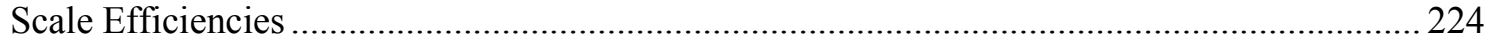

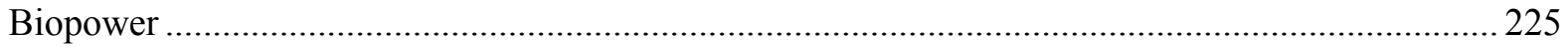

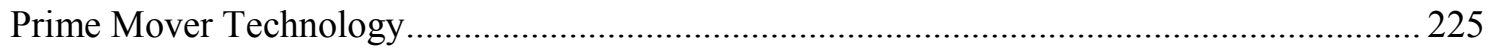

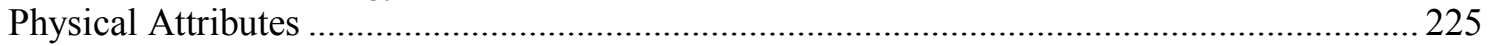

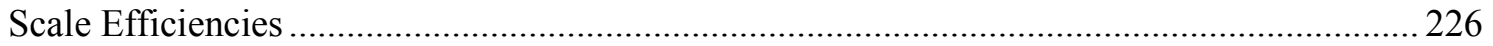

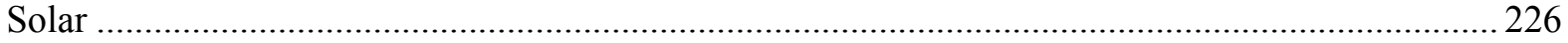

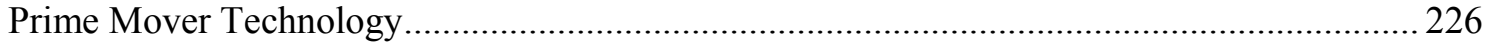

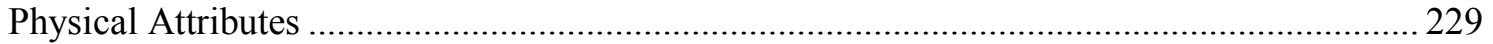

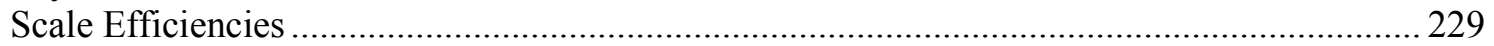

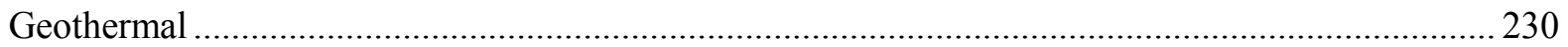

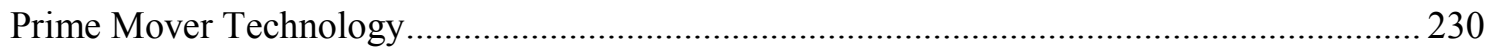

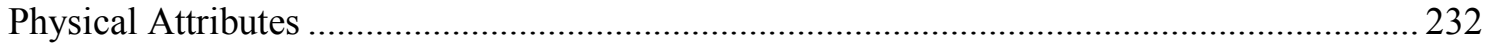

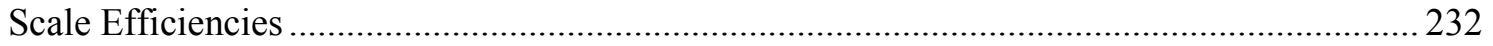

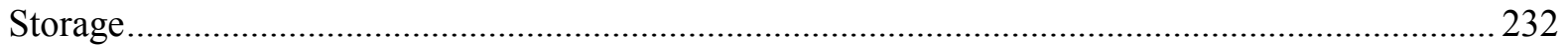

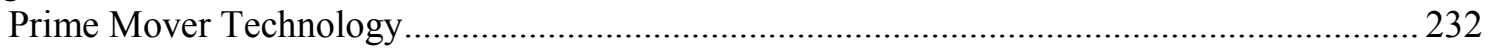

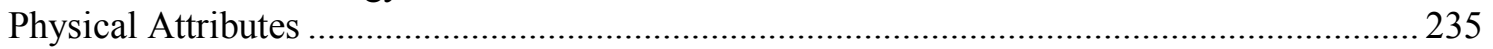

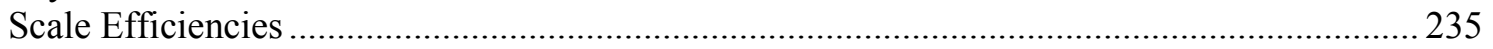

Appendix B: Levelized Cost of Electricity (LCOE) Methodology and Assumptions........................ 236

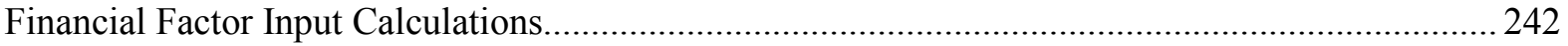

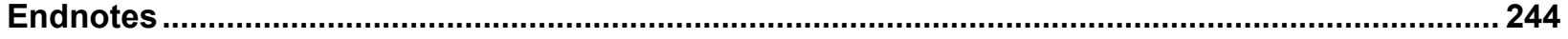




\section{List of Figures}

Figure ES-1. Net capacity additions (GW) by fuel type, 1950-2015 ...............................................viii

Figure ES-2. Annual net generation from all sectors ........................................................................ ix

Figure ES-3. Annual generation from select technologies in the United States, 1950-2015 (left), and generation from coal and natural gas (right-top) and non-hydro renewables (right-bottom), 2008-2015.

Figure ES-4. Comparison of electricity, natural gas, gasoline, medical care, and all commodities prices,

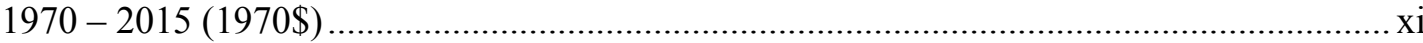

Figure ES-5. Percentage of generation by fuel, 2014: FRCC (left); MRO (right) ......................................ii

Figure ES-6. Percentage of generation by fuel in 2014 in the WECC region........................................... xiii

Figure ES-7. SERC net capacity additions or retirements (GW) by fuel, 2000-2024............................ xiii

Figure ES-8. Distributed solar PV installed capacity (MW), top 10 states, as of September 2015 ........... XV

Figure ES-9. Change in U.S. LCOE for wind and PV, 2009-2016 ................................................... xvi

Figure 1-1. Annual electricity generation by generation technology in the United States, 1950-2015 (left), and generation for coal and natural gas (right-top) and non-hydro renewables (right-bottom) for 2008-2015.

Figure 2-1. U.S. dry shale gas production, 2002-2016 .................................................................. 3

Figure 2-2. Average monthly cost of delivered fossil fuels in the U.S. power sector, 1995-2016 ............. 4

Figure 2-3. Change in U.S. LCOE for wind and PV, 2009-2016 ........................................................ 6

Figure 2-4. Installed capacity (MW) of distributed wind and distributed solar PV, 2002-2014............... 7

Figure 2-5. Projected generation (TWh) under the QER 1.2 Base Case, 2016-2040 ............................. 10

Figure 2-6. Projected U.S. generation (TWh) and capacity (GW) under EPSA's QER 1.2 Base Case...... 11

Figure 2-7. U.S. electricity use and economic growth, 1950-2020 ................................................... 12

Figure 2-8. U.S. electricity generation by fuel for all sectors, 2008-2017 ........................................... 13

Figure 2-9. Projected annual light-duty vehicle stock, 2014-2050 ................................................. 14

Figure 2-10. Comparison of electricity and other consumer price trends, 1970-2015 ........................... 15

Figure 3-1. Simplified representation of a coal-fired steam boiler and generator ................................... 17

Figure 3-2. Representative traditional electricity demand profiles in summer and winter ....................... 18

Figure 3-3. Capacity factor as a function of hours operated vs. percentage of full output ....................... 19

Figure 3-4. U.S. annual and monthly capacity factor by major fuel and technology combinations ........... 20

Figure 3-5. U.S. annual heat rates for fossil fuel technologies, 2003-2013 ......................................... 22

Figure 3-6. Reported (x values) and estimated (range) LCOE values for dispatchable and nondispatchable

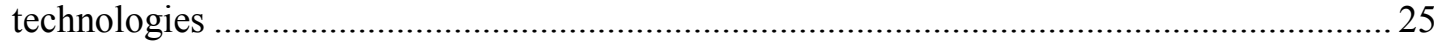

Figure 3-7. Life-cycle GHG emissions for select generation technologies based on a meta-study literature

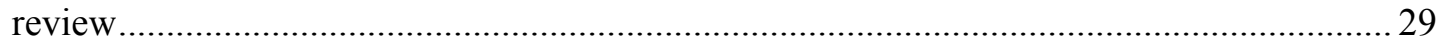

Figure 3-8. Life-cycle air emissions for select generation technologies.............................................. 31

Figure 3-9. U.S. generation fleet capacity (left) and share of capacity (right) by ownership and fuel type,

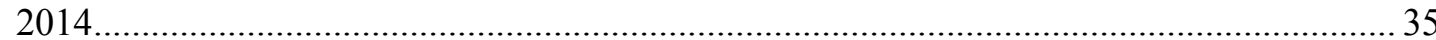

Figure 3-10. U.S. generation fleet by ownership type, 1980-2014 .............................................. 36

Figure 3-11. U.S. generation by fuel type for various ownership types, 1980-2014 …......................... 37

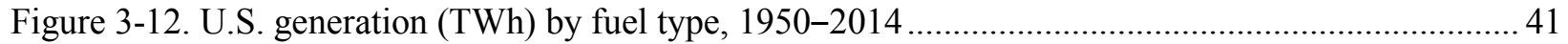

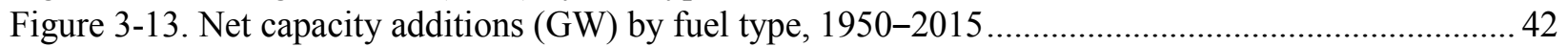

Figure 4-1. U.S. electricity generation (TWh) by fuel type, 1950-2014 ............................................ 43

Figure 4-2. Share of U.S. electricity generation by fuel type in percent, 1950-2015 ........................... 44

Figure 4-3. Monthly and annual generation in the United States (top) and historical and planned capacity

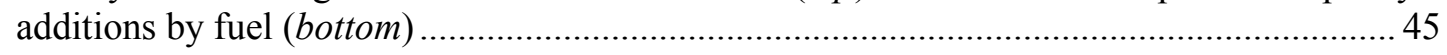

Figure 4-4. U.S. monthly and annual generation (TWh) by sector, 2001-2015 .................................. 46

Figure 4-5. U.S. monthly and annual generation (TWh) from the power sector by fuel, 2001-2015 ....... 47

Figure 4-6. U.S. monthly and annual generation (TWh) from the industrial sector by fuel, 2001-2015 ... 48 
Figure 4-7. U.S. monthly and annual generation (TWh) from the commercial sector by fuel, 2001-201548 Figure 4-8. Sales and generation by U.S. state in 2014. Top: total sales (left) and generation (right) in GWh. Bottom: difference between generation and sales shown in GWh (left) and percent (right).

Figure 4-9. Electrical generating capacity in the U.S. by NERC region............................................... 52

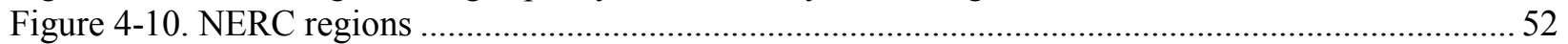

Figure 4-11. Monthly and annual generation in SERC (top) and historical and planned capacity additions

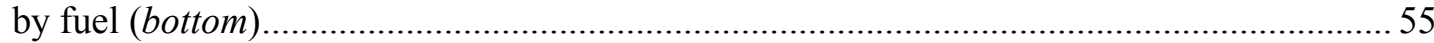

Figure 4-12. Monthly and annual generation in RFC (top) and historical and planned capacity additions

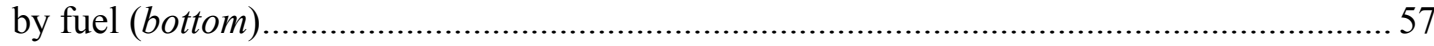

Figure 4-13. Monthly and annual generation in NPCC (top) and historical and planned capacity additions

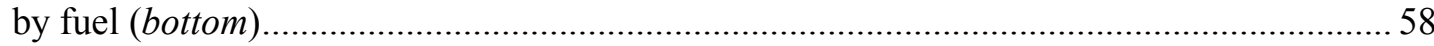

Figure 4-14. Monthly and annual generation in SPP (top) and historical and planned capacity additions by

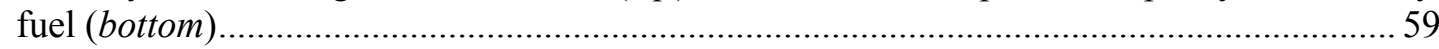

Figure 4-15. Monthly and annual generation in MRO (top) and historical and planned capacity additions

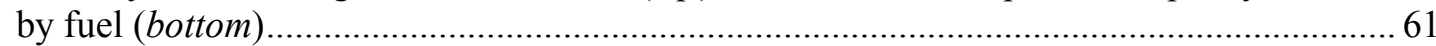

Figure 4-16. Monthly and annual generation in FRCC (top) and historical and planned capacity additions

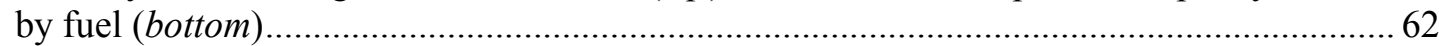

Figure 4-17. Monthly and annual generation in WECC (top) and historical and planned capacity additions by fuel (bottom).....

Figure 4-18. Monthly and annual generation in TRE (top) and historical and planned capacity additions by fuel (bottom).

Figure 4-19. Monthly and annual generation in Hawaii (top) and historical and planned capacity additions by fuel (bottom).....

Figure 4-20. Monthly and annual generation in Alaska (top) and historical and planned capacity additions by fuel (bottom). 67

Figure 4-21. Capacity and generation shares for generation technologies and region.............................69

Figure 4-22. Coal monthly spot contractual fuel cost (\$/ton), 2002-2015 ............................................. 70

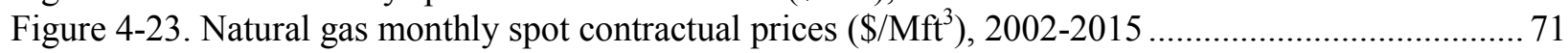

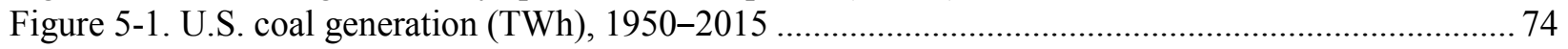

Figure 5-2. Annual and monthly capacity factors for coal generators .................................................. 74

Figure 5-3. Coal capacity (left), generation (middle), and capacity factor (right) by state. Top: 2010;

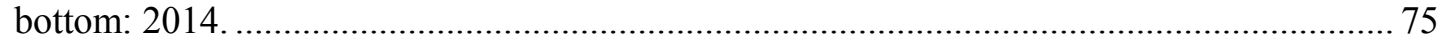

Figure 5-4. Age profile of U.S. coal generation fleet, 2014 ................................................................... 76

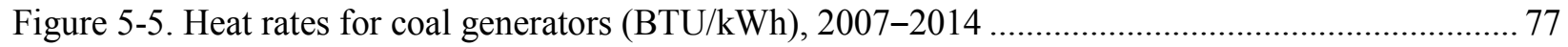

Figure 5-6. Annual average minemouth coal prices (2013\$) by U.S. region, 1990-2015...................... 79

Figure 5-7. Transportation cost share of delivered coal price by mode, 2010-2015 ............................. 80

Figure 5-8. Rail transportation cost share of delivered coal price by origin, 2010-2015 ....................... 80

Figure 5-9. Historical annual coal capacity additions and retirements (GW), 1950-2015 .................... 85

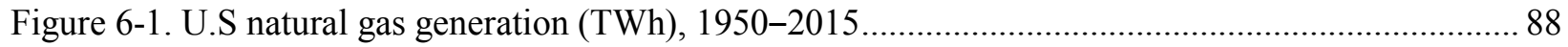

Figure 6-2. Share of U.S. operating natural gas-fired capacity and generation by technology type, 201489

Figure 6-3. U.S. average annual and monthly natural gas generator capacity factors .............................. 90

Figure 6-4. Natural gas CC capacity (left), generation (middle), and capacity factor (right) by state. Top:

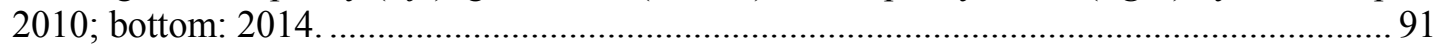

Figure 6-5. Natural gas CT capacity (left), generation (middle), and capacity factor (right) by state. Top:

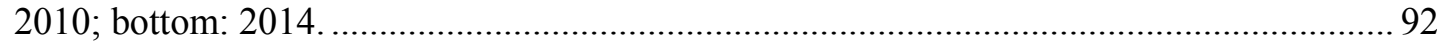

Figure 6-6. Age profile of U.S. natural gas generation fleet, 2014 .................................................... 93

Figure 6-7. Heat rates for fossil generators (BTU/kWh), 2007-2014 _............................................... 94

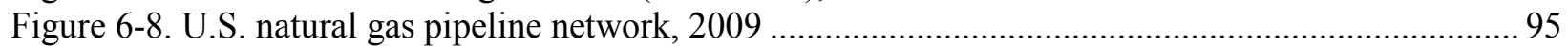

Figure 6-9. Henry Hub natural gas spot price (\$/MMBtu), 1997-2016 ................................................ 96 
Figure 6-10. Historical annual natural gas capacity additions and retirements, 1950-2015................. 100

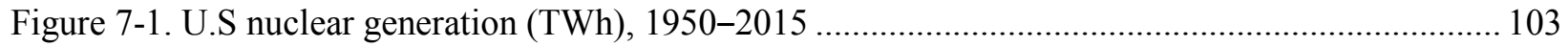

Figure 7-2. U.S. annual and monthly nuclear generator capacity factors ........................................... 103

Figure 7-3. Nuclear capacity (left), generation (middle), and capacity factor (right) by state. Top: 2010;

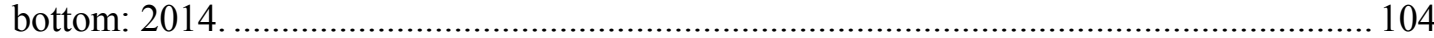

Figure 7-4. Age profile of U.S. nuclear generation fleet, 2014 ........................................................ 105

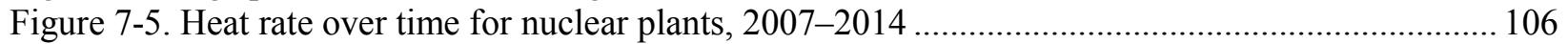

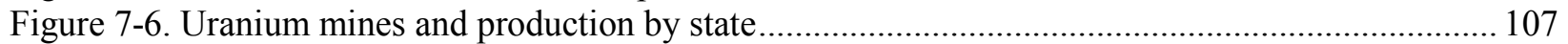

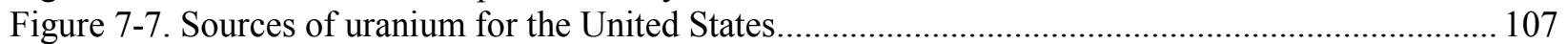

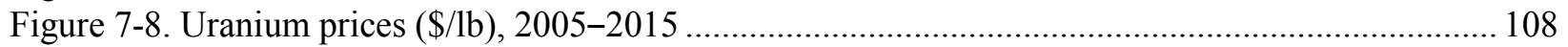

Figure 7-9. Historical annual nuclear capacity additions and retirements (MW), 1950-2015 ............... 112

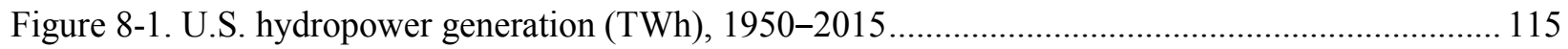

Figure 8-2. U.S. annual and monthly hydropower generator capacity factors..................................... 116

Figure 8-3. Hydropower capacity (left), generation (middle), and capacity factor (right) by state. Top:

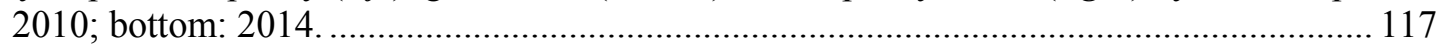

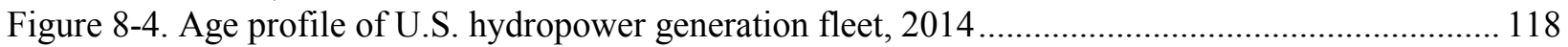

Figure 8-5. U.S. new stream-reach hydropower technical resource development potential..................... 119

Figure 8-6. U.S. non-powered dam hydropower technical resource potential...................................... 120

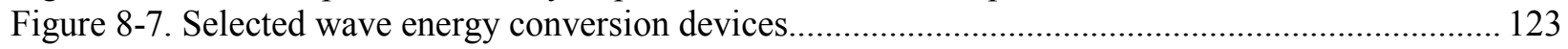

Figure 8-8. Historical annual hydropower capacity additions and retirements (MW), 1920-2015......... 126

Figure 8-9. Timeline for hydropower capacity additions in the U.S. (MW), 1890-2015 .................... 126

Figure 8-10. Installed hydropower capacity (GW) in the IEA New Policies scenario ............................ 128

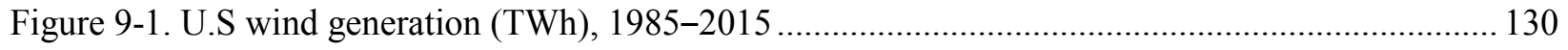

Figure 9-2. U.S. annual and monthly wind generator capacity factors .............................................. 131

Figure 9-3. Wind capacity (left), generation (middle), and capacity factor (right) by state. Top: 2010;

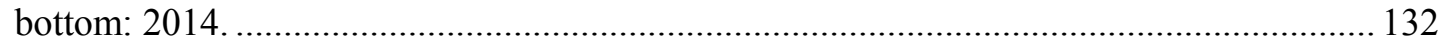

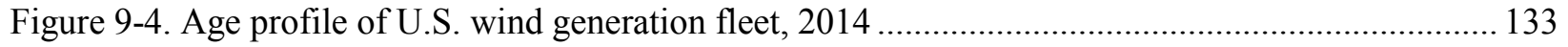

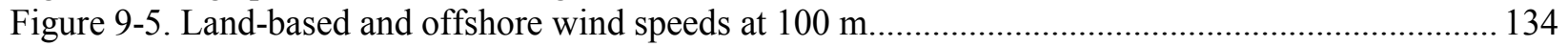

Figure 9-6. Historical annual wind capacity additions (GW), 1990-2015 ......................................... 138

Figure 9-7. Global wind power capacity installed (GW) by region in the New Policies Scenario........... 140

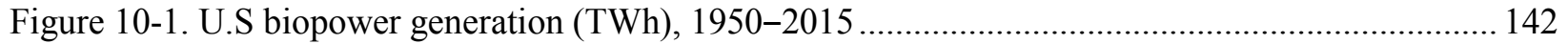

Figure 10-2. U.S. annual and monthly biopower generator capacity factors........................................ 143

Figure 10-3. Biomass capacity (left), generation (middle), and capacity factor (right) by state. Top: 2010;

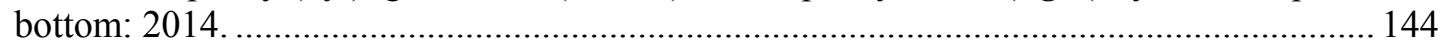

Figure 10-4. Age profile of U.S. biopower generation fleet, 2014 ...................................................... 145

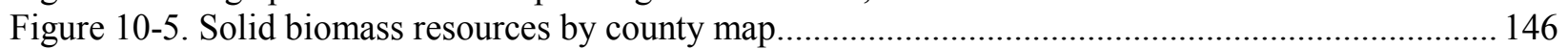

Figure 10-6. Methane generation potential from biogas sources ....................................................... 147

Figure 10-7. Historical annual biopower capacity additions and retirements (GW), 1975-2015........... 150

Figure 10-8. Projected biopower capacity additions (GW) in the New Policies Scenario of the WEO ... 151

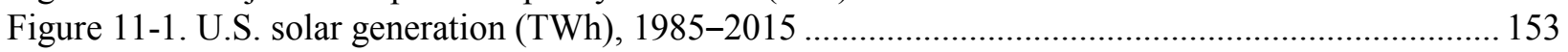

Figure 11-2. Solar electricity generating capacity (MW), November 2015 ....................................... 153

Figure 11-3. Share of U.S. operating solar capacity and generation by utility-scale vs. distributed, 2014154

Figure 11-4. U.S. annual and monthly utility solar PV generator capacity factors ............................... 154

Figure 11-5. Utility-scale solar capacity (left), generation (middle), and capacity factor (right) by state.

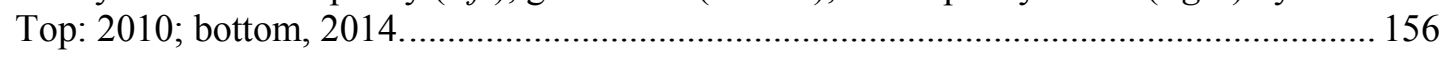

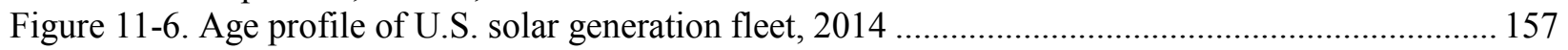

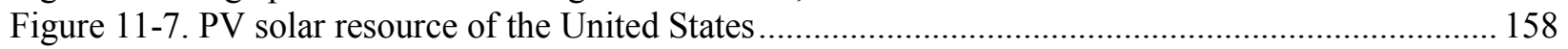

Figure 11-8. Concentrating solar resource of the United States ........................................................ 159

Figure 11-9. Historical annual utility-scale solar capacity additions (GW), 2000-2015 ....................... 163

Figure 12-1. U.S. geothermal generation (TWh), 1950-2015 ........................................................ 166 
Figure 12-2. U.S. annual and monthly geothermal generator capacity factors. 166

Figure 12-3. Geothermal capacity (left), generation (middle), and capacity factor (right) by state. Top: 2010; bottom: 2014.

Figure 12-4. Age profile of U.S. geothermal generation fleet, 2014 ..................................................... 168

Figure 12-5. Geothermal resource of the United States ................................................................ 169

Figure 12-6. Historical annual geothermal capacity additions and retirements (GW), 1950-2015......... 172

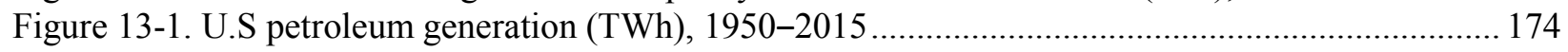

Figure 13-2. Share of U.S. operating petroleum capacity and generation by technology type, 2014....... 175

Figure 13-3. U.S. annual and monthly petroleum generator capacity factors....................................... 175

Figure 13-4. Petroleum capacity (left), generation (middle), and capacity factor (right) by state. Top:

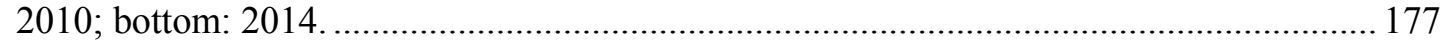

Figure 13-5. Age profile of U.S. petroleum generation fleet, 2014 …............................................. 178

Figure 13-6. Heat rates for petroleum generators (BTU/kWh), 2007-2014 .................................... 178

Figure 13-7. Pipelines in the U.S. and Canada that transport petroleum products ................................ 180

Figure 13-8. Spot prices of West Texas Intermediate crude oil at the Cushing, Oklahoma hub (\$/bbl),

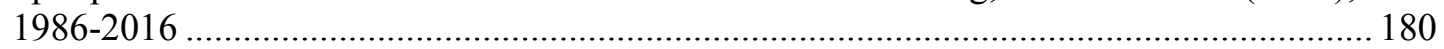

Figure 13-9. Historical annual petroleum capacity additions and retirements (GW), 1950-2015 .......... 182

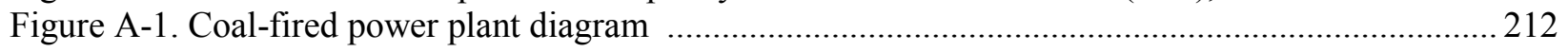

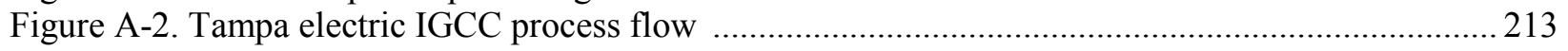

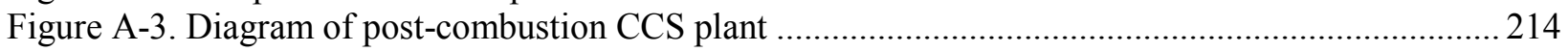

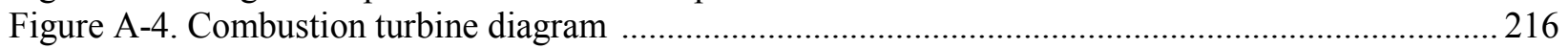

Figure A-5. Combined cycle generation process flow diagram ...................................................... 216

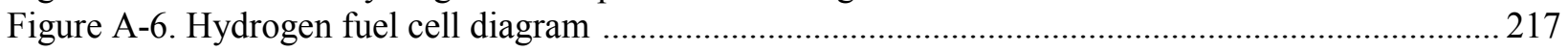

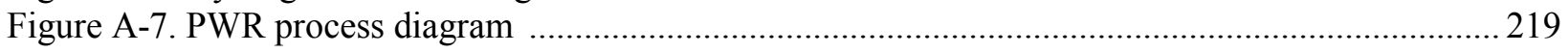

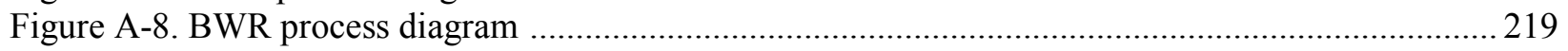

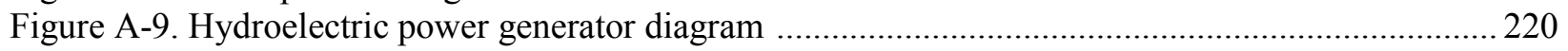

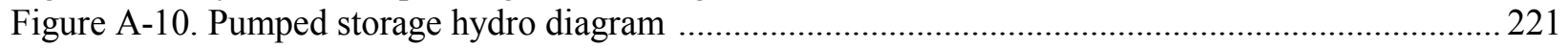

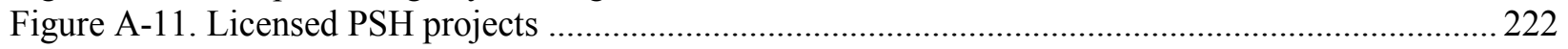

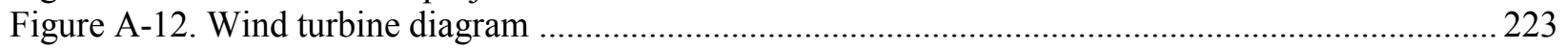

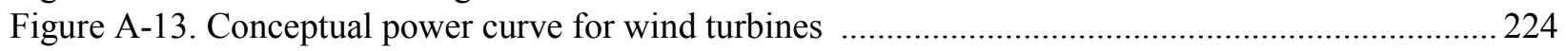

Figure A-14. Wind turbine capacity, hub height, and rotor diameter over time .................................. 224

Figure A-15. Waste to energy process diagram with pollution controls ............................................. 225

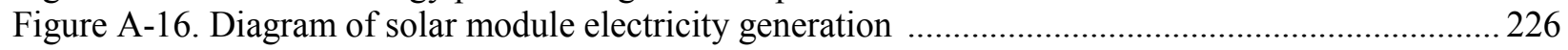

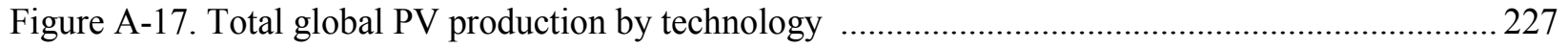

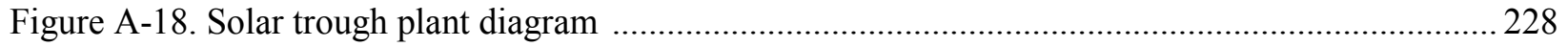

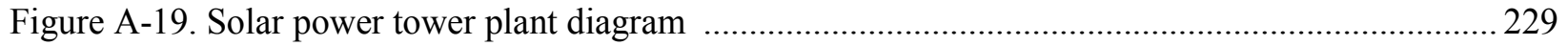

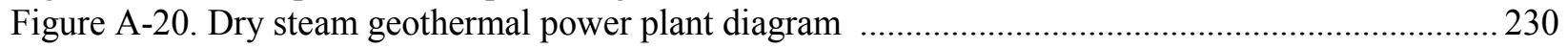

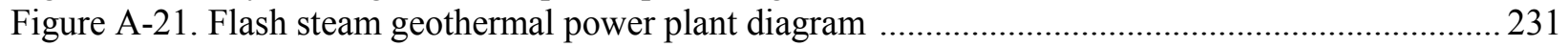

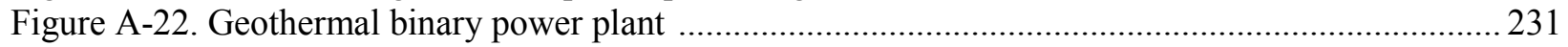

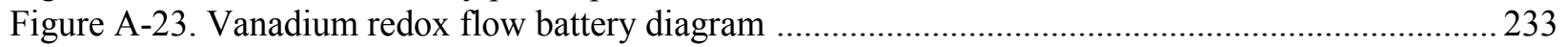

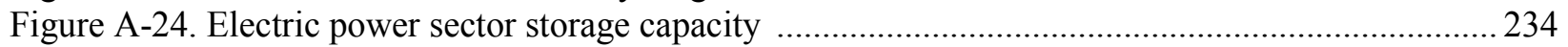

Figure A-25. Energy storage projects in the United States 2015 ...................................................... 234

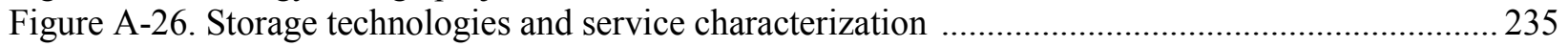




\section{List of Tables}

Table 3-1. Reported LCOEs for Deployment of Select Generation Technologies in 2022 and 2040

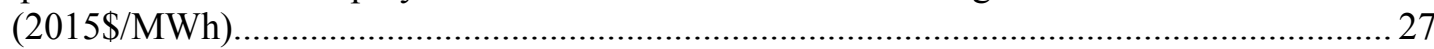

Table 3-2. Differences between Publicly Owned Utilities (POUs) and IOUs in California....................... 38

Table 4-1. Change in Generation from Major Fuel Types by Region, 2009-2014 ................................... 53

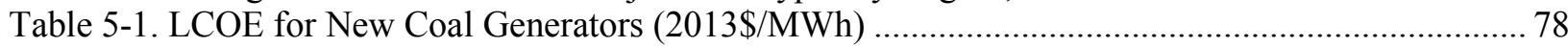

Table 5-2. QER 1.2 Base Case Generation for U.S. Coal in TWh ..................................................... 85

Table 5-3. Historical and Projected Global Coal Generation by Scenario Outlook, 2000-2040.............. 86

Table 5-4. Current and Projected Coal-Fired Capacity (GW) in the WEO New Policies Scenario, 2014-

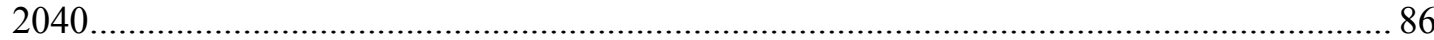

Table 6-1. LCOE Natural Gas Generators (2013\$(MWh) .................................................................. 94

Table 6-2. QER 1.2 Base Case and Side Case Generation (TWh) for CC Plants, 2014-2040 ............... 101

Table 6-3. Historical and Projected Global Natural Gas Generation by Scenario Outlook, 2003-2040 .. 101

Table 7-1. LCOE for Nuclear Generators (2013\$/MWh) ...................................................................... 106

Table 7-2. QER 1.2 Base Case Generation for Advanced Nuclear (TWh), 2014-2040 ...................... 113

Table 7-3. Historical and Projected Global Nuclear Generation by Scenario Outlook, 2000-2040 ........ 113

Table 8-1. LCOE for New Hydropower Generation (2013\$/MWh) .................................................. 119

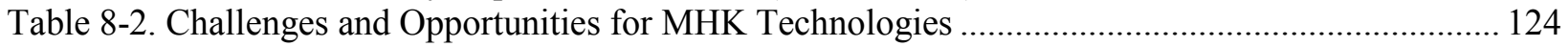

Table 8-3. QER 1.2 Base Case Generation for Hydropower (TWh), 2014-2040 ................................. 127

Table 8-4. Historical and Projected Global Hydroelectric Generation by Scenario Outlook ................... 127

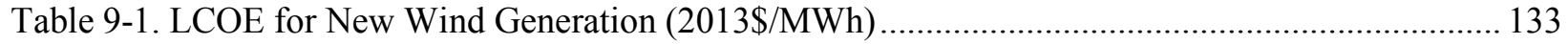

Table 9-2. QER 1.2 Base Case Generation for Wind (TWh), 2014-2040 .......................................... 139

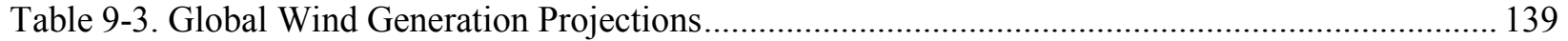

Table 10-1. Share of U.S. Operating Biomass Capacity by Subfuel Type, 2014 .................................. 142

Table 10-2. LCOE for New Direct Biomass Generation (2013\$(MWh) ............................................. 145

Table 10-3. QER 1.2 Base Case Generation for Biopower (TWh), 2014-2040 _..................................... 151

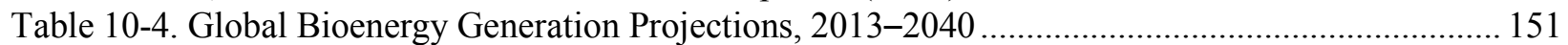

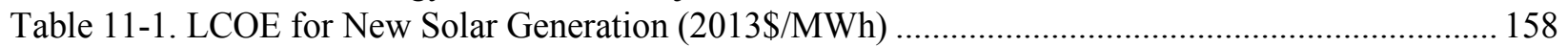

Table 11-2. QER 1.2 Base Case Projections for Solar Generation (TWh), 2014-2040 ........................ 163

Table 11-3. Global Solar Generation Projections, 2013-2040 ............................................................. 164

Table 12-1. LCOE for New Geothermal Generation (2013\$/MWh) .................................................. 168

Table 12-2. QER 1.2 Base Case Generation for Geothermal (TWh), 2014-2040 ................................ 172

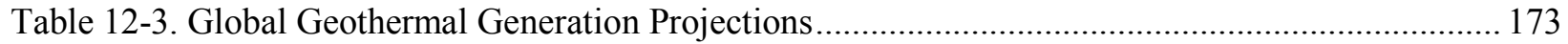

Table 13-1. QER 1.2 Base Case Projections for Petroleum (TWh), 2014-2040 ................................... 183

Table B-1. Finance Assumptions for LCOE Calculation..................................................................... 237

Table B-2. Technology Operational Assumptions for LCOE Calculation, 2015 .................................. 238

Table B-3. Range of Cost and Heat Rate Assumptions and LCOE for Dispatchable Technologies ........ 239

Table B-4. Range of Cost and Heat Rate Assumptions and LCOE for Non-Dispatchable Technologies 241

Table B-5. Maximum and Minimum Financial Factors by Technology Used for LCOE Calculations ... 243 


\section{Introduction: A Changing Generation Sector}

The U.S. fleet of electric power generators is undergoing transformational change (Figure 1-1). The share of annual electricity generation from coal-fired resources fell from approximately 50 percent in 2005 to 33 percent in 2015, while electricity generation from natural gas-fired and non-hydro renewable resources increased from 19 to 33 percent and 2 to 7 percent, respectively, over the same time period ${ }^{\mathrm{iii}}$. But not all technologies or regions are experiencing changes equally. Nuclear and hydroelectric generation outputs are relatively flat, and while the shift from coal-fired to natural gas-fired generation is strongest in the eastern half of the country (where growth in renewable electricity is modest), the western half of the country is experiencing rapid growth in renewables ${ }^{22}$.

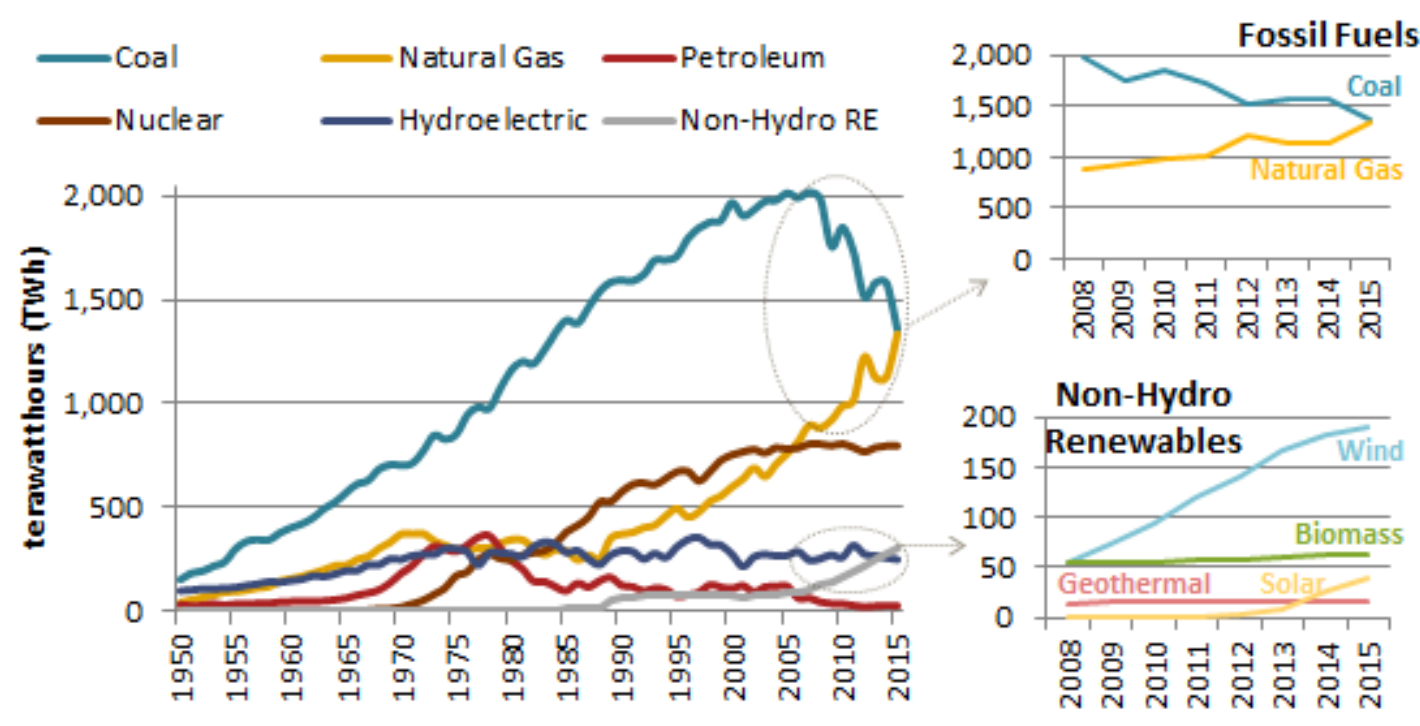

Figure 1-1. Annual electricity generation by generation technology in the United States, 1950-2015 (left), and generation for coal and natural gas (right-top) and non-hydro renewables (right-bottom) for 2008-2015

The U.S. power generation mix is experiencing rapid change, with natural gas and non-hydro renewable generation growing strongly while coal generation is declining. Solar data include distributed PV starting in 2014. Sources: EIA $2016^{23}$.

The share of electricity generation from different sources has arguably changed more quickly since 2007 than at any time since 1950 . At least three trends are catalyzing these changes: the low price of natural gas; the rise in renewable generation and distributed generation; and recent Federal and State policies impacting generation. Additionally, the decoupling of electricity demand from GDP and GHG emissions and the increasing electrification of the economy further contribute to uncertainties and opportunities for the electricity generation sector.

This report:

- Identifies trends and uncertainties impacting the U.S. generation fleet

\footnotetext{
iii Generation is the amount of electricity a generator produces over a specific period of time. Capacity is the maximum electric output an electricity generator can produce under specific conditions (EIA 2016u).
} 
- Provides a comparison of generation attributes that drive current generation investment and operational decisions

- Provides an overview of generation at the national and regional levels

- Provides a status update on major existing and emerging generation sources.

The report limits itself to the generation sector and does not address in detail parallel issues in electricity end use, environment, transmission and distribution, markets and policy design, security, and other important segments. 


\section{Trends and Uncertainties Impacting Generation}

\subsection{The Impact of Low Natural Gas Prices}

From 2000 to 2012, electricity generation from natural gas more than doubled as natural gas prices fell to relatively low levels ${ }^{24}$. Low natural gas prices are the result of the surge in natural gas production, largely due to the combination of horizontal drilling and hydraulic fracturing ${ }^{25}$. These low prices have impacted deployment of electricity produced by natural gas plants, both through increasing use of existing natural gas power plants and driving investments in new natural gas power plants.

Only a decade ago, U.S. energy policymakers were grappling with the challenge of planning and permitting dozens of new liquefied natural gas import terminals. During that time, domestic natural gas production was in decline while demand continued to grow, especially in power generation. That imbalance in domestic supply of and demand for natural gas began to change appreciably in 2007 and 2008 when new domestic supplies of hydraulically fractured natural gas began to enter the market (Figure 2-1). Gradual improvements in the economics of producing shale gas had occurred throughout the decade ${ }^{26}$ and by 2010 the game-changing nature of the cumulative breakthroughs was apparent ${ }^{27}$.

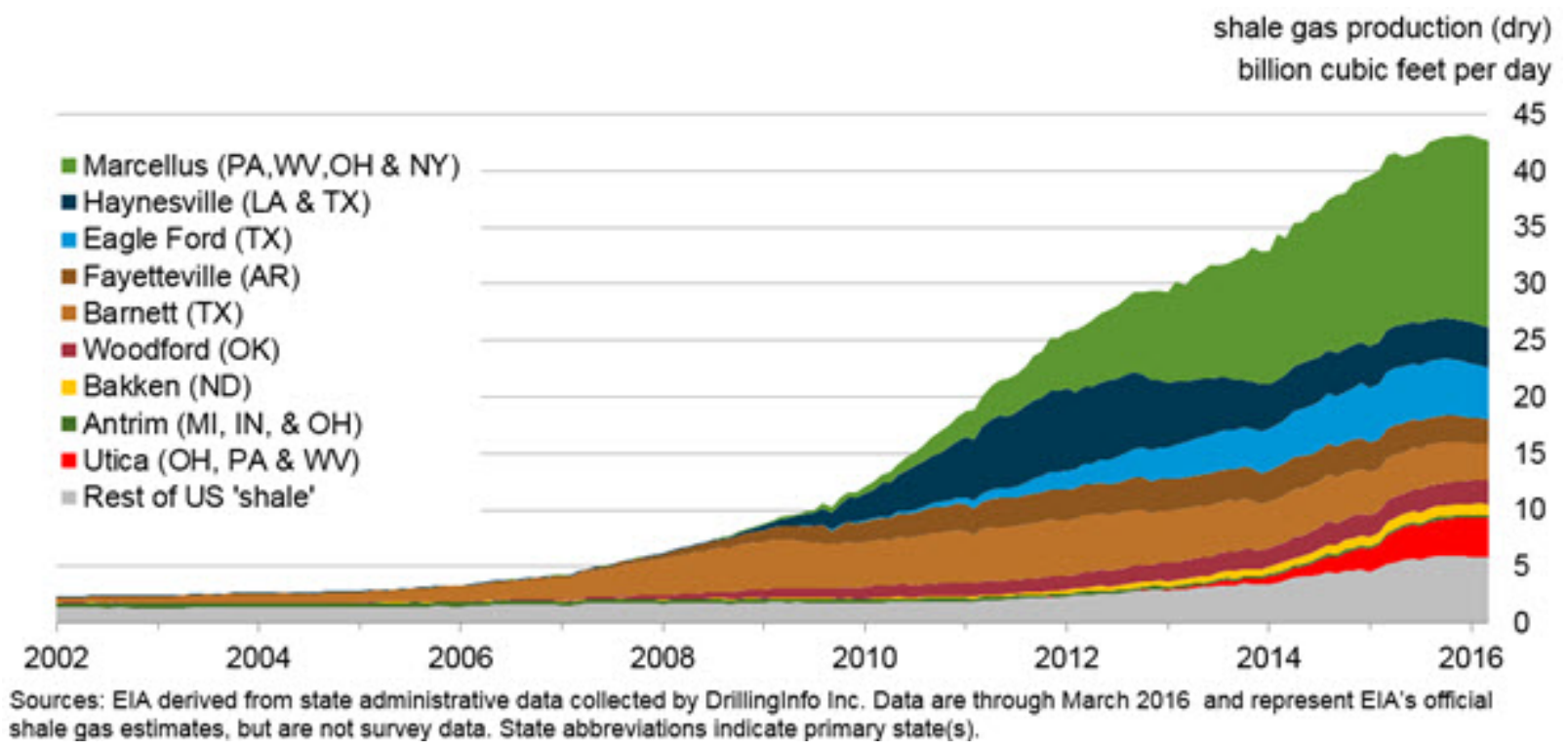

Figure 2-1. U.S. dry shale gas production, 2002-2016

The production of gas from the Marcellus and Eagle Ford plays, enabled by advances in hydraulic fracturing, contributed largely to the U.S. gas surge. Source: EIA $2016^{28}$.

In fact, by 2010, the United States surpassed Russia as the world's largest producer of natural gas $^{29}$. Total domestic natural gas production grew from approximately 18 trillion cubic feet in 2005 to nearly 27 trillion cubic feet at the end of $2015^{30}$. In 2015 , over 55 percent of total U.S. natural gas production was coming from hydraulically fractured wells, up from less than 5 percent a decade earlier ${ }^{31}$. Although natural gas prices have remained somewhat volatile over the past 7 years - briefly spiking during the winter of 2013-2014 due to unusually cold temperatures - they are down sharply from the summer peak of 2008 when they exceeded $\$ 13$ per million British thermal units (MMBtu) at the Henry Hub. As of August 26, 2016, natural gas 
working inventories stood at 3,401 billion cubic feet ( $8 \%$ higher than the previous year) and month-ahead futures prices were at $\$ 2.70 / \mathrm{MMBtu}$. Natural gas stock levels remain higher than year-ago and five-year averages going into the 2016-2017 winter heating season due in part to high inventories from warm winter weather in $2015-2016^{32}$.

A comparison of the average cost of fossil fuels per unit of heat available (MMBtu) delivered to electricity generators in the United States since 2006 shows the dramatic drop in natural gas prices both overall and compared to coal (Figure 2-2). Coal prices rose slowly from 2000 to 2011 and have since declined slightly, while petroleum prices first fell after the impact of the recession of 2008 and then rose again following economic recovery, before falling again in mid-2014 due to global oversupply. Natural gas prices, on the other hand, declined after the recession and stayed low due to the surging output from many domestic shale gas plays, a number of warm winters $^{33}$ and low overall electricity demand growth.

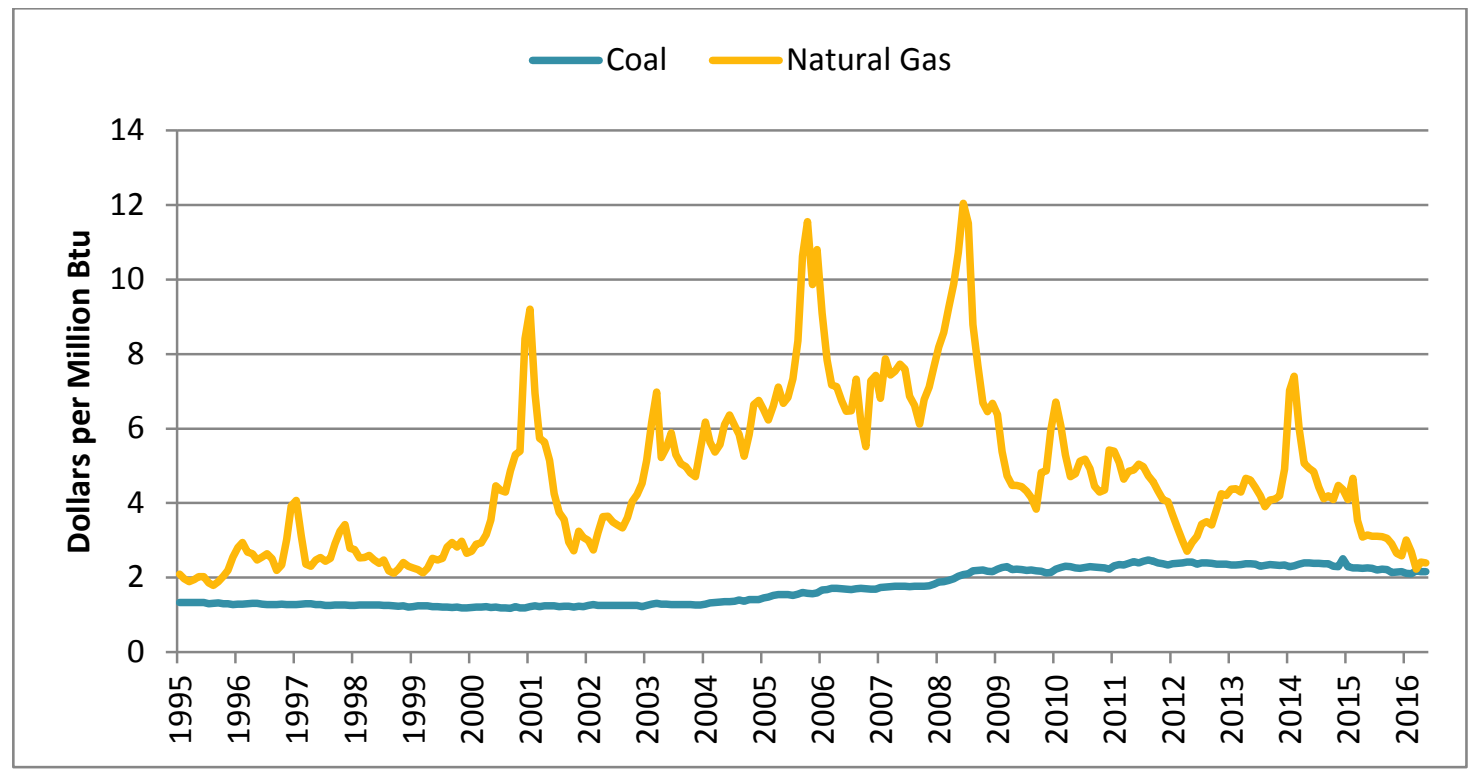

Figure 2-2. Average monthly cost of delivered fossil fuels in the U.S. power sector, 1995-2016

The drop in natural gas prices since 2008 has made natural gas more competitive with coal for electricity generation. Source: EIA $2016^{34}$.

There have been two main "surge" periods during which generation fleet owners ramped down dispatch of their coal plants in favor of more natural gas generation: 2011-2012 and again in 2014-2016. These periods of low delivered fuel prices have resulted in the increased utilization of existing NGCC units, with the capacity factor for NGCC plants increasing from an annual average capacity factor of 40 percent in 2009 to 48 percent in 2013 and 2014, and 56 percent in $2015^{35}$. This increase in natural gas generation, due to low fuel prices and the low cost of new NGCC units, has corresponded to a reduction in coal power plant utilization, declining from prerecession (2003-2008) levels of 73 percent to 60 percent in 2013-2014 and 55 percent in 2015 despite coal plant retirements ${ }^{36}$.

Trends of increasing natural gas generation are due to delivered natural gas prices approaching the price of coal, and the lower non-fuel variable expenses of operating a gas generator compared to a coal generator. Although delivered natural gas prices have remained above those for coal on 
a per BTU (or energy unit) basis, the average efficiency of a combined-cycle natural gas plant is higher than that of coal, making the former fuel currently more economic in some regions of the country to generate electricity on a dollar per megawatt-hour (MWh) basis. The future of the ongoing surge of natural gas generation remains uncertain as gas prices could rise relative to coal depending on a number of other supply and demand factors.

As natural gas prices are often the fuel for the marginal generating unit, they usually determine the marginal cost of electricity. Low-priced natural gas is putting downward pressure on wholesale electricity prices in some competitive wholesale markets (Mid-Continent Independent System Operator [MISO] and New York Independent System Operator [NYISO], for example). While low gas prices are positive for consumers, they are potentially one factor threatening the continued viability of certain generators, especially coal and nuclear.

This newfound abundance of natural gas has been a major contributor to a shift from coal to natural gas in new and projected power generating capacity additions. Additional factors, such as the comparatively low capital cost and scalability of NGCC units, as well as the costs of compliance with Clean Air Act regulations, have also played a role ${ }^{\text {iv }}$. The competitiveness and continued high utilization of natural gas units depends largely on continued low natural gas prices; ${ }^{v}$ however, other factors, such as the reduced carbon footprint of gas, as well as market and regulatory drivers, may also impact the competitiveness of this electricity source.

\subsection{The Rise in Renewable and Distributed Generation}

Advances in technology and cost reductions for renewables and distributed generation are spurring rapid growth in most non-hydro renewables. In 2014, generation from non-hydro renewables surpassed that from hydropower for the first time, contributing 7.0 percent and 6.1 percent to total U.S. generation, respectively. In 2015, this trend continued as non-hydro renewables grew to 7.5 percent of generation and hydro to 6.3 percent. The increase in renewables is in part due to a large buildout of wind turbines since 2009, which has largely been driven by State renewable portfolio standards (RPS) and the availability of the production tax credit (PTC). Solar installments have also grown rapidly, with generation nearly tripling from 2013 to $2015^{37}$. Solar differs from wind and other renewables in that approximately one-third of new capacity is in the form of small-scale, distributed installations. In 2015, over $12 \mathrm{TWh}$ were generated by distributed solar panels, about 30 percent of total solar generation and 0.3 percent of total generation in the United States ${ }^{38}$.

Technological advancements also contributed to increased non-hydro renewable deployment. The cost and performance profiles of certain renewable sources of generation began to improve significantly around $2008^{39}$. As shown on the right side of Figure 2-3, utility-scale solar PV cost reductions have been widely reported as the most significant, with organizations like Lazard

\footnotetext{
iv The relatively low capital cost of NGCC units, in conjunction with their short construction times, results in a lower financial risk to utilities when evaluating capacity choice additions.

${ }^{v}$ The cost of natural gasfired generation is sensitive to the delivered price of natural gas, which constitutes a large portion of the levelized cost of electricity (LCOE). High prices can therefore have strong impacts on whether these plants dispatch and on the outlook for such plants. Difficulties in obtaining long-term supply contracts, lack of longterm onsite storage options, and historical price volatility can exacerbate these concerns. See NETL 2015; NETL n.d.[b]; FERC n.d.; EIA 2014c.
} 
reporting a decline in $\mathrm{LCOE}^{\mathrm{vi}}$ for utility-scale PV projects of 85 percent between 2009 and $2016^{40}$. While PV technology advancements have continued to improve more modestly, much of the cost reduction is attributed to larger economies of scale in the manufacturing process, especially in China ${ }^{41}$. Several recent PPAs in the United States report utility-scale PV contracts being offered at less than $\$ 40 / \mathrm{MWh}$, which includes the benefits of the 30 percent investment tax credit (ITC) ${ }^{42}$. In comparison, nationwide wholesale power prices ranged from approximately $\$ 29 / \mathrm{MWh}$ to $\$ 65 / \mathrm{MWh}$ in $2014^{43}$.
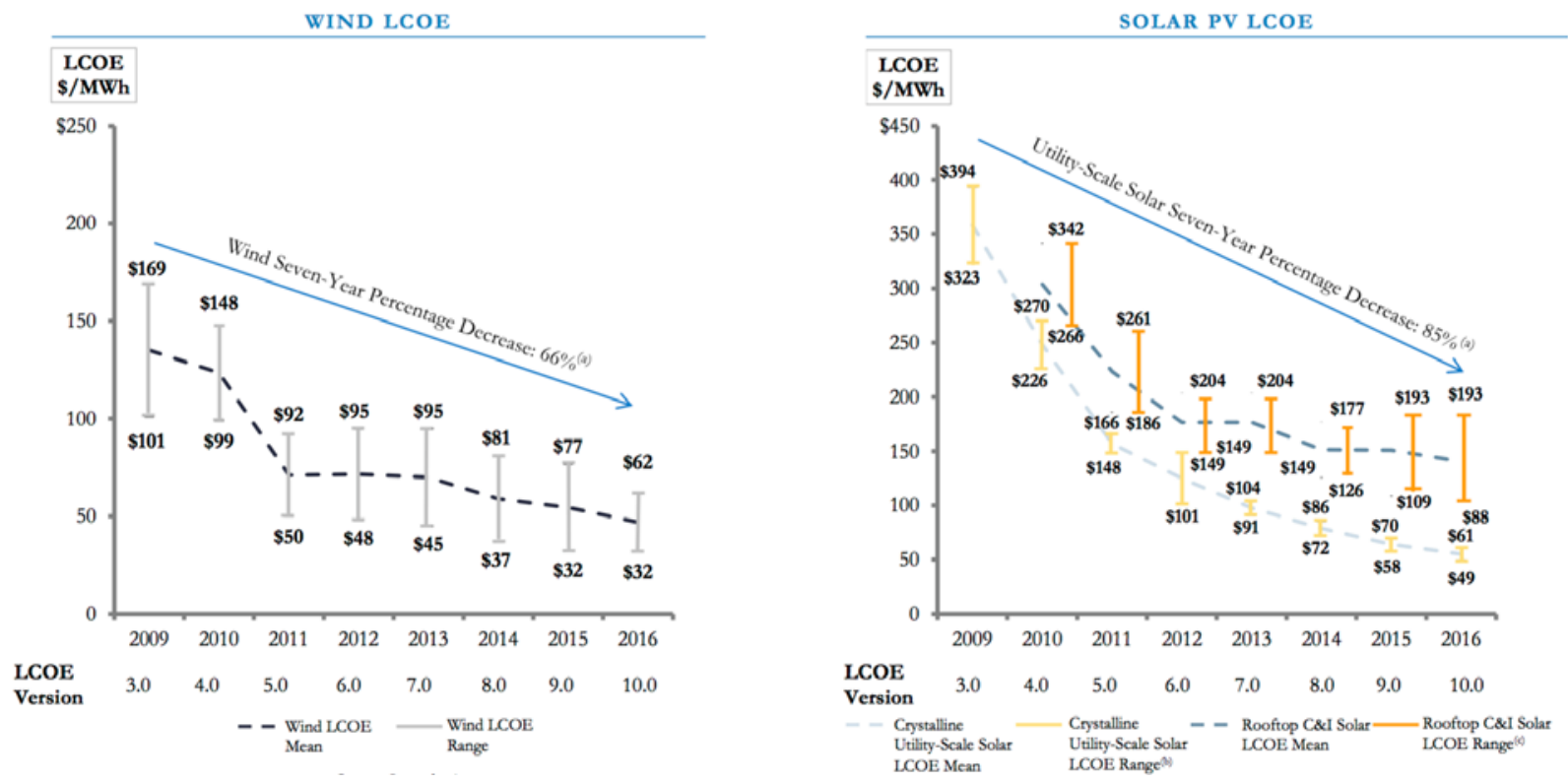

Figure 2-3. Change in U.S. LCOE for wind and PV, 2009-2016

Wind and solar generation costs have declined significantly over the past 6 years, helping drive deployment to higher levels. Source: Lazard $2016^{44}$.

Distributed solar PV is also growing rapidly due to Federal and State incentives, a greater number of commercial offerings, and more robust financing options.

Figure 2-4 shows growth of distributed solar PV and distributed wind (below $1 \mathrm{MW}$ ) on a logarithmic scale, indicating that distributed solar PV generating capacity grew by nearly a factor of 100 between 2004 and 2014, while distributed wind increased by about a factor of $14^{45}$.

\footnotetext{
${ }^{\mathrm{vi}} \mathrm{LCOE}$ is a convenient summary measure of the overall generation cost of different generating technologies, but it does not represent all cost or investment considerations. None of the LCOE numbers presented in this report include tax incentives, unless otherwise noted. The EIA summarizes important limitations of LCOE metrics here: http://www.eia.gov/forecasts/aeo/electirity generation.cfm.
} 


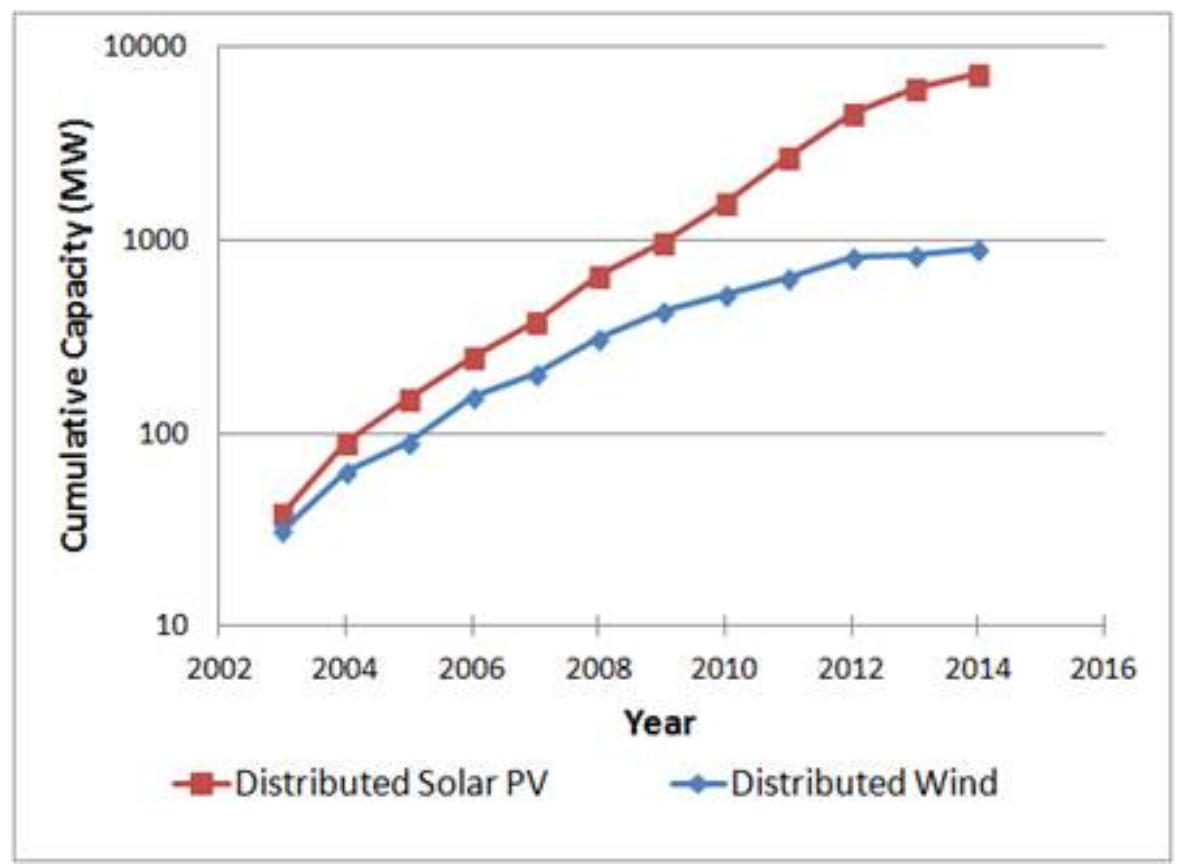

Figure 2-4. Installed capacity (MW) of distributed wind and distributed solar PV, 2002-2014

Renewable sources of distributed generation have grown sharply in recent years. NOTE: Cumulative capacity given in MW-DC (direct current) for distributed solar. Sources: LBNL $2017^{46}$.

Distributed PV accounted for 12.1 TWh of generation in 2015, or 0.3 percent of total national generation, according to newly released data from the U.S. Energy Information Administration (EIA) ${ }^{47}$, although the percentage of distributed PV generation can be much higher in regions of the country where deployment has grown rapidly (California and Hawaii, for example). While utility-scale PV is less expensive than distributed PV, the latter is still expected to continue growing rapidly due to factors such as tax and rate incentives and third-party ownership options that simplify financing ${ }^{48}$. Further, depending on the local regulatory rate structures, distributed generation does not incur costs for transmission and distribution costs from remote sites, lowering delivered energy costs for the portion generated on-site.

Wind generators have experienced similar cost reductions and technology improvements (Figure 2-3), with Lazard estimating a 66 percent reduction in the LCOE between 2009 and $2016^{49}$. Wind LCOE reductions are much more prominent pre-2009, however, as costs declined from over $\$ 600 / \mathrm{MWh}$ in 1980 to less than $\$ 100 / \mathrm{MWh}$ in $1997^{50}$. Much of the cost reduction for wind generators comes from reduced commodity prices in the post-recession global economy ${ }^{\text {vii }}$, larger turbine diameters that increase efficiency, and increased turbine heights that allow capture of stronger winds ${ }^{51}$. Wind PPAs that include the effects of the PTC are now routinely contracted at less than $\$ 30 / \mathrm{MWh}$, which is competitive with new combined cycle (CC) natural gas plants and, in some cases, existing natural gas plants ${ }^{52}$.

\footnotetext{
${ }^{v i i}$ Reduced commodity prices are typically not mentioned as a reason for lower wind costs, but the global price of steel, copper, and many other inputs rose significantly between 2000 and 2008 before the recession hit. These increases were correlated with rising wind capital cost estimates, as illustrated in Wiser and Bolinger (2015). Wind turbine costs have since declined, partly due to the drop in commodity prices, but also due to technological improvements.
} 
Importantly, grid operators in many regions of the country are becoming familiar with the integration challenges of more variable renewable sources of electricity in their systems ${ }^{53}$. Some of the early concerns about the difficulty and expense of integrating variable renewable generation into the grid ${ }^{\text {viii }}$ have been allayed, although operational hurdles to maintaining reliability with higher penetrations of variable renewables still exist ${ }^{54}$.

Longer-term challenges for variable wind and solar are the decreasing marginal economic value they provide to the grid at increasing penetration levels ${ }^{55}$ and the need for provision of essential reliability services, such as frequency and voltage support and ramping moderation ${ }^{56}$. While cost reduction is a continued focus of ongoing research and development (R\&D) and installation best practices, system impact mitigation methods are subject to ongoing debate among industry, regulators, and independent system operator/regional transmission organization (ISO/RTO) market operators. DOE, FERC, NERC, the Electric Power Research Institute (EPRI), and others have begun to pay critical attention to the need for variable renewables to provide essential reliability services, particularly in the area of frequency response and voltage support. Recent actions by FERC and NERC on the design of variable renewable generators represent the first steps toward addressing the longer-term challenges for variable renewable generation; however, new market designs, policy measures, and technologies would be required to help completely overcome these concerns. For example, in December 2015, NERC issued five general recommendations ${ }^{\text {ix }}$ as part of its Essential Reliability Services Task Force Measures Framework Report that focus on the incorporation of these services into the design of variable generating resources in the future ${ }^{57}$. Shortly thereafter, on February 18, 2016, FERC issued a Notice of Inquiry, Docket RM16-6000, seeking comment on the need for market reforms to support the provision of essential reliability services by all generators ${ }^{58}$.

Recent research into other impacts, such as accounting for integration costs or the operational and maintenance impacts on generators that maintain grid stability, will continue to be critical to grid operators, policy makers, and researchers in identifying the most efficient policy, market, and technical solutions to increased deployment ${ }^{59}$.

\footnotetext{
viii These include concerns that an equal amount of fully dispatchable generating capacity is needed to "back-up" the variable generation and that storage is required to maintain reliability in a system with significant (up to 30 percent) variable renewable electricity production. For more on this subject, see Milligan et al. (2009) and Palchak (2015).

${ }^{\text {ix }}$ The NERC recommendations are:

1. "All new resources should have the capability to support voltage and frequency. Automatic voltage regulators and governors have been standard on conventional generators for decades, and comparable capabilities are currently available for new VERs and other resources. Ensuring that these capabilities are present in the future resource mix is prudent and necessary.

2. Monitoring of the Measures and investigation of trends. The Measures are intended to highlight aspects of reliability that could suggest future reliability concerns if not addressed with suitable planning and engineering practices.

3. Planning and operating entities should use the Industry Practices. While the results of Industry Practices will be system specific and difficult to quantify or compare between different regions, they will help ensure that emerging concerns are addressed with suitable planning and engineering practices.

4. While beyond the formal scope of the ERSTF, the task force recognized that Distributed Energy Resources (DERs) will increasingly affect the net distribution load that is observed by the BPS. The ERSTF recommends coordination of NERC Reliability Standards with DER equipment standards such as IEEE 1547. Pursuant with NERC's reliability assessment obligations, the ERSTF further recommends that NERC establish a working group to examine the forecasting, visibility, control, and participation of DERs as an active part of the BPS. With prudent planning, operating and engineering practices, and policy oriented to support reliability, DERs should be able to be reliably integrated into BPS operation.
}

5. Open sharing of experiences and lessons learned. The reliability of the system can be maintained or improved as the resource mix evolves, provided that sufficient amounts of essential reliability services are available" 


\subsection{Recent Federal and State Policies Impacting Generation}

In addition to low natural gas prices, Federal and State regulations have also played a significant role as drivers of change in the generation mix over the last decade. Federal and State policies such as tax credits for renewables, energy efficiency measures, and RPS are among the key policy drivers. In addition, compliance costs associated with Federal and State environmental regulations coupled with low natural gas generation costs have impacted electricity generators.

In 2015 alone, approximately $14 \mathrm{GW}$ of coal-fired generators retired ${ }^{60}$. A number of coal plants chose to retire rather than comply with the Mercury and Air Toxics Standard due to aging infrastructure and the difficulty of recovering capital expenditures in an environment of low natural gas prices and low demand growth ${ }^{61}$. Given the market environment, the effect of the Federal and State regulations have tended to move forward in time these retirements, rather than increase the overall long-term level. Select other rules impacting generation include the Cross States Air Pollution Rule, ${ }^{\mathrm{x}}$ coal combustion residuals, ${ }^{\mathrm{xi}}$ water intake structures, ${ }^{\mathrm{xii}}$ and New Source Performance Standards for air pollution from power plants. ${ }^{\text {xiii }}$ Ground-based ozone concentration requirements were recently reduced from 75 parts per billion to 70 parts per billion, which could impact power generation options in some regions of the country. ${ }^{\text {xiv }}$ The Clean Power Plan (CPP) is projected to achieve a 32 percent reduction in power sector $\mathrm{CO}_{2}$ emissions from 2005 levels by $2030^{62, x v}$. Even if some states are on their way to meeting the carbon standards defined in the CPP due to factors unrelated to the CPP, many states will need to make changes to their electric sector to comply ${ }^{63}$.

\subsubsection{EPSA QER 1.2 Outlook for Generation Through 2040}

EPSA developed a projection of U.S. electricity generation and capacity out to the year 2040 based on the current existing market and regulatory framework. The QER 1.2 Base Case presents outputs developed with the EPSA-NEMS (National Energy Modeling System) model (DOE 2015h). The analysis uses a modified version of EIA's NEMS model that EPSA maintains consistent with the Annual Energy Outlook 2015 (AEO2015) High Oil and Gas Resource Case with the following changes:

- Mass-based implementation of the CPP with new source complement to 2030 (goals assumed constant post-2030). The implementation covers all existing (except CT) and all new fossil generation, assumes national trading (no banking or borrowing), includes energy efficiency using EIA's rebate code, and excludes the Clean Energy Incentive Program.

- Recent renewable tax credit extension legislation passed in late 2015.

\footnotetext{
${ }^{\mathrm{x}} \$ 110(\mathrm{a})$ of the Clean Air Act of 1963,42 U.S.C. $\$ 7401$.

${ }^{x i}$ Subtitle D of the Resource Conservation and Recovery Act of 1976, 42 U.S.C. $§ 6901$.

xii $\$ 316($ b) of the Clean Water Act of 1972,33 U.S.C. $\$ 1251$.

xiii $\S 111($ b) of the Clean Air Act of 1963, 42 U.S.C. $\$ 7401$.

${ }^{x i v}$ More information on this is available here: https://www.epa.gov/ozone-pollution/setting-and-reviewingstandards-control-ozone-pollution

${ }^{\mathrm{xv}}$ On February 9, 2016, the U.S. Supreme Court stayed the rule implementing the CPP until the current litigation against it concludes. Chamber of Commerce, et al. v. EPA, et al., Order in Pending Case, 577 U.S. (2016), http://www.supremecourt.gov/orders/courtorders/020916zr3 hf5m.pdf. As of that date, a challenge to the rule was pending before the United States Court of Appeals for the District of Columbia Circuit.
} 
- Updated projections of CCS cost and performance numbers.

- Updated projections of renewable energy cost and performance data.

This Base Case assumes some improvement in cost of performance of most generation technologies between now and 2040, but no new policies. Summary graphics of projected generation and capacity from each technology out to 2040 are provided in Figures 2-5 and 2-6. The latter plot shows that coal capacity is projected to continue retiring out to 2040, to be replaced by new natural gas, solar, and wind capacity to meet increasing demand. In this Base Case, solar and wind capacity make up roughly 14 percent of national generation in 2040.

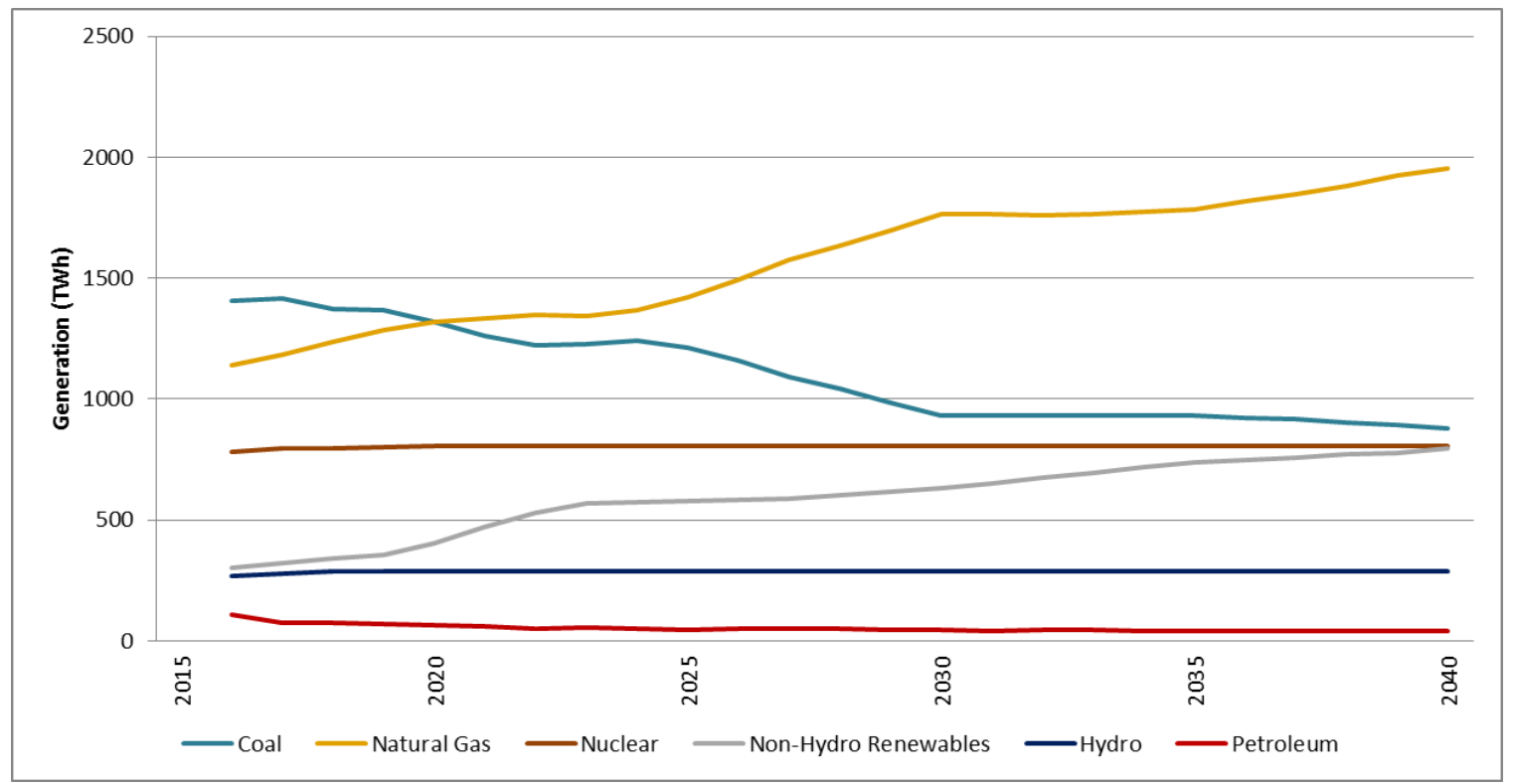

Figure 2-5. Projected generation (TWh) under the QER 1.2 Base Case, 2016-2040

The QER 1.2 Base Case projection, which includes a mass-based implementation of the CPP, projects that the generation mix will undergo significant changes through 2040. Generation from natural gas and non-hydro renewables is projected to grow the most, while coal sees almost a 40\% decline. Source: EPSA $2016^{64}$

The QER 1.2 Base Case results are itemized for each of the generation technologies in Sections 5-13. In addition, a global outlook for each generation technology is presented from the International Energy Agency's World Energy Outlook. In that publication, three scenarios are considered: Current Policies (existing legal and market framework), New Policies (likely new modifications to government frameworks), and 450 Scenario (a pathway needed to stabilize global increase in temperature to $2^{\circ} \mathrm{C}$ by limiting GHG concentrations at 450 parts per million of $\mathrm{CO}_{2}$ ). 


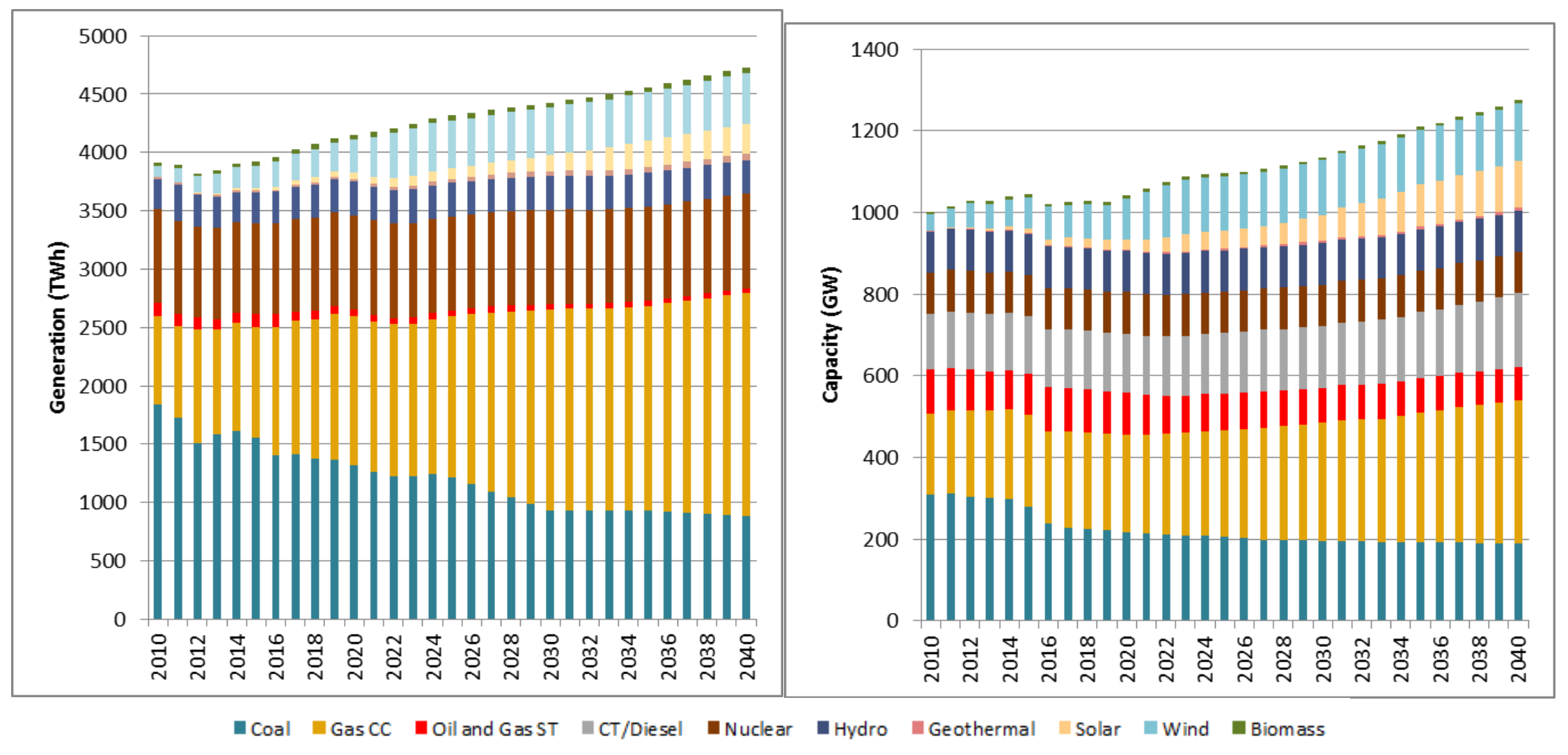

Figure 2-6. Projected U.S. generation (TWh) and capacity (GW) under EPSA's QER 1.2 Base Case

EPSA designed a scenario to estimate a reference case for electricity generation. This Base Case considers existing policies, including the CPP and tax extenders. Generation under the Base Case is on the left, and capacity is on the right. New capacity out to 2040 comes primarily from natural gas, wind, and solar installations. Source: EPSA $2016^{65}$. 


\subsection{Changing Relationship Among GDP, Electricity Demand, and GHG Emissions}

The relationship between the growth of the economy and the growth of electricity demand is changing. Between 1950 and 1995, the U.S. economy and electricity demand growth were strongly correlated, with growth in GDP occurring alongside growth in electricity demand, as shown in Figure 2-7. Prior to 1995, there is a 40-year correlation between the growth rate of GDP and electricity, especially between 1975 and 1995 when the two measures were nearly equal, with each reflecting about 2-3 percent growth per year ${ }^{66}$. However, in the past decade, electricity demand growth has slowed disproportionately to GDP growth, slowing to less than 1 percent annually. Going forward, these two indicators are likely to continue to be correlatedincreased production of goods will still lead to increased power use - but the growth rate for electricity demand may be far below that of GDP growth ${ }^{67}$. There are many drivers for this trend, including energy efficiency standards, slowed population growth, and fundamental change in the economy away from energy intensive industries toward a service economy ${ }^{68}$. However, this trend suggests that decreased electricity use and GHG emissions are not inconsistent with a strong economy. While the U.S. economy has grown by 10 percent since 2007 , electricity demand growth has been flat ${ }^{69}$.

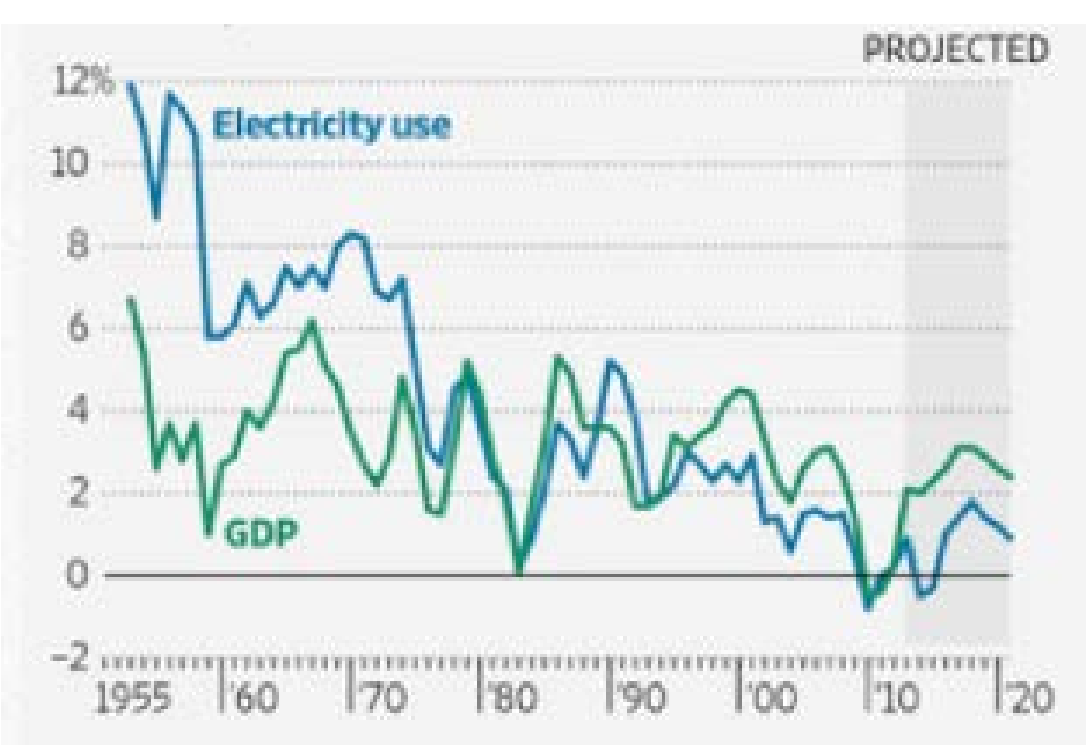

Figure 2-7. U.S. electricity use and economic growth, 1950-2020

Between 1950 and 1995, GDP growth and electricity demand growth were strongly correlated, but after 1995 to the present they have begun to diverge with electricity demand growth remaining lower than GDP growth. Source: DOE $2015^{70}$.

Power sector carbon emissions in 2015 had declined by nearly 21 percent since 2005 equivalent to an average decline of roughly 2 percent per year ${ }^{71}$. These changing relationships have positive implications for the United States' ability to enjoy economic growth while reducing GHG emissions in the absence of significant demand growth. 


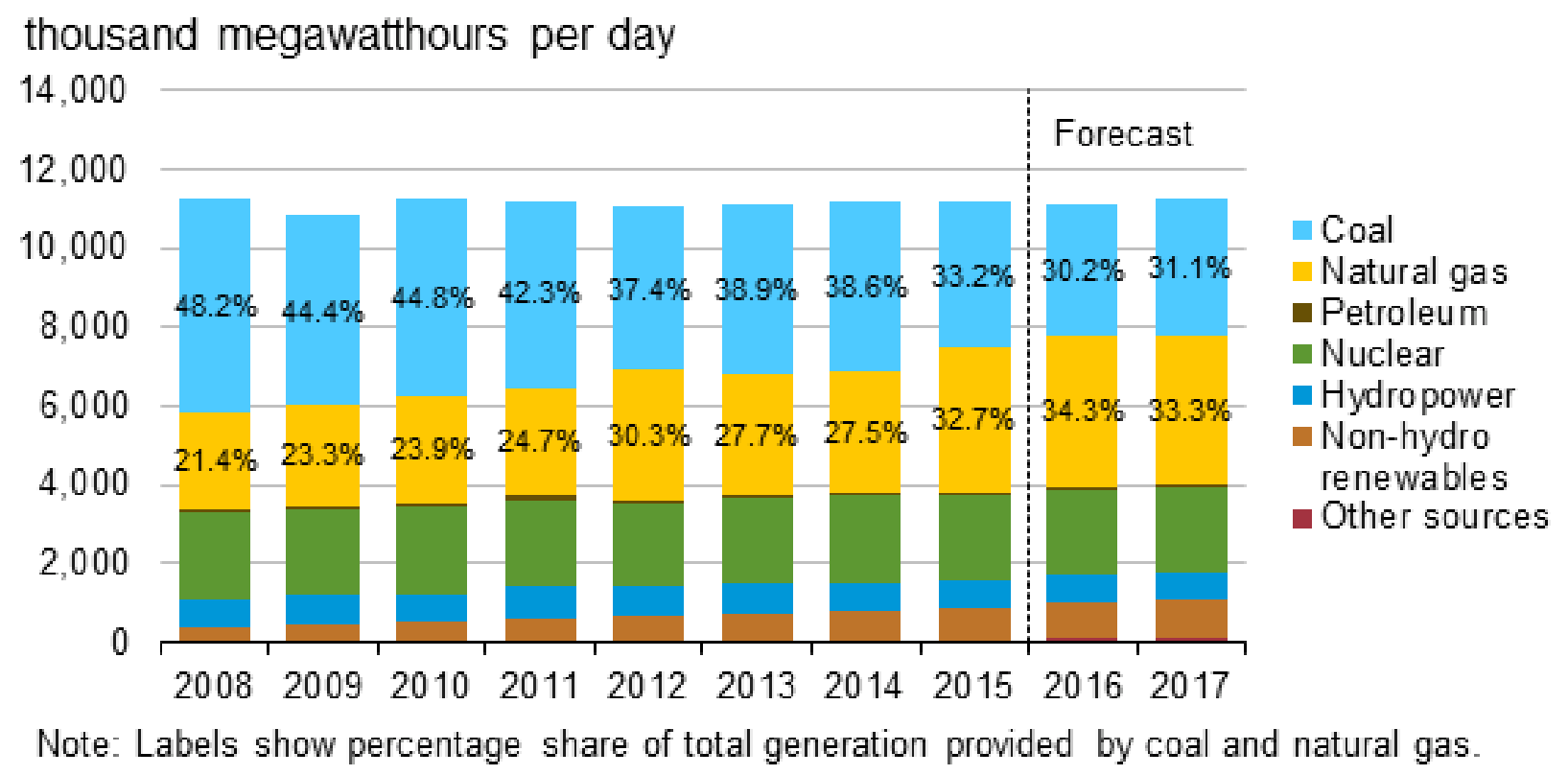

Figure 2-8. U.S. electricity generation by fuel for all sectors, 2008-2017

U.S. power generation since 2008 shows a decline of coal generation (light blue) as both natural gas (yellow) and new renewables (brown) rose; nuclear (green) and hydro (dark blue) remain flat. Source: EIA $2016^{72}$.

The 2007-2008 global financial crisis had a profound impact on energy use around the world. In the United States, electricity demand, transportation fuel demand, and industrial energy use declined significantly after the recession. This initial drop, coupled with energy efficiency improvements and structural shifts in the U.S. economy, has resulted in slowed demand growth $^{73}$. National electricity generation growth has slowed on average to less than 0.5 percent annually from 2012-2015 compared to 1.4 percent on average from 2000-2007 ${ }^{74}$. The need for new generation supply has thus been muted given the lack of additional demand, although generation retirements have driven new capacity investments to some degree.

The reduction in overall electricity use is not only a result of the recession. Spending on Federal and State energy efficiency programs has continued to grow in recent years, and consumers have changed behavior to reduce their energy use and have invested in more efficient lighting, insulation, and heating equipment to cut consumption ${ }^{75}$. The emergence of distributed generation - primarily solar PV - at the residential level has also begun to cut into utility electricity sales, although as noted previously, distributed PV generation accounted for only 0.3 percent of total net generation in 2015 . $^{\text {xi }}$

The changing relationship among GDP, electricity demand, and GHG emissions has positive implications for the health of the U.S. economy and U.S. efforts to address climate change.

\subsection{Future Uncertainty: Electrification of the Transportation Sector}

A future uncertainty is the impact on electricity demand growth by potential electrification of the transportation sector. In 2015, electricity consumption in the transportation sector represented only 0.2 percent of total U.S. electricity consumption ${ }^{76}$. Future trends for increased electricity

\footnotetext{
${ }^{x v i}$ The EIA began reporting distributed PV generation data in its Electric Power Monthly in November 2015.
} 
use in the transportation sector depend upon a variety of factors, including the rate of market adoption of electric passenger vehicles (EVs) and whether EVs are charged in relation to peak or non-peak periods. Forecasts of future market adoption vary significantly indicating long term planning challenges. The AEO2016 Reference Case projects that plug-in EVs (PEVs) will account for 4 percent of new light-duty vehicle sales in $2040^{77}$. Alternatively, some analysts forecast the market penetration of PEVs to be as high as 50 percent in 2040 (Figure 2-9).

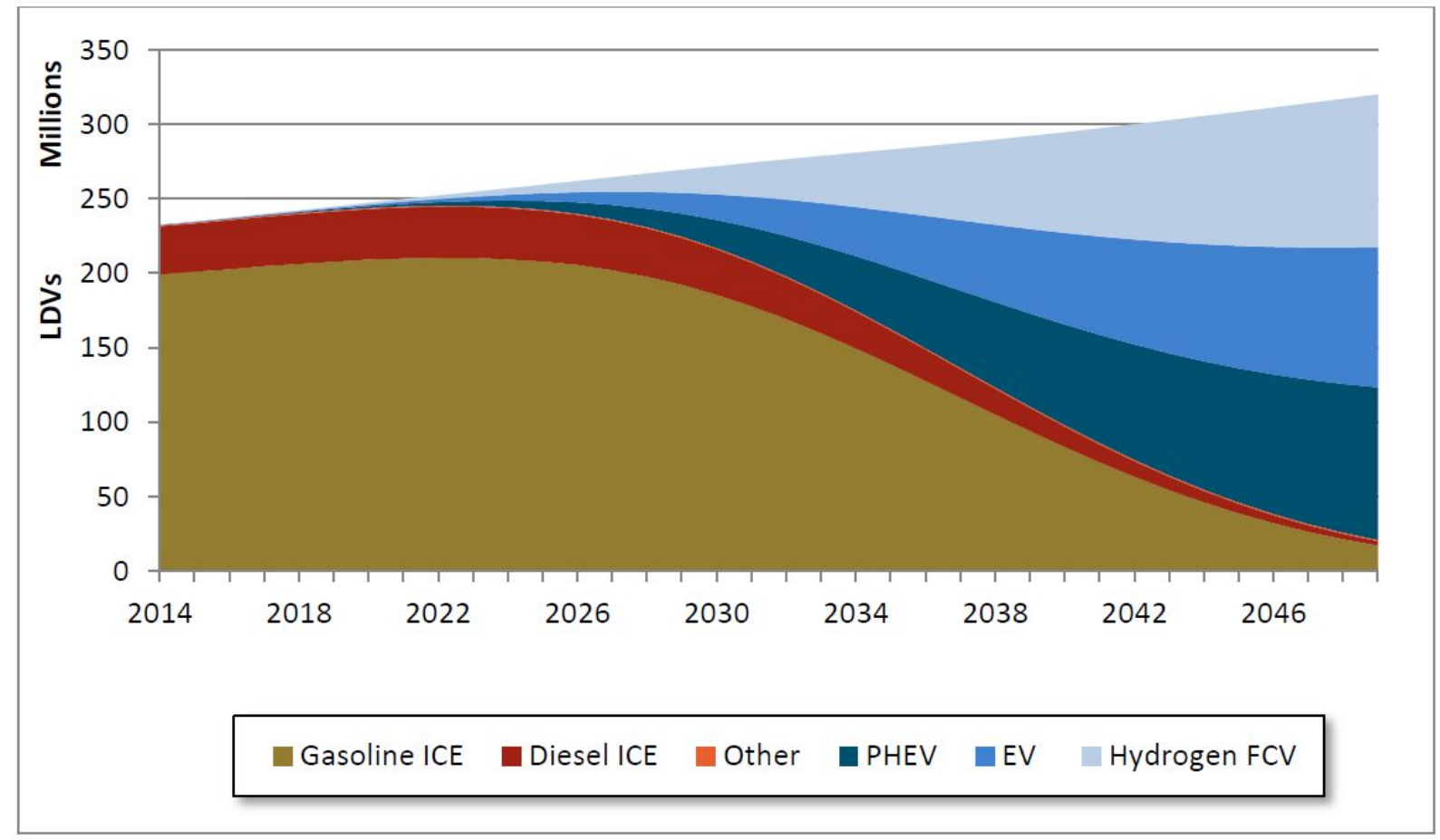

Figure 2-9. Projected annual light-duty vehicle stock, 2014-2050

One scenario projects that plug-in hybrid EVs and PEVs can make up nearly 50 percent of the light-duty vehicle fleet by 2040. Source: Williams et al. $2015^{78}$. 


\subsection{Future Uncertainty: Prices of Electricity}

Although the price of electricity increased between 1970 and 2015, the rate of increase has been slower than that for medical care, natural gas, gasoline, and other commodities (Figure 2-10).

\section{Comparison of Electricity and Other Consumer Price Trends}

(1970 to 2015)

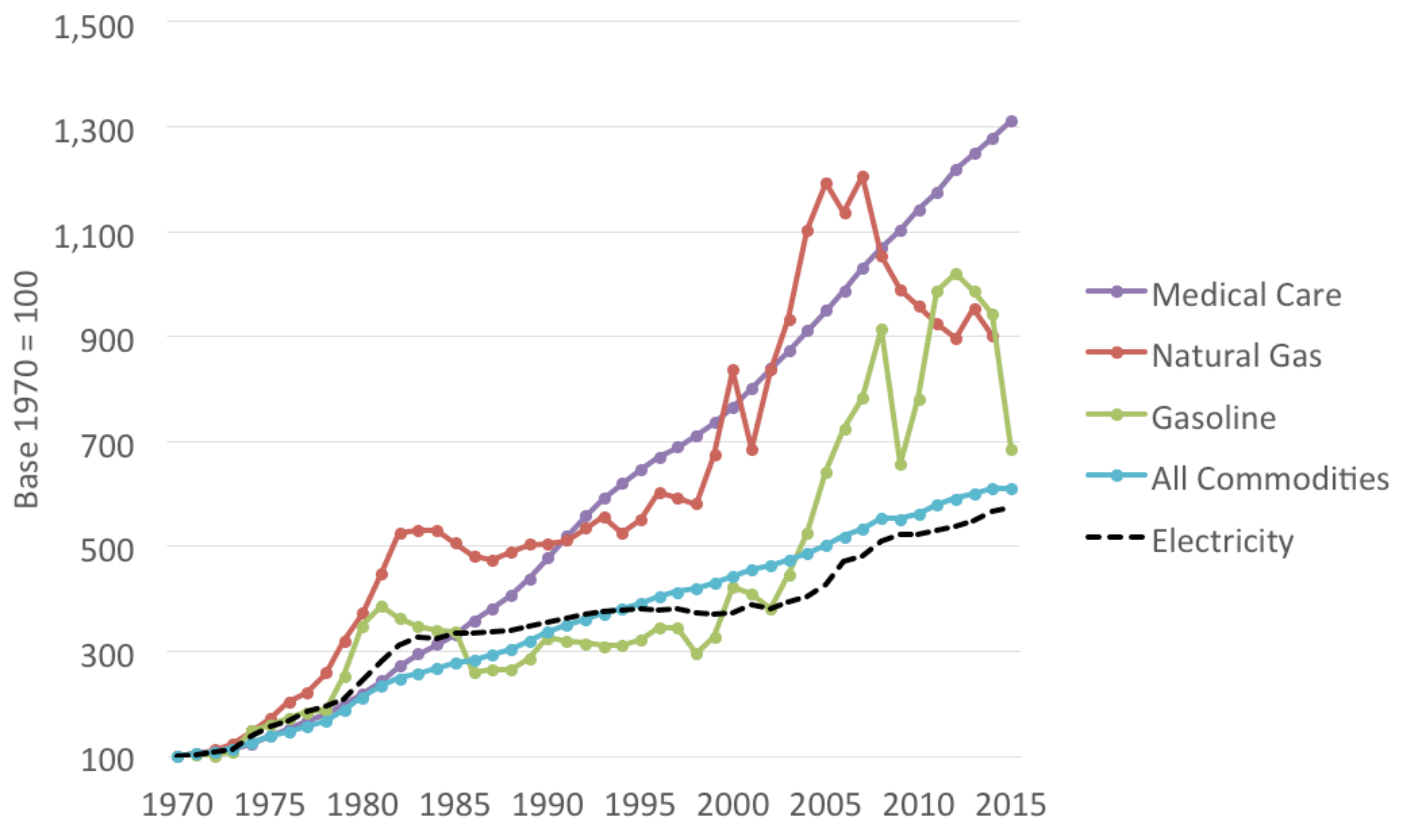

Figure 2-10. Comparison of electricity and other consumer price trends, 1970-2015

Electricity prices have risen over time, but less in comparison to other commodities. Source: EIA 2016 and BLS $2016^{79}$

However, over that same period of time, electricity prices have been steadily rising. The generation fleet in particular is sensitive to current and predicted changes. DOE modeling projects that, under the given assumptions, despite relatively stable price growth, certain segments of the industry will likely see significant changes. These changes include reductions in nuclear power, increases in renewable energy, reductions in the coal fleet, and natural gas vulnerabilities. 


\section{Crosscutting Attributes of the U.S. Power Generation Sector}

This chapter presents a high-level discussion of generation attributes and compares generation technologies by key factors that can impact investment decision making. This section summarizes and compares the information contained in chapters 5-13. Please see these chapters for more details regarding specific fuels or technologies.

\subsection{Physical System Overview}

In 2014, there were over 6,500 operational power plants of at least $1 \mathrm{MW}^{\mathrm{xvii}}$ in the U.S. electric power sector $^{\text {xiii, } 80}$. These generators deliver electricity to end users through one of the most complex "system of systems" in the world: the North American electricity grid.

There are a variety of techniques used to generate electricity, although three-phase synchronous generators that rely on electromagnetic induction (i.e., rotation of a magnet within closed loops of a conducting material like copper wire) dominate the market. The vast majority of generators uses rotary axis turbines (a series of blades that spin around a central shaft connected to the rotating magnet, or rotor) and are typically classified as either thermal or non-thermal, although other categories also exist. Thermal plants create steam or air under pressure by (1) using a heat source from combusting fossil or biomass fuels, (2) accessing heat beneath the surface of the earth (geothermal), (3) creating heat through the nuclear fission process (nuclear energy), or (4) concentrating solar energy. This heat is used to create high-temperature steam or air under pressure that is then expanded through a turbine connected to a generator. A simplified schematic of a coal-fired steam turbine (ST) generation unit is shown in Figure 3-1. Note that for most large generators, a transformer steps up the voltage of the alternating current (AC) power so that it can be transmitted across high-voltage lines with fewer losses.

\footnotetext{
${ }^{x v i i}$ Only units of $1 \mathrm{MW}$ and greater are considered utility-scale generation, which is the primary subject of this report.

${ }^{x v i i i}$ The electric power sector is defined by the EIA as an energy-consuming sector that consists of electricity-only and combined-heat-and-power plants whose primary business is to sell electricity, or electricity and heat, to the public and includes both electric utilities and independent power producers. See EIA, "Electric Power Monthly," 2016, http://www.eia.gov/electricity/monthly/.
} 


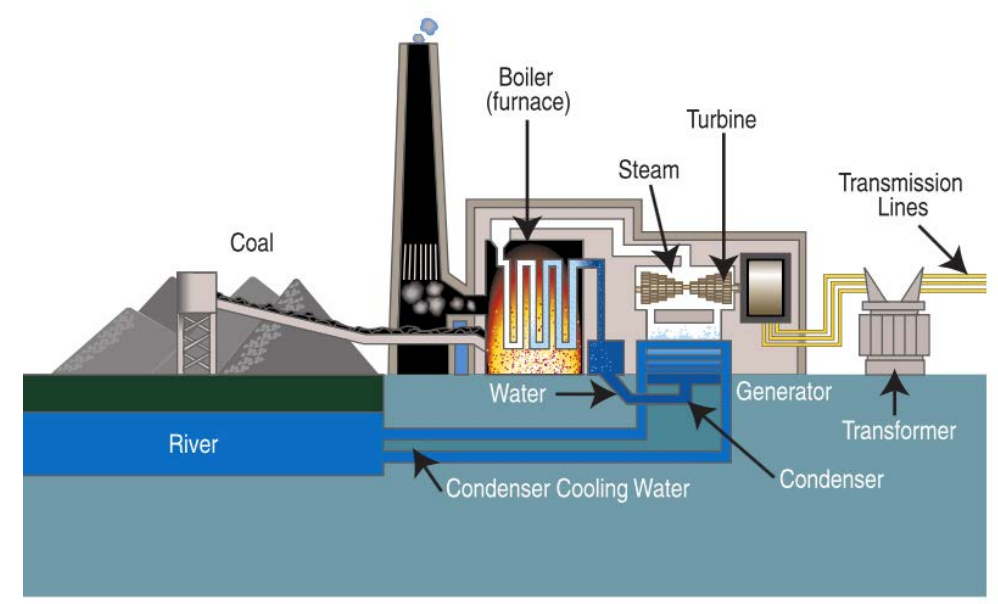

Figure 3-1. Simplified representation of a coal-fired steam boiler and generator

In thermal plants like the coal-fired steam boiler above, a fuel is used to heat water, generating steam. The steam then spins a turbine that is connected to a generator, which generates electricity through induction. Source: TVA $2013^{81}$.

Non-thermal plants have no heat source and rely on capturing some of the potential pressure and/or kinetic energy associated with a working fluid (e.g., water or air) as it passes through a turbine to similarly turn a generator shaft that produces electricity. Wind turbines extract some of the kinetic energy in the wind, so the air, and hence wind, slows down on passing through the turbine. For hydroelectric power, the kinetic energy of water flowing through the penstock drives a turbine, which converts some fraction of this energy to electricity.

Solar PV is a rapidly growing form of power generation that directly converts sunlight into electricity through the photovoltaic effect. Concentrating solar power (CSP) works by heating a working fluid that drives a steam turbine. Electrochemical generators, such as batteries and fuel cells, are other ways to produce electricity, although these latter technologies account for a small percentage of total generation today in the United States.

\subsection{Operational Attributes and Requirements}

Electricity is generated near-instantaneously to meet demand. The consequence of flipping a light switch or changing a thermostat that controls an air conditioner leads to a generator somewhere on the grid either ramping up or ramping down in near-real time to meet the change in demand. The most electricity is generated during the middle of the day, as illustrated in Figure 3-2. Different fuel and technology types serve different parts of this load. 

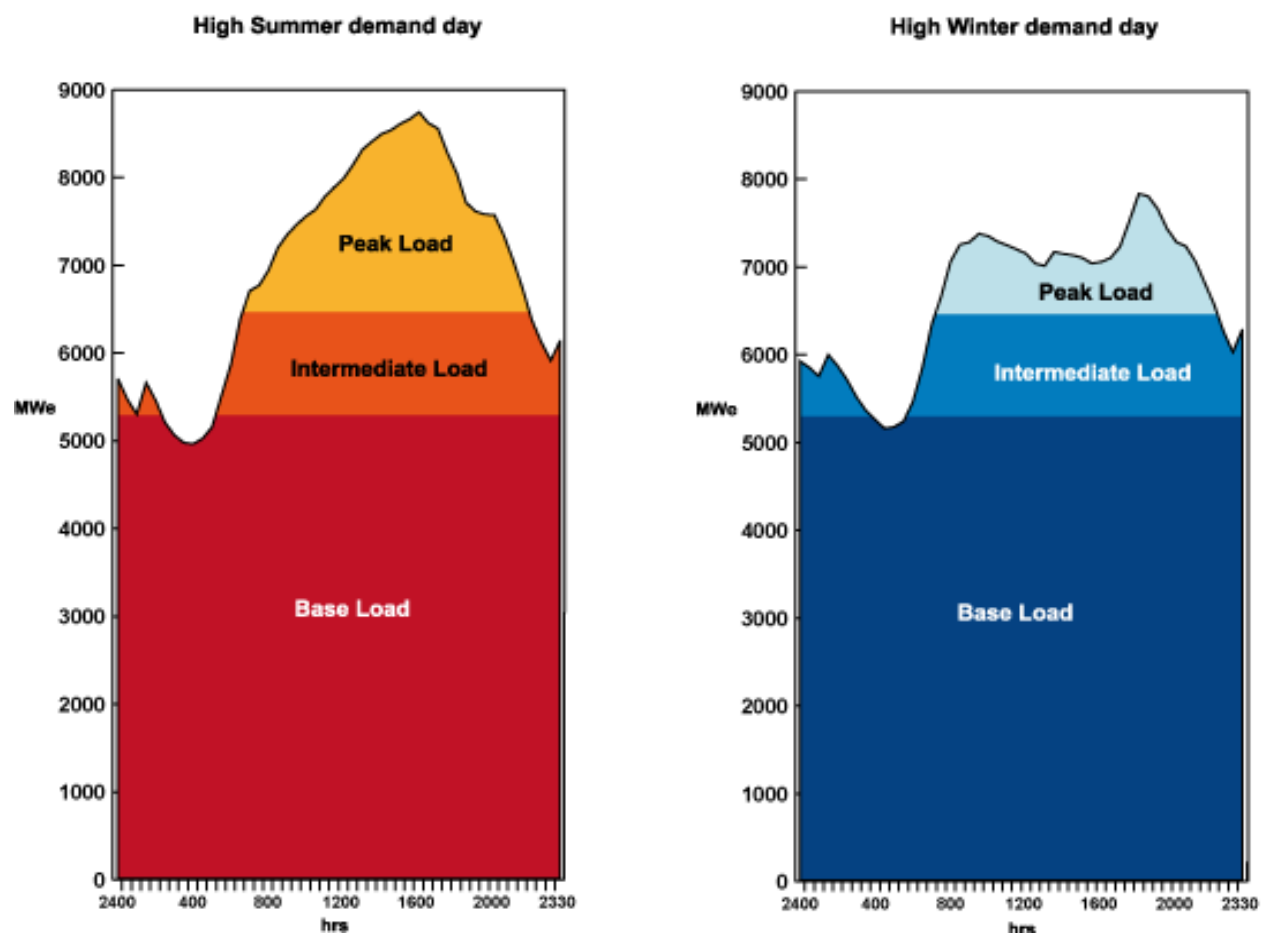

Figure 3-2. Representative traditional electricity demand profiles in summer and winter

A variety of generation types contribute to keeping electricity supply in balance with demand. While grid operators are accustomed to variability in the demand for electricity, they are now learning to deal with variability in supply as well. Source: WNA $2015^{82}$.

For example, nuclear power plants are large generators with high inertia that perform most efficiently when operating continuously at full power. They generally have limited ramping capability, meaning it takes them a long time to turn up or turn down the amount of electricity they are producing. These characteristics have contributed to nuclear power being used to function primarily as baseload power generators.

Other technologies, such CTs, are more expensive to operate, and therefore are only used during times of peak load, where demand is the greatest. They typically have faster ramping capability and therefore are quicker to respond to instantaneous changes in demand.

Some renewable technologies, such as wind and solar, have been classified as variable generators. This means that operators have limited capability to dispatch them on demand. For example, wind speeds at any given location vary widely over an array of time slices, and PV can be impacted by the weather (e.g., clouds) and can only produce power during the day without storage. Since renewable technology fuel sources are free, the technologies tend to operate whenever they are capable of generating electricity. There have been places, where, at times, these sources generate more electricity than local grid operators anticipated or more than the grid circuit itself can handle; in these cases, either the variable generators are turned down or off, or other existing generators are ramped down to compensate. Which scenario occurs depends on a number of factors, including regulatory requirements, tax incentives, RPS requirements, and grid reliability constraints. When renewable generation is turned off, it is referred to as curtailment. However, a number of variable renewable energy grid integration tools are now able to help 
operators reduce curtailment and lower the cost of integrating variable renewable energy into the $\operatorname{grid}^{83}$.

The U.S. generation fleet is transitioning from one dominated by centralized generators with high inertia and dispatchability to one that is more hybridized, relying on a mixture of traditional, centralized generation and variable, nondispatchable utility-scale and distributed renewable generation with synthetic inertia ${ }^{84}$.

\subsection{Capacity Factors and Heat Rates}

This section reviews two different characteristics of generation technologies: capacity factors and heat rates. Capacity factors measure the overall utilization of a generation facility or fleet of generators. Capacity factor is the annual generation of a plant (or fleet of generators) divided by the product of the capacity and the number of hours over a given period of time. In other words, it measures a plant's actual generation compared to the maximum amount it could generate in a given period of time without any downtime. As power plants sometimes operate at less than full output, the annual capacity factor is a measure of both how many hours in the year the plant operated, and at what percentage of its full output (Figure 3-3). The annual capacity factor of a power plant is therefore a measure of availability (how many hours it is available to generate electricity) and an indirect measure of the marginal cost of generation (for nonvariable sources) and other characteristics such as flexibility and startup times. Recent trends in both annual and monthly capacity factors of major fuel and technology types are shown in Figure 3-4.

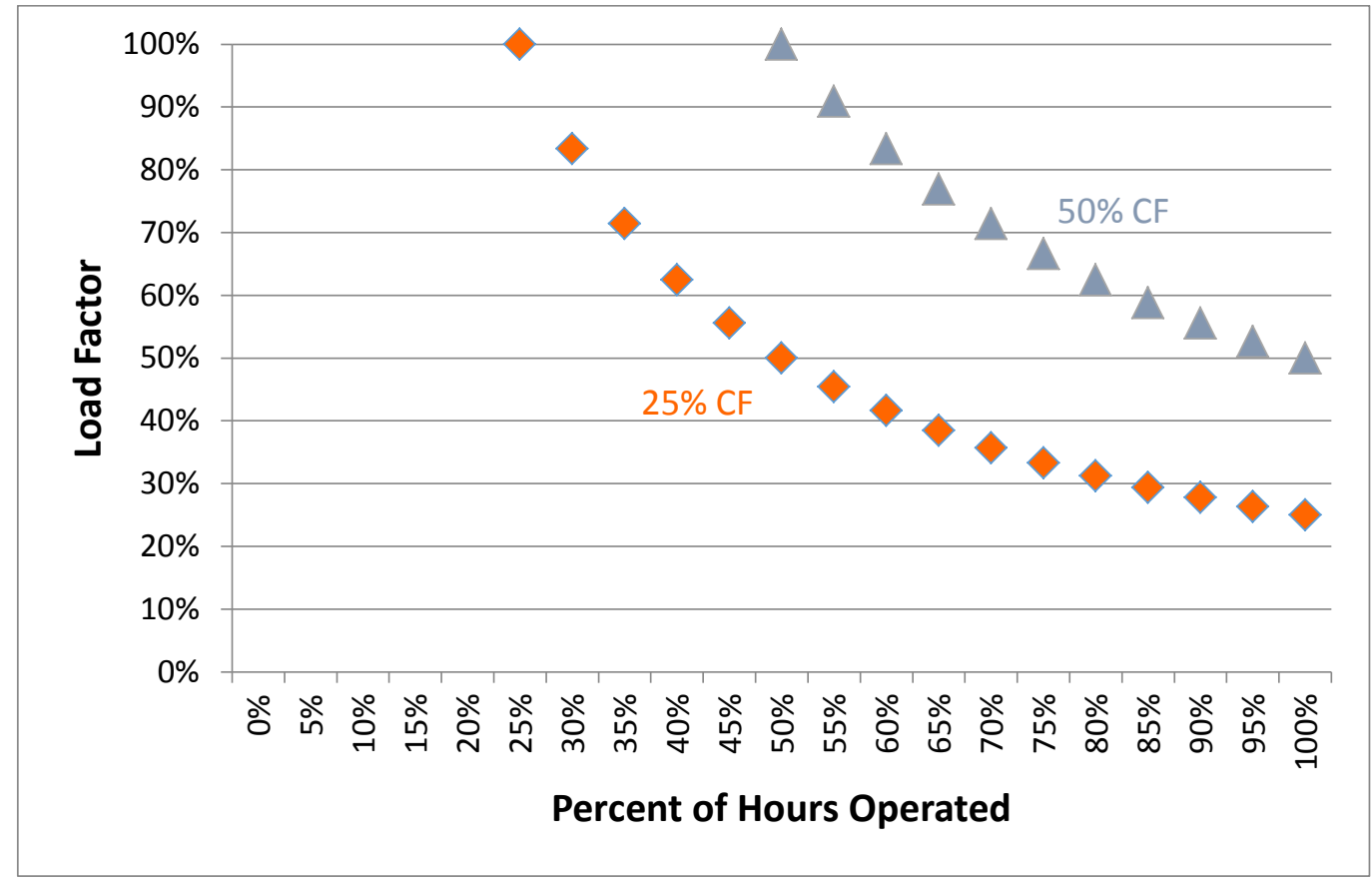

Figure 3-3. Capacity factor as a function of hours operated vs. percentage of full output

A power plant with a rated output of $500 \mathrm{MW}$ electrical (MWe) that operates at 100 percent load factor will output $500 \mathrm{MW}$ of electricity to the grid. If this power plant operates all 8,760 hours of the year, it will have a capacity factor of 100 percent. If it operates only 4,380 hours of the year (50 percent of 8,760) at 100 percent load factor, it will have a 50 percent capacity factor. Alternately, if it operates at 50 percent load factor ( $250 \mathrm{MWe}$ output) for 8,760 hours of the year, it will also have a 50 percent annual capacity factor. 

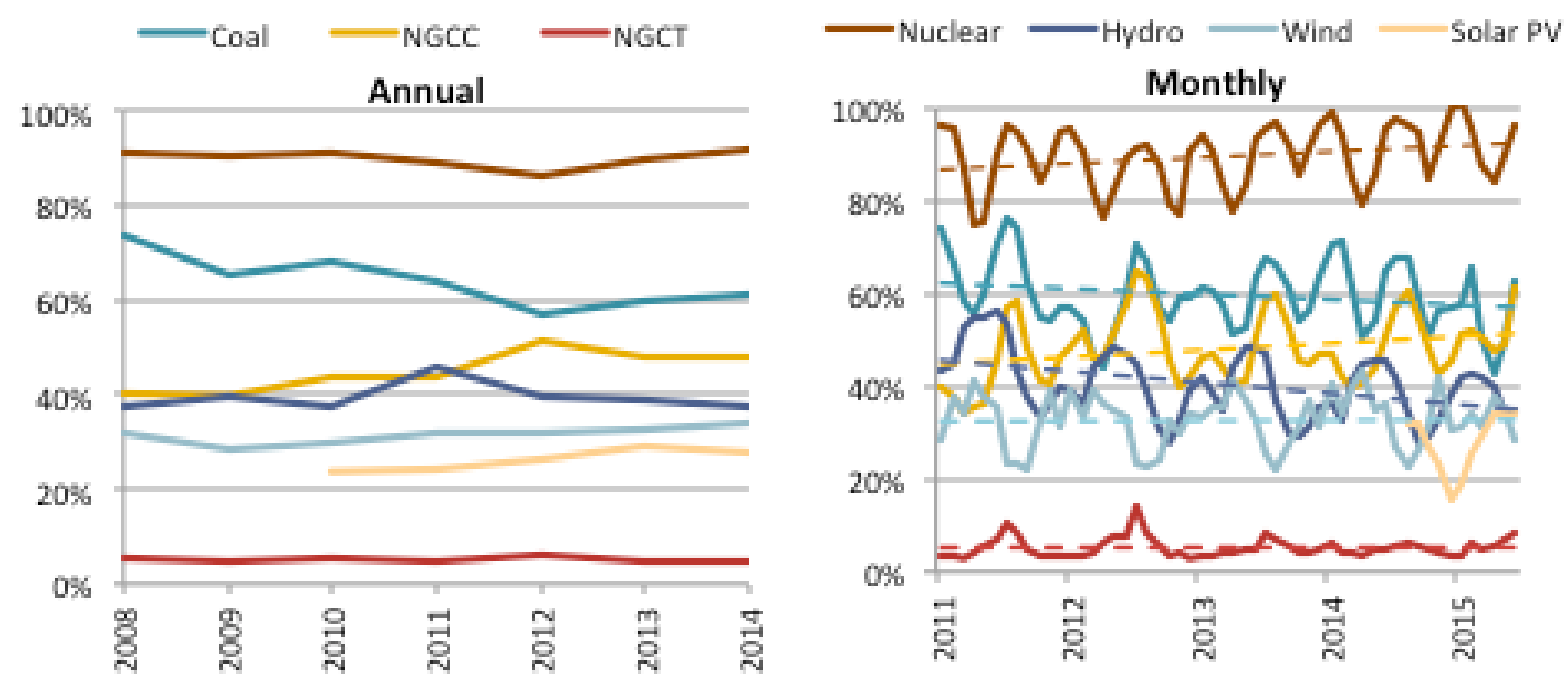

Figure 3-4. U.S. annual and monthly capacity factor by major fuel and technology combinations

The utilization of coal plants has declined significantly since abundant, low-priced natural gas supply became available beginning around 2010. The capacity factor from the fleet of coal generators fell from over 70 percent in 2008 to under 60 percent in 2015. The capacity factor of NGCC units grew from about 40 percent in 2008 to over 50 percent in 2015. Nuclear generators continue to have fleet-wide capacity factors of 90 percent. Source: SNL $2015^{85}$.

Technologies such as nuclear and coal have historically had the highest capacity factors because they have had high levels of availability and were the lowest marginal cost generators. Nuclear units also have long startup and shutdown times dictated by regulatory procedures required to ensure power plant safety. Consequently, these units typically limit their scheduled outages to every 18 to 24 months.

While coal plants generally have greater flexibility than nuclear units for startup and shutdown, operating at high capacity factors has been historically desirable as it limits the wear and tear of power plant components caused by thermal expansion and contraction during startup/shutdown or ramping between different load points. Reduced wear not only ensures reduced maintenance costs, but improves the likelihood of the power plant being available during times of peak demand.

Changes in electricity markets, fleet composition, and usage patterns in recent years have seen U.S. power plant operators and engineering, permitting, and construction vendors adapt both coal and nuclear plants for more flexible operation. This has come out of necessity in some casesunits have begun to operate as peaking or load-following units, and modifications have been required to maintain unit availability — or in anticipation of being able to compete in the changing market ${ }^{86}$.

NGCC and natural gas combustion turbine (NGCT) plants have significantly different capacity factors, due primarily to operating characteristics and costs, which dictate their roles in dispatch. NGCT plants are less efficient and therefore have higher operating costs and emissions than NGCC units. However, the short startup times and fast ramp rates of NGCT units make them important for maintaining grid reliability, and their low capital costs make them well suited to use at low annual capacity factors. The flexibility of NGCT plants is useful in complementing 
variable generation such as wind and solar because it allows these generators to follow variable generators and load.

Whereas most NGCT units contribute primarily to peak load and only need to be operated a few hours out of the year, NGCC plants operate throughout the year. NGCC plants retain many of the flexible characteristics of NGCTs, but operate at higher efficiency and, therefore, lower cost. Consequently, these units dispatch more frequently than NGCTs; although, before recently sustained low natural gas prices, most NGCC units were utilized for intermediate and peak loads, rather than baseload power. However, flexible operation can come at a cost: reduced efficiency, higher emissions, and increased wear and tear on the equipment, which increase maintenance $\operatorname{costs}^{87}$. Vendors now offer NGCC units specifically designed for flexible operation, and these can reduce the maintenance impacts (in particular), but these units can cost up to 30 percent more than the standard commercial offering ${ }^{88}$.

Fuel prices have a significant impact on how existing power plants are used. For example, when natural gas prices become competitive with coal prices, as they currently are in the low U.S. gas price environment, the U.S. NGCC fleet operates at a higher capacity factor. For example, in 2015, NGCC plants in the United States operated at an average 56 percent capacity factor, relative to an average 36 percent capacity factor in $2005^{89}$.

Capacity factors also change significantly on a monthly basis, as shown in the right side of Figure 3-4. Most dispatchable U.S. generators operate at the highest level in the summer, when demand for electricity is highest. U.S. solar generation is also highest in the summer months due to stronger solar availability. Wind generators, which are nondispatchable, produce more electricity in the winter months than in the summer on average in the United States ${ }^{90}$. Wind generators may also produce more power at night than during the day in some regions. In such cases, wind and solar may be good complementary sources of electricity, up to a given level of penetration.

Heat rates are a way to measure the efficiency of a power plant. The heat rate is the amount of input energy used by an electrical generator or power plant to generate $1 \mathrm{kWh}$ of electricity ${ }^{91}$. Figure 3-5 illustrates the heat rates for fossil fuel-fired generators over time. Heat rates are inversely related to efficiency: a lower heat rate means a plant is more efficient. Natural gas heat rates have been decreasing over the past decade, most likely due to the recent increase in new NGCC plant installations, which tend to have lower heat rates or higher efficiencies. 


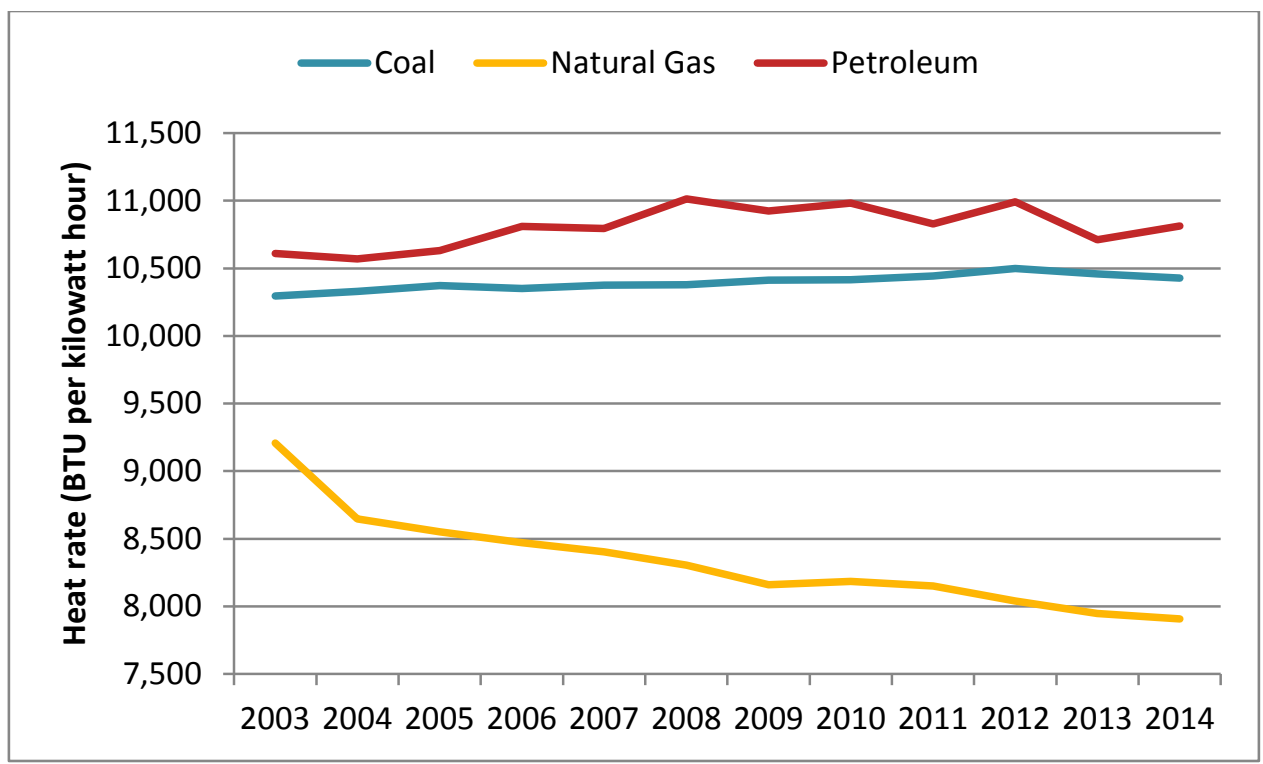

Figure 3-5. U.S. annual heat rates for fossil fuel technologies, 2003-2013

Generator heat rates measure the efficiency of fuel use in producing power. Natural gas generation heat rates have varied significantly over the past decade. Source: EIA $2016^{92}$.

\subsection{Generation Costs and Comparisons}

Generation costs in the electric power sector vary by fuel and technology. Comparing generation technologies based only on their capital costs is limiting because some are more capital intensive, but have lower operation and maintenance (O\&M) or fuel costs, which may make them more cost competitive when considering the plant's generation across its economic lifetime. To compare across the economic lifetime of these technologies, LCOE is a summary metric often used.

\subsubsection{Levelized Cost of Energy (LCOE)}

$\mathrm{LCOE}^{\mathrm{xix}}$ analysis is often used to compare generation costs of different technologies, although doing so on a true "apples to apples" basis can be complex given the different roles and characteristics that generators have. While LCOE is a convenient summary measure of the overall generation cost of different generating technologies, actual plant investment decisions are affected by the specific technological and regional characteristics of a project, which involve numerous other factors, including the projected utilization rate, generator availability, and the existing resource mix in a region. The capacity value ${ }^{\mathrm{xx}}$ of a resource, is also not included in LCOE. Capacity value, which depends on both the existing capacity mix and load characteristics in a region, can also be important: since load must be balanced on a continuous basis, units whose output can be varied to follow demand (dispatchable technologies) generally have more

\footnotetext{
${ }^{\text {xix }}$ Appendix B contains details on the methodological approach and assumptions used in calculating the LCOE values shown in Figure 3-6.

${ }^{\mathrm{xx}}$ Capacity value is the economic value to a generator or system operator of having confidence that a given resources is available to be dispatched to meet load. This is a function of forced outage probability, inherent variability (from wind and solar, for example), and how quickly a resource can be dispatched (including ramp-up to full capacity). While capacity value is a relatively straightforward concept, its calculation can be complex, somewhat akin to an actuarial exercise in insurance.
} 
value to a system than less controllable units (nondispatchable technologies). Furthermore, LCOE values do not typically capture external costs or valuations, such as environmental costs, value of meeting a regulatory requirement such as emissions limits or renewable portfolio standards, or flexibility attributes (the ability to ramp up or down rapidly, for example). Also, caution should be used when comparing LCOE values when costs elsewhere in the bulk power or distribution system must be separately incurred and, typically, are ultimately paid by the enduse customer ${ }^{93}$ xxi LCOE should not be used to compare distributed and utility-scale generation technologies due to different regulations and electricity costs.

Figure 3-6 illustrates LCOEs for selected generation technologies from three sources used in the analysis: EIA, the National Renewable Energy Laboratory (NREL) or National Energy Technology Laboratory (NETL), and Lazard ${ }^{94}$. These sources were chosen based on their wide use and referencing in other publications, data transparency and range, and range of assumptions. This effort tries to eliminate some confusion in comparing LCOE across sources by controlling for financial and other non-technology factors by harmonizing certain variables used in the different LCOE calculations to better control for distinctions. As a result, the re-estimated LCOEs should better reflect the key differences in technology cost assumptions among the three sources examined; however, they do not reflect different costs of financing different types of projects. Figure 3-6 shows national estimates for LCOEs by fuel type using cost and heat rate data ranges from the three sources, with a shared range of financial and operational assumptions. These values shown represent a broader range than values estimated in the respective sources because of the shared set of assumptions. The " $X$ " symbols represent the reported values from each of the respective sources and may differ from the median or average of the ranges due to differences between the shared set of assumptions and individual source assumptions. For EIA and NREL, these are the national 2020 values; for Lazard, they are the midpoints that represent technologies starting construction in 2015. While this approach enables a more neutral consideration of LCOE estimates across technologies, ranges are greater than what is reported in individual sources.

As seen in Figure 3-6, there is considerable variation in range for some LCOEs and notable differences in reported values. LCOE ranges for renewable technologies are generally intended to reflect variation in renewable resource quality across the country. Note that LCOE values shown do not include tax credits. For example:

- For dispatchable generation, NGCC is the lowest cost with the smallest spread, while for nondispatchable technologies, wind is the lowest cost with the smallest spread.

- NGCC with CCS and nuclear have similar LCOE values as low- or no-carbon, dispatchable generation sources, with utility-scale solar PV (with the exception of EIA) falling within the same price range for nondispatchable generation.

- While cost is not the only consideration in adding new generation, these LCOE trends, once tax credits are included correspond with observed for capacity additions in 2015, with

\footnotetext{
${ }^{x x i}$ Caution should be used when comparing LCOE between systems that do not have the same duty cycle because the value of energy (or cost of displaced energy or "avoided cost") of the systems can be different. For example, a CT is primarily used to serve peak load, while a coal plant primarily serves baseload. Similarly, wind has its own, distinct duty cycle derived from its diurnal and seasonal output characteristics of the wind, making it difficult to compare its LCOE to other technologies.
} 
land-based wind, NGCC plants, and solar PV making up the majority of capacity additions at 41 percent, 30 percent, and 26 percent of total additions, respectively ${ }^{95}$. 

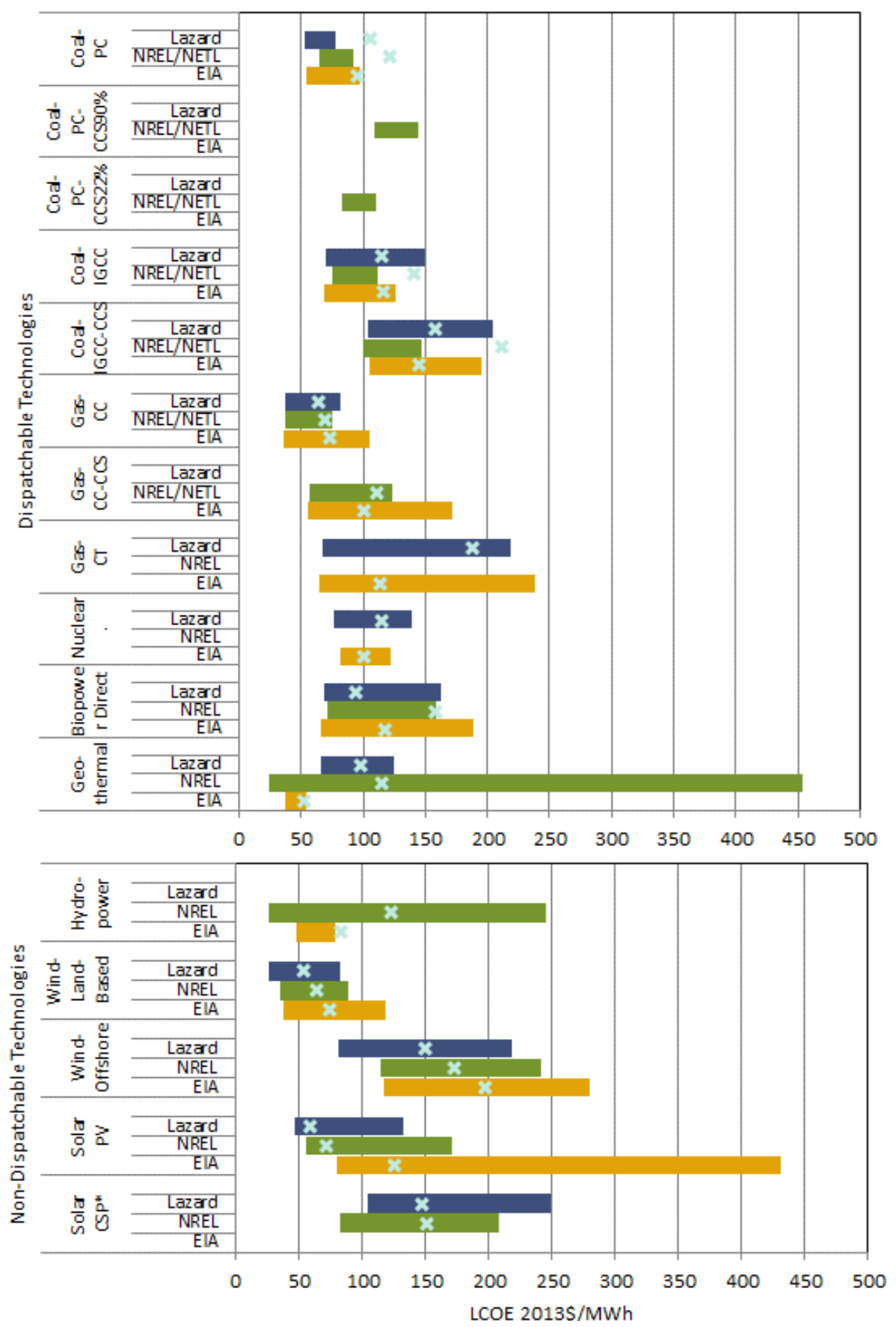

Figure 3-6. Reported (x values) and estimated (range) LCOE values for dispatchable and nondispatchable technologies

While LCOE values are an imperfect metric to compare electricity generation costs across all technologies, they can provide important insights over time and within ranges of technologies. NGCC plants typically have the lowest estimated LCOE among all dispatchable generation types, while land-based wind, hydropower, and utility-scale solar PV have the lowest costs among not-fully-dispatchable technologies. Sources: NREL 2015a; EIA 20151; Lazard 2015; NETL, 2015.

Notes: X values represent published values. For EIA and NREL, values reflect plants coming online in 2020; for Lazard, values reflect those starting construction in 2015. These values do not reflect any subsidies, including the PTC or ITC. Lazard capital cost ranges for coal IGCC and coal IGCC-CCS were estimated by using the midpoint between the IGCC range, the low end representing IGCC and the high end representing IGCC-CCS. EIA's CSP capital cost estimates do not include storage; NREL and Lazard estimates include storage. The LCOE range for EIA CSP without storage is 254-748 2013\$/MWh. Solar PV is utility-scale only. Hydro is considered nondispatchable due to multiple-use obligations and seasonal variability. The low end of the geothermal range for EIA represents expansion of an existing facility and is not representative of development of a new facility. 


\subsubsection{LCOE and Levelized Avoided Cost of Energy (LACE)}

In this section, we consider two economic metrics that can shed light on the relative changes in the cost of electric generation technologies over time. As noted previously, LCOE is designed to enable comparison across different technologies that have much different capital and operational cost profiles, although it does not capture all costs or considerations. For example, LCOE does not take into account the variable nature of wind and solar generation. It also does not value other attributes of generation such as capacity value and the ability to provide ancillary services. The levelized avoided cost of energy (LACE) attempts to focus on value that a particular technology offers by representing the avoided costs that would have been incurred by the existing resources had they been used to generate the new marginal unit of electricity instead. To achieve this, LACE calculations use the modeled wholesale electricity price for a region with the existing generation mix and the projected capacity that a new unit would add. Like LCOE, LACE is limited in that it may not fully capture all the factors that ultimately inform a decision. EIA, however, suggests that when used in tandem, the two metrics can provide greater insight than either one alone. For a more complete discussion of the methodology, advantages, and limitations of the LCOE and LACE metrics, see EIA (20151) and Namovicz (2013) ${ }^{96}$.

We limited our LCOE and LACE comparisons to only EIA estimates since no other organization publishes LACE estimates. It should be noted that other estimates of LCOE can vary significantly from EIA ${ }^{97}$, but the intent here is to consider how the cost and performance of technologies may change over time - not how they differ at a point in time.

LACE and LCOE estimates are provided below in Table 3-1 for generation technologies entering service in 2020 and 2040. When the LACE value exceeds the LCOE value, the particular technology may be considered attractive to build, although again other considerations are excluded in this representation. Focusing first just on LCOEs, EIA projects that biopower, utility-scale PV, and offshore wind will see the largest reductions in LCOE between 2022 and 2040. This is due to the learning curve for these technologies, which is represented in the model. Some technologies like conventional geothermal are projected to have increased LCOEs over time. This can be due to factors such as increasing fuel costs and the quality of the available resource for new capacity.

Next, looking at the difference in LACE and LCOE, the more negative the value, the less attractive the technology might be as this represents "delivered value less cost". A positive number may indicate that the technology is cost-effective to deploy, all else being equal. In 2022, conventional geothermal is the only technology with a positive LACE-LCOE, according to EIA estimates, although this likely reflects only a few cost-effective sites and does not capture development risks associated with geothermal power. NGCC is the only technology with LACE and LCOE differences that are only slightly negative. By 2040, geothermal continues to have a positive LACE-LCOE value and is joined by NGCC, utility-scale PV, and onshore wind. Most technologies by 2040 will have less negative LACE-LCOE values than in 2020, except geothermal, which can indicate a drop in technology costs, as well as an increase in the delivered value of electricity. Again it is important to note that, although many technologies have a negative LACE-LCOE value, this result does not suggest that they would not be economically attractive to build as all the relevant factors informing investments in capacity, such as potential future policies, are not considered in the metric. 
Table 3-1. Reported LCOEs for Deployment of Select Generation Technologies in 2022 and 2040 $(2015 \$ / M W h)$

\begin{tabular}{|c|c|c|c|c|c|c|}
\hline & \multicolumn{3}{|c|}{ LCOE } & \multicolumn{3}{|c|}{ LACE-LCOE } \\
\hline & 2022 & 2040 & $\begin{array}{l}\text { Difference } \\
\text { (percent) }\end{array}$ & 2022 & 2040 & $\begin{array}{c}\text { Difference } \\
\text { (percent) }\end{array}$ \\
\hline \multicolumn{7}{|c|}{ Dispatchable Technologies } \\
\hline Biopower & 101 & 79 & -22 & -35 & -15 & 57 \\
\hline $\begin{array}{l}\text { Advanced Coal } \\
\text { with CCS }\end{array}$ & 140 & 126 & -10 & -108 & -62 & 43 \\
\hline $\begin{array}{l}\text { Conventional } \\
\text { Geothermal }\end{array}$ & 45 & 57 & 27 & 15 & 7 & -53 \\
\hline NGCC, Advanced & 57 & 56 & -2 & -8 & 8 & 200 \\
\hline $\begin{array}{l}\text { NGCC, Advanced } \\
\text { with CCS }\end{array}$ & 84 & 81 & -4 & -33 & -17 & 48 \\
\hline $\begin{array}{l}\text { Advanced } \\
\text { Nuclear }\end{array}$ & 103 & 93 & -10 & -52 & -29 & 44 \\
\hline \multicolumn{7}{|c|}{ Not Fully Dispatchable Technologies } \\
\hline Solar PV, Utility & 85 & 71 & -16 & -28 & 5 & 118 \\
\hline Water, Hydro & 68 & 65 & -4 & -18 & -3 & 83 \\
\hline $\begin{array}{l}\text { Wind, Land- } \\
\text { Based }\end{array}$ & 65 & 59 & -9 & -17 & 0 & 100 \\
\hline Wind, Offshore & 158 & 133 & -16 & -139 & -69 & 50 \\
\hline
\end{tabular}

Source: EIA (20151) ${ }^{\mathrm{xxii}}, 98$

\subsection{Environmental Impacts}

A complete life-cycle analysis of electricity generation considers the full supply chain associated with producing the materials and fuels that go into constructing and operating the generator, and factors in downstream issues such as decommissioning. In this section, we look at the following life-cycle factors: life-cycle GHG emissions, select air emissions, water withdrawal and use, and land use. These metrics can be important tools for decision makers when planning investment and licensing for power plants. For a more in-depth discussion of GHG emissions and other environmental impacts, please see the QER 1.2 Environment Baseline Vol. 1 - Greenhouse Gas Emissions from the U.S. Power Sector: Baseline and Outlook to 2040, and the QER 1.2 Environment Baseline Vol. 2 - Environmental Quality and the U.S. Power Sector: Air Quality, Water Quality, Land Use, and Environmental Justice.

\footnotetext{
xxii Note that these values were not harmonized and were taken directly from AEO2016. Simple average of reported regional LCOE and LACE values were used due to data missing for technologies in capacity-weighted average tables.
} 


\subsubsection{GHG Emissions}

Life-cycle GHG emissions estimates for a variety of generation technologies are summarized in Figure 3-7. The illustration was derived from a meta-study of more than 2,000 published reports on life-cycle GHG emissions of both conventional and renewable generation technologies, only some of which passed a set of screening criteria to be included in the final results ${ }^{99}$. A range of life-cycle GHG emissions are provided for each generation option, including the median, upper, and lower quartiles, and maximum and minimum values. Point estimates are provided for options that include CCS (orange diamonds). The number of published studies and estimates from each are provided at the bottom of the figure.

Coal generators report a median value of approximately $1,000 \mathrm{~g} \mathrm{CO}_{2}$ equivalent $\left(\mathrm{CO}_{2}\right.$ eq) per $\mathrm{kWh}$ of generation. Oil and natural gas have median values approximately 20 percent lower and more than 50 percent lower, respectively. All other generation options have median values below $50 \mathrm{~g} \mathrm{CO}_{2} \mathrm{eq} / \mathrm{kWh}$. Biopower generation exhibits a wide range of potential emissions, primarily reflecting the assumptions used in calculating land-use change impacts. Biopower with CCS, also referred to as bioenergy with CCS, is also the only generation option that can exhibit significant negative emissions, although there is debate over methodological approaches to characterizing biopower emissions ${ }^{100}$. Coal and natural gas with CCS report average values approximately 75 percent lower than estimates that do not assume CCS. 


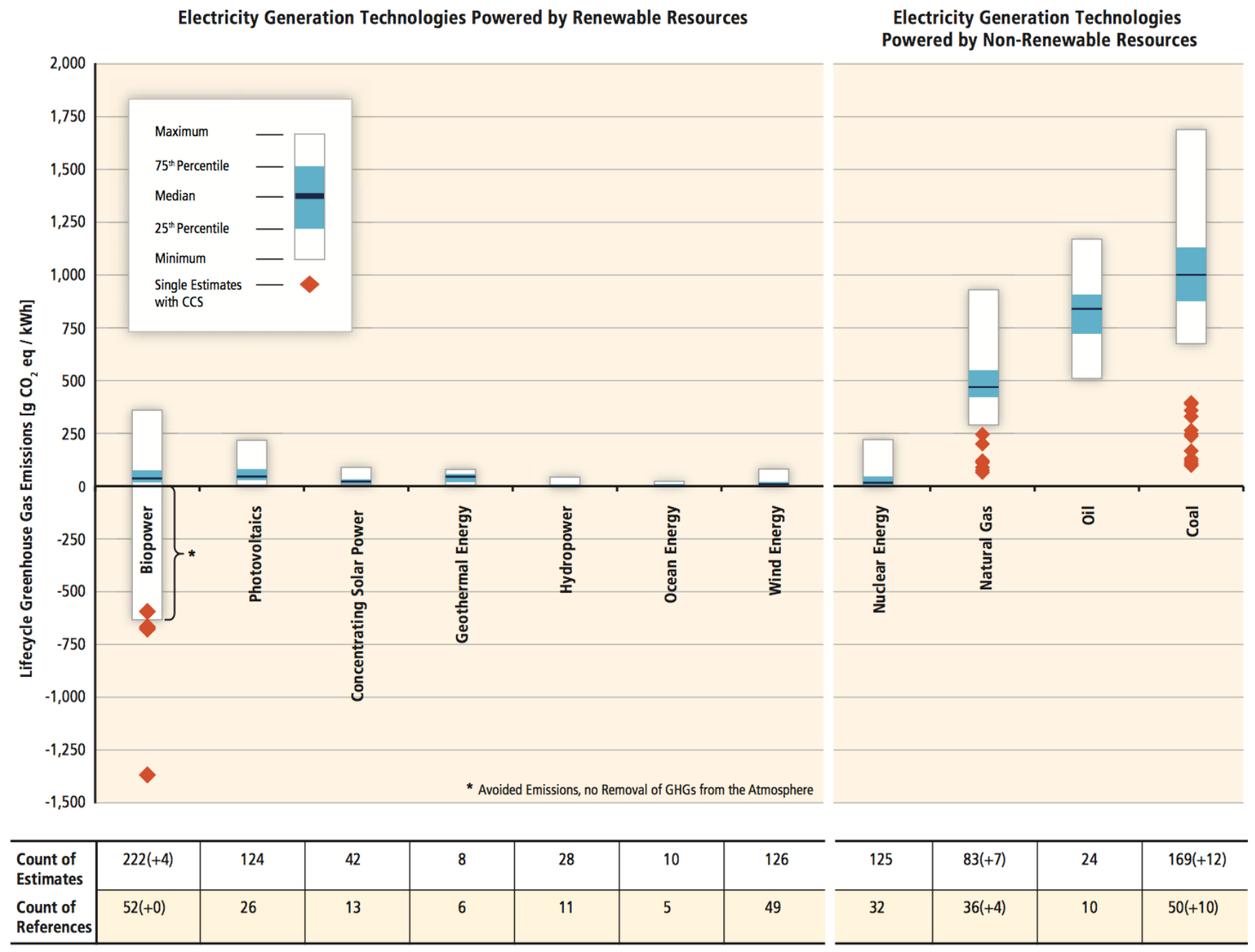

Figure 3-7. Life-cycle GHG emissions for select generation technologies based on a meta-study literature review

Over 2,000 published studies were analyzed to estimate the full life-cycle emissions of electric generating options in this meta-study. Coal emissions were highest, with median natural gas emissions just over 50 percent lower. Nuclear and most renewable generators had median values less than $50 \mathrm{~g} \mathrm{CO} 2 \mathrm{eq} / \mathrm{kWh}$. Biopower with CCS is the only generation option that can achieve negative emissions. Source: Sathaye et al. $2011^{101}$. 


\subsubsection{Life-Cycle Emissions: Criteria Pollutants and Particulates}

Electricity generators also exhibit a wide range of emissions of non-GHG air pollutants, which have a range of human health and environmental impacts. Life-cycle emissions of oxides of nitrogen and sulfur dioxide for a variety of generating options and fuels are shown in the upper half (a) of Figure 3-8, while life-cycle emissions of particulate matter 2.5 micrometers or less and non-methane volatile organic compounds (NMVOCs) ${ }^{\text {xxiii }}$ are shown in the lower half (b). This figure offers a measure of the emissions intensity $(\mathrm{g} / \mathrm{kWh})$ for different generation technologies and fuel types and does not reflect the relative total emissions from these technologies in the United States (i.e., when accounting for the current fuel mix).

Life-cycle sulfur dioxide emissions are highest for fossil fuels, especially lignite, used in STs (Figure 3-8). Nitrogen oxides follow a similar pattern, although biomass combusted in STs can produce high emissions as well. For particulate matter 2.5 microns or less $\left(\mathrm{PM}_{2.5}\right)$, which is considered especially dangerous to human health ${ }^{102}$, the direct emission characteristics are similar to those for nitrogen oxides, with fossil STs and, especially, biomass STs capable of the highest intensity levels. NMVOC emissions are greatest for oil used in STs and across the range of natural gas generation technologies.

\footnotetext{
xxiii NMVOCs are ubiquitous organic chemicals that readily evaporate or sublimate from the liquid or solid forms from which they originate. They contribute to the formation of ground-level ozone and can also pose dangers in indoor environments. Examples of NMVOCs that are harmful to humans or the environment include benzene, formaldehyde, chlorofluorocarbons, and methyl chloride.
} 


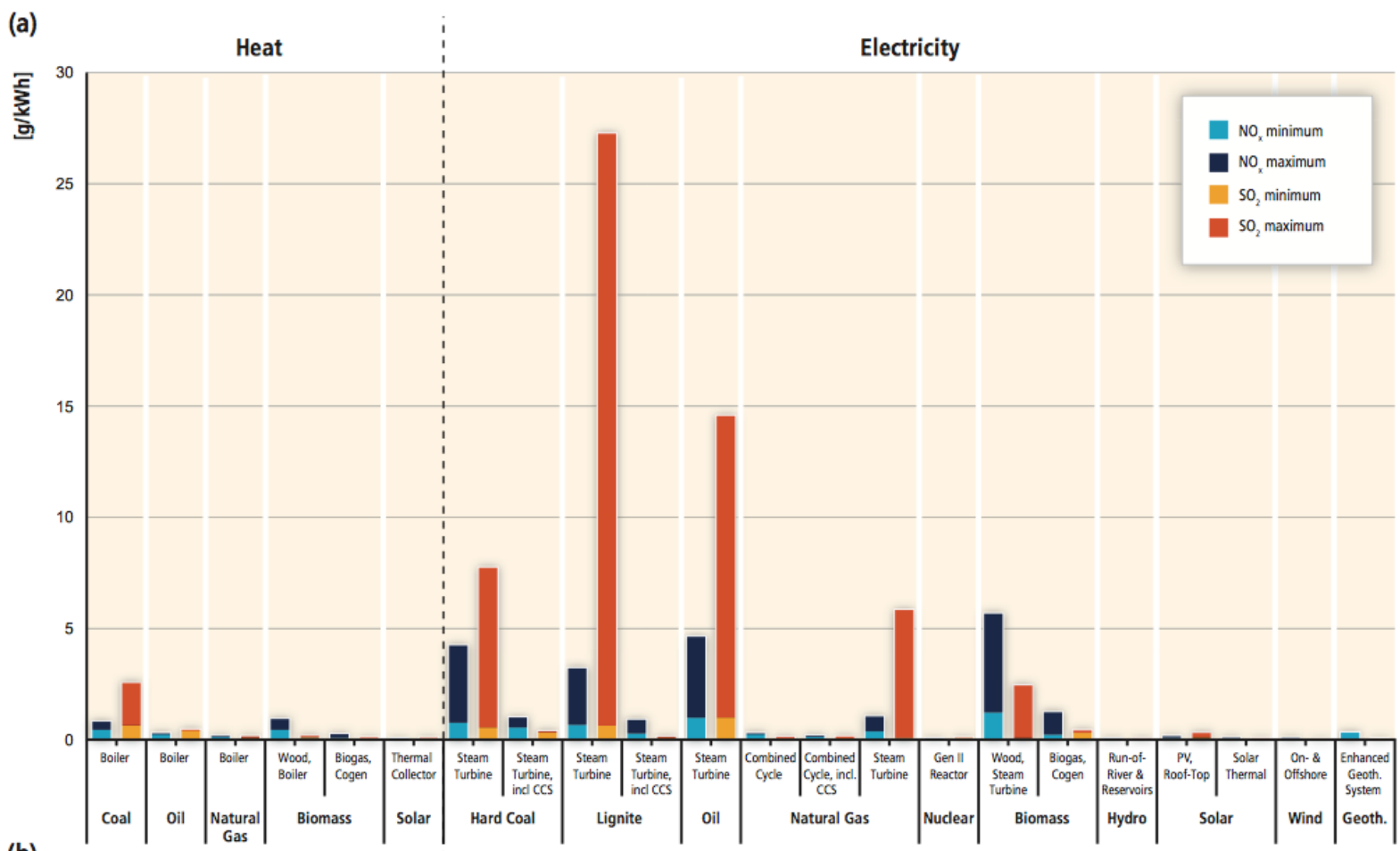

(b)

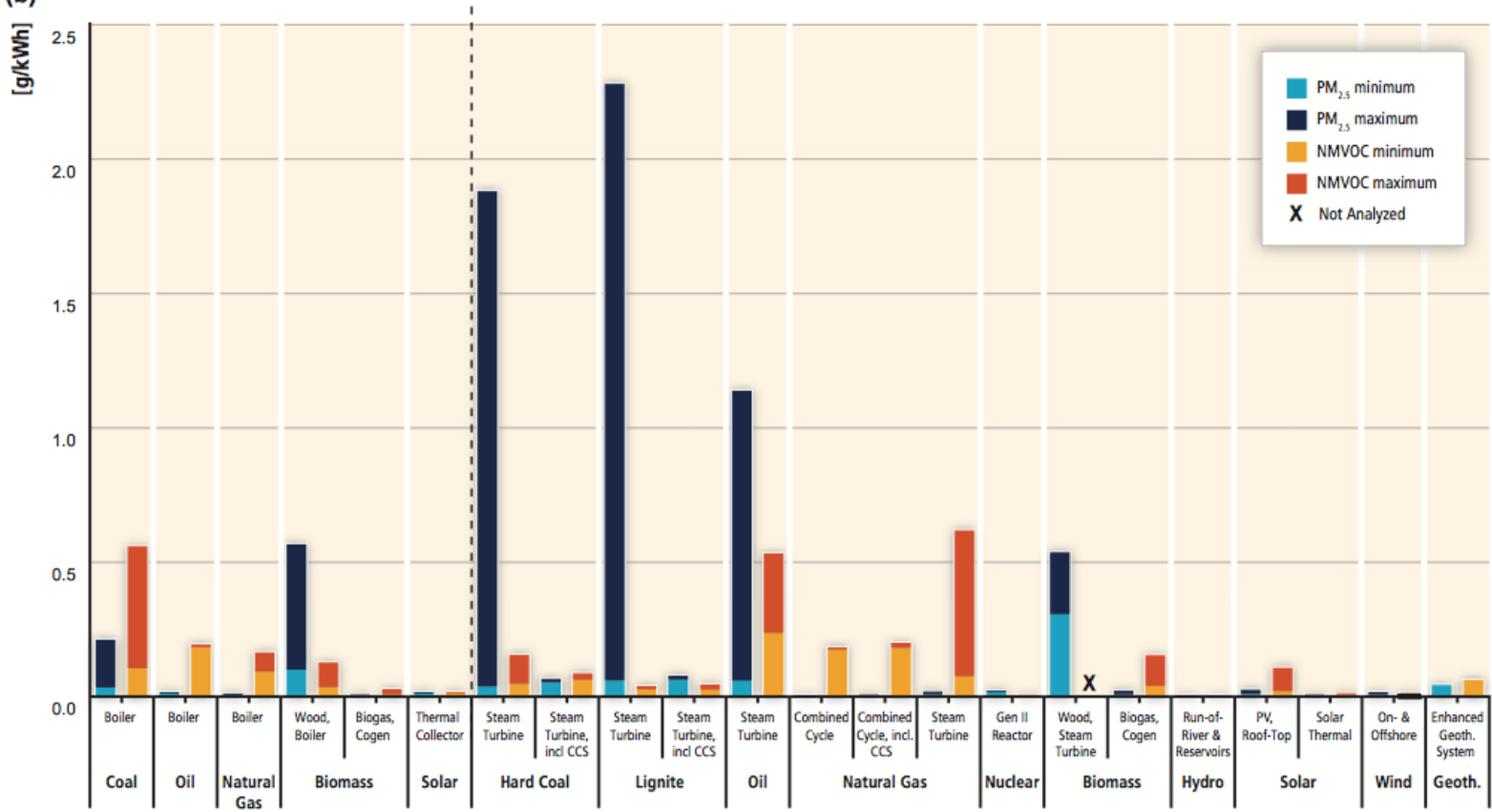

Figure 3-8. Life-cycle air emissions for select generation technologies

Air emissions from electricity generators vary widely depending on fuel and technology type. Coal and oil generators typically have the highest emissions of sulfur oxides, while biomass, oil, and coal have the greatest emissions of nitrogen oxides. Similarly, coal and biomass have high particulate emissions, while natural gas, oil, and coal have the highest levels of NMVOC emissions. Source: Sathaye et al. $2011^{103}$. 


\subsubsection{Water Withdrawal and Consumption}

All electricity generation technologies use water throughout their life cycles, but water withdrawal and consumption factors vary across and within fuel technologies. Total life-cycle water use across generation technologies is typically lowest for solar PV and wind, and highest for CSP with wet cooling, conventional coal technologies and nuclear ${ }^{104}$, but the specific type of cooling technology used impacts the results. Non-thermal renewable generation technologies have no water requirements associated with fuel extraction, and use almost no water for operational purposes, but require some water for construction and manufacturing.

Across all generation technologies, operations dominate life-cycle water use with the exception of solar PV, wind, and dry-cooled thermoelectric technologies ${ }^{105}$. On the other hand, water use for solar PV is largely dominated by manufacturing relative to other life-cycle stages. For example, estimates of water withdrawals for solar PV power plant equipment life cycles range from 1 to 1,600 gallons/MWh with a median of 94 gallon/MWh. However, water use for operations is minimal as few operators actually wash PV panels in practice ${ }^{106}$. For wind, the median water withdrawal is 26 gallons/MWh with consumption around one gallon/MWh. Because wind turbines require no fuel and little washing or maintenance, operational water use is minimal.

Thermoelectric power plants, such as coal, natural gas, nuclear, geothermal, and CSP, require significant volumes of water for power generation, ranging from hundreds to thousands of gallons per MWh. Water use is reported in water withdrawals - the amount of water withdrawn from the water source, some of which may be returned to said source- and water consumption (generally consumed by evaporation into the atmosphere). Water withdrawals and consumption vary substantially by cooling technology.

In once-through cooling systems, water is withdrawn from a river or other body of water, used for cooling, and then returned to the water source. In general, there is a trend to move away from once-through cooling for power generators in the United States, where large withdrawals are required ${ }^{107}$.xiv Instead, recirculating and dry cooling are becoming more commonly used. Recirculating, or "closed-loop" cooling, has greatly reduced water withdrawal requirements compared to once-through cooling, but it consumes more water. Dry cooling requires no water use but comes with an energy penalty, reducing the efficiency of the power plant. Plant efficiency also affects water use: a plant that is more efficient will use less water than a similar plant that is less efficient.

One meta-study that reviewed the literature on water withdrawal and consumption found that CSP power plants consume the most water, followed by nuclear, coal, and geothermal, when using the same cooling system ${ }^{108}$. Water consumption from natural gas plant operations is the least of all thermoelectric power plants, ranging from one-half to one-third of the water consumption for coal according to the meta-study.

\footnotetext{
${ }^{\text {xxiv }}$ Greater withdrawals are required because of the limited capabilities of sensible heating compared to latent heat transfer (evaporation) of water, along with environmental requirements limiting how much the temperature of the water can be changed prior to returning it to the environment.
} 
Finally, water use by hydro plants varies considerably depending on the site features and plant configuration. Hydroelectric plants with large reservoirs, for example, may consume large amounts of water due to evaporation, although such reservoirs have other uses besides power generation (recreation, flood control, etc.), so attribution can be complex. Water use characteristics of different electricity generation technologies are discussed more in the QER 1.2 Environment Baseline Vol. 4 -Energy-Water Nexus.

\subsubsection{Land Use}

Estimating life-cycle land use for power generation is complex, mainly due to the difficulty of quantifying "upstream" footprints, such as mining of coal or uranium (for nuclear generation), or determining how much land is actually "used." As a result, few comprehensive analyses have received widespread support among the research community ${ }^{109}$. For renewable energy generators, the operational footprints account for most or all of the land used, while the upstream impacts are relatively low since there is no mining required for fuel. For nonrenewable generators, the opposite is typically true, although waste disposal for nuclear and coal generation can increase the operational footprint substantially ${ }^{110}$. The operational land needs of renewable energy generators can be misleading, though, because the land is usually not completely taken out of production for other uses. Turbines for onshore wind farms, for example, are estimated to take up about 1-5 percent of the actual land used by the entire project. The other 95-99 percent of the land can thus often be used to grow crops or raise livestock ${ }^{11}$. For solar PV, the quality of the solar resource available can have a significant impact on the amount of land needed to produce a unit of electricity. In Arizona, for example, land use is estimated at $250 \mathrm{~m}^{2} / \mathrm{GWh} /$ year, while the average for the entire United States is more than twice that level ${ }^{112}$. Land use characteristics of different electricity generation technologies are discussed more in the QER 1.2 Environment Baseline Vol. 2 - Environmental Quality and the U.S. Power Sector: Air Quality, Water Quality, Land Use, and Environmental Justice.

\subsection{Generation and Ownership Types}

The role of ownership impacts generation under a number of Federal electricity policies. For example, Government and nonprofit generation owners are either not eligible or have limited benefits from Federal tax credits. Municipally owned utilities can issue tax-exempt bonds; electric cooperatives receive loans from sources such as the U.S. Department of Agriculture Rural Utilities Service; and investor owned utilities (IOUs) can finance generation through stocks and private bonds (see, for example, California Energy Commission 2016; USDA 2016). The Tennessee Valley Authority's (TVA's) power system financings consist primarily of the sale of debt securities and secondarily of alternative forms of financing such as lease arrangements. As a wholly owned Government corporation, TVA is not authorized to issue equity securities ${ }^{113}$.

Non-utility generators, or independent power producers, own 42 percent of the U.S. electric generation fleet capacity, followed by IOUs at 36 percent, public power (non-Federal) entities at 10 percent, and Federal entities and cooperatives at 6 percent each (Figure 3-9). The generation types are:

- Non-utility generators: (also referred to as independent power producers): Entities that own power plants and sell their power into the wholesale market. They may be owned by an investor-owned holding company. 
- IOUs: Generating entities that are privately owned and regulated by State authorities

- Federal agencies: Government agencies with the authority to deliver energy to end-use customers

- Federally owned utilities include TVA and the four Power Marketing Administrations (PMAs): the Bonneville Power Administration, the Western Area Power Administration, the Southeastern Power Administration, and the Southwestern Power Administration.

- PMAs are primarily marketers of electricity generated by federally owned generating facilities. PMAs do not directly service residential or commercial customers, nor do they generally own electric generating facilities (there are some exceptions such as Bonneville Power Administration owning the Columbia Nuclear Generating Station). With the exception of Southeastern Power Administration, PMAs own and operate transmission systems to market power ${ }^{114}$. They make wholesale electricity sales to municipal and cooperative utilities and some direct sales to large industrial customers. The electricity generating facilities are primarily owned and operated by the U.S. Department of the Interior's Bureau of Reclamation, the U.S. Army Corps of Engineers, and the International Boundary and Water Commission.

- TVA is a corporate agency of the United States that provides electricity for business customers and local power distributors serving 9 million people in parts of seven southeastern states. TVA receives no taxpayer funding, deriving virtually all of its revenues from sales of electricity, but benefits from Congressionally authorized borrowing and extended repayment authorities. In addition to operating and investing its revenues in its electric system, TVA provides flood control, navigation, and land management for the Tennessee River system and assists local power companies and State and local governments with economic development and job creation.

\section{- Publicly owned utilities (non-Federal):}

- State: Entities that own or operate facilities or provide a public service

- Municipal: Entities that are voted into existence by the residents of a municipality and organized under authority of State statute to provide a public service to its residents

- Joint action agencies: Entities that are formed by a group of municipal utilities to provide reliable and competitively priced energy or energy-related services, typically through asset ownership

- Political subdivision: Independent of city or county government, entities voted into existence by a majority of the residents of any given area for the specific purpose of providing the utility service to the voters

- Cooperatives: Member-owned electric utilities

- Other ownership types: These entities may participate in different parts of the electricity transaction process, for example: 
- Power marketer: Entities that do not own generating facilities but buy and sell power in the wholesale market or market power to retail customers in states that allow retail competition

- Transmission-only: Entities that provide bulk power services over high-voltage transmission wires

- Behind-the-meter provider: Entities that directly supply electricity to an end-use customer site without a distribution provider involved, or customers that generate electricity to serve their needs or supply back to the grid

- Non-utility demand-side management administrator: Only involved with demandside management activities ${ }^{115}$

- Community solar: Multiple entities (individuals or organizations) that jointly own a distributed solar facility.
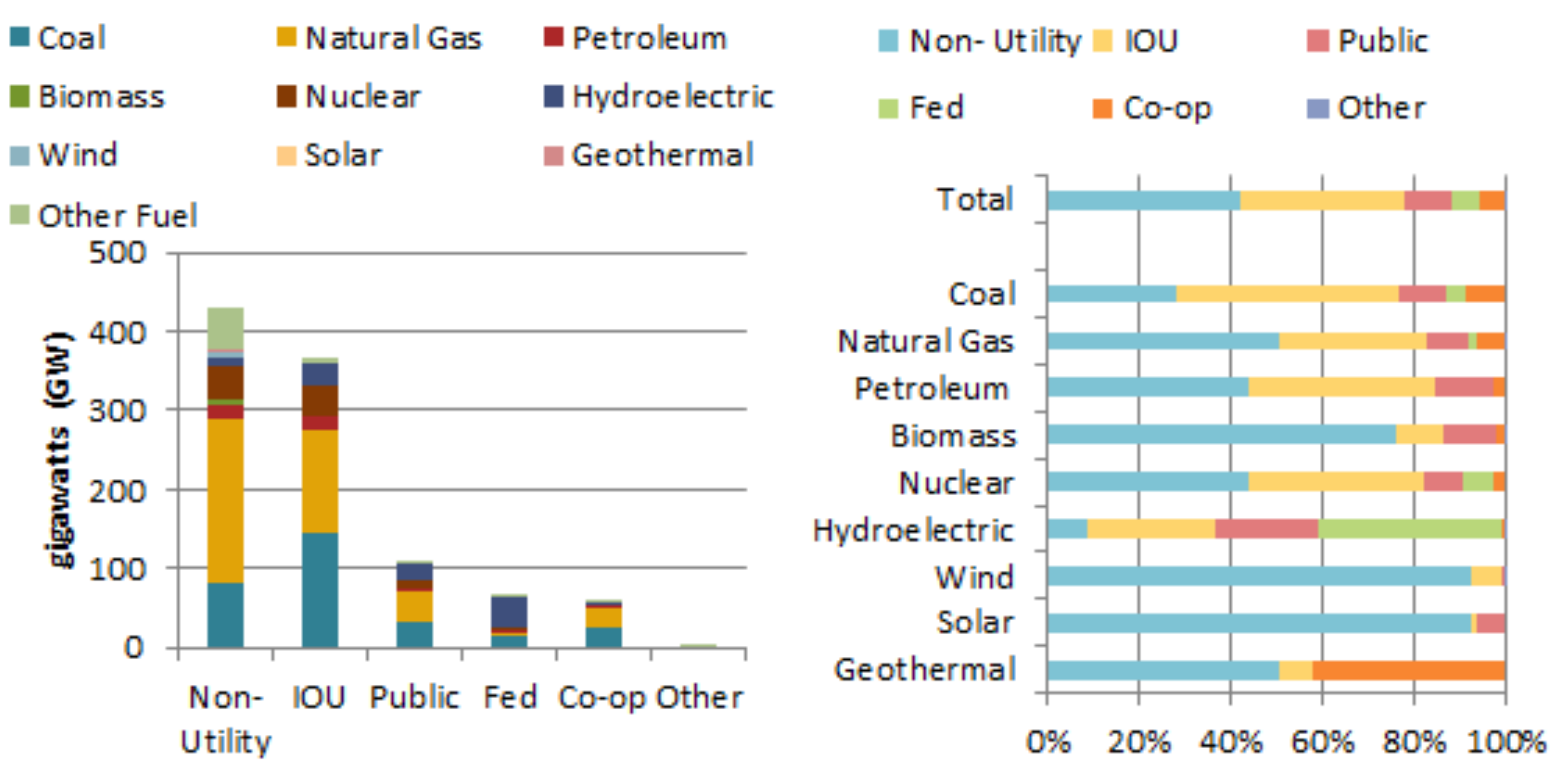

Figure 3-9. U.S. generation fleet capacity (left) and share of capacity (right) by ownership and fuel type, 2014

Non-utility generators, or independent power producers, own more of the U.S. electric generation fleet capacity than IOUs. Non-utility generators own the majority of most renewable capacity, with the exception of hydro. IOUs own the majority of coal, while non-utility generators own the majority of natural gas, nuclear, and petroleum. Source: ABB Velocity Suite $2015^{116}$.

Note: Solar is utility-scale only.

The share of fuel type across ownership varies; 2014 data are shown in Figure 3-9 (right). Nonutility generators and non-Federal public power entities generate predominately from natural gas, at 48 percent and 37 percent, respectively, while IOUs generate predominately from coal at 40 percent, and Federal entities predominately provide hydroelectric capacity at 59 percent. Cooperatives own almost exclusively coal (45 percent) and natural gas (46 percent) generation, with the latter growing rapidly since the year 2000. Non-utility generators own most of the nonhydro renewable sources, such as biomass (76 percent), wind (93 percent), solar (93 percent), and geothermal (50 percent), as shown in Figure 3-9 (left). 
Publicly owned utilities, State agencies, and cooperatives own 24 percent of hydropower capacity ${ }^{117}$. Forty-nine percent of hydropower generation capacity is owned by the Federal Government, including the U.S. Bureau of Reclamation, U.S. Army Corps of Engineers, and TVA. The U.S. Army Corps of Engineers' multipurpose dams are the largest producers of hydropower in the United States. However, electricity production is just one of the purposes. For example, the Flood Control Act of 1944 led to the establishment of the Pick-Sloan Missouri Basin Program, which has six purposes: hydropower, recreation, water supply, navigation, flood control, and fish and wildlife. Federal hydropower must be sold at the lowest possible cost by TVA and the PMAs with a statutory right of first refusal granted to nonprofit entities, including public power systems and rural electric cooperatives.

Ownership over time has also changed significantly as illustrated in Figure 3-10 and Figure 3-11. Specifically, there was a dramatic shift in the late 1990s and early 2000s from IOUs to nonutility generators, as well as additional buildout. This change in ownership type was influenced in part by market restructuring within certain regions of the United States. More recent growth in non-utility generation ownership is primarily in non-hydroelectric renewable capacity, while all other ownership types have grown primarily in natural gas-fired capacity.

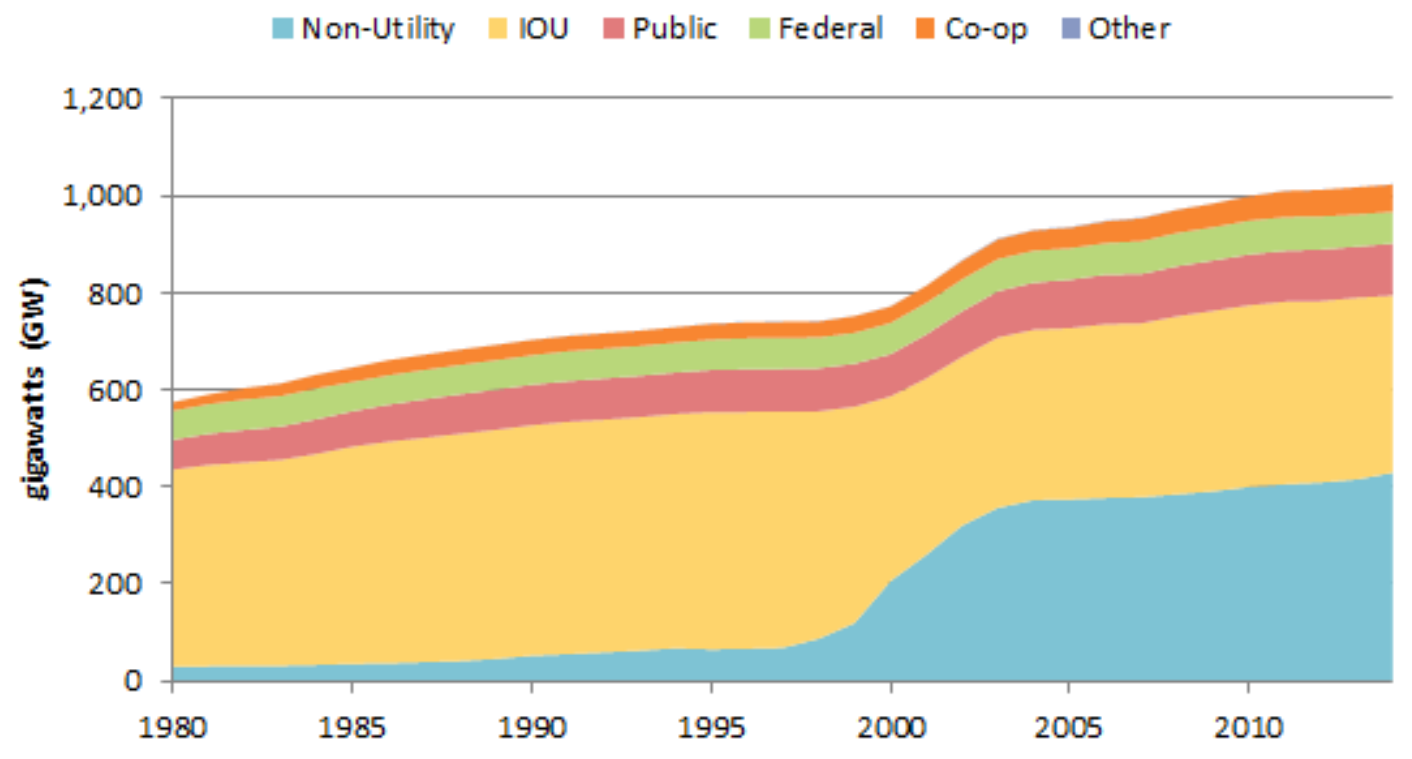

Figure 3-10. U.S. generation fleet by ownership type, 1980-2014

Non-utility ownership of generation capacity grew rapidly from 1998 to 2004 as vertically integrated utilities shed ownership of their generation assets in some regions of the country to comply with new market designs. Many independent power producers built new NGCC units during that time as the technology had improved significantly. Source: ABB Velocity Suite $2015^{118}$. 

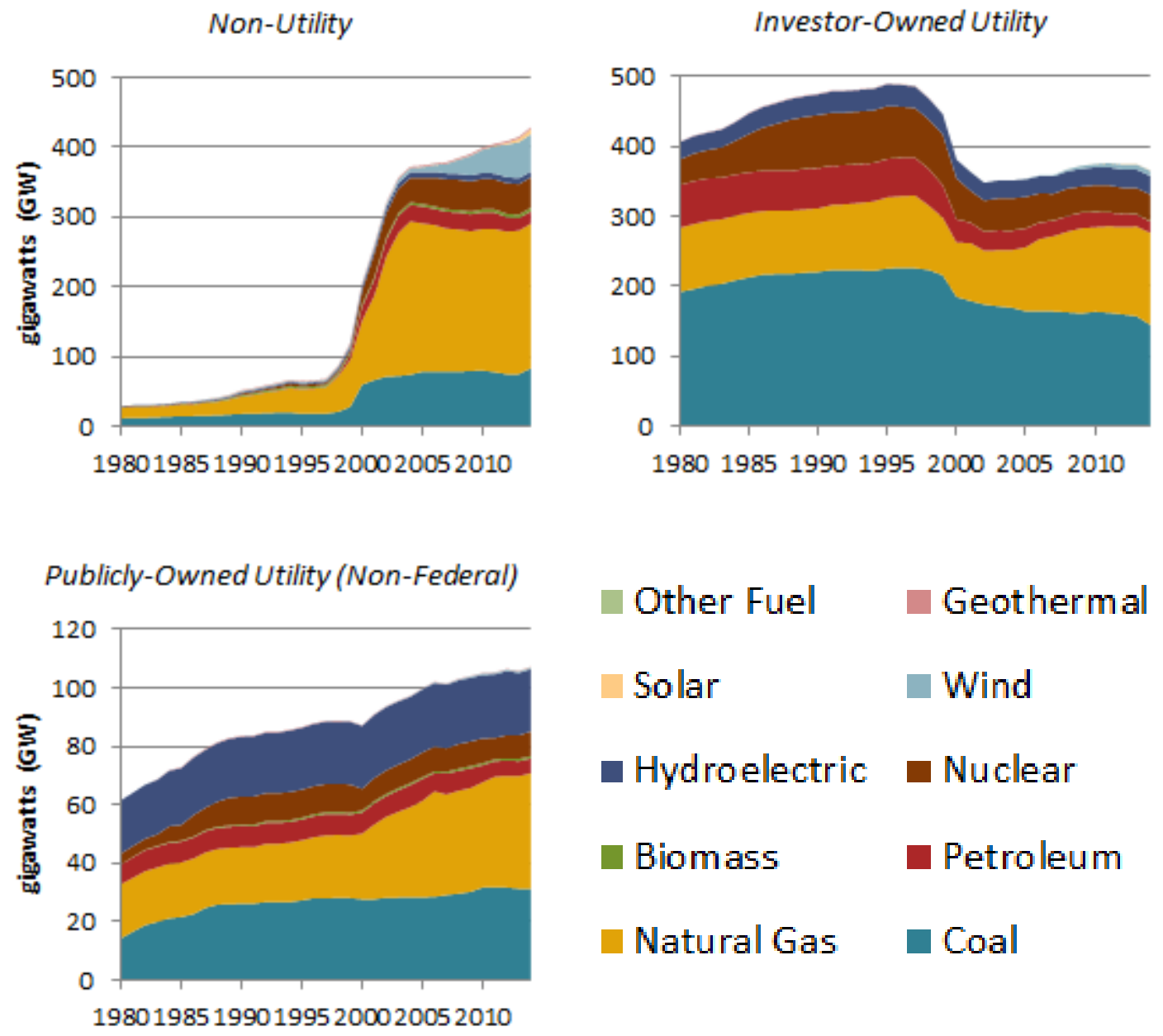

- Other Fuel $\quad$ Geothermal

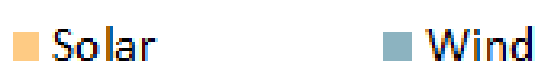

- Hydroelectric $\quad$ Nuclear

Biomass $\quad$ Petroleum

Natural Gas $\quad$ Coal
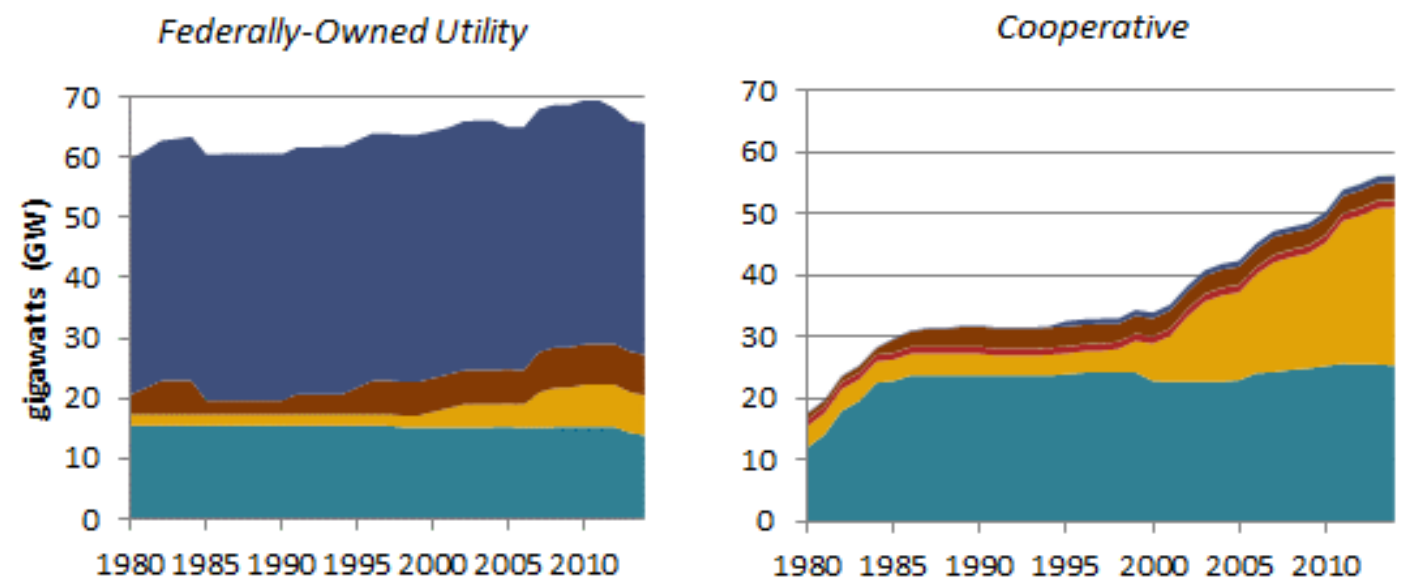

Figure 3-11. U.S. generation by fuel type for various ownership types, 1980-2014

Generation sources vary significantly by type of ownership. Source: ABB Velocity Suite 2015 Note: Solar is utility-scale only. 
Table 3-2. Differences between Publicly Owned Utilities (POUs) and IOUs in California

\begin{tabular}{|c|c|c|}
\hline & POU & IOU \\
\hline Ownership & $\begin{array}{l}\text { A local government body } \\
\text { and/or customers/members of } \\
\text { the utility. Usually limited to } \\
\text { the service area. }\end{array}$ & $\begin{array}{l}\text { Shareholders or investors. Not limited to the } \\
\text { service area. }\end{array}$ \\
\hline $\begin{array}{l}\text { Structure/ Management/ } \\
\text { Regulation }\end{array}$ & $\begin{array}{l}\text { Nonprofit public entity } \\
\text { managed by locally elected } \\
\text { officials/ public employees. }\end{array}$ & $\begin{array}{l}\text { Private company. Shareholder-elected board } \\
\text { appoints management team of private sector } \\
\text { employees. Regulated by California Public } \\
\text { Utilities Commission (CPUC). }\end{array}$ \\
\hline $\begin{array}{l}\text { Rates Setting and } \\
\text { Regulation }\end{array}$ & $\begin{array}{l}\text { Customer rates are set by } \\
\text { each utility's governing body- } \\
\text { board or city council in a } \\
\text { public forum. }\end{array}$ & $\begin{array}{l}\text { Customer rates are set and regulated by the } \\
\text { California Public Utilities Commission through } \\
\text { a public process that includes some customer } \\
\text { participation. }\end{array}$ \\
\hline Mission/Goals & $\begin{array}{l}\text { Optimize benefits for local } \\
\text { customer owners, usually in } \\
\text { the form of lower energy } \\
\text { rates. }\end{array}$ & $\begin{array}{l}\text { Optimize return on investment for } \\
\text { shareholders. }\end{array}$ \\
\hline Financing & $\begin{array}{l}\text { Public utilities have access to } \\
\text { tax-free bonds and co-ops } \\
\text { have access to low-interest } \\
\text { loans usually at the local level. }\end{array}$ & $\begin{array}{l}\text { Stockholders (investors), the sale of bonds, } \\
\text { and bank borrowing help finance the utility's } \\
\text { operations. }\end{array}$ \\
\hline Power Generation & $\begin{array}{l}\text { Operate their own generation } \\
\text { facilities or purchase power } \\
\text { through contracts. }\end{array}$ & $\begin{array}{l}\text { Purchase power through contracts and operate } \\
\text { their own generation facilities. After the energy } \\
\text { crisis, IOUs resumed electricity procurement in } \\
2002 \text { (Public Utility Code } 454.5 \text { ). Every } 2 \\
\text { years, the California Public Utilities } \\
\text { Commission holds a Long Term Procurement } \\
\text { Plan proceeding to review and adopt the } \\
\text { IOUs's 10-year procurement plans. The Long } \\
\text { Term Procurement Plan proceeding evaluates } \\
\text { the utilities's need for new fossil-fired } \\
\text { resources and establishes rules for rate } \\
\text { recovery of procurement transactions. }\end{array}$ \\
\hline Profit/Net Revenue & $\begin{array}{l}\text { Rates are set to recover costs } \\
\text { and earn additional return to } \\
\text { maintain bond ratings and } \\
\text { invest in new facilities. }\end{array}$ & $\begin{array}{l}\text { Utility rates are set to recover costs and earn a } \\
\text { reasonable return as profits for investors in } \\
\text { return for the risk they bear for investing in new } \\
\text { facilities. }\end{array}$ \\
\hline Size/ Heterogeneity & $\begin{array}{l}\text { Although POUs dramatically } \\
\text { differ in size and number of } \\
\text { customers they serve, most } \\
\text { are small or midsized with an } \\
\text { exception of LADWP and } \\
\text { SMUD. }\end{array}$ & $\begin{array}{l}\text { Very large in size and number of customers. } \\
\text { Complex, heterogeneous customer mix. }\end{array}$ \\
\hline
\end{tabular}

Source: California Energy Commission 2016. ${ }^{119}$ 


\subsection{Federal Policy and Generation ${ }^{x \times v}$}

Federal policies have played a significant role in the development of power generation in the United States. In general, Federal policies in the 1930s and 1940s fostered the development of hydropower; Federal policies in the 1940s and 1950s led to the transformation of nuclear technology to electric generation; the Fuel Use Act favored coal-fired over gas- and oil-fired generation from the 1970s to the 1980s; natural gas-fired generation took off in the late 1980s; and non-hydro renewables have seen the most growth in the 2010s. Federal policies combined with key historic events - such as the Great Depression and World War II — and technological advancements - such as shale gas technology and advances in solar and wind generation - have had especially significant impacts. Below are some examples of the impact of Federal policies on power generation in the United States. Figures 3-12 and 3-13 show generation and capacity additions, respectively, over time, with selected legislation overlaid.

\subsubsection{Hydropower}

The Great Depression and widespread floods and drought in the West during the 1930s led to the creation of TVA in 1933, the extension of the Federal Power Commission's authority over hydropower in 1935, the enactment of the Rural Electrification Act of 1936, and the establishment of the Bonneville Power Administration in 1937. This was the "big dam" period ${ }^{120}$ when public policy supported harnessing the nation's resources for the public good, i.e., providing low-cost hydropower to the public through nonprofit entities ${ }^{121}$.

At the outbreak of World War II, Germany, Italy, and Japan combined had three times more power generating capacity than the United States, and U.S. energy demand associated with the war program surged. Hydropower proved to be one of the best ways to meet this demand, which was estimated in 1942 to be 154 billion kWh of electric energy annually, an amount that exceeded the total production capacity of all existing generation in the United States ${ }^{122}$.

\subsubsection{Nuclear}

Prior to and during World War II, nuclear research focused mainly on weapons development. Later, the focus shifted to peaceful applications of nuclear technology, including power generation. The Atomic Energy Act of 1946 created the Atomic Energy Commission to regulate nuclear energy development and to explore and promote peaceful uses of nuclear energy. The Atomic Energy Act of 1954 provided increased access for the civilian program to nuclear technology. The Price-Anderson Nuclear Industries Indemnity Act facilitated the development of nuclear powered generating capacity by establishing a program for covering claims of members of the public if a major accident occurred at a nuclear power plant and by providing a ceiling on the total amount of liability for nuclear accidents. The Energy Reorganization Act of 1974 divided the AEC into the U.S. Energy Research and Development Administration (combined in 1977 with the Federal Energy Administration to become DOE ${ }^{\text {xxvi }}$, which focused on R\&D efforts to address the nation's growing need for additional sources of energy, and the U.S. Nuclear Regulatory Commission (NRC), which focused on the regulation of civilian uses of nuclear energy. More recently the Energy Policy Act of 2005 included a number of measures for

\footnotetext{
${ }^{\mathrm{xxv}}$ This section is intended to be illustrative of the relationship between federal policies and generation development rather than a comprehensive treatment of the subject.

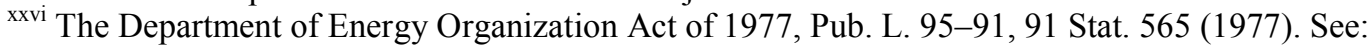

https://www.gpo.gov/fdsys/pkg/STATUTE-91/pdf/STATUTE-91-Pg565.pdf.
} 
existing and new nuclear plants, including a 20-year renewal of Price-Anderson, updating tax treatment of decommissioning trust funds, creating a loan guarantee program that could be used for new nuclear plants, and authorized additional R\&D.

\subsubsection{Coal}

Coal-fired generation grew every year between 1949 and 2007 except for 1986, 1991, and 2006. However, coal's share of electricity generation has begun falling. In 2015, coal-fired generation and natural gas generation each made up roughly $33 \%$ of U.S. electricity generation, representing the first time in the modern electricity system that coal was not the dominant fuel of choice for electricity generation ${ }^{123}$. Nearly $15 \mathrm{GW}$ of coal-fired electric generating capacity were retired in 2015, a relatively high amount compared with recent years. In 2016, EIA expects data to show that lower natural gas prices will result in natural gas fueling over 34 percent of U.S. electricity generation in 2016 compared with about 30 percent for coal ${ }^{124}$.

The decline of coal-fired generation has largely been due to competition with low natural gas prices, an aging fleet, and environmental regulations. About 30 percent of the coal-fired capacity that retired in 2015 occurred in April, which is when the U.S. Environmental Protection Agency's (EPA's) Mercury and Air Toxics Standards rule compliance period expired. The coal units that were retired in 2015 tended to be smaller and were mainly built between 1950 and 1970. The average age of the retired units is 54 years. The rest of the coal-fired fleet that continues to operate is relatively younger, with an average age of 38 years $^{125}$.

\subsubsection{Natural Gas}

The Powerplant and Industrial Fuel Use Act was enacted in 1978 in response to concerns over national energy security related to the 1973 oil crisis and the natural gas curtailments of the mid1970s. The act restricted construction of power plants using oil or natural gas as a primary fuel and instead encouraged the use of coal, nuclear energy, and alternative fuels. Falling natural gas demand and prices led to repeal of the Powerplant and Industrial Fuel Use Act in 1987, which allowed the use of natural gas and oil for large, new baseload electric power plants.

Natural gas consumption for electric generation increased from 2.6 trillion cubic feet in 1988 to 5.7 trillion cubic feet in 2002, an increase of almost 119 percent. In 2016, EIA predicts that natural gas will become the largest source of power generation ${ }^{126}$.

\subsubsection{Renewable Energy (Non-Hydro)}

Growth in renewable generation has been driven by improvements in technology, high and volatile fossil fuel prices, Federal tax incentives, State RPS, and consumer preference for renewable energy ${ }^{127}$.

Originally enacted in the Energy Policy Act of 1992, the PTC provides an inflation-adjusted tax credit per kWh of electricity generated for 10 years after a plant is placed in service. In 2014, the PTC was $\$ 0.023 / \mathrm{kWh}$ for wind, closed-loop biomass, and geothermal energy resources and $\$ 0.012 / \mathrm{kWh}$ for open-loop biomass, landfill gas, municipal solid waste (MSW), qualified hydroelectric, and marine and hydrokinetic (MHK) energy resources ${ }^{128}$ The PTC has been renewed and expanded numerous times, most recently by the American Recovery and Reinvestment Act of 2009, the American Taxpayer Relief Act of 2012, the Tax Increase Prevention Act of 2014, and the Consolidated Appropriations Act of 2016. The Consolidated 
Appropriations Act of 2016 instituted a stepped phase down of the PTC from 100 percent for plants starting construction by the end of 2016 to 60 percent of the credit for plants starting construction by the end of 2019. Development of certain renewable generators, especially wind, has been particularly dependent on the availability of the PTC, as discussed in Section 9.

The Energy Tax Act of 1978 established a residential energy tax credit for solar and wind energy equipment but the credit was allowed to expire at the end of 1985. The Energy Policy Act of 2005 established a 30 percent residential solar credit with a cap at $\$ 2,000$, which expired at the end of 2007. The Tax Relief Act of 2006 extended the credit through the end of 2008 and established a 10 percent business tax credit for solar, wind, geothermal, and ocean energy equipment. The Energy Policy Act of 2005 increased the solar business credit to 30 percent through the end of 2007 . It was extended to the end of 2008 by the Tax Relief Act of $2006^{129}$.

The Federal business energy ITC was expanded significantly by the Energy Improvement and Extension Act of 2008. This law extended the duration - by 8 years - of the existing credits for solar energy, fuel cells, and micro-turbines; increased the credit amount for fuel cells; established new credits for small wind-energy systems, geothermal heat pumps, and combined heat and power systems; allowed utilities to use the credits; and allowed taxpayers to take the credit against the alternative minimum tax, subject to certain limitations. The credit was further expanded by the American Recovery and Reinvestment Act of 2009. Most recently, the Consolidated Appropriations Act of 2016, signed in December 2015, included several amendments to this credit that apply to solar technologies and PTC/ITC-eligible technologies. Notably, the expiration date for these technologies was extended, with a gradual step down of the credits between 2019 and $2022^{130}$.

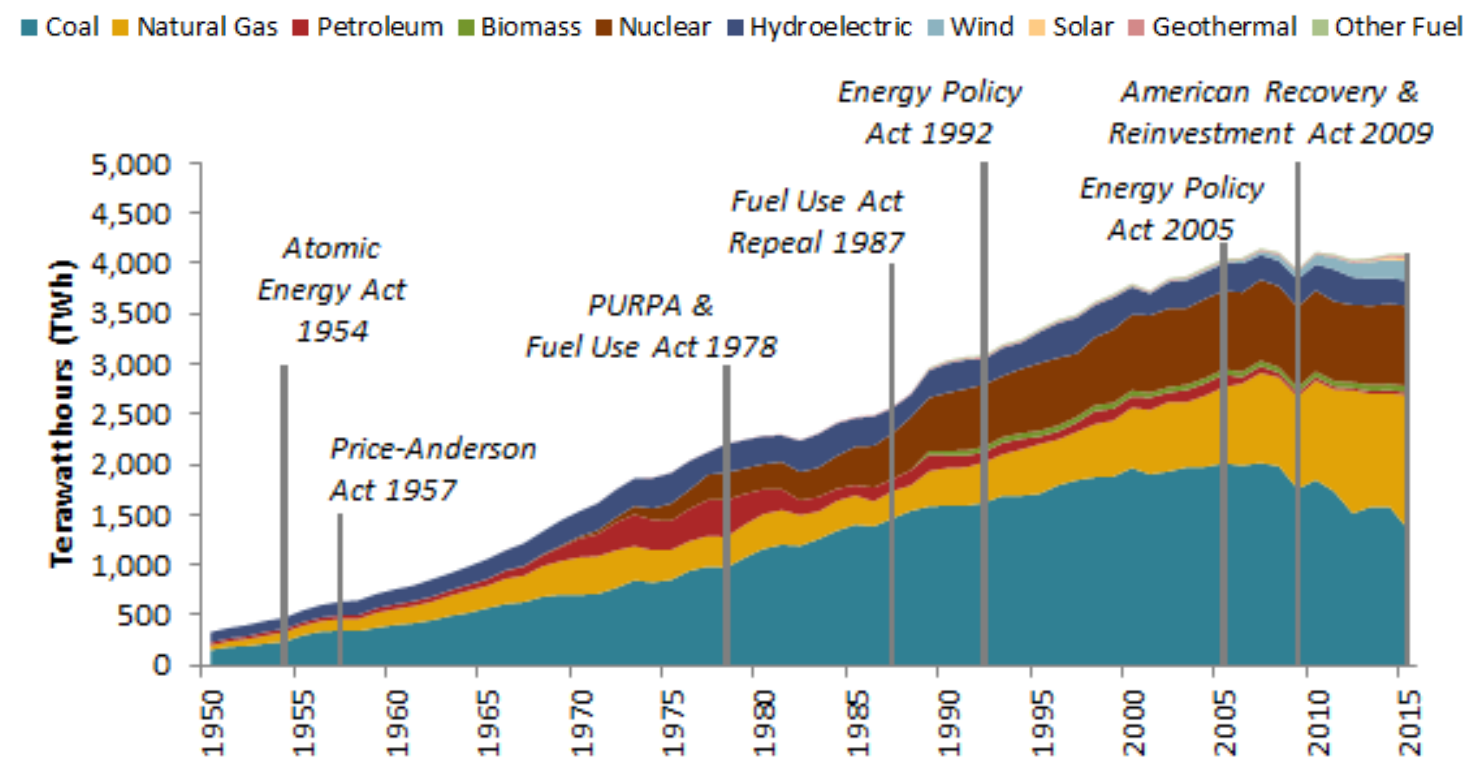

Figure 3-12. U.S. generation (TWh) by fuel type, 1950-2014

A wide variety of energy and non-energy legislation has helped shape the U.S. power sector. Source: EIA $2016^{131}$. 


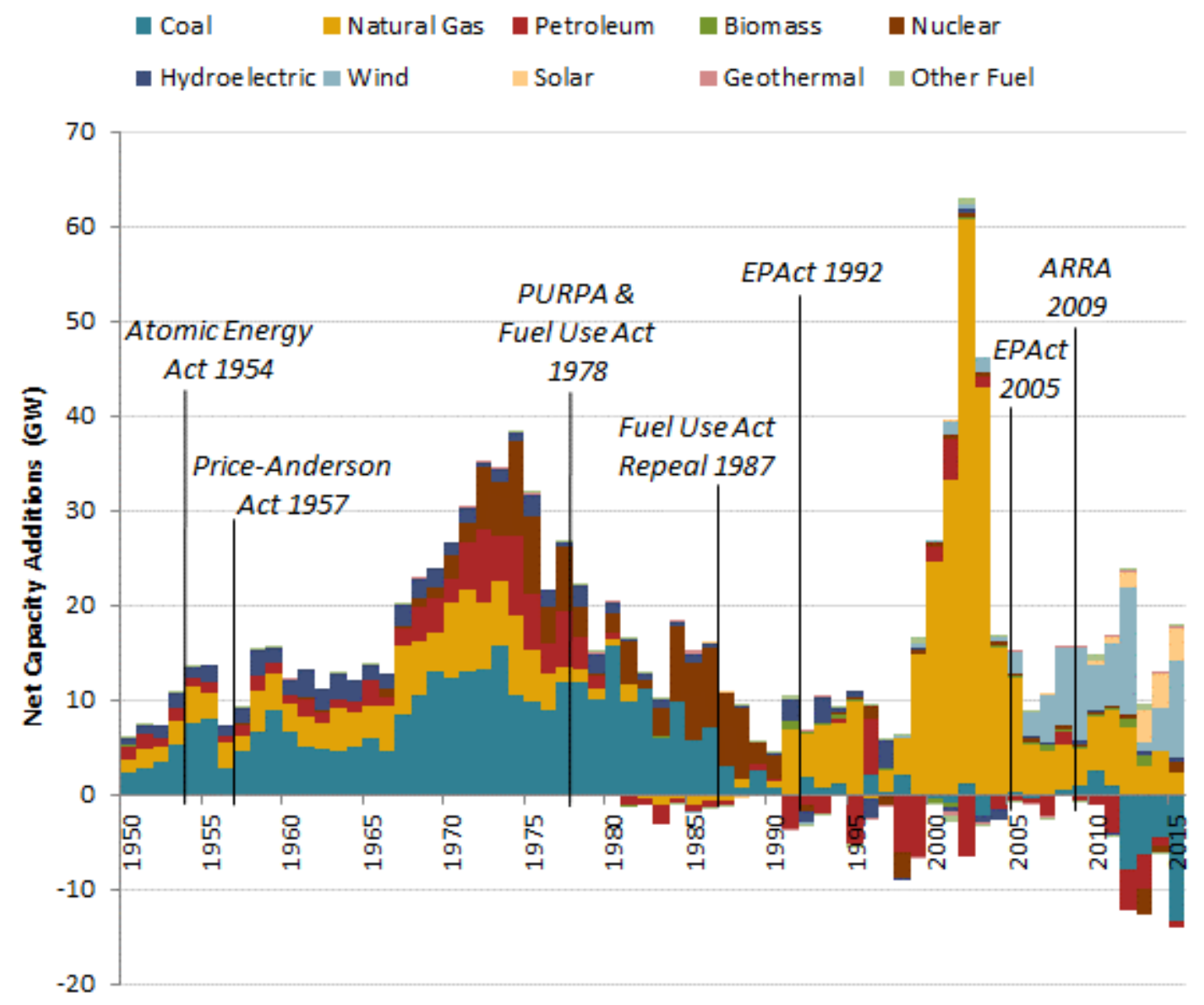

Figure 3-13. Net capacity additions (GW) by fuel type, 1950-2015

Capacity additions came in waves that were largely influenced by policy, as well as technology and market trends. The 1930s and 1940s fostered the development of hydropower; nuclear power boomed in the 1960s and 1970s; natural gas additions peaked in the 2000s; and non-hydro renewables are quickly growing in the 21 st century. Source: EIA $2016^{132}$. 


\section{National and Regional Generation Data}

This chapter reports on common metrics used to characterize power generation and uses them to identify trends. It begins with a summary of generation and capacity trends at the national level. Section 4.2 addresses similar trends at the regional level.

\subsection{National Generation and Capacity}

The U.S. electric power system has evolved significantly over the past $60+$ years. Most notably, electricity generation within the United States has grown more than ten-fold, from $334 \mathrm{TWh}$ in 1950 to 4,087 TWh in 2014. During this time frame, the generation fleet and the fuels that supply it have also shifted, sometimes in dramatic ways. The primary fuels and sources that make up the U.S. electric power sector include coal, natural gas, petroleum, nuclear, hydropower, biomass, wind, solar, and geothermal, as shown in Figure 4-1. The share of generation by fuel type has also changed over time, as shown in Figure 4-2.

\begin{tabular}{|c|c|c|c|}
\hline Natural Gas & Petroleum & Biomass & - Nuclear \\
\hline Hydroelectric 1 Wind & Solar & Geothermal & Other Fuel \\
\hline
\end{tabular}
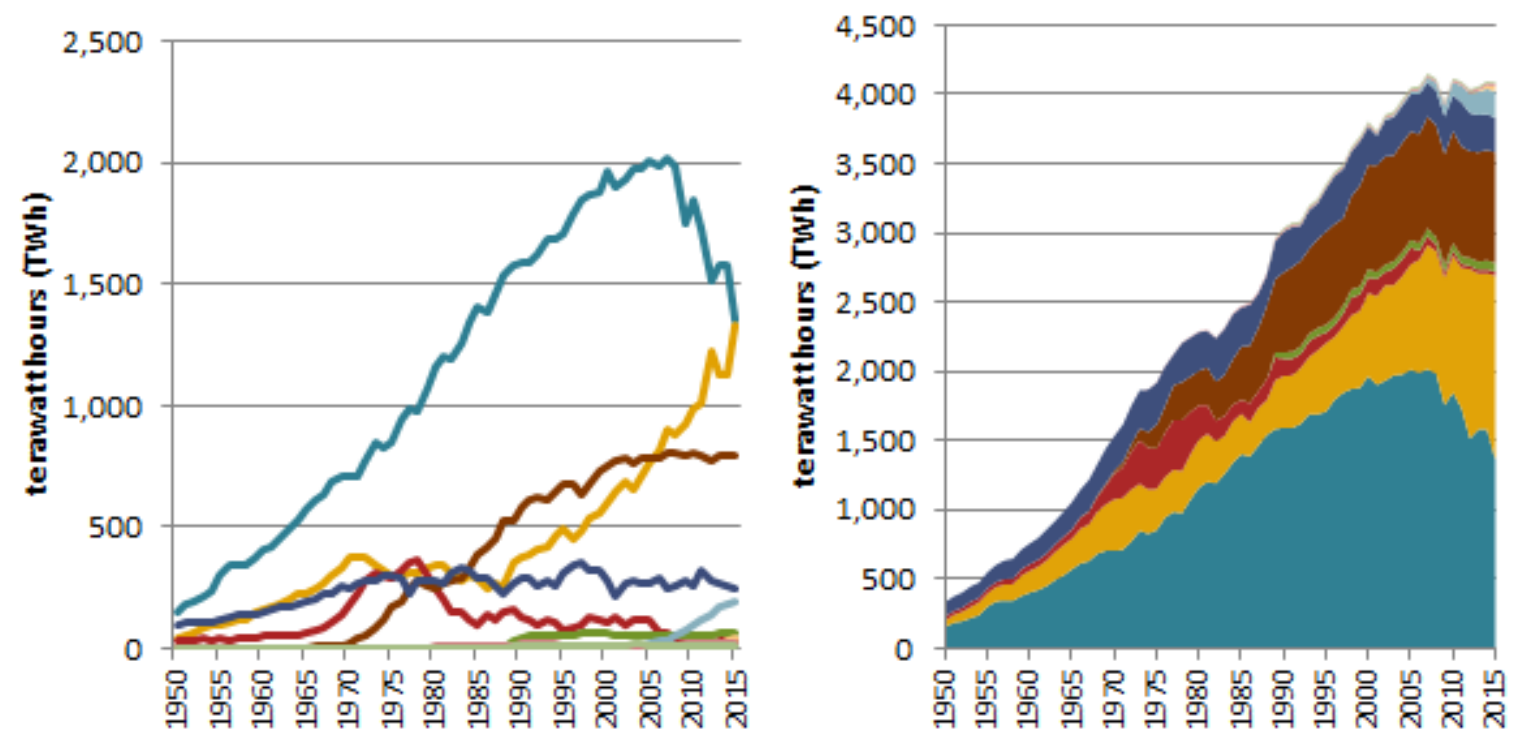

Figure 4-1. U.S. electricity generation (TWh) by fuel type, 1950-2014

Coal generation has declined significantly since its peak in 2007, while natural gas and renewables have largely replaced the lost coal. Source: EIA $2016^{133}$.

As seen, coal-fired generation has declined substantially from its peak in 2007, with much of the lost generation made up by natural gas-fired and non-hydroelectric renewable sources. The breakout of non-hydro renewable generation, as shown to the right in Figure 4-2 is composed mostly of biomass, wind, utility-scale solar ${ }^{\text {xxvii }}$, and geothermal. Although these fuel types have

xxvii EIA began publishing estimates of distributed PV in November 2015. Estimates of distributed PV generation are available starting in 2014 and account for approximately 35 percent of total solar PV generation. Data in this figure thus do not include distributed PV. 
grown significantly in recent years, individually, each represented less than 5 percent of total U.S. generation as of 2014. Total non-hydro renewable generation surpassed conventional hydroelectric generation for the first time in 2014.
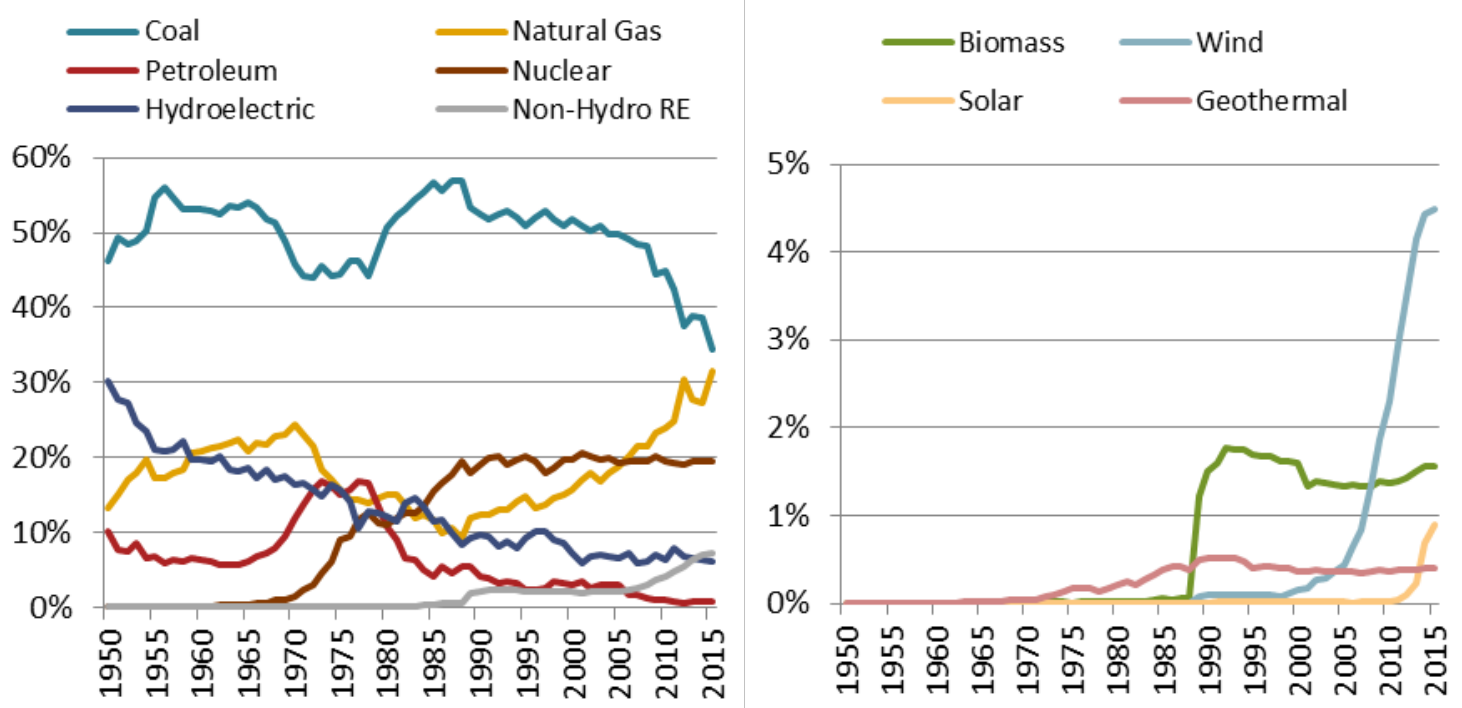

Figure 4-2. Share of U.S. electricity generation by fuel type in percent, 1950-2015

The share of coal generation declined to approximately 33 percent in 2015, nearly tying that from natural gas, while wind and solar shares grew rapidly, but from a small base. Data in this figure do not include distributed PV. Source: EIA $2016^{134}$.

The top two images in Figure 4-3 show more recent changes in monthly and annual power generation by fuel source at the national level. Total generation peaked in 2007 due primarily to declining electricity demand. Coal- and oil-fired generation declined by over 21 percent and 50 percent, respectively, between 2005 and 2014, while natural gas-fired generation increased by nearly 25 percent. Hydroelectric and nuclear generation remained essentially stable, while nonhydro renewable electricity generation grew by over 160 percent, although starting from a much smaller base.

The bottom left image of Figure 4-3 shows both historical and certain types of planned ${ }^{\text {xxviii }}$ cumulative generation capacity, while the bottom right figure illustrates annual capacity changes. Natural gas-fired and wind capacity have seen substantial increases; these technologies as well as solar will likely see continued expansion based on relatively advanced planning for new construction. Coal-fired capacity saw its last notable deployment in 2010 as plants planned before the financial crisis of 2008 came online. Nuclear deployment will also be relatively small out to 2024, with only two plants (four units) currently under construction.

xxviii SNL data captures plants that are under construction or in the advanced planning and financing stage, or that have announced firm retirement dates. SNL data for these future capacity additions and retirements are considered not inclusive of all new changes. These data were gathered before the passage of the tax credit extensions in December 2015, so certain renewable energy projects may be less pressured to bring generators online in anticipation of earlier planned expirations. SNL data do not include distributed PV. 


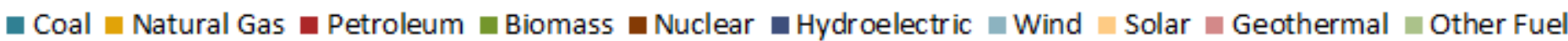
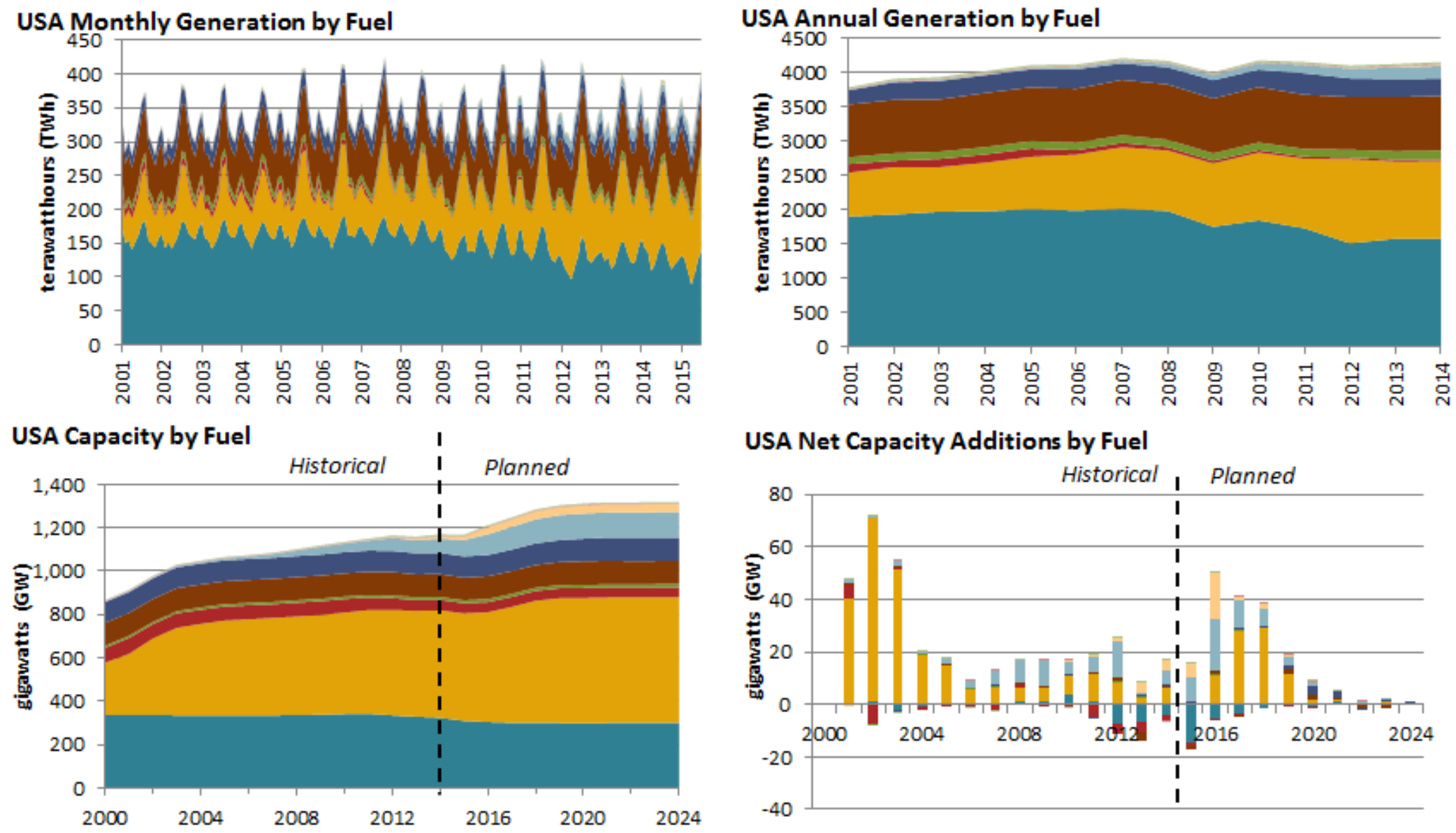

\section{USA Net Capacity Additions by Fuel}

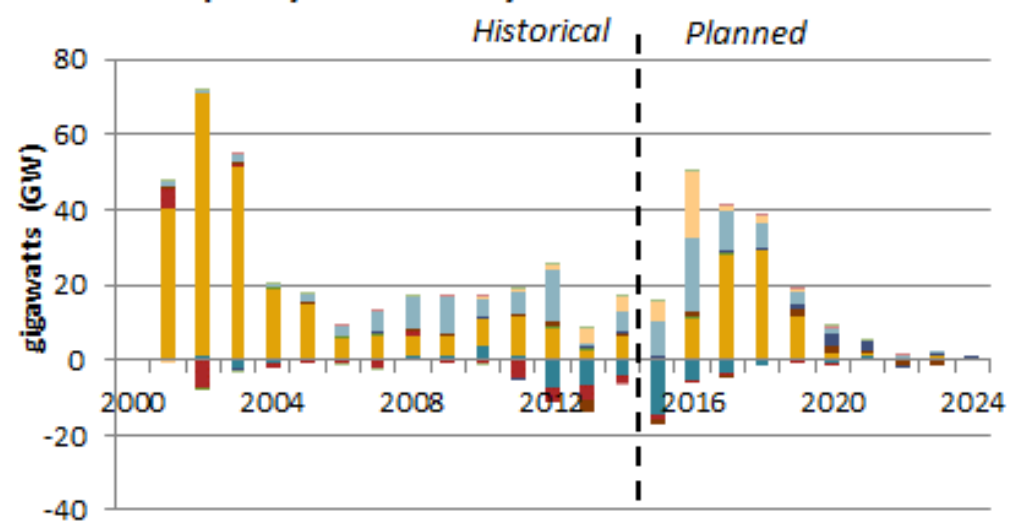

Figure 4-3. Monthly and annual generation in the United States (top) and historical and planned capacity additions by fuel (bottom)

Total generation peaked in 2007 due largely to declining demand. Coal and oil fired generation declined by 33 and 58 percent, respectively, by 2015 . The largest capacity additions in recent years have come from natural gas and wind, and this trend is expected to continue out to 2020. Source: SNL $2015^{135}$. 
It is also useful to look at the different sectors within the United States that generate power and the fuels that they rely on. The U.S. electric power industry includes all electricity generated in the electric power, industrial, and commercial sectors ${ }^{136}$. The electric power sector is defined by the EIA as an energy-consuming sector that consists of electricity-only and combined-heat-andpower plants whose primary business is to sell electricity, or electricity and heat, to the public and includes both electric utilities and independent power producers ${ }^{137}$. In 2013, 96 percent of all electricity generated in the U.S. was generated in the electric power sector, while 3.7 percent was generated at utility-scale facilities in the industrial sector, with the commercial sector responsible for the remaining 0.3 percent ${ }^{138}$.

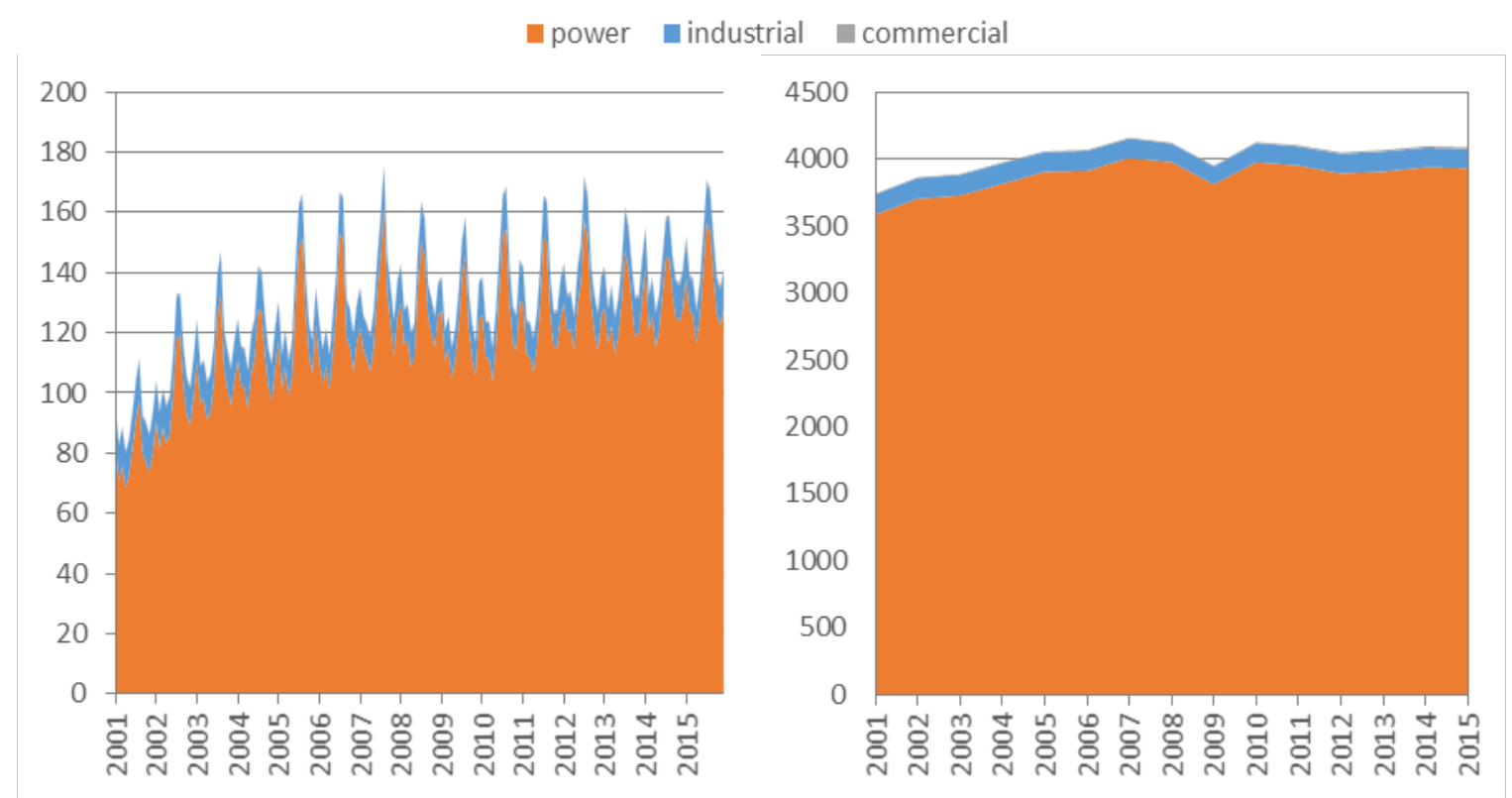

Figure 4-4. U.S. monthly and annual generation (TWh) by sector, 2001-2015

The power sector made up 96 percent of all generation, followed by the industrial sector at 3.7 percent and the commercial sector at 0.3 percent. Source: EIA $2016^{139}$.

Figure 4-5 shows the generation by fuel from the power sector. Since this sector makes up the largest contribution to the total generation in the United States, the mix generally resembles that of the nation, with coal- and natural gas-fired capacity providing 34 percent and 32 percent of generation, respectively, in 2015. 

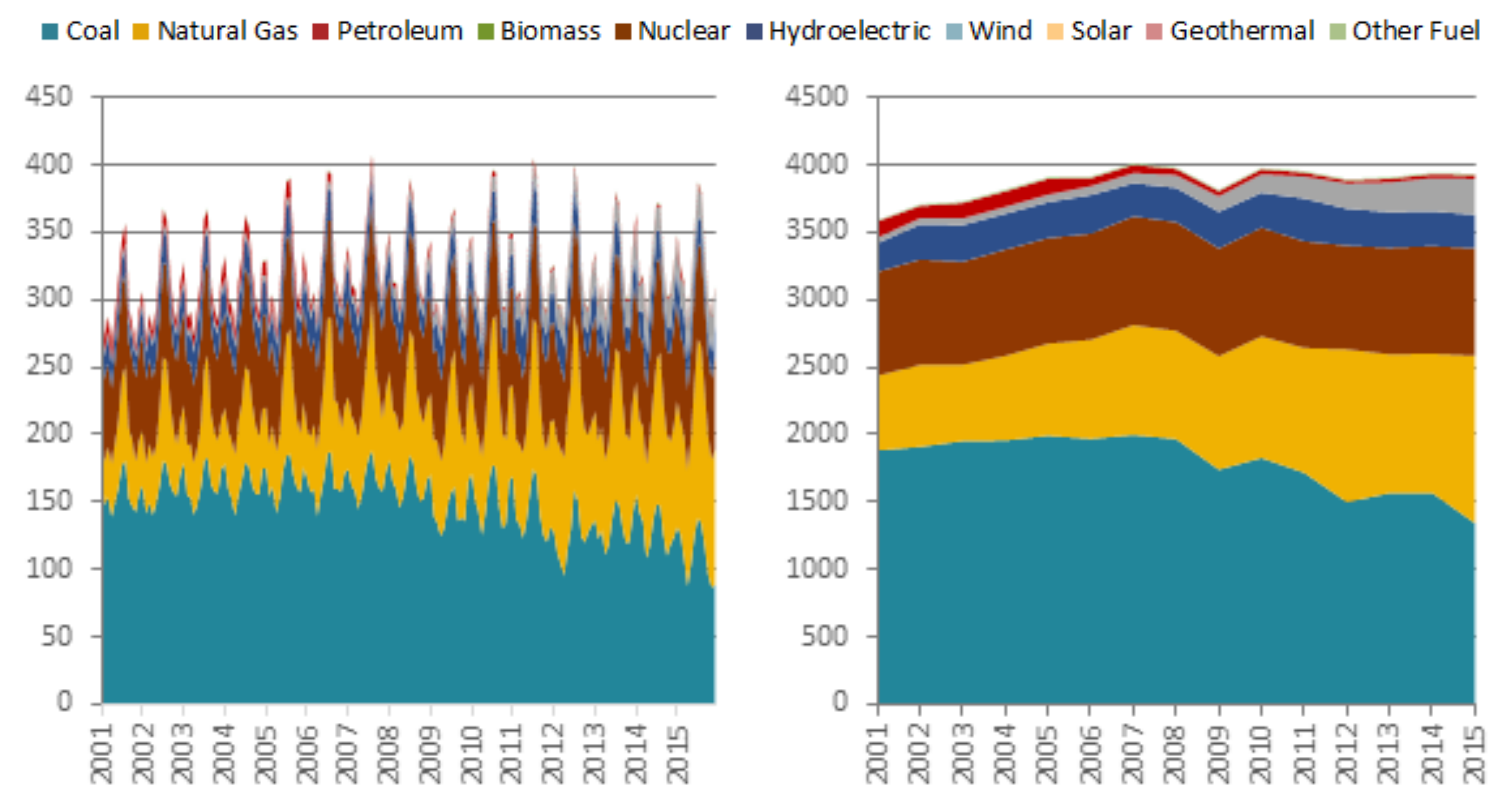

Figure 4-5. U.S. monthly and annual generation (TWh) from the power sector by fuel, 2001-2015

The generation portfolio of the power sector closely resembles that of the entire United States, with 34 percent of generation coming from coal and 32 percent from natural gas in 2015. Source: EIA $2016^{140}$.

Although the power sector generally resembles the national generation mix, the industrial sector varies significantly and is comprised primarily of natural gas-firing at nearly 60 percent of generation in 2015. The industrial sector also has a much larger contribution from non-hydro renewables than the power sector, at 20 percent of total U.S. generation in 2015. There is currently no contribution from nuclear in this sector (Figure 4-6).

The commercial sector has a similar portfolio to the industrial sector, with 59 percent of generation from natural gas-fired sources and 26 percent from non-hydro renewables in 2015. This sector has seen the largest growth since 2001, adding 5.5TWh of generation by 2015 that was predominantly composed of natural gas-firing capacity (Figure 4-7). 

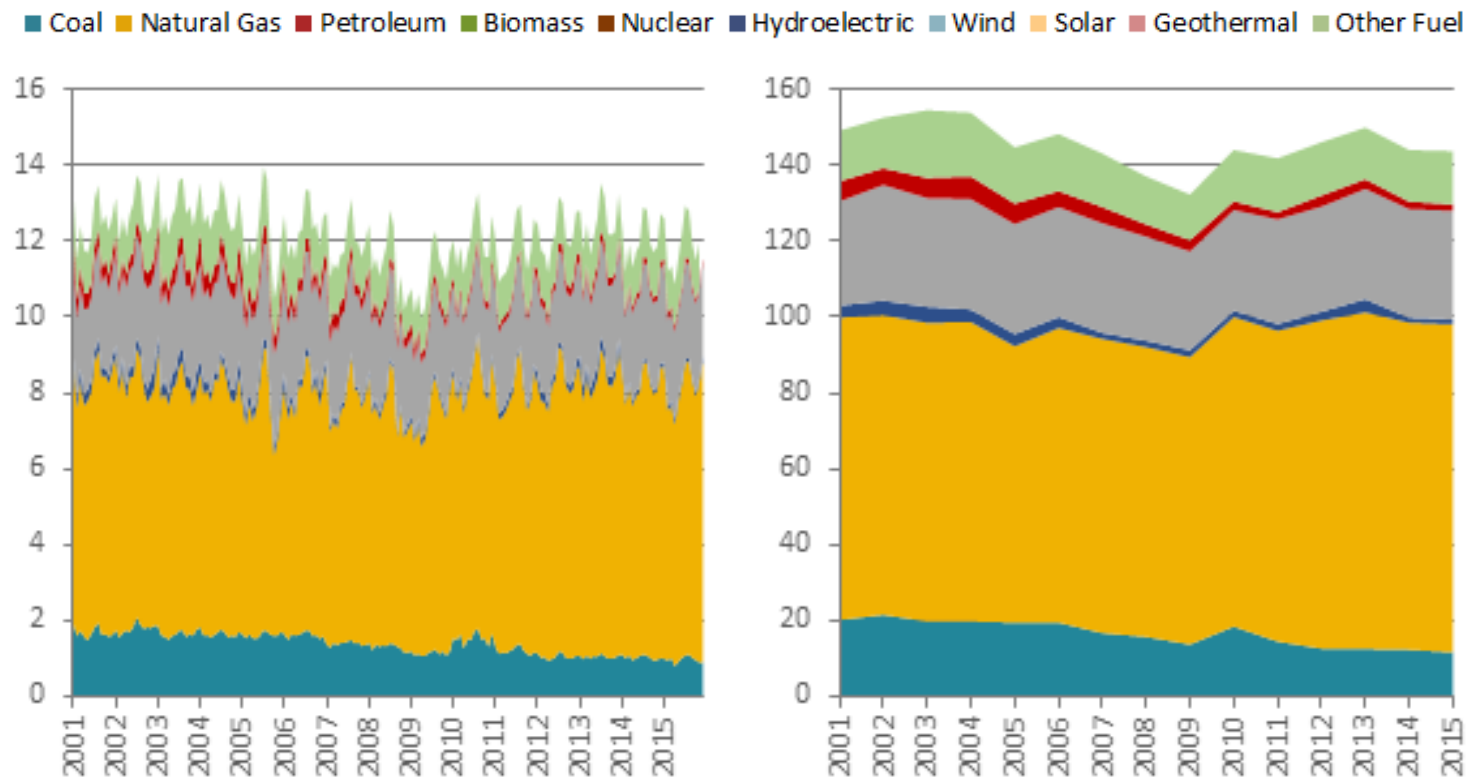

Figure 4-6. U.S. monthly and annual generation (TWh) from the industrial sector by fuel, 20012015

The generation portfolio of the industrial sector is largely made up of natural gas, followed by non-hydro renewables and coal. Source: EIA $2016^{141}$.

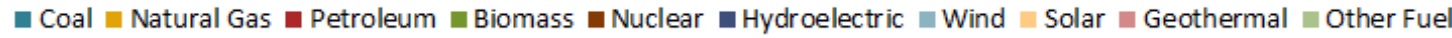
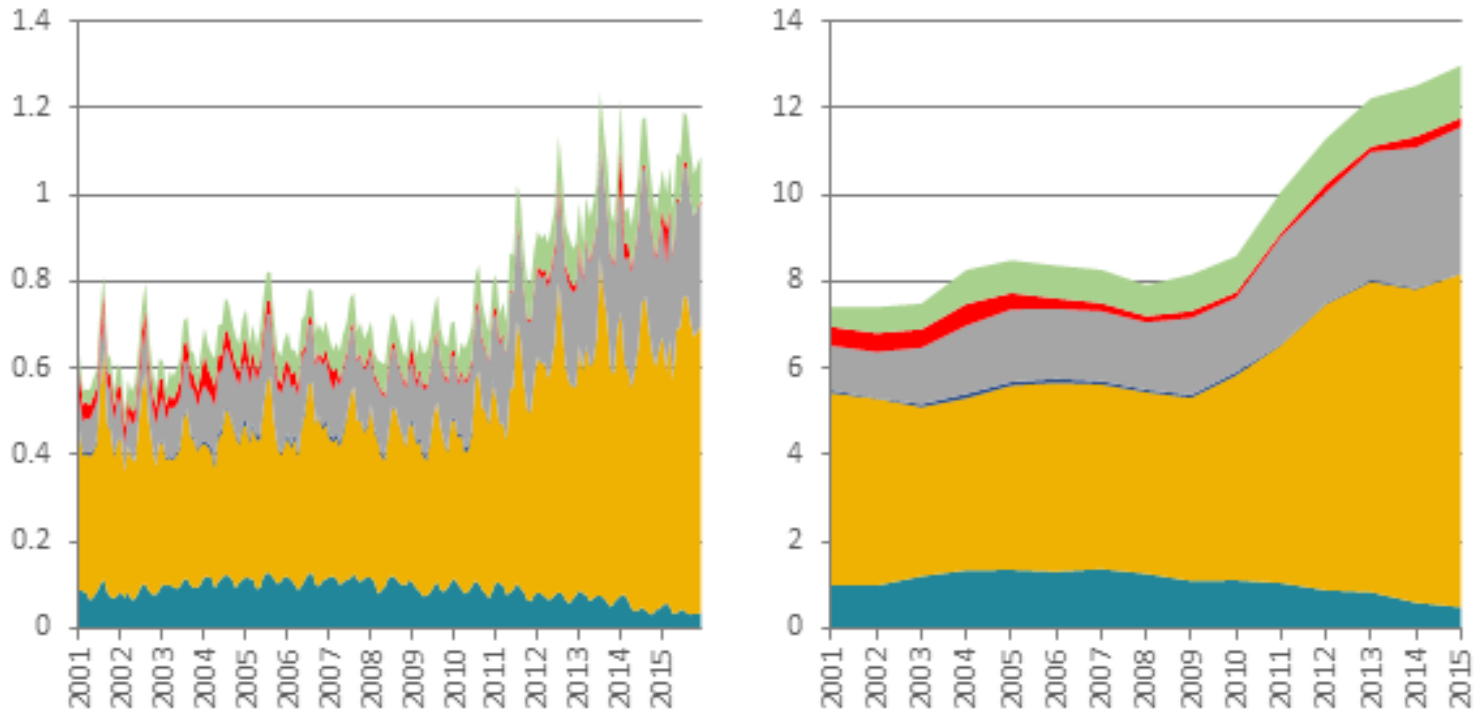

Figure 4-7. U.S. monthly and annual generation (TWh) from the commercial sector by fuel, 20012015

In 2015, the commercial sector had the largest contribution, compared to the other sectors, from renewables at 26 percent, while natural gas made up the majority of generation at 60 percent. Source: EIA $2016^{142}$. 
Figure 4-8 shows electricity generation and retail sales from all sectors by state ${ }^{143}$. Where sales exceed generation, the state runs an electricity deficit and must import power. Several states stand out as large net importers as measured in GWh: California, Virginia, Massachusetts, Tennessee, and Ohio. Massachusetts is particularly notable for its small size but large amount of net imports. Proportional to its total sales, Massachusetts far exceeds any other state in net imports. Idaho and Delaware, while not large net importers in terms of total energy, import high percentages of their total sales.

The largest net exporters of electricity are Illinois, Pennsylvania, West Virginia, Alabama, and Texas. Because West Virginia has a low amount of total sales, it is also one of the highest proportional exporters. Lower-consumption states in the western United States, such as Wyoming, Montana, and North Dakota, also are large exporters on a proportional basis.

While regional patterns are difficult to discern, generally high net-importing states abut at least one high net-exporting state, with Massachusetts being the notable exception. Extremes in total energy import and export tend to occur in more populous states, though Alabama and several others do not fit this pattern. 

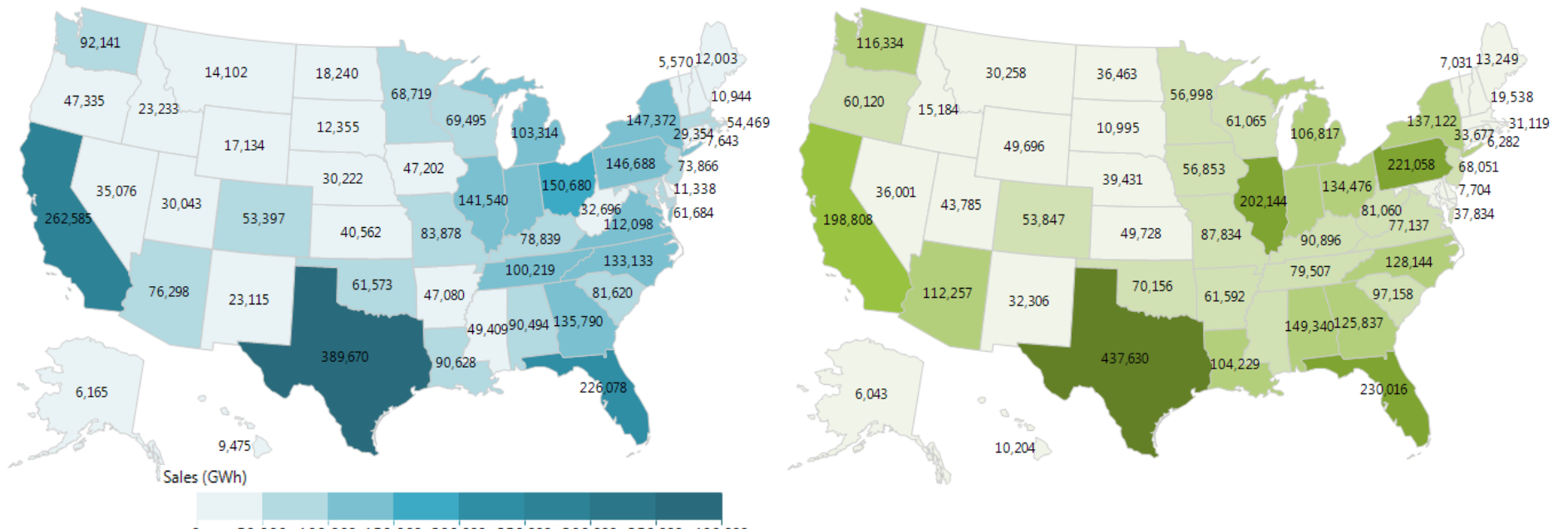

$50,000 \quad 100,000 \quad 150,000200,000 \quad 250,000 \quad 300,000 \quad 350,000 \quad 400,000$

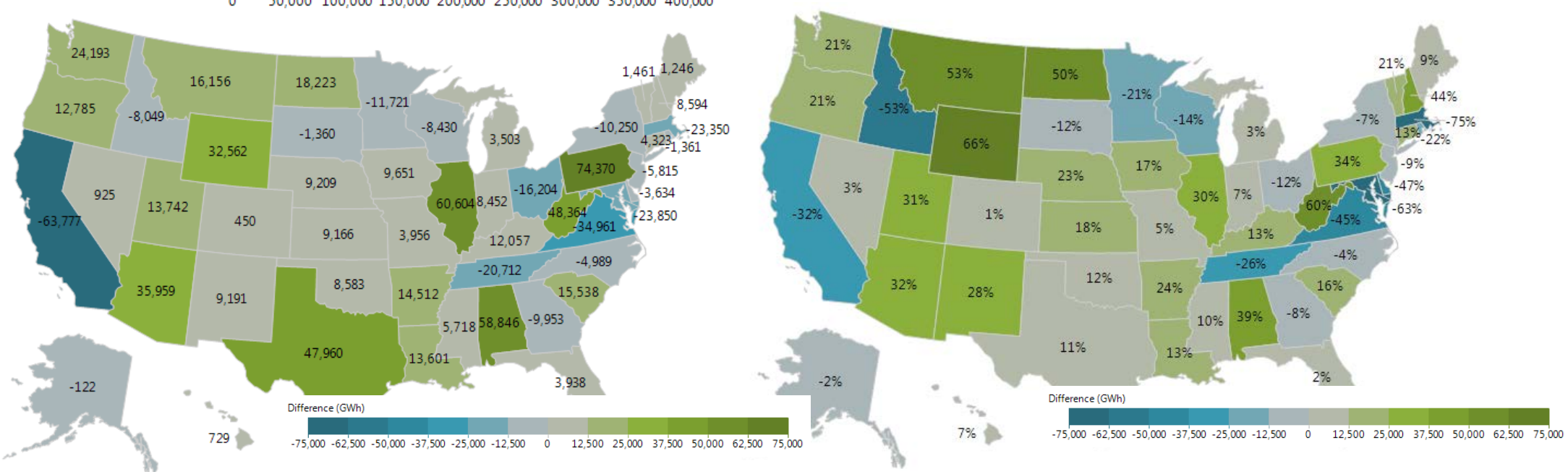

Figure 4-8. Sales and generation by U.S. state in 2014. Top: total sales (left) and generation (right) in GWh. Bottom: difference between generation and sales shown in GWh (left) and percent (right).

The largest net importers on an energy basis are California, Virginia, and Massachusetts. The largest net exporters on an energy basis are Illinois, Pennsylvania, and Alabama. Note that these data are for 2014 only and can vary annually. Sources: EIA $2016^{144}$ 


\subsection{Regional NERC Trends}

The previous section addressed generation trends and metrics at the national level. This section focuses on more granular regional issues in order to illuminate changes that are happening at a less aggregated level. This report represents data at the NERC regional level to appropriately capture regional generation differences. All data come from SNL 2015 and do not include distributed solar PV unless otherwise noted.

\subsubsection{Regional Categories}

The U.S. electricity grid does not always fit neatly within state boundaries. The 48 continental states are comprised of three synchronous interconnections: the Eastern Interconnection, the Western Interconnection (or WECC), and the Electric Reliability Council of Texas (ERCOT). ${ }^{\text {xix }}$ In addition, Alaska and Hawaii manage and operate their own grid systems. Each of these interconnections and state grids operate at their own level of synchronization, and there is limited capacity to import or export electricity through direct current (DC) interties. The Eastern Interconnection is further broken down into six NERC Regional Entities (Regions):

- SERC (formerly Southeastern Electric Reliability Council)

- ReliabilityFirst Corporation (RFC)

- Northeast Power Coordinating Council (NPCC)

- Southwest Power Pool (SPP)

- Midwest Reliability Organization (MRO)

- Florida Reliability Coordinating Council (FRCC).

Figure 4-9 shows the total generating capacity in each region, interconnection, and Hawaii and Alaska, as well as the totally generating capacity for the entire country. The boundaries for each NERC region correspond to the bar color in the chart.

Grid operations can vary significantly between regions. Table 4-1 summarizes select generation metrics between 2009 and 2014 at the national level and by NERC region, including Hawaii and Alaska. Note that although several NERC regions include large portions of Canadian territory and a small amount of Mexico, these data only capture U.S. generation characteristics. A larger illustration of the NERC regional boundaries is shown in Figure 4-10.

\footnotetext{
${ }^{\text {xxix }}$ Both the Eastern and Western Interconnections extend beyond the borders of the United States to include the non-territorial areas of Canada. The Western Interconnection also extends beyond the U.S. southern border to include a portion of Baja California Norte in Mexico. In addition to its asynchronous DC ties to the Eastern Interconnection, ERCOT also maintains $280 \mathrm{MW}$ of asynchronous connection to northern Mexico.
} 


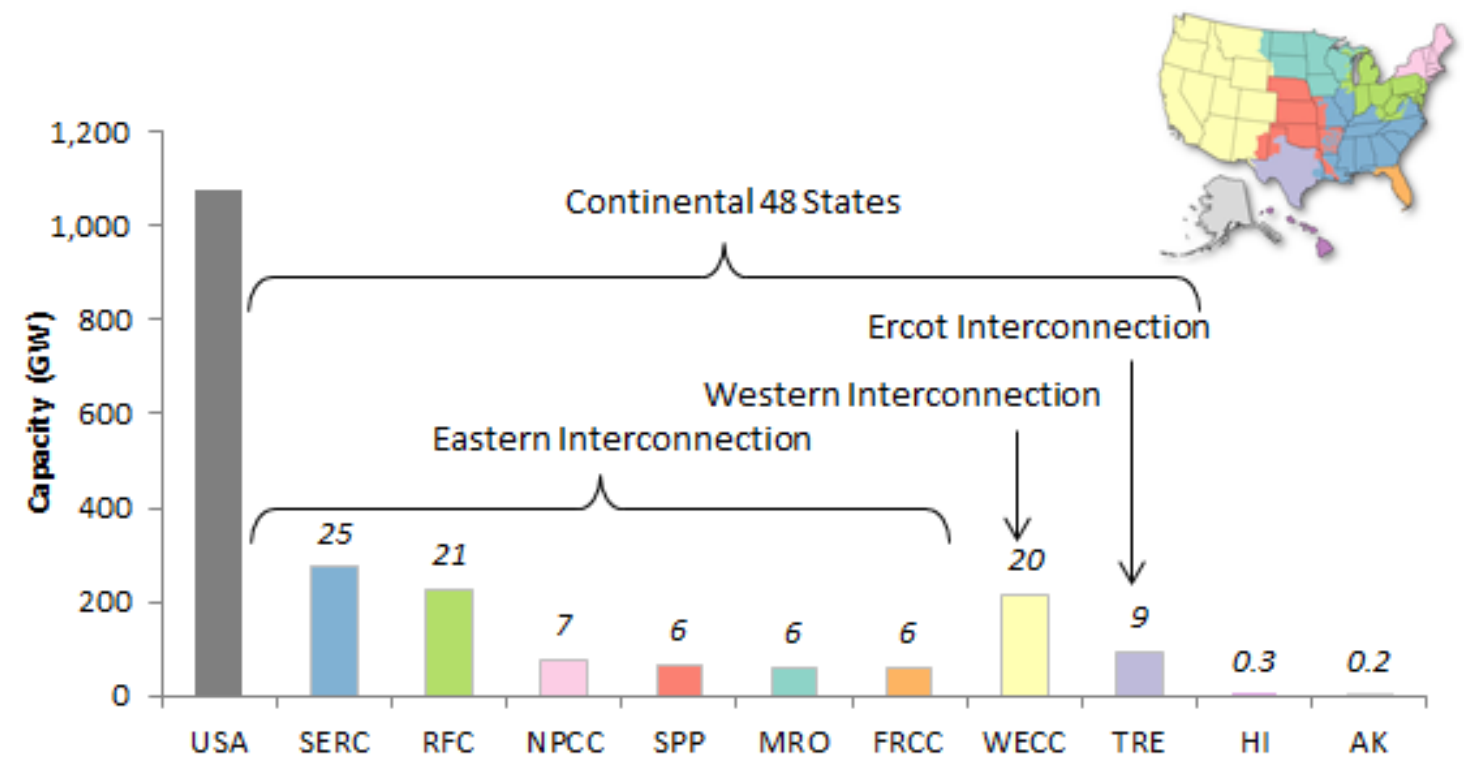

Figure 4-9. Electrical generating capacity in the U.S. by NERC region

The United States (and North America) is divided up into a number of reliability regions of varying size and market structures. Six NERC regions comprise the Eastern Interconnection, with the one region in the West comprising the

Western Interconnection, and the one in Texas comprising ERCOT. These interconnections, plus Hawaii and Alaska, operate at their own frequencies and have limited capability to share electricity through DC interties. The percentage of each region's total capacity is shown above the column. Source: SNL $2015^{145}$.

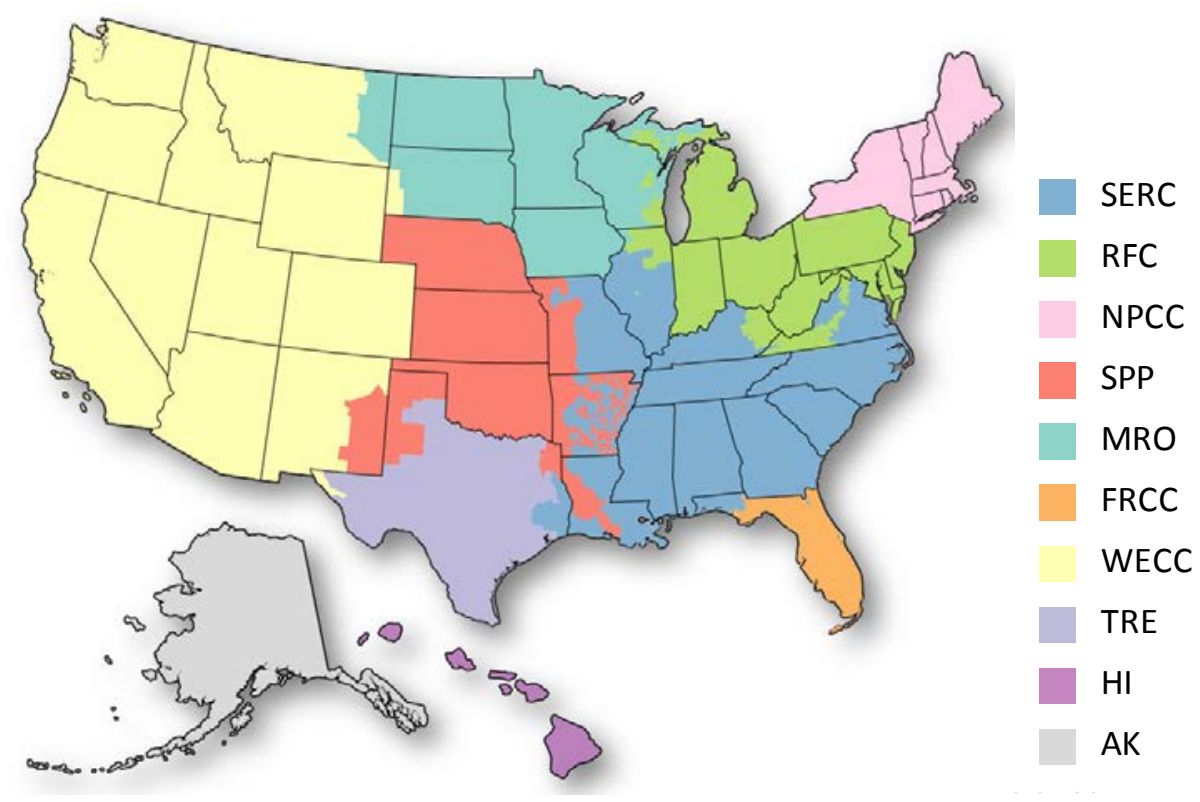

Figure 4-10. NERC regions

WECC is the largest reliability region in the continental United States while FRCC is the smallest. Source: NERC $2015^{146}$. 
Table 4-1. Change in Generation from Major Fuel Types by Region, 2009-2014

\begin{tabular}{|c|c|c|c|c|c|c|c|c|c|c|}
\hline & \multicolumn{2}{|l|}{ Coal } & \multicolumn{2}{|l|}{ Natural Gas } & \multicolumn{2}{|l|}{ Nuclear } & \multicolumn{2}{|c|}{ Non-Hydro Renewable } & \multicolumn{2}{|l|}{ Total } \\
\hline & $\begin{array}{c}\text { Absolute } \\
\text { Change (TWh) }\end{array}$ & $\begin{array}{l}\text { Percent } \\
\text { Change }\end{array}$ & $\begin{array}{c}\text { Absolute } \\
\text { Change (TWh) }\end{array}$ & $\begin{array}{l}\text { Percent } \\
\text { Change }\end{array}$ & $\begin{array}{c}\text { Absolute } \\
\text { Change (TWh) }\end{array}$ & $\begin{array}{l}\text { Percent } \\
\text { Change }\end{array}$ & $\begin{array}{c}\text { Absolute Change } \\
\text { (TWh) }\end{array}$ & $\begin{array}{l}\text { Percent } \\
\text { Change }\end{array}$ & $\begin{array}{c}\text { Absolute } \\
\text { Change (TWh) }\end{array}$ & $\begin{array}{l}\text { Percent } \\
\text { Change }\end{array}$ \\
\hline US & -171.3 & -10 & 204.6 & 22 & -1.7 & 0 & 130.8 & 85 & 132.0 & 3 \\
\hline WECC & -13.8 & -6 & -4.3 & -2 & -10.3 & -15 & 43.4 & 92 & 11.9 & 2 \\
\hline SERC & -53.9 & -11 & 94.8 & 51 & 3.8 & 1 & 12.7 & 52 & 49.8 & 5 \\
\hline RFC & -83.0 & -15 & 65.1 & 85 & 12.1 & 5 & 17.5 & 102 & 13.5 & 1 \\
\hline NPCC & -17.4 & -62 & 11.8 & 12 & 0.2 & 0 & 14.5 & 148 & -6.4 & -2 \\
\hline SPP & -0.8 & -1 & -5.7 & -10 & -0.2 & -2 & 4.0 & 29 & 3.4 & 2 \\
\hline MRO & -9.6 & -6 & 2.7 & 31 & -3.9 & -11 & 19.2 & 105 & 12.2 & 6 \\
\hline FRCC & -4.1 & -7 & 30.6 & 29 & -1.2 & -4 & 0.0 & -1 & 9.7 & 4 \\
\hline TRE & 11.4 & 10 & 9.7 & 6 & -2.2 & -5 & 19.4 & 105 & 37.8 & 12 \\
\hline Alaska & -0.1 & -11 & -0.3 & -8 & 0.0 & 0 & 0.2 & 1484 & -0.7 & -10 \\
\hline Hawaii & 0.0 & 1 & 0.0 & 0 & 0.0 & 0 & 0.5 & 74 & -1.3 & -12 \\
\hline
\end{tabular}

The shift from coal to natural gas generation is occurring fastest in the eastern half of the country, where growth in renewables is modest. The opposite behavior is observed in the western part of the country (including Texas). Source: SNL $2015^{147}$. 


\subsubsection{SERC}

Electricity in SERC is predominately sourced by coal-fired, natural gas-fired, and nuclear generation (Figure 4-11); SERC saw the largest absolute increase in demand for electricity (and third fastest growth rate) among all NERC regions and other states between 2009 and 2014 (Table 4-1). In 2014, the region had more natural gas-fired capacity than coal-fired (40 percent and 34 percent, respectively), but coal-fired generation exceeded generation from natural gas (41 percent and 25 percent, respectively). The region is undergoing a rapid shift from coal to natural gas, however, and monthly data through the first half of 2015 showed the gap in generation between the two fuel sources narrowing. Non-hydro renewable generation has expanded by nearly 10 percent each year on average since 2009, but is starting from a very low base. Current and near-term changes in capacity are primarily natural gas-fired additions and some coal-fired retirements. The region also had one of the lowest shares of wind capacity and generation at 1.3 percent and 0.9 percent, respectively, in 2014. SERC is also the only region with new nuclear capacity expected to come online in the near term, with over $5 \mathrm{GW}$ expected by roughly 2020. Nuclear generation development is enabled by the "construction work in progress" (CWIP) incentives sometimes offered in the southeastern region, by federal loan guarantees under the Energy Policy Act of 2005, as well as by the vertically integrated market structure. 


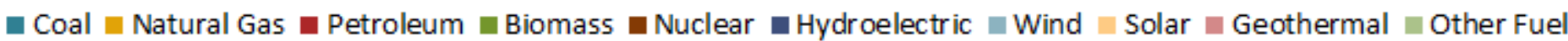
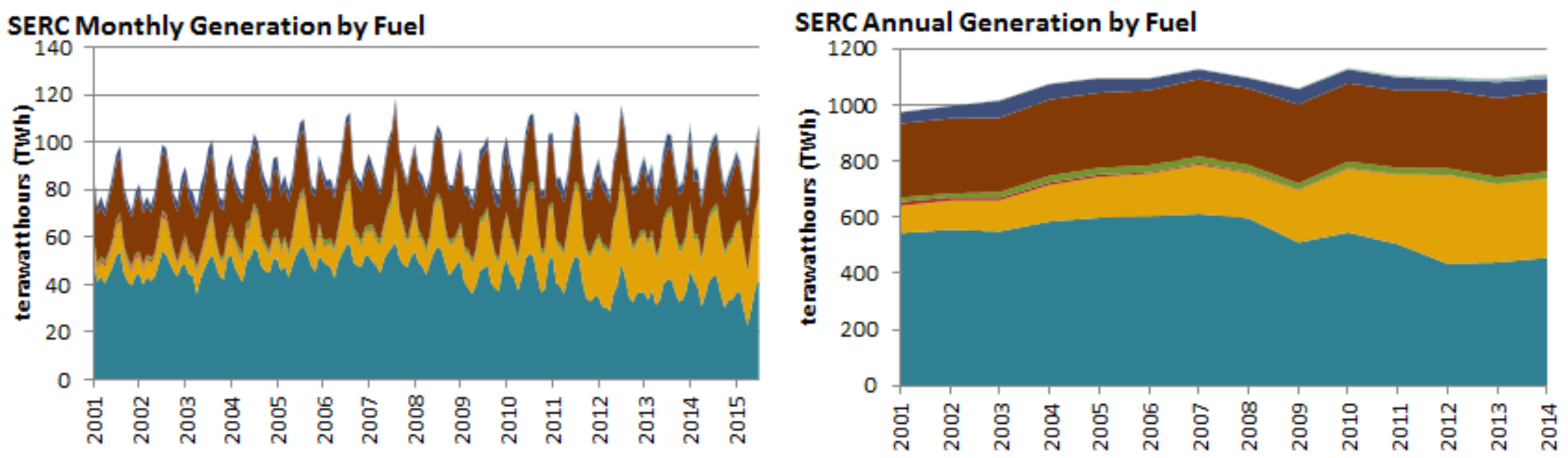

\section{SERC Annual Capacity by Fuel}

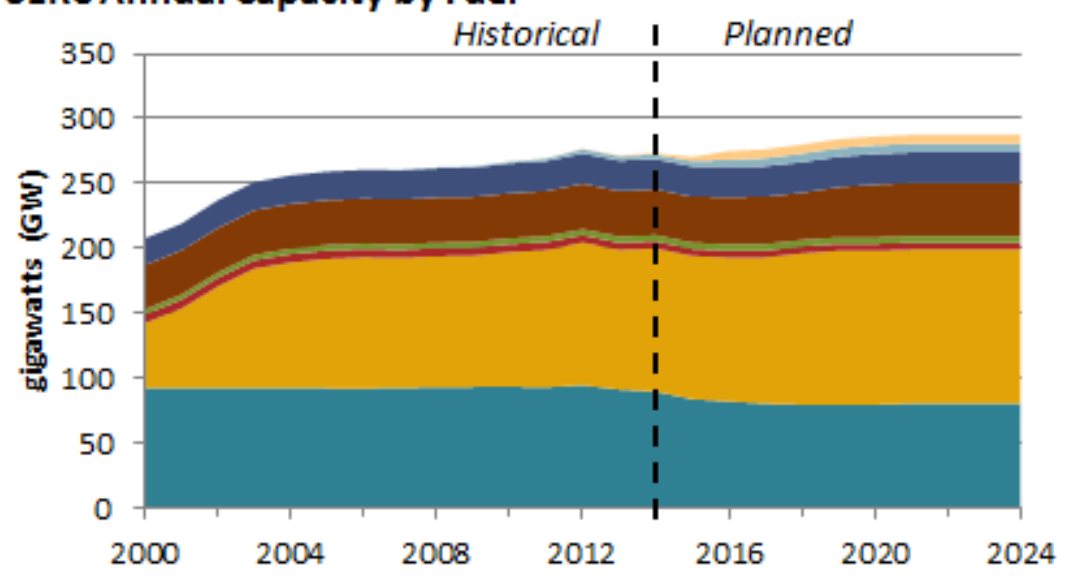

SERC Net Capacity Additions by Fuel

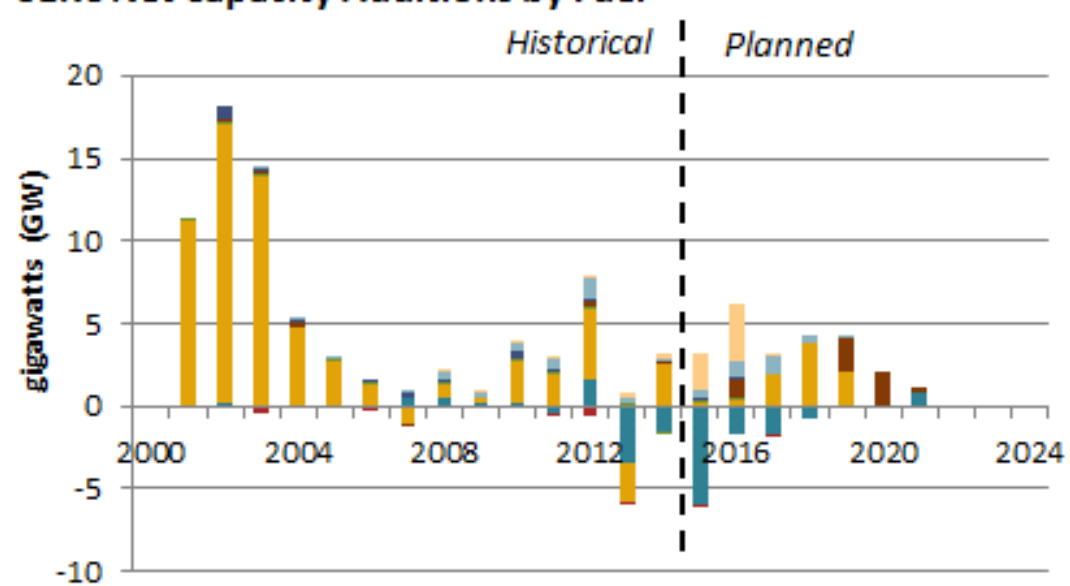

Figure 4-11. Monthly and annual generation in SERC (top) and historical and planned capacity additions by fuel (bottom)

SERC has experienced a rapid shift from coal to natural gas generation and is the only region building new nuclear plants. Source: SNL $2015^{148}$. 


\subsubsection{RFC}

Generation in RFC is primarily fueled by coal, which made up 43 percent of the region's capacity and 51 percent of its generation in 2014 (Figure 4-12). The region also has the largest share of nuclear capacity. RFC has seen the greatest absolute reduction in coal-fired generation since 2009 compared to other regions. Natural gas-fired capacity has expanded in recent years, and additional capacity is planned; however, generation from natural gas represented only 14 percent of total generation in 2014. Despite this relatively low level, natural gas-fired generation has nearly doubled since 2009, and this region has experienced the fastest growth in natural gasfired generation. RFC expects to have the highest share of the nation's recent and future coalfired retirements. Wind capacity is expected to continue growing based on the reported queue of projects under development (Figure 4-12). Electricity demand has been essentially flat in the RFC for the past 5 years.

\subsubsection{NPCC}

NPCC has seen a significant decline in the need for generation since it peaked in 2005. It had the lowest share of coal-fired capacity and generation of all the NERC regions within the 48 continental states, at 6 percent and 5 percent, respectively, in 2014. Conversely, the region had some of the highest shares of nuclear capacity and generation at 13 percent and 32 percent, respectively, and biomass at 3 percent and 4 percent, respectively. Natural gas has become the largest single source of capacity and generation in NPCC, and both are expected to continue growing. In 2014, petroleum-fired capacity was as high as 17 percent of total capacity within the region but only represented 1 percent of generation. Petroleum-fired generation is primarily used to ensure sufficient and reliable power supply in the Northeast during cold winter months, with a significant number of combined-cycle plants able to operate on both petroleum and natural gas. The former can be stored at or near the power generator in significant quantities. The NPCC region has driven much of the concern over lack of coordination between the natural gas and electricity sectors given its limited spare natural gas pipeline capacity. During the Polar Vortex of 2014, the region experienced high electricity prices due to gas shortages, resulting from increased need for gas use for heating. New measures are underway to help alleviate risks of natural gas shortages for electric generators during the coldest winter months (Logan et al. 2015). Looking forward, natural gas, wind, and solar have the most capacity in the development queue, while additional coal- and petroleum-fired generation is scheduled to retire in 2016 (Figure 413).

\subsubsection{SPP}

SPP relies primarily on coal and natural gas as generation fuels and has seen modest growth in new electricity generation, as shown in Figure 4-14 and Table 4-1. Natural gas-fired generation has declined in SPP more than any other NERC region since 2009. Capacity and generation shares for coal were 35 percent and 59 percent, respectively, and 48 percent and 25 percent for natural gas in 2014. SPP has only a minor reliance on nuclear power, and hydroelectric generation has declined to a very small share of total generation. Over the next few years, wind projects, which currently dominate the development pipeline, are likely to nearly double available wind capacity (Figure 4-14). 


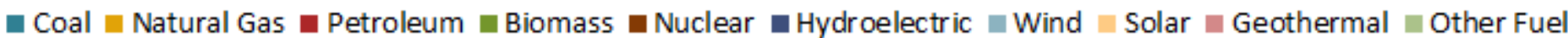

\section{RFC Monthly Generation by Fuel}

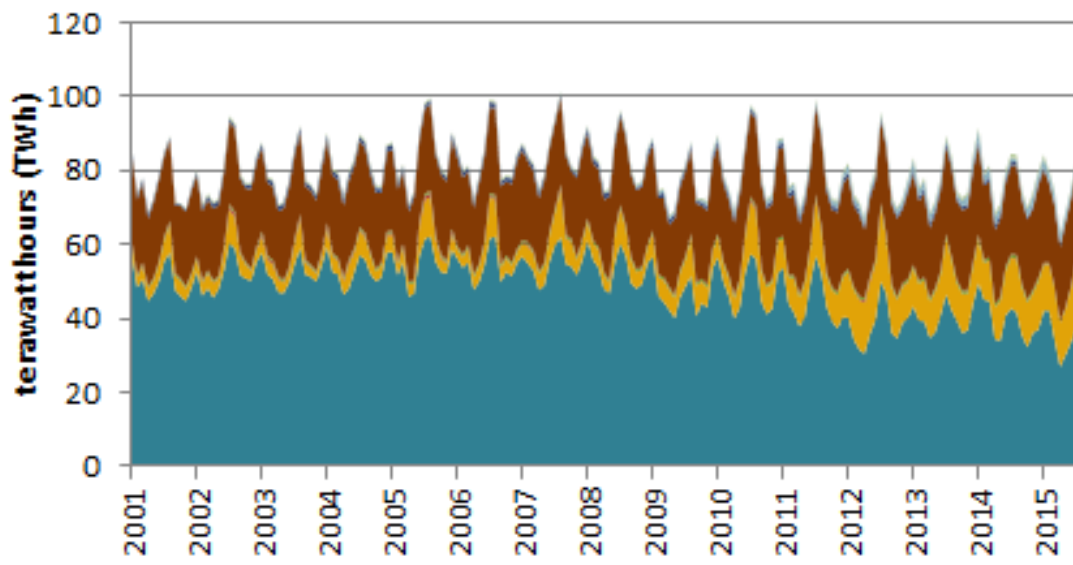

RFC Annual Capacity by Fuel

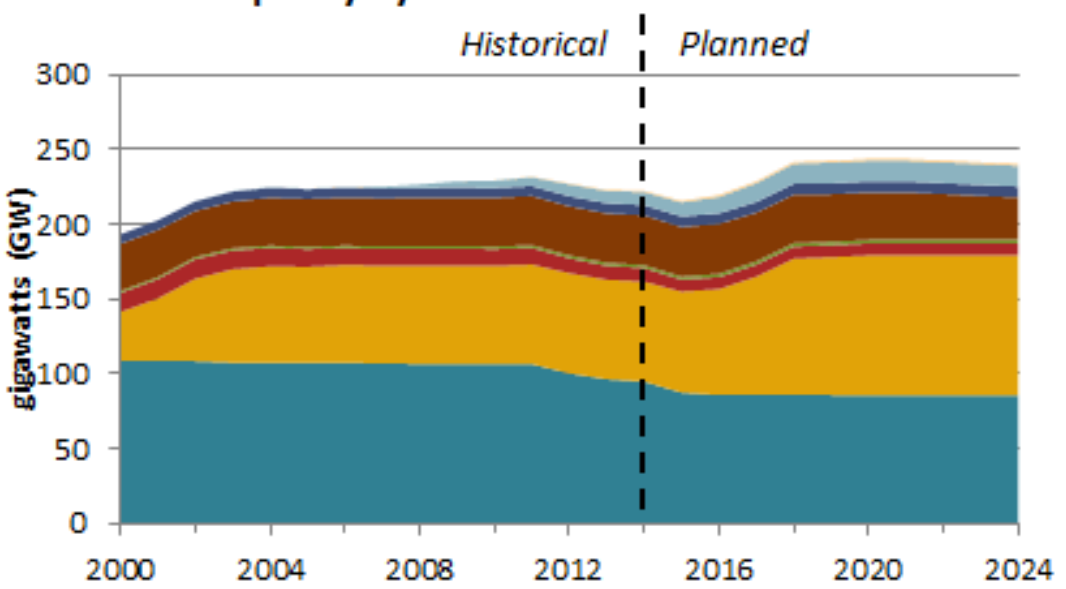

RFC Annual Generation by Fuel

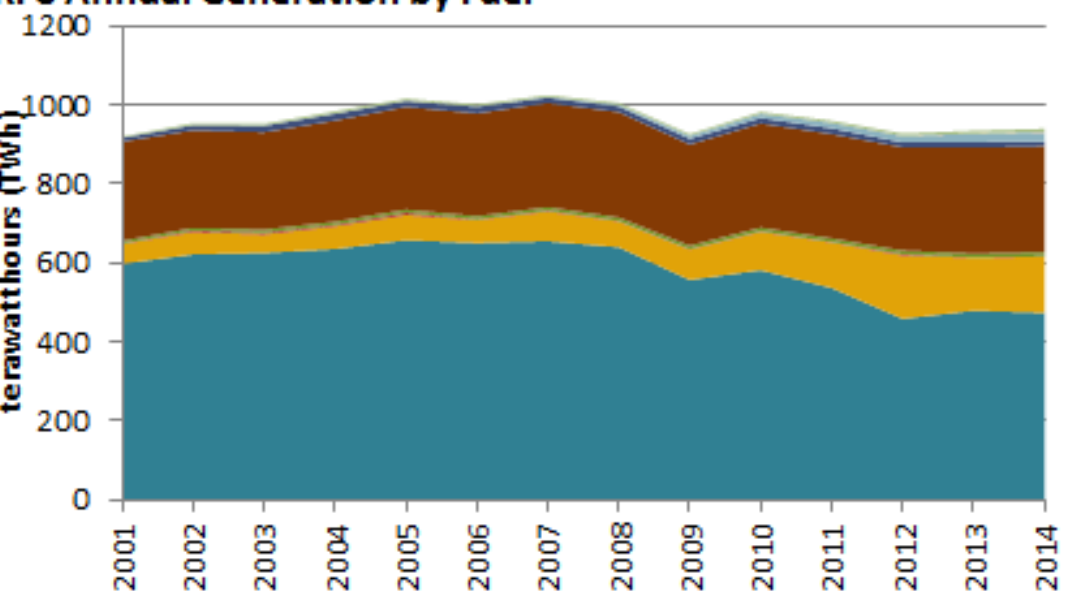

RFC Net Capacity Additions by Fuel

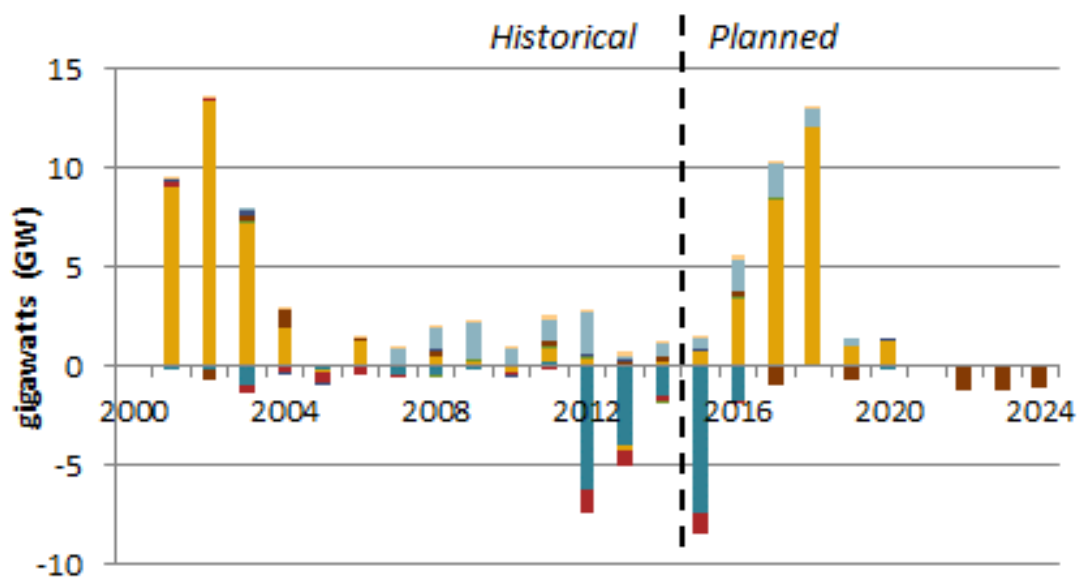

Figure 4-12. Monthly and annual generation in RFC (top) and historical and planned capacity additions by fuel (bottom) RFC has seen a sharp drop in coal generation since 2008, with natural gas making up most of the lost generation. Source: SNL $2015^{149}$. 


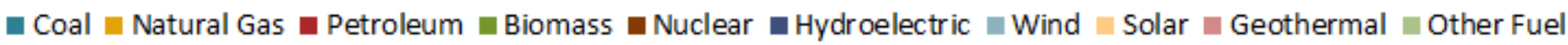

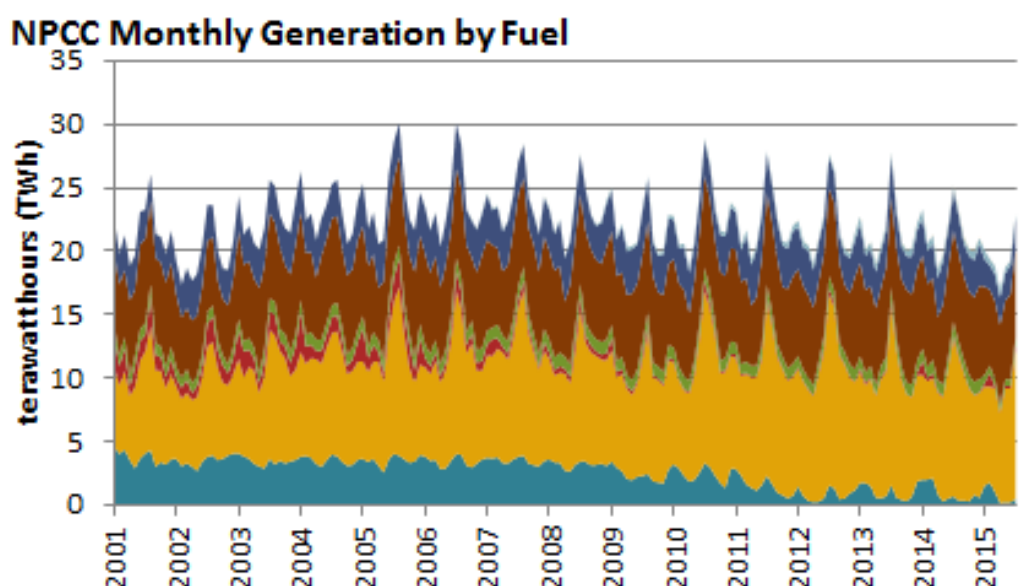

\section{NPCC Annual Generation by Fuel}

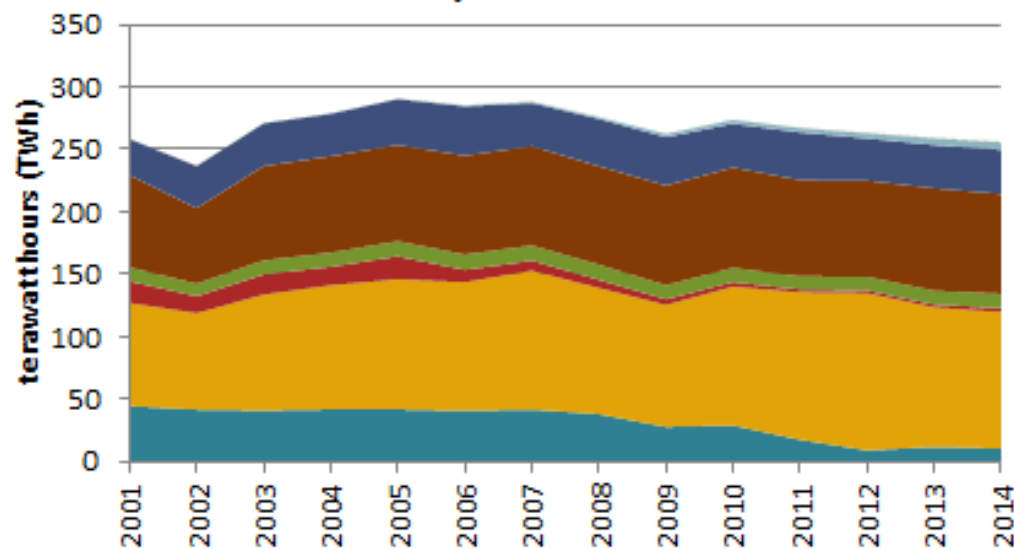

NPCC Net Capacity Additions by Fuel
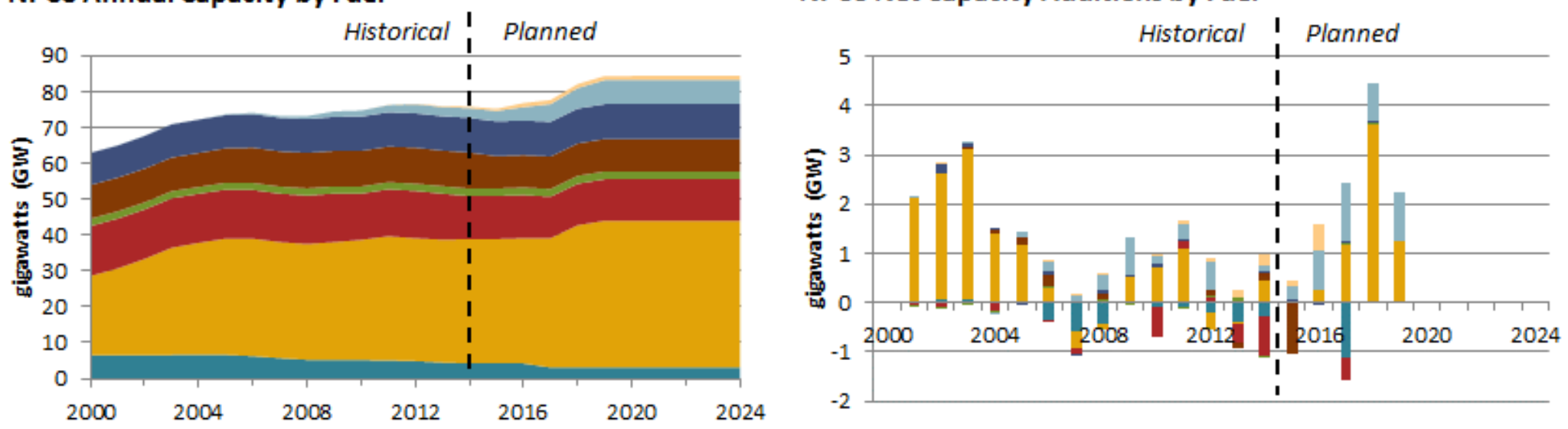

Figure 4-13. Monthly and annual generation in NPCC (top) and historical and planned capacity additions by fuel (bottom) NPCC is heavily reliant on natural gas and nuclear; generation has declined significantly since it peaked around 2005. Source: SNL $2015^{150}$. 


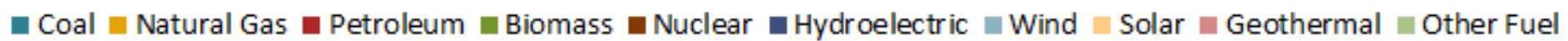

\section{SPP Monthly Generation by Fuel}

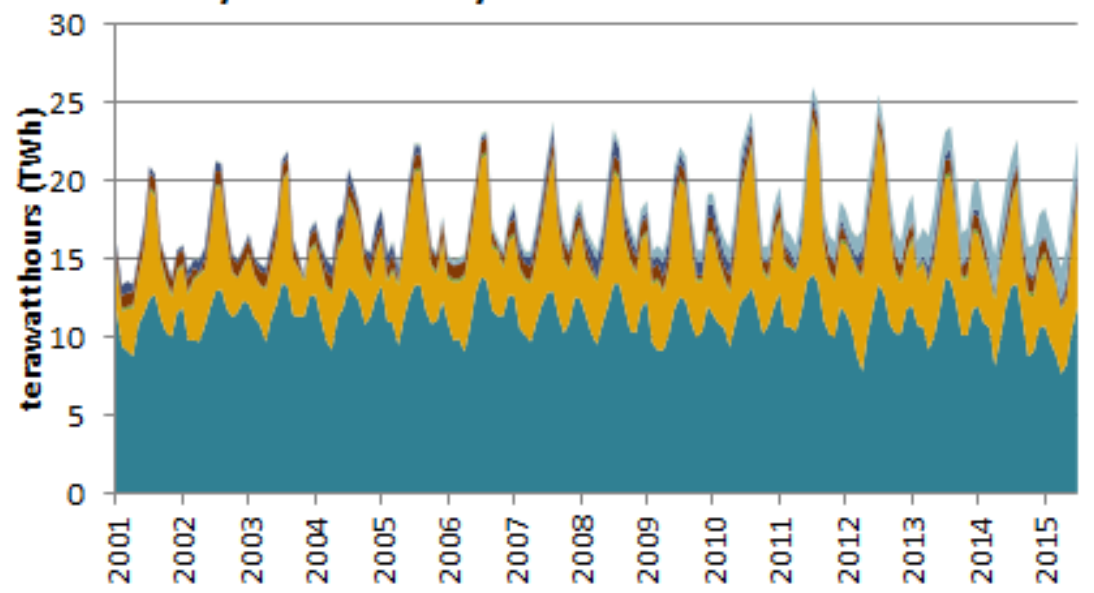

SPP Annual Capacity by Fuel

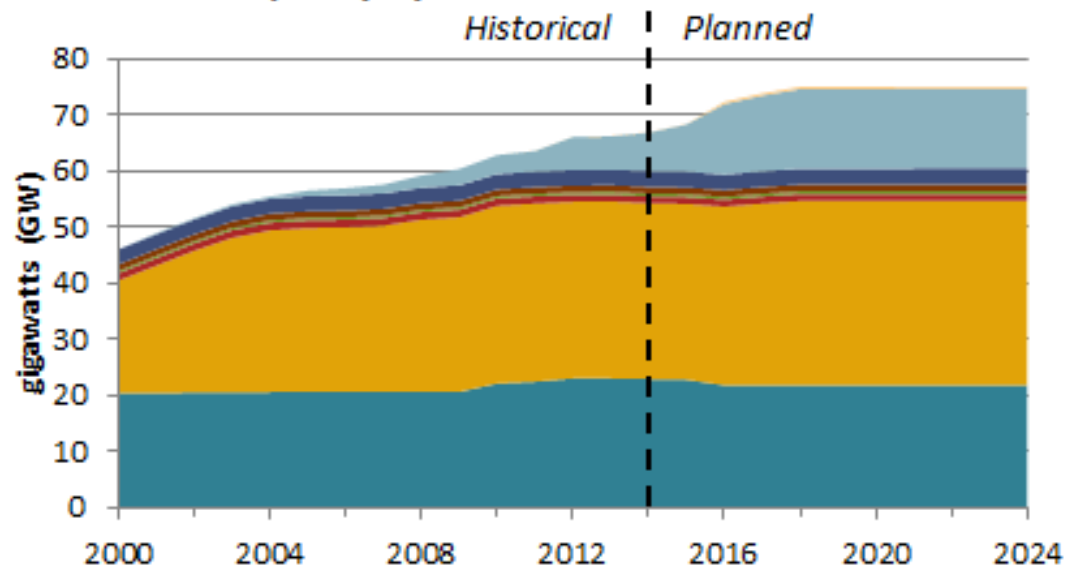

SPP Annual Generation by Fuel

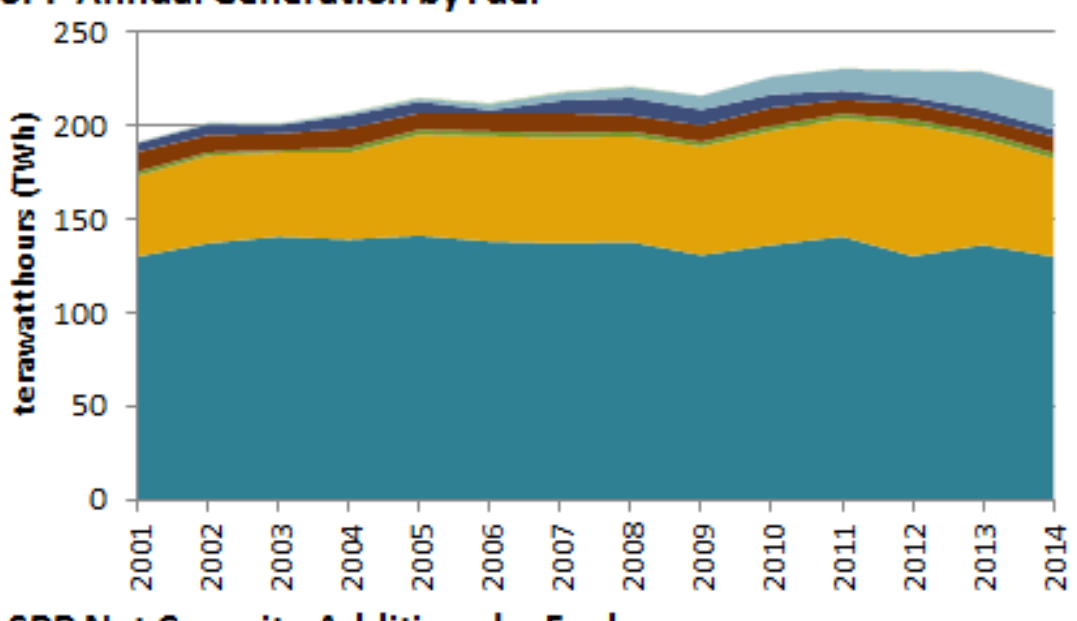

SPP Net Capacity Additions by Fuel

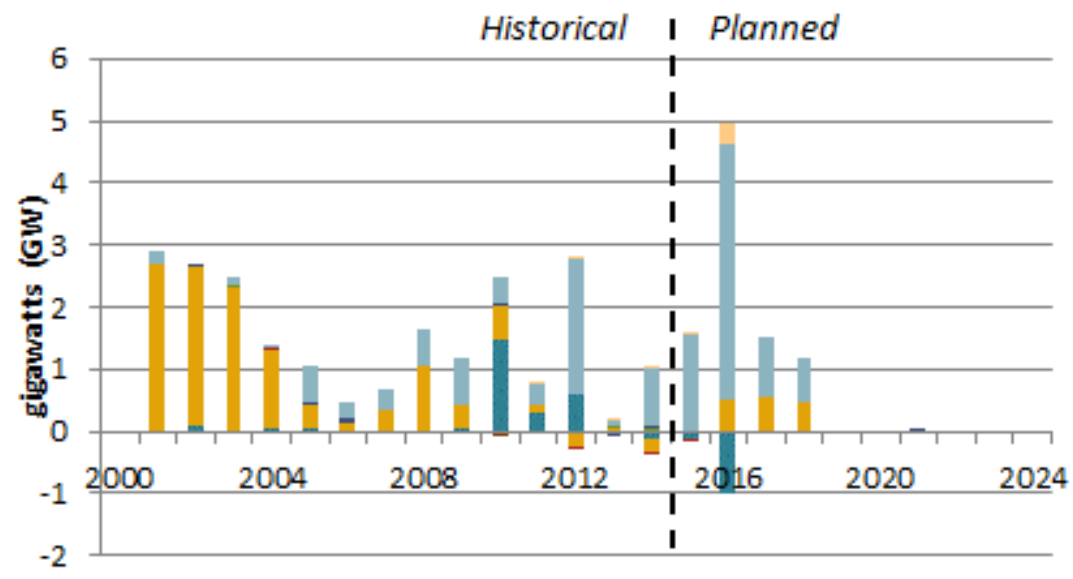

Figure 4-14. Monthly and annual generation in SPP (top) and historical and planned capacity additions by fuel (bottom) SPP relies on coal for over half of its generation, while natural gas and wind account for much of the remainder. Source: SNL $2015^{151}$. 


\subsubsection{MRO}

MRO had the highest share of coal-fired and wind generation in the United States, with shares at 62 percent and 14 percent, respectively, in 2014. The region had the second-fastest growth in power generation between 2009 and 2014, just behind Texas Reliability Entity (TRE) (Table 41). MRO also continues to see expanded growth in wind capacity, with planned generation additions consisting primarily of wind capacity until 2019, when more natural gas comes online (Figure 4-15). High shares of coal and wind have led to less demand for natural gas. The region had the lowest shares of natural gas-fired capacity and generation in 2014 of the NERC regions within the 48 continental states, at 24 percent and 6 percent, respectively.

\subsubsection{FRCC}

FRCC relies heavily on natural gas and had the highest share of both gas capacity and gas generation at 62 percent and 60 percent, respectively, of all NERC regions and other states in 2014. Recent capacity additions and planned capacity additions are almost entirely natural gas, as shown in Figure 4-16. Approximately $2 \mathrm{GW}$ of oil- and coal-fired generation is slated to be retired between 2016 and 2018, although these are primarily used as peaking capacity. FRCC has the lowest capacity shares of hydro at 0.1 percent and wind at essentially 0 percent (utility-scale). Like NPCC, FRCC is highly reliant on natural gas-fired generation and is becoming even more so.

\subsubsection{WECC}

WECC has the highest shares of renewable capacity and generation among NERC regions (Figure 4-17). Capacity for utility-scale solar and hydro stood at 3 percent and 26 percent, respectively, in 2014, while the corresponding generation shares were 1 percent and 22 percent, respectively. Over $10 \mathrm{GW}$ of utility-scale solar capacity was expected to come online in 2016, although the estimate was derived before extension of the ITC in December 2015; as a result, some project developers may feel less rushed to complete their projects before the previous deadline. All of the geothermal capacity within the continental United States comes from the WECC region, but this accounted for only 2 percent of total generation in the region in 2014. The 2014 shares of generation from coal and natural gas were 27 percent and 30 percent, respectively.

\subsubsection{TRE}

TRE had the fastest growth in electricity generation among all regions between 2009 and 2014 (Table 4-1; Figure 4-18). In 2014, TRE had the second highest share of wind capacity and generation, at 12 percent and 9 percent, respectively. There have been significant additions of new wind capacity in recent years, with more capacity expected to come online through 2016. The region has some of the lowest shares of hydroelectric and biomass generation, at 0.1 percent and 0.2 percent, respectively. The region's primary fuel source is natural gas, which represented 59 percent and 45 percent of capacity and generation in 2014, respectively. TRE also expects a large amount of new natural gas-fired capacity in the next few years. 


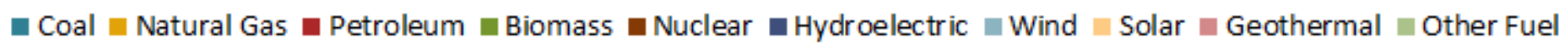

MRO Monthly Generation by Fuel

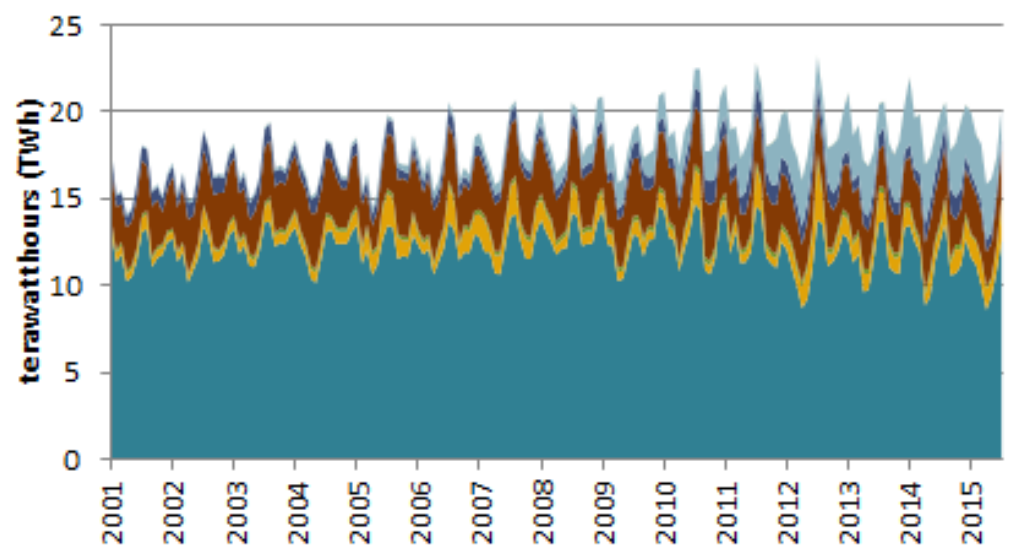

MRO Annual Capacity by Fuel

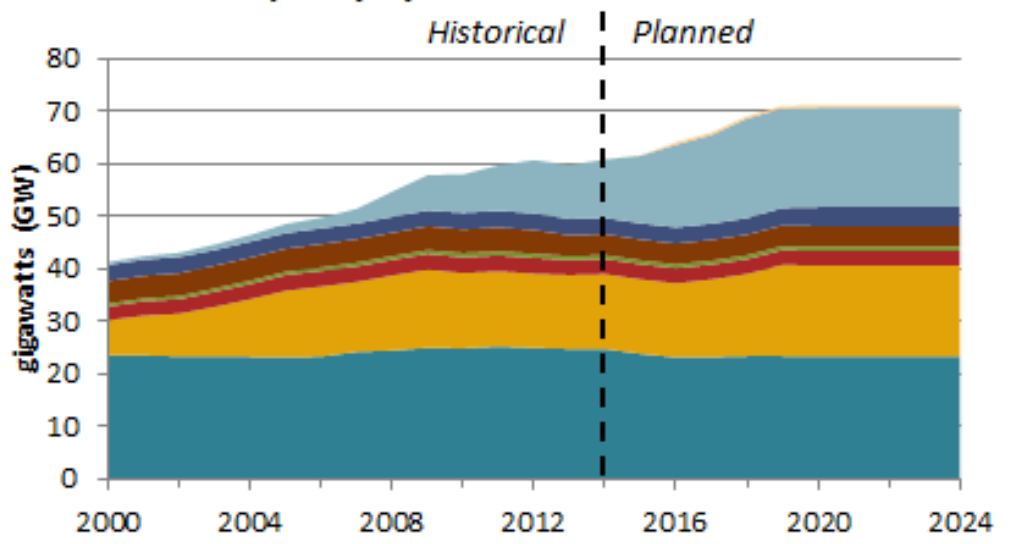

MRO Annual Generation by Fuel

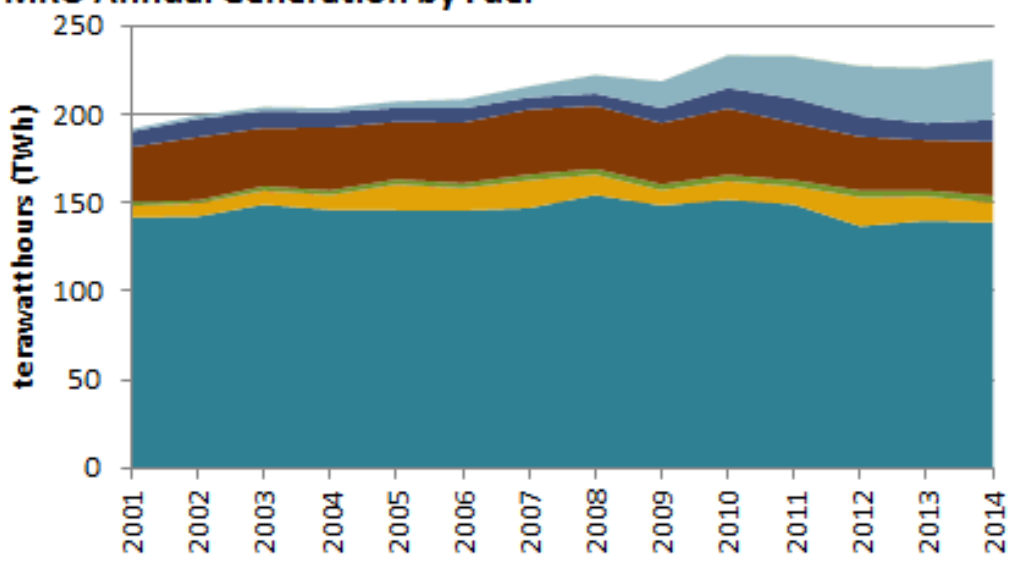

MRO Capacity Additions by Fuel

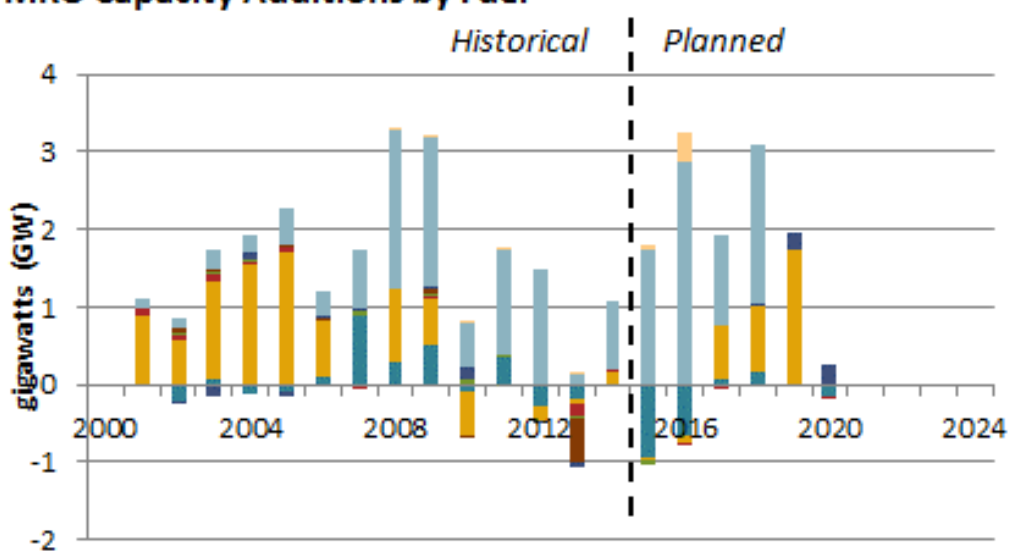

Figure 4-15. Monthly and annual generation in MRO (top) and historical and planned capacity additions by fuel (bottom)

MRO is heavily dependent on coal, although coal generation is down from its peak in the mid-2000s and wind generation is growing rapidly. Source: SNL $2015^{152}$. 


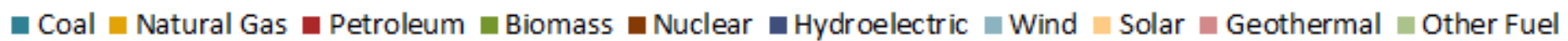

\section{FRCC Monthly Generation by Fuel}

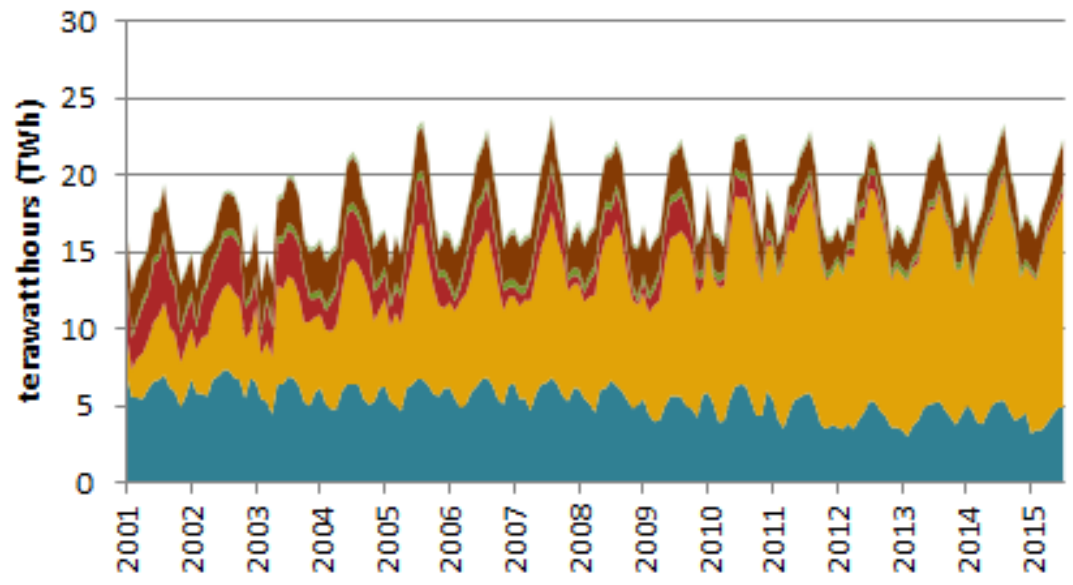

FRCC Annual Capacity by Fuel

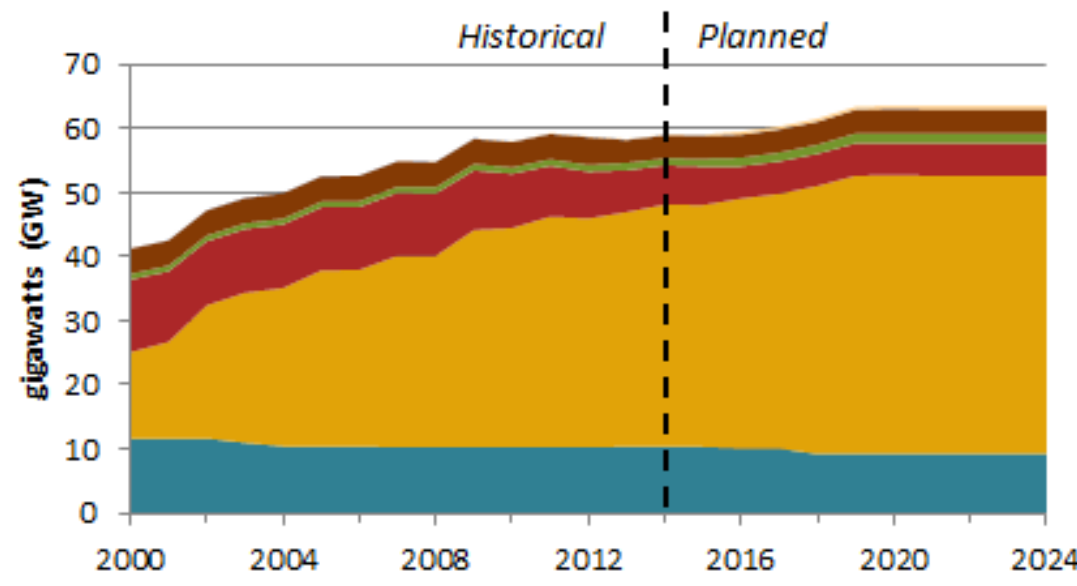

FRCC Annual Generation by Fuel

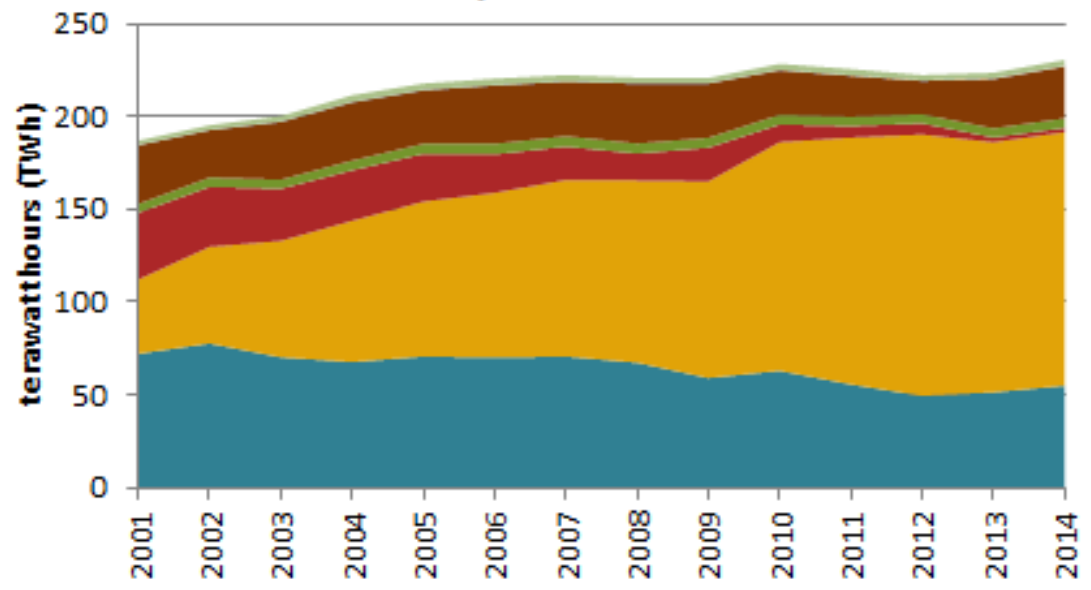

FRCC Capacity Additions by Fuel

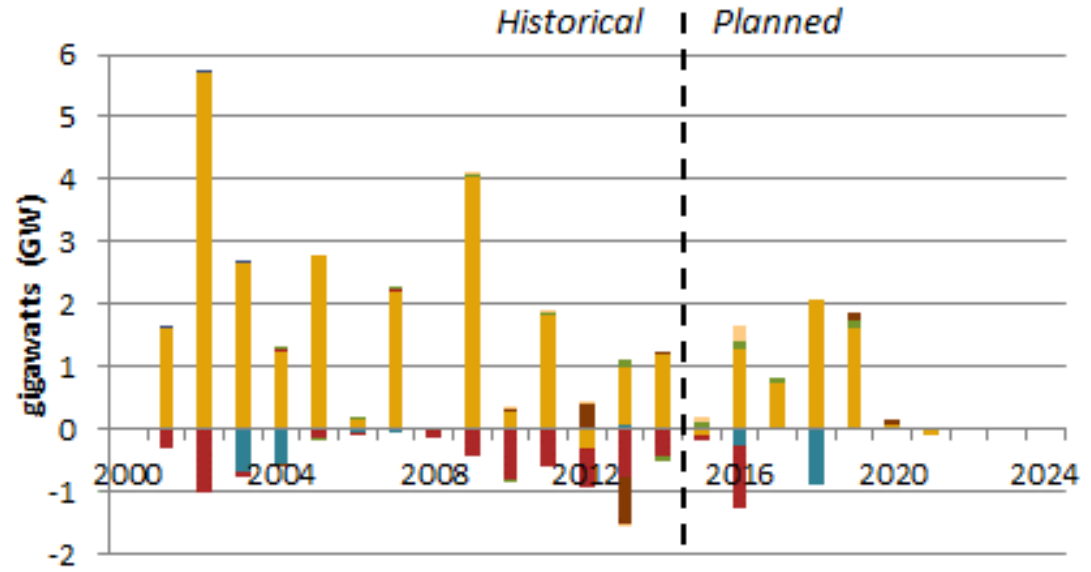

Figure 4-16. Monthly and annual generation in FRCC (top) and historical and planned capacity additions by fuel (bottom) FRCC gets over half of its generation from natural gas and is expected to become even more reliant on the fuel. Source: SNL $2015^{153}$. 


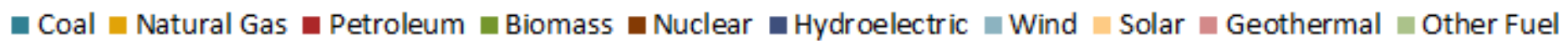

\section{WECC Monthly Generation by Fuel}

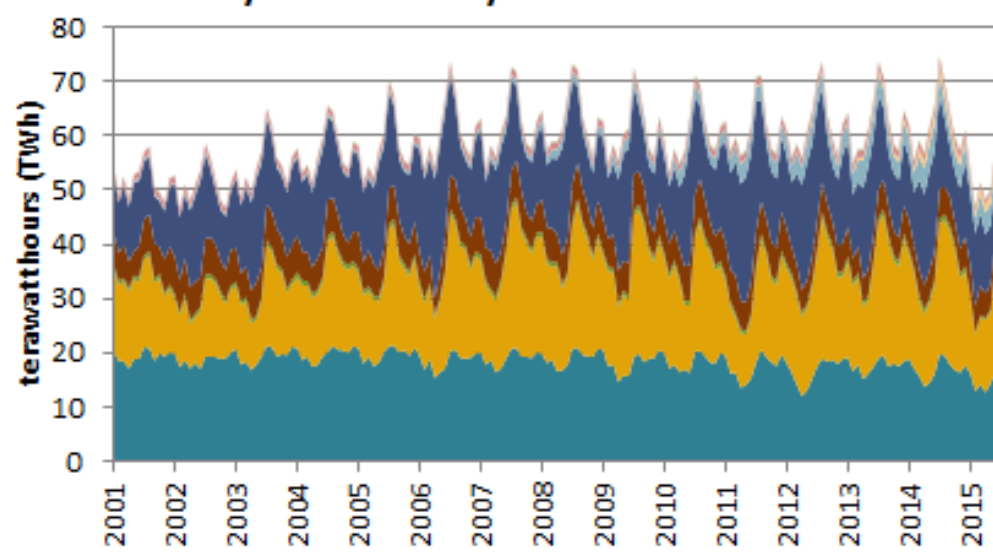

WECC Annual Capacity by Fuel

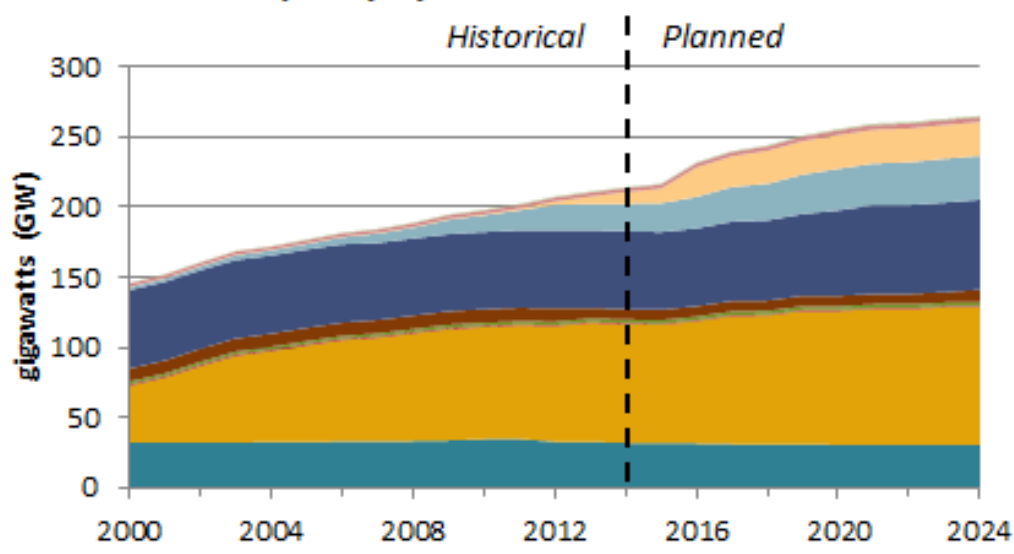

WECC Annual Generation by Fuel

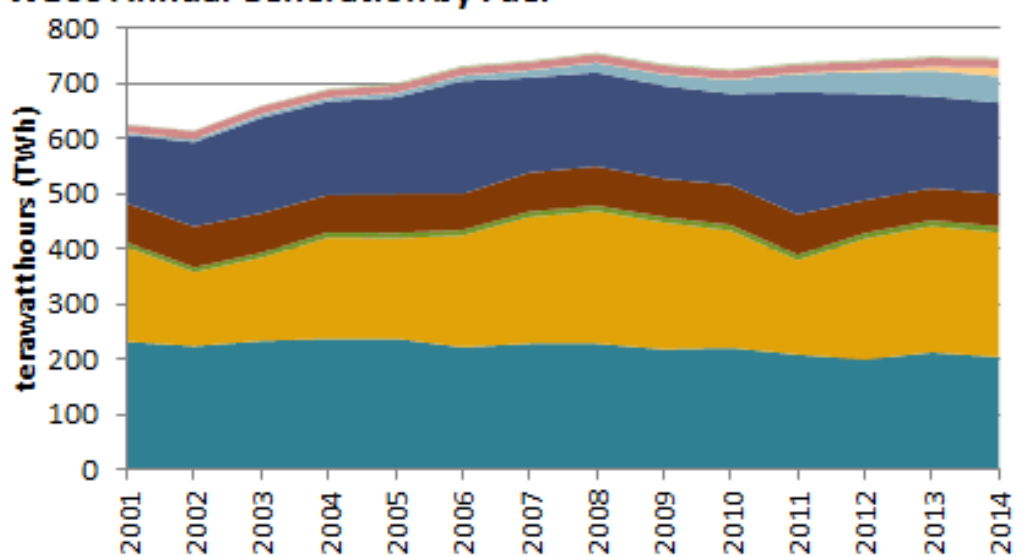

\section{WECC Net Capacity Additions by Fuel}

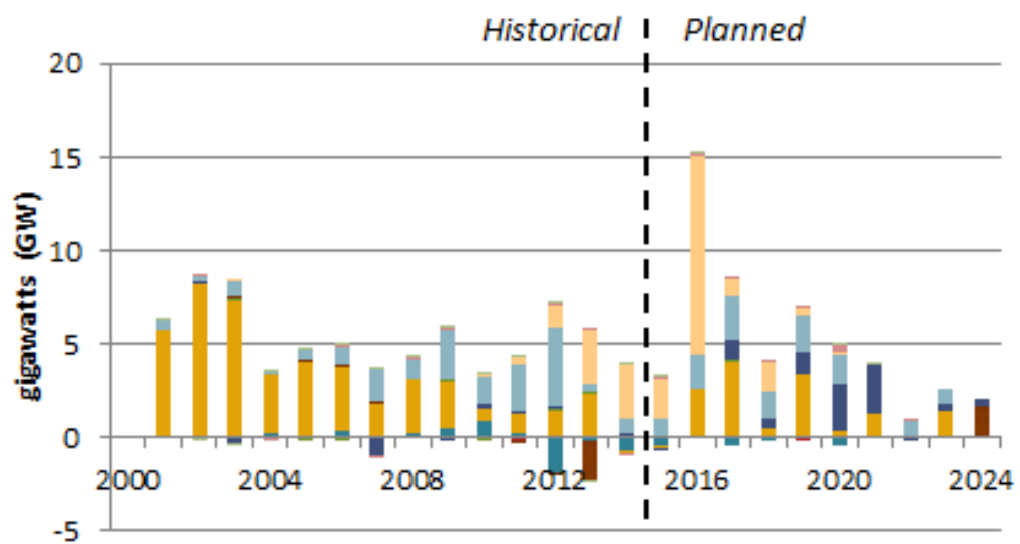

Figure 4-17. Monthly and annual generation in WECC (top) and historical and planned capacity additions by fuel (bottom) WECC has a relatively diverse generation portfolio and relies on a combination of coal, natural gas, nuclear, and renewables. Source: SNL $2015^{154}$. 


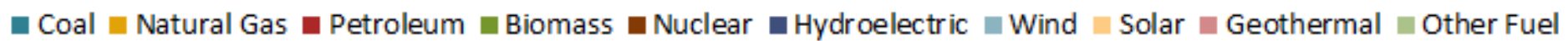

\section{TRE Monthly Generation by Fuel}

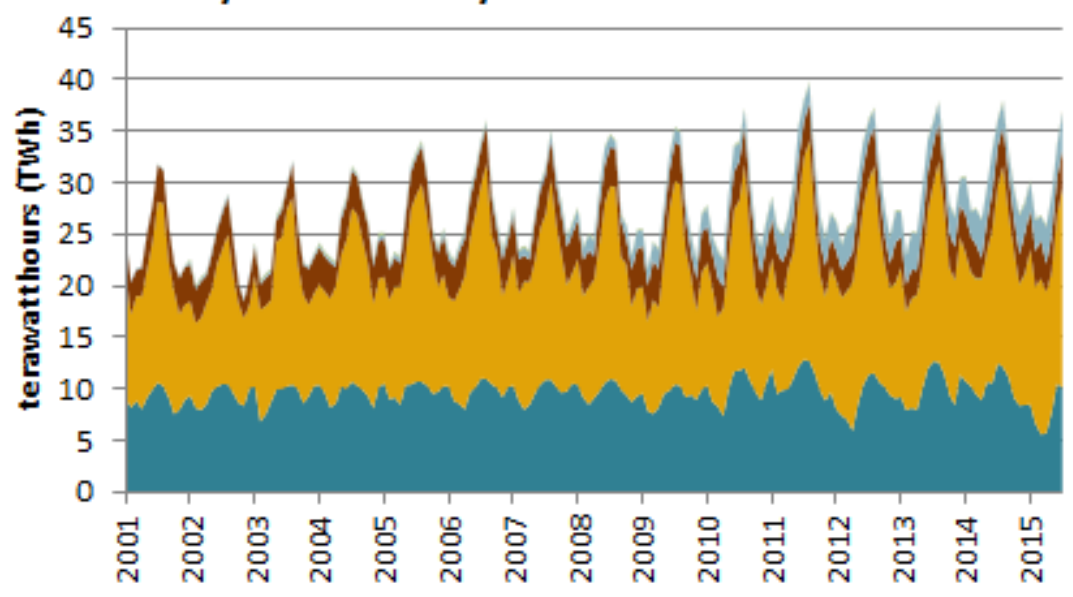

TRE Annual Capacity by Fuel

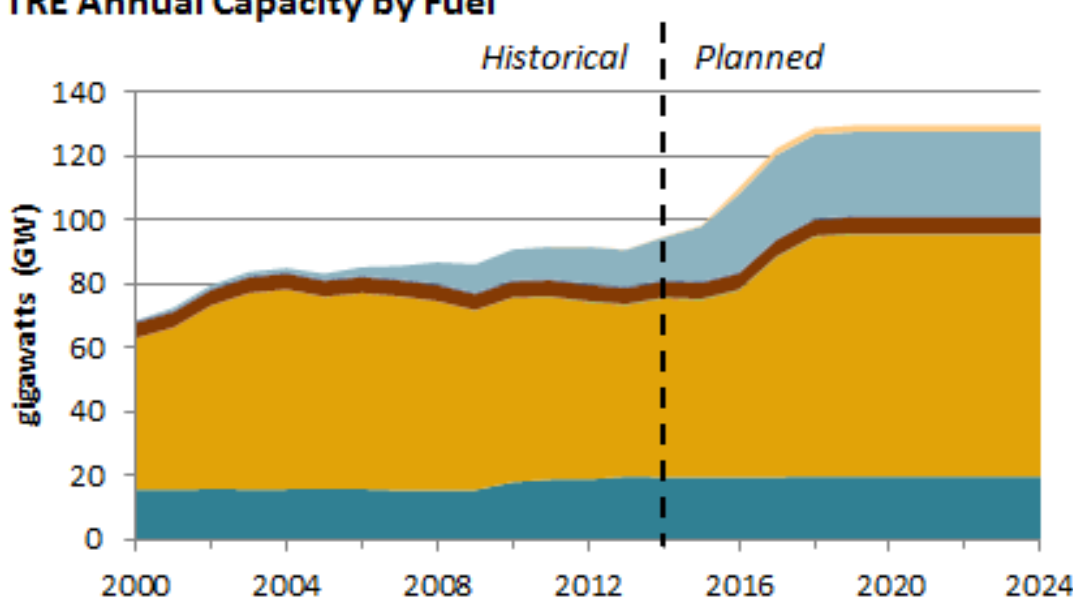

TRE Annual Generation by Fuel

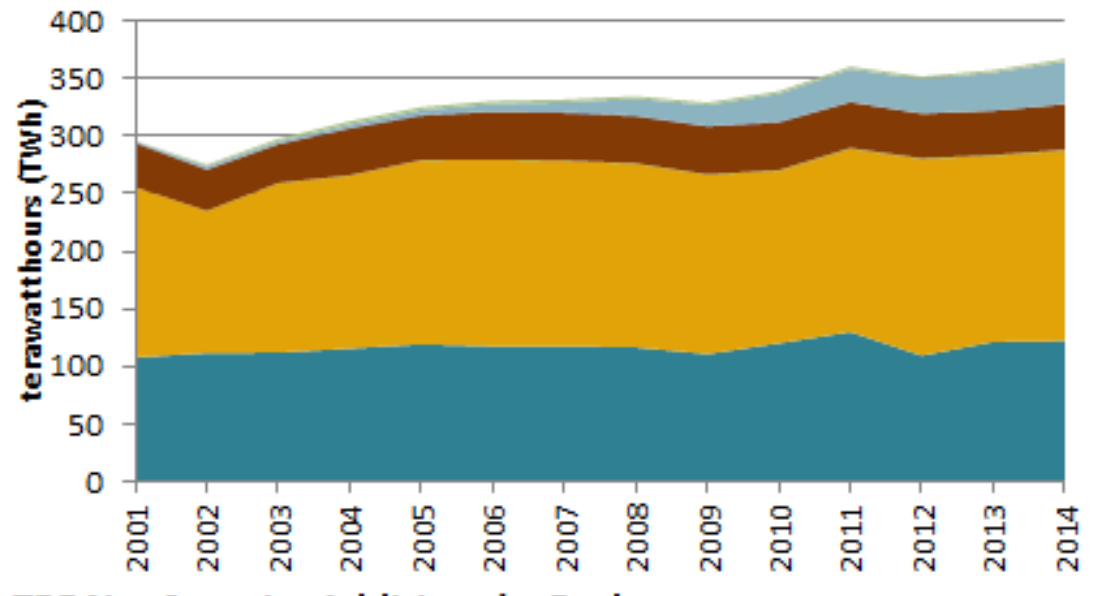

TRE Net Capacity Additions by Fuel

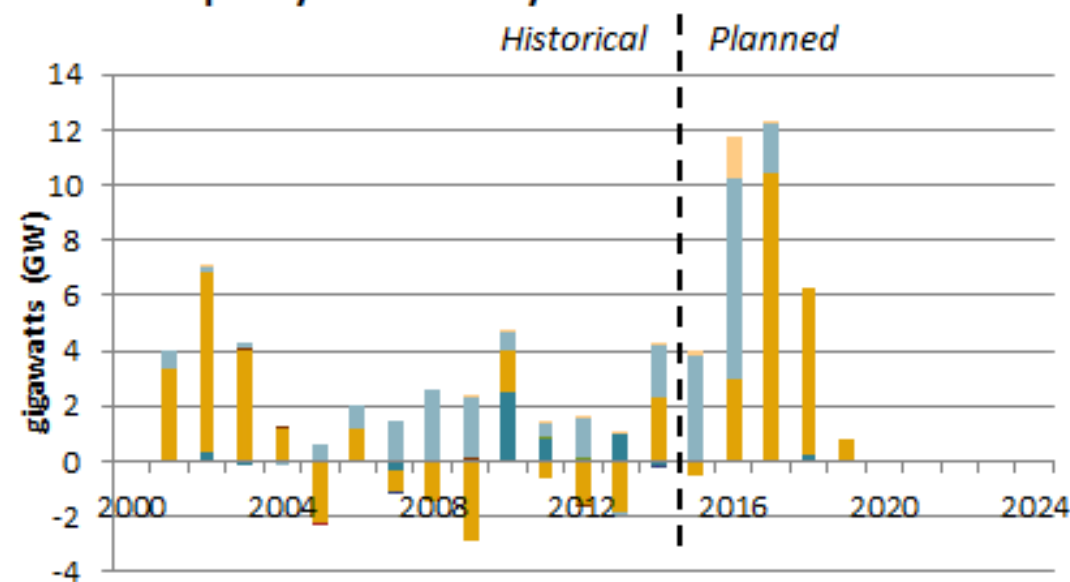

Figure 4-18. Monthly and annual generation in TRE (top) and historical and planned capacity additions by fuel (bottom) Texas power generation is dominated by natural gas and wind. Source: SNL $2015^{155}$. 


\subsubsection{Hawaii}

Hawaii has a number of operating constraints that make its capacity and generation profile very different than the rest of the country. As indicated in Figure 4-19, Hawaii's primary fuel source is petroleum, which represented 69 percent and 68 percent of capacity and generation shares in 2014. The state has little to no nuclear or natural gas-fired capacity. Coal-fired capacity and generation in 2014 represented 6 percent and 15 percent, respectively, and the remainder was primarily from non-hydro renewable resources such as biomass, wind, geothermal, and solar. The state has an aggressive target for renewable electricity (100 percent RPS by 2045 ; see DSIRE 2015), and its strong growth in many forms of renewables over the past few years is expected to continue. For example, 12 percent of Hawaii's electricity customers now have solar panels on their roofs, compared to the 0.5 percent average for the United States (Tierney 2016).

\subsubsection{Alaska}

Alaska has little to no generation from nuclear, biomass, solar, or geothermal (Figure 4-20). It also had the lowest 2014 regional capacity shares in coal at 5 percent. Alaska is, however, second in generation shares for a number of fuel types, including natural gas at 56 percent, hydro at 21 percent, and petroleum at 12 percent. 


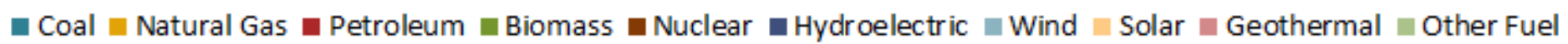

HI Monthly Generation by Fuel

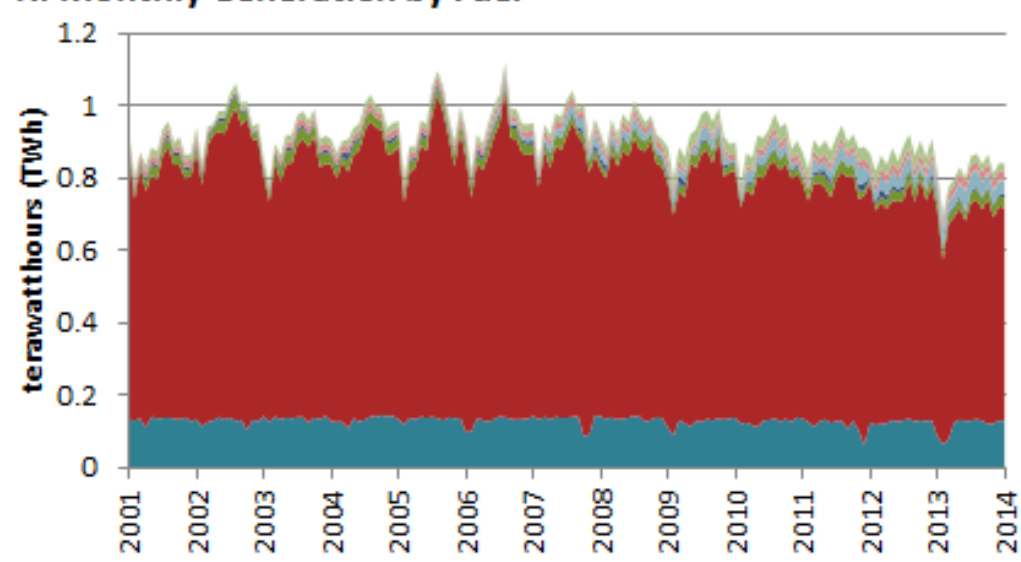

HI Annual Generation by Fuel

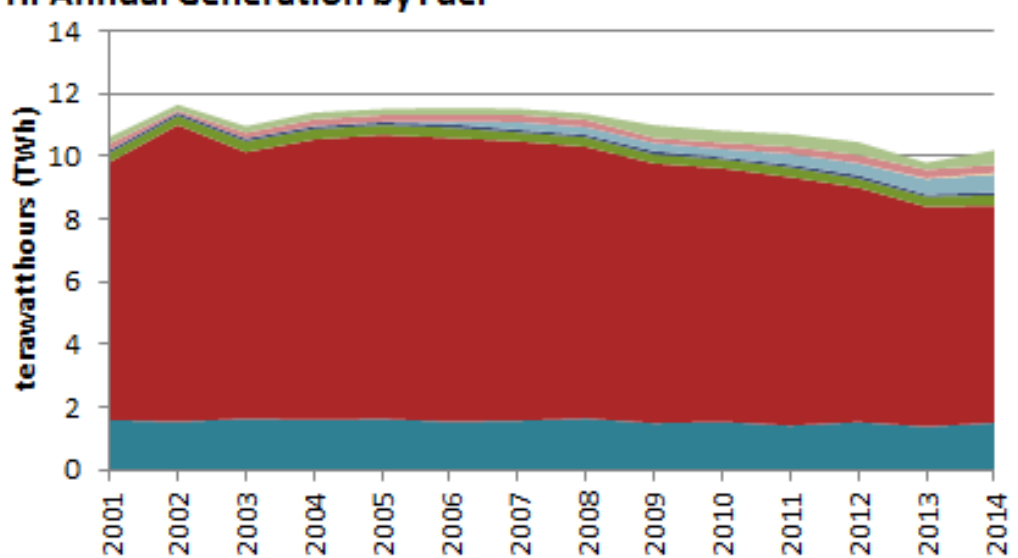

HI Capacity Additions by Fuel

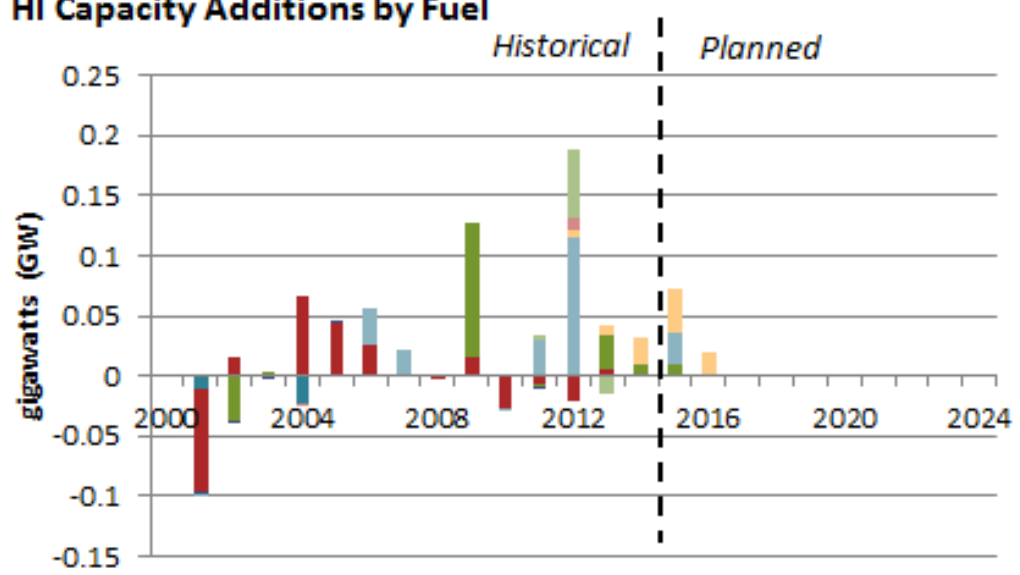

HI Annual Capacity by Fuel

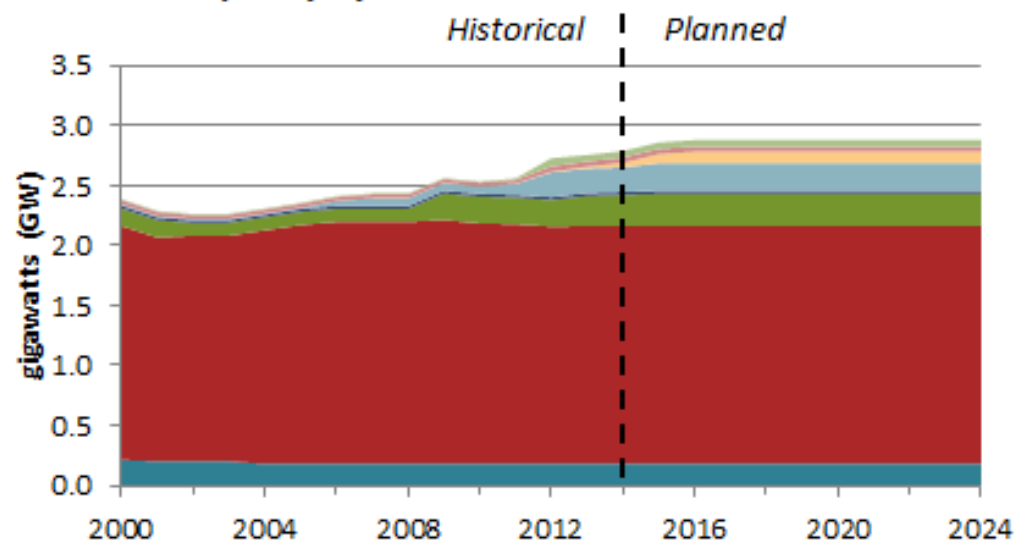

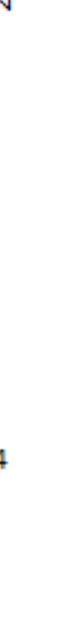

Figure 4-19. Monthly and annual generation in Hawaii (top) and historical and planned capacity additions by fuel (bottom)

Hawaii is heavily dependent on petroleum generation but has ambitious plans to generate $100 \%$ of its electricity from renewable resources. Source: SNL $2015^{156}$. 


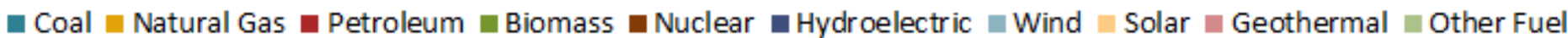

\section{AK Monthly Generation by Fuel}

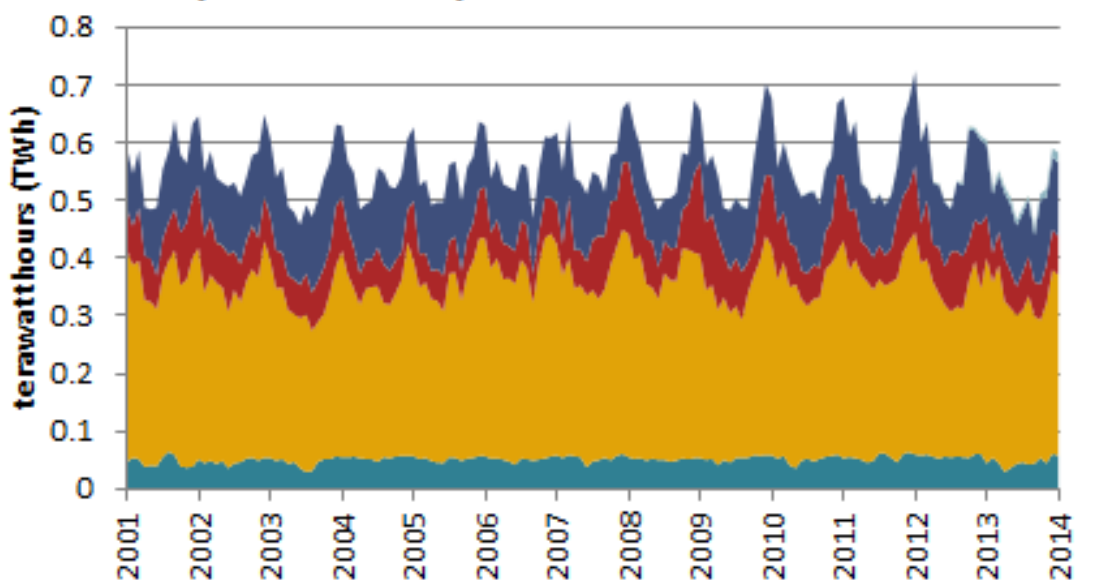

AK Annual Capacity by Fuel

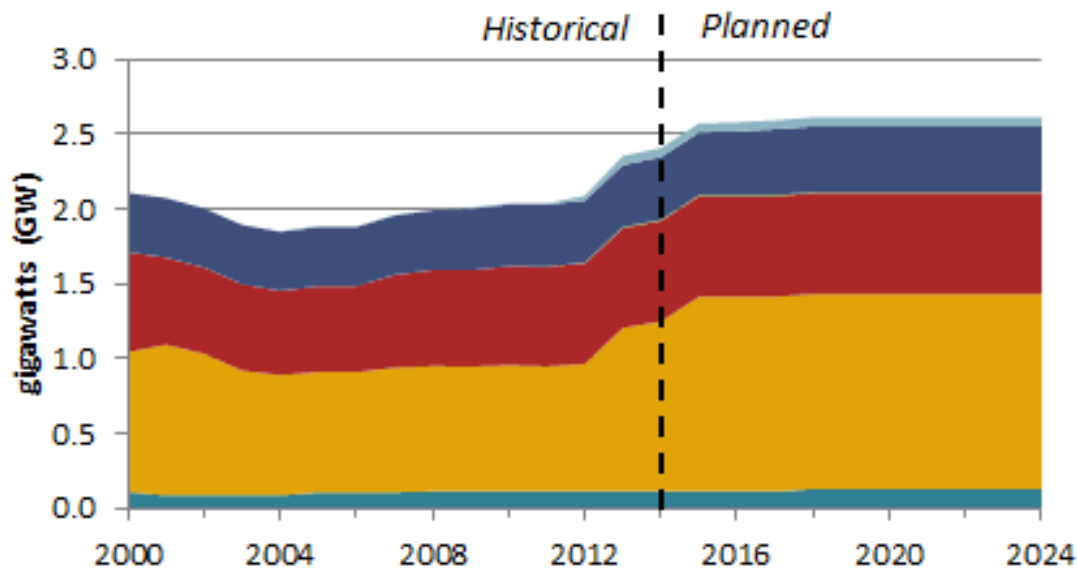

\section{AK Annual Generation by Fuel}

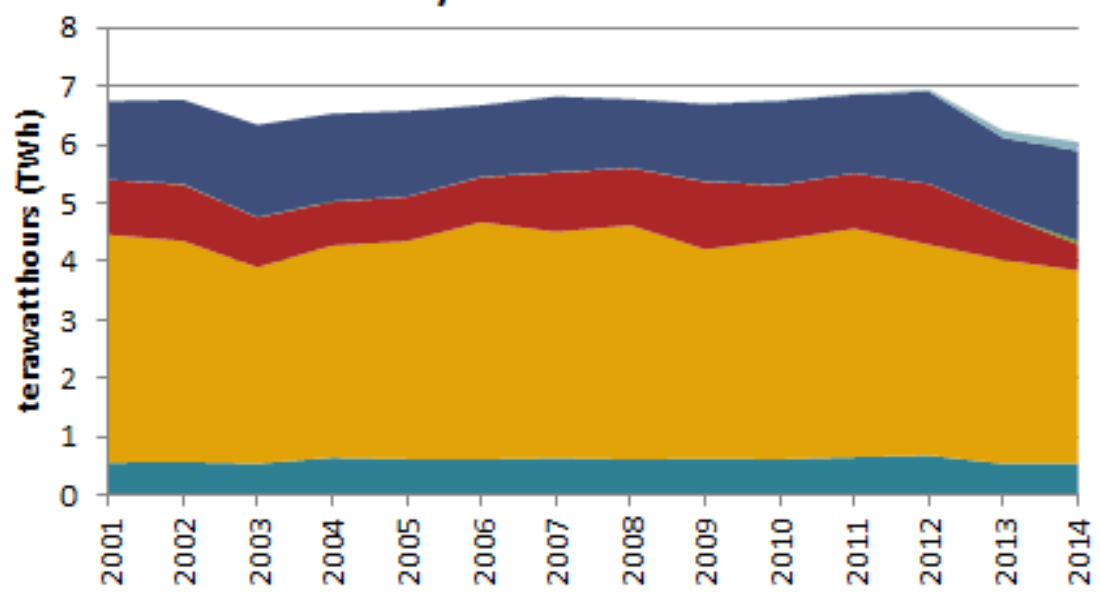

AK Capacity Additions by Fuel

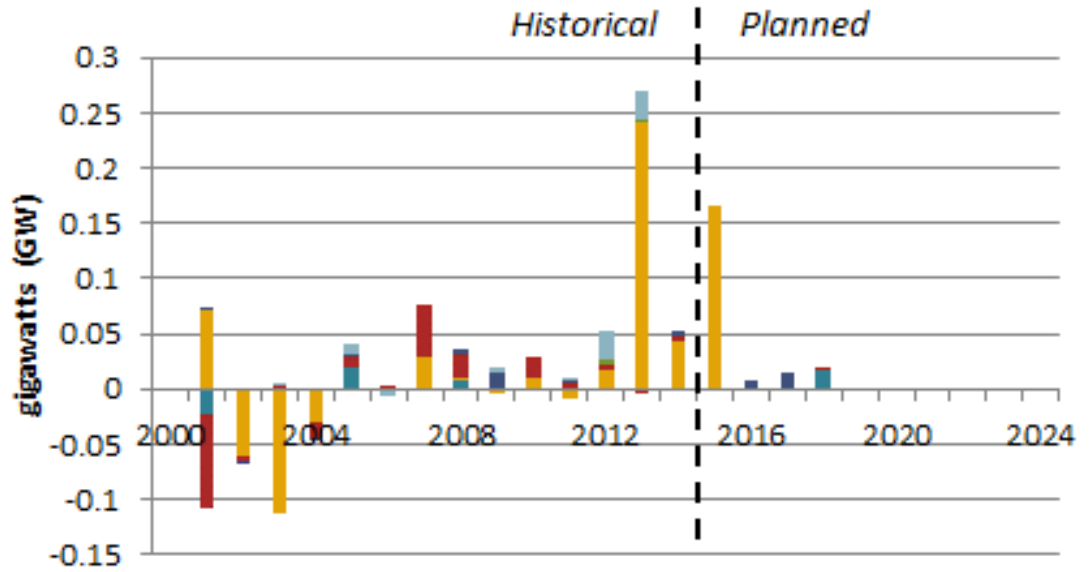

Figure 4-20. Monthly and annual generation in Alaska (top) and historical and planned capacity additions by fuel (bottom)

Alaska relies on natural gas and petroleum for much of its generation. Source: SNL $2015^{157}$. 


\subsubsection{Regional Capacity and Generation by Fuel}

Differences in fuel use between NERC regions tend to follow geographic patterns. Figure 4-21 shows regional capacity and generation shares for each fuel. Nuclear capacity and generation are highest in NPCC, RFC, and SERC, which make up the entire East Coast except for Florida. Solar shares of capacity and generation for WECC, in the West, are several times higher than solar shares in any other region. WECC also has significantly more hydro than other regions, except for Alaska. Geothermal is only present in WECC and Hawaii, and makes up small shares in each. Only Alaska and Hawaii generate significant shares of their electricity from petroleum, though other regions do have significant petroleum-fired capacity. Wind shares are highest in the central part of the country (MRO, TRE, and SPP) and West (WECC). Coal and natural gas do not have as clear-cut regional differences, though the share of coal-fired generation is highest in SPP and MRO in the center of the country.

Relationships between capacity share and generation share for a fuel tend to be similar across regions. Coal makes up a larger percentage of generation than of capacity in every region except for NPCC (which has very little of either). Wind capacity share is larger than generation share for all regions. The largest difference between capacity share and generation share is for nuclear, where shares of generation are roughly double the shares of capacity for every region that has nuclear in its portfolio. This is due to the high capacity factor ( $\sim 90$ percent) for nuclear compared to other fuels. There are, however, several exceptions where regions deviate from the national trend. Hawaii stands out for biomass: its capacity share is much larger than its generation share for this fuel; nationally, however, generation share leads capacity share for biomass, and the two values are relatively together. Natural gas does not exhibit a clear pattern across regions. 

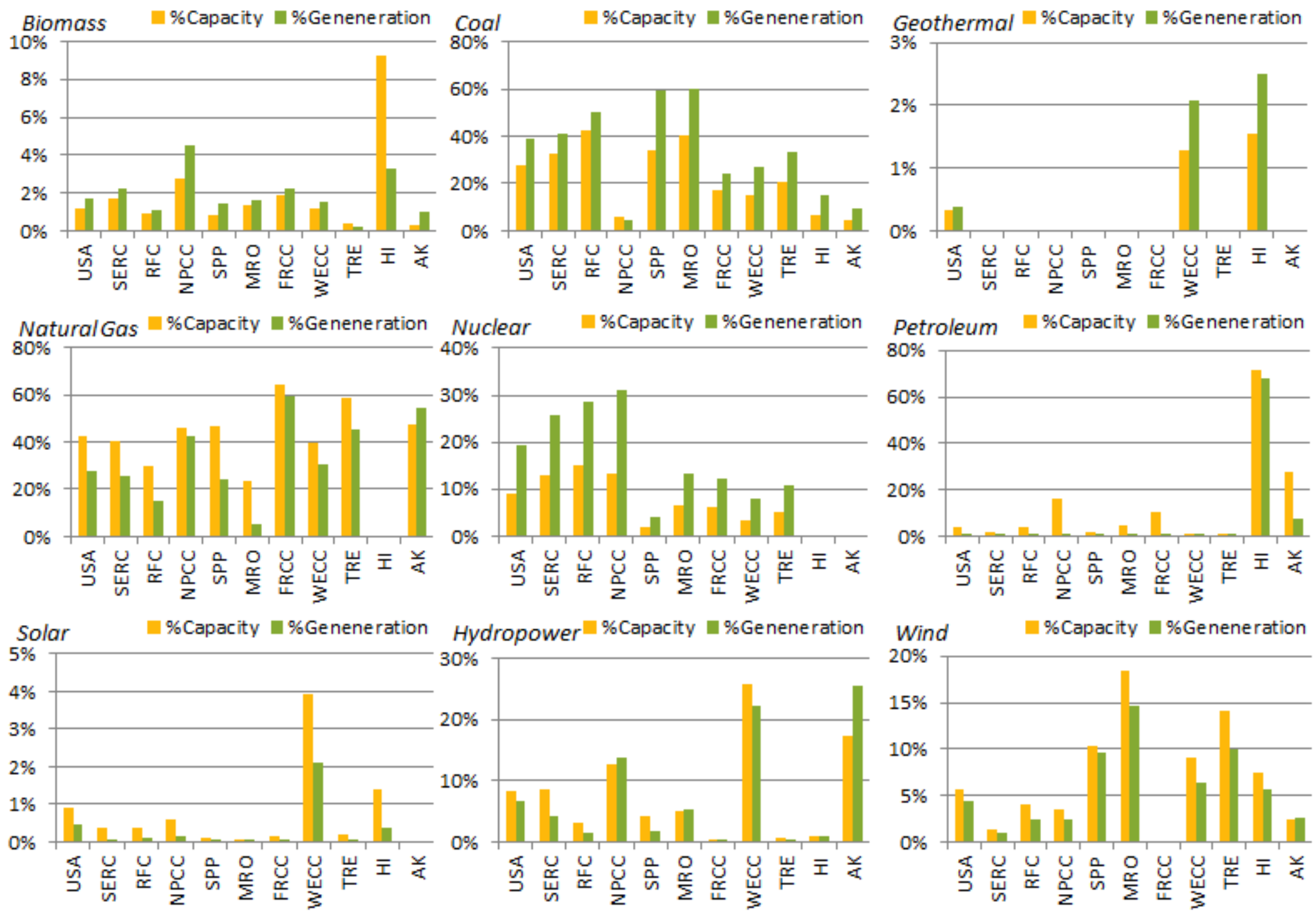

Figure 4-21. Capacity and generation shares for generation technologies and region

Differences in fuel use between NERC regions tend to follow geographic patterns. Relationships between capacity share and generation share for a fuel tend to be similar across regions. Source: SNL $2015^{158}$. 


\subsubsection{Regional Fuel Prices}

Fuel prices also have changed over time and vary across regions mainly as a function of transportation costs. Coal prices are presented in Figure 4-22 below and show a significant increase through 2008 before the financial crisis, followed by stable behavior since 2009. Coal prices vary by distance from source, with Florida and New England generally experiencing the highest prices.

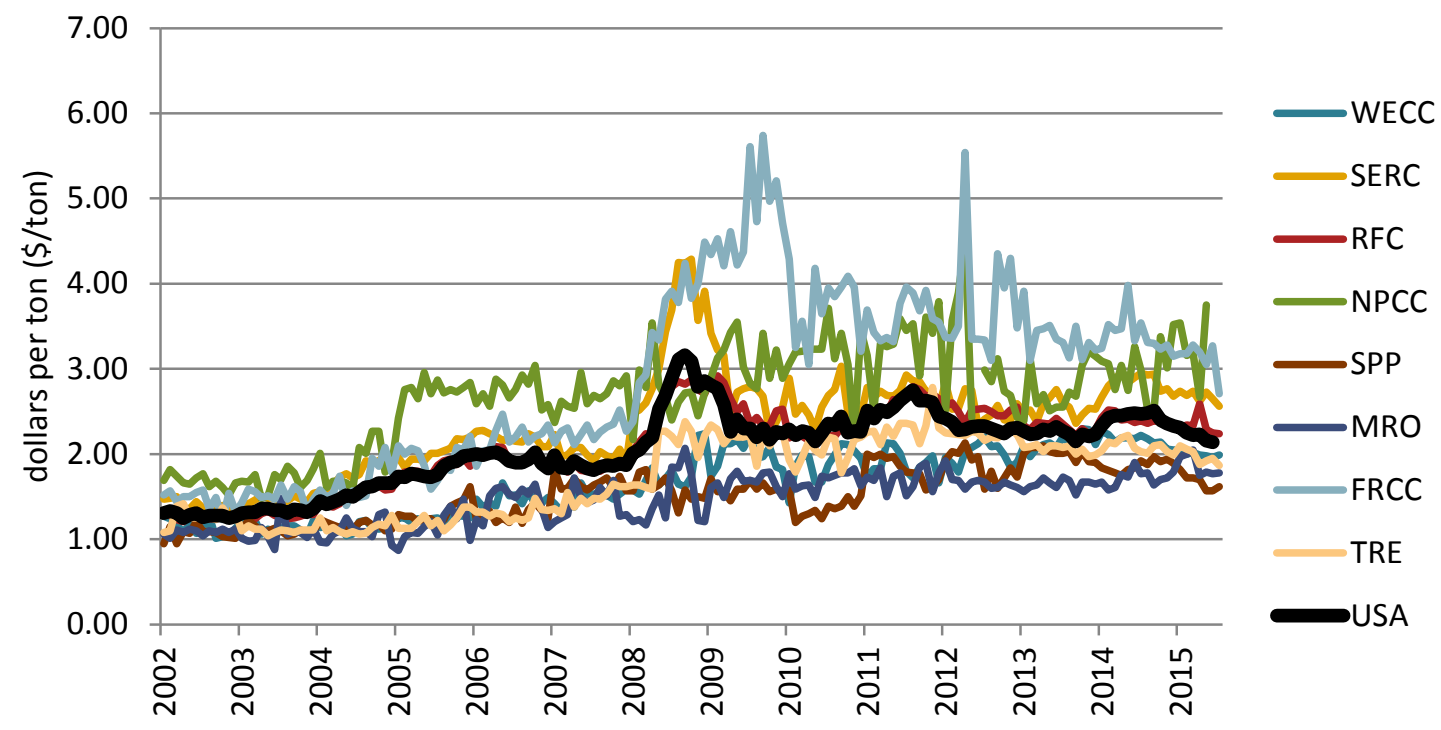

Figure 4-22. Coal monthly spot contractual fuel cost (\$/ton), 2002-2015

Coal prices rose before the recession of 2008 and have remained stable or declined slightly since then. Source: SNL $2015^{159}$.

Natural gas prices (Figure 4-21) have historically experienced greater volatility than coal. However, the expansion of domestic production over the past 7 years has led to a steadier supply and more stable prices, as well as prices at near historic lows in 2015-2016. 


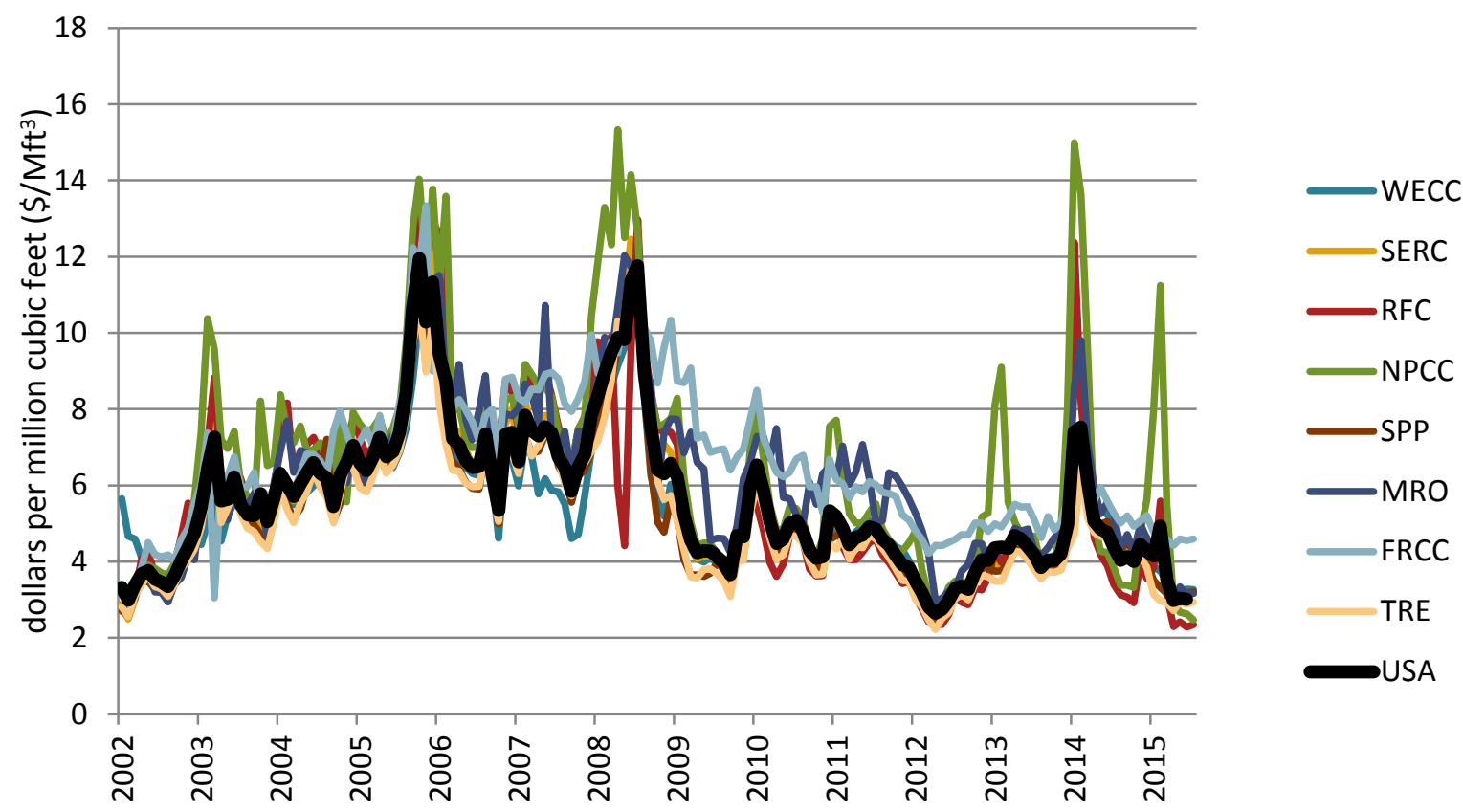

Figure 4-23. Natural gas monthly spot contractual prices $\left(\$ / \mathrm{Mft}^{3}\right)$, 2002-2015

Natural gas prices have been relatively low and less volatile since 2009, although prices have spiked during exceptionally cold winters, especially in New England. Source: SNL $2015^{160}$. 


\section{Coal}

\subsection{Technologies}

There are three main types of coal plants operating in the United States today: pulverized coal (PC), fluidized bed combustion, and integrated gasification combined cycle (IGCC). ${ }^{\mathrm{xxx}}$ The vast majority of existing U.S. coal plants rely on PC configurations. PC plants use a coal-fired boiler to raise steam that is expanded through an ST, which in turn drives an electric power generator. Most existing PC plants use subcritical steam operating conditions, whereas newer, more efficient plants make use of supercritical or ultra-supercritical operating conditions (efficiency increases with higher steam pressure and temperature).

Fluidized bed and IGCC plants make up much smaller portions of the market and have only been considered commercial since the 1980s (at the beginning of 2016, there were only 3 operating IGCC plants in the United States). Fluidized bed boilers use steam in the same manner as PC plants, but the heat is generated by suspending solid fuel particles in the boiler by injecting air, thereby creating a turbulent mixture of the fuel, ash, and air during combustion. This results in more efficient combustion, the ability to fire low-rank coals, lower combustion temperatures (resulting in lower pollutant emissions, such as $\mathrm{NO}_{\mathrm{x}}$ ), modest plant efficiency improvements, and the ability to remove sulfur by adding limestone to the fluidized bed. IGCC plants first convert coal into a synthesis gas (syngas) rich in hydrogen $\left(\mathrm{H}_{2}\right)$ and carbon monoxide (CO) within a coal gasifier, which is then cleaned as desired and combusted in a CT. The exhaust heat resulting from this process is then used to raise steam to power a ST, thus the $\mathrm{CC}$ designation (see Section 5.2 on natural gas below).

New coal plants in the United States are required to meet a $\mathrm{CO}_{2}$ emissions limit in order to comply with EPA's Carbon Pollution Standards (EPA 2016a), which were finalized in October 2015. These standards (1,400 lb CO $2 / \mathrm{MWh}$-gross for new coal units and $1,000 \mathrm{lb} \mathrm{CO} 2 / \mathrm{MWh}^{-}$ gross for new gas units) are based upon EPA's designation of supercritical PC plants with partial CCS (approximately 20 percent capture) as the best system of emissions reduction for coal generation.

Using CCS technologies, $\mathrm{CO}_{2}$ can be captured precombustion (in IGCC plants) or postcombustion from the flue gas using postcombustion technologies (for use with PC or fluidized bed combustion plants) or oxygen combustion (combustion of coal in an oxygen environment, creating a stream of less-dilute $\mathrm{CO}_{2}$ as a flue gas). Once isolated and captured, the $\mathrm{CO}_{2}$ is then transported for utilization (e.g., enhanced oil recovery) or geological storage in saline aquifers. These and other advanced technologies are under development by NETL (see Section 5.7 and the private sector) ${ }^{161}$.

In addition to research on advanced CCS and crosscutting technologies, efforts are underway across the globe to demonstrate CCS technology at scale and "learn by doing" in the field ${ }^{162}$. The Carbon Sequestration Leadership Forum is one global network that is sharing best practices, operational experience, and key lessons to advance the deployment of CCS. DOE is playing a substantial role in CCS demonstrations, helping to overcome the technical and economic

\footnotetext{
${ }^{\mathrm{xxx}} \mathrm{PC}$ and fluidized bed combustion plants, which both utilize the Rankine cycle for power generation, are sometimes referred to as conventional coal plants.
} 
uncertainties associated with first-of-a-kind demonstrations of new technologies. However, even with Government support, these projects, by their nature, are ambitious and challenging-some projects will not go forward to completion. See Section 5.7 for a more detailed discussion of CCS-related demonstrations. Appendix A contains additional information on coal generation technologies.

\section{Text Box 1. The Kemper IGCC Plant with CCS}

IGCC with CCS is under development, and DOE has an active RDD\&D program focused on reducing costs along the entire process chain. The Kemper IGCC plant under construction in Mississippi-the second such commercial U.S. plant using "transport integrated gas" technology - is a 582-MW unit that is expected to capture approximately $65 \%$ of its emissions for use in nearby enhanced oil recovery (EOR). The plant is expected to come online in early 2017. The plant will use locally available lignite fuel, but will emit fewer air pollutants than traditional coal plants and use fewer water resources, including less water for cooling than a conventional coal plant. The plant expects to sell most or all of the captured $\mathrm{CO}_{2}$ for EOR applications. The original cost estimate for the plant was $\$ 1.8$ billion, but it has since risen to $\$ 6.2$ billion $^{\mathrm{i}}$. More field experience and "learning by doing" could reduce these costs significantly in the future ${ }^{i}$. The only other coal power-based CCS project in North America is the Boundary Dam Plant in Saskatchewan, Canada, which uses post-combustion capture and sells the $\mathrm{CO}_{2}$ for EOR ${ }^{\mathrm{i}}$. A third project, NRG Energy's Petra Nova project in Parish, Texas, is the world's largest post-combustion plant, and became operational in early 2017.

\subsection{Operational Attributes and Fleet Characteristics}

Coal has been the predominant source for electric power in the United States, and generation steadily increased until 2007. In that year, coal generation peaked at 2,016 TWh (49 percent of the nation's annual generation). By 2015, coal generation had dropped to 1,356 TWh (33 percent of annual generation), a level not seen since 1989 (Figure 5-1). The reduction in coal-fired generation is due to a variety of factors, including low natural gas prices, higher maintenance costs of an aging fleet, growing regulatory pressure with respect to emissions, water consumption constraints, Federal and State incentives for renewable electricity options, and low electricity demand growth. Figure 5-2 shows the decline in coal capacity factor. The maps in Figure 5-3 illustrate capacity (left) and generation (middle) in 2010 and 2014, as well as the corresponding capacity factors (right). With few exceptions, capacity and generation from coal went down across the United States over the illustrated time period. Capacity factors also generally decreased modestly in most of the country, with notable exceptions in New England and the Mid-Atlantic, where many states saw capacity factors from coal decrease by over 50 percent. 


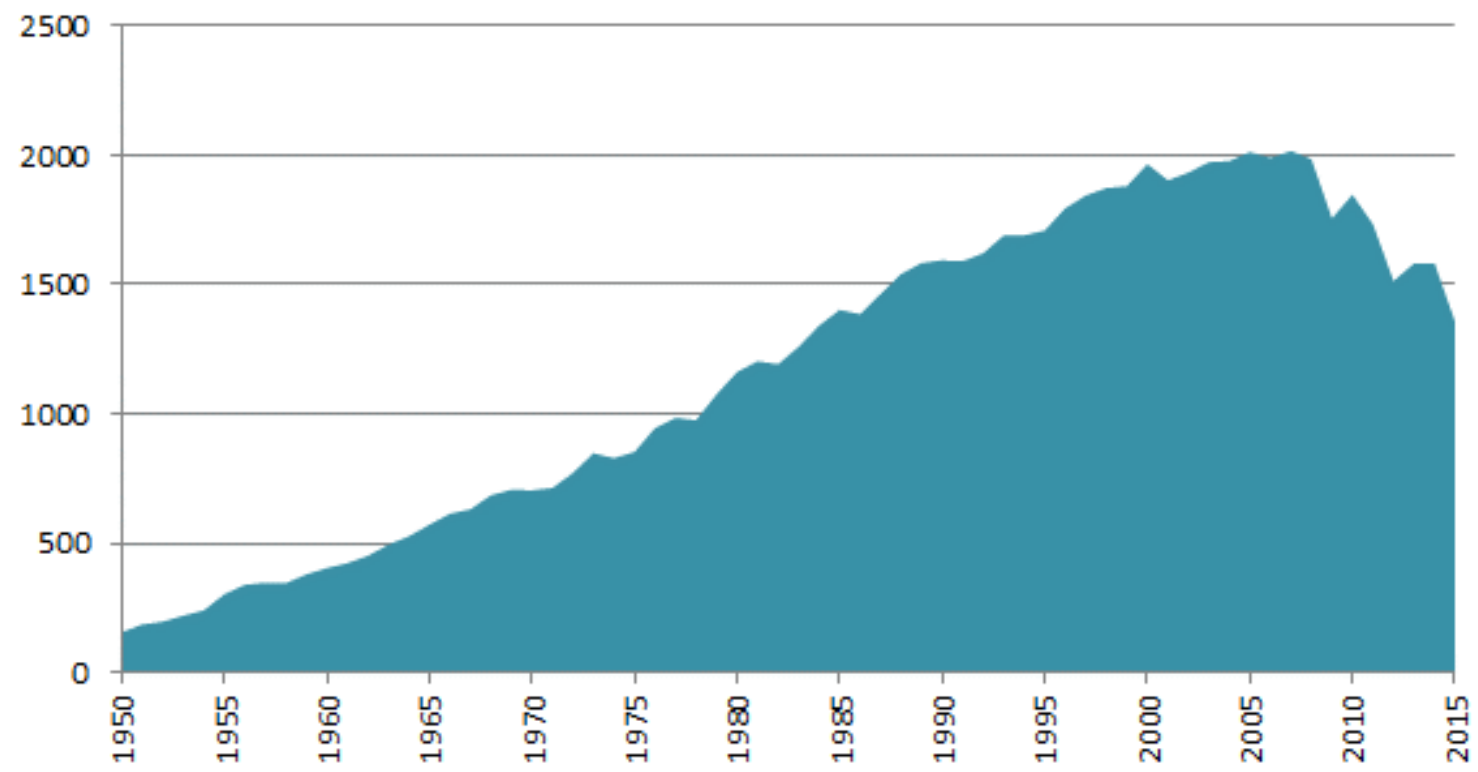

Figure 5-1. U.S. coal generation (TWh), 1950-2015

Annual generation from coal peaked in 2007 and has been declining in recent years. Source: EIA $2016^{163}$

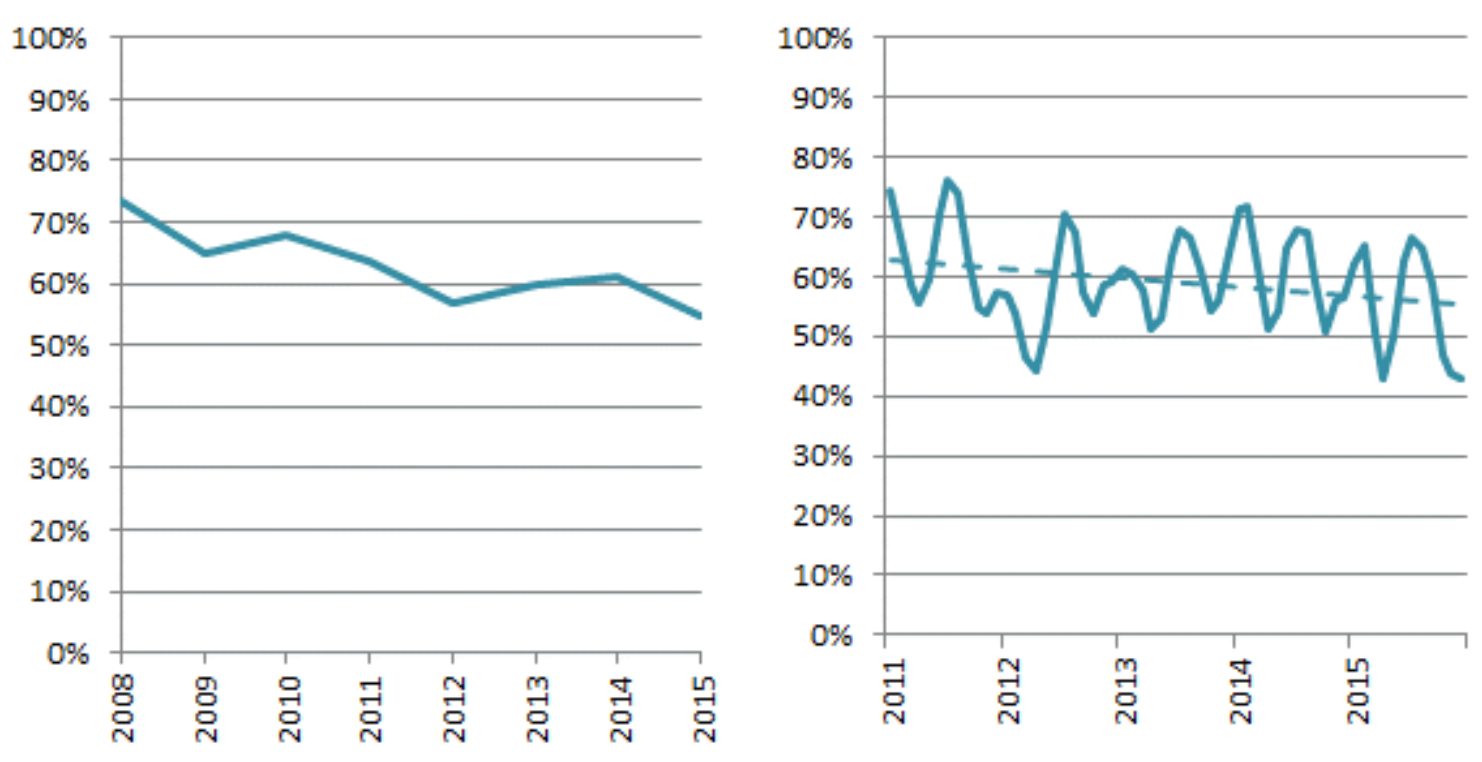

Figure 5-2. Annual and monthly capacity factors for coal generators

The capacity factor from the U.S. coal generating fleet fell from over 70 percent in 2008 to under 60 percent in 2015. Source: SNL $2015^{164}$. 


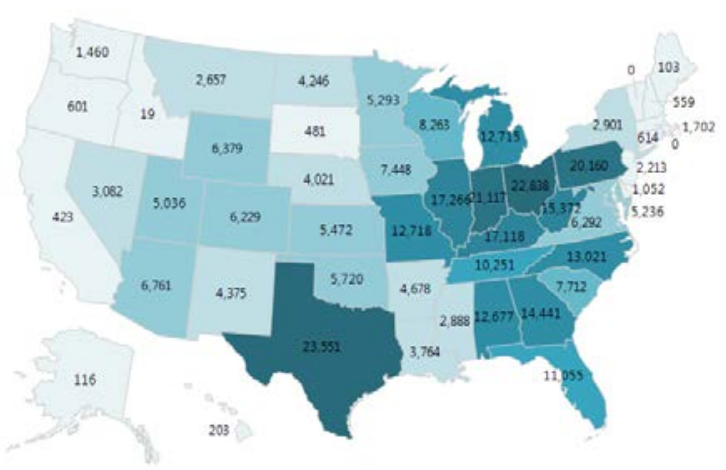

Capsery (MM) 2010

2.5005 .0007 .50010 .00012 .50015 .00017 .50020 .00022550025 .000

2014

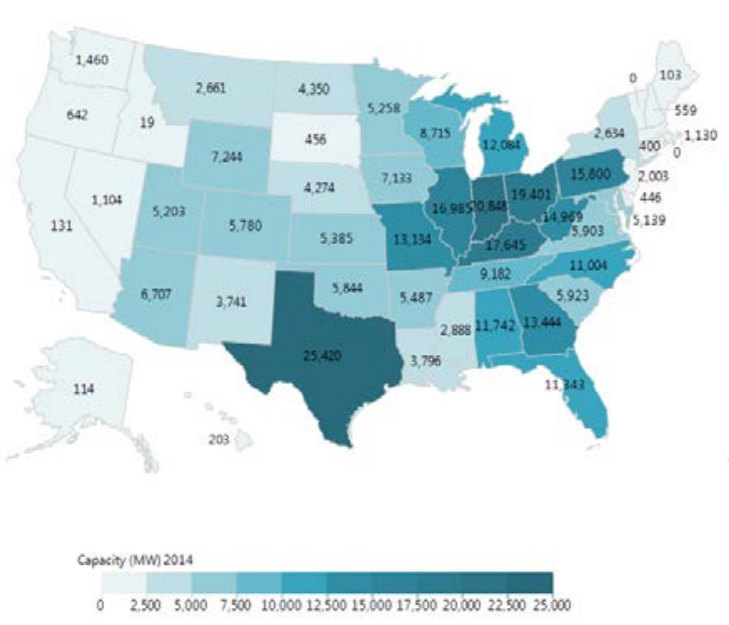

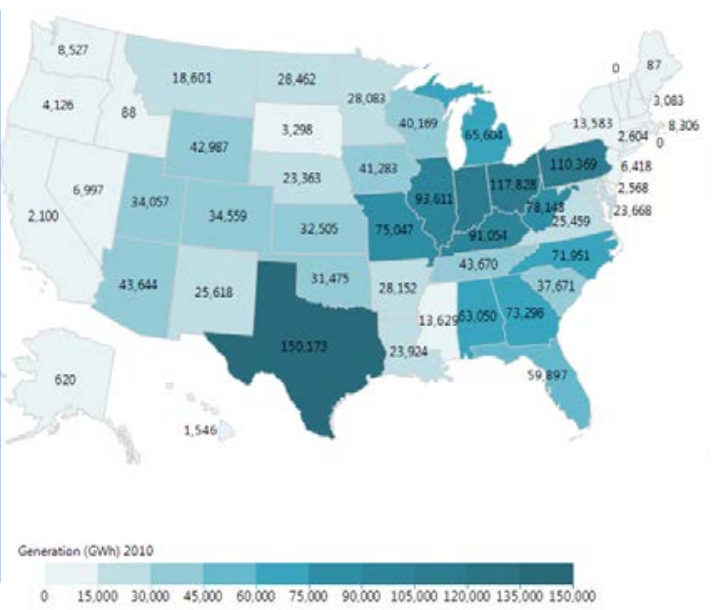

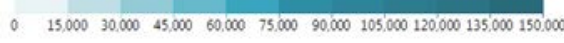
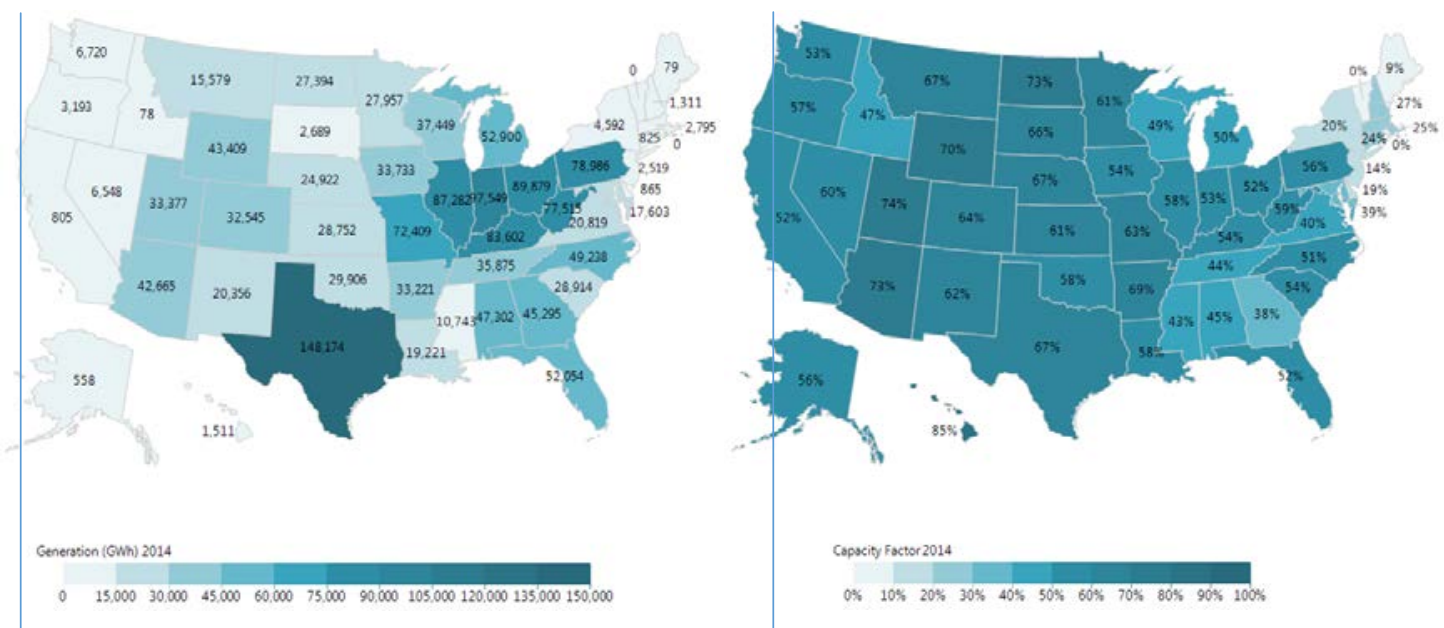

Figure 5-3. Coal capacity (left), generation (middle), and capacity factor (right) by state. Top: 2010; bottom: 2014.

Capacity, generation, and capacity factors for coal generally declined across the United States between 2010 and 2014. Source: EIA $2016^{165}$. 
Almost 90 percent of coal plant capacity was built over 30 years ago (Figure 5-4). The result is an aging fleet of plants that average around 40 years in age ${ }^{166}$. Life expectancies for coal plants are 55 years for units under $100 \mathrm{MW}$ and 65 years for units over $100 \mathrm{MW}{ }^{167}$. The reported age of any power plant might be deceptive as component plant equipment is often upgraded on a regular basis, and can extend plant life beyond the original life expectancy.

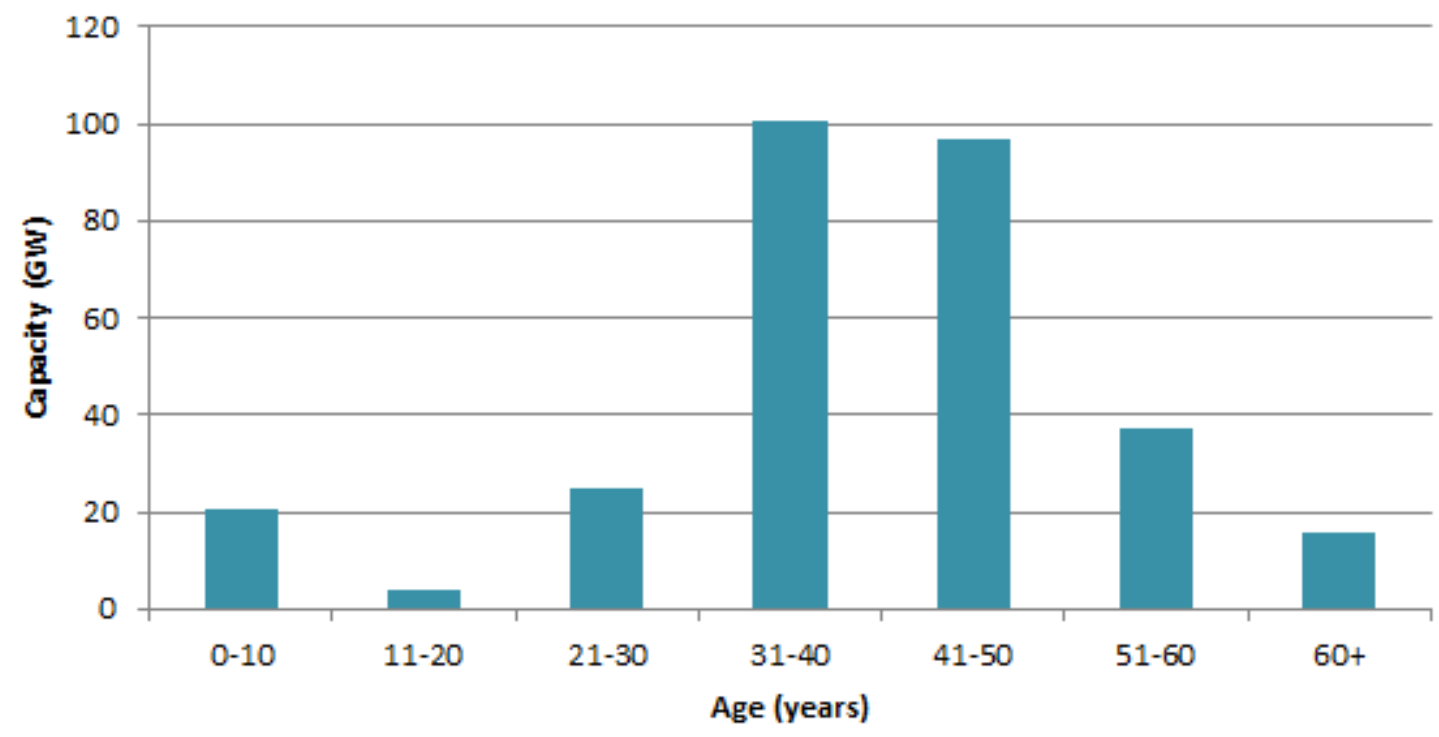

Figure 5-4. Age profile of U.S. coal generation fleet, 2014

A majority of the U.S. coal fleet capacity is between 30 and 50 years old. Source: SNL $2015^{168}$.

The average heat rate for the U.S. fleet of coal-fired ST generators has gradually improved since 2007, mainly due to the retirement of smaller, older, or otherwise less efficient units (Figure 55). Heat rate improvement of existing coal plants is one of the building blocks of the "best system of emissions reduction" under the CPP. 


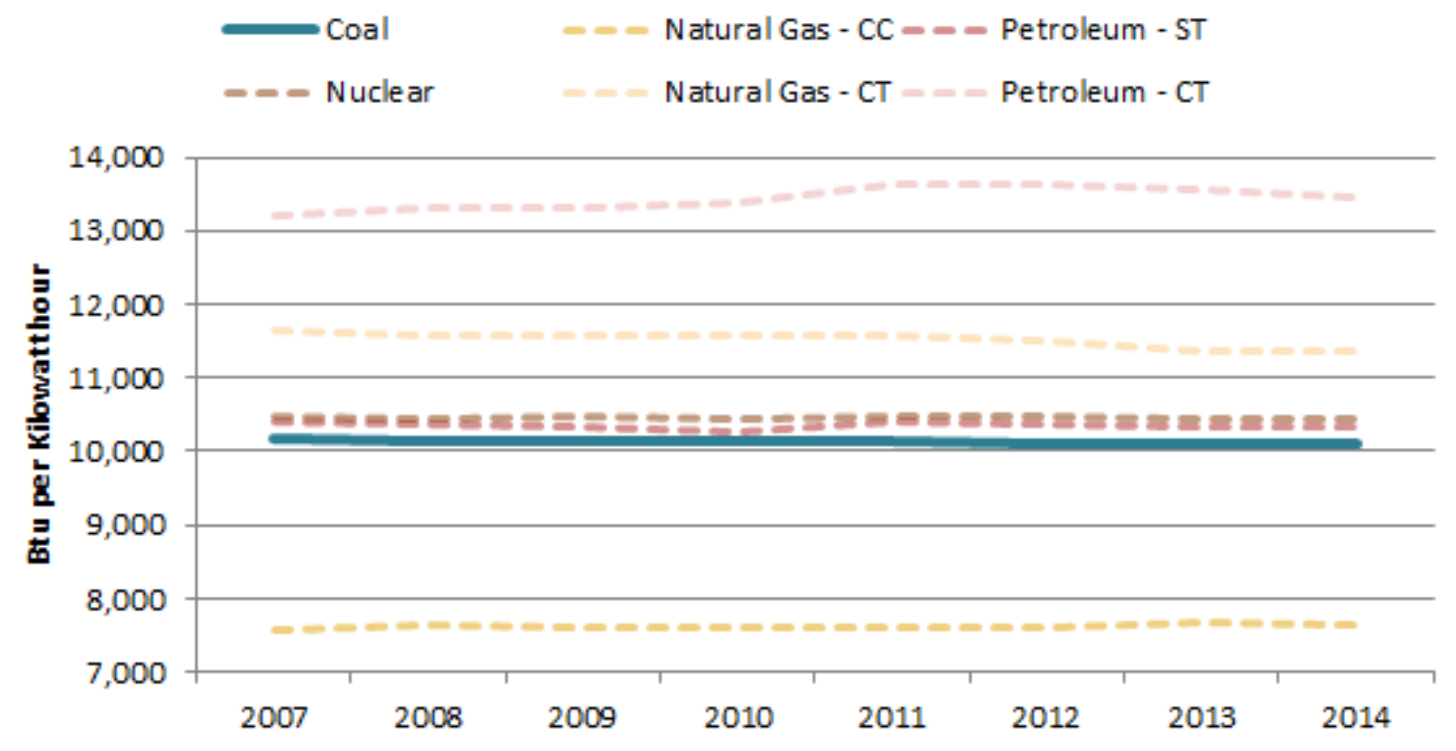

Figure 5-5. Heat rates for coal generators (BTU/kWh), 2007-2014

The heat rate for coal generators has declined slightly since 2007, meaning that, on average, the U.S. coal fleet is more efficient. Efficiency upgrades and retirements of older, less efficient units have contributed to this decrease in heat rate. Source: EIA $2015^{169}$.

Heat rate estimates for modern, state-of-the-art coal generators are given in Table B-3 in Appendix B; these are the heat rates used in the LCOE calculations presented in this report. While these estimates are representative of the current state-of-the-art technology, actual plant heat rates depend on a number of factors, including coal quality, specific plant design and operating conditions, site-specific factors including atmospheric conditions, and the temperature of available cooling water.

\subsection{Technology Costs}

The LCOE for new plants is shown in Table 5-1 (2013\$). The range of values for the LCOE of PC is slightly lower than for IGCC, and adding CCS (at a 90 percent $\mathrm{CO}_{2}$ capture rate) significantly increases LCOE for both. Publicly and privately supported research, development, and demonstration programs, including those managed by DOE, are focused on reducing the cost and performance penalties and risks associated with commercial CCS deployment (see Section 5.7). 
Table 5-1. LCOE for New Coal Generators (2013\$/MWh)

\begin{tabular}{|l|l|l|l|l|l|l|}
\hline & \multicolumn{2}{|c|}{ EIA } & \multicolumn{3}{c|}{ NETL } & \multicolumn{3}{c|}{ Lazard } \\
\hline Technology & Low & High & Low & High & Low & High \\
\hline Coal - PC & 54.81 & 97.53 & 65.01 & 91.43 & 52.53 & 77.95 \\
\hline $\begin{array}{l}\text { Coal - PC - CCS (90 } \\
\text { percent) }\end{array}$ & - & - & 108.96 & 144.66 & - & - \\
\hline $\begin{array}{l}\text { Coal - PC - partial } \\
\text { CCS (22 percent) }\end{array}$ & - & - & 88.33 & 110.58 & - & - \\
\hline Coal - IGCC & 68.87 & 125.49 & 75.68 & 111.06 & 69.47 & 148.99 \\
\hline $\begin{array}{l}\text { Coal - IGCC - CCS } \\
\text { (90 percent) }\end{array}$ & 105.74 & 195.68 & 99.97 & 147.28 & 103.80 & 204.16 \\
\hline
\end{tabular}

Current ranges of coal technology LCOEs based on cost assumptions from three sources: EIA 20151, NETL 2015, and Lazard $2015^{170}$. See Appendix B for more information on LCOE calculations.

\subsection{Fuel/Resource}

Coal has been a major fuel for electricity generation for more than a century in the United States. The three main types of coal used for power generation, in order of descending rank, are bituminous, subbituminous, and lignite. In general, higher-rank coals such as bituminous have higher energy content (characterized as the higher heating value, with units of Btu/lb), fixed carbon content, and sulfur, and less ash and moisture than lower rank coals ${ }^{171}$. Higher moisture coals have a lower heating value due to the latent heat of vaporization of the water. The mineral matter that comprises the ash content of coal is not combustible; consequently, its presence adversely impacts the energy content of the coal.

The 345 underground mines in the United States produced 354,704 tons of coal in 2014, or 30 percent of total domestic coal production. Underground mining is more prevalent east of the Mississippi River, where bituminous and anthracite coals are generally found at deeper depths, accounting for 61 percent of coal produced in that region. The 613 surface mines in the United States accounted for almost 70 percent of domestic coal production in 2014. Surface mining is the most prevalent form of coal mining west of the Mississippi, used for over 90 percent of coal production in that region, while it is only used for 29 percent of coal production in the East.

Surface mining has declined 21 percent since 2008 due in part to a reduction in demand for coal (total production is down 15 percent over the period) ${ }^{172}$. In 2014, U.S. production of coal consisted of 48 percent bituminous coal, 44 percent subbituminous coal, 8 percent lignite, and less than 1 percent anthracite ${ }^{173}$, ${ }^{x x i}$.

\subsubsection{Coal Price History}

The majority of coal is sold under long-term contracts, with spot market sales making up the remainder of sales. The price of coal varies significantly by the source of coal, its heat content (Btu/lb), how much sulfur and ash it contains, and how far the coal is from the point of use. The minemouth prices for steam coal to the electric sector are shown in Figure 5-6, although there are wide variations in price by type of coal and location.

\footnotetext{
xxxi Totals may not add up to 100 percent due to rounding errors.
} 


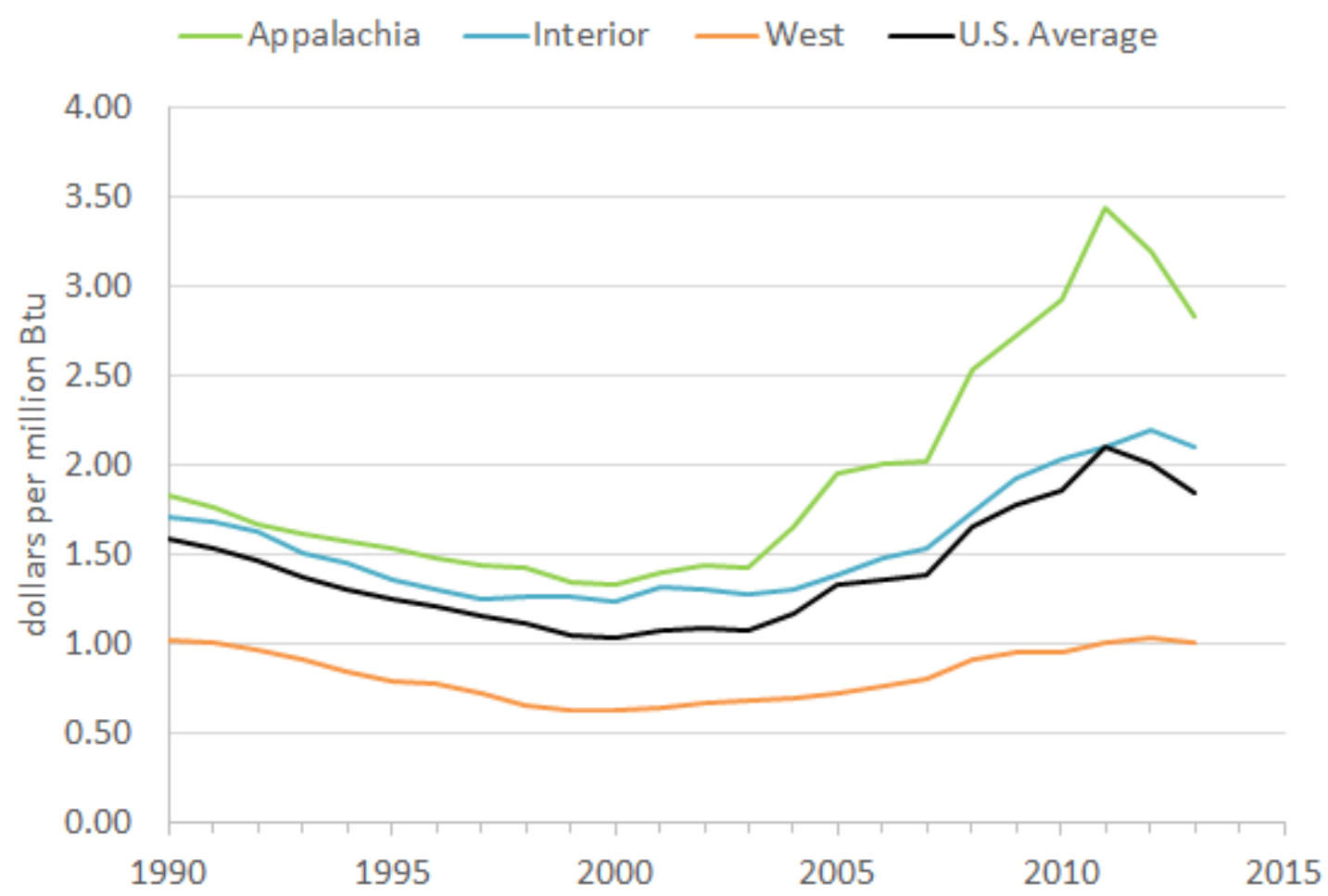

Figure 5-6. Annual average minemouth coal prices (2013\$) by U.S. region, 1990-2015

Appalachian minemouth coal prices are the highest while minemouth prices are the lowest in the West. Source: EIA $2016^{174}$.

Transportation can make up a significant portion of the delivered cost (the minemouth price plus transportation cost) of coal depending on the transportation method and year as shown in Figure 5-7. This is especially true for coal from the Powder River Basin (PRB) in Wyoming, as it must be shipped long distances by rail to coal plants and international markets (Figure 5-8) ${ }^{175}$. . $x x i i$ PRB coal is also produced from open pit or surface mining, which is a much less expensive extraction method than underground mines, which are more prevalent in production of eastern coals.

\footnotetext{
xxxii Even with its high transport cost share of price on a percentage basis, Powder River Basin coal is still significantly lower cost than coal produced in other basins on a dollar per ton-mile basis. From 2010-2015, Powder River Basin coals averaged 3.1 cents per ton-mile delivered while Illinois Basin coals averaged 14.4 cents per tonmile delivered and Central Appalachian Basin coals averaged 19.9 cents per ton-mile delivered. Over the period, the only coals that were competitive with Powder River Basin on a dollar per ton-mile basis were those imported from Indonesia ( 0.8 cents per ton-mile delivered) and South America (4.1 cents per ton-mile delivered); however, deliveries of these coals were constrained primarily to coastal power generators.
} 


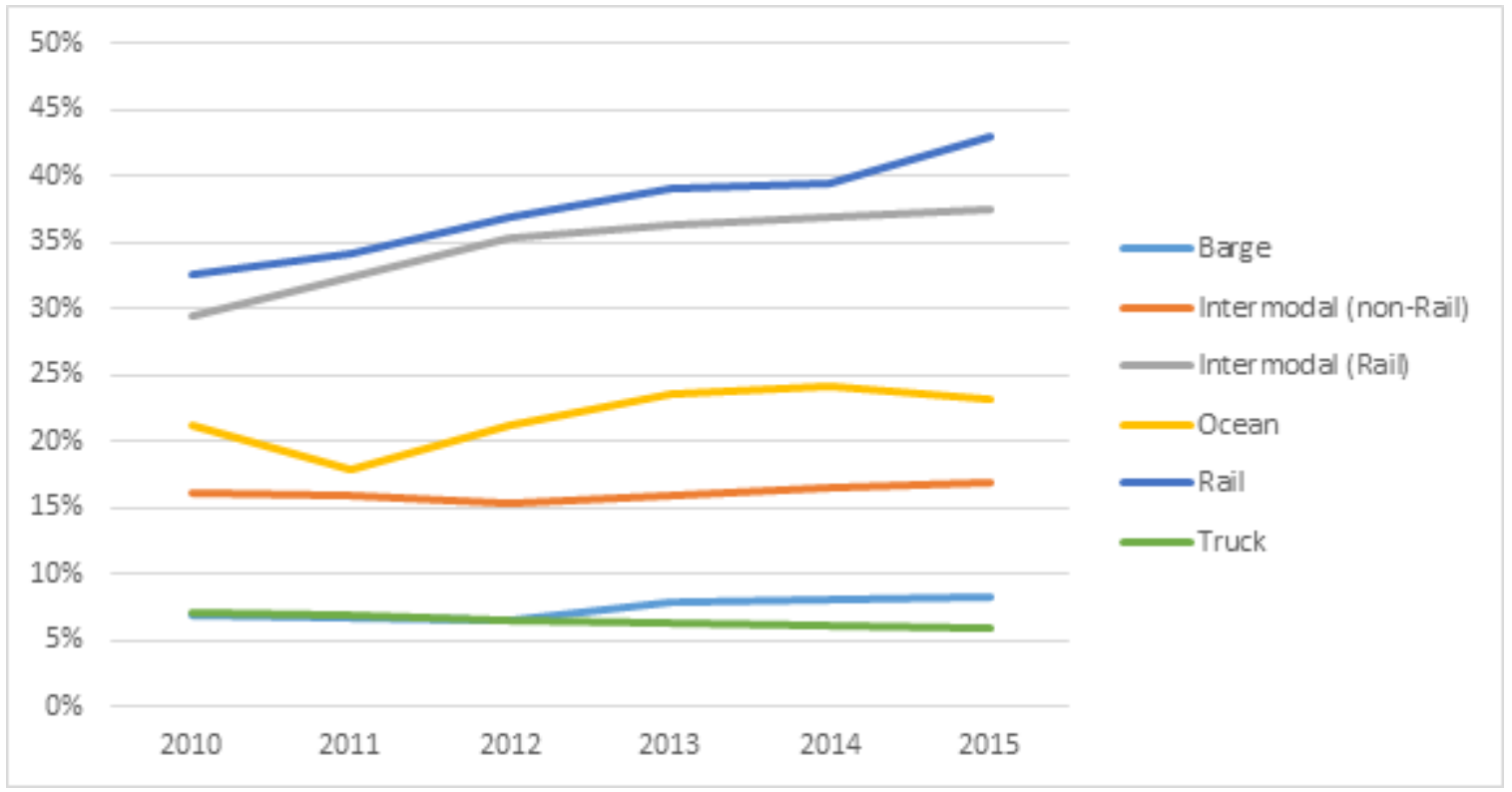

Figure 5-7. Transportation cost share of delivered coal price by mode, 2010-2015

Transportation costs by railroad make up a much larger percentage of delivered coal prices than waterway or truck. Source: Mintz et al. $2015^{176}$.

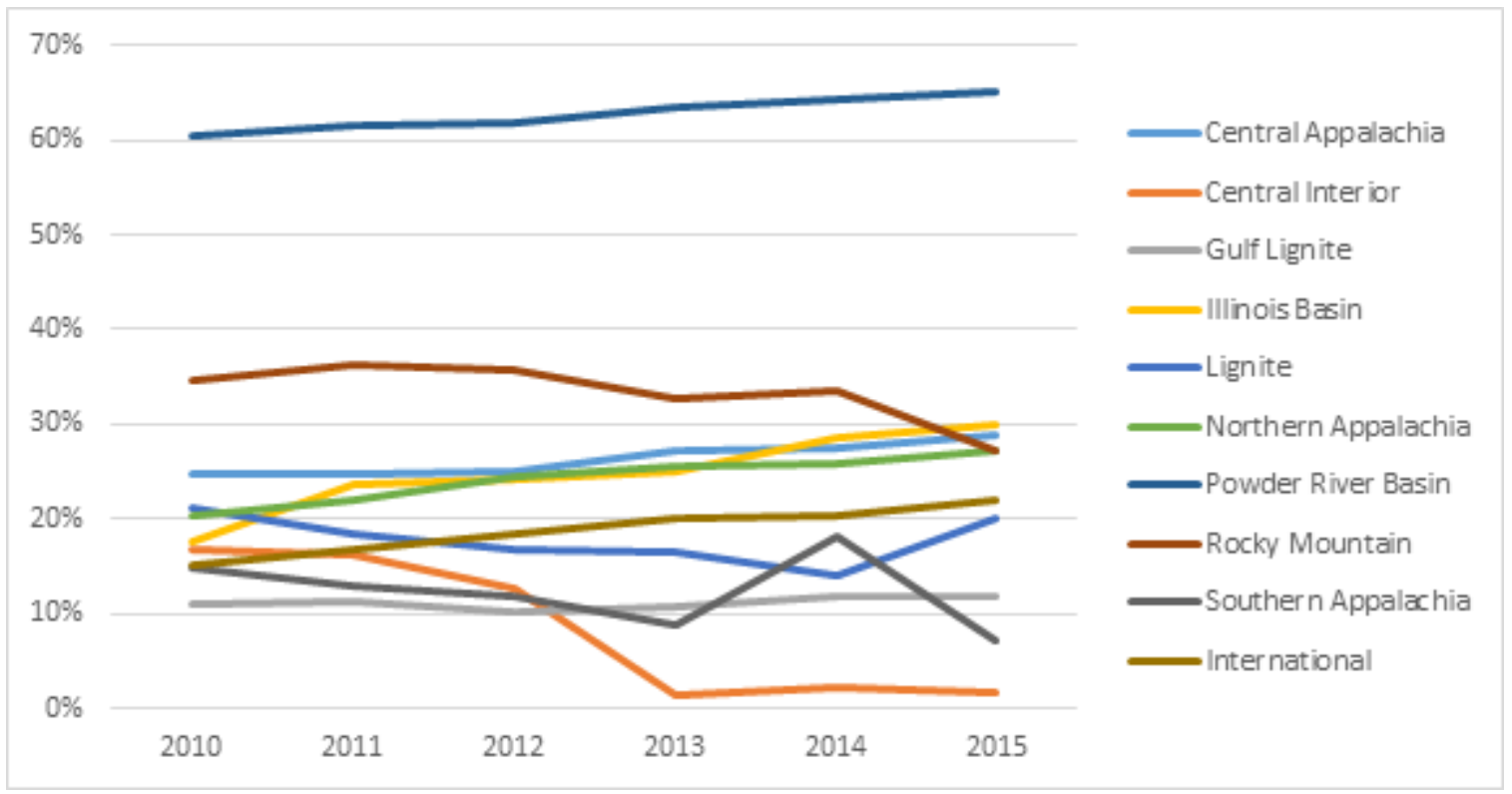

Figure 5-8. Rail transportation cost share of delivered coal price by origin, 2010-2015

Rail transportation costs made up a large portion of the delivered coal price from the Powder River Basin. Source: Mintz et al. $2015^{177}$.

\subsection{Environmental Impacts}

\subsubsection{Upstream}

Coal mining is conducted both on the surface and underground. Underground mining involves mining deep into the earth to extract coal in place and generally results in fewer disturbances at 
the surface, but has the potential to affect groundwater and, in some cases, emit methane, a potent GHG (in the case of gassy coal seams). These impacts, particularly related to the groundwater impacts of mining, can be mitigated through best practices and regulations such as the Coal Mining Effluent Guidelines and Standards and others promulgated under the Clean Water Act, which have been enacted and regularly amended.

Legacy environmental impacts exist, particularly from abandoned mines, and some of these impacts are still being felt. The most significant of these is perhaps the problem of acid mine drainage (AMD), which occurs when water flows over sulfur-containing materials ${ }^{178}$. AMD is considered one of the largest nonpoint sources of pollution in the Mid-Atlantic region by the EPA; it can contaminate drinking water, disrupt ecosystems for aquatic life and bacteria, and corrode infrastructure such as bridges ${ }^{179}$. Most of the mines that have led to AMD problems have been legacy mines that operated before environmental regulations were in place to prevent impacts to the ecosystem.

Surface mining involves removing the top layers of soil or rock to expose shallow coal seams. While surface mining practices vary by state, it is common for the soil to be set aside during coal production and replaced after mining operations have ceased. The Surface Mining Control and Reclamation Act of 1977 requires coal mining areas to be restored to "a condition capable of supporting the uses which is [sic] was capable of supporting prior to any mining, or higher or better uses" ${ }^{180}$. The interpretation of the Surface Mining Control and Reclamation Act can vary by state, but it is common practice in certain states to remediate the mined area to the original contours of the land, while in other instances the now-cleared area is repurposed for other uses $^{181}$. The practice of surface mining has undergone a steeper decline where remediation is difficult, such as in eastern states with varied topography. This is partly a result of increased environmental regulations and permitting constraints ${ }^{182}$.

There is generally no manufacturing needed to produce coal, outside of equipment for mining and cleaning coal. Cleaning coal (beneficiation) removes impurities such as sulfur, ash, and rock in an effort to increase the value of coal. The main environmental concern during cleaning coal is the release of particulate matter to the air created from coal dust ${ }^{183}$. Water is used in this process and can be contaminated by this same dust. Wastes from this process include slurry, which is stored in impoundments onsite ${ }^{184}$.

\subsubsection{Emissions and Environmental Impact}

The conversion of coal into electricity produces many emissions, resulting primarily from inorganic materials found in the coal. Waste streams can be minimized or mitigated by choice of conversion technology (e.g., gasification versus combustion), use of environmental control technologies, or maximization of the conversion efficiency of the process.

Airborne emissions from coal generation contain $\mathrm{NO}_{\mathrm{x}}, \mathrm{SO}_{\mathrm{x}}$, particulate matter, NMVOCs, mercury, and $\mathrm{CO}_{2}$, among others. $\mathrm{NO}_{\mathrm{x}}$ is a common cause of smog in cities, and $\mathrm{SO}_{\mathrm{X}}$ is one of the leading contributors to acid rain and is a precursor to particulate matter. Particulate matter can affect the health of humans, lead to respiratory issues, and increase premature death rates. $\mathrm{CO}_{2}$ is one of the leading contributors to anthropogenic climate change. The Clean Air Act of 1970 first regulated these air pollutants and has been successful in driving the development of specific environmental control technologies for emissions reductions, improving the science related to 
energy conversion, and effecting efficiency improvements. Only recently, however, has the Clean Air Act been interpreted to include $\mathrm{CO}_{2}{ }^{185}$.

Combustion controls modify the operating conditions to reduce the production of $\mathrm{NO}_{\mathrm{x}}$ during combustion. They include (1) lowering the combustion temperature (2) creating a fuel-rich environment or (3) reducing the time that oxidation can occur ${ }^{186}$. Postcombustion technologies, often selective catalytic reduction, use chemicals (ammonia) and a rare-earth element catalyst to convert $\mathrm{NO}_{\mathrm{x}}$ to $\mathrm{N}_{2}{ }^{187}$.

$\mathrm{SO}_{\mathrm{x}}$ emissions are generally controlled through either using low-sulfur fuel or using a limestone scrubber to remove sulfur from the flue gas ${ }^{188}$. Emissions are regulated by EPA, and regulations have been largely successful in reducing problems from acid rain. The Cross-State Air Pollution Rule $^{189}$, which replaced the Clean Air Interstate Rule regulation on cross-border air pollution transport in $2015^{190}$, was challenged in courts but remains in place. The CSAPR requires states to significantly improve air quality by reducing power plant emissions that contribute to ozone and/or fine particle pollution in other states.

Particulate matter emissions can be controlled by removing and capturing the fine particles contained in the plant flue gas. Control technologies include electrostatic precipitators, fabric filters, mechanical collectors, and venturi scrubbers ${ }^{191}$. The Mercury and Air Toxic Standards were implemented in 2012 to control mercury and air toxic (hydrogen chloride, hydrogen fluoride, heavy metals) emissions from coal- and petroleum-based generators ${ }^{192}$.

$\mathrm{CO}_{2}$ emissions for new coal-fired plants are regulated under a Federal program set forth in Section 111(b) of the Clean Air Act. EPA promulgated rules for new stationary sources under 111(b) in August 2015 that set the emissions requirements for any new coal-fired plants ${ }^{193}$. New supercritical PC plants emit greater than the allowed $\mathrm{CO}_{2}$ volume ${ }^{194}$, thus requiring at least partial CCS for most new plants. However, certain IGCC configurations (as well as specific coals, site-specific conditions, etc.) may be able to meet this limit without incorporation of CCS equipment $^{195}$. As noted previously, Section 111(d) of the Clean Air Act would establish statelevel carbon reduction goals for existing power plants, but the rule was under a legal challenge at the time of this writing.

\subsubsection{Downstream}

In addition to these gaseous emissions, burning coal also produces solid coal combustion residues, which can pose additional dangers when released to the environment. The two largest forms of solid combustion wastes are fly ash (accounting for roughly half the combustion waste) and $\mathrm{SO}_{\mathrm{x}}$ "scrubber" slurry, which results from emissions reduction efforts at the plant. Bottom ash contains materials that are too large to be carried by the hot gases and therefore settle at the bottom of the boiler. When temperatures are high enough to melt ash, boiler slag can form and collect at the bottom of the boiler and in the exhaust stack filters. About 45 percent of these wastes are reused in other products, such as concrete products and drywall ${ }^{196}$.

Waste is often stored onsite in retention ponds. This coal ash-containing water in retention ponds can have impacts on local ecosystems as shown in past leaks and releases. In 2015, EPA's new Disposal of Combustion Coal Residue rule took effect, which provides for the safe disposal of coal ash $^{197}$. 


\subsection{Constraints ${ }^{x \times x i i i}$}

New coal-fired plants in the United States are required to meet a $\mathrm{CO}_{2}$ emissions limit in order to comply with EPA's Carbon Pollution Standards ${ }^{198}$, finalized in October 2015. While in some instances compliance can be achieved without CCS, the majority of new plants will likely require the capture of $\mathrm{CO}_{2}$ produced during coal conversion to electricity.

\subsection{Technical RDD\&D}

DOE has active RDD\&D programs in place for advanced coal generation and CCS technologies along the entire value chain. ${ }^{\text {xxiv }}$ This value chain includes advanced energy systems $\mathrm{R} \& \mathrm{D} ; \mathrm{CO}_{2}$ capture $\mathrm{R} \& \mathrm{D} ; \mathrm{CO}_{2}$ injection and storage $\mathrm{R} \& \mathrm{D}$, including utilization of $\mathrm{CO}_{2}$ (mainly for $\mathrm{EOR}$ ); and monitoring, verification, and accounting of underground storage volumes.

Advanced energy systems R\&D focuses on innovative, near-zero-emissions technologies that are integrated with CCS and improved fuel conversion. The R\&D portfolio includes advanced combustion, gasification, turbines, and fuel cell energy conversion systems. The research is targeted at improving overall system efficiency, reducing capital and operating costs, and enabling affordable carbon capture.

Advanced combustion systems R\&D focuses on the development of high-efficiency oxycombustion and chemical-looping combustion technologies and novel concepts optimized for coal-fueled power plants with carbon capture. New systems are also being developed that generate power at higher efficiencies while also enabling carbon capture. Advanced combustion system R\&D also includes research on gasification systems and advanced turbines (including supercritical $\mathrm{CO}_{2}$-based cycles).

Carbon capture $\mathrm{R} \& \mathrm{D}$ is focused on the development of postcombustion and precombustion $\mathrm{CO}_{2}$ capture technologies for new and existing power plants to improve efficiency while minimizing the cost and energy penalty of $\mathrm{CO}_{2}$ capture.

Postcombustion $\mathrm{CO}_{2}$ capture offers the greatest near-term potential for reducing power sector $\mathrm{CO}_{2}$ emissions because it can be retrofitted to existing coal-based power plants. This technology can also be leveraged in other power- and nonpower applications, including carbon capture from natural gas and biomass electricity systems.

Precombustion capture $\mathrm{R} \& \mathrm{D}$ focuses on ways to capture $\mathrm{CO}_{2}$ before combustion, primarily in IGCC plants. The continued deployment of IGCC systems such as the Kemper plant (Text Box 1), either domestically or internationally, should continue to bring down capital costs through "learning by doing" and aid in the advancement of this pathway. Precombustion capture is also applicable to certain industrial processes, such as the production of hydrogen through steam methane reforming.

\footnotetext{
xxxiii The "Constraints" section does not address environmental or RDD\&D constraints that are addressed elsewhere in this report.

${ }^{\text {xxiv }}$ Much of the information in this subsection comes from the DOE RDD\&D program for CCS website, available at:

http://energy.gov/fe/science-innovation/carbon-capture-and-storage-research. NETL (2015c, 2012a) contributes significantly to this effort.
} 
In both pre- and postcombustion cases, R\&D is underway to develop solvent-, sorbent-, and membrane-based capture technologies

Carbon storage R\&D is focused on developing and advancing technologies to enable safe, costeffective, permanent geologic storage of $\mathrm{CO}_{2}$. The technologies being developed should benefit both industrial and power sector facilities that will need to mitigate future $\mathrm{CO}_{2}$ emissions and apply to both land-based and offshore applications, in different depositional environments. The R\&D effort also serves to increase understanding of the effectiveness of these advanced technologies in different geologic reservoirs appropriate for $\mathrm{CO}_{2}$ storage and to improve the ability to understand the behavior of $\mathrm{CO}_{2}$ in the subsurface. These objectives are key to increasing confidence in future safe, effective, and permanent geologic $\mathrm{CO}_{2}$ storage. There are several options for geologic $\mathrm{CO}_{2}$ storage in the subsurface, including saline formations, oil reservoirs, natural gas reservoirs, unmineable coal seams, basalt formations, and organic-rich shale basins.

\subsection{Development and Projected Future Deployment}

Coal-fired generation technologies achieved continuous improvements in economies-of-scale through approximately 1965. As plant size grew and performance improved (e.g., higher steam temperatures and pressures), utilities could charge less and still remain profitable. As such, the market alone drove deployment without the pressure for strong price regulation. But as technological limits led to a leveling off in economies-of-scale, and growing concern over environmental impacts from coal use began to be felt in the 1970s and 1980s, coal faced growing challenges, especially given strong growth in nuclear power. The energy crisis of the 1970s and early 1980s did result in some new laws that encouraged greater use of domestic coal, but new coal additions began to decline in the mid-1980s and have remained low since, with the possible exception of 2010 when the last large units came online. Regulations associated with Section 111(b) of the Clean Air Act now require new coal plants to limit their $\mathrm{CO}_{2}$ emissions intensity to $1,400 \mathrm{lb} \mathrm{CO} / \mathrm{MWh}$, which is a level achievable by a supercritical PC unit capturing about 20 percent of its carbon emissions (Figure 5-9) ${ }^{199}$

There were roughly $25 \mathrm{GW}$ of coal retirements from 2012 to 2014 (SNL 2015). In 2015 alone, $13 \mathrm{GW}$ of coal capacity retired. The plants retired in 2015 had an average age of 54 years and an average net summer capacity of $133 \mathrm{MW}$, much older and smaller in capacity than the coal fleet remaining in operation. 


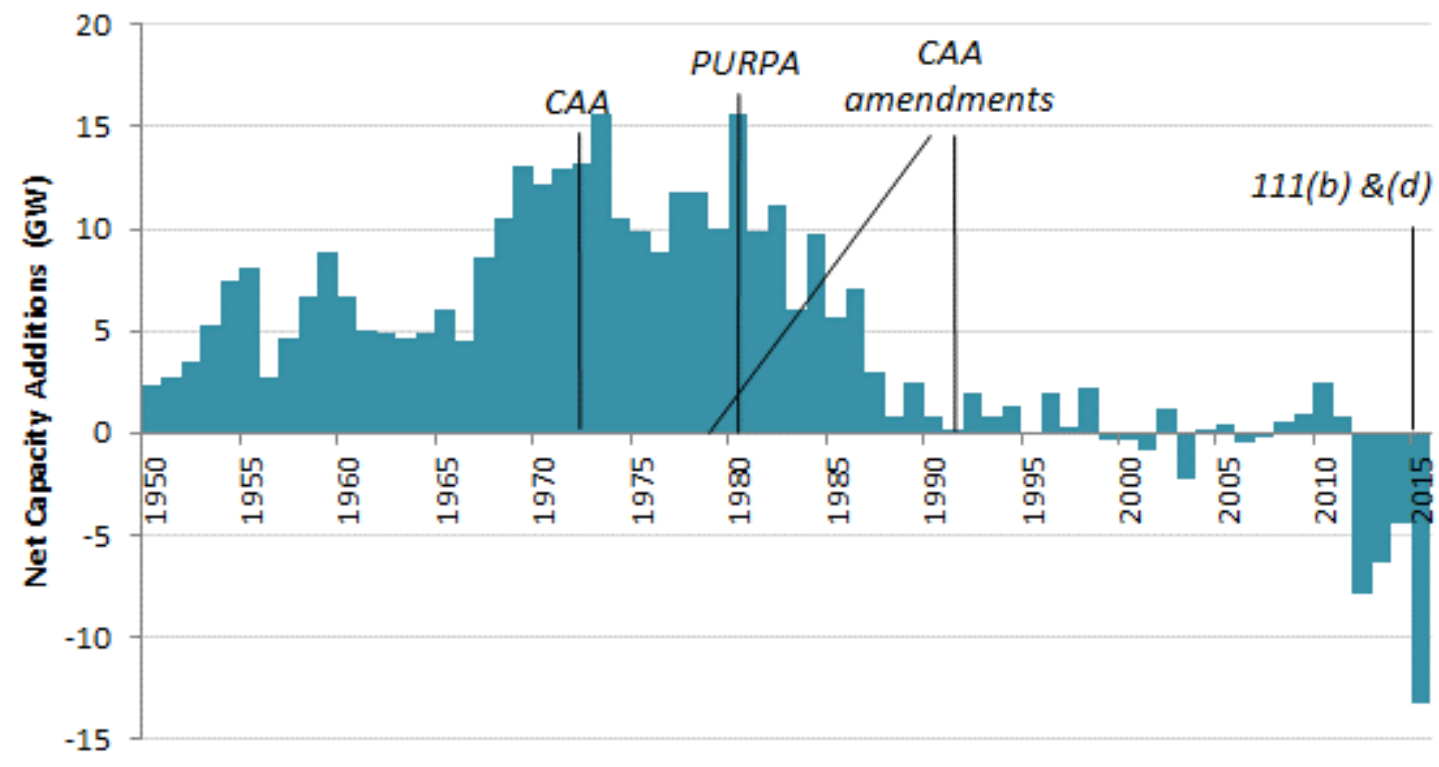

Figure 5-9. Historical annual coal capacity additions and retirements (GW), 1950-2015

Coal capacity grew steadily during the 1950s and 1960s, and accelerated during the 1970s and early 1980s in part due to global oil market turmoil. Growth slowed from the mid-1980s until 2004 or so, when economic growth combined with concerns of natural gas shortages drove new coal investment. The economic recession, shale gas revolution, and new environmental regulations have reduced new coal builds since 2010. Aging coal units have retired in recent years due to environmental regulations and the availability of other, less expensive generating resources (natural gas and renewables). Source: EIA $2016^{200}$.

Many of the recent coal retirements were the result of market forces and new environmental regulations; some power plant operators decided that retrofitting units to meet the new environmental standards would be cost-prohibitive or too risky (based on market and regulatory uncertainty) and chose to retire these units instead. The drivers for the recent reduction in coalfired generation include low-cost natural gas generation, environmental regulations, Federal and State policies associated with renewable energy (e.g., PTCs and RPSs) and flat electricity demand ${ }^{201}$. Projections vary as to the potential for CCS retrofits on the existing fleet or the construction of new coal-fired plants that meet the requirements of 111(b) and 111(d). Table 5-2 shows the projected generation from coal under the QER 1.2 Base Case scenario.

Table 5-2. QER 1.2 Base Case Generation for U.S. Coal in TWh

\begin{tabular}{|l|c|c|}
\hline & 2014 Actual & $\begin{array}{c}\text { QER 1.2 Base Case } \\
(2040)\end{array}$ \\
\hline Conventional Coal & 1,607 & 879 \\
\hline Coal with CCS & 0 & 6 \\
\hline
\end{tabular}

Projected generation from coal under the QER 1.2 Base Case. For more details on the analysis methodology, see Section 2.3.1. Source: EPSA 2016 ${ }^{\mathbf{2 0 2}}$.

In the International Energy Agency's (IEA's) World Energy Outlook(WEO), global coal-fired generation is projected to grow between 23 percent (New Policies Scenario) and 72 percent (Current Policies Scenario) through 2040, with much of the expansion coming in developing 
countries (Tables 5-3 and 5-4). In the 450 Scenario, however, projected global coal generation would need to decline by over 57 percent compared to 2013 levels. Over this time period, coalfired generation in IEA's Organization for Economic Co-operation and Development countries is projected to stay mostly flat in the Current Policies Scenario or decline by over one-third in the New Policies Scenario ${ }^{203}$. As shown in Table 5-4, the New Policies Scenario results in advanced coal and CCS deployments, with capacity increases expected in supercritical and advanced coal, and a projected $63 \mathrm{GW}$ of coal with CCS by 2040.

Table 5-3. Historical and Projected Global Coal Generation by Scenario Outlook, 2000-2040

\begin{tabular}{|l|c|c|c|c|c|c|c|c|}
\hline IEA Scenario & \multicolumn{2}{|c|}{} & \multicolumn{2}{|c|}{ New Policies } & \multicolumn{2}{|c|}{ Current Policies } & \multicolumn{2}{|c|}{450 Scenario } \\
\hline & 2000 & 2013 & 2020 & 2040 & 2020 & 2040 & 2020 & 2040 \\
\hline $\begin{array}{l}\text { Coal-Fired } \\
\text { Generation } \\
\text { (TWh) }\end{array}$ & 6,001 & 9,612 & 10,171 & 11,868 & 10,918 & 16,534 & 9,185 & 4,107 \\
\hline $\begin{array}{l}\text { Percentage of } \\
\text { Global Total }\end{array}$ & 39 & 41 & 37 & 30 & 39 & 38 & 35 & 12 \\
\hline
\end{tabular}

Source: IEA 2015 204 .

The IEA projects a modest rise in global coal generation in the New Policies Scenario, and a significant drop in order to meet the 450 Scenario requirements.

Table 5-4. Current and Projected Coal-Fired Capacity (GW) in the WEO New Policies Scenario, 2014-2040

\begin{tabular}{|c|c|c|c|c|c|c|c|c|c|c|}
\hline & & & 2014 & & & & & 2040 & & \\
\hline & OECD & China & India & $\begin{array}{l}\text { Rest of } \\
\text { world }\end{array}$ & World & OECD & China & India & $\begin{array}{l}\text { Rest of } \\
\text { world }\end{array}$ & World \\
\hline Total & 647 & 864 & 174 & 238 & 1922 & 412 & 1175 & 438 & 443 & 2468 \\
\hline Subcritical & 415 & 529 & 149 & 158 & 1251 & 161 & 476 & 196 & 210 & 1044 \\
\hline Supercritical & 147 & 205 & 25 & 28 & 405 & 120 & 318 & 222 & 103 & 764 \\
\hline Advanced & 85 & 130 & 0 & 51 & 266 & 98 & 355 & 21 & 123 & 597 \\
\hline $\operatorname{ccs}$ & 0.1 & - & - & - & 0.1 & 33 & 25 & - & 6 & 63 \\
\hline Subcritical & $64 \%$ & $61 \%$ & $86 \%$ & $67 \%$ & $65 \%$ & $39 \%$ & $41 \%$ & $45 \%$ & $48 \%$ & $42 \%$ \\
\hline Supercritical & $23 \%$ & $24 \%$ & $14 \%$ & $12 \%$ & $21 \%$ & $29 \%$ & $27 \%$ & $51 \%$ & $23 \%$ & $31 \%$ \\
\hline Advanced & $13 \%$ & $15 \%$ & $0 \%$ & $21 \%$ & $14 \%$ & $24 \%$ & $30 \%$ & $5 \%$ & $28 \%$ & $24 \%$ \\
\hline CCS & $0 \%$ & - & - & - & $0 \%$ & $8 \%$ & $2 \%$ & $0 \%$ & $1 \%$ & $3 \%$ \\
\hline
\end{tabular}

Global coal deployment is projected to grow modestly through 2040, with much of the expansion coming in developing countries. Much of the coal-fired capacity increase is expected in supercritical and advanced coal technologies. Source: IEA $2015^{205}$. 


\section{Natural Gas}

\subsection{Technologies}

The main technologies for natural gas-fired electricity generation are CTs (commonly referred to as "simple cycles") and CCs (commonly referred to as "natural gas combined cycles," or NGCCs), which integrate a CT with an ST bottoming cycle. Both CT and CC units can be and are run on secondary fuels such as fuel oil, distillate, and other fuels, allowing for dual-fired back-up capabilities; however, due to the current low price of natural gas, this is the fuel of choice for CTs and CCs in the electric sector for most regions of the country. On a total heating value basis, the price of natural gas has fallen below the cost of coal in some regions.

A CT is comprised of three main sections: the compressor, the combustor, and the expander. The compressor compresses incoming air to high pressure and feeds it to the combustor. Then, natural gas (or another fuel) is injected into the combustion chamber and combusted to produce a high-temperature and high-pressure gas stream. This gas stream is then expanded through the expander section that is linked to a generator to produce electricity ${ }^{206}$.

$\mathrm{CC}$ generators use exhaust heat from a CT to generate steam to run a secondary ST generator. After the air has expanded through the primary CT, the combustion gas remains hot $\left(750-930^{\circ} \mathrm{F}\right)$ and can generate steam to power a ST. Generally a CC produces two-thirds of its power from the $\mathrm{CT}$ and one-third from the ST. Use of a regenerator is another option where the still hot exhaust gas is used to partly preheat the compressed gas before it enters to the combustor. Similarly, advanced ST designs for converting hot gas and steam into kinetic energy are increasing the efficiency of power production. The combination of these advancements has increased the overall efficiency of CC to around 60 percent lower heating value, while older CC generally achieve at least 50-55 percent lower heating value efficiency.

Natural gas is also burned in standard boiler packages, where natural gas is combusted to create steam, which is then passed through a turbine to create rotational energy for the generator. This is often the case for combined heat and power systems, and coal-fired power plants that have been converted to gas-fired units. However, due to competition with CCs, older natural gas STs have recently been retired from service in significant quantities. In some instances, low gas prices have also made gas-fired boilers less expensive to operate than coal-fired boilers.

CCS can also be applied to natural gas-fired generators, although minor differences exist in capturing the $\mathrm{CO}_{2}$ from the flue gas, primarily due to the lower $\mathrm{CO}_{2}$ concentrations. These differences go beyond the scope of this report; nevertheless, many of the postcombustion technologies under development by DOE for coal may be applicable to CCS for natural gasfueled plants.

Natural gas can also be used in an internal combustion engine, typically for small-scale applications like residential back-up generation or for support of isolated power grids. These engines can also be linked together to provide significant ancillary services for grid applications, such as the Plains End plant in Jefferson County, Colorado, which helps integrate increasingly large amounts of wind power there. Natural gas may also be used in distributed generation-scale $(1 \mathrm{MW}+)$ fuel cells, such as certain solid oxide or molten carbonate fuel cells. A 59 MW molten carbonate fuel cell plant composed of twenty-one $2.8 \mathrm{MW}$ units began operation in South 
Korea in $2014^{207}$. Finally, natural gas is also one feedstock for hydrogen production by a process known as methane steam reforming. This hydrogen can be used to generate electricity in proton exchange membrane fuel cells. Appendix A has additional information on natural gas generation technologies and issues.

\subsection{Operational Attributes and Fleet Characteristics}

Electricity generation from natural gas has steadily increased from $45 \mathrm{TWh}$ in 1950 (12 percent of total generation) to 1,335 TWh and 33 percent of total generation in 2015 (Figure 6-1). In 2006, natural gas became the second largest source for electricity generation in the United States - surpassing nuclear power - and continued to expand in 2015. Natural gas-fired generation exceeded that of coal for 7 of the 12 months of 2015; this was the first time ever that monthly natural gas-fired generation was greater than coal ${ }^{208}$.

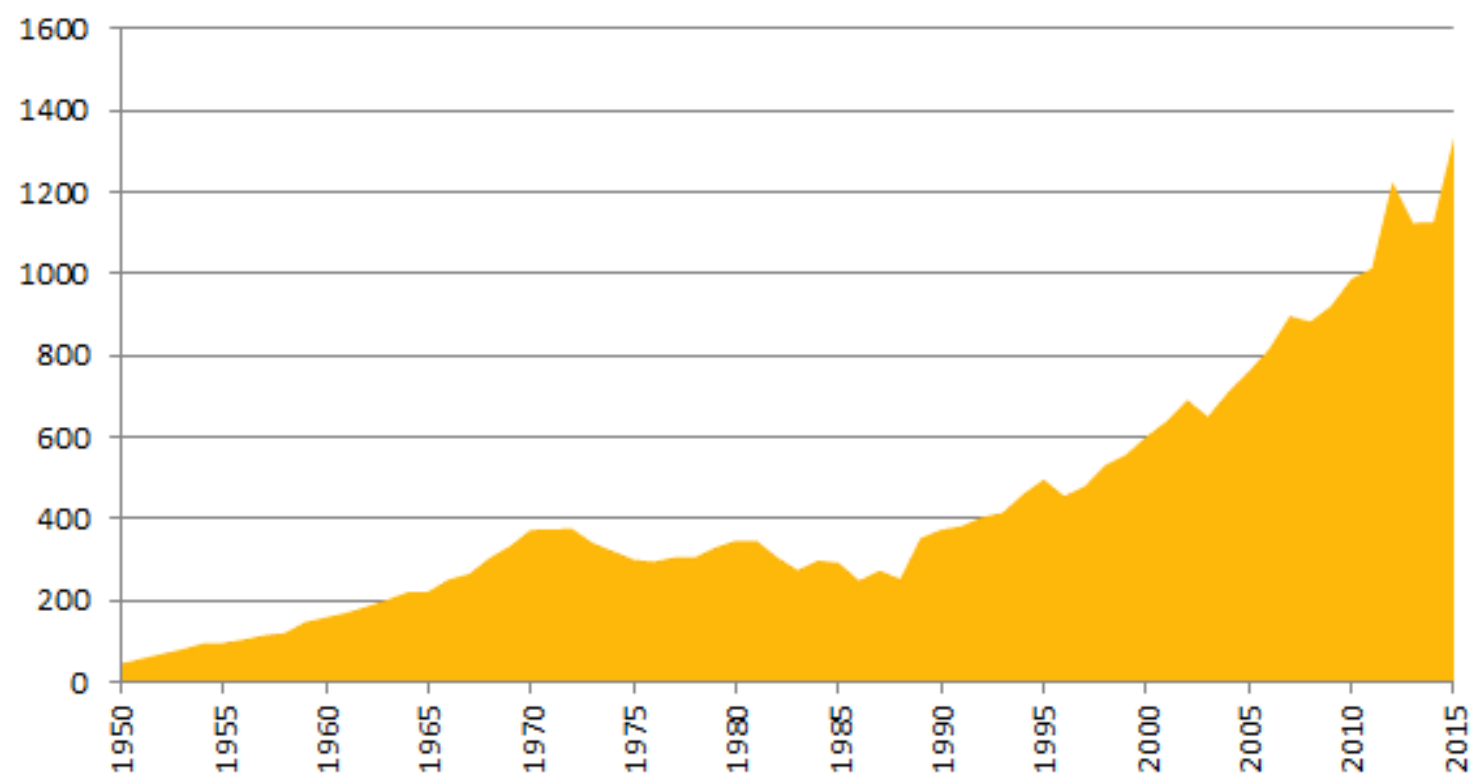

Figure 6-1. U.S natural gas generation (TWh), 1950-2015

Natural gas generation has grown nearly continuously since the late $1980 \mathrm{~s}$ - well before the shale gas revolution started in the mid-2000s. Source: EIA $2016^{209}$.

Figure 6-2 shows shares of natural gas installed capacity and generation by technology type. While generation is dominated by CC plants, capacity is more evenly distributed. 


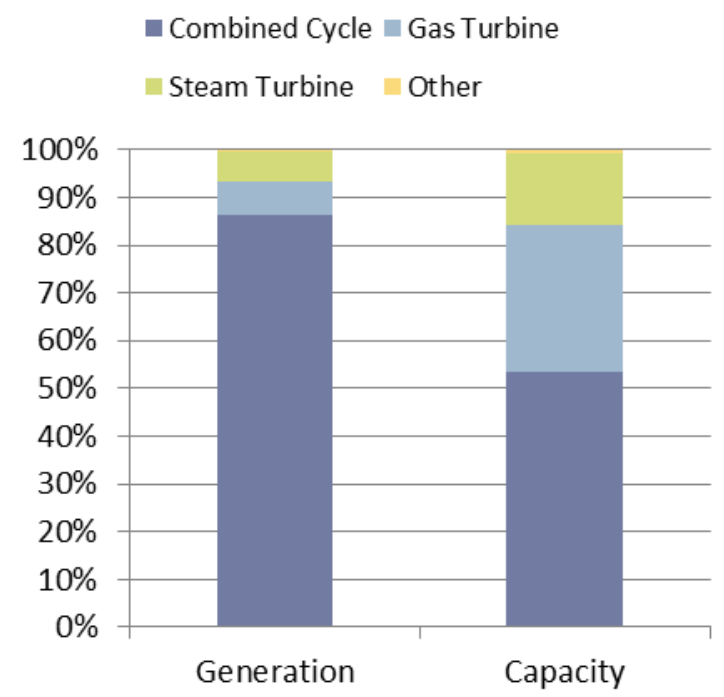

Figure 6-2. Share of U.S. operating natural gas-fired capacity and generation by technology type, 2014

While NGCC plants only make up about 55 percent of capacity, they make up about 85 percent of generation, indicating their high dispatch rate. Conversely, gas turbines make up 30 percent of capacity but less than 10 percent of generation because they are used primarily for meeting peak load. Sources: EIA $2016^{210}$.

Natural gas CCs and CTs have significantly different capacity factors, due primarily to operating characteristics and costs, which dictate their roles in dispatch. CTs are less efficient and therefore have higher operating costs and emissions than CC units. However, CTs short startup times and fast ramp rates make them indispensable for maintaining grid reliability, and their low capital costs make them well suited to use at low annual capacity factors. Thus, natural gas CT units contribute primarily to peak load and as such only need to be operated a few hours out of the year. NGCC plants retain some of the flexible characteristics of NGCTs but operate at a higher efficiency and, therefore, lower cost. Consequently, these units dispatch more frequently than CTs and are often used for baseload power. Until recent sustained low natural gas prices, however, most NGCC units were utilized for intermediate and peak loads, rather than baseload.

CTs can quickly start up and shut down, as well as ramp their outputs without major reliability or maintenance concerns. This flexibility makes CTs useful in complementing variable generation, such as wind and solar, because it allows for load following. NGCCs retain some of the flexibility characteristics of NGCTs, but flexible operation comes at a cost: reduced efficiency, higher marginal emissions, and increased wear and tear on the equipment, increasing maintenance $\operatorname{costs}^{211}$. Vendors now offer NGCC units that are specifically designed for flexible operation. While these units can reduce the maintenance impacts (in particular), they cost up to 30 percent more than the standard commercial offerings ${ }^{212}$.

Natural gas single-cycle turbines, in particular, are viewed as important for reliability purposes, with their fast startup times (as little as 7 to 11 minutes from cold startup to 100 percent output), fast ramping capability, and reduced propensity to cycling damage (as they have no steam cycle $)^{213}$. CC turbines also add flexibility to the system because of their easy ramp up and turn down capabilities, but the steam cycle can result in slightly reduced ramp rates and longer startup 
times from cold start to full output, depending on the system ${ }^{214}$. Both types of generation are complementary to systems that have high proportions of variable renewable energy generation. In contrast, coal-fired units ramp on the order of hours, and doing so incurs increased O\&M costs. It is worth noting that both coal-fired and nuclear generation technologies are also moving in the direction of increasingly flexible operation; however, they are unlikely to achieve the performance of single-cycle turbines without substantial advances. During low-load operation times, simple-cycle gas turbines experience a much more substantial efficiency penalty than coal units.

The capacity factors over time for each technology are shown below in Figure 6-3. The maps in Figures 6-4 and 6-5 show the increased use of NGCC generators over the 2010-2014 timeframe. The maps also indicate that some states rely on CTs more regularly than other locations, most notably Texas, Louisiana, Wyoming, New Hampshire, Maine, and Rhode Island all have CT capacity factors greater than 20 percent.

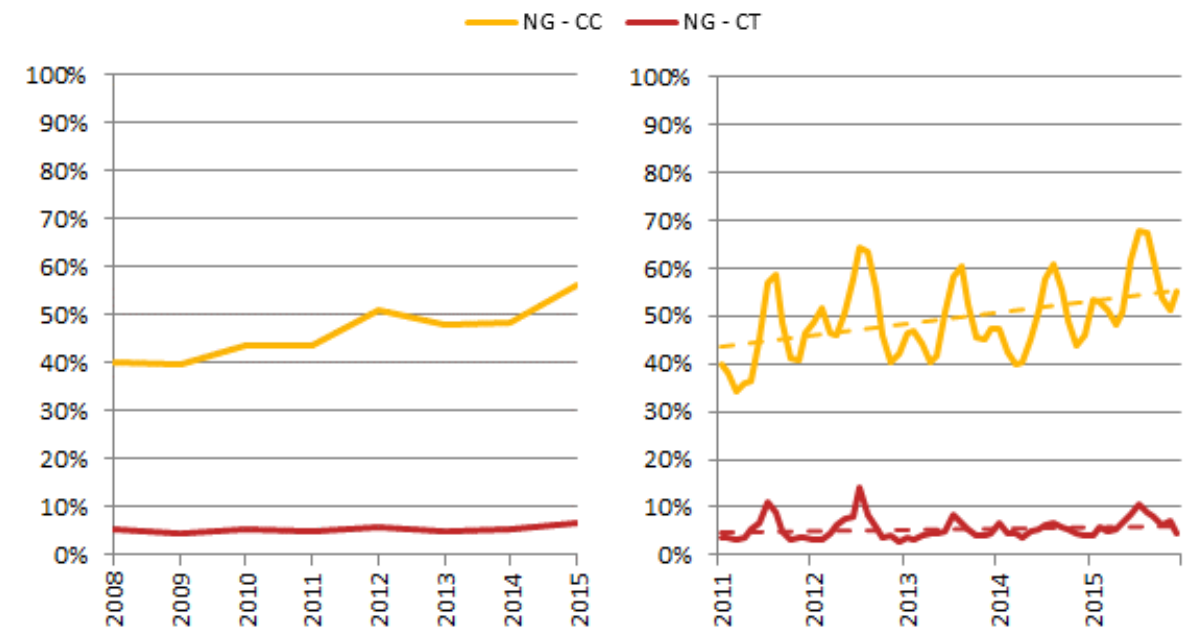

Figure 6-3. U.S. average annual and monthly natural gas generator capacity factors

NGCC capacity factors have increased over time due to low-priced natural gas and retirements of older coal plants. CTs still provide peaking needs, leading to lower capacity factors. Source: SNL $2015^{215}$. 


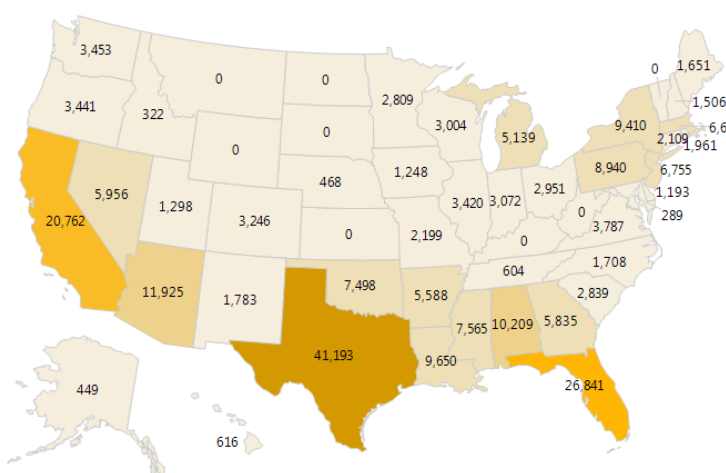

Capacity (MW) 2010

$5.00010 .00015,00020.00025 .00030 .00035,00040,00045.00050,000$

2014

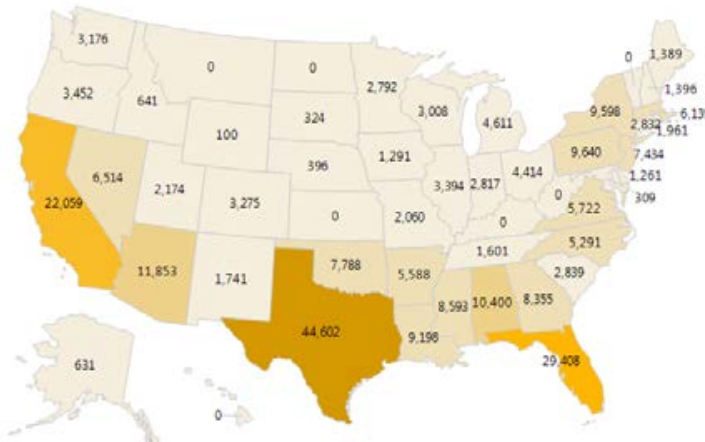

Copscity (Mm) 201

5000100001500020000250003000035000400004500050000
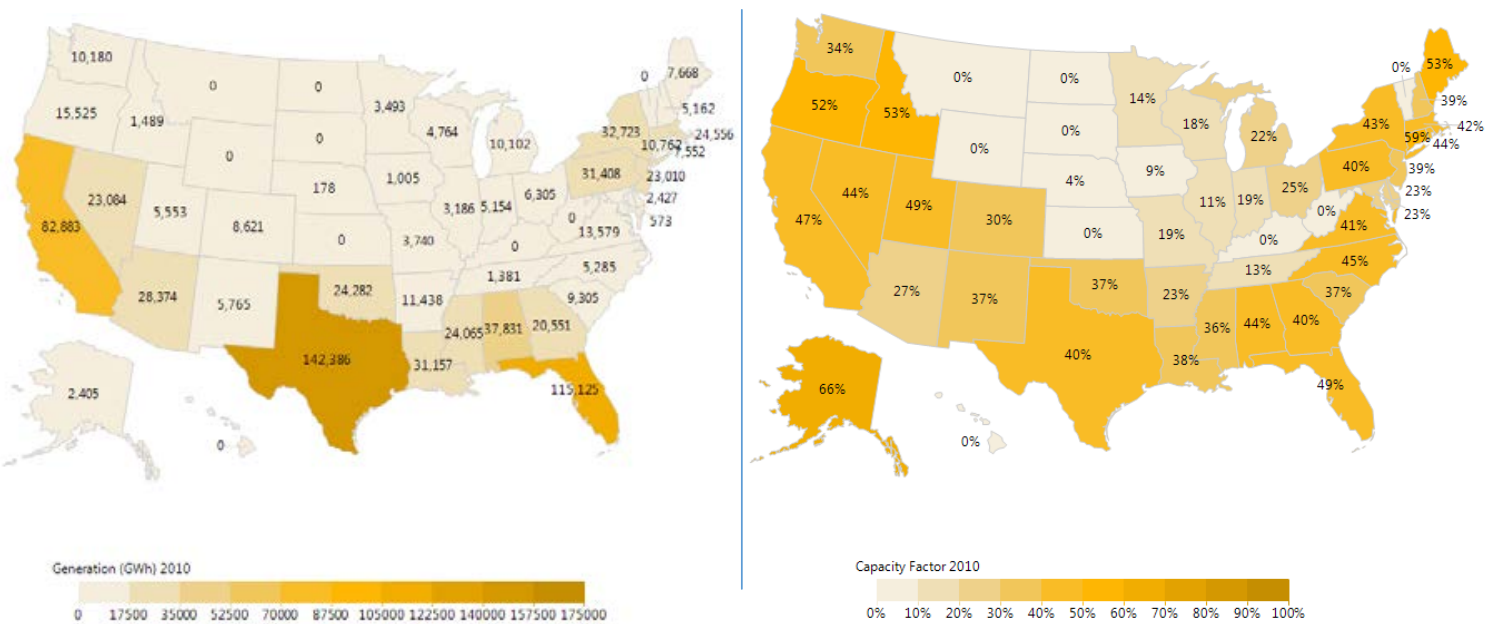

$0 \% \quad 10 \% \quad 20 \% \quad 30 \% \quad 40 \% \quad 50 \% \quad 60 \% \quad 70 \% \quad 80 \% \quad 90 \% \quad 100 \%$
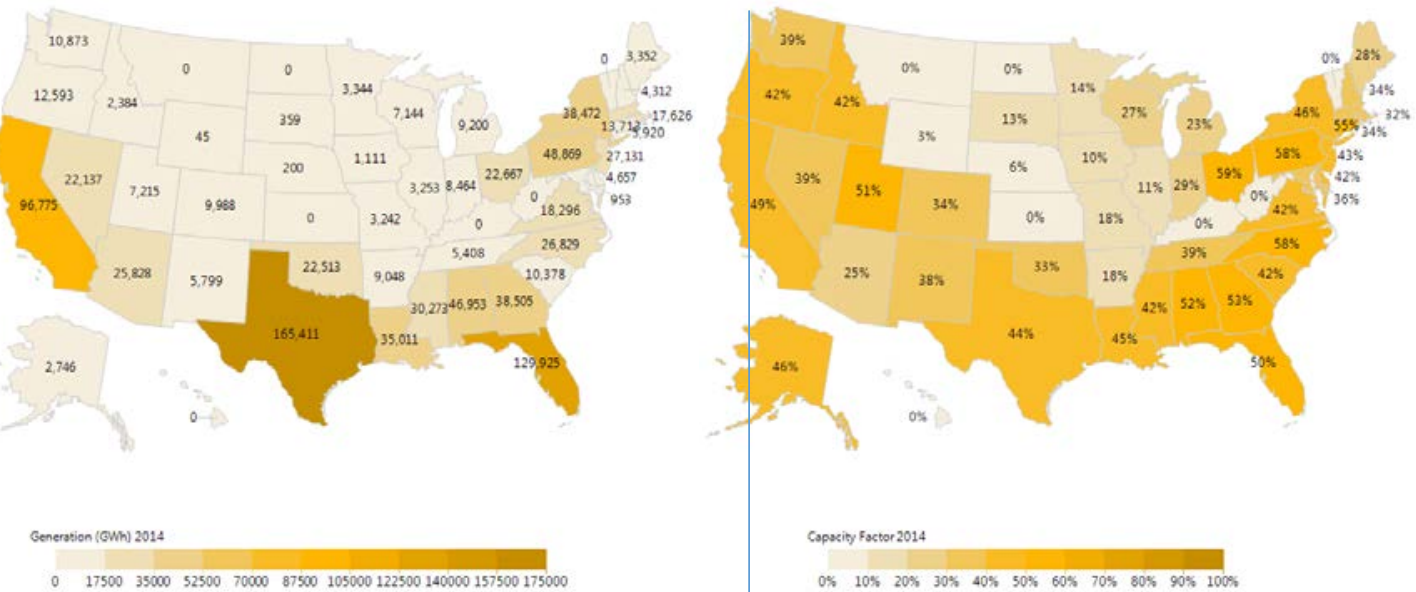

Figure 6-4. Natural gas CC capacity (left), generation (middle), and capacity factor (right) by state. Top: 2010; bottom: 2014.

Capacity, generation, and capacity factor for natural gas CCs all generally increased across the U.S. from 2010 to 2014. Source: EIA $2016^{216}$. 


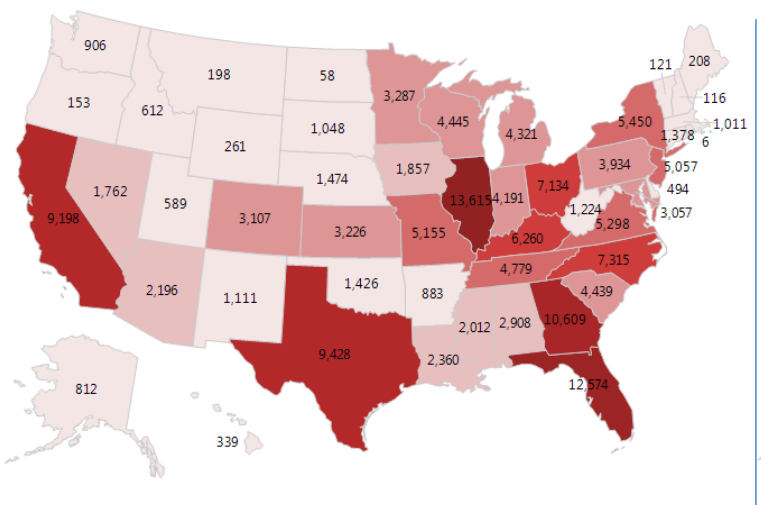

Capacity (MW) 2010

o $1,500 \quad 3,000 \quad 4,500 \quad 6,000 \quad 75009000010500120001350015000$

2014

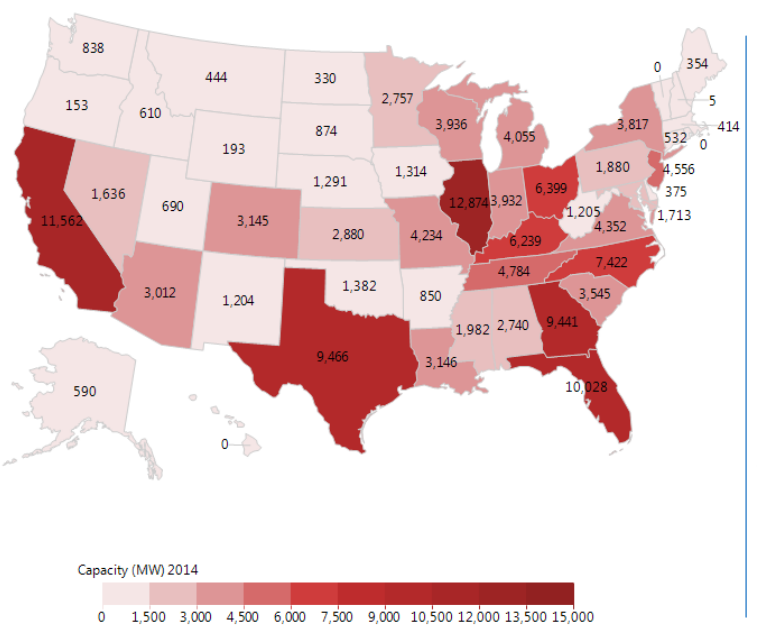

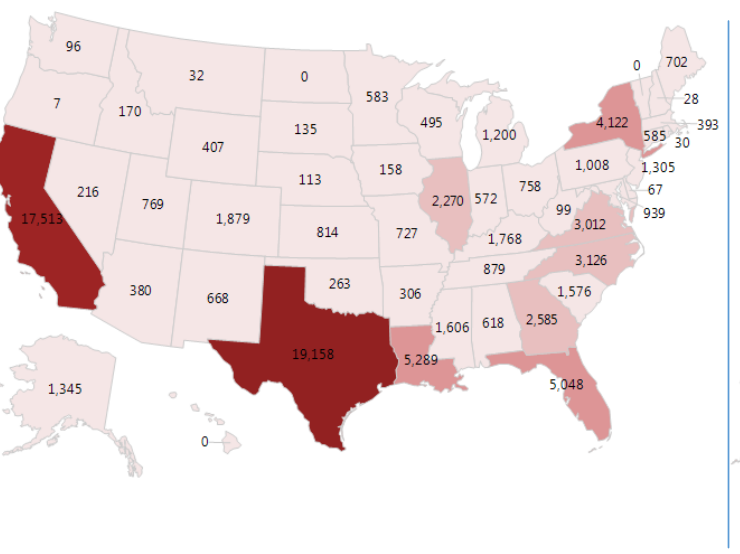

Generation (GWh) 2010

2000400060008000100001200014000160001800020000

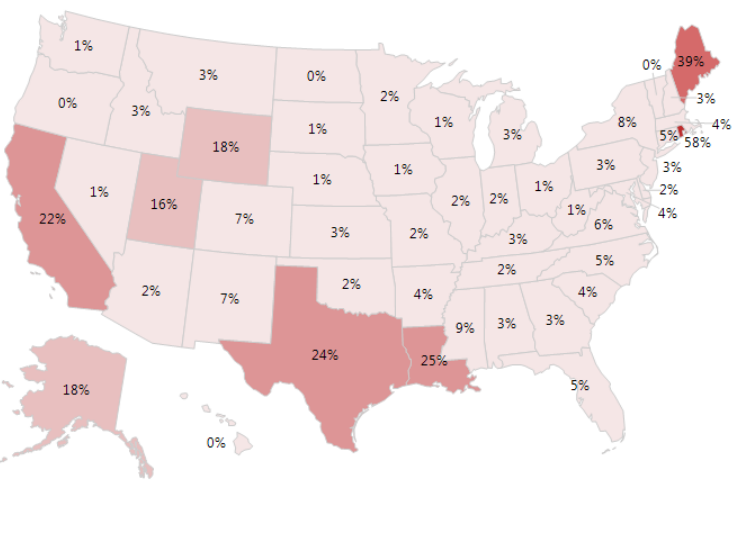

Capacity Factor 2010

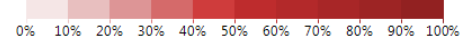

Figure 6-5. Natural gas CT capacity (left), generation (middle), and capacity factor (right) by state. Top: 2010; bottom: 2014.

Capacity, generation, and capacity factor from natural gas CTs varied regionally, with a few states-Texas, Louisiana, Wyoming, New Hampshire, Maine, and Rhode Island —relying more heavily on this technology (>20\% capacity factor) from 2010 to 2014. Source: EIA 2016. 
Figure 6-6 shows the range of ages in the entire U.S. natural gas generation fleet. There is not much regional differentiation, with the exception of NYISO in which the average age for NGCCs is 28 years $^{217}$. The average expected lifetime for both CTs and NGCCs is 55 years, depending on the modeling source and equipment manufacturer ${ }^{218}$; however, maintenance programs could help extend the life of many plants.

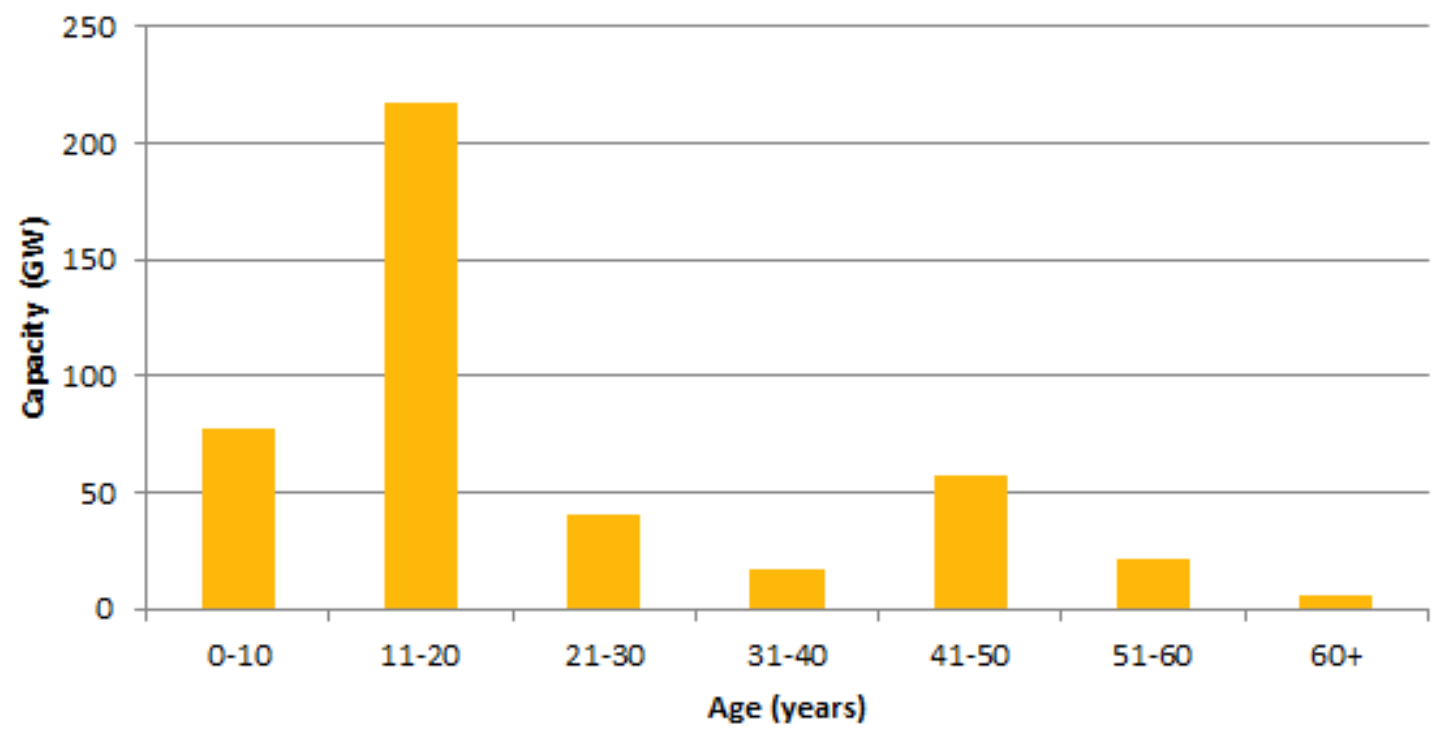

Figure 6-6. Age profile of U.S. natural gas generation fleet, 2014

A majority of natural gas generation capacity has been installed in the past 20 years, so large scale overhauls will not be required over the near to mid-term. Source: SNL $2015^{219}$.

The average heat rate for the fleet of NGCC plants has remained steady since 2007, as shown in Figure 6-7. For gas-fired CTs, heat rate has declined modestly. As a result of increased deployment and higher capacity factors of NGCC plants, the national average heat rate for natural gas plants has declined significantly since 2003 (Figure 6-7). 


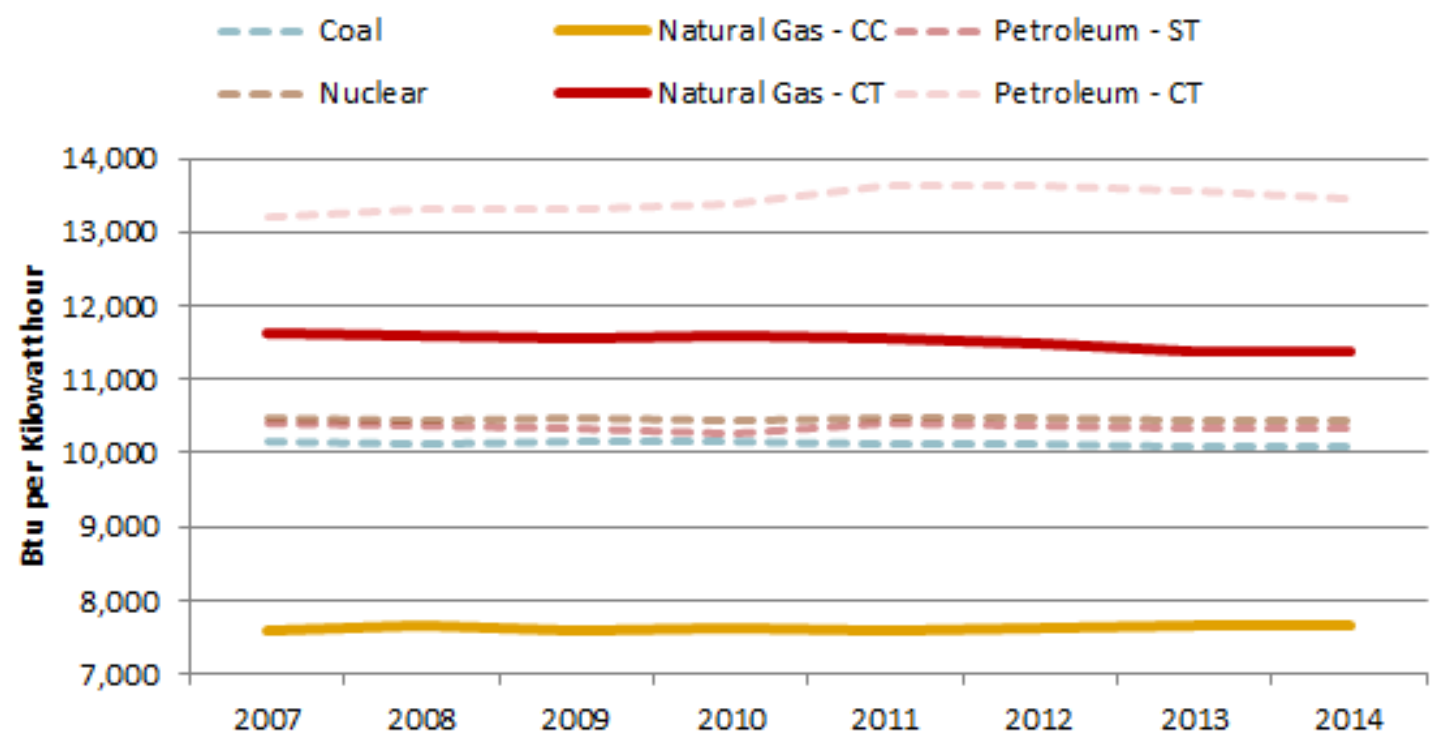

Figure 6-7. Heat rates for fossil generators (BTU/kWh), 2007-2014

Actual plant heat rates depend on a number of factors, including fuel quality; specific plant design and operating conditions; site-specific factors, including atmospheric conditions and the temperature of available cooling water, etc. Source: EIA $2015^{220}$.

\subsection{Technology Costs}

The LCOE for natural gas CT units and for NGCC units with and without CCS are shown in Table 6-1. LCOE for natural gas is highly dependent on fuel costs, which are expected to increase over time. The range of values for the LCOE of NGCCs is lower than for CTs, even when CCS is added to NGCC units. The LCOE of NGCC with CCS is roughly commensurate with that of nuclear as a low- or no-carbon dispatchable technology. The LCOE of NGCC generators (without CCS) also overlaps with land-based wind, although it is difficult to compare between dispatchable and nondispatchable technologies.

Table 6-1. LCOE Natural Gas Generators (2013\$/MWh)

\begin{tabular}{|l|l|l|l|l|l|l|}
\hline & \multicolumn{3}{|l|}{ EIA } & NETL & Lazard \\
\hline Technology & Low & High & Low & High & Low & High \\
\hline Gas - CC & 36.53 & 105.54 & 37.23 & 74.95 & 36.77 & 81.51 \\
\hline $\begin{array}{l}\text { Gas - CC - } \\
\text { CCS }\end{array}$ & 55.34 & 171.21 & 56.74 & 123.14 & - & - \\
\hline Gas - CT & 65.24 & 238.49 & - & - & 66.70 & 219.30 \\
\hline
\end{tabular}

Current ranges of natural gas technology LCOEs using cost assumptions from three sources: NETL 2015; EIA 2015; Lazard $2015^{221}$. See Appendix B for more information on LCOE calculations. 


\subsection{Fuel/Resource}

Currently, the vast majority of natural gas is transported through pipelines in an extensive network that spans most of the continental United States. Production from a series of wells is transported through a network of pipelines to natural gas processing facilities, where the gas is stripped of contaminants, including value-added products such as natural gas liquids, as well as waste like $\mathrm{CO}_{2}$ and sulfur compounds, and sent to the transmission pipeline system ${ }^{222}$. A map of the intrastate and interstate pipelines is shown in Figure 6-8.

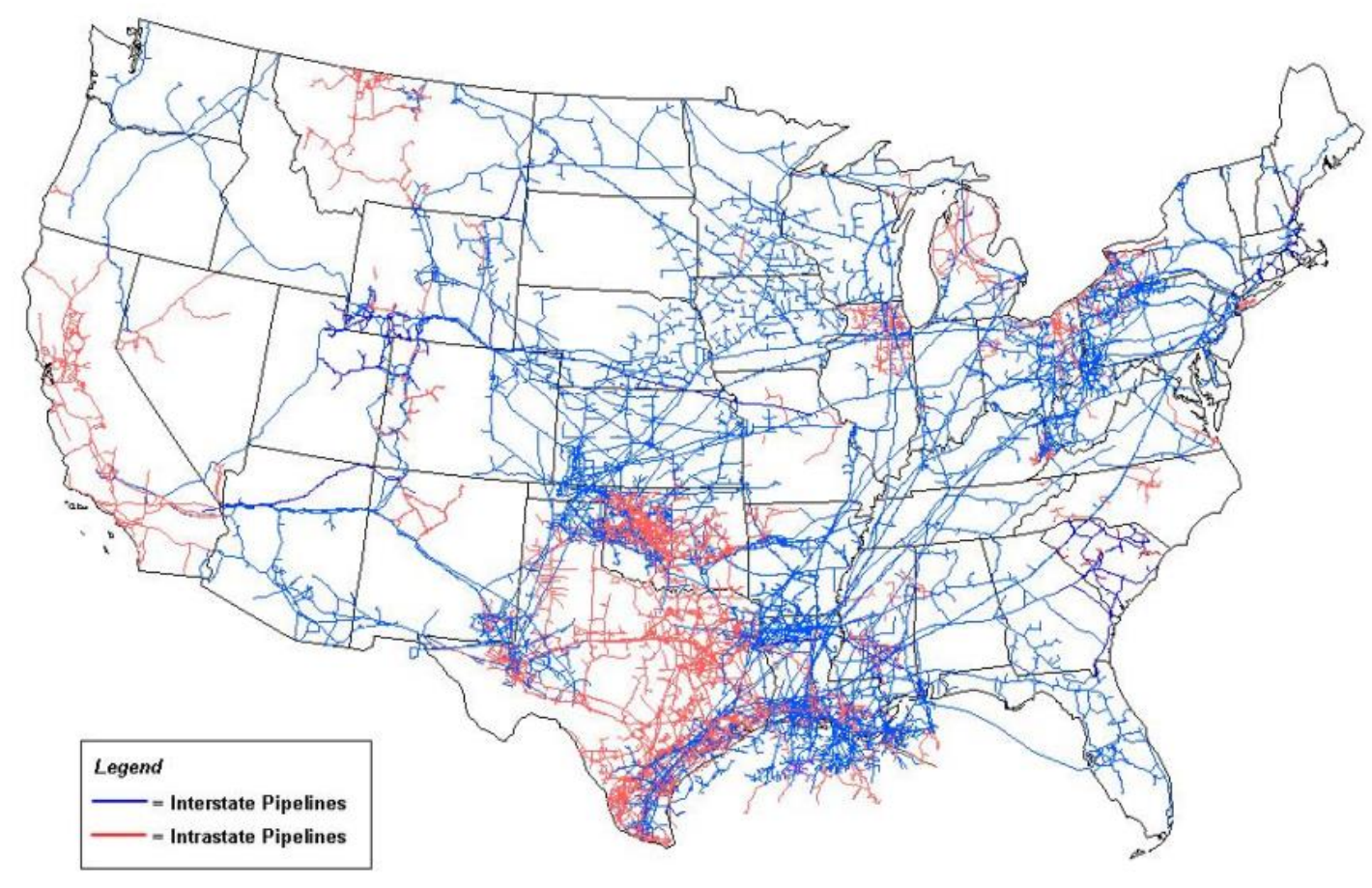

Source: Energy Information Administration, Office of Oil \& Gas, Natural Gas Division, Gas Transportation Information System

Figure 6-8. U.S. natural gas pipeline network, 2009

Natural gas pipelines are required to transport natural gas from production facilities to end-use locations. Pipeline networks are more concentrated in high production areas (e.g., south Texas and Pennsylvania). Source: EIA $2009^{223}$.

\subsubsection{Natural Gas Price History}

Natural gas prices were generally coupled with oil prices until roughly 2009, as natural gas was generally a byproduct of oil production until the ${ }^{224}$. Since then, the price of natural gas has become largely disconnected from oil due primarily to production from gas-only wells. Further, while oil is a global commodity, natural gas is priced locally given the high costs and energy losses involved in shipping natural gas as liquefied natural gas (liquefied natural gas adds a variable cost premium to the price of local natural gas). The Henry Hub price of natural gas since 1997 is shown in Figure 6-9. 


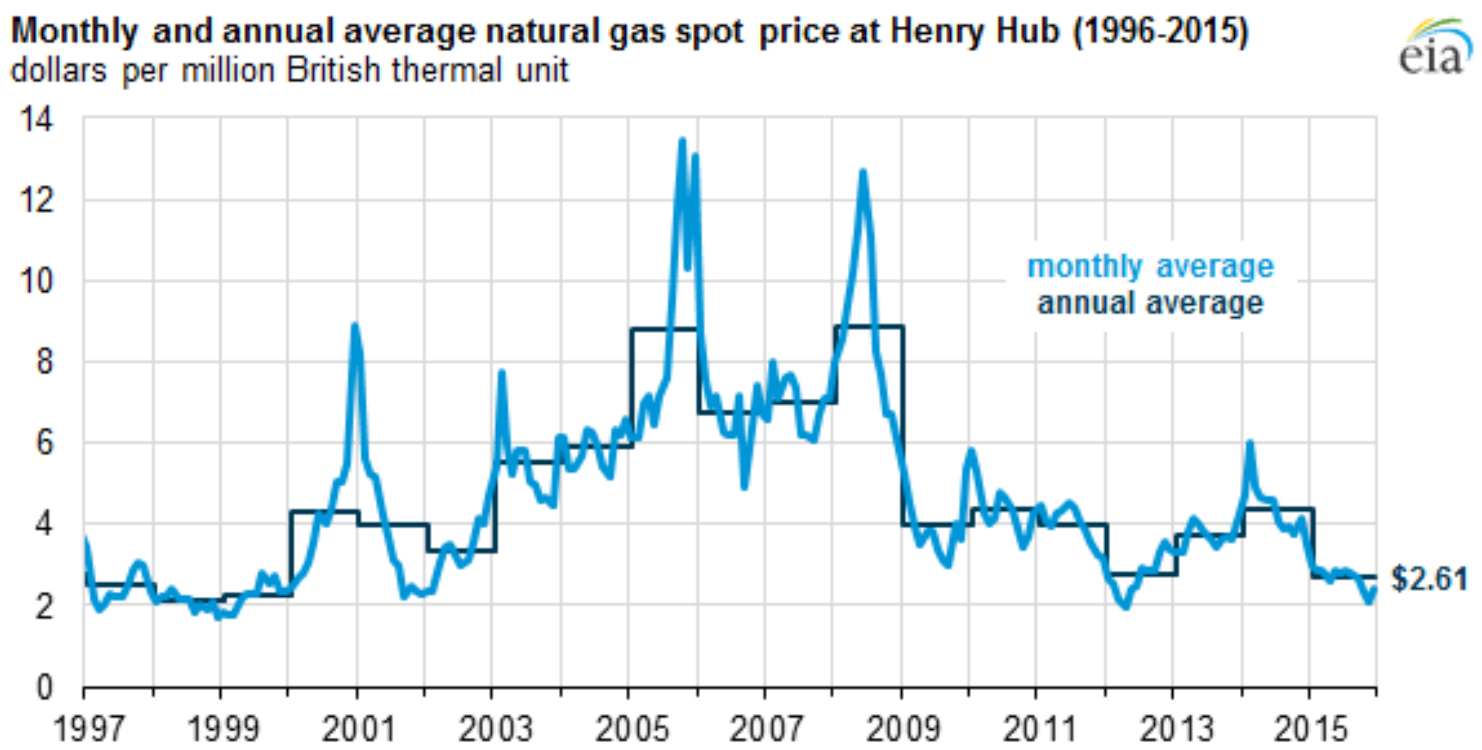

Figure 6-9. Henry Hub natural gas spot price (\$/MMBtu), 1997-2016

Henry Hub natural gas prices were relatively high and volatile through mid-2008, but they have become lower and less volatile since then as unconventional gas output surged. Source: EIA $2016^{225}$.

\subsection{Environmental Impacts}

\subsubsection{Upstream}

Natural gas is extracted from underground by drilling wells into subsurface reservoirs. With the shale revolution and widespread use of hydraulic fracturing, there have been public concerns in the United States of environmental degradation and disruption from the production of natural gas. The shale revolution has caused some of these concerns to become exacerbated at a regional level in areas of large shale development; typically, the public is more worried about hydraulic fracturing and natural gas production if they do not have a history of living near production sites $^{226}$. These concerns include, but are not limited to ${ }^{227}$ :

- Water withdrawals for hydraulic fracturing competing with other water uses (agriculture, municipal, etc.)

- Spills, leaks, and explosions from natural gas and produced water

- Produced water spills on the surface during onsite storage, handling, and disposal

- Underground water aquifer contamination by methane or produced water through wellbores

- Methane leakage from the wellhead and at gathering facilities

- Air quality impacts from diesel generators to run drilling rigs and fracturing equipment

- Induced seismicity.

The main source of waste during natural gas production is produced water (a byproduct of production). Produced water generally contains constituents that can be harmful to human health, if exposed in large enough concentrations. This waste is generally disposed of through injection 
into Underground Injection Control wells, treatment at a centralized waste facility, beneficial reuse in other industries or for other fracturing jobs, or disposal in evaporation ponds ${ }^{228}$. These ponds are normally lined to prevent infiltration of the surrounding ground surface. There are potential concerns from inadequate treatment and disposal of produced water leading to environmental contamination along with induced seismicity from injection into underground injection control wells. Induced earthquakes in Oklahoma, for example, coincide with the injection of saltwater (primarily produced water) into underground formations but not from the hydraulic fracturing process itself ${ }^{229}$.

\subsubsection{Emissions and Environmental}

A new NGCC plant emits roughly 50 to 60 percent less burner-tip $\mathrm{CO}_{2}$ compared to a typical coal-fired power plant on a per MWh basis ${ }^{230}$. There are four reasons for the lower $\mathrm{CO}_{2}$ emissions: (1) the specific heat of combustion is higher for natural gas than for coal on a carbon basis (more heat generated per ton of carbon in the fuel, and therefore more heat per ton of $\mathrm{CO}_{2}$ generated); (2) natural gas has a higher atomic ratio of hydrogen; (3) the efficiency of NGCCs are much greater than coal; and (4) fuel feed systems and off-gas cleanup are simpler and use much less parasitic power. The case for natural gas CTs is less clear because about two-thirds of the thermal energy created by combustion of natural gas is lost with discharge of heat from the CT to its surroundings.

There are two measures that can be used to reduce $\mathrm{NO}_{\mathrm{x}}$ emissions from gas-fired generation The first is a dry low $\mathrm{NO}_{\mathrm{x}}$ burner. The second is selective catalytic reduction, which uses ammonia and a catalyst to reduce $\mathrm{NO}_{\mathrm{x}}$ emissions, similar to coal plants ${ }^{231}$.

Improved understanding of a natural gas generator's life-cycle GHG emissions is currently a subject of robust research interest, as methane leakage associated with natural gas production and delivery is not well characterized ${ }^{232}$. This is largely because up to 30 percent of life-cycle emissions are a result of fuel provision, including fugitive emission and gas used to power equipment for gas production and transportation. Liquefying natural gas contributes further emissions, given the energy intensity of the liquefaction process ${ }^{233}$. However, most estimates indicate natural gas-fired electricity generation produces lower $\mathrm{CO}_{2}$-equivalent emissions than other fossil energy sources. The majority of life-cycle analyses conducted to date indicate that natural gas-fired power plants enjoy a roughly 50 percent advantage over coal in life-cycle GHG emissions, though research points to the need for better data sets and new methodologies to determine the actual life-cycle emissions from natural gas-fired generation ${ }^{234}$.

\subsection{Constraints}

Nationally, natural gas consumption for power generation has increased over 60 percent since 2005 , and $\mathrm{CO}_{2}$ emission regulations may further increase its use ${ }^{235}$. Natural gas generators provide baseload power as well as ramping resources to meet the needs of the electric system. Natural gas is well suited to provide increased system flexibility as variable renewable generation is added to the grid.

Several market and policy challenges also exist for natural gas-fired power plants. First, hydraulic fracturing (fracking) has polarized the public in some regions of the country at the state and local levels ${ }^{236}$, drawing opposition to gas-related developments. Both gas production 
operations and new gas transportation pipelines have met with public opposition, and the perceived risk associated with natural gas fracking, especially ground water contamination related to the treatment of produced waters at the surface and induced seismicity due to waste water injection, has the potential to derail new development in some regions. A 2015 EPA report cited no "widespread, systemic impacts on drinking water resources in the US," though the report also admits several key limitations to the study, including lack of baseline data for a majority of wells ${ }^{237}$. Oklahoma saw an approximate doubling of wastewater injections into saltwater aquifers between 1997 and 2014, and also experienced a 200-fold increase in magnitude 3 and 4 earthquakes since $2009^{238}$. Researchers from Stanford and Southern Methodist University who study induced seismicity say that a lag between increasing injections and increased seismic activity is expected, as it takes time for pressure to build up at appropriate depths and propagate to nearby faults. Thus a causal relationship between seismicity and natural gas production is possible ${ }^{239}$. In New York, the governor has banned hydraulic fracturing until environmental concerns are better understood and can be controlled.

Second, some regions of the country could become overly dependent on natural gas-fired generation $^{240}$. Risks associated with gas-fired generation dependence include electric system reliability and/or financial impacts should there be a disruption in natural gas supply or a significant surge in natural gas prices. Reliability risks to the electric system could also occur as a result of a loss or lack of a nearby high deliverability facility such as a pipeline or storage facility, which could lead to load curtailment at existing facilities. The recent leak at the Aliso Canyon gas storage facility provides one example: loss of the facility led to concerns about to disruptions in electric supply times of local peak demands to the system ${ }^{241}$. Electric system reliability could also be impacted by pipeline congestion, particularly during the heating season. Modeling projections by the Eastern Interconnection Planning Collaborative indicates that in the winters of 2018 and 2023, over 90 percent of natural gas-fired generation in regions of NYISO and ISO - New England could be affected by gas system constraints, accounting for 27 percent and 29 percent of total anticipated generation, respectively, across the scenarios examined ${ }^{242}$. These issues are compounded by some natural gas-fired generators not maintaining firm primary gas transportation contracts with pipeline companies, meaning that they are more likely to see service curtailment in situations of high gas system utilization, such as during periods of cold weather when residential gas demand rises.

Third, as natural gas use in power generation increases, aligning gas and electric market and dispatch schedules will become more important. This issue was highlighted during extended cold weather experienced during the winter of 2013-2014. Pennsylvania, New Jersey, and Maryland Interconnection LLC (PJM) experienced the prolonged cold weather of January 17-29, 2014, and pointed out that the timing differences between the gas and electric markets forced generators to commit to buying gas before knowing whether their units would be scheduled to operate $^{243}$. Following extensive stakeholder engagement that was ongoing at the time of this situation in PJM, FERC issued Order No. 809 adopting the North American Energy Standards Board's changed natural gas pipeline nomination schedule that better matches electric dispatch scheduling. The ruling also requires organized electric markets to ensure their day-ahead dispatch schedules better aligned with natural gas pipeline scheduling. While these rules will likely improve reliability for some generators, such as those in the desert Southwest where there is little or no high deliverability storage, the impacts will vary by region, and the rules do not 
address issues related to pipeline congestion. The rule went into effect April 1, 2016, so its impact is not yet fully understood ${ }^{244}$.

Natural gas is dependent on processing facilities to create a standard British thermal unit (Btu) content and to remove contaminants and water. The gas is then compressed and goes into the pipeline transmission network. Processing plant operation is highly dependent on electric power for processing, as well as upstream and downstream constraints. It is also important that capacity at downstream facilities for the natural gas liquids is available, or the plant will shut down. A dramatic increase in shale gas production and reserves has caused natural gas supply to increase, which is heavily tied to the hydraulic fracturing process. With low natural gas prices, the rate of shale production declined in the second half of $2015^{245}$. Also, concerns about the environmental impacts of the fracturing life cycle could potentially impact domestic natural gas supply across the United States.

Several concerns surround making sure pipelines are in place to supply natural gas generation facilities: the time lag in power plant commissioning and pipeline construction, pipeline cost recovery, and size constraints of existing pipelines. There is a time lag of several years from the time a pipeline need is identified to when a new pipeline enters service. By the time a pipeline operator is ready to apply for a certificate from FERC, the demand for additional capacity may already exist. However, it generally takes 1.5 to 3 years for the permitting and construction of a new pipeline after the pipeline operator has decided to move forward with building it. Thus, pipelines may experience constraints before new capacity can be built to meet demand growth. Existing pipeline operators also may have concerns about capital cost recovery. Most shippers currently only want to commit to 10- to15-year contracts, which is not a term sufficient, in and of itself, to repay the capital costs of construction; while shippers generally renew their contracts, the pipeline does not start out with assurance of full cost recovery. In order to receive a permit to build from FERC, a pipeline operator will often prefer to have enough commitments from firm transportation customers to cover the cost of building the pipeline. Moreover, most electric power generators rely on interruptible transmission service, which is more economical than reserving firm capacity, and have not traditionally been among those customers who commit to new pipelines.

Permitting and construction of pipelines can take many years, a fact that and needs to be considered when deciding where to site a new power plant ${ }^{246}$. CTs and NGCCs need to be sited in areas that take into consideration gas transmission and water sources. Long gas transmission lines can increase the capital costs of the project and increase overall costs of delivered power. For NGCCs, cooling water is needed for the condenser of the ST bottoming cycle. NGCCs are considered compact and therefore can be sited close to urban demand centers and will generally not experience problems with transmission. Low emissions and minimal requirements for fuel storage (natural gas liquids) lead to minimal impact on siting procedures, although new generator availability penalty and incentive structures in certain ISOs/RTOs may change this by incentivizing onsite fuel storage. Natural gas-fired plants will also need to be sited near pipeline infrastructure to ensure adequate supply for operation. 


\subsection{Technical RDD\&D}

Much of the Federal RDD\&D being done on advanced energy systems and postcombustion CCS applies to natural gas-fired generation as well as coal-fired generation. Additional fundamental research is supported by DOE focusing on advances in materials, combustion, and simulation that can lead to continued incremental improvements in gas turbine efficiency ${ }^{247}$. The private sector (e.g., GE, Siemens, and EPRI) is also conducting significant RDD\&D on further improving the operational efficiency of CT and NGCC systems.

\subsection{Development and Projected Future Deployment}

Natural gas-fired capacity additions were consistently less than those from coal until 1991, at least partially due to the Industrial Power Plant and Fuel Use Act of 1978, which banned construction of new gas-fired generation until its repeal in 1989. Since the repeal, improvements in gas turbine technology, lower natural gas prices, and environmental regulations led to a massive surge in new CC generating capacity from about 1999 to 2003. Other factors that contributed to this surge were the availability of lower-cost financing, shorter construction lead times, and momentum gained from the experience in construction, which lowered construction costs and lead times to completion (gas plants essentially became 'cookie cutter projects').

While natural gas capacity additions have decreased since their peak, in recent years they have been larger than any other nonrenewable generating source (Figure 6-10).

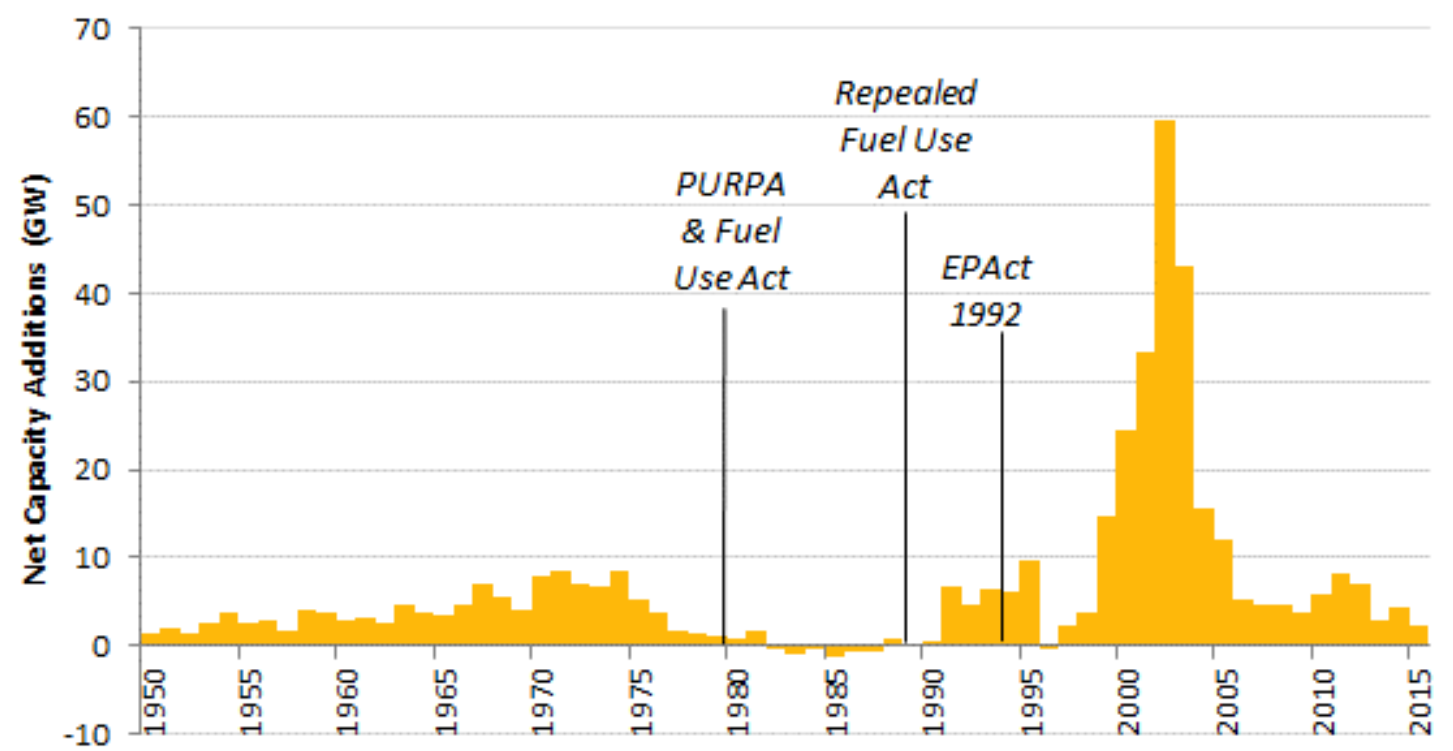

Figure 6-10. Historical annual natural gas capacity additions and retirements, 1950-2015

Annual natural gas capacity additions reached a peak in 2002, likely as a result of improved technology, low gas prices, and Clean Air Act amendments impacting coal generation. Source: EIA 1990 and EIA 2016.

The domestic outlook for NGCC generation is generally strong over the short to mid-term, but varies over the longer term, depending on assumptions about how cost and performance will change for other generation options and what carbon constraints are imposed (Table 6-2). The 
QER 1.2 Base Case sees sustained growth in NGCC generation, which is deployed in this scenario at a higher rate than non-hydro renewables.

Table 6-2. QER 1.2 Base Case Generation (TWh) for CC Plants, 2014-2040

\begin{tabular}{|l|c|c|}
\hline & 2014 Actual & $\begin{array}{c}\text { QER 1.2 Base Case } \\
(2040)\end{array}$ \\
\hline Gas CC Generation & 1,133 & 1919 \\
\hline Gas CC with CCS & 0 & 0 \\
\hline
\end{tabular}

Source: EPSA $2016^{248}$.

In both IEA's New Policies Scenario and Current Policies Scenario, gas generation is projected to nearly double by 2040 , while in the 450 Scenario $^{\mathrm{xxxv}}$, it is projected to soon peak and then begin declining by 2040 (Table 6-3), in turn putting pressure on domestic natural gas producers, natural gas generators, and equipment manufacturers.

Table 6-3. Historical and Projected Global Natural Gas Generation by Scenario Outlook, 2003-2040

\begin{tabular}{|l|c|c|c|c|c|c|c|c|}
\hline IEA Scenario & \multicolumn{2}{|c|}{} & \multicolumn{2}{|c|}{ New Policies } & \multicolumn{2}{|c|}{ Current Policies } & \multicolumn{2}{|c|}{450} \\
\hline $\begin{array}{l}\text { NG Generation } \\
\text { (TWh) }\end{array}$ & $\mathbf{2 0 0 0}$ & $\mathbf{2 0 1 3}$ & $\mathbf{2 0 2 0}$ & $\mathbf{2 0 4 0}$ & $\mathbf{2 0 2 0}$ & $\mathbf{2 0 4 0}$ & $\mathbf{2 0 2 0}$ & $\mathbf{2 0 4 0}$ \\
\hline $\begin{array}{l}\text { Percentage of } \\
\text { Global Total }\end{array}$ & 18 & 22 & 21 & 23 & 21 & 24 & 22 & 16 \\
\hline
\end{tabular}

Source: IEA $2015^{249}$.

\footnotetext{
${ }^{x x x v}$ IEA's scenario assumes new policies that bring about emissions reductions to meet the Intergovernmental Panel on Climate Change goal of $2{ }^{\circ} \mathrm{C}$ global temperature rise, which requires a stabilization of atmospheric GHG concentrations at about 450 parts per million in 2100 . For more details on the exact policies used in the scenario see IEA's WEO 2015.
} 


\section{Nuclear}

\subsection{Technologies}

The most common types of existing nuclear reactors, which use uranium as a primary fuel source, are pressurized water reactors (PWRs) and boiling water reactors (BWRs). Both are commonly referred to as light water reactors (LWRs). In PWRs, water is heated by nuclear fission within the reactor, but it is not allowed to boil due to the pressurization of the system. This water is then run through a heat exchanger, which produces steam that drives a turbine with a traditional steam cycle. A BWR, on the other hand, contains only a single closed system, and water in the reactor is heated to form steam, which drives a turbine before being condensed, pressurized, and reheated. PWRs are able to operate at a higher temperature and pressureleading to higher turbine efficiencies - and are able to separate radiation contamination from the generating equipment. BWRs, on the other hand, are able to achieve higher thermal efficiencies with direct contact, and output is easier to control by adjusting the amount of water entering the reactor.

Another reactor type uses "heavy water" with deuterium atoms, although these are not deployed in the United States. A small number of other reactor types (gas cooled, light water graphite, and fast neutron) are also in operation outside of the United States. Nuclear reactors are called fission $^{\mathrm{xxxvi}}$ reactors since they rely on capturing energy from the breaking apart of uranium atoms.

Nuclear generators typically serve as baseload providers since they perform best, and are most economic, when operating at full capacity. The fleet of nuclear generators in the United States operates at the highest capacity factor compared to other generators and typically delivers power to the grid about 90 percent of the time ${ }^{250}$. LWRs are typically shut down every 18-24 months for refueling. LWRs have some capability to ramp up or down output, and thus follow load, when they are in the early phase of just having been refueled ${ }^{251}$. Research is underway to better understand how nuclear plants, sometimes in combination with renewable energy options, might be operated in a more flexible fashion ${ }^{252}$. Additional information on nuclear generators is available in Appendix A.

\subsection{Operational Attributes and Fleet Characteristics}

In 2015, nuclear generation stood at $797 \mathrm{TWh}$, and its share of total generation was 20 percent, relatively unchanged for the past decade (Figure 7-1). ${ }^{\text {xxxii }}$ In 2015, the fleet-wide capacity factor for nuclear was an estimated 92.2 percent $^{253}$ with 99 reactors, compared to 91.7 percent in 2014 with 100 reactors (Figure 7-2). Nuclear plants' availability factor is very close to their capacity factor at 90 percent $^{254}$. This indicates that nuclear plants generally only shut off for maintenance activities and that forced outages are very rare. While the amount of generation and capacity

\footnotetext{
${ }^{\text {xxxvi }}$ Fusion reactors are an entirely different technology under development that relies on capturing energy from fusing lighter atoms.

xxxvii The last two nuclear generators to enter service in the United States were units 1 and 2 at TVA's Watts Bar Nuclear Plant in 1996 and 2016, respectively. Five generating units have been retired since 2013, while four additional units have announced their intentions to retire before 2020, and other units are evaluating the economic viability of continued operation.
} 
were level across most of the country between 2010 and 2014, Figure 7-3 shows a dramatic drop in capacity for California due to the closing of the San Onofre $2 \& 3$ reactors.

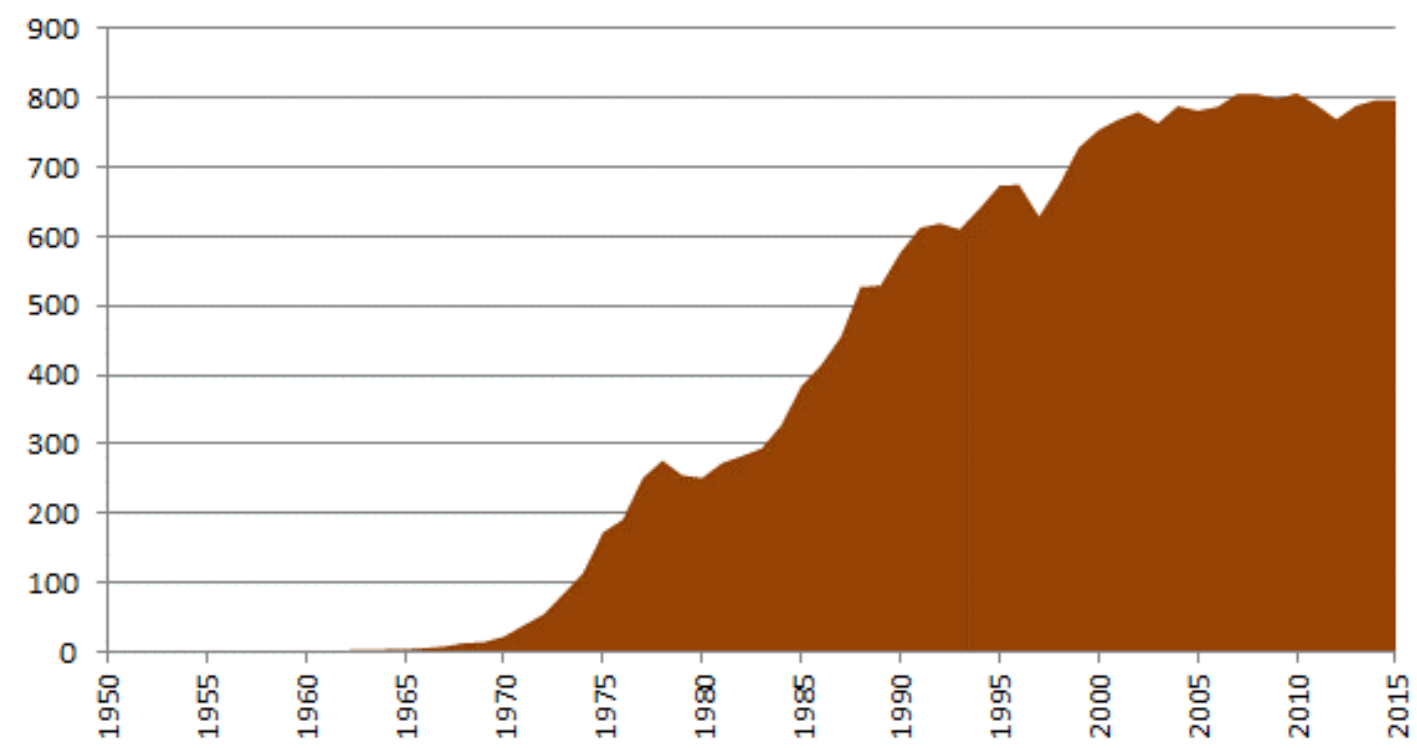

Figure 7-1. U.S nuclear generation (TWh), 1950-2015

Nuclear generation grew rapidly from 1970 to 2000 before stabilizing. Source: EIA $2016^{255}$.
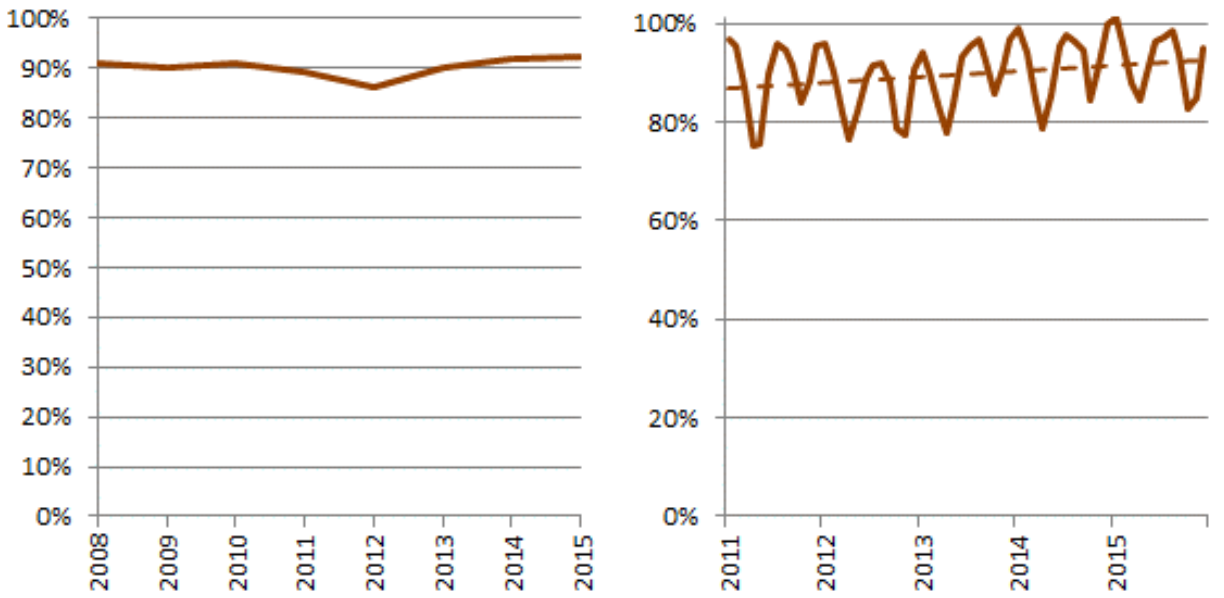

Figure 7-2. U.S. annual and monthly nuclear generator capacity factors

Nuclear capacity factors have remained relatively constant over time due to their ability to operate constantly, except for infrequent refueling operations. Source: SNL 2015. 

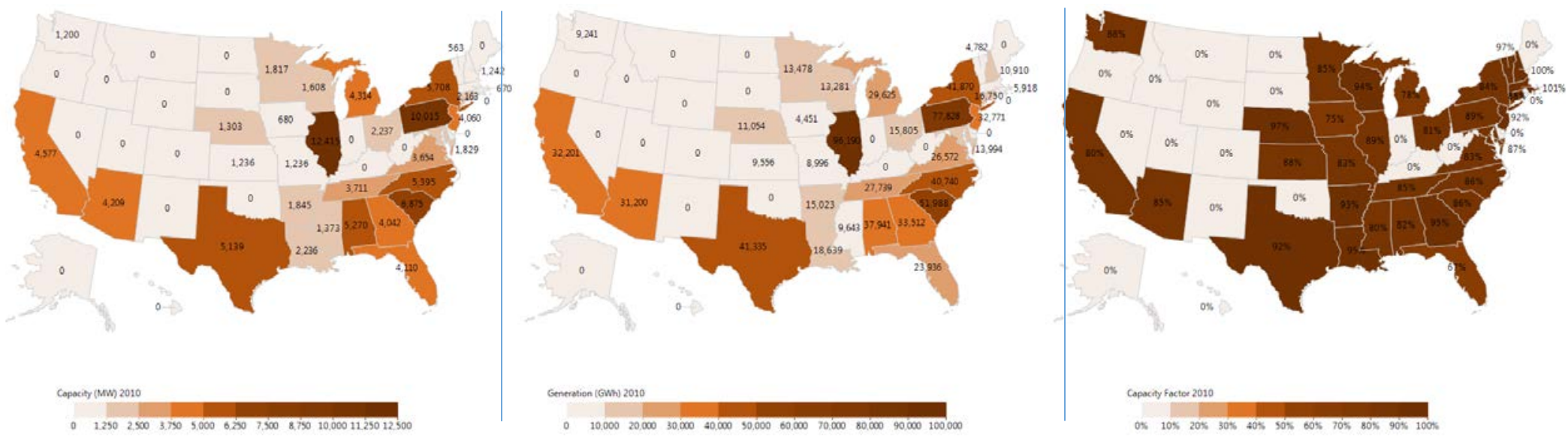

2014
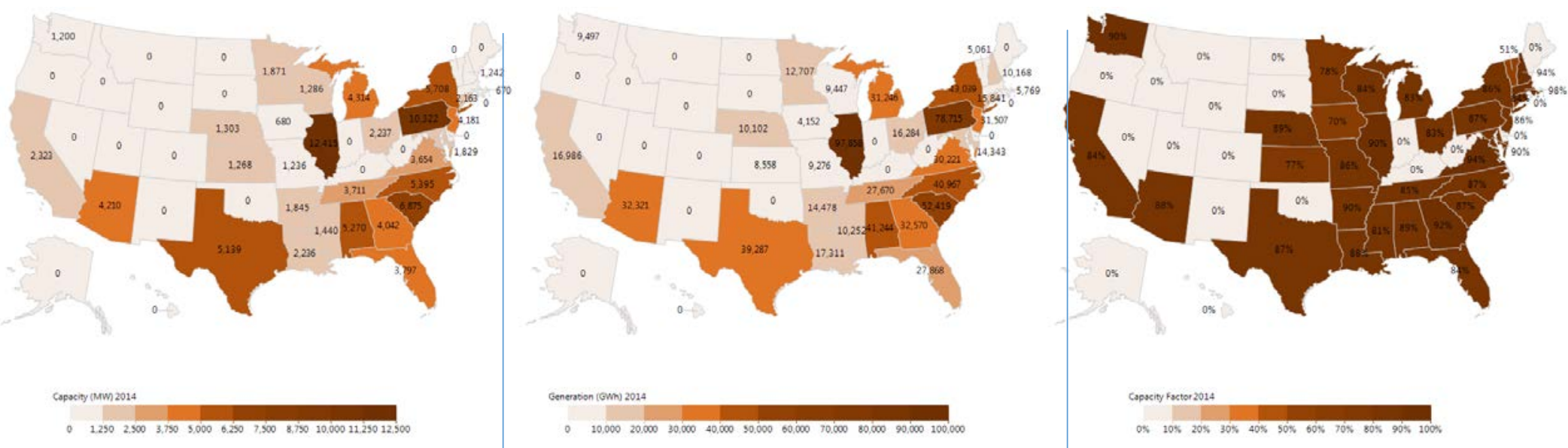

Figure 7-3. Nuclear capacity (left), generation (middle), and capacity factor (right) by state. Top: 2010; bottom: 2014.

Capacity, generation, and capacity factor from nuclear remained constant across the United States between 2010 and 2014, except in California, which lost significant nuclear capacity when the San Onofre 2 \& 3 reactors ceased operation. Source: EIA $2016^{256}$. 
The average age of the nuclear power fleet is 34 years (Figure 7-4), and plants are given an initial 40 -year operating permit. To date, 84 plants have received a 20 -year operating license extension, with 12 additional license extension applications pending and 5 more expected to be filed $^{257}$. Additionally, two plants (Surry Power Station and Peach Bottom Nuclear Generating Station) have announced intentions to seek subsequent life extensions. NRC is expecting these and other applications for license extensions to 80 years of operation and is currently developing the Standard Review Plan for Review of Subsequent License Renewal Applications for Nuclear Power Plants ${ }^{258}$.

The current nuclear power operating fleet (99 reactors) consists of approximately $54 \mathrm{GW}$ electrical (GWe) of generating capacity in regulated markets, and 45 GWe in restructured electricity markets. In states with restructured electricity markets, nuclear operators have found increasing difficulty competing in a low-energy price environment, arising from flat or declining energy demand, low natural gas prices, increased operating costs, and other factors. Economic pressure on nuclear plants grew during 2015 as average monthly wholesale electricity prices declined from their 2014 levels by approximately 30 percent at most major trading hubs, again due largely to lower natural gas prices ${ }^{259}$. Since a peak of 104 operating reactors, 5 units have already shut down earlier than their licensed lifetime (note: three of these also faced costly repairs). As of June 23, 2016, an additional 9 units have announced intentions to close prematurely, although the decision to close could be reversed for 6 units in Illinois and New York, pending passage of proposed legislation to enact clean energy standards, building on the renewable energy portfolio standards already in existence in 30 states and the District of Columbia. Additionally, as a result of California's evolving energy policy, Pacific Gas and Electric Company announced that it would not pursue license extension of its 2-unit Diablo Canyon Power Plant.

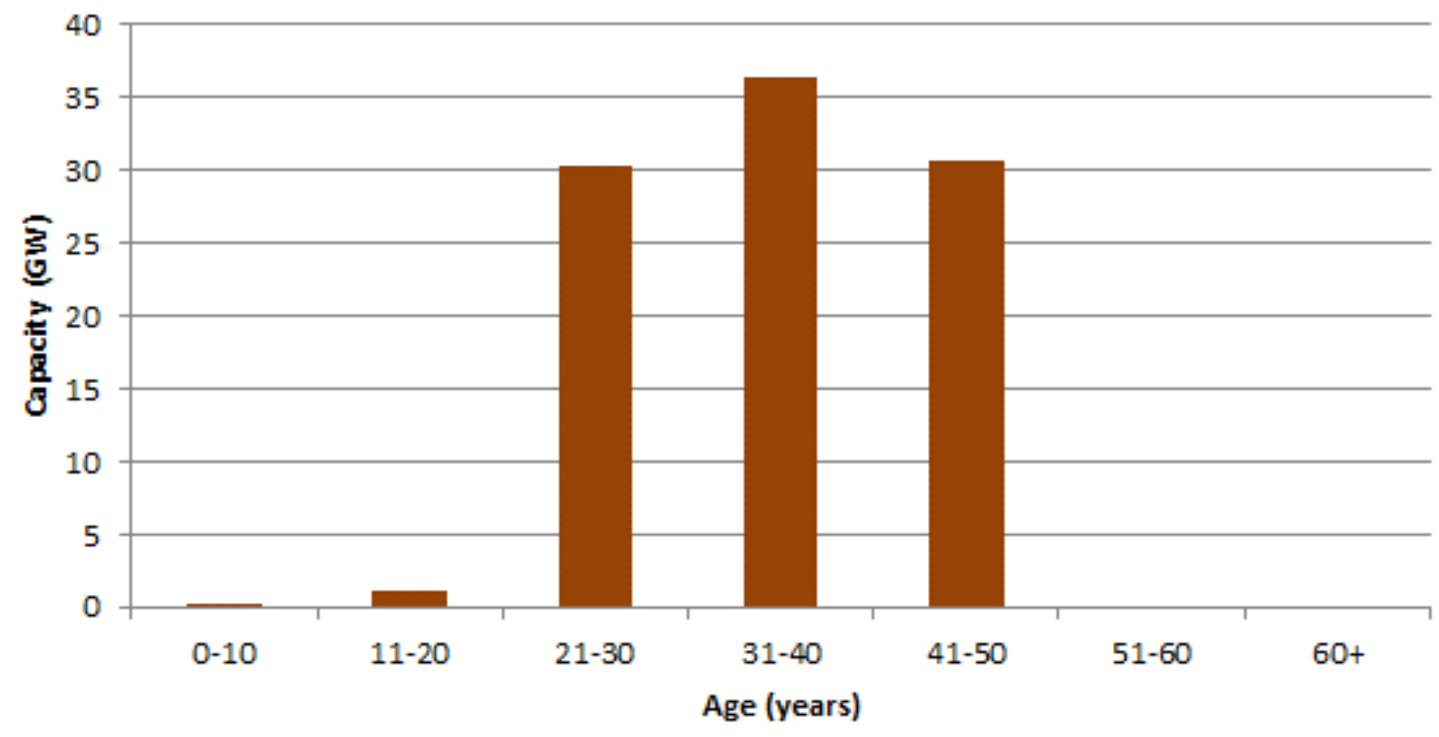

Figure 7-4. Age profile of U.S. nuclear generation fleet, 2014

Most nuclear plants were built in the 1970s and 1980s, so the average age of the fleet is now 34 years. Source: SNL $2015^{260}$. 
The average heat rate for the fleet of nuclear generators has remained steady since 2007, as shown in Figure 7-5.

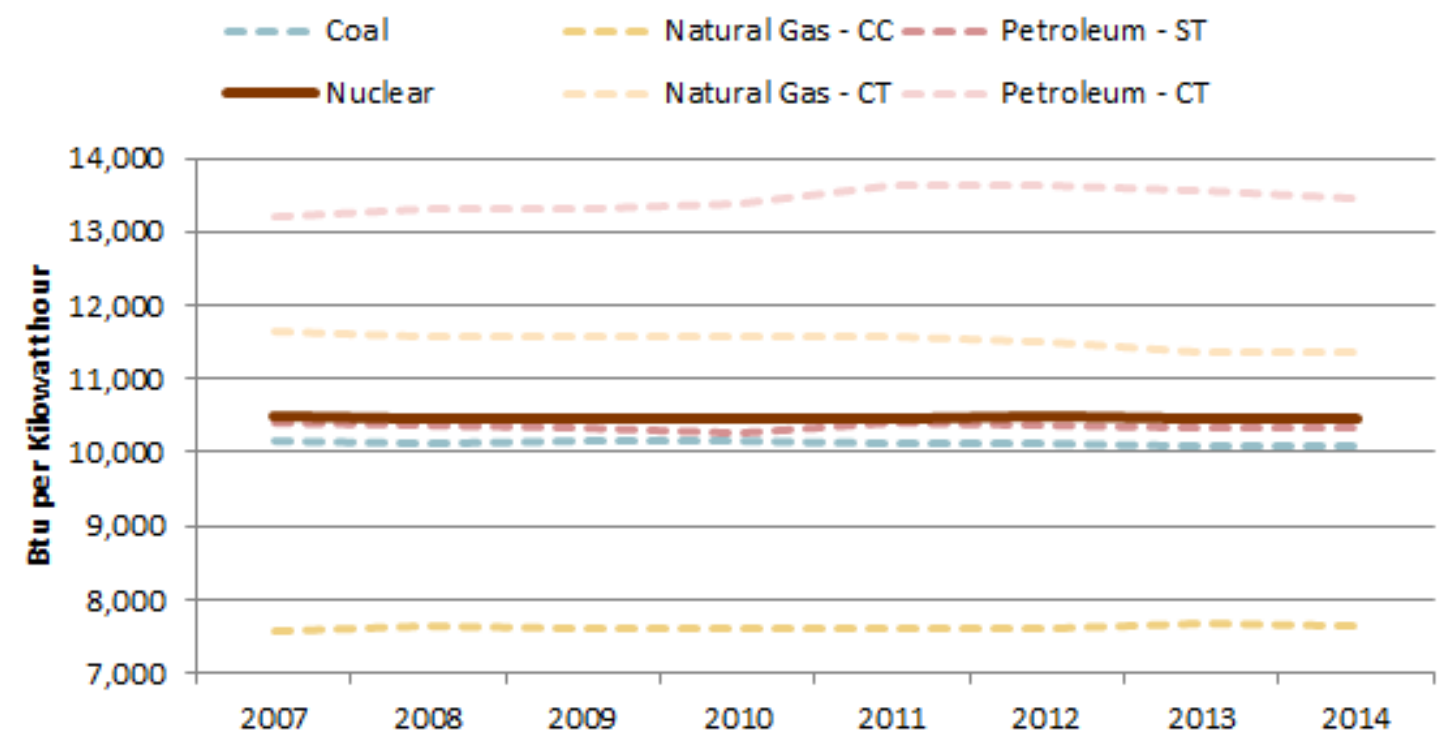

Figure 7-5. Heat rate over time for nuclear plants, 2007-2014

Source: EIA $2015^{261}$

\subsection{Technology Costs}

The LCOE for nuclear generation is shown in Table 7-1. The cost range for nuclear plants is one of the smallest across all three sources, and is roughly on par with NGCC-CCS generators.

Table 7-1. LCOE for Nuclear Generators (2013\$/MWh)

\begin{tabular}{|l|l|l|l|l|l|l|}
\hline & \multicolumn{3}{|l|}{ EIA } & \multicolumn{2}{l|}{ NREL } & Lazard \\
\hline Technology & Low & High & Low & High & Low & High \\
\hline Nuclear & 81.71 & 122.62 & -- & -- & 76.77 & 138.67 \\
\hline
\end{tabular}

Current ranges of nuclear technology prices using cost assumptions from three sources: NREL 2015; EIA 2015; Lazard $2015^{262}$. See appendix B for more information on LCOE calculations.

\subsection{Fuel/Resource}

Uranium is mined in several states in the United States, but the majority of uranium today is imported. Uranium mines and production by state is shown in Figure 7-6, and the international makeup of uranium sources is shown in Figure 7-7. As of 2013, the United States had 207,400 tonnes of recoverable uranium ${ }^{263}$. However, some of these reserves are only economic at high uranium prices. 


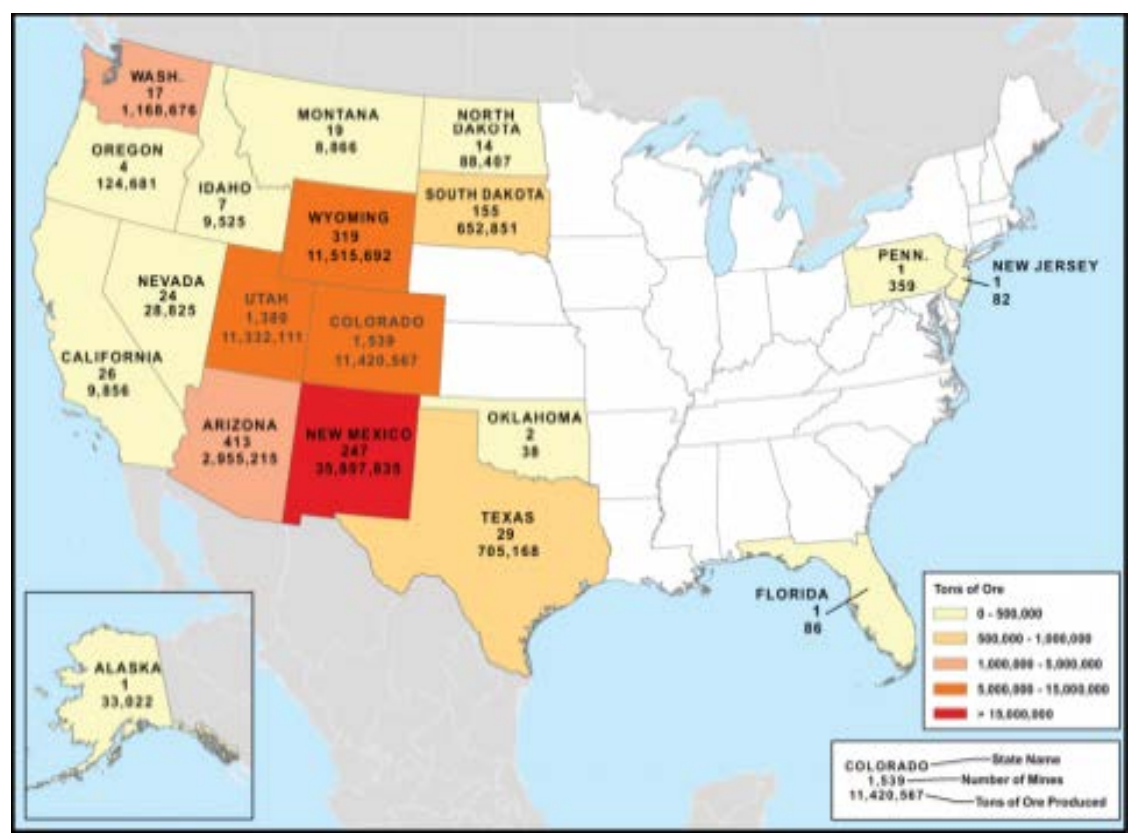

Figure 7-6. Uranium mines and production by state

A majority of domestic uranium production occurs in the Rocky Mountain western states. Transportation to processing facilities and to the eastern United States (where most nuclear power plants are located) needs to be accounted for. Source: DOE $2014^{264}$.

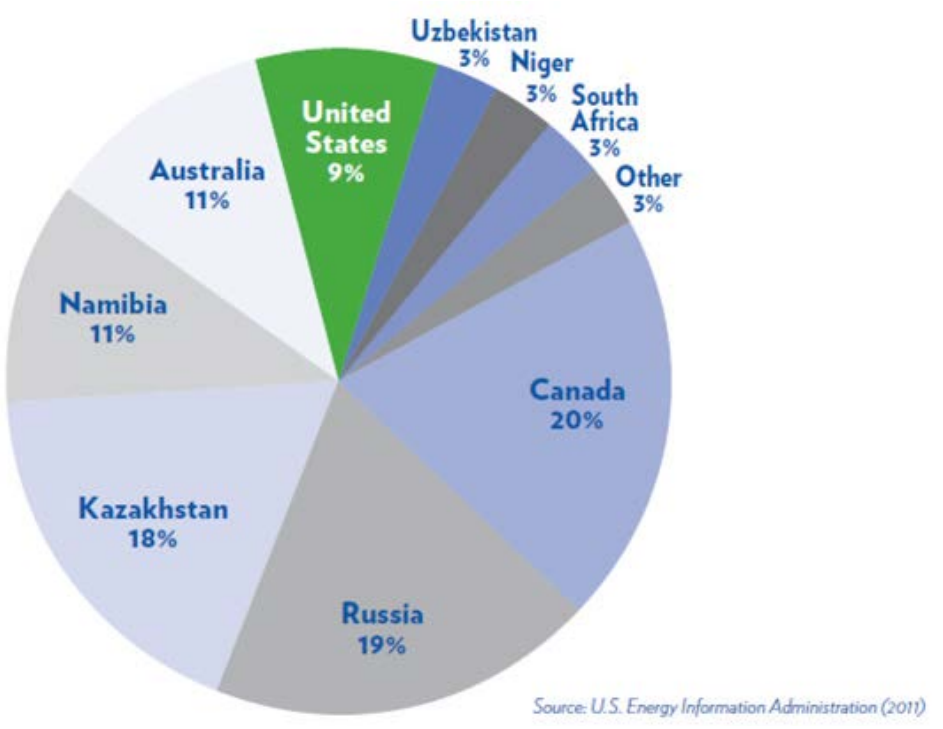

Figure 7-7. Sources of uranium for the United States

Over 90 percent of uranium used in the United States comes from international sources. There is a potential for global competition for uranium if installed nuclear capacity increases. Source: Virginia Uranium $2012^{265}$.

Uranium is shipped via highway, rail, air, or water and is regulated by NRC and the Department of Transportation. There are requirements for packaging and physical protection of materials along with hazard communication. 


\subsubsection{Uranium Price History}

Virtually all uranium is not traded on public markets; instead, buyers and sellers negotiate prices privately ${ }^{266}$ xxxviii. Spot and longer-term prices are illustrated for the past decade in Figure 7-8. Although remaining relatively constant from 1985 to 2005, prices spiked in 2007, possibly due to projected rising demand from China and India and flooding at uranium mines in Australia and Canada, but they have since leveled off.

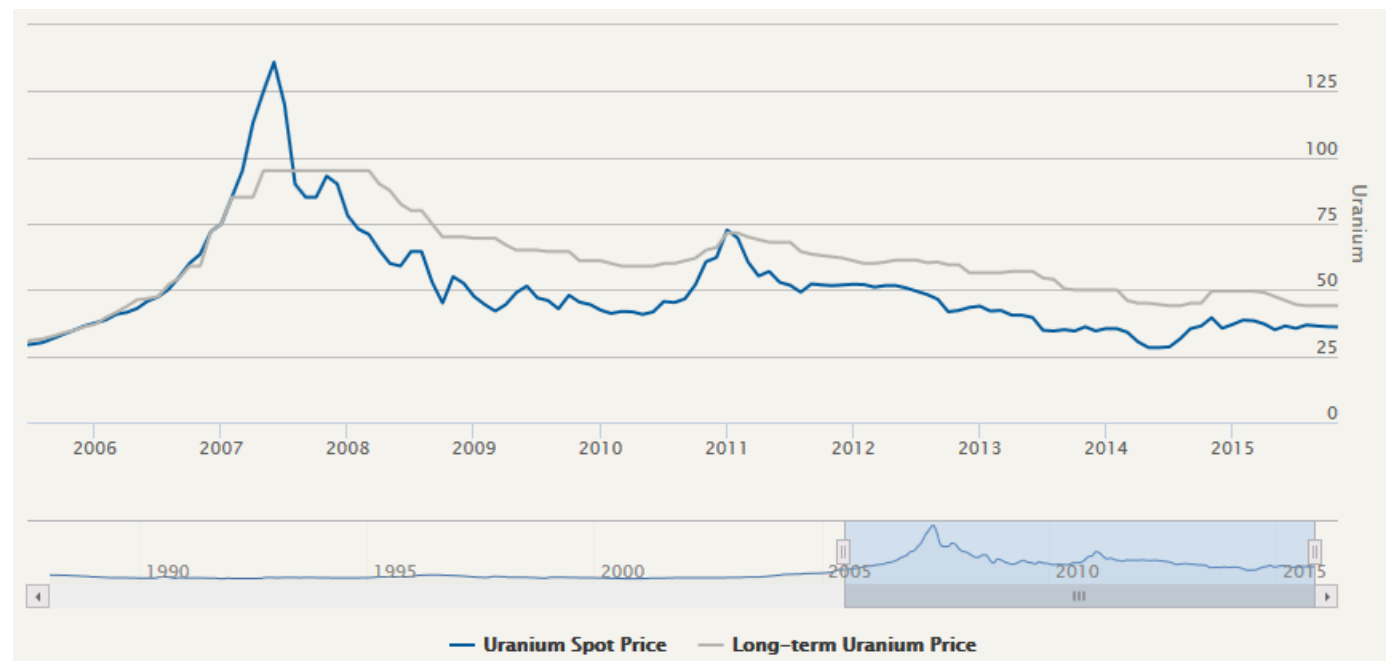

Figure 7-8. Uranium prices $(\$ / / b)$, 2005-2015

Most uranium is sold on long-term contracts, and prices have been relatively flat in the past 4 years. The price spike in 2007 can possibly be attributed to projected rising demand from India and China and uncertainty over production from existing mines. Source: Cameco $2015^{267}$.

\subsection{Environmental Impacts}

\subsubsection{Upstream}

Mining uranium has potential environmental impacts similar to other metalliferous mining operations (e.g., aluminum, gold, and platinum mining operations) ${ }^{268}$, which include (but are not limited to) water contamination from acid mine drainage release and heavy metal exposure to the surrounding ecosystems ${ }^{269}$. Airborne exposure from mine tailings is also a concern as they contain uranium and radium ${ }^{270}$. Radium decays into radon and poses a threat to human health. Because of this, most tailings are covered with water in holding ponds to reduce this risk ${ }^{271}$. Water used during mining may contain traces of radium, and most mines adopt a "zerodischarge" policy ${ }^{272}$.

Because the half-life of uranium-238, the non-fissile primary isotope of uranium, is 4.5 billion years, it has relatively low radioactivity, similar to granite ${ }^{273}$. Mine workers may potentially be exposed to gamma radiation during the mining process, and dust suppression and ventilation are necessary to maintain safe working conditions ${ }^{274}$.

Uranium must be enriched to increase the concentration of uranium-235, the fissile isotope used in reactors. The enriching process causes the resulting fuel to be able to sustain fission. Uranium

xxxviii Prices are from independent market consultants Ux Consulting and TradeTech. 
is initially mined as one form of uranium oxide $\left(\mathrm{U}_{3} \mathrm{O}_{8}\right)$, is converted to uranium hexafluoride $\left(\mathrm{UF}_{6}\right)$ due to its low sublimation temperature for enrichment, and is converted again to a different form of uranium oxide $\left(\mathrm{UO}_{2}\right)$ for use as nuclear fuel. In the United States, uranium is enriched through gaseous diffusion ${ }^{275}$; however, this process has been largely replaced by centrifuge processes in the rest of the world ${ }^{276}$.

\subsubsection{Emissions and Environmental Impacts}

Nuclear reactors do not produce any $\mathrm{CO}_{2}$ during generation. However, there are other environmental issues that impact the efficacy of nuclear power, such as concerns about radioactive contamination, waste disposal, and large water withdrawals. As with all generation sources, $\mathrm{CO}_{2}$ is emitted during the manufacturing and decommissioning phases, and this needs to be accounted for in the life-cycle analysis. The Intergovernmental Panel on Climate Change estimates the life-cycle $\mathrm{CO}_{2}$ emissions of nuclear power plants at $13 \mathrm{~g} / \mathrm{kWh}$ (comparable to wind turbines and smaller than any other energy source ${ }^{277}$. A single $1 \mathrm{GW}$ nuclear reactor would emit 6 million fewer tons of $\mathrm{CO}_{2}$ each year than a coal-fired plant that generated the same amount of electricity.

Once the uranium fuel reaches a specific depleted burnup, the reactor must be shut down to replace the fuel rods. Burnup is expressed in gigawatt-days per metric ton uranium in the fuel rods (GWd/MTU). Average burnup was $35 \mathrm{GWd} / \mathrm{MTU}$ two decades ago, but it is now over 45 $\mathrm{GWd}$ /MTU. The specific burnup allowable is determined through certification by NRC and takes into consideration radioactive fission product buildup, residual heat generation, and NRC specifications for storage of the used fuel rods. Also, materials used for O\&M are considered low-grade radioactive waste. These materials need to be properly managed to ensure that radiation does not impact the environment.

\subsubsection{Downstream}

The U.S. fleet of commercial nuclear power generators produces approximately 2,200 tons of used fuel each year. There is currently no centralized storage or disposition facility for used nuclear fuel in the United States, so it is stored at the nuclear power plants awaiting construction of a permanent waste handling facility ${ }^{278}$. This used fuel is currently stored first in pools onsite and then moved to concrete casks, if room is needed in the pools.

Other countries recycle used fuel rods to separate the uranium and plutonium for potential reuse, but this process is currently not done in the United States. A commercial mixed oxide fuel facility was under construction in Barnwell, South Carolina, in the late 1970s, but this facility has been put on standby and is unlikely to resume construction given the cost of fuel recycling relative to producing fresh new fuel elements. The DOE Savannah River Site in South Carolina has been developing a mixed oxide fuel facility for noncommercial processing; however, the continued viability of this facility is currently a topic of debate.

\subsection{Constraints}

Light-water PWR and BWR nuclear power plants are water-cooled, so they need to be located near sources of water. With potential climate change causing changes in weather patterns and rising temperatures, there is some concern over water availability for cooling nuclear plants. Rising inlet temperatures could reduce the thermal efficiency of the steam cycle and potentially 
lead to shut downs due to regulatory restrictions. Palo Verde, a nuclear plant in Arizona, uses municipal effluent for cooling to reduce impacts of water withdrawal in the desert environment $^{279}$. The Diablo Canyon nuclear plant in California operates a reverse osmosis plant to desalinate seawater for plant cooling loads. The reverse osmosis plant is operated during offpeak hours and at times when power generation curtailment might be necessary.

Large-scale environmental events (like Fukushima) have created concerns regarding nuclear power into the future. Siting new nuclear power plants near population centers has been an issue of contention due to the risk of radioactivity if containment is breached. Nuclear plants are designed with numerous safety features to prevent a breach. The perceived fear of a breach may be much larger than the actual chance of it occurring.

High capital costs and long construction times are most likely the largest barrier limiting further expansion of nuclear power technology in the United States ${ }^{280}$. Underestimated costs and construction delays were evident for many nuclear projects during the pre-1990s expansion, and both are still evident in the four units currently under development ${ }^{281}$. While loan guarantees and other incentives like "construction work in progress"xxxix provisions can help overcome financing challenges, delays and cost overruns at the Vogtle and Summer projects have caused the Fitch ratings agency, for example, to claim that the efficiencies and cost reductions expected with the new Westinghouse AP1000 "modular construction" scheme have fallen short of expectations ${ }^{282}$. These two examples could be temporary setbacks that provide important lessons on how to improve the modular construction techniques at future plants should they enter the development pipeline.

Transportation of nuclear material is highly regulated under U.S. Code of Federal Regulations title 10, chapter 1, part 71 by NRC and the Department of Transportation (49 CFR 173.417) ${ }^{283}$. Because the United States receives most of its uranium from other countries, there is the potential for disruptions to uranium supply due to geopolitical conflicts. There are also some concerns about scarcity and cost increases of uranium supply if nuclear power expansion increases demand, but there have been no shortages yet ${ }^{284}$. These concerns, however, are mitigated by both the supply of depleted uranium in the United States and the large recoverable reserves of uranium in the United States.

The United States has significant reserves of unmined uranium. Wyoming, for example, as the top supplier of uranium in the country, has the potential to significantly increase production, and the Wyoming Mining Association projects there are 456 million pounds of recoverable uranium in the state 285 . This is enough uranium to power the U.S. nuclear reactor fleet for 140 years. Additionally, DOE is sponsoring R\&D to separate uranium from seawater.

Another issue is the supply chains for heavy construction plants to build high pressure reactor components. There are no forging facilities in the United States that can fabricate large reactor pressure vessels of the nature used at the Vogtle or Summer projects. Capabilities for this size exist globally in France, Japan, South Korea, and now in China. Currently, Westinghouse has the AP1000 reactor vessels manufactured in South Korea by Dooson Industries and shipped to the

${ }^{\text {xxxix }}$ Construction work in progress, known as CWIP, allows certain plant owners to begin collecting revenue from rate payers before construction work is complete. 
United States. Domestic forging capabilities exist to manufacture smaller diameter reactor pressure vessels used in small modular reactors (SMRs). The demand for building materials (steel, concrete, etc.) can rise during periods of high global economic development and may increase the overall plant cost.

\subsection{Technical RDD\&D}

DOE has active programs on extending the life of existing nuclear power plants, as well as additional work on SMR commercialization, advanced reactors, and fuel cycles. Advanced technologies could allow nuclear power to contribute more readily to a diverse, sustainable, affordable, and reliable electricity system.

To potentially prolong the life of the existing fleet of generation assets beyond their 60 -year operating window (assuming an initial 40-year license and one 20-year renewal), DOE has developed the Light Water Reactor Sustainability Program. ${ }^{\mathrm{xl}}$ In December 2015, the nuclear industry also launched a major effort to further improve the efficiency and, particularly, the economics of existing units ${ }^{286}$. Elements of the programs focus on understanding material aging and degradation; advanced instrumentation, information, and control systems technologies; riskinformed safety margin characterization; and advanced LWR nuclear fuels. Efficiency improvements through power upgrades and advanced modeling and simulation tools to better understand safety performance are also part of this effort ${ }^{287}$.

To address the economic, public safety, waste disposal, and proliferation concerns that have existed over the past decades, DOE is leading the development of new nuclear technology that uses higher temperatures, novel cooling techniques, and more modular sizes. SMRs up to 300 MW in size could overcome many of these barriers by offering smaller capacities that can integrate into power grids of limited size, reducing financial risk and cutting costs through factory manufacturing of key components. There are a number of potential SMRs under development around the world. In the United States, DOE is cost sharing NRC Design Certification of the NuScale Integral PWR and is targeting commercial operation of the first reactor in the mid-2020s ${ }^{\mathrm{xli}}$.

Other types of advanced nuclear reactors classified as generation IV (Gen IV) technology are under development and offer promise ${ }^{288}$. Gas-cooled reactors that operate at high temperature and include advanced passive safety features may be closest to deployment. Other technologies, including liquid metal-cooled fast reactors, fluoride and chloride molten salt-cooled hightemperature reactors, and advanced SMRs, are under development ${ }^{289}$. Many advanced nuclear reactors could provide outputs beyond electricity production, such as process heat for industrial applications or hydrogen production; this fuel source could be important in transport applications or as an energy storage mechanism.

\footnotetext{
${ }^{\mathrm{xl}}$ More information on DOE's Light Water Reactor Sustainability Program is available here: http://www.energy.gov/ne/nuclear-reactor-technologies/light-water-reactor-sustainability-lwrs-program.

${ }_{\text {xli }}$ More information on DOE's Small Modular Reactor Program is available here:

https://www.energy.gov/ne/nuclear-reactor-technologies/small-modular-nuclear-reactors
} 


\subsection{Development and Projected Future Deployment}

Nuclear generation began in 1960 at less than 1 TWh and grew rapidly through the 1970s and 1980s to become the leading source of zero-carbon operational electricity generation in the United States (Figure 7-9). Much of this capacity was enabled by the Atomic Energy Act and the Price-Anderson Act, which established a program for covering public claims in the event of an accident. Most of the U.S. nuclear fleet commenced construction between 1967 and $1990^{290}$.

More recently, with growing concerns over fuel diversity and GHG emissions, several new nuclear plants have begun construction in the United States, including the $2.2 \mathrm{GW}$ Vogtle project (units 3 and 4) and the $2.2 \mathrm{GW}$ Summer project (units 2 and 3). All four units are based on the Westinghouse AP1000 design, considered a Gen III+ reactor $^{x \text { xii }}$ that has passive safety features for up to 72 hours of cooling without human or external electricity needs. In addition, the 1.2 GW Watts Bar 2 unit-which began construction in 1973, and then sat unfinished until construction recommenced in 2007-received an operating license in October 2015 and commenced commercial operational in October 2016. This unit is the first new nuclear reactor brought online in the United States since 1996, when Watts Bar 1 entered service, and is likely to be the last Gen II reactor built in this country.

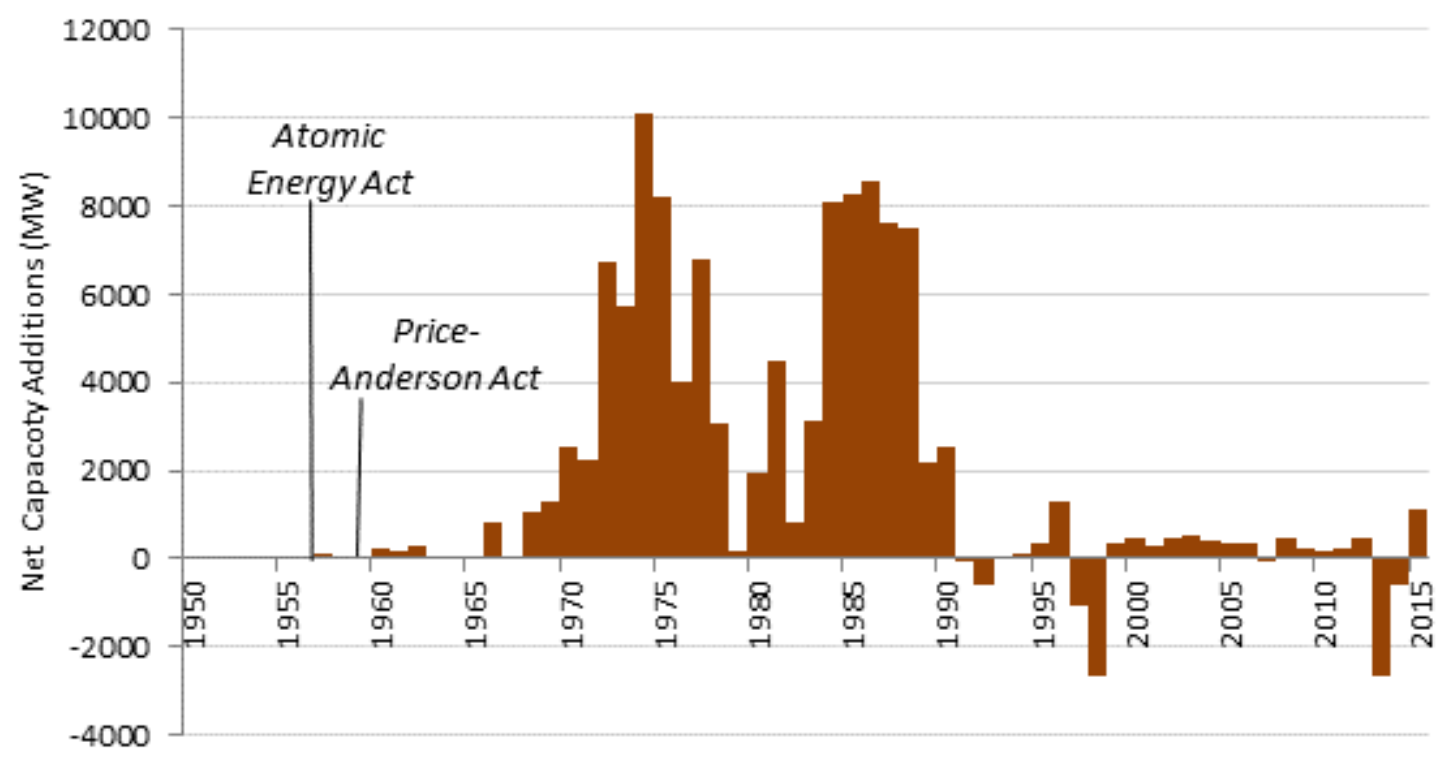

Figure 7-9. Historical annual nuclear capacity additions and retirements (MW), 1950-2015

Most of the U.S. nuclear capacity additions occurred between 1967 and 1990, and until 2013, there was a 30-year gap in new construction of plants. Source: EIA 1990 and EIA $2016^{291}$.

The domestic outlook for nuclear energy from two QER 1.2 projections shows modest growth through 2040, with slightly more growth anticipated in the Side Case (Table 7-2).

\footnotetext{
xlii Gen I technology is the label applied to the very first reactor designs; Gen II includes the vast majority of technologies deployed in the United States through the 1980s and 1990s. Gen III and III+ technology includes standardized design and advanced passive safety features, while Gen IV is the next generation of nuclear technology currently under development.
} 
Table 7-2. QER 1.2 Base Case Generation for Advanced Nuclear (TWh), 2014-2040

\begin{tabular}{|l|c|c|}
\hline & 2014 (Actual) & $\begin{array}{c}\text { QER 1.2 Base Case } \\
(2040)\end{array}$ \\
\hline Nuclear Generation & 784 & 808 \\
\hline
\end{tabular}

QER 1.2 projections show modest growth through 2040, with slightly more growth in the Side Case. Sources: EPSA $2016^{292}$.

Globally, nuclear generation has lost a significant share of the global total since 2000 as other forms of generation have expanded more rapidly. Sixty-five reactors are under construction in several countries (China, South Korea, and India, especially), with two in the final stages of $\operatorname{startup}^{293}$, which is likely to reverse the recent decline in global output. In IEA's 450 Scenario, nuclear output more than doubles by 2040 compared to today's level (see Table 7-3). Whether U.S. manufacturers will engage in this potential will depend on a host of factors. As electricity grids across the globe move towards more flexible architectures, smaller nuclear plants may have an advantage.

Table 7-3. Historical and Projected Global Nuclear Generation by Scenario Outlook, 2000-2040

\begin{tabular}{|l|c|c|c|c|c|c|c|c|}
\hline IEA Scenario & \multicolumn{5}{|c|}{ New Policies } & Current Policies & \multicolumn{2}{c|}{450} \\
\hline Year & 2000 & 2013 & 2020 & 2040 & 2020 & 2040 & 2020 & 2040 \\
\hline Nuclear Generation (TWh) & $\begin{array}{c}2,59 \\
1\end{array}$ & 2,478 & 3,186 & 4,606 & 3,174 & 3,974 & 3,218 & 6,243 \\
\hline $\begin{array}{l}\text { Percentage of Global } \\
\text { Total }\end{array}$ & 17 & 11 & 12 & 12 & 11 & 9 & 12 & 18 \\
\hline
\end{tabular}

Source: IEA $2015^{294}$. 


\section{Water Power}

\subsection{Technologies}

Hydropower is one of the oldest and most established forms of power generation, with much of the large, existing capacity developed and managed by Federal agencies and greater numbers of smaller plants operated by the private sector. Hydroelectric plants capture the energy in moving water to spin a turbine and generate electricity. Plants can consist of impoundments, where a dam blocks the entire flow of a waterway, or diversions, where water is diverted from a waterway to flow through a turbine. Impoundments may include water storage, which allows for greater flexibility in electricity generation. Plants can include dams (impoundments) upstream of the generating equipment to ensure more reliable production, or be simple "run of the river" systems, which, like diversions, may only be available during certain months of the year when water flows are sufficient to support generation.

Hydropower is often divided in two categories: conventional hydroelectric power and pumped storage hydro (PSH). Conventional hydroelectric power historically uses impounded water (dams) to control gravitational potential (head) or diversions to better control electricity dispatch. The era of building large new dams came to an end in the 1970s when the current regulatory paradigm was put into place based on environmental and ecosystem concerns. Many of the large Federal dams built prior to that time continue to comprise the majority of hydropower capacity. PSH uses electricity when both price and demand are low to pump water uphill into a storage compound (often at night) and releases the water through a turbine during times of higher demand and higher prices (usually in the day). PSH was traditionally installed to help balance baseload generators like nuclear, but it is increasingly used to help integrate variable renewable generators $^{295}$. There are far fewer PSH plants than conventional hydropower plants in the United States.

Hydropower is often used as baseload in the U.S. power system due to low variable fuel costs and low operational costs. It is often dispatched early due to low prices, but some operating conditions affect its dispatch schedule. Projected reservoir levels, environmental controls, and use in balancing for variable generators can lead to complicated dispatch schedules ${ }^{296}$.

Conventional hydropower generators, and especially PSH, can be used in peaking and balancing applications to maintain grid reliability.

There have been several U.S. deployments of marine hydrokinetic (MHK) energy devices, which convert the energy of waves, tides, and river and ocean currents into electricity. Their historical contribution to U.S. electricity generation is negligible, but these technologies offer potential for the future, as discussed in Section 8.7. Additional information on water power generation is available in Appendix A.

\subsection{Operational Attributes and Fleet Characteristics}

Conventional hydroelectric power contributed 6.3 percent of the electricity generated in the United States in $2015^{297}$. While conventional hydropower generation has been relatively stable in absolute terms (Figure 8-1), its share of total generation has declined from 30 percent in 1950 as generation from other sources has increased over time with higher electricity demand. PSH is not a net-positive generation source as it net loses energy due to efficiency losses from charging 
versus discharging. If those losses are included, then conventional hydro and PSH generation would be slightly reduced to 6.2 percent of total generation.

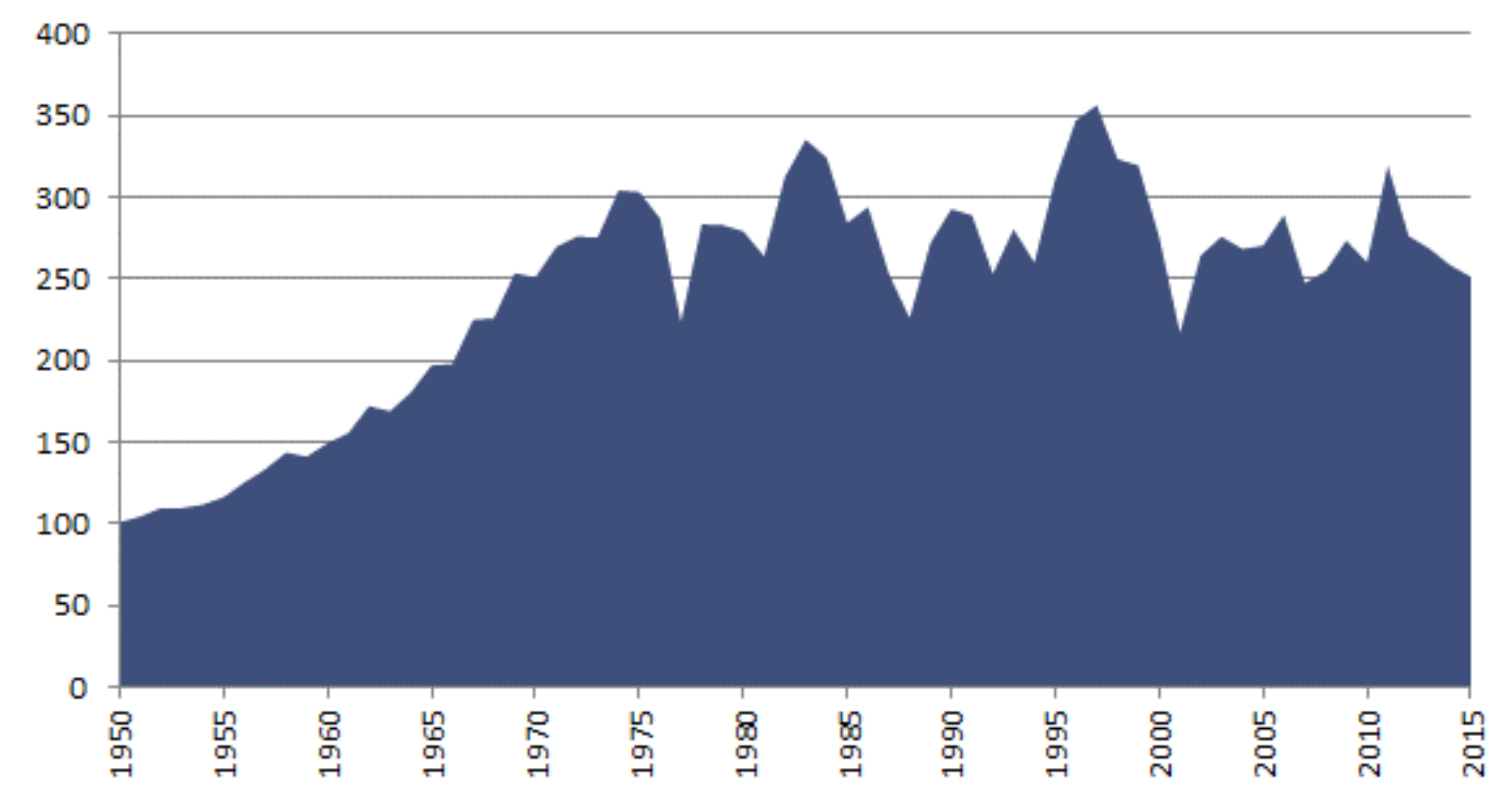

Figure 8-1. U.S. hydropower generation (TWh), 1950-2015

Source: EIA 2016 ${ }^{298}$.

Note: This chart only includes net generation from conventional hydropower generators and does not include subtractions from PSH.

In 2014, there were $79.6 \mathrm{GW}$ of installed hydropower capacity from conventional facilities and $21.6 \mathrm{GW}$ from PSH. The average capacity factor of conventional hydroelectric generators was 40 percent (Figure 8-2). Hydropower output can fluctuate from year to year based on natural variability of the water cycle such as the level of rainfall or snowpack. In addition, unlike impoundment hydroelectric, run-of-river facilities have little to no ability to control generation and are more sensitive to long- and short-term natural variability of water flows. Because the majority of hydropower facilities support multiple purposes, such as recreation, flood management, irrigation, navigation, and water supply, requirements for uses other than power generation (e.g., reservoir elevation rules upstream, dissolved oxygen, or flow requirements downstream) can also impact when the plant is able to release or store water ${ }^{299}$. Figure 8-3 shows that between 2010 and 2014, certain states experienced a significant decrease in generation and capacity factor, including California and several states in the Midwest and Southwest, likely due to decreased water supply from drought conditions. 

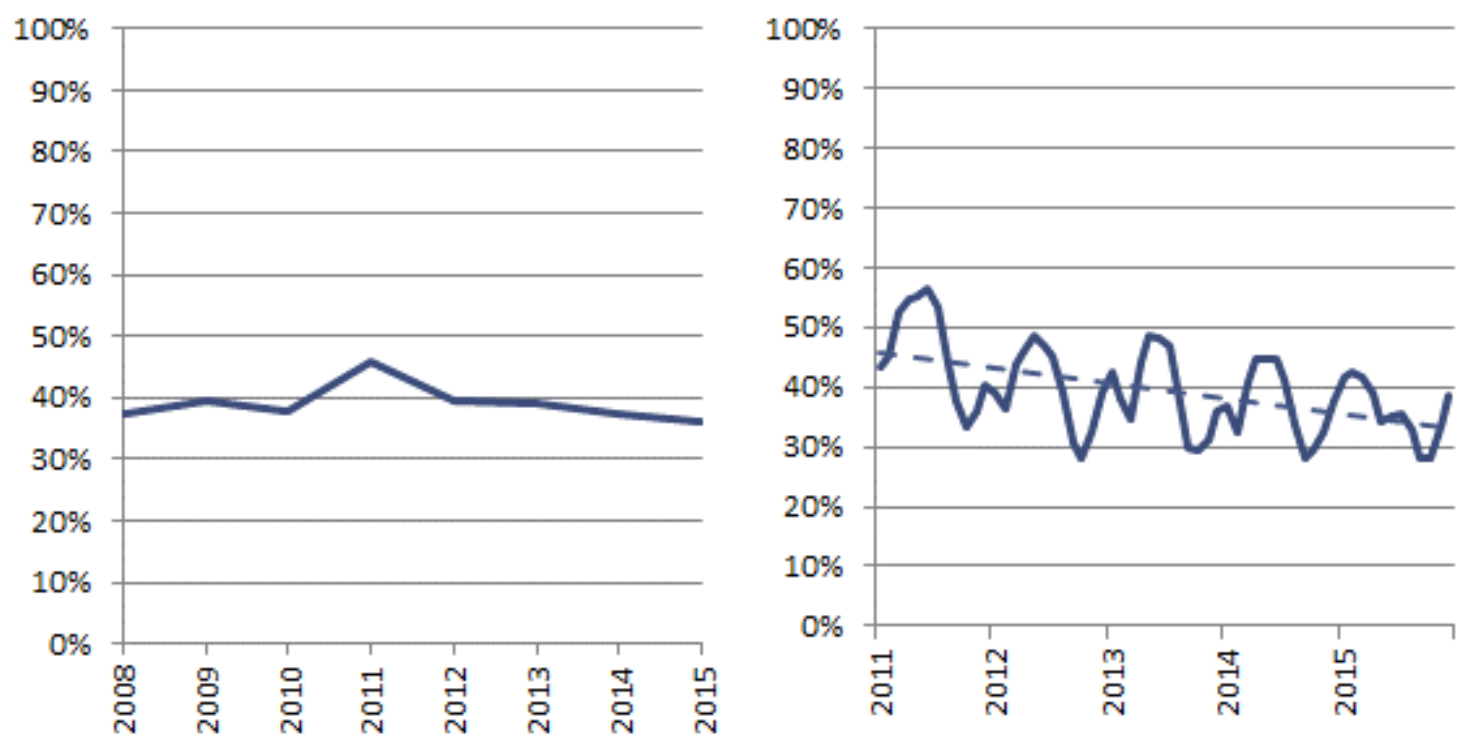

Figure 8-2. U.S. average annual and monthly hydropower generator capacity factors

Conventional hydropower capacity factors have hovered around 40 percent, with fluctuations primarily due to water availability. Source: SNL $2015^{300}$. 

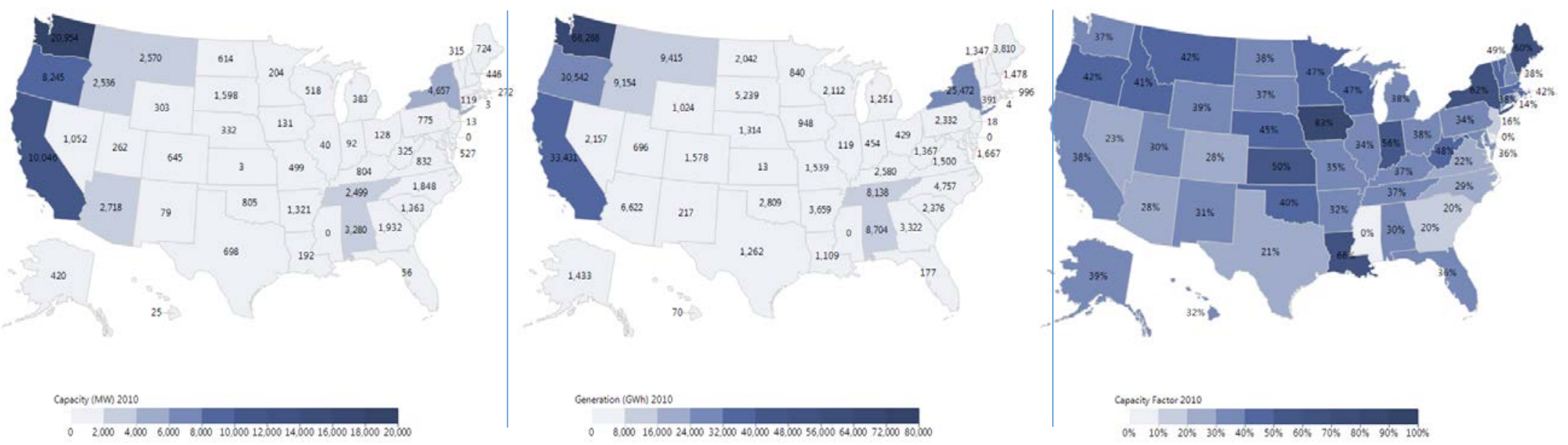

2014
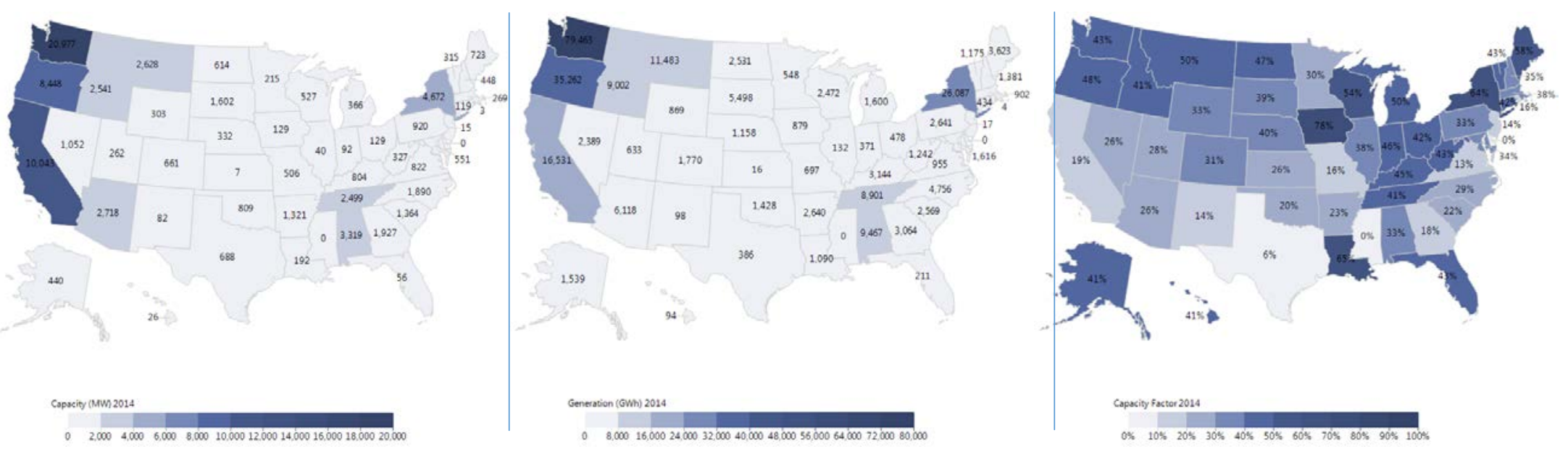

Figure 8-3. Hydropower capacity (left), generation (middle), and capacity factor (right) by state. Top: 2010; bottom: 2014.

Capacity from hydropower remained relatively constant across the United States between 2010 and 2014; however, generation and capacity factor decreased in several states, including California and Midwest and Southwest states (Kansas, Oklahoma, Missouri, Texas, New Mexico).

Note: This chart only includes net generation from conventional hydropower and does not include subtractions from PSH. Source: EIA $2016^{301}$. 
About half the U.S. hydroelectric fleet is over 50 years old since many large dams were built between the 1940s and 1960s (Figure 8-4) ${ }^{302}$. However, with routine maintenance and refurbishment of turbines and electrical equipment, the expected life of hydropower facilities is likely to be 100 years or more ${ }^{\text {xliii }}$.

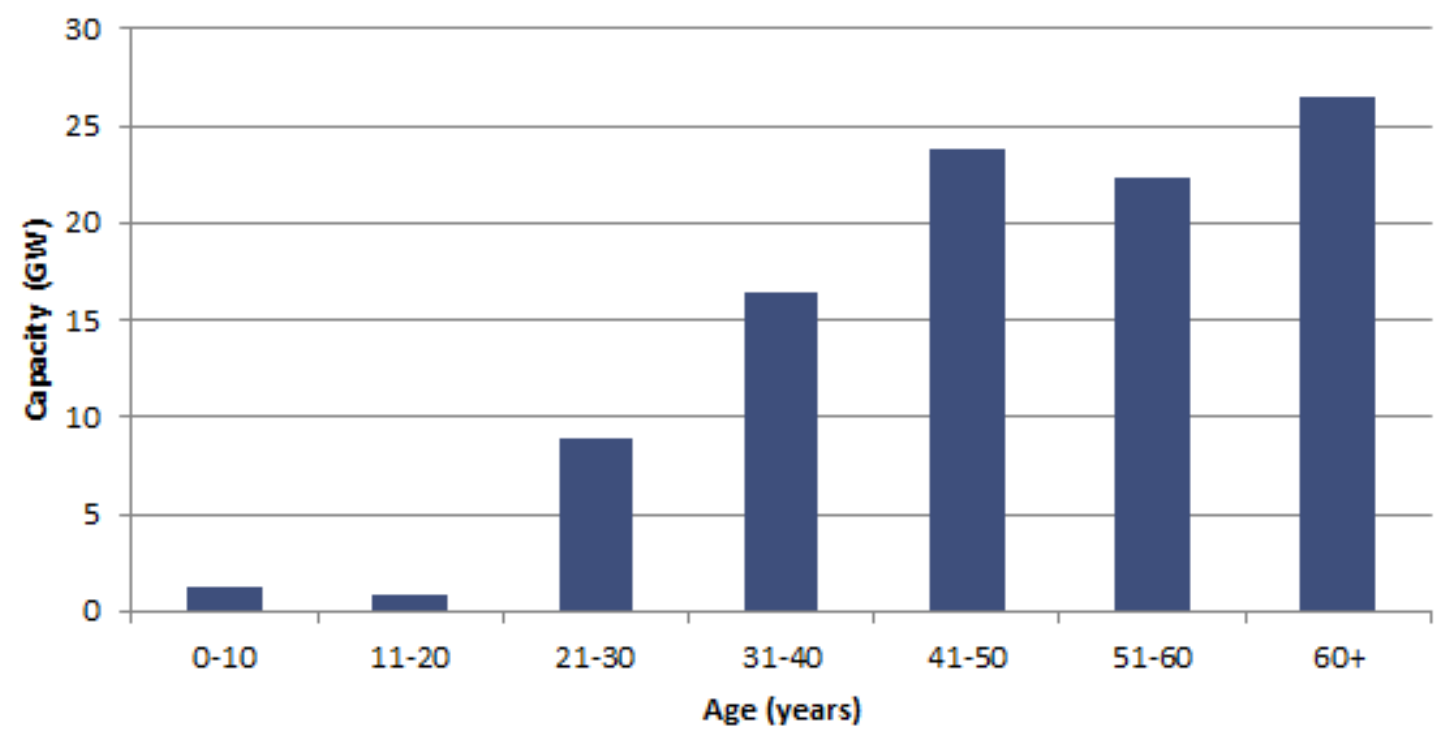

Figure 8-4. Age profile of U.S. hydropower generation fleet, 2014

About half the U.S. hydroelectric fleet is over 50 years old since many large dams were built between the 1940s and 1960s. Source: SNL $2015^{303}$.

Hydropower provides a variety of ancillary services that are beneficial to the electricity system. One example is regulation and frequency response (including inertia), in which hydropower generators can quickly respond to sudden changes in system frequency. Other ancillary services include spinning and supplemental reserves enabled by high ramping capability, reactive power and voltage support, and black start capability. There has been a renewed interest in the flexibility benefits that many hydropower projects can offer the grid, given the growth in variable renewable sources like wind and solar. A recent report notes that about half of all installed hydropower capacity $(39 \mathrm{GW})$ has high flexibility potential and could play an important role in low-cost integration of variable renewable generators ${ }^{304}$. PSH can also be used in peaking and balancing applications to maintain grid reliability and can play a balancing role in areas with high penetrations of VERs.

\subsection{Technology Costs}

The LCOE for hydropower generation is shown in Table 8-1. Costs for MHK technologies are not shown, but they are assumed to be much higher due to lower technology maturity. Hydropower has the potential to be very competitive with other forms of generation, but the costs of different hydropower installations vary significantly.

\footnotetext{
xliii The DOE's Hydropower Vision Report outlines additional needs for extending plant lifetime: https://energy.gov/sites/prod/files/2016/10/f33/Hydropower-Vision-10262016_0.pdf
} 
Table 8-1. LCOE for New Hydropower Generation (2013\$/MWh)

\begin{tabular}{|l|l|l|l|l|l|l|}
\hline & \multicolumn{3}{|l|}{ EIA } & \multicolumn{2}{l|}{ NREL } & Lazard \\
& Low & High & Low & High & Low & High \\
\hline Hydropower & 47.22 & 78.83 & 25.31 & 245.68 & N/A & N/A \\
\hline
\end{tabular}

Current ranges of hydropower technology prices using cost assumptions from three sources: NREL 2015; EIA 2015; Lazard $2015^{305}$. See Appendix B for more information on LCOE calculations.

\subsection{Fuel/Resource}

A report prepared by ORNL for DOE detailed the new stream-reach hydropower development potential available in the United States. This report found that the technical resource potential for new hydropower development was $65.5 \mathrm{GW}$ of capacity, when excluding federally protected lands (Figure 8-5). Another ORNL report found a technical resource potential of over $12 \mathrm{GW}$ capacity at the over 50,000 existing non-powered dams in the United States (Figure 8-6).

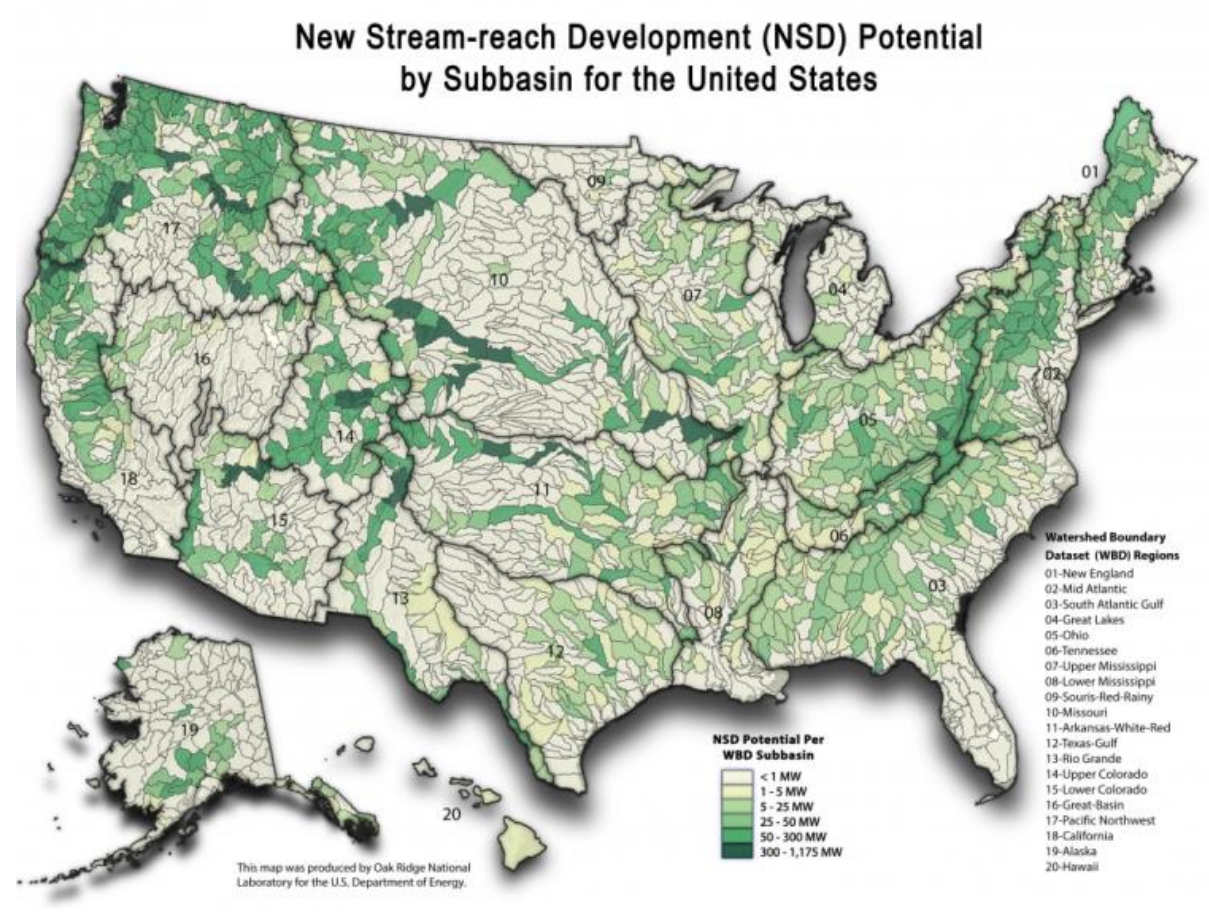

Figure 8-5. U.S. new stream-reach hydropower technical resource development potential

The technical resource potential for new hydropower developments is $65.5 \mathrm{GW}$, focused largely in the Pacific Northwest and Rocky Mountain West. Source: Kao et al. 2014 ${ }^{306}$. 


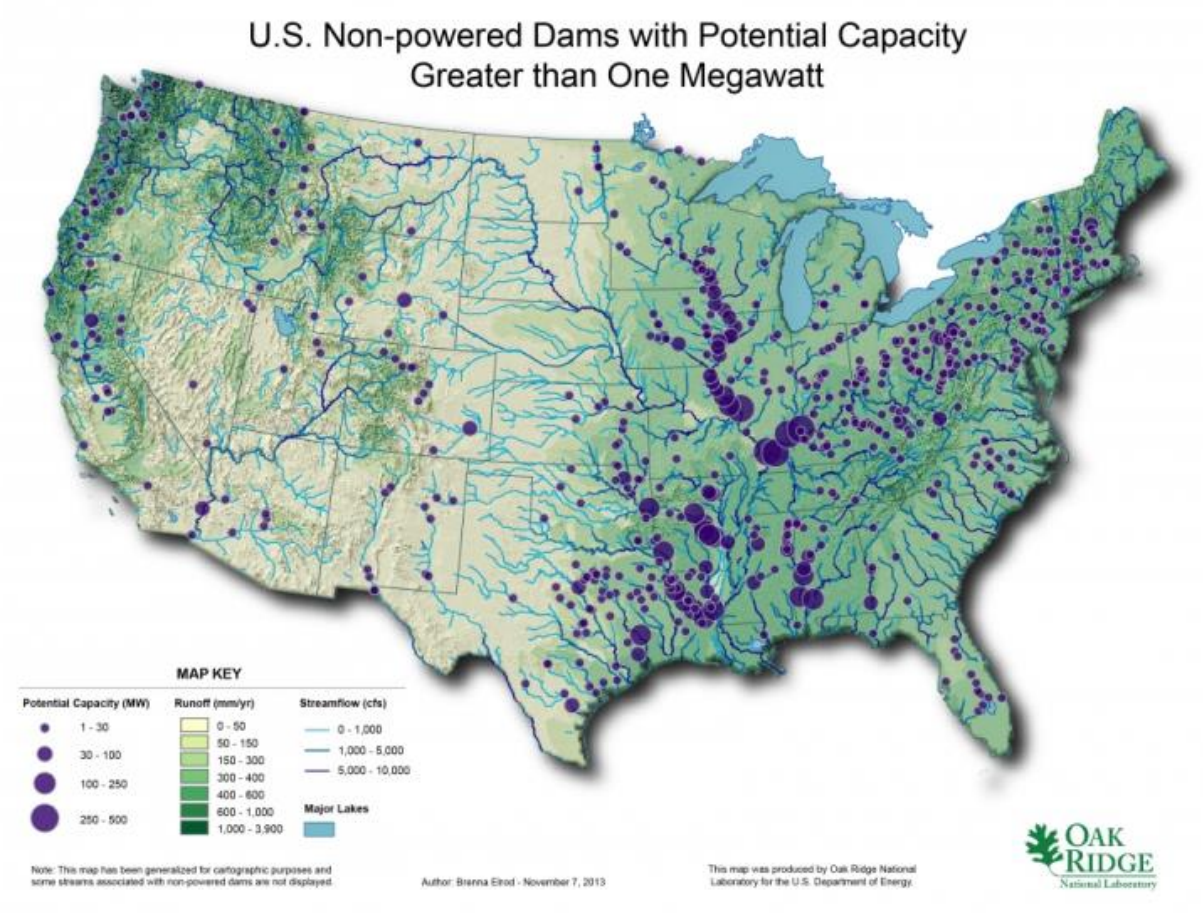

Figure 8-6. U.S. non-powered dam hydropower technical resource potential

The technical resource potential for powering non-powered dams is $12 \mathrm{GW}$, focused mainly on the Mississippi River and its major tributaries such as the Ohio and Red Rivers. Source: Hadjerioua, Kao, and Wei $2012^{307}$.

\subsection{Environmental Impacts}

\subsubsection{Upstream}

In the creation of hydroelectric reservoirs, large swaths of land may need to be flooded, which can allocate land away from other uses and can have an impact on aquatic life both in the reservoir and downstream of the facility ${ }^{308}$. Reservoirs can also lead to stagnant water conditions that can lead to the spread of water-borne diseases. In addition, dams can alter water quality in a variety of different ways, from reductions in dissolved oxygen to the degradation of other water quality attributes. Stagnant water and reservoirs can also lead to silt and nutrient buildup up- and downstream of the dam that can affect aquatic ecosystems. Also, large reservoirs of water can lead to temperature changes in water, which can affect all stages of aquatic life. In addition, dams can block and disrupt access to fish spawning or rearing habitats and directly kill fish by turbine entrainment. Furthermore, dams can alter instream flows, which impact habitat for fish and other aquatic organisms. Some fish and organisms can be impacted if drawn into turbine blades, so mitigation measures need to be taken to protect aquatic life. These mitigation measures include fish passage devices such as ladders or elevators and intake screens to prevent fish from entering turbine runs ${ }^{309}$.

Run-of-river and diversion projects can impact aquatic life in many of the same ways as hydroelectric dams, but their environmental impacts are less in comparison due to the typically smaller size of any impoundments used and significant reductions in flooded areas. 


\subsubsection{Emissions and Environmental Impact}

Hydropower is a renewable energy source that does not consume fossil fuel and therefore does not produce $\mathrm{CO}_{2}$ during generation. However, the damming of rivers causes significant disruptions to the local environment to construct the dam and to the resulting land area that is submerged when the reservoir is filled.

\subsubsection{Downstream}

Downstream, the hydroelectric dam causes environmental disruptions by restricting the flow of water and nutrients, thus affecting plants and animals living along and in the stream. Diversion projects divert water from the main stream reach through a channel to the hydroelectric facility; this can allow fish to continue through the main stream reach without a fish passage device.

\subsection{Constraints}

New large-scale hydroelectric dams are unlikely to be built due to environmental and siting concerns; in fact, some dams are now being removed to return rivers to free-flowing conditions. The licensing and relicensing of hydropower projects often takes so much time that it acts as an impediment to new projects and existing projects. Over the next 10 years, existing FERC licenses will expire for nearly 250 hydropower projects, totaling more than 16,000 MW of installed capacity. On average, it takes 8 to 10 years to relicense an existing hydro project, with at least 5 years of pre-filing activity and then at least another 3 years after the application is filed. However, only 2,198 dams are currently used for hydroelectricity -3 percent of the nation's total dams. (Other uses for dams include navigation, flood control, irrigation, and recreation.) Adding hydroelectricity to these preexisting dams may not be subject to as many siting constraints because some of the environmental impacts from dam construction have already been incurred; this, combined with the ability to leverage existing infrastructure at nonpowered dams, can reduce costs. New development of smaller projects, including diversions or conduits, may also face fewer siting constraints due to lower expected environmental impacts, but these projects may face economic constraints due to their smaller size and potentially less water and greater seasonal variability.

New proposed PSH development could occur on existing dams or be built entirely off-stream, leading to different implications for siting. PSH development at an existing dam would require the construction of an upper reservoir separate from the river system, but the dam would still have one reservoir on a naturally flowing water body and therefore be considered "open loop." An example of this is the recently considered Iowa Hill project by the Sacramento Municipal Utility District. A PSH facility built entirely off-stream is considered "closed-loop" and would not face the same environmental concerns because it is not connected to a river system. An example of this is the Eagle Mountain project (also recently licensed), where both upper and lower reservoirs would be in abandoned open-pit mines ${ }^{310}$.

Since MHK technologies encompass a large array of archetypes and the technologies are relatively new, there are still many unknowns when it comes to their environmental impacts. This has led to permitting and regulatory agencies generally taking a conservative approach and has hampered the deployment of many demonstration-scale projects. Some common environmental concerns that are raised include the acoustic impacts of operational devices, the 
impacts of electromagnetic fields from subsea cables, and the collision of marine animals with tidal turbine blades ${ }^{311}$.

Hydroelectric power is impacted by the water cycle (i.e., snowpack and rainfall), which varies regionally, seasonally, and annually. The regional and seasonal trends have historically been somewhat predictable, although there are many factors that can influence water flow and power production. For example, hydroelectric generation typically is lowest in the fall and peaks in the spring when snowpack melts; this peak is more notable in the mountainous $\mathrm{West}^{312}$. Climate change, however, could impact the seasonal availability of water and its management, potentially creating challenges and opportunities for hydropower going forward ${ }^{313}$. Many existing hydropower facilities are considered multi-use and offer flood control, recreation, and navigation. These additional uses for the facility may be higher priority than energy production, resulting in uncertainty regarding power generation.

Large-scale hydropower projects are often difficult to finance due to high capital costs, lengthy permitting periods, and environmental concerns. While the prospects for building very large new dams are low, there are other opportunities for hydropower to expand in the U.S. generation portfolio. Upgrading equipment at existing sites to expand capacity is likely to continue, and projects at currently nonpowered dam sites could continue to advance. New low-impact, environmentally sustainable developments could also occur.

\subsection{Technical RDD\&D}

Large-scale hydropower technologies are mature and well understood; however, smaller, lowimpact projects present an opportunity to develop low-head and modular technologies optimized for these new applications. Low-head sites generally have a change in elevation ranging from approximately 2 to 30 meters and can be incorporated at existing nonpowered dams, canals, and conduits across the United States.

DOE-funded hydropower RDD\&D focuses on developing technologies for low-head hydropower, materials and manufacturing, improved turbines, and system evaluation metrics. ${ }^{\text {xliv }}$ Through its national laboratories, DOE also supports the development of specialized design and evaluation tools that will enable new turbine designs to meet power production goals while minimizing environmental effects. Researchers are also focusing on ways to lower the environmental impact during the construction and operation of new and existing dams, although recent history indicates a limited opportunity to build new hydropower facilities with dams.

New MHK technologies are also an area of active RDD\&D ${ }^{314}$. Most MHK technologies capture kinetic energy in waves, tides, or currents, although others also focus on capturing energy from temperature and salinity gradients. There are dozens of MHK technologies under development, with a select group illustrated in Figure 8-7 that focus on capturing energy from waves. While electricity production from $\mathrm{MHK}$ is variable, tides are predictable over the long term, and waves are forecastable over the short term ${ }^{315}$.

\footnotetext{
${ }^{\text {xliv }}$ More information on DOE's hydropower program is available here: http://energy.gov/eere/water/hydropowertechnology-development.
} 

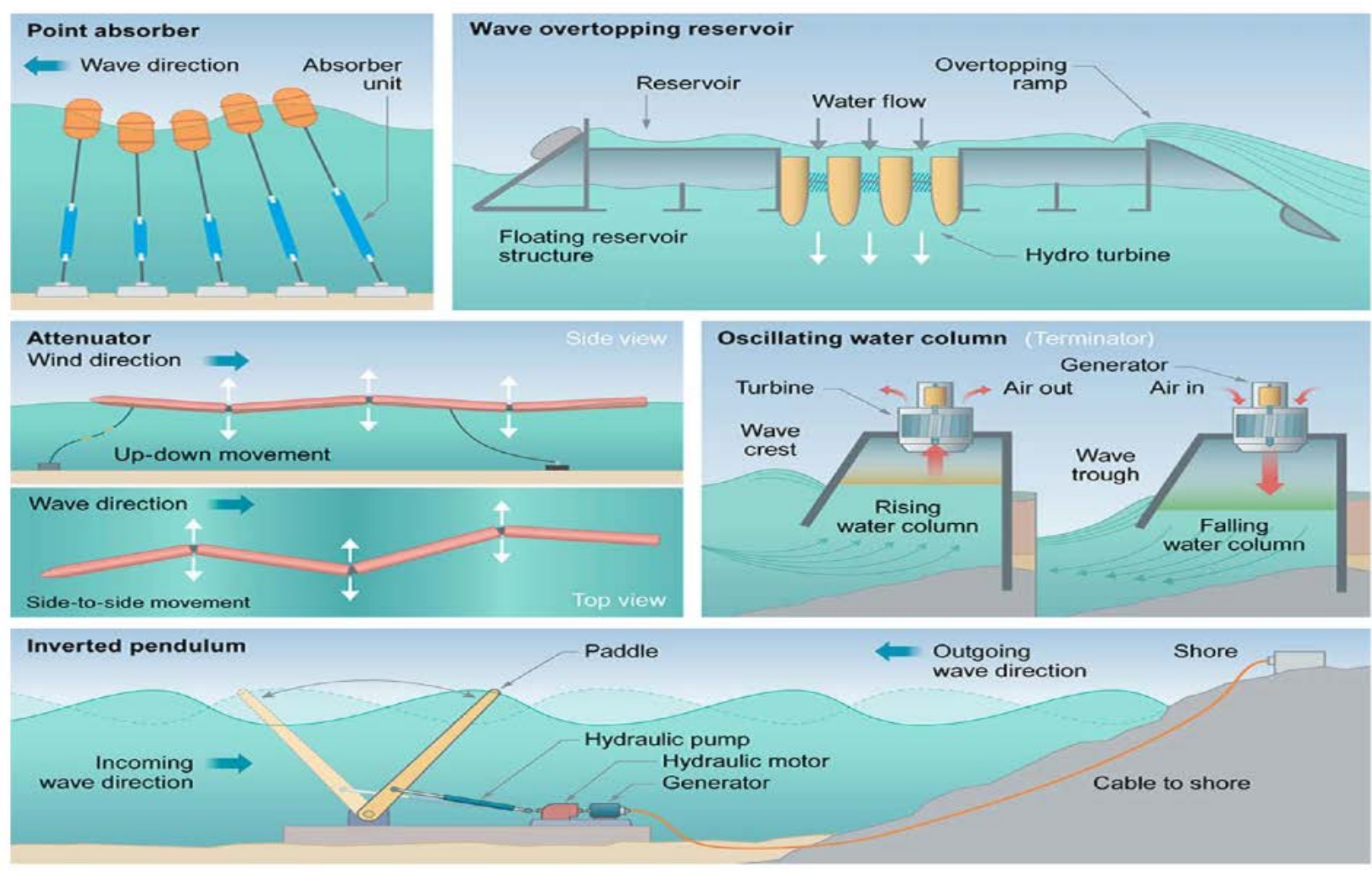

Figure 8-7. Selected wave energy conversion devices

A wide spectrum of MHK power generation technologies is under development, with most MHK technologies at an early stage of testing and pilot-scale demonstration. Wave and tidal energy conversion devices, among others, have the potential to supply coastal populations with significant quantities of renewable electricity. Source: Augustine et al. $2012^{316}$.

MHK technologies are currently in the R\&D phase, with some pilot-scale technology demonstrations. ${ }^{\text {xlv }}$ Challenges and opportunities for MHK technologies are summarized in Table 8-2. High costs are probably the single largest barrier to greater deployment, although overcoming engineering challenges of operating in harsh conditions and concerns over potential environmental impacts are also notable. With continued technology development and subsequent cost reductions, MHK applications could power remote locations or provide a substantial amount of renewable electricity for coastal load centers where electricity prices are highest ${ }^{317}$. For example, the first U.S. MHK demonstrations have occurred in Maine, Alaska, and Hawaii.

\footnotetext{
${ }^{x l v}$ More information on the DOE portfolio of MHK technology RDD\&D is available here: http://energy.gov/eere/water/marine-and-hydrokinetic-energy-research-development.
} 
Table 8-2. Challenges and Opportunities for MHK Technologies

\begin{tabular}{|c|c|c|}
\hline Issue & Challenge & Opportunity \\
\hline $\begin{array}{l}\text { Resource } \\
\text { Assessment and } \\
\text { Characterization }\end{array}$ & $\begin{array}{l}\text { Today's national resource assessments are at a } \\
\text { low resolution, making industry decisions on } \\
\text { technology development and deployment high risk. }\end{array}$ & $\begin{array}{l}\text { Higher resolution regional assessments for MHK } \\
\text { will support resource classification schemes } \\
\text { and provide more detailed information. These } \\
\text { will reduce risk for investment opportunities in } \\
\text { technology development and deployment. }\end{array}$ \\
\hline $\begin{array}{l}\text { Technology } \\
\text { Maturity }\end{array}$ & $\begin{array}{l}\text { The marine and hydrokinetic energy sector is } \\
\text { currently represented by a great diversity of } \\
\text { technology solutions and there are limited data } \\
\text { available to identify low-cost, high-performance } \\
\text { solutions with high reliability, so investments are } \\
\text { spread across all of the technology types rather } \\
\text { than focused on the most promising technology } \\
\text { development pathways. }\end{array}$ & $\begin{array}{l}\text { There are many new players taking interest in } \\
\text { development of what could be winning solutions } \\
\text { in this sector, and a national effort could with } \\
\text { entrepreneurs could develop solutions with high } \\
\text { potential to be cost competitive and environmentally } \\
\text { responsible. Identifying winning solutions would } \\
\text { establish the United States as a global leader for } \\
\text { domestic and international markets. }\end{array}$ \\
\hline Cost Reduction & $\begin{array}{l}\text { Significant innovation is still needed to bring } \\
\text { costs down by more than } 50 \% \text { to achieve cost } \\
\text { competitiveness of MHK devices. Devices need to } \\
\text { capture more energy and reduce both capital and } \\
\text { operating costs. }\end{array}$ & $\begin{array}{l}\text { Innovation mechanisms and a large body of } \\
\text { knowledge to draw from other scientific and } \\
\text { industrial sectors are available today to accelerate } \\
\text { the cost-reduction profile. }\end{array}$ \\
\hline Demonstration & $\begin{array}{l}\text { Developers who are ready to test full-scale } \\
\text { prototypes lack access to test facilities and } \\
\text { permitted demonstration sites. This impedes the } \\
\text { developer's ability to validate device performance } \\
\text { in its intended resource; test and iterate installation, } \\
\text { operation, and maintenance logistics; and monitor } \\
\text { device-to-environment interactions. }\end{array}$ & $\begin{array}{l}\text { Access to world-class test facilities and other } \\
\text { demonstration opportunities and associated } \\
\text { instrumentation have the potential to accelerate } \\
\text { technology evolution while substantially reducing } \\
\text { technology development and demonstration costs } \\
\text { to the industry. Specifically, early-adopter markets } \\
\text { may present demonstration opportunities. }\end{array}$ \\
\hline Deployment & $\begin{array}{l}\text { The process for permitting device deployments } \\
\text { can be expensive and time consuming, leaving } \\
\text { fewer resources for R\&D and increasing project } \\
\text { development costs. The lack of scientific } \\
\text { information, for example baseline environmental } \\
\text { data, and high monitoring costs can drive } \\
\text { environmental and regulatory expenses to } 30 \%- \\
50 \% \text { of total early-stage MHK project cost. }\end{array}$ & $\begin{array}{l}\text { By assessing and addressing potential } \\
\text { environmental impacts now through scientific } \\
\text { research, developing new instruments, and } \\
\text { validating them with initial device demonstrations, } \\
\text { this sector can avoid serious deployment barriers. } \\
\text { National support for environmental monitoring } \\
\text { can help reduce the monitoring cost burden } \\
\text { for developers, allowing them to focus funds } \\
\text { on technology development to approach cost } \\
\text { competitiveness and facilitate more widespread } \\
\text { deployments. }\end{array}$ \\
\hline
\end{tabular}

Source: DOE $2015^{318}$.

DOE sponsors an active research program to explore the potential for MHK, which includes research along the entire value chain - from resource characterization and technology development to simulations and multi-metric environmental impact studies. According to technical resource assessments, ${ }^{\text {xlvi }} \mathrm{MHK}$ technologies harnessing energy from waves, tides, and currents have the technical ability to produce 538-757 $\mathrm{TWh}^{\text {xlvii }}$ per year in the continental United

\footnotetext{
xlvi There are three levels of resource assessments: (1) Theoretical potential is the annual average amount of physical energy that is hypothetically available. (2) Technical resource potential is the portion of a theoretical resource that can be captured and converted into electricity using a specific technology. (3) Practical resource potential is the portion of the technical resource that is available when other siting considerations and constraints - including economic, environmental, and regulatory - are factored in.

xlvii Of this total, 378-472 TWh/year is from wave energy; 15-22 TWh/year is from tidal current energy; 45-163 $\mathrm{TWh} /$ year is from ocean current energy; and $100 \mathrm{TWh} /$ year is from river current energy.
} 
States, and 1,285-1,846 TWh per year in the entire United States (including Alaska and Hawaii) ${ }^{319}$.

\subsection{Development and Projected Future Deployment}

Forty-nine percent of U.S. hydroelectric capacity ( 8 percent of total plants) is federally owned by the Army Corps of Engineers, the Bureau of Reclamation, and TVA ${ }^{320}$, and these agencies accounted for much of the hydropower expansion through the 1960s. Additionally, billions of dollars in investments from public power, municipal, and private entities have made extensive use of Clean Renewable Energy Bonds, Build America Bonds, Qualified Energy Conservation Bonds, and other federally subsidized bond mechanisms to install hydroelectric dams, accounting for the other 51 percent of capacity and 92 percent of total plants.

The environment for construction of new or expanded hydropower capacity changed in the 1960s and 1970s with the passage of new environmental legislation such as the Clean Water Act, the National Environmental Policy Act, the Wild and Scenic Rivers Act, and the Endangered Species Act, which altered the way hydropower facilities were licensed by FERC (previously called the Federal Power Commission until 1977); the environment for construction of new or expanded hydropower capacity was also affected by changes in electricity markets that introduced wholesale generation competition ${ }^{321}$. The main focus of current hydropower expansion is a combination of equipment upgrades at existing plants; new lower-impact, run-ofriver modular component or small-scale plants; "conduits," where energy is captured from the flow of water through existing water conveyance infrastructure such as irrigation pipes; and conversion of existing nonpowered dams to include generation ${ }^{322}$. However, only about $1.4 \mathrm{GW}$ of net capacity was added between 2005 and 2013, and the vast majority of added capacity was associated with upgrades to or powering of existing dams. Capacity additions to existing powered dams, from investments in generator upgrades, accounted for the largest capacity increase, with additions to nonpowered dams coming in second. Conduit and new facilities accounted for a very small portion of new generation.

Private developments of hydroelectric dams have taken advantage of Federal tax credits, but these credits have not spurred development to the same level as other renewable generating technologies. The PTC is available to hydropower developers at $\$ 0.012 / \mathrm{kWh}$, which is half the rate of the PTC for wind and geothermal generators. Also, hydropower is only eligible for expanding and upgrading existing facilities and powering of existing dams. New stream-reach developments are currently ineligible. Most State RPS programs include hydropower as a qualified source for RPS compliance, but with some limitations such as project size (e.g., up to $30 \mathrm{MW}$ ) or a specification that no new impoundments be built ${ }^{323}$. The U.S. Congress passed legislation in 2013 that streamlined the approval process for small hydropower (less than 10 MW $)^{\text {xlviii }}$. Multiple factors, largely the environmental concerns surrounding large dams, are moving the industry away from larger plants and toward smaller plants (Figures 8-8 and 8-9).

FERC maintains a current list of PSH projects that have submitted applications for licenses and is experimenting with a new, expedited 2-year licensing process for certain hydroelectric

\footnotetext{
xlviii See the Hydropower Regulatory Efficiency Act (HR 267, S 6162) and the Bureau of Reclamation Small Conduit Hydropower Development and Rural Jobs Act (HR 678, S 6257).
} 
plants $^{324}$. As of April 2016, approximately $2.03 \mathrm{GW}$ of new PSH capacity had applied for licensing with FERC $^{325}$.

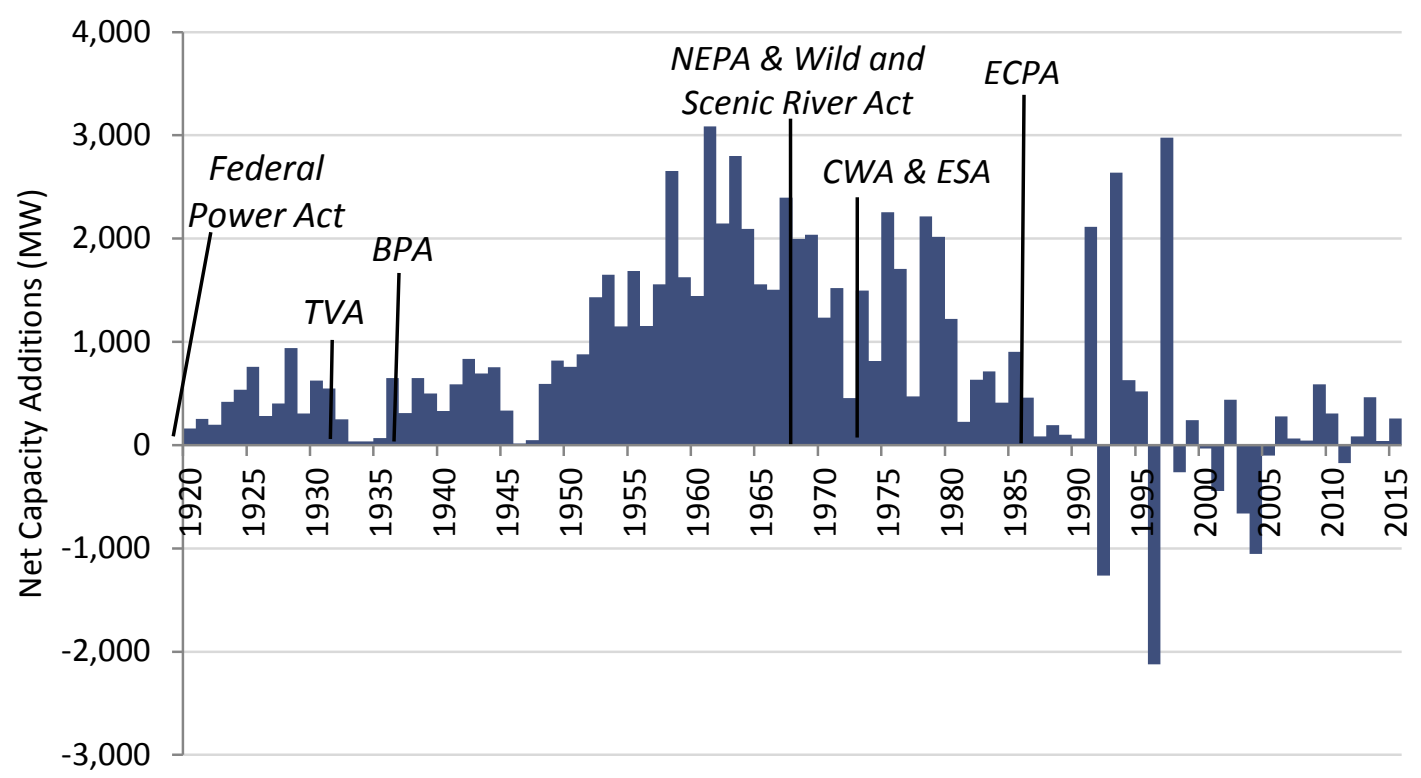

Figure 8-8. Historical annual hydropower capacity additions and retirements (MW), 1920-2015

Following policy in the 1960s and 1970s that altered FERC licensing for dams, as well as changes to market structures, the buildout of hydropower capacity has slowed ${ }^{\text {xlix }}$. Source: EIA 1990 and EIA $2016^{326}$.

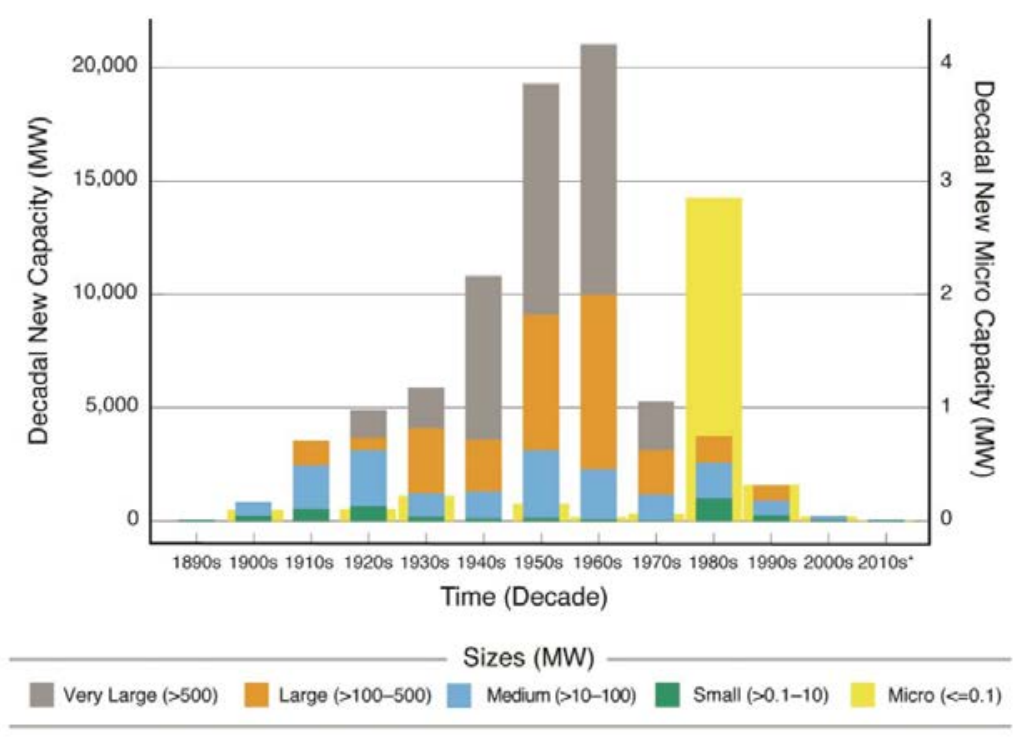

- Data for the 2010s only cover 2010-2013.

Figure 8-9. Timeline for hydropower capacity additions in the U.S. (MW), 1890-2015

The buildout of large and very large hydropower facilities peaked in the 1950s and 1960s, and has diminished since. Source: Uria-Martinez et al. $2015^{327}$.

${ }^{x l i x}$ Note: NEPA is the National Environmental Protection Act, ECPA is the Electronic Communications Privacy Act, CWA is the Clean Water Act, and ESA is the Endangered Species Act. 
Table 8-3 presents estimates of hydropower generation in 2040 from the QER 1.2 Base Case. Projections show a modest increase in hydropower generation, with the Base Case generating slightly more hydropower resources than in 2014. Potential MHK generation is not included in these projections.

Table 8-3. QER 1.2 Base Case Generation for Hydropower (TWh), 2014-2040

\begin{tabular}{|l|c|c|}
\hline & 2014 Actual & QER 1.2 Base Case \\
Hydropower & 255 & $290)$ \\
\hline
\end{tabular}

The QER1.2 Base Case and Side Case both show modest deployment of hydropower. Source: EPSA $2016^{328}$

Global growth of hydroelectric generation is expected to be fairly robust in nearly all of the IEA scenarios (Table 8-4). Generation is expected to increase by nearly 60 percent by 2040 in the Current and New Policies scenarios, and by nearly 80 percent in the 450 Scenario. Much of the new capacity is expected to be installed in China, Latin America, Africa, and India (Figure 8-10).

Table 8-4. Historical and Projected Global Hydroelectric Generation by Scenario Outlook

\begin{tabular}{|l|c|c|c|c|c|c|c|c|}
\hline & \multicolumn{2}{|c|}{} & \multicolumn{2}{|c|}{ New Policies } & Current Policies & \multicolumn{2}{|c|}{450} \\
\hline & $\mathbf{2 0 0 0}$ & $\mathbf{2 0 1 3}$ & $\mathbf{2 0 2 0}$ & $\mathbf{2 0 4 0}$ & $\mathbf{2 0 2 0}$ & $\mathbf{2 0 4 0}$ & $\mathbf{2 0 2 0}$ & $\mathbf{2 0 4 0}$ \\
\hline $\begin{array}{l}\text { Hydro Generation } \\
\text { (TWh) }\end{array}$ & 2,620 & 3,789 & 4,456 & 6,180 & 4,423 & 5,902 & 4,464 & 6,836 \\
\hline $\begin{array}{l}\text { Percentage of Global } \\
\text { Total }\end{array}$ & 17 & 16 & 16 & 16 & 16 & 14 & 17 & 20 \\
\hline
\end{tabular}

Source: IEA $2015^{329}$. 


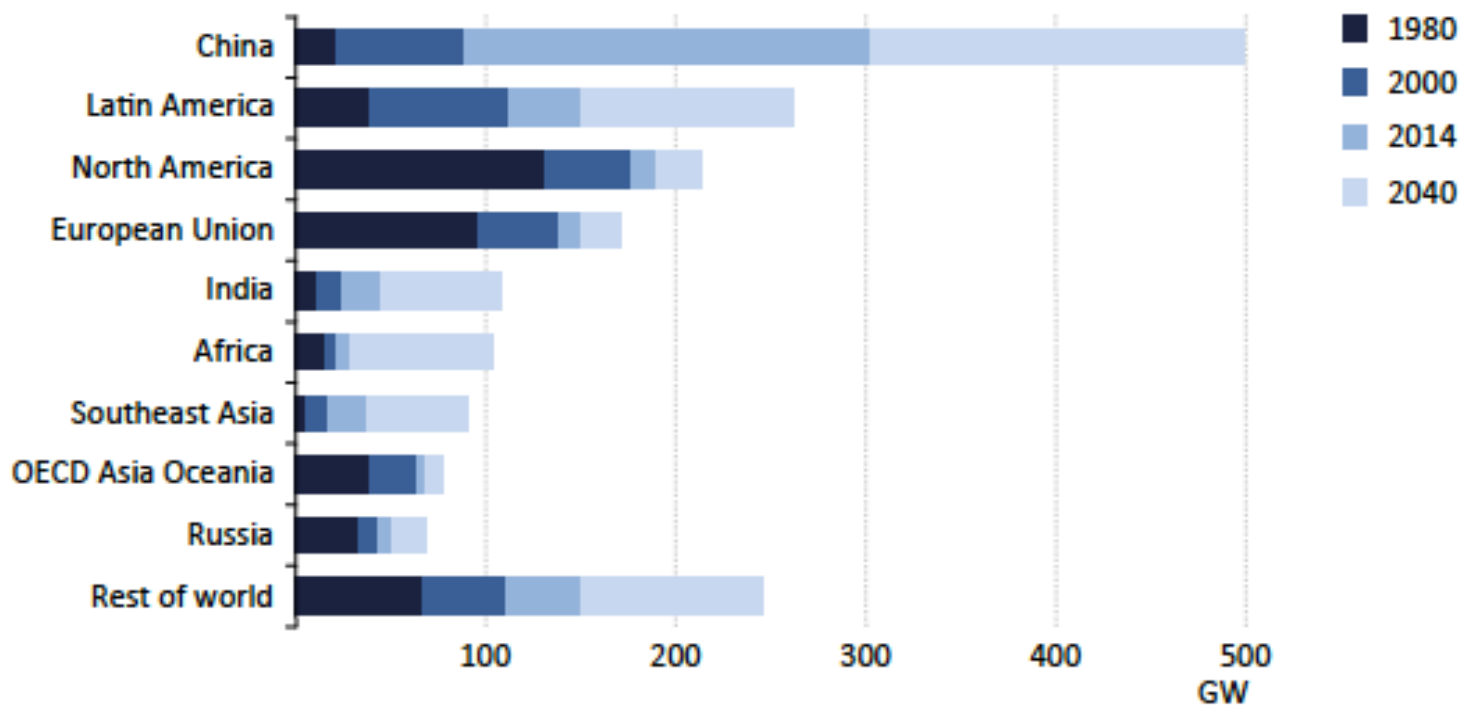

Figure 8-10. Historical and projected hydropower capacity (GW) by region (IEA New Policies Scenario)

Much of the new hydropower capacity is expected to be installed in China, Latin America, Africa, and India. Source: IEA $2015^{330}$. 


\section{Wind}

\subsection{Technologies}

Wind turbines utilize the kinetic energy of wind to turn a rotor. While there are several possible configurations for wind turbines, most have three blades mounted on a horizontal axis at the top of a tower. The blades turn a rotor that is connected to a shaft, which spins a generator to produce electricity. Most turbines maintain an upwind orientation, meaning they use a weather vane and yaw drive/motor to keep the blades facing into the wind.

In the United States, nearly all operating capacity currently comes from land-based wind turbines. While there has been significant deployment of offshore wind in Europe, to date, there has been little offshore wind deployment domestically. However, in July 2015, Deepwater Wind began construction of what became the first offshore wind farm in the United States, ${ }^{1}$ with the first commercial delivery of power announced in December 2016. Over the past 30 years, utilityscale wind turbine technology has made notable advances, including higher hub heights, longer rotor blades, and more sophisticated electronics ${ }^{331}$. These improvements allow for access to faster and more consistent wind speeds, which increases the capacity factor, resulting in lower LCOE.

Wind turbines are generally available to produce power around 95 percent of the time. However, wind power is variable and depends on the local weather conditions and cannot be fully dispatched on demand. Further, the wind speed must be great enough to turn the turbine, which is a limiting factor for generating availability. Wind turbines generally have a cut-in and cut-out wind speed so that they are only spinning in a range of wind conditions where they can operate efficiently and safely. ${ }^{\text {li }}$ The ability to forecast wind, and thus anticipate its dispatch availability, has also improved in recent years and is critical to the future viability of wind power.

The generating capacity of a single wind turbine can range anywhere from $2 \mathrm{~kW}$ to $8 \mathrm{MW}$, depending on application, hub height, and blade length. Wind turbines can be utility-scale - in which multiple turbines are usually grouped together or along a ridgeline to form a "wind farm" or wind plant —or they can be used in distributed applications. Variable generator output of the rotating blades is converted by power control equipment at the base of each tower to match power output with the frequency of the electrical grid. Over time, turbines have increased in nameplate capacity, and hub heights and blade lengths have grown to increase the total energy captured by each turbine; however, even with these improvements, which have led to greater energy extraction, wind turbine technologies remain constrained by the Betz limit of 59.3 percent maximum efficiency ${ }^{332}$. Higher hub heights allow for access to faster and more consistent wind speeds, which can lower the life-cycle cost of electricity and increase the capacity factor for wind turbines ${ }^{333}$. Turbines originally designed for lower wind speeds have also rapidly gained market share in recent years, enabling wind deployment for a wider variety of wind resources ${ }^{334}$. Additional information on wind turbine generators is available in Appendix A.

\footnotetext{
${ }^{1}$ Offshore wind is more developed in Europe, where offshore wind technology has 25 -year performance record and now accounts for $11 \mathrm{GW}$ of generation capacity on the continent (Cusick 2016).

${ }^{\mathrm{li}}$ Utility-scale wind turbines generally require an average wind speed of 9 miles per hour minimum to achieve cutin. The typical cut-out speed, for safety reasons, is normally around 55 miles per hour for utility-scale turbines (Duke Energy 2012).
} 


\subsection{Operational Attributes and Fleet Characteristics}

Power generation from wind has grown rapidly over the past decade (Figure 9-1) and by 2015, contributed nearly 5 percent of the total electricity generation (191 TWh) in the United States ${ }^{335}$. According to the American Wind Energy Association (AWEA), installed wind capacity was more than $74 \mathrm{GW}$ in $2015^{336}$. Wind capacity has grown significantly in the last decade, starting from a base of less than $9 \mathrm{GW}$ installed nationally in 2005 and slowing only in the last few years ${ }^{337}$. A small portion of total wind generating capacity is classified as distributed, and this accounted for approximately $1 \mathrm{GW}$ in $2014^{338}$, lii.

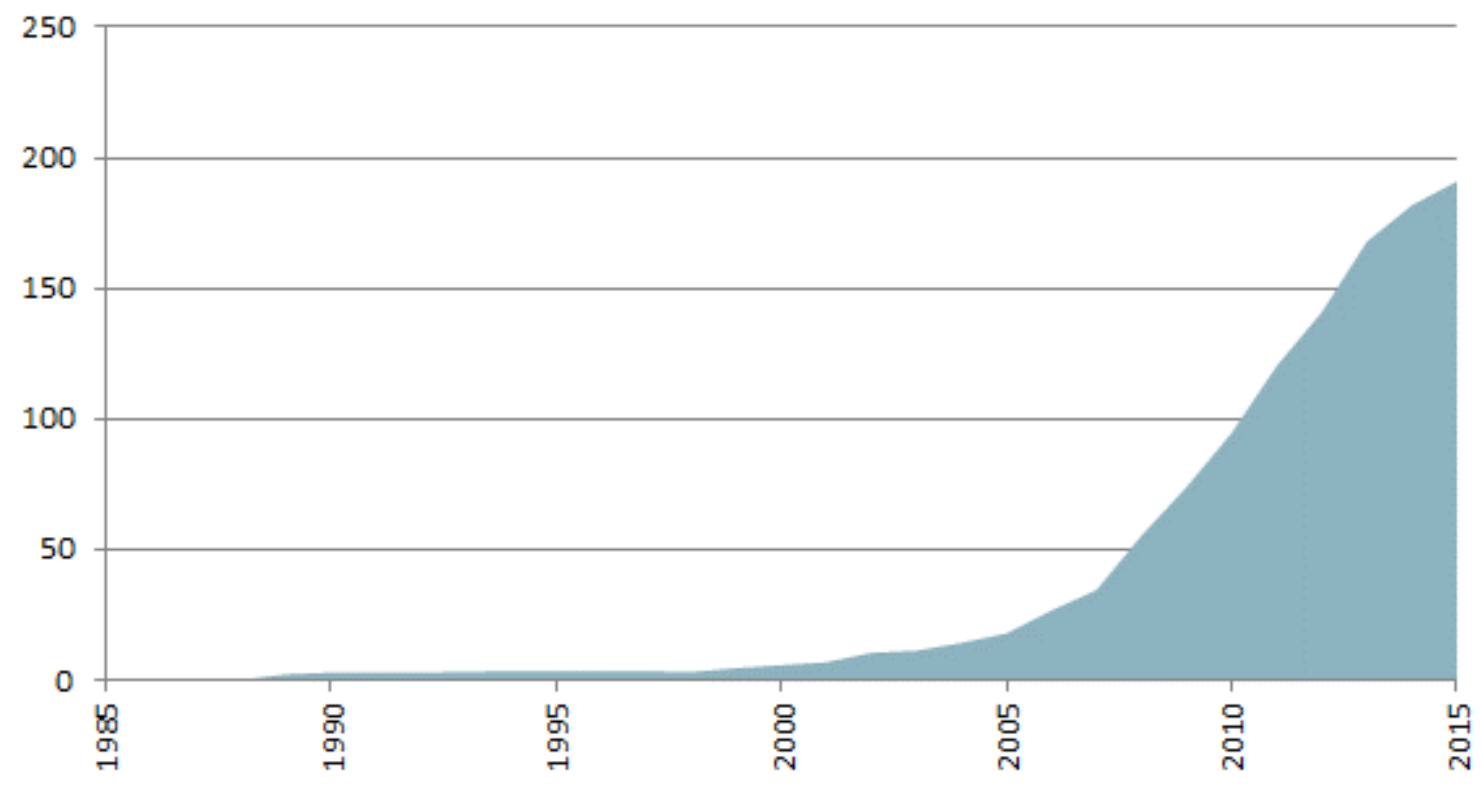

Figure 9-1. U.S wind generation (TWh), 1985-2015

Source: EIA $2016^{339}$.

In 2015, the average capacity factor for the existing fleet of wind turbines was around 35 percent (Figure 9-2). Capacity factors of wind are highly dependent on the resource, and higher hub heights and longer blades can increase the capacity factor in areas with high wind shear and low turbulence.

Figure 9-3 shows that Texas has the largest installed wind capacity and generation of all the states, with California and Iowa coming in second for capacity and generation, respectively. Notably, several states in the southeastern United States do not have any installed utility-scale wind capacity, due in part to relatively lower wind speeds (Figure 9-3).

\footnotetext{
${ }^{\text {lii }}$ Distributed wind systems are connected on the customer side of the meter to meet the onsite load or are connected directly to distribution or microgrids to support grid operations or offset large loads nearby. Distributed wind systems are defined by technology application, not technology size, and are typically smaller than $20 \mathrm{MW}$ (DOE 2015f).
} 

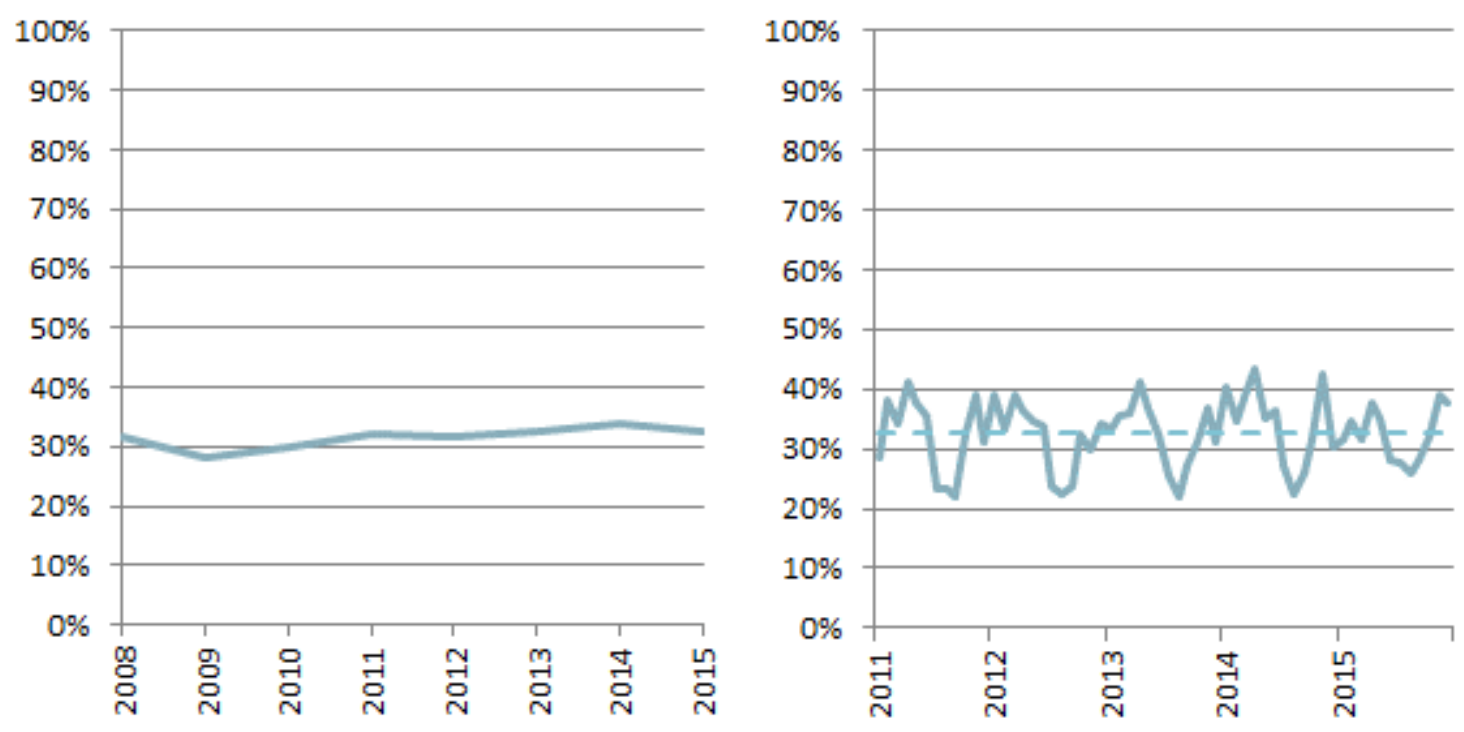

Figure 9-2. U.S. average annual and monthly wind generator capacity factors

Wind capacity factors have increased slightly from a low in 2009. Generating availability is based on local weather conditions, but advances in turbine design could contribute to future increases in capacity factors. Sources: SNL $2015^{340}$. 


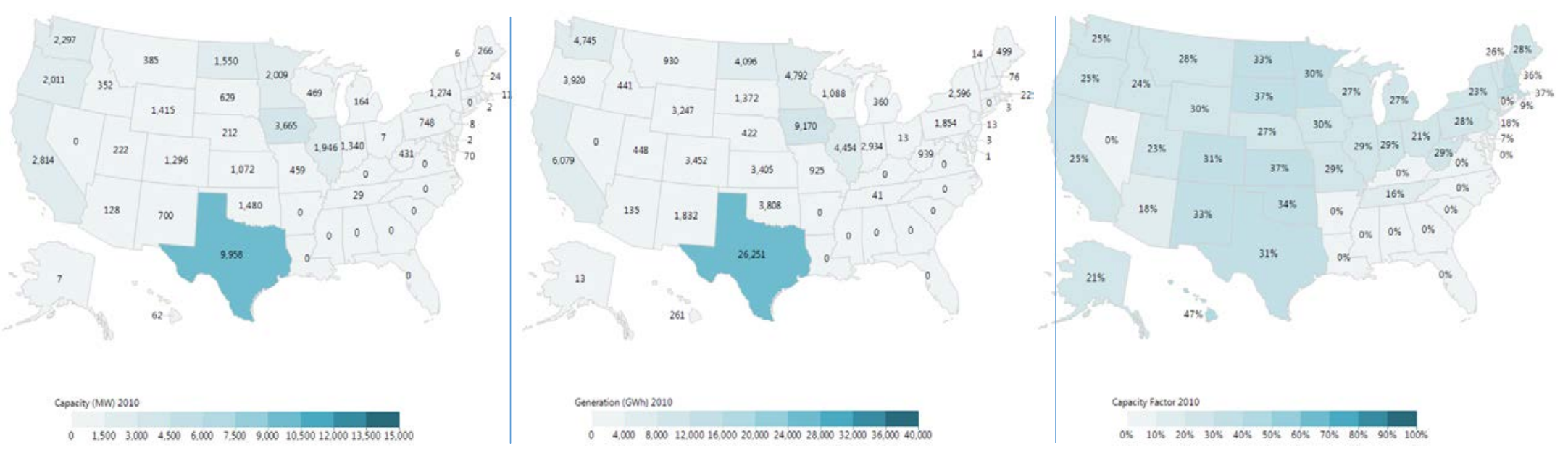

2014

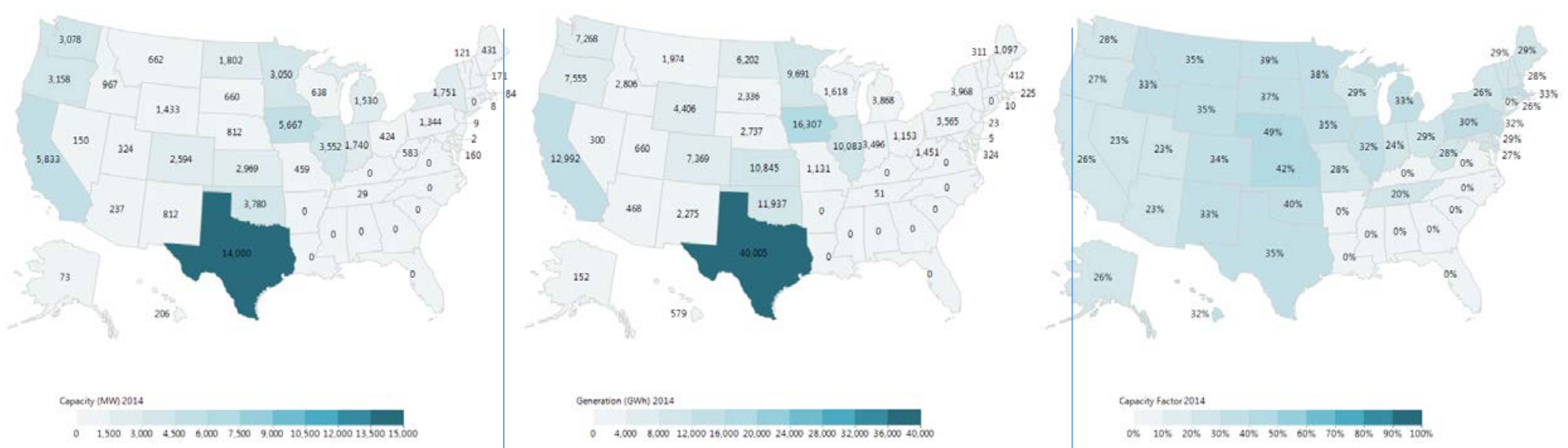

Figure 9-3. Wind capacity (left), generation (middle), and capacity factor (right) by state. Top: 2010; bottom: 2014.

Installed wind capacity increased by over 60 percent from 2010 to 2014. Texas had the largest capacity and generation, with California and Iowa next over the 5 year period. The southeastern United States has a notable dearth of wind installations. Source: EIA $2016^{341}$. 
A majority of wind capacity was installed in the last 10 years, as shown in Figure 9-4 ${ }^{342}$. Wind turbines are modeled to have an effective life of between 20 and 30 years $^{343}$. At the end of life, turbines can be replaced with newer, more efficient turbines, utilizing the existing power system infrastructure. This process is referred to as repowering.

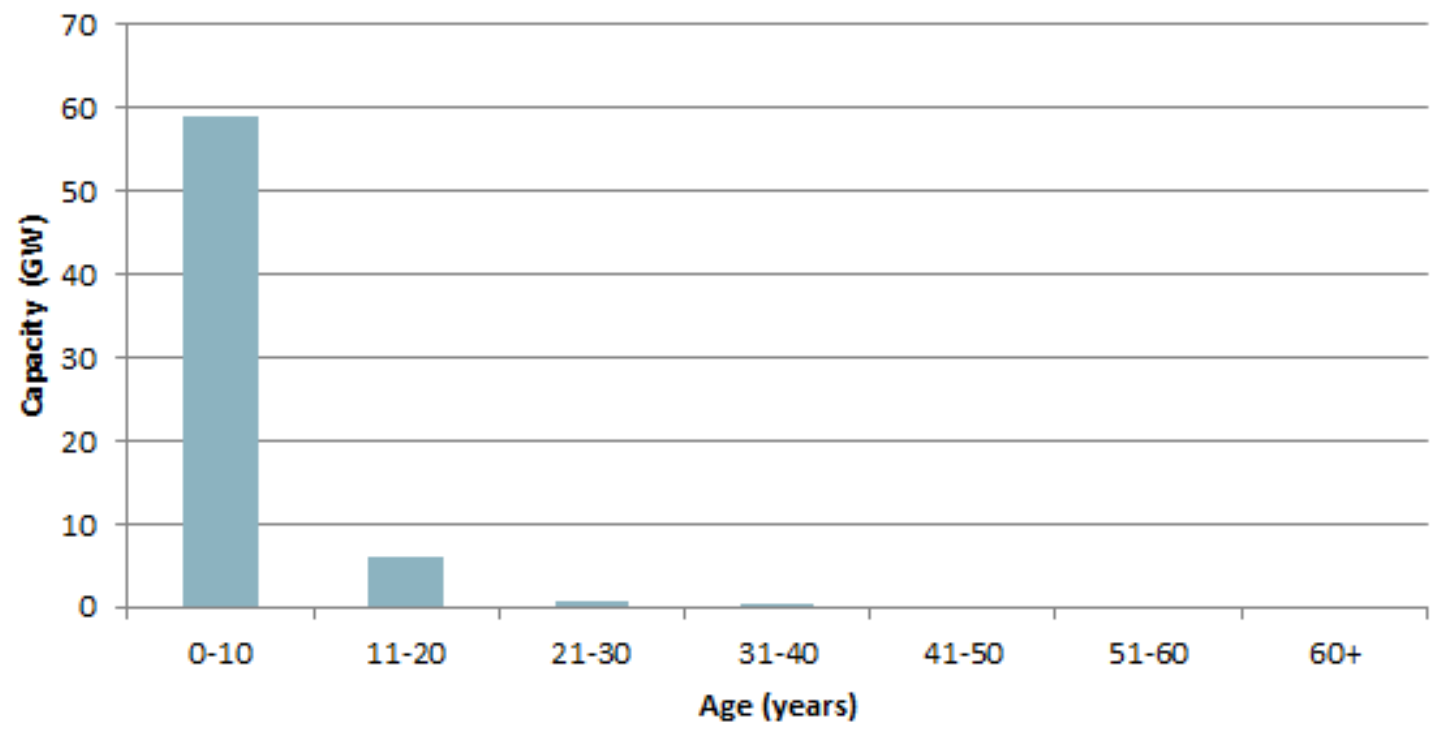

Figure 9-4. Age profile of U.S. wind generation fleet, 2014

The majority of wind capacity is less than 10 years old. Source: SNL $2015^{344}$.

\subsection{Technology Costs}

The LCOE for land-based and offshore wind power generation is shown in Table 9-1. The LCOE of land-based wind is comparable with other forms of generation such as NGCC, although as discussed further in Section 3.4.1, it is difficult to directly compare dispatchable and nondispatchable technologies. The LCOE of offshore wind is higher than land-based wind due to lower technology maturity and the difficulty of operating in the marine environment, which increases balance of plant (foundations, transmission cables, etc.), installation, and O\&M costs.

Table 9-1. LCOE for New Wind Generation (2013\$/MWh)

\begin{tabular}{|l|l|l|l|l|l|l|}
\hline & \multicolumn{3}{|l|}{ EIA } & \multicolumn{2}{l|}{ NREL } & \multicolumn{2}{l|}{ Lazard } \\
& Low & High & Low & High & Low & High \\
\hline Wind, Land-Based & 37.09 & 117.76 & 35.36 & 88.87 & 26.30 & 81.86 \\
\hline Wind, Offshore & 117.22 & 279.25 & 114.75 & 241.09 & 81.27 & 218.10 \\
\hline
\end{tabular}

Current ranges of wind technology prices using cost assumptions from three sources: NREL 2015; EIA 2015; Lazard 2015 $5^{345}$. Calculation does not include the PTC. See Appendix B for more information on LCOE calculations.

\subsection{Fuel/Resource}

Wind resources in the United States vary from state to state, but, in general, the largest resources are located in the Midwest and offshore from the coast. As of mid-2016, only land-based wind resources are developed, but offshore resources hold great potential for future development. 
Wind speeds at 100 meters above the surface for land-based and offshore applications are shown in Figure 9-5. Wind speeds tend to be higher and steadier at higher altitudes and in off-shore locations. According to a 2012 study by NREL, the technical potential for onshore wind generation was $32,700 \mathrm{TWh}$ and for offshore wind power $17,000 \mathrm{TWh}^{346}$.

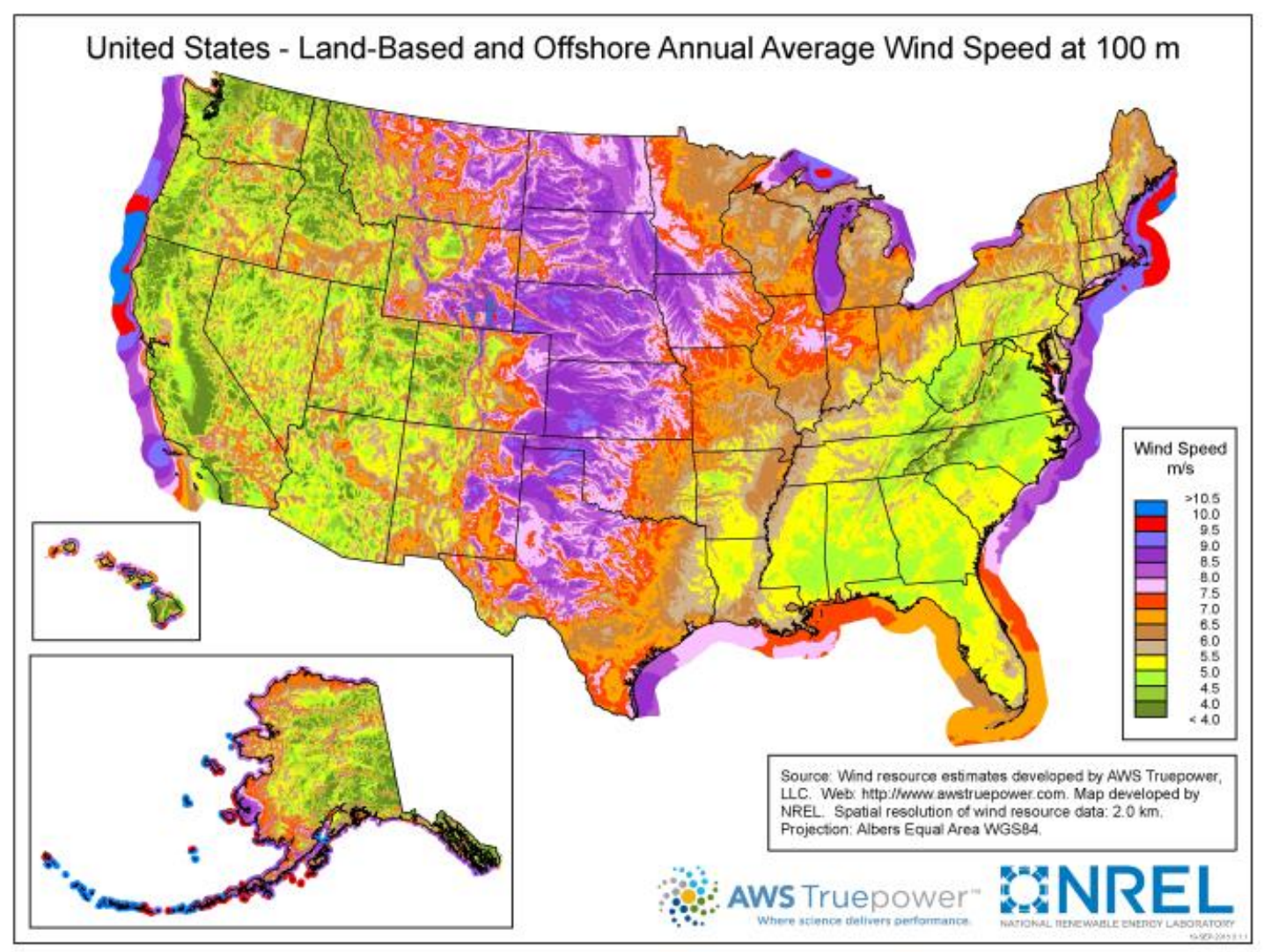

Figure 9-5. Land-based and offshore wind speeds at $100 \mathrm{~m}$

In general, the largest U.S wind resources are located in the Midwest and offshore from the coasts. Source: NREL $2014^{347}$.

\subsection{Environmental Impacts}

\subsubsection{Upstream}

Wind turbines often rely on magnets made of rare earth elements to generate electricity. Some environmental concerns with mining rare earth metals are potential radioactivity, acidification, eutrophication, toxicity, and large energy footprint for extraction ${ }^{348}$. These impacts will vary by mining method. There is also some concern over supply chains for some of these materials, as most of the U.S. supply is imported from China ${ }^{349}$. Rare earth elements are only a small portion of the total materials needed to build a turbine, however. Fiberglass is another major component of turbines that is used in the blades, and its main ingredient is sand, which must also be mined $^{350}$. Two of the most important materials for construction are steel and copper, but these materials are not unique to wind turbines. 
The effects of noise associated with pile-driving and other construction activities on marine mammals are a significant concern for offshore wind.

\subsubsection{Emissions and Environmental Impact}

Except for construction and decommissioning, wind turbines do not have any emissions associated with power generation. The life-cycle carbon emissions per $\mathrm{kWh}$ of wind are estimated at about 50 times less than that of coal-fired power plants ${ }^{351}$.

Birds and bats occasionally collide with wind turbines; on land, these impacts are generally more significant for bats than for most birds. Impacts to protected species such as Bald and Golden Eagles are of particular concern. Wind development may also displace some ground-nesting birds from key habitats. Potential impacts to human communities and land use include concerns about noise and visual impacts on communities if sited too close to residences, as well as interference with air traffic control, surveillance, and weather radar systems.

Bird collisions and habitat displacement impacts are an issue for offshore wind as well, though these impacts are likely to be smaller because bird abundance declines with distance from shore.

\subsection{Constraints}

One of the main challenges to utilizing wind energy is integrating it into the electrical grid because of the variability and uncertainty of its output ${ }^{352}$. Wind speed is highly dependent on weather patterns, which can lead to variability in power production (wind power is proportional to the cube of wind speed). Improvements in wind forecasting technologies have the potential to further reduce integration costs and increase wind dispatchability. Connected to variability is uncertainty in wind resource forecasting. In order to bid accurately into power markets, dayahead forecasts of wind resources are needed to determine expected production. Forecast systems generally follow the same steps: prediction of wind or solar patterns based on weather forecasts and onsite observations, simulation of power generation, and regional power forecast $^{353}$.

For example, ERCOT and MISO, which coordinate, control, and monitor the electricity transmission grid in Texas and the Midwest, respectively, and contain a significant amount of the nation's installed wind capacity, both operate day-ahead and real-time energy markets, which allow for grid operators to balance uncertainty and variability from wind production ${ }^{354}$. The European electricity system further includes intraday markets, which aid in wind integration ${ }^{355}$. Also, operating a large balancing area reduces the variability of wind power production by aggregating the output from multiple generators ${ }^{356}$.

Long-distance, high-voltage transmission lines are required to connect wind plants in highquality resource areas (such as the Great Plains) to highly populated urban centers on the East and West Coasts. Planning, obtaining regulatory approval, and building high-voltage transmission lines can take more than a decade ${ }^{357}$. Legal challenges can add additional delay ${ }^{358}$. Barriers to transmission infrastructure expansion include regulatory hurdles, multiple layers of overlapping jurisdictions, and public opposition. Not all wind plants need new transmission lines, and plant retirements may open capacity in existing transmission corridors. 
Transmission congestion may also be a barrier to incorporating large amounts of wind energy. In Texas, significant transmission congestion in the northern part of the state was causing wind curtailments and negative wholesale electricity prices. As a result, the Public Utility Commission of Texas created Competitive Renewable Energy Zones with high wind resource potential and authorized transmission expansion to these areas. The result was a significant build out of wind resources and a reduction in congestion that limited wind curtailments ${ }^{359}$.

In addition to transmission congestion, curtailment of wind generation can occur when wind generation occurs during off-peak or nighttime hours when electricity demand is low. If other generators on the system with minimum generation requirements, such as nuclear or fossil units, cannot have generation further reduced, then the wind generation is curtailed.

Beyond integration and transmission issues, opportunities to increase deployment and generation from wind energy include the following: increasing wind plant performance through better understanding of the physics of intraplant flows and turbine-turbine interactions to inform plant level control strategies; reducing costs for offshore wind, particularly in floating applications; overcoming logistical limits (e.g., highway overpasses, turning radius) associated with the transport of taller towers and larger rotors to installation sites; and alleviating siting challenges associated with wildlife.

Wind power development might continue to face challenges of siting opposition and transmission constraints ${ }^{360}$. Siting wind plants can sometimes be contentious due to concerns over wildlife, radar interference, and nearby residences, where noise and flicker ${ }^{\text {liii }}$ can be an issue if homes are too close to turbines. Wind turbines are generally impacted by zoning ordinances if sited within urban and rural inhabited spaces. Bird and bat mortality due to collision with wind turbines remains an important consideration in siting and operating wind plants nationwide, although changes in wind technology may have reduced some of the earlier concerns. ${ }^{\text {liv }}$ Concerns about endangered bat mortality have made siting more challenging in the East, and concerns about impacts to Bald and Golden Eagles and about habitat displacement of groundnesting birds like Greater Sage-Grouse are significant issues in the West. ${ }^{\text {lv }}$ There is substantial research underway to minimize the impacts of wind power on wildlife ${ }^{361}$.

Wind turbines can interfere with civilian and military radar, causing 'clutter' (i.e., false targets) if sited in certain locations ${ }^{362}$. The Federal Aviation Administration has jurisdiction over structures sited over $200 \mathrm{ft}$ (current blade tip heights are approaching $500 \mathrm{ft}$ ), and siting concerns about radar are covered in the permitting process ${ }^{363}$. If wind farm siting is found to potentially impact radar systems, there are a variety of software and hardware solutions available, and more modern solutions are in development. For cases of severe impacts or where an individual radar is affected by multiple facilities, software and hardware mitigation measures are being developed ${ }^{364}$.

\footnotetext{
liii Flicker refers to the changing projections of shadow and light that can occur when turbines are located between the sun (when it is low on the horizon) and residences. Flicker has been reported to create disturbances for residents near wind plants, but these can be obviated by siting plants a minimum distance from residential neighborhoods.

${ }^{\text {liv }}$ For example, early wind turbines spun at 60-80 rotations per minute and were mounted on lattice towers at $60-80$ feet above the ground. Today's turbines rotate at 11-28 rotations per minute and are mounted nearly 300 feet above the ground. For more, see NWCC 2010.

${ }^{\mathrm{lv}}$ For more, see NWCC 2010.
} 
With the increasing size of rotors and towers, transportation of turbine pieces is presenting challenges. Trucks and rail cars need to be specially designed to carry longer turbine blades across the country ${ }^{365}$. Some manufacturing constraints have been seen in the manufacturing process for pieces that make up the motor in the nacelle, potentially leading to project delays ${ }^{366}$. Rare earth metals used for magnets in the generator may be a limiting factor, depending on the mining supply and the rate of wind development.

\subsection{Technical RDD\&D}

Wind plants now have the ability to provide important grid services, including synthetic inertia, governor response, and regulation ${ }^{367}$; however, they are not currently required to do so. ${ }^{\text {lvi }}$ Power converters can provide several services to assist in the integration of wind, such as frequency and voltage disturbance ride-through, voltage and ramping control, and reactive power control ${ }^{368}$. Converters can also allow wind power plants to provide a controlled inertial response ${ }^{369}$. Still, increasing amounts of variable generation like wind introduce uncertainty that grid operators must understand and manage.

Technological improvements can reduce LCOE by decreasing capital costs or improving performance and capacity factors. Taller towers, for example, improve turbine performance and can increase capacity factor in areas with high wind shear, as well as support the use of larger rotors that sweep larger areas and utilize more of the available wind resource ${ }^{370}$. In addition, larger rotor-swept areas combined with turbine technologies designed for lower wind speeds can boost capacity factors in lower wind resource areas, increasing the potential areas that are viable for wind deployment ${ }^{371}$.

With technologies considered 'near future,' wind turbines could approach the capacity factor of coal-fired power plants (average of 60 percent) at $140 \mathrm{~m}$ hub heights ${ }^{372}$.

Developing advanced materials for wind components and tower structures can make turbines lighter, more resistant to wear and tear, and more responsive to sudden shifts in wind speeds ${ }^{373}$. New blade designs and materials can enable larger rotor diameters and facilitate fabrication, transportation, and assembly ${ }^{374}$.

A current priority area for wind research is plant optimization. DOE is targeting significant LCOE reductions through systems-level research on the complex physics governing electricity generation from wind plants, leveraging high-fidelity modeling and high-performance computing platforms. For example, systems-level controls can monitor how wind turbines interact with air inflow and with one another, and use active wake control to mitigate energy and performance $\operatorname{losses}^{375}$.

Offshore wind generally offers stronger, more consistent winds and higher capacity factors than land-based wind in many parts of the country. With technical innovations in offshore wind platforms and turbine materials, offshore wind could achieve lower LCOE by siting plants in

\footnotetext{
lvi In December 2015, NERC issued five general recommendations as part of its Essential Reliability Services Task Force Measures Framework Report that focus on the incorporation of these services into the design of variable generating resources in the future (NERC 2015c). Shortly thereafter, on February 18, 2016, FERC issued a Notice of Inquiry, Docket RM16-6000, seeking comment on the need for market reforms to support the provision of essential reliability services by all generators (FERC 2016).
} 
locations that allow developers to utilize more energetic wind resources. These sites are usually farther from shore or in deeper waters, which increases capital and O\&M costs. More than 60 percent of the offshore wind resources within 50 miles of U.S. coasts are located in deep water, where traditional bottom-fixed foundations such as those already developed and deployed in Europe cannot be used ${ }^{376}$. DOE has supported research into several different types of floating foundations, which could have lower materials and installation costs than fixed-bottom foundations.

\subsection{Development and Projected Future Deployment}

Wind deployment has been sensitive to the availability of the PTC, and new builds declined significantly as recently as 2013 when the PTC temporarily expired (Figure 9-6). In December 2015, Congress included an extension of the PTC in its omnibus spending bill. The PTC currently offers qualified wind projects a $\$ .023 / \mathrm{kWh}$ tax credit and is now available until December 31, 2019, with a phase-down commencing construction clause for projects beginning after December 31, $2016^{377}$.

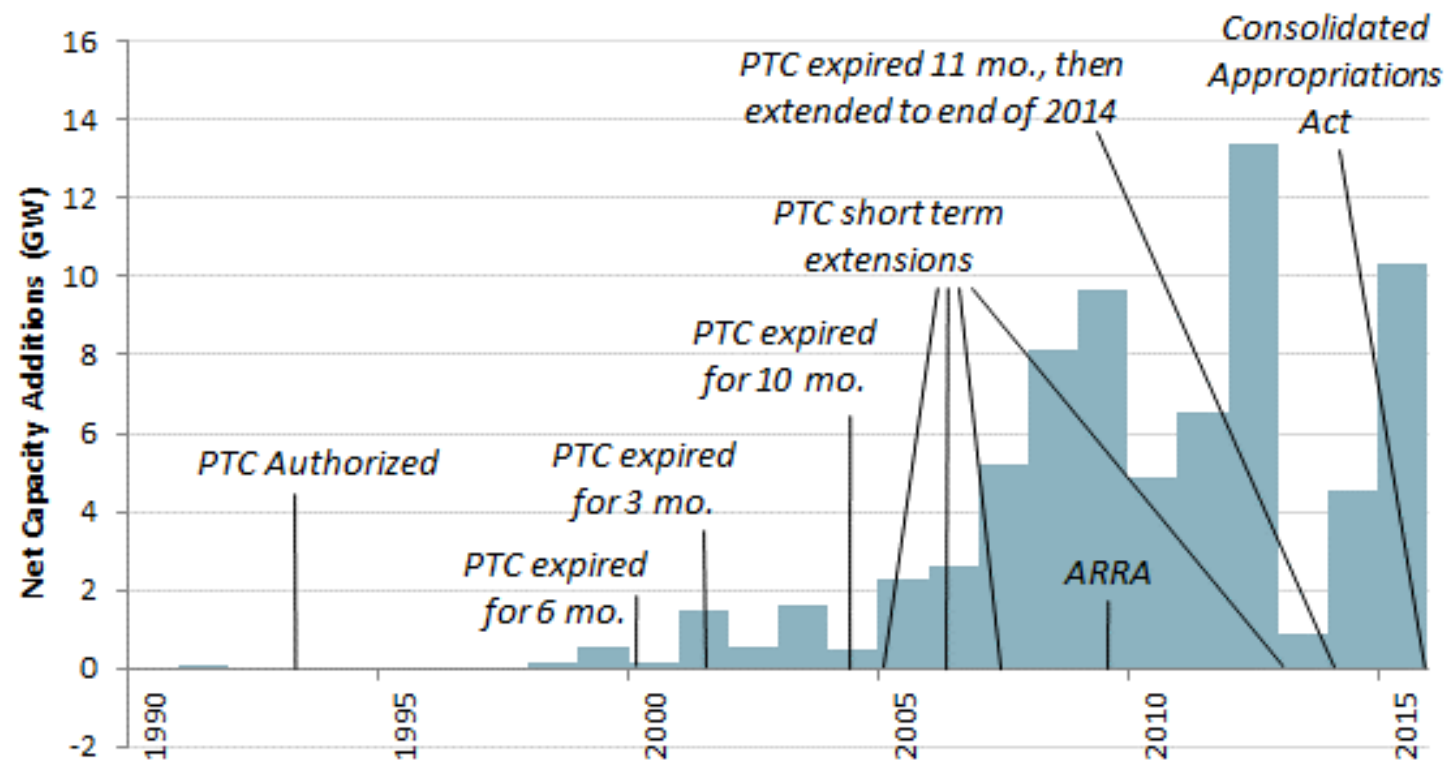

Figure 9-6. Historical annual wind capacity additions (GW), 1990-2015

Wind development has been sensitive to the availability of the PTC, with significant drops in buildout observed following expirations of the credit. Source: EIA 1990 and EIA $2016^{378}$.

State RPS policies are a driver of wind deployment, as wind energy is a cost-effective way for regulated utilities to achieve compliance. Roughly 54 percent of wind capacity built from 1998 to 2014 serves an entity with RPS mandates ${ }^{379}$.

Because wind sales are generally contracted at a fixed price over 20 years in the form of a PPA, wind can also be used to provide a "hedge" against rising or uncertain natural gas prices ${ }^{380}$. The continued decline in average levelized wind PPA prices, along with a continued rebound in wholesale power prices, left average wind PPA prices signed in 2014 (including the PTC) below the bottom of the range of nationwide wholesale power prices at approximately $\$ 23.50 / \mathrm{MWh}$. 
Wind PPA prices are most competitive with wholesale power prices in the interior region. The average price stream of wind PPAs executed in 2014 also compares favorably to a range of projections of the fuel costs of natural gas-fired generation extending out through $2040^{381}$.

Advances in wind power technologies are opening new wind markets. Higher towers allow developers to access higher quality resources or to expand wind development to new regions like the Southeast that typically have low-wind resources ${ }^{382}$.

The 5-year extension of the PTC for wind that occurred in late 2015 could help smooth out the construction glut expected for 2016, relieving pressure on supply chains, and could increase the expected cumulative installations between 2016 and 2021 by 76 percent, from $25 \mathrm{GW}$ to 44 $\mathrm{GW}^{383}$. After the expiration of the PTC in 2019, the CPP's Clean Energy Incentive Program could further boost wind installations, depending on how states draft their compliance plans. Additionally, RPS mandates and low LCOE could promote increased wind installations in the United States.

In the QER 1.2 Base Case, the outlook for wind generation is strong while the existing tax credits are available (Table 9-2). Between 2017 and 2024, wind generation nearly doubles.

Table 9-2. QER 1.2 Base Case Generation for Wind (TWh), 2014-2040

\begin{tabular}{|l|c|c|}
\hline & 2014 Actual & $\begin{array}{c}\text { QER 1.2 Base Case } \\
(2040)\end{array}$ \\
\hline $\begin{array}{l}\text { Wind Generation } \\
\text { (Land-Based) }\end{array}$ & 178 & 432 \\
\hline
\end{tabular}

Source: EPSA $2016^{384}$

Global growth of wind generation is expected to be strong in all the IEA scenarios (Table 9-3). Generation is projected to increase nearly 6-fold by 2040 in the New Policies Scenario. To reach the goals of the 450 Scenario, nearly twice as much wind generation will be needed than the current policies are forecast to incent. Between 2015 and 2024, China, the EU, and North America are expected to be the countries with the highest demand for wind installation (Figure 9-7).

Table 9-3. Global Wind Generation Projections

\begin{tabular}{|l|c|c|c|c|c|c|c|}
\hline IEA Scenario & & \multicolumn{2}{|c|}{ New Policies } & \multicolumn{2}{|c|}{ Current Policies } & \multicolumn{2}{|c|}{450} \\
\hline & $\mathbf{2 0 1 3}$ & $\mathbf{2 0 2 0}$ & $\mathbf{2 0 4 0}$ & $\mathbf{2 0 2 0}$ & $\mathbf{2 0 4 0}$ & $\mathbf{2 0 2 0}$ & $\mathbf{2 0 4 0}$ \\
\hline $\begin{array}{l}\text { Wind Generation } \\
\text { (TWh) }\end{array}$ & 635 & 1,407 & 3,568 & 1,319 & 2,778 & 1,507 & 5,101 \\
\hline $\begin{array}{l}\text { Percentage of Global } \\
\text { Total }\end{array}$ & 2.7 & 5.2 & 9 & 4.7 & 6.4 & 5.8 & 15 \\
\hline
\end{tabular}

The 450 Scenario results in nearly twice as much wind generation as the Current Policies Scenario. Source: IEA $2015^{385}$. 


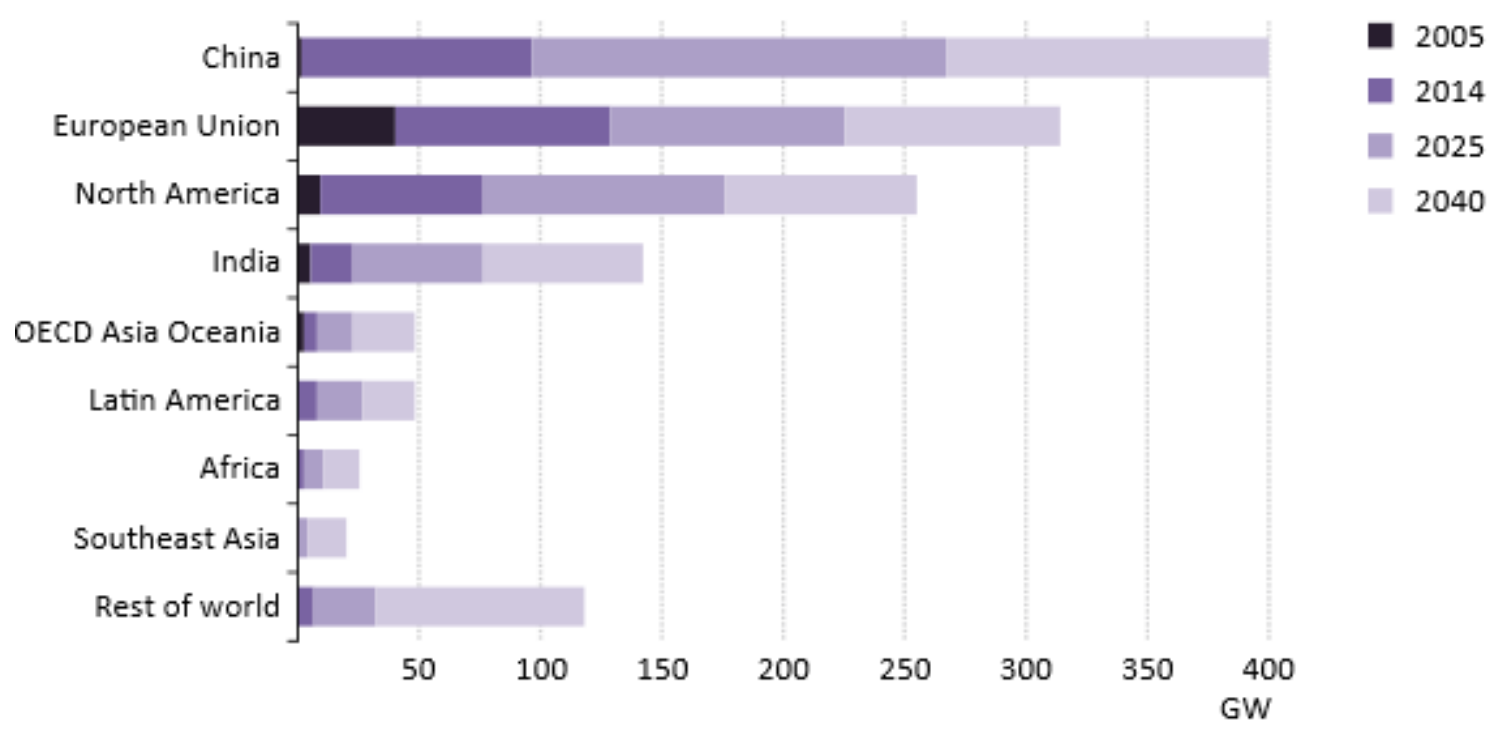

Figure 9-7. Global wind power capacity installed (GW) by region in the New Policies Scenario

By 2025, China is projected to be the leader in installed wind capacity, followed by the EU and North America. Source: IEA $2015^{386}$. 


\section{Biopower}

\subsection{Technologies}

There are three primary processes for producing electricity from biomass. Direct-fired plants typically combust biomass fuel in a steam boiler that powers a generator. Co-fired plants mix a portion of biomass fuel (typically up to 10 percent heat content) with a conventional fossil fuel (usually coal); they then produce electricity in a traditional plant-usually an ST/generator combination - that has been slightly modified to accept the biomass contribution. Gasification plants first heat biomass fuels without combustion in a special environment to create a syngas that is later combusted in a gas turbine or boiler. While some biomass gasification technologies have reached commercial use, there is still significant opportunity for further development of these technologies to reach higher levels of deployment ${ }^{387}$.

Biomass fuels include a broad range of sources, including wood and wood-derived fuels, black liquor (primarily pulp residuals in the paper production process), municipal solid waste (MSW), landfill gas (LFG), and others. Biopower plants are typically fully dispatchable and are generally dispatched as baseload generation if variable and fuel costs are low enough. Biopower plants can also be used for ancillary services to provide frequency regulation, contingency, and other reserves $^{388}$. Depending on the technology, biopower can be a dispatchable and distributed resource $^{389}$.

Biopower plants that rely on direct combustion are often small so that they can be sited close to an appropriate fuel supply ${ }^{390}$. They can also be used in combined heat and power applications depending on the need for auxiliary heating or cooling. Biomass fuel production can be an important engine of rural economic development, but there are also concerns about how to measure the life-cycle environmental impacts of different biomass fuel options. Currently, biopower plants are typically considered by State and Federal regulators to be "carbon neutral," although some use conflicting definitions ${ }^{391}$. Efforts are underway to develop more nuanced classifications depending on how the fuel is grown, processed, and combusted, and on what consequential impacts result from its production ${ }^{392}$.

Biopower plants can use CCS processes ${ }^{\text {lvii }}$ to limit GHG impacts, and they are the only powergeneration option that can result in negative GHG emissions ${ }^{393}$. If CCS technologies used in the fossil-generation fleet are able to achieve cost and performance improvements, the biopower industry will also likely benefit ${ }^{394}$. Appendix A contains additional information on biopower plants.

\subsection{Operational Attributes and Fleet Characteristics}

In 2015, dedicated biopower generation reached 64 TWh (Figure 10-1), which was 1.6 percent of total annual U.S. generation ${ }^{395}$. Operating plant capacity in 2014 for dedicated biopower plants consisted of 44 percent wood and wood derived fuels, 28 percent black liquor, 12 percent MSW, and 11 percent landfill gas, with the remaining 4 percent consisting of other types of biomass in

\footnotetext{
${ }^{\text {lvii }} \mathrm{CCS}$ is a process that can be used on biopower and all fossil fuel power plants. We describe CCS technology under Section 5.1 (in the chapter on coal) and in Appendix A. There are some differences in how CCS applies to biomass, coal, or natural gas combustion but we limit our analysis here to the generic level as the differences go beyond the scope of this report.
} 
solid, liquid, and gas forms, as shown in Table 10-1. Co-fired generation was 35 TWh in 2014. Currently, biopower makes up 12 percent of U.S. renewable generation ${ }^{396}$.

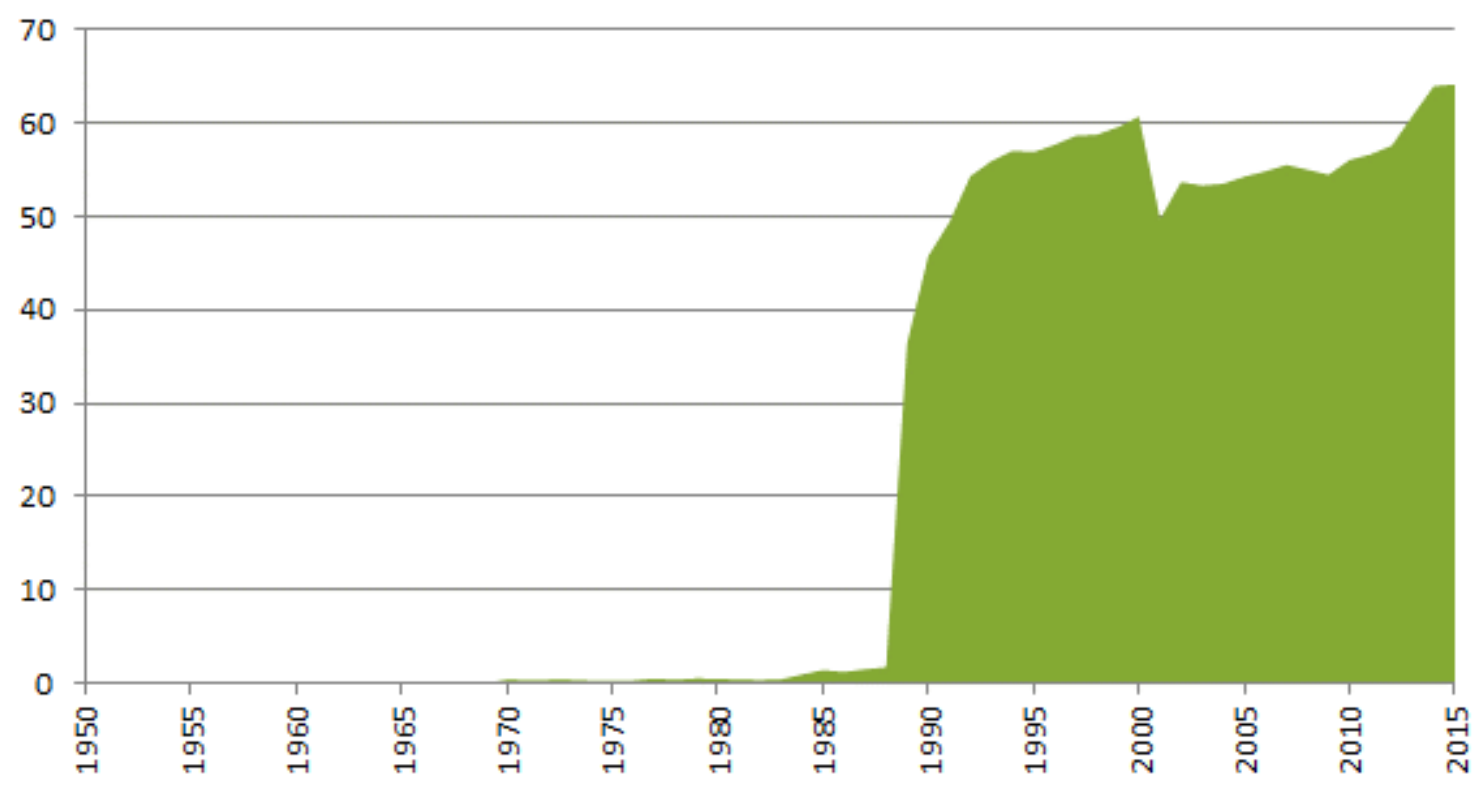

Figure 10-1. U.S biopower generation (TWh), 1950-2015

Source: EIA $2016^{397}$.

Table 10-1. Share of U.S. Operating Biomass Capacity by Subfuel Type, 2014

\begin{tabular}{|c|c|c|c|c|}
\hline Biomass Category & Prime Mover & $\begin{array}{l}\text { Number of Facilities } \\
\text { (2012) }\end{array}$ & $\begin{array}{l}\text { Name Plate } \\
\text { Capacity (GW) }\end{array}$ & $\begin{array}{l}\text { Annual Net } \\
\text { Production } \\
\text { (TWh) }\end{array}$ \\
\hline \multicolumn{5}{|l|}{ EIA Tracked Feedstocks } \\
\hline Wood and Wood-Derived Fuels & STG & 186 & 8.3 & 43.1 \\
\hline Landfill Gas & ICE & 275 & 2.1 & 11.0 \\
\hline Biogenic Municipal Solid Waste & STG & 74 & 2.2 & 7.4 \\
\hline Other Waste Biomass & STG & 37 & 0.8 & 2.9 \\
\hline $\begin{array}{l}\text { Sub-Total from EIA Tracked } \\
\text { Feedstocks }\end{array}$ & & 572 & 13.4 & 64.3 \\
\hline \multicolumn{5}{|l|}{ Other Biomass Feedstocks } \\
\hline Black Liquor & STG & 111 & 5.3 & 26.3 \\
\hline Co-Fired with Coal & STG & 45 & $\sim 5.0$ & 35.0 \\
\hline Co-Fired with Fuel Oil & STG & 13 & $<0.1$ & 0.2 \\
\hline $\begin{array}{l}\text { Sub-Total from Other Biomass } \\
\text { Feedstocks }\end{array}$ & & 169 & 10.3 & 61.5 \\
\hline Total & & 741 & 23.7 & 125.8 \\
\hline
\end{tabular}

A variety of biomass fuels provide energy for biopower plants. Some of these feedstocks, like black liquor and landfill gas, would otherwise be considered waste. Note: STG is steam generator and ICE is internal combustion engine. Source: DOE $2015^{398}$. 
In the 2011-2015 time frame, the average monthly capacity factor of MSW and landfill gas plants was around 70 percent, while other biopower plants were lower, with a 55 percent average monthly capacity factor (Figure 10-2) ${ }^{399}$. The availability factor of biopower plants is around that of coal-fired power plants in that they are available roughly 80-85 percent of the time $e^{400}$. Reliability of biopower plants, especially those using gasification, can sometimes be a challenge.

On a state-by-state basis, California had the highest installed capacity and generation from biomass in 2010 and 2014, followed by Florida (Figure 10-3).

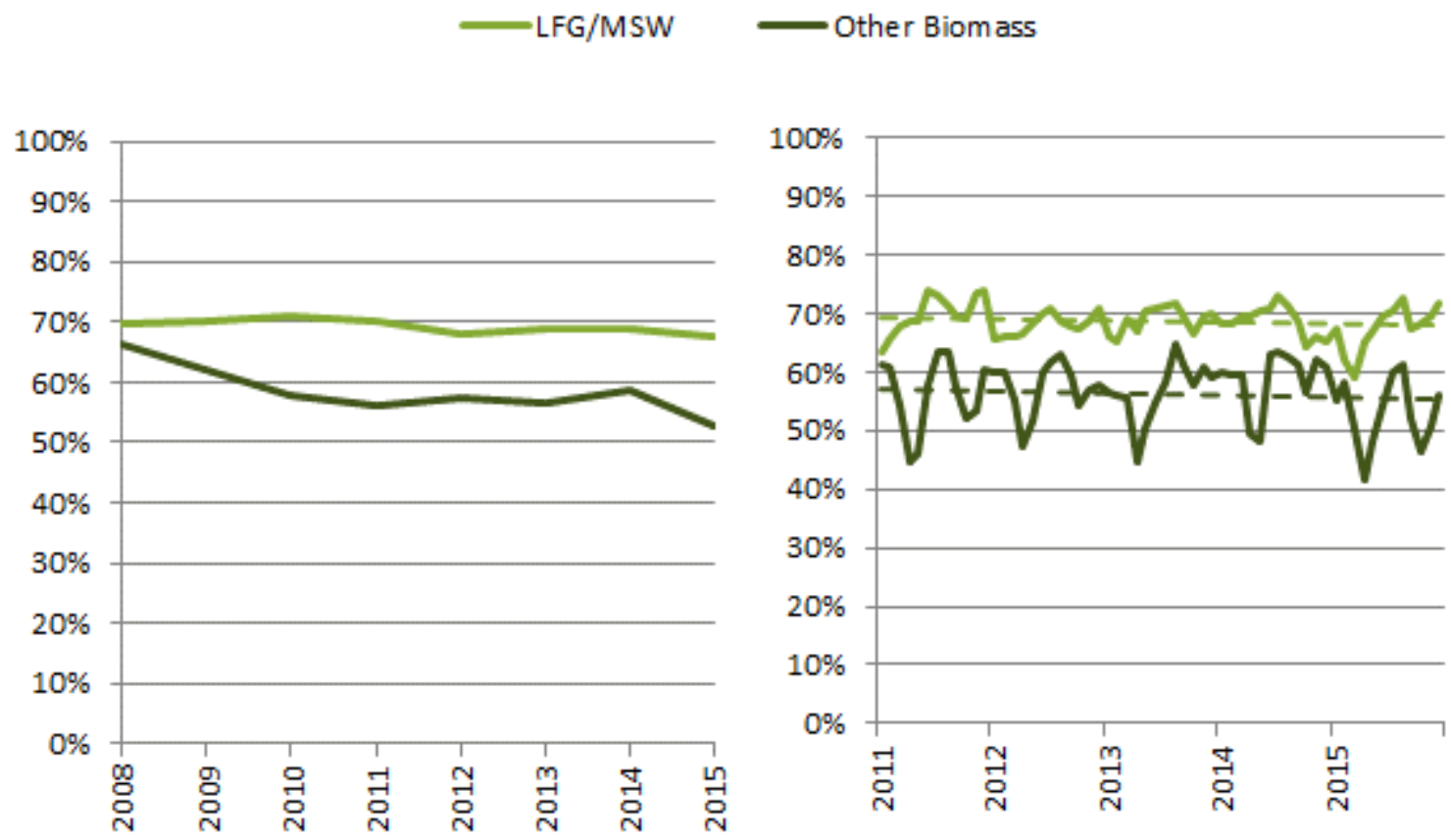

Figure 10-2. U.S. average annual and monthly biopower generator capacity factors

The average monthly capacity factor of MSW and landfill gas plants was around 70 percent, while other biopower plants were lower with 55 percent average monthly capacity factor. Note: LFG is landfill gas. Source: SNL $2015^{401}$. 

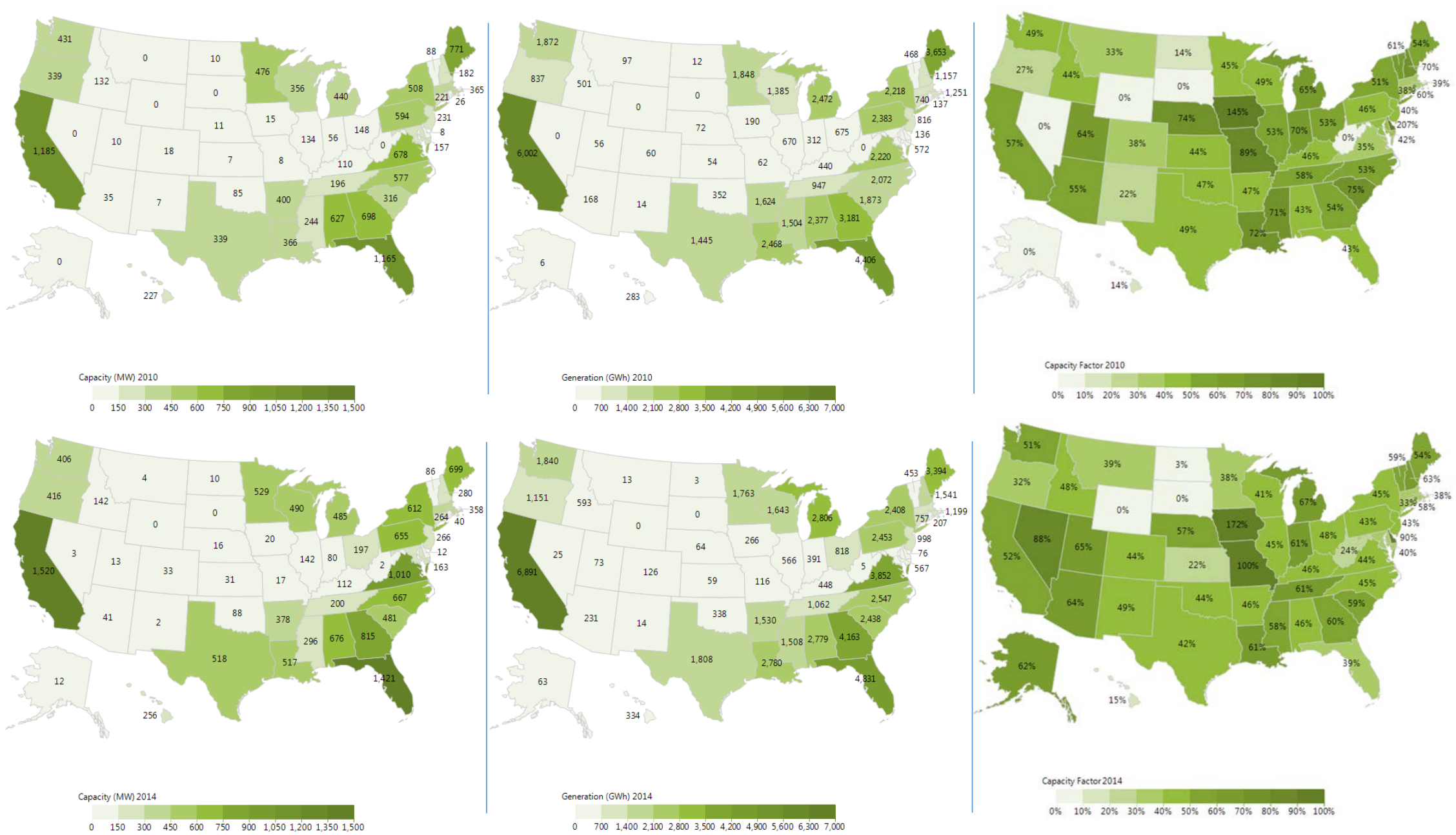

Figure 10-3. Biomass capacity (left), generation (middle), and capacity factor (right) by state. Top: 2010; bottom: 2014.

On a state-by-state basis, California had the highest installed capacity and generation from biomass in 2010 and 2014, followed by Florida ${ }^{\text {Iviii }}$. Source: EIA $2016^{402}$.

\footnotetext{
lviii Note: Co-fired biomass is included in generation, but not capacity, so some capacity factors may be distorted. There is no way to separate the data to remove this distortion.
} 
Direct and co-fired biopower plants are relatively young when compared to the rest of the U.S. thermal generation fleet and are expected to have the same operating life of 45 years (Figure 10$4)^{403}$. Roughly 70 percent of generators are less than 30 years old ${ }^{404}$.

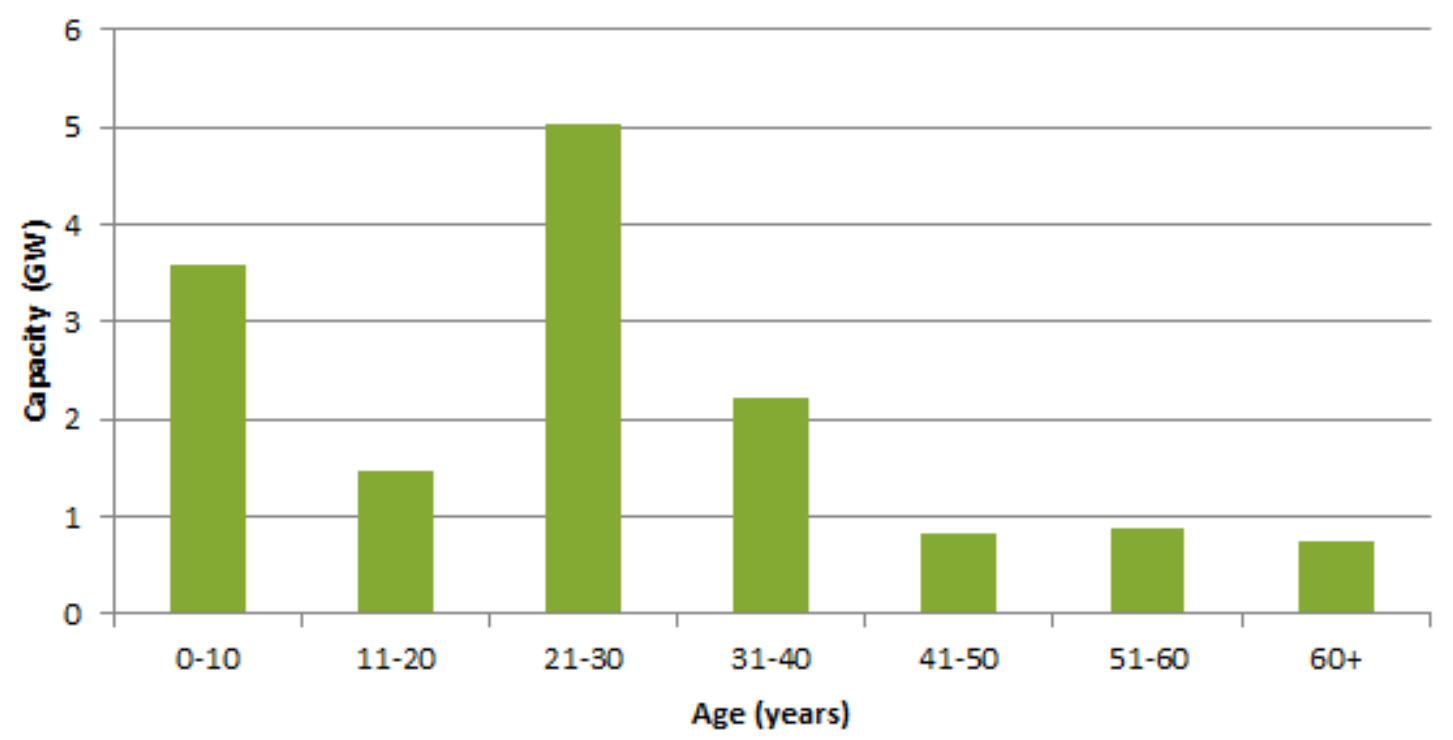

Figure 10-4. Age profile of U.S. biopower generation fleet (direct and co-fired), 2014

About 70 percent of the U.S. biopower fleet is less than 30 years old with an expected lifetime of 45 years. Source: SNL $2015^{405}$.

\subsection{Technology Costs}

The LCOE for direct biomass generation is shown in Table 10-2. The LCOE for biomass is about on par with that for nuclear, but the expected range is much wider.

Table 10-2. LCOE for New Direct Biomass Generation (2013\$/MWh)

\begin{tabular}{|l|l|l|l|l|l|l|}
\hline & \multicolumn{3}{|l|}{ EIA } & \multicolumn{2}{l|}{ NREL } & Lazard \\
\hline & Low & High & Low & High & Low & High \\
\hline Biomass Direct & 65.42 & 188.34 & 71.09 & 158.61 & 68.03 & 162.16 \\
\hline
\end{tabular}

Current ranges of biopower technology LCOEs using cost assumptions from three sources: NREL 2015; EIA 2015; Lazard $2015^{406}$. See Appendix B for more information on LCOE calculations.

\subsection{Fuel/Resource}

The United States has a diverse range of solid biomass resources (Figure 10-5). The top fuels used for biopower generation in the United States are black liquor, wood waste, MSW, and landfill gas ${ }^{407}$. This section will focus primarily on these fuel types along with methane creation from waste water treatment plants (WWTPs). Use of biomass to create biofuels is outside the scope of this section as these biofuels contribute a negligible portion of the generation mix.

Black liquor is produced during the Kraft process in paper production ${ }^{408}$. It is primarily made up of pulping residues and inorganic chemicals used during the process. It was considered a waste 
until the invention of recovery boilers, and now it is used to create steam for electricity production $^{409}$. Wood waste includes, but is not limited to, urban wood waste (tree trimming, construction wastes, wood chips, and pallets), mill residues, forest residues, and crop residues.

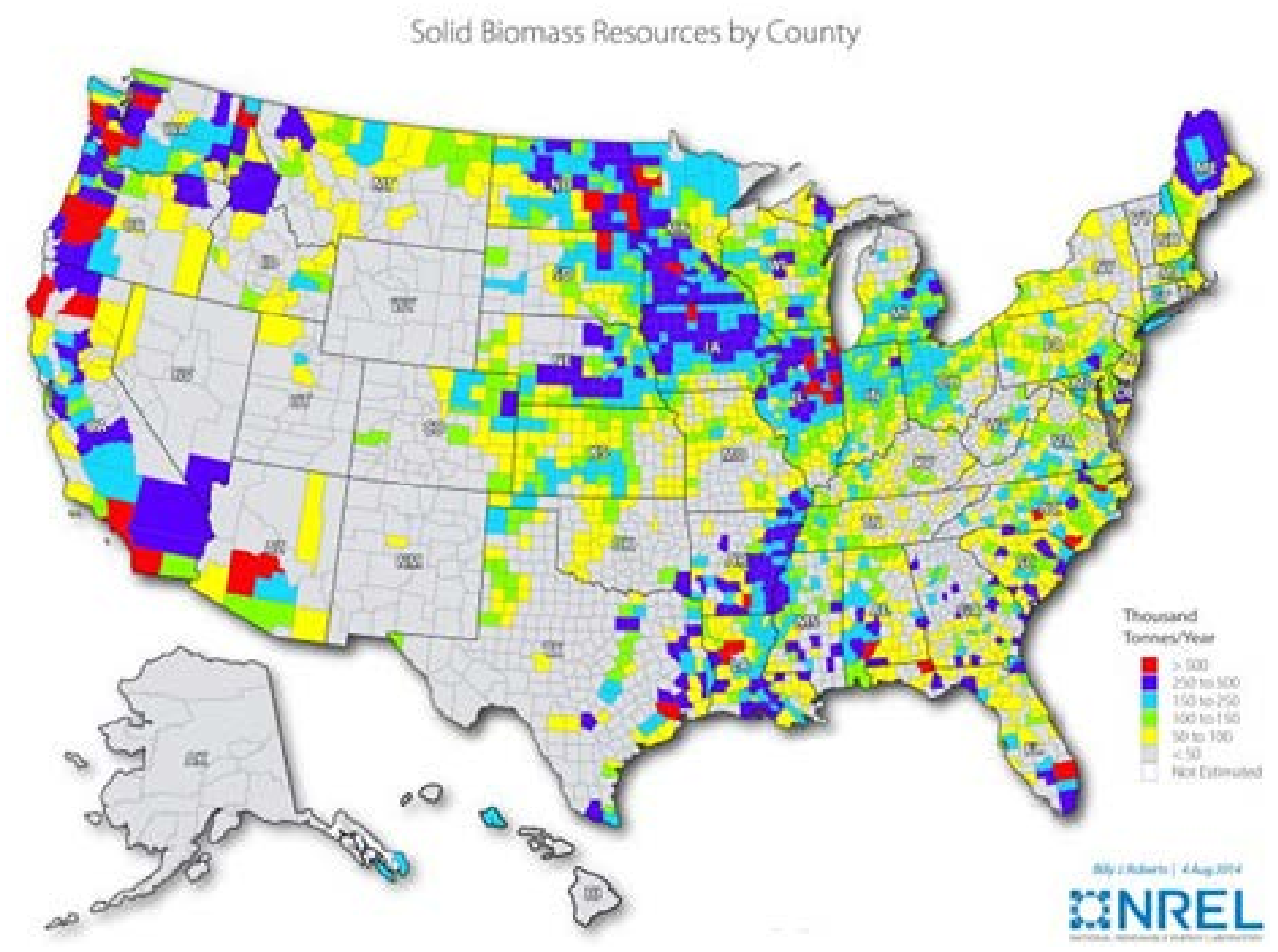

Figure 10-5. Solid biomass resources by county

Resources include the following feedstock categories: crop residues (2012), forest and primary mill residues (2012), secondary mill residues (2012), and urban wood waste (2012). Source: NREL $2015^{410}$.

MSW involves the incineration of solid, biogenic wastes to produce energy. Many MSW plants sort waste before incineration to remove recyclable products, but some do not ${ }^{411}$. About 13 percent of all collected municipal waste is burned at landfills to produce electricity and steam ${ }^{412}$. Burning MSW can reduce the amount of material sent to the landfill by 87 percent; residual combustion products and ash are still sent to the landfill ${ }^{413}$. MSW plants are often called wasteto-electricity plants.

Landfill gas is created during the anaerobic decomposition of organic materials in the MSW deposited in landfills and is made up of roughly 50 to 55 percent methane ${ }^{\text {lix }}$ and 45 to 50 percent $\mathrm{CO}_{2}{ }^{414}$. This landfill gas can be captured, treated to remove moisture and impurities, and burned to produce electricity and/or heat ${ }^{415}$. Roughly 70 percent of landfill gas is burned in internal combustion engines to produce electricity, with the remainder being burned in CTs (generally for larger projects $)^{416}$. As of March 2015, there are 854 landfill gas facilities in operation, producing 2,765 million cubic feet per day of landfill gas ${ }^{417}$.

\footnotetext{
lix Roughly 1 million tons of MSW produces 0.43 million cubic feet of methane per day and will produce for 20-30 years. For reference, in 2012, 135 million tons of MSW were landfilled in the United States (EPA 2014a).
} 
Another source of biogas is through processing of municipal wastes at waste water treatment plants (WWTPs). Organic compounds in municipal waste are decomposed in an anaerobic digester to produce methane. As of 2015, 1,270 WWTPs in the United States use anaerobic digesters to produce biogas ${ }^{418}$.

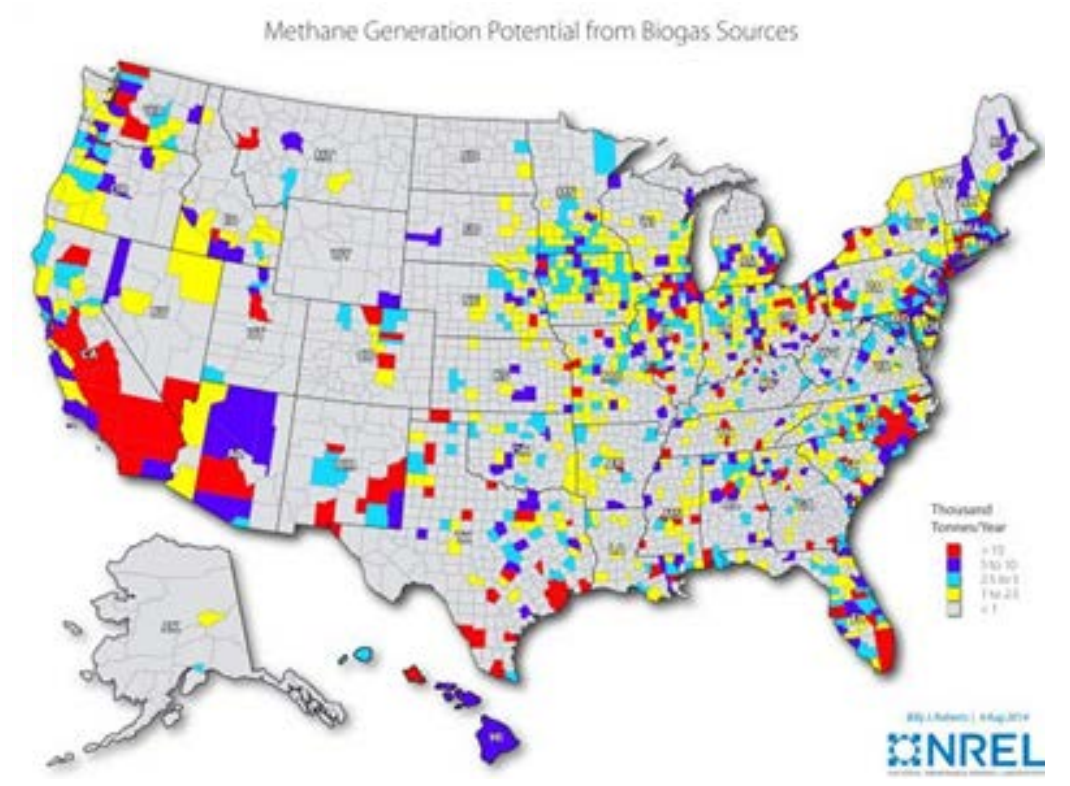

Figure 10-6. Methane generation potential from biogas sources

This map of methane production potential includes the following biogas sources: landfills; animal manure; wastewater treatment; and industrial, institutional, and commercial organic waste. Source: NREL $2015^{419}$.

Currently, there are not any domestic, large-scale dedicated feedstock (i.e., biomass that is grown specifically for power production) biopower plants, but there is some potential in the future for large-scale development, especially when combined with CCS.

Transporting biomass for electricity production can be a large part of the per-unit feed stock price, especially due to the low energy content of biomass ${ }^{420}$. Biomass is mostly transported via trucks, making short hauls for urban wastes. In some cases, like pulp and paper mills, there is no transportation required as the biomass fuel is consumed onsite. MSW is transported during the waste collection process and is generally consumed on or near a landfill. Likewise, landfill gas and biogas from WWTPs are transported short distances within landfill boundaries to be used either onsite or injected into pipelines for use elsewhere.

Biomass fuel prices are dependent on the moisture content contained in the biomass, the amount of processing required, transportation costs, and acquisition costs ${ }^{421}$. Fuel prices are also dependent on source, with agricultural wastes generally the least expensive and dedicated feedstocks the most expensive ${ }^{422}$. Some biomass stocks (such as MSW) have zero cost as they are waste streams. 


\subsection{Environmental Impacts}

\subsubsection{Upstream Extraction/Manufacturing}

A majority of biopower fuels currently used in the U.S. electricity system are derived from wastes. Black liquor, wood waste, MSW, landfill gas, and waste water methane all are derived from a material that is either disposed of or emitted to the environment. Processing and cleaning wood waste may use some energy and water to remove any impurities. For fuels derived from the waste feedstocks mentioned above, the land-use impacts are assumed to be zero because the land use is associated with the primary production activity and not with the biomass feedstock production.

\subsubsection{Emissions and Environmental Impact}

Biopower generation offers lower $\mathrm{SO}_{\mathrm{x}}, \mathrm{NO}_{\mathrm{x}}$, and $\mathrm{CO}_{2}$ emissions when compared to coal-fired generation ${ }^{423}$. In co-fired systems, substituting biomass for coal can reduce $\mathrm{SO}_{\mathrm{x}}$ emissions of coal plants. However, particulate matter and heavy metal emissions can rise depending on the feedstock and fuel processing method ${ }^{424}$. Particulate matter emissions can be controlled by a mechanical collector and a baghouse or electrical precipitator ${ }^{425}$. With co-fired plants, the addition of biomass may affect the quality of the fly ash that is produced from normal coal combustion and impede its sale in the cement and drywall production process ${ }^{426}$.

There is controversy about whether biopower should be classified as a carbon-neutral energy source. Carbon neutrality for biomass is dependent on the feedstock type, the management and procurement of feedstock, the feedstock transportation method, the generating technology, and the time frame in which the feedstock needs to be replenished ${ }^{427}$. Sustainable production of biomass is important in determining if biopower is carbon neutral ${ }^{428}$. See the QER 1.2 Environment Baseline Vol. 1 - Greenhouse Gas Emissions from the U.S. Power Sector: Baseline and Outlook to 2040 baseline document for further analysis and discussion of this topic.

In the case of landfill gas, the combustion of methane gas creates $\mathrm{CO}_{2}$, but the atmospheric warming potential of methane is greater than $\mathrm{CO}_{2}$, leading to reduced amounts of overall GHG emissions compared to releasing methane into the atmosphere. Bioenergy with CCS can reduce atmospheric $\mathrm{CO}_{2}{ }^{429}$. It is one of the only energy sources currently available that can have negative $\mathrm{CO}_{2}$ emissions with CCS over a lifetime of generation.

\subsection{Constraints}

One of the main challenges in utilizing biopower is securing a sufficient supply of feedstocks that have acceptable impacts on the environment, food supply, and other ecosystem considerations. Biomass availability for power production can be limited by geographic availability constraints, competing uses (e.g., liquid fuel production), and the increasing severity of droughts ${ }^{430}$. The biopower industry also faces uncertainty from an evolving life-cycle GHG methodology that could jeopardize its current classification as a carbon-neutral or carbonnegative source of electricity, particularly when including direct and indirect land-use change effects ${ }^{431}$. Fundamental biopower technology breakthroughs-including more productive and acceptable feedstock sources, more efficient generators and cost-competitive CCS - are needed to catalyze the deployment of biopower to a level commensurate with other sustainable, reliable, and economic power generation options. 
For combined heat and power applications, integration challenges could depend on the demand profile for heat and the ratio of heat-to-power it was designed to deliver. Also for biopower combined heat and power applications, securing demand for steady heat supply, especially when sited in remote locations close to feedstock supply, can sometimes be challenging.

For expanded development of biopower, competition may emerge with biofuels for land, water, and feedstock use. Some argue that feedstock use for biofuels will be more profitable for feedstock producers, leading to less biomass supply dedicated to electricity production ${ }^{432}$.

Siting impacts of biopower plants are similar to coal and natural gas power plants, but plants are generally distributed geographically close to feedstocks to cut down on transportation costs ${ }^{433}$. With increased particulate matter production, there are concerns about siting biopower plants close to population centers.

\subsection{Technical RDD\&D}

Biopower generation technologies have the unique potential of being carbon-negative depending on design of the generator, type and management of the feedstock, and other operational considerations ${ }^{434}$. This could become a very valuable capability depending on how global carbon mitigation policies unfold. Other benefits of biopower include being dispatchable, serving as an engine for rural economic development in feedstock production, diverting organic waste from landfills, and assisting regular forest maintenance ${ }^{435}$.

One core area of research for biopower is advancing feedstocks that have high yields and energy content while reducing environmental impact. This research is focused on foundational biogenetics, soil chemistry, and pretreatment of biomass, but there are also opportunities to improve techno-economic models to characterize the supply chain and system sustainability ${ }^{436}$.

Direct biopower technology is fairly mature, although some engineering problems, such as corrosion and cost-effective emissions control, remain as barriers ${ }^{437}$. Ongoing RDD\&D in materials chemistry may help address these barriers.

Biomass gasification fluidization reactors are a well-known technology, although there are technical challenges (e.g., filtering contaminates and enriching syngas quality). In the near- to med-term, fluidization appears to be one of the gasification processes with the most technoeconomic potential ${ }^{438}$. Some current gasification systems have relatively high capital costs due to nonstandardized plant designs. Efforts are needed to lower O\&M and balance-of-plant costs while improving durability. These issues depend on the type of feedstock and the specific technology employed ${ }^{439}$.

\subsection{Development and Projected Future Deployment}

The biopower industry expanded significantly during the 1990s following the passage of PURPA in 1978, which required utilities to purchase generation from "qualifying facilities" like biopower at their avoided cost $\mathrm{t}^{\mathrm{x}}$ (Figure 10-7). More recently, biopower generation growth since 2005 has primarily occurred due to new capacity additions or conversion of coal plants to

\footnotetext{
${ }^{1 x}$ Avoided cost is the expense that utilities would have incurred to generate additional electricity. During the 1980s, avoided costs were relatively high, so this sent a signal for more qualifying facilities to emerge.
} 
biomass in the southeastern parts of the country in order to meet voluntary or required renewable generation goals or to improve resource diversity ${ }^{440}$.

Biopower plants are currently eligible for "renewable energy attributes" and the associated renewable energy credits and tax incentives in most states ${ }^{441}$. Some states, however, have specific requirements for carbon neutrality of biopower plants to qualify for these tax credits. EPA is in the process of reevaluating its framework for biogenic carbon accounting. "Qualifying biomass" is allowed to be included in state compliance plans in the CPP, but it remains unclear what forms of biomass will be deemed acceptable ${ }^{442}$.

Closed-loop biomass, defined as "any organic material from a plant which has been grown exclusively for bioenergy use," is eligible for the full value of the renewable electricity PTC, currently $\$ 23 / \mathrm{MWh}^{443}$. Open-loop systems (which are all other forms of biomass) are eligible for the PTC at half that level, currently \$11/MWh. The December 2015 omnibus budget bill passed by Congress extends the PTC for qualified generators for projects that commence construction before $2017^{444}$.

Policies such as tax incentives, clean renewable energy bonds, RPS, and, potentially, the CPP currently support biopower generation and may drive more biopower installation. Competitive financing is often dependent on biopower facilities's ability to provide combined heat and power, which may impact the siting of power plants (plants need to be close to heating needs).

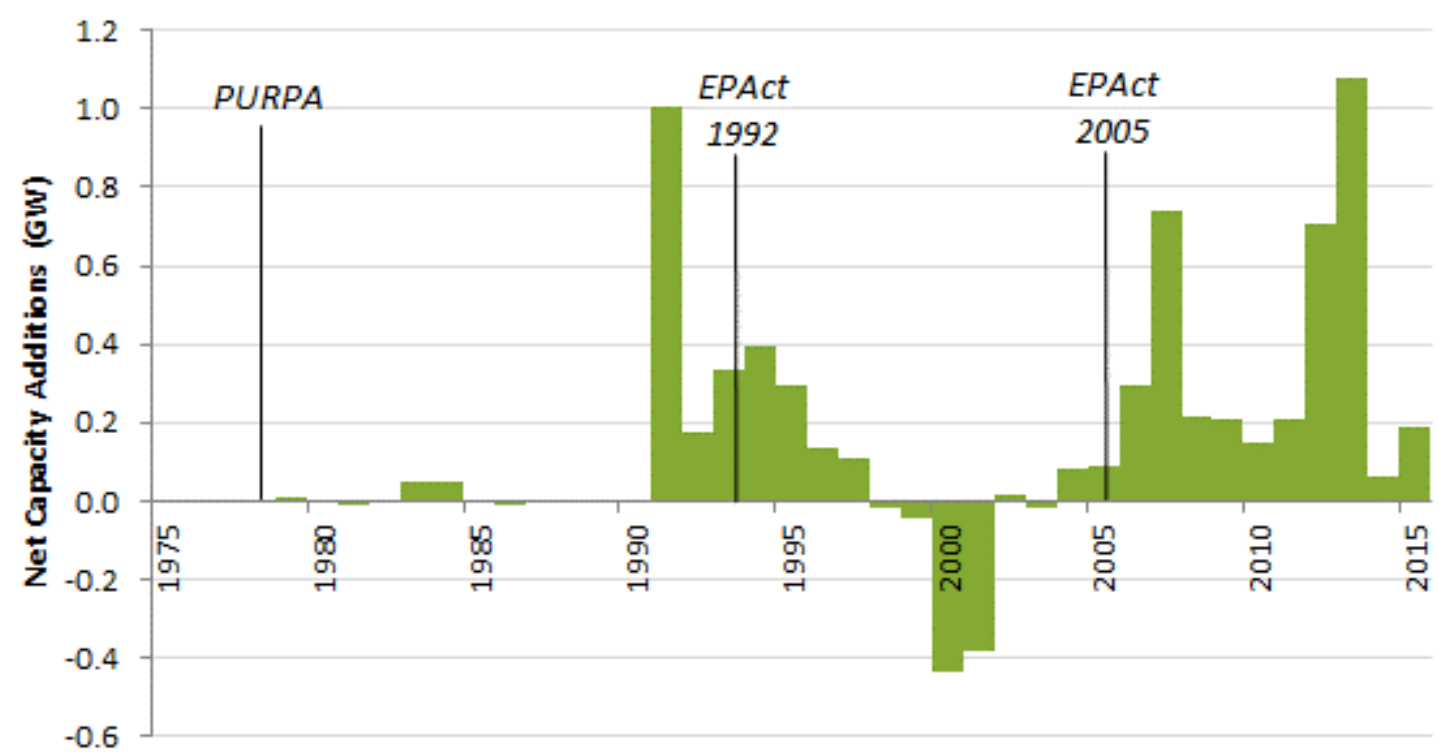

Figure 10-7. Historical annual biopower capacity additions and retirements (GW), 1975-2015

Biopower capacity additions grew modestly in the early 1990s, and then again since 2006. Note: EPAct is the Energy Policy Act and PURPA is the Public Utility Regulatory Policies Act. Source: EIA 1990 and EIA $2016^{445}$.

Depending on the overall emission impacts of biopower and the reduction of $\mathrm{CO}_{2}$ entailed in the CPP, biopower may be utilized to comply with regulations. Projected biopower generation in the QER 1.2 Base Case in 2040 is shown in Table 10-3. 
Table 10-3. QER 1.2 Base Case Generation for Biopower (TWh), 2014-2040

\begin{tabular}{|l|c|c|}
\hline & 2014 (Actual) & $\begin{array}{c}\text { QER 1.2 Base Case } \\
(2040)\end{array}$ \\
\hline MSW & 23 & 21 \\
\hline Wood \& Other Biopower & 40 & 30 \\
\hline
\end{tabular}

Source: EPSA $2016^{446}$

Global growth of biopower is expected to be modest compared to other technologies according to IEA's WEO 2015 (Table 10-4, Figure 10-8).

Table 10-4. Global Biopower Generation Projections, 2013-2040

\begin{tabular}{|l|c|c|c|c|c|c|c|}
\hline IEA Scenario & & \multicolumn{2}{|c|}{ New Policies } & \multicolumn{2}{|c|}{ Current Policies } & \multicolumn{2}{|c|}{450} \\
\hline & $\mathbf{2 0 1 3}$ & $\mathbf{2 0 2 0}$ & $\mathbf{2 0 4 0}$ & $\mathbf{2 0 2 0}$ & $\mathbf{2 0 4 0}$ & $\mathbf{2 0 2 0}$ & $\mathbf{2 0 4 0}$ \\
\hline $\begin{array}{l}\text { Biopower Generation } \\
\text { (TWh) }\end{array}$ & 464 & 728 & 1,454 & 717 & 1258 & 732 & 2077 \\
\hline $\begin{array}{l}\text { Percentage of Global } \\
\text { Total }\end{array}$ & 2 & 3 & 4 & 3 & 3 & 3 & 6 \\
\hline
\end{tabular}

The 450 Scenario could lead to twice as much bioenergy compared to current policies, but the overall contribution of bioenergy is expected to be very small. Note: The IEA uses the term "bioenergy" instead of biopower in its analysis. Source: IEA $2015^{447}$.

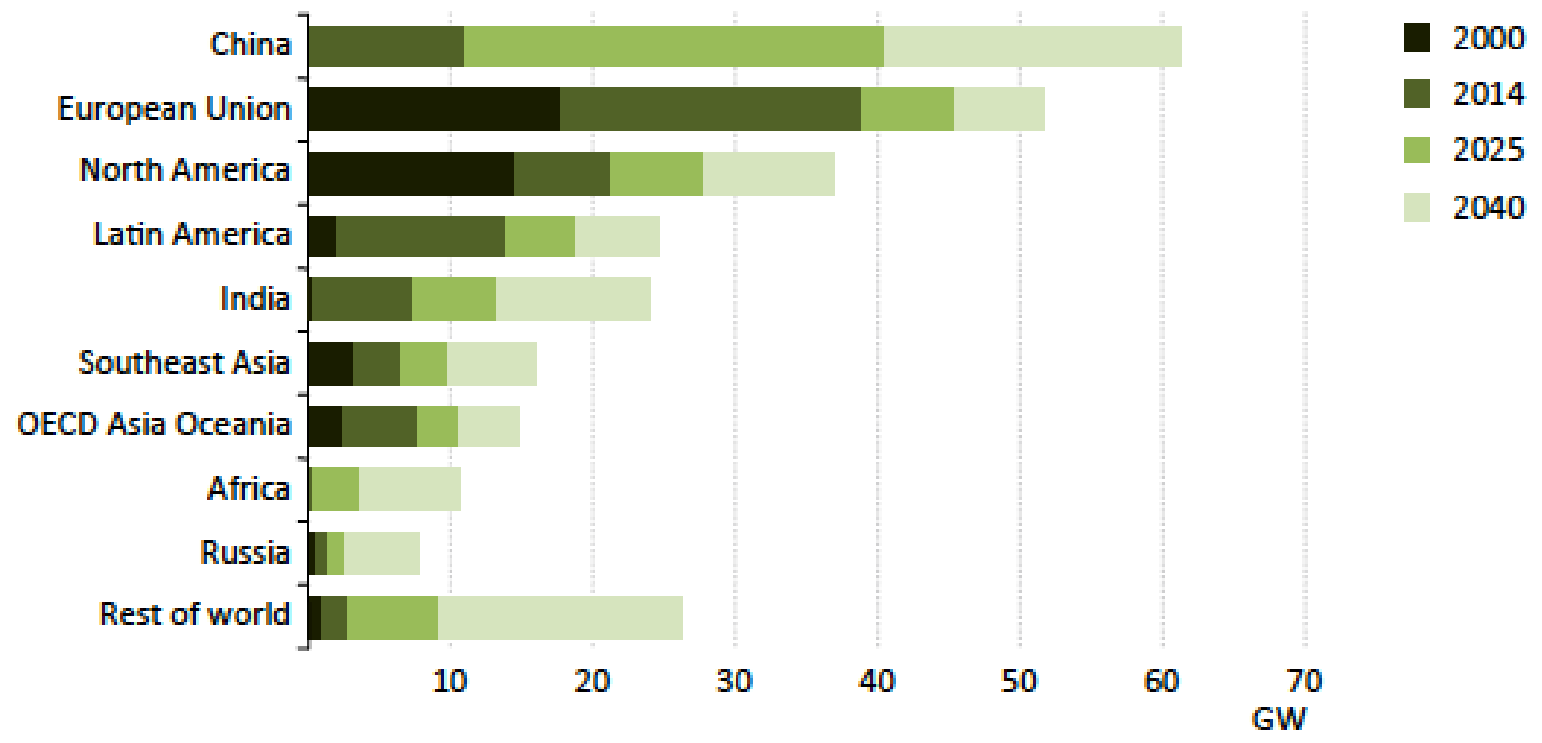

Figure 10-8. Projected biopower capacity additions (GW) (IEA New Policies Scenario) by region

In the 2014-2025 timeframe, China is projected in this scenario to have the largest buildout of biopower, surpassing the EU. Source: IEA $2015^{448}$. 


\section{Solar}

\subsection{Technologies}

There are two primary types of solar generation technology: PV and CSP. PV modules use semiconductors to convert sunlight directly to electricity, as described further in Appendix A. A variety of silicon, thin film, and more novel PV technologies exist and are under development. Modules can either be fixed, track along a single axis, or track along two axes. Sun-tracking increases the power output of modules but also requires increased capital and O\&M costs. PV plants can range in size from a few $\mathrm{kW}$ (distributed) to hundreds of MW (utility-scale). ${ }^{\text {1xi }}$

CSP uses an array of mirrors to concentrate solar heat at a liquid medium to capture thermal energy from the sun's radiation. This thermal energy is used to create steam to drive a turbine. There are two main designs currently used for CSP (solar troughs and power towers), but other options also exist. CSP plants can include thermal storage, which allows them to provide power even after the sun goes down and add flexibility to the grid. CSP plants are generally large in size in order to create enough steam to power a turbine. Plant capacities are generally 10$300 \mathrm{MW}$.

Solar PV is considered a variable generation technology and can only produce power during daylight hours. Output from modules is dependent on the time of year and weather conditions. Transient clouds may impact production as well. Maximum PV production occurs for a few hours before and after solar noon, which typically coincides with periods of high electricity demand during the day (especially in the summer with high cooling needs). However, increased solar installations can change the net load shape for utilities and change how other sources of electricity are dispatched ${ }^{449}$. Geographically diverse solar projects can be used to lessen the impacts of production variation for PV projects. CSP also produces power at peak periods, and thermal storage can allow for load smoothing and production after the sun goes down.

\subsection{Operational Attributes and Fleet Characteristics ${ }^{\text {Ixii }}$}

Solar power, including utility-scale and distributed PV and CSP, currently contributes just over 1 percent to the total U.S. generation of electricity ${ }^{450}$. Solar generation is growing rapidly in the United States but from a very small base. Utility-scale solar (PV and CSP) generation grew from less than 0.5 TWh in 2010 to 26 TWh in 2015 (Figure 11-1). The capacity and generation values discussed in this section focus primarily on utility-scale solar (defined as having $1 \mathrm{MW}$ or greater capacity); data on distributed PV generation only became available through EIA beginning in November 2015 and starts from the year $2014^{451}$. Distributed solar PV has also experienced significant growth in recent years (Figure 11-2). As shown in Figure 11-3, distributed solar accounted for 32 percent of total solar generation, and also represented 42 percent of total solar capacity, as of June 2016. Still, distributed PV accounted for only 0.3 percent of total net generation, about $12 \mathrm{TWh}$, in $2015^{452}$.

\footnotetext{
${ }^{\text {lxi }}$ Distributed PV installations are defined by EIA as those that have a capacity of less than 1 MW and that are on the customer side of the meter (EIA 2015g).

${ }_{\text {lxii }}$ All generation and capacity numbers for solar PV included in this section are in units of alternating current (AC) generation or capacity.
} 


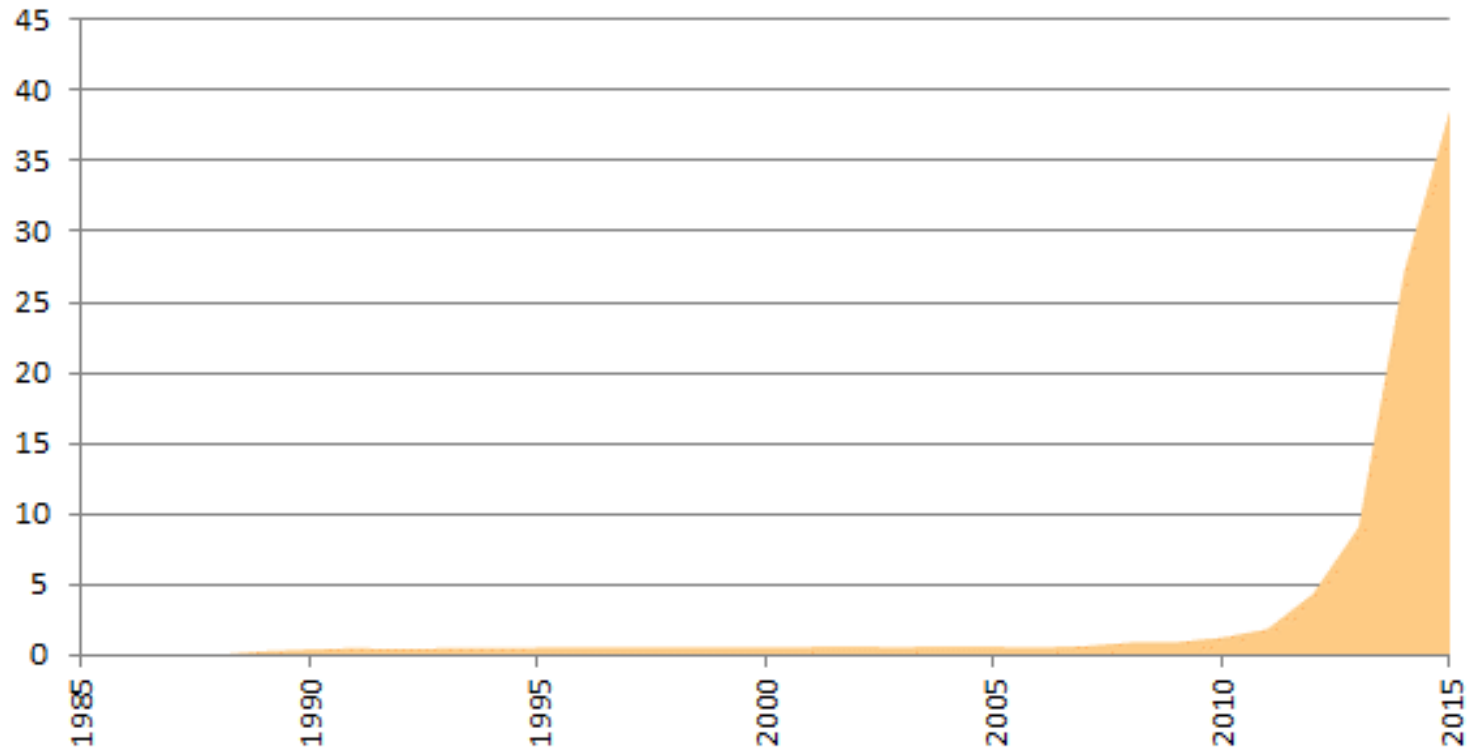

Figure 11-1. U.S. solar generation (TWh), 1985-2015

Source: EIA $2016^{453}$.

Note: This includes both utility-scale and distributed solar starting in 2014.

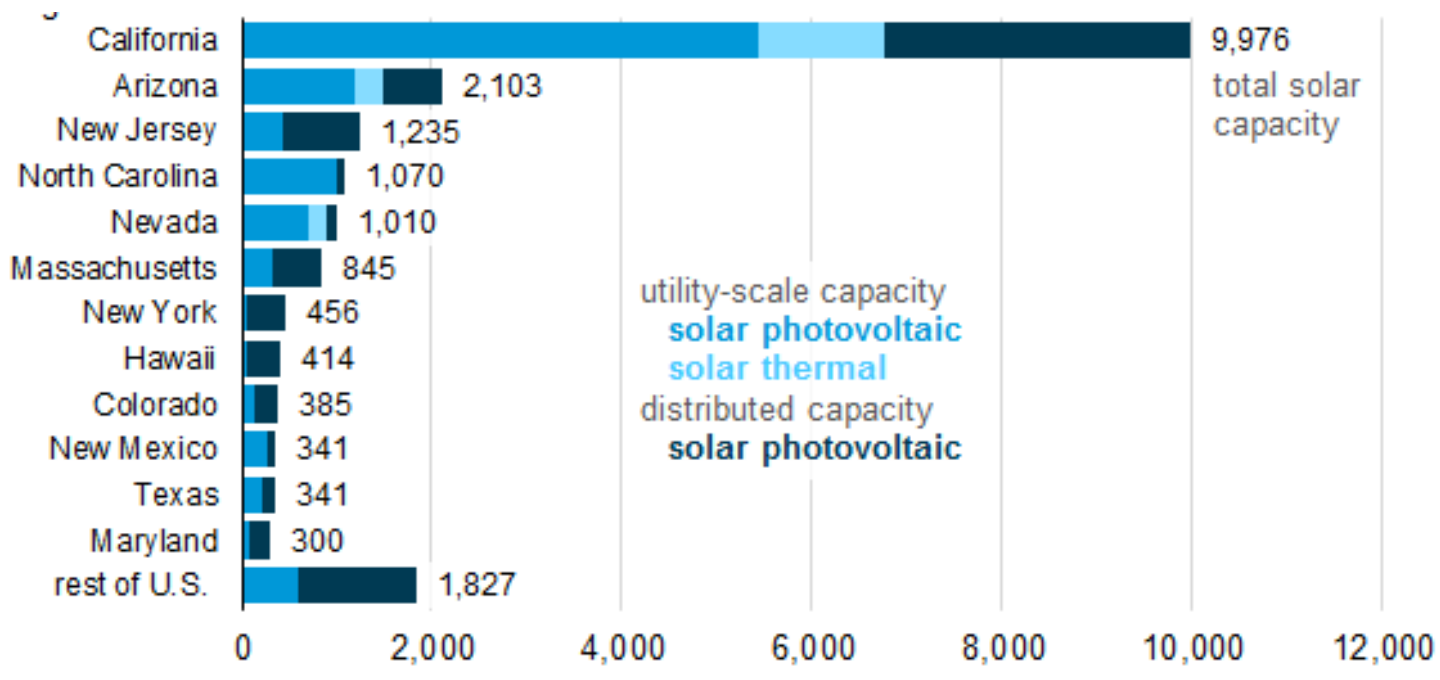

Figure 11-2. Solar electricity generating capacity (MW), November 2015

California has the most installed capacity of all types of solar (utility-scale PV, CSP, and distributed PV).

Source: EIA $2016^{454}$. 


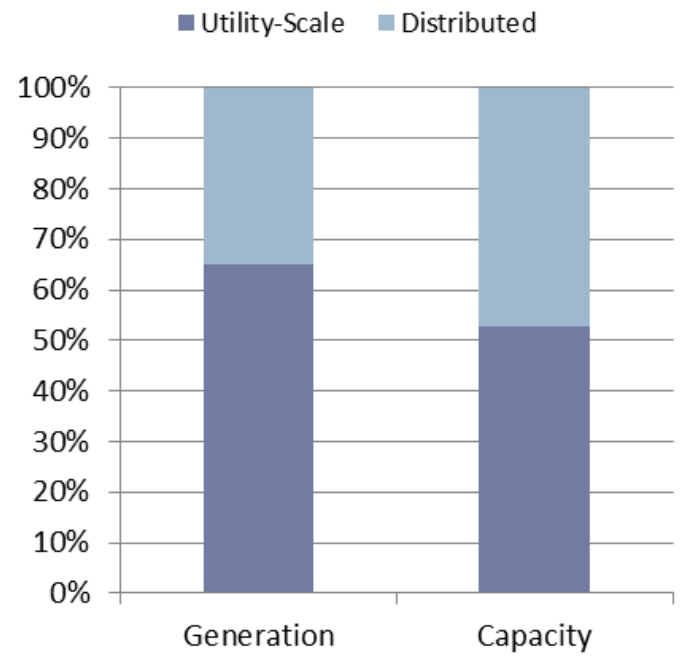

Figure 11-3. Share of U.S. operating solar capacity and generation by utility-scale vs. distributed, 2014

Solar generation includes utility-scale PV, distributed PV, and CSP. Total solar generation reached 18 TWh in 2014, accounting for 0.7 percent of the nation's total. Distributed PV generation accounted for 0.2 percent of the total, but was much higher in some regions of the country. Sources: EIA 2016a; EIA $2016^{455}$.

The average annual capacity factor for utility-scale PV solar as of 2015 is around 27 percent, but this can change (15 to 34 percent) with the season (Figure 11-4) ${ }^{456}$. Solar PV and CSP production can be impacted by dirt accumulating on panels or mirrors, and can potentially lead to a 10 percent reduction in power production. PV modules generally have a power degradation rate of 0.5 percent per year, but this degradation eventually tapers down over the life of the module ${ }^{457}$.
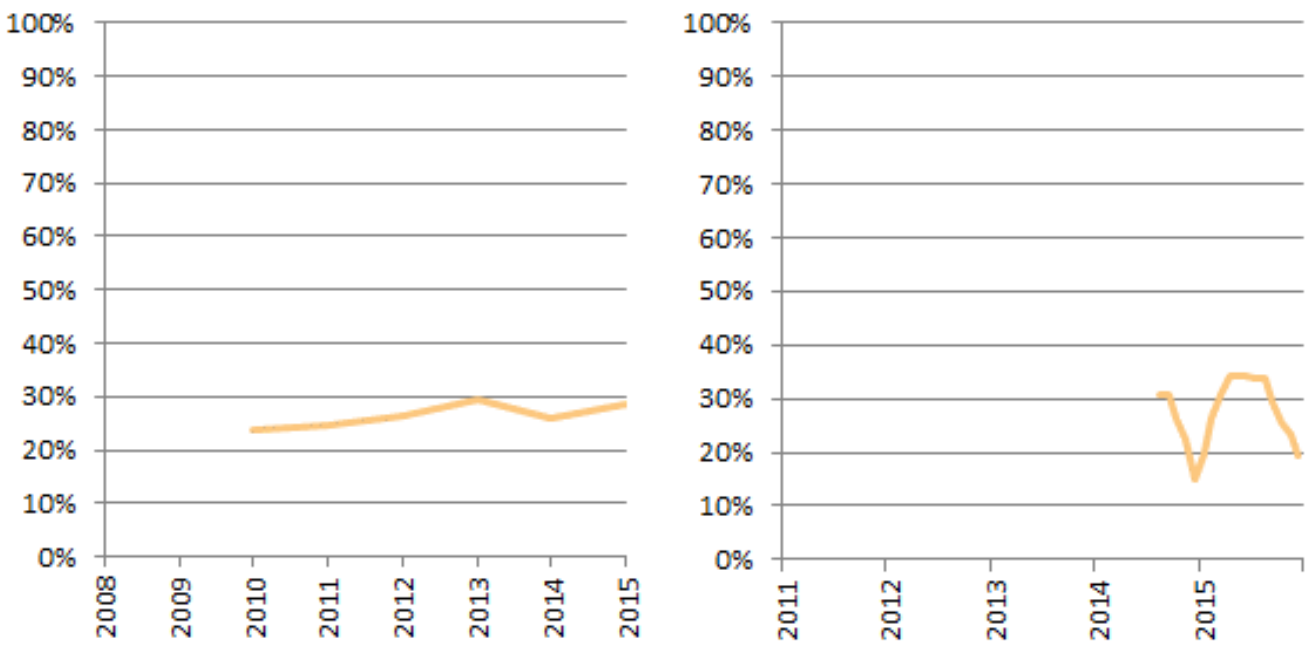

Figure 11-4. U.S. average annual and monthly utility solar PV generator capacity factors

The average annual capacity factor for solar increased by about 20 percent between 2010 and 2015 . The capacity factor can change significantly (15 to 34 percent) with the season. Sources: SNL $2015^{458}$. 
Between 2010 and 2014, 1.3 GW of CSP capacity was installed in the United States. Of this total, 71 percent was installed in California and 61 percent was installed in 2014, the largest year for CSP deployment to date. As of 2014, there were still many states without any installed utility-scale solar capacity as shown in the bottom-left panel of Figure 11-5. California had the highest installed utility-scale solar capacity and generation in 2014, followed by Arizona, Nevada, and North Carolina. Many states experienced rapid growth in capacity between 2010 and 2014. 


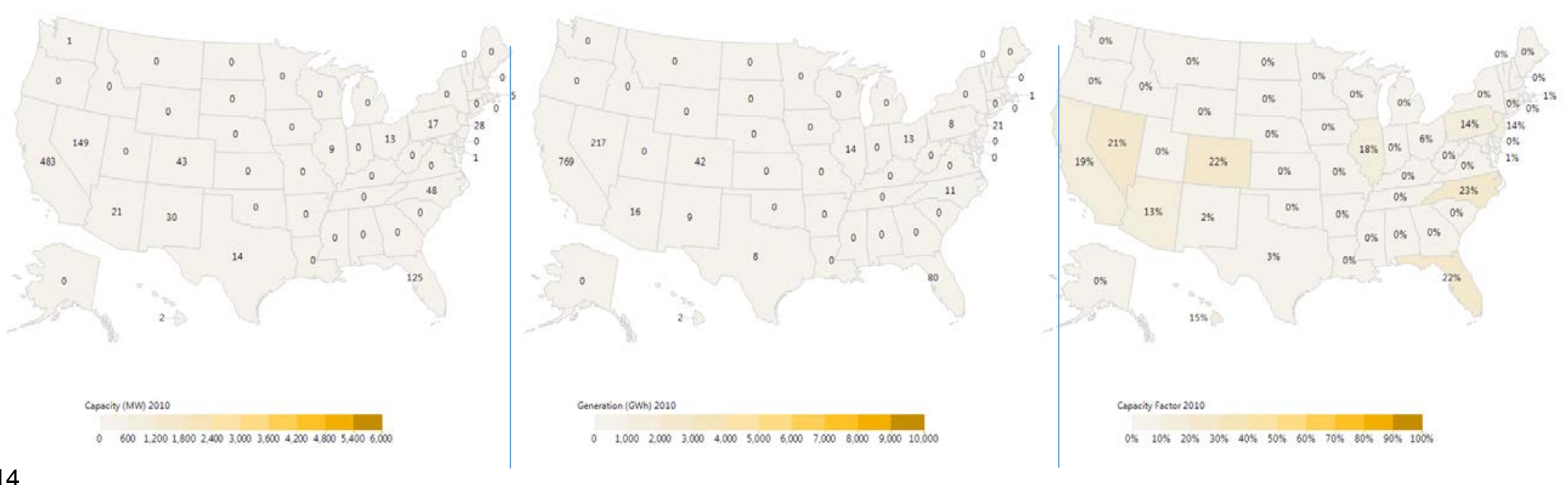

2014

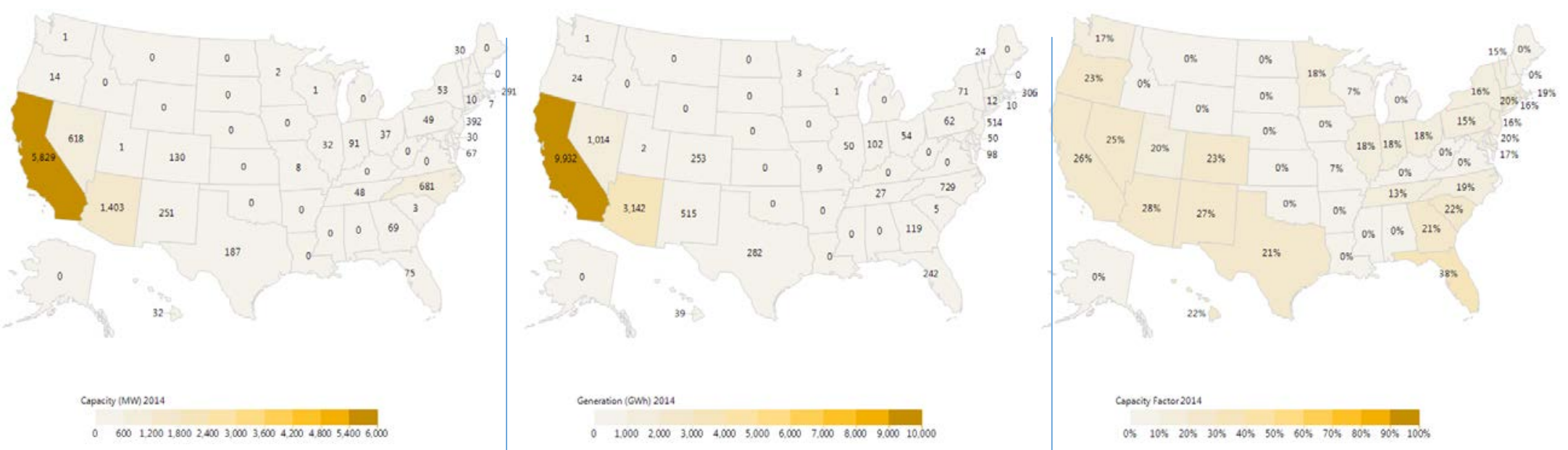

Figure 11-5. Utility-scale solar capacity (left), generation (middle), and capacity factor (right) by state. Top: 2010; bottom, 2014.

California had the highest installed capacity and generation from utility-scale solar in 2014, followed by Arizona, Nevada, and North Carolina. Many states experienced rapid growth in capacity between 2010 and 2014. Source: EIA $2016^{459}$. 
PV modules have an expected lifespan of 25 to 30 years, while the inverters-which convert the DC power from modules to AC power to match the grid-typically have a 10-year lifespan ${ }^{460}$. However, a majority of solar installations have been constructed within the past 2 years, so there is little data on long-term lifespan and performance (Figure 11-6) ${ }^{461}$. CSP plants are modeled to have a 30 -year life ${ }^{462}$. However, this assumption is simply a parameter for projecting economic pro forma, and such plants may conceivably be operated beyond that life with regular maintenance and equipment replacement.

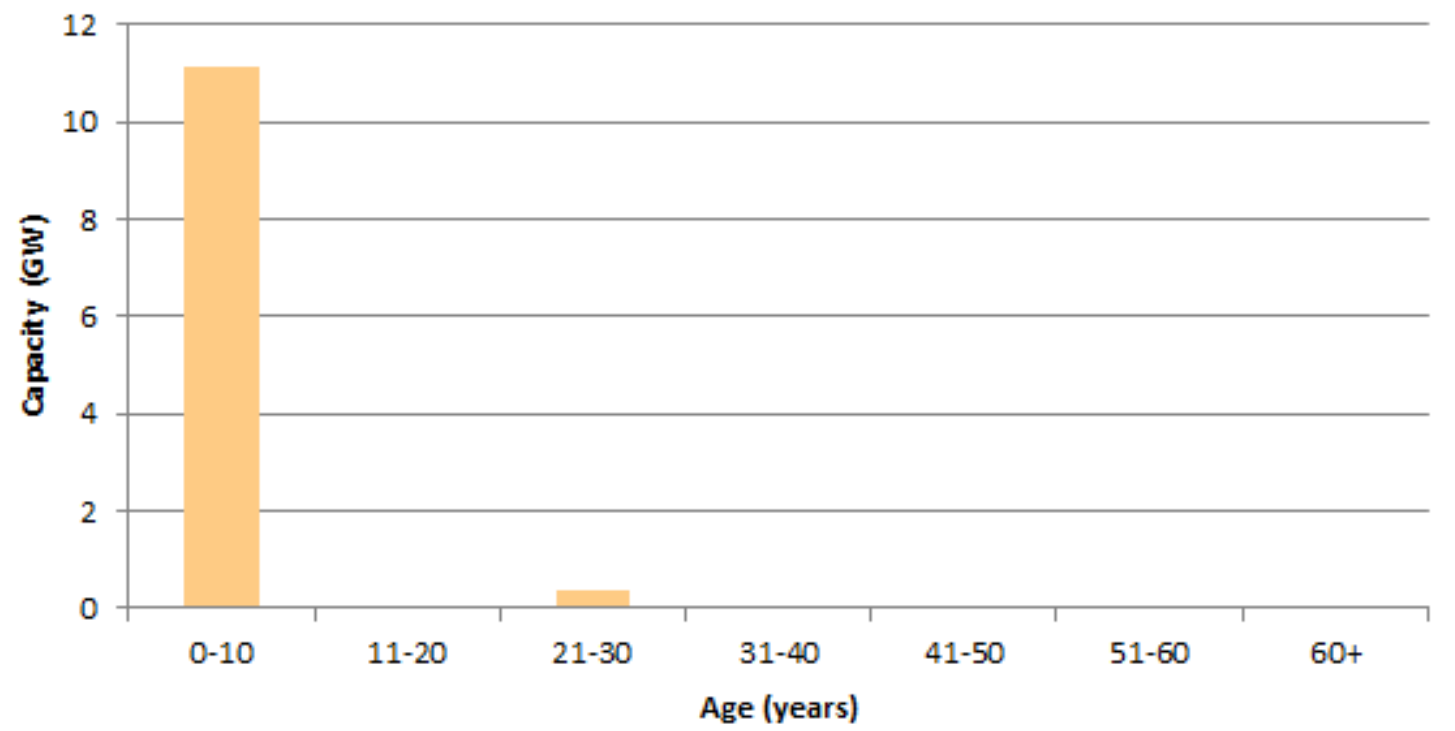

Figure 11-6. Age profile of U.S. utility-scale solar generation fleet, 2014

The majority of solar generators are less than 10 years old. Note: This includes only utility-scale capacity, which is defined as $1 \mathrm{MW}$ or greater. Source: SNL $2015^{463}$.

\subsection{Technology Costs}

The LCOE for solar generation from utility PV and from CSP is shown in Table 11-1. The range of values for the LCOE of utility PV is lower than for CSP, although both types of solar generation can experience a wide range in LCOE. The range for solar PV is within the LCOE range for land-based wind, although probably higher on average. Solar CSP is closer in LCOE to offshore wind.

Lazard's cost ranges for utility-scale solar directly correlate to improved capacity factors. Lazard's utility PV capital costs are higher for the low LCOE estimate because they assume that the higher cost pays for improvements in the capacity factor (e.g., fixed-tilt vs. single-axis tracking), while NREL's and EIA's values only represent single-axis tracking, and wider ranges are due to variations in regional resource quality. The result is a tighter range for Lazard for utility-scale solar. 
Table 11-1. LCOE for New Solar Generation (2013\$/MWh)

\begin{tabular}{|l|l|l|l|l|l|l|}
\hline & EIA & \multicolumn{2}{l|}{ NREL } & Lazard \\
& Low & High & Low & High & Low & High \\
\hline Utility PV & 80.00 & 430.52 & 54.94 & 171.03 & 46.06 & 132.61 \\
\hline CSP* $^{*}$ & 140.20 & 271.89 & 82.61 & 207.35 & 104.44 & 249.46 \\
\hline
\end{tabular}

Current ranges of solar technology LCOEs using cost assumptions from three sources: * EIA 2015, no storage; NREL 2015; and Lazard 2015, with storage ${ }^{464}$. See Appendix B for more information on LCOE calculations.

Please refer to Section 3.4.1 for further discussion on the methodologies and assumptions used to calculate these LCOE values.

\subsection{Fuel/Resource}

Figures 11-7 and 11-8 detail the solar resource in the United States for both PV and CSP applications. Generally, the southwestern United States has the best solar resources for both PV and CSP technologies; this is especially true for CSP, which relies on direct radiation, whereas PV can use both direct and diffuse radiation. The estimated PV resource is dependent on tilt and tracking technology. The solar resource varies greatly by location, and both latitude and longitude matter. At any given location, the incident radiation from the sun changes substantially by season and year to year depending on weather patterns; the maps below show averages from 10 years of weather data ${ }^{\text {xiii }}$.

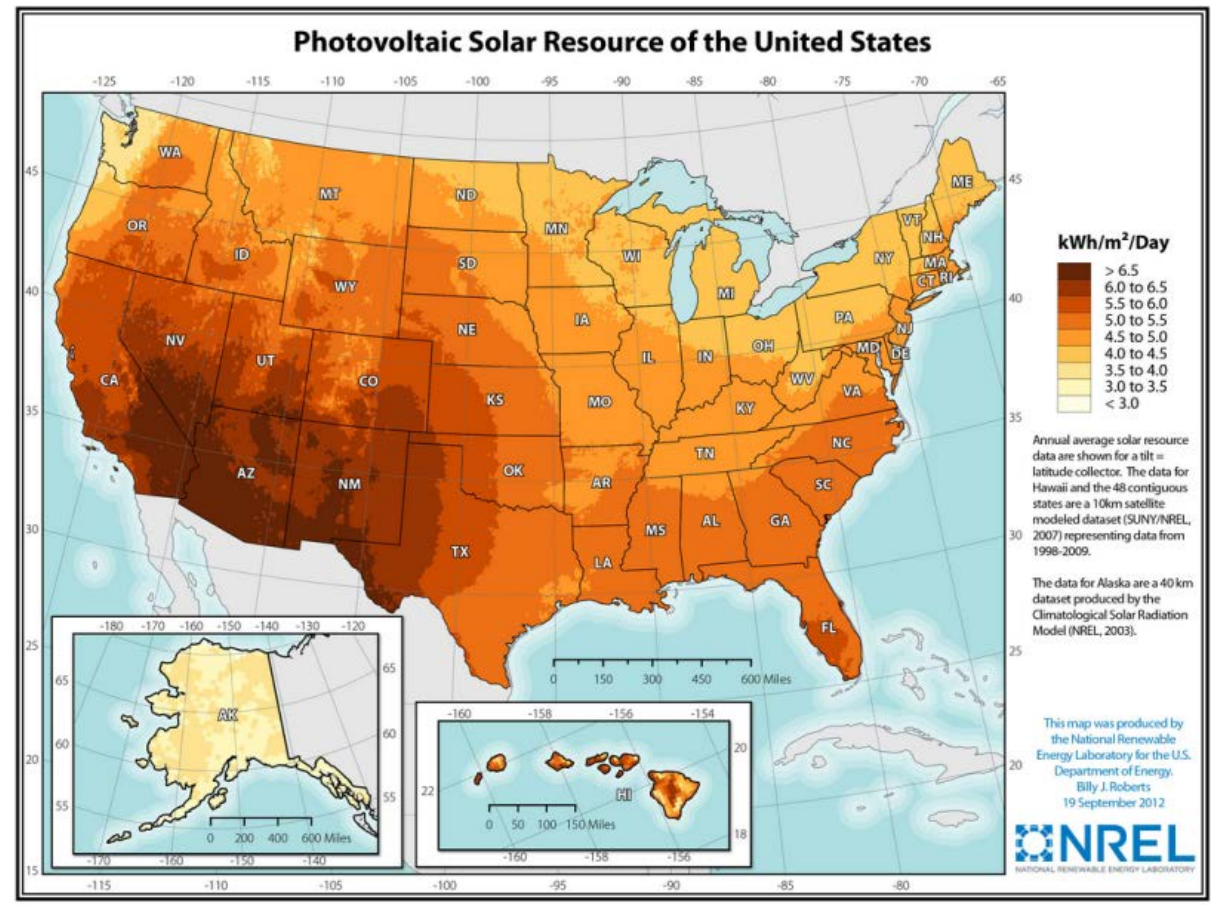

Figure 11-7. PV solar resource of the United States

The solar PV resource is best in the southwestern United States, with good resources spanning most of the southern states. Source: NREL $2015^{465}$.

\footnotetext{
Ixiii The solar irradiance varies roughly \pm 10 percent about the average irradiance for each state, although this also varies from state to state based on geographic location.
} 


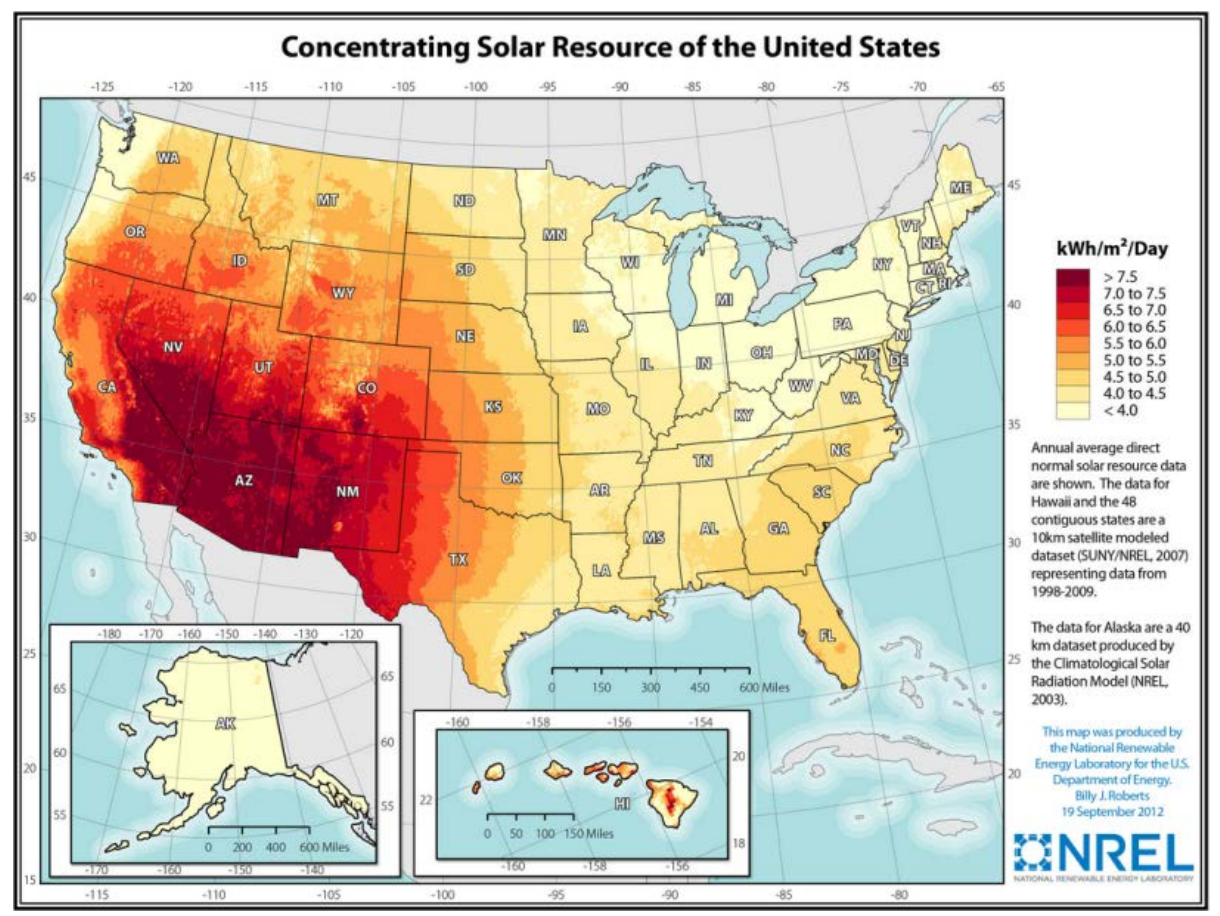

Figure 11-8. Concentrating solar resource of the United States

The best CSP resource is located in the southwestern United States, centered around Arizona. Source: NREL $2015^{466}$.

\subsection{Environmental Impacts}

\subsubsection{Upstream}

Different solar PV cell technologies use different types of materials, which have varying environmental concerns. See Appendix A for further discussion of the PV technologies. Materials for solar cell production need to be mined, and environmental impacts will be similar to ferrous mining operations. Some solar cell materials for certain thin-film PV technologies (such as cadmium and telluride) are toxic and need to be handled safely to prevent contamination of workers and the environment. The toxic nature of these materials needs to be considered when disposing modules at the end of life as well. During production of certain solar cells, many hazardous chemicals are needed to refine, polish, and dope (treat) the material, and 50 percent of material can be lost during the sawing process ${ }^{467}$.

Manufacturing of solar cells is energy intensive and is often the largest source of GHG emissions in life-cycle analysis. PV module manufacturing, production, and installation result in emissions of, on average, 40 pounds of $\mathrm{CO}_{2} / \mathrm{MWh}^{468}$.

\subsubsection{Emissions and Environmental Impact}

After manufacturing and installation, $\mathrm{PV}$ and CSP plants do not produce any $\mathrm{CO}_{2}$ and have zero marginal fuel costs. Life-cycle $\mathrm{CO}_{2}$ emissions on a per $\mathrm{kWh}$ basis from PV and CSP plants are roughly an order of magnitude less than $\mathrm{CO}_{2}$ emissions from natural gas plants ${ }^{469}$.

Utility-scale projects can be located in the desert environments of the southwestern United States and could have impacts on desert habitats and endangered desert species. Utility-scale 
developers in these areas must complete environmental review procedures to assess their projects' impacts on desert environments.

\subsection{Constraints}

Certain non-silicon based thin-film solar cell materials, such as tellurium and indium, are rare earth elements. While material availability will likely not be a factor limiting overall PV deployment, PV production of certain technologies could be affected by global supply ${ }^{470}$. Rare earth elements may be less abundant in the earth's crust. Since they are a potential byproduct of minerals processing (such as phosphorous and soda-ash), the supply of rare earth elements is dependent on the economics of the primary product. Presently, China is producing rare earth elements for lower cost than is possible in the United States. Silicon solar cells have an advantage in this respect, as silicon is abundant in the earth's crust. Also, balance-of-system materials are dependent on global material supply chains and prices.

PV for residential scale can be installed on the rooftop of the home without requiring any additional land area. Commercial-scale PV is often installed on the rooftop of a building and may require only a small land area for the inverter adjacent to the building. Utility-scale projects are usually located in desert environments in the United States, and there has been concern about impacting desert habitats and endangered desert species ${ }^{471}$.

CSP plants often require large amounts of land, generally in desert climates. A source of water for cooling and steam production is needed and can be an issue for large-scale development in arid regions. There have also been concerns over power towers resulting in bird deaths, as birds can fly through the heliostat field and be burned; however, proper procedures can reduce these mortalities $^{472}$.

As PV modules produce DC power, inverters are needed to convert output to AC so that it can be incorporated into the grid. Smart inverters can provide several services to assist in the integration of PV generation. Such services include frequency and voltage disturbance ride-through, voltage and ramping control, and reactive power control $^{473}$. Inverters can also limit their active (i.e., real) power output and control their power ramping to maintain system stability. Voltage and ramping controls can be programmed as a function of grid voltage or frequency or can be triggered remotely. Ramping can also be set as a maximum rate. Inverters can provide reactive power injection or absorption. This function, when coupled with an algorithm that can rapidly respond to grid conditions, can provide stability for the distribution grid ${ }^{474}$.

Frequency and voltage disturbance ride-through allows PV systems to continue to operate for a limited time during events when the grid's voltage or frequency operates outside of predetermined ranges. The grid may be able to recover if the disturbance is small or short. However, if inverters are not programmed to operate during disturbances, a large number of PV systems could disconnect simultaneously, triggering a sharp reduction in voltage and leading to a large-scale grid failure in high-penetration scenarios ${ }^{475}$. This issue has prompted Germany to spend considerable resources retrofitting more than 400,000 installed PV inverters ${ }^{476}$. German regulators have redefined inverter output levels as a function of frequency during over-frequency periods. 
At high PV penetration levels (i.e., share of total generation), there is concern with peak demand shifting to later in the afternoon, resulting in a need for large thermal generators to ramp up when the sun starts to set. For thermal generators designed to operate at a consistent output, more frequent output cycling can result in increased maintenance costs and reduced life ${ }^{477}$. This phenomenon is referred to as the "duck-curve," as published by CAISO in 2013. However, by increasing overall system flexibility through responsive demand and energy storage technologies, more flexible thermal generators, and enhanced operations, this issue can be managed $^{478}$.

Increased installations of utility-scale solar projects may lead to further investments in transmission as these projects are generally located away from demand centers. Increased installation of distributed solar projects may potentially delay transmission and distribution upgrades in the short term by curbing demand for utility-scale generation, but high penetration rates may require grid modernization to provide for widespread solar installation in the long term.

Like wind, solar energy is variable and nondispatchable. As the levels of VERs increase, their value to the grid decreases, both because VER integration costs increase and because VERs reduce the marginal cost of electricity due to their negligible costs of operation. This will be a future challenge for solar PV as penetration levels increase. Soft costs - costs beyond procurement of hardware - are both an opportunity and a concern, as it remains to be seen whether their contribution to the total cost of installed PV in the United States can be reduced significantly.

Distributed PV has benefited from net energy metering, financing innovations, and specific RPS requirements for distributed solar. The potential for future PV deployment in the distribution network is high because of the ITC extension and future reductions in installed costs. However, the increased expansion of distributed PV is causing a number of states to reevaluate their net energy metering policies to address cost allocation and rate designs ${ }^{479}$.

\subsection{Technical RDD\&D}

RDD\&D for PV technologies is outlined in the DOE's SunShot 2020 goals. The SunShot goals call for the reduction of unsubsidized, utility-scale solar LCOE to $\$ .06 / \mathrm{kWh}$ (estimates for current LCOE range from $\$ 0.05$ to $\$ 0.43 / \mathrm{kWh}$, according to Table $11-1)$. In order to achieve this SunShot goal, DOE has funded R\&D projects aimed at lowering manufacturing costs, increasing efficiency and performance, and improving reliability of $\mathrm{PV}^{480}$.

For a review of PV technologies and different materials, please see Appendix A. DOE lists the following manufacturing and technical improvements for the various cell technologies ${ }^{481}$ :

- Crystalline-Silicon (C-Si): Reduce raw materials requirements, reduce material waste during sawing, and optimize crystal growth process

- Thin films: Increase cell efficiencies through increased crystal quality, improve doping control, increase minority carrier lifetime, and reuse/recycling of toxic cell materials

- Multi-junction: Decrease cost of manufacturing and materials (substrates, absorbers, etc.), increase cell efficiency, and extend multi-junction concept to other cell materials 
- Perovskite: Increase cell stability, identify degradation mechanisms, and improve durability.

Increasing the efficiency of silicon cell manufacturing can be achieved by reducing wasted material. Inefficient ingot casting and sawing can result in a waste of 50 percent of purified and $\mathrm{C}-\mathrm{Si}$. Companies have reduced wafer costs by 60 percent by eliminating the need for sawing machines and are working on achieving competitive module efficiencies and further reducing manufacturing costs ${ }^{482}$. In 2014, crystalline silicon (c-Si) modules represented $94 \%$ of all global PV module shipments ${ }^{483}$.

Increasing module efficiency could also help improve panel economics. The average efficiency of commercially available solar PV modules has been rising for decades. Some scientists believe 50 percent efficiency could be possible with newer approaches and materials ${ }^{484}$. Higher module efficiencies could also reduce installation and maintenance costs by reducing the size of PV systems.

Perovskite cells (see Appendix A for details about cell types) have shown rapid improvements in efficiency of converting light to electricity in the laboratory, but are still far from commercialization. Hurdles that need to be overcome include the rapid pace at which cells degrade and safety concerns over the quantity of lead used in cell manufacturing ${ }^{485}$.

DOE SunShot initiatives are also aimed at reducing soft costs of solar installation. These costs can account for up to 64 percent of the PV system ${ }^{486}$. R\&D funding is aimed at increasing market transparency, training the solar workforce, developing and communicating process improvements, and focusing on local solutions for PV installation ${ }^{487}$.

Other DOE SunShot funding is allocated to the system integration of PV. System integration includes programs for grid performance and reliability, dispatchability, power electronics (smart inverters), and communications ${ }^{488}$.

CSP RDD\&D is sponsored under the SunShot initiative at DOE and is focused on reducing costs, increasing efficiencies, and increasing operating reliability. Demonstration projects include different materials for collectors, receivers, thermal storage equipment, working fluids, and power-cycle equipment ${ }^{489}$.

\subsection{Development and Projected Future Deployment}

Utility-scale solar PV capacity in the United States has been growing steadily since 2009 (Figure 11-9) ${ }^{490}$. Tax credits at the Federal level, RPS policies, and significant cost reductions have been the main drivers for utility-scale PV growth. RPS policies have expanded the market for renewable energy technologies in 29 states and the District of Columbia. Carve-outs for distributed generation (included in the RPS of 16 states), net metering, financing innovations, and system resiliency planning are some of the drivers for the continuing expansion of distributed generation installed capacity. 


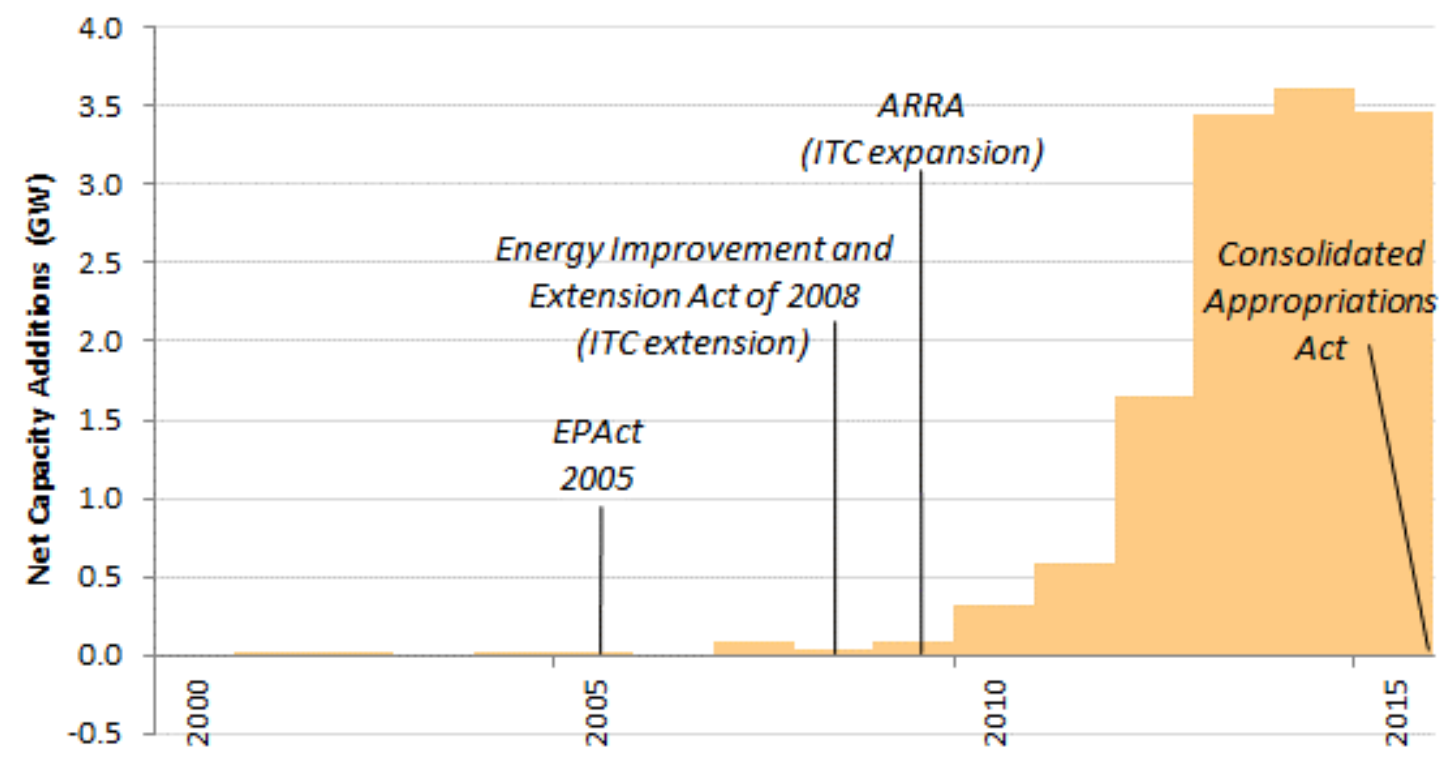

Figure 11-9. Historical annual utility-scale solar capacity additions (GW), 2000-2015

Solar development has been incentivized by the ITC, state RPS policies, net metering, and significant reductions in cost. Only federal policies are shown. Capacity is reported in GW-AC. Source: EIA 1990 and EIA $2016^{491}$.

Numerous analysts have concluded that solar resource abundance, declining costs, increasing module efficiencies, and supportive policies at the Federal and State levels could sustain the growth in PV capacity additions seen in the United States over the last 10 years. The new legislation extending and then phasing out the ITC for projects that begin construction before $2022^{\text {lxiv }}$ and the CPP's Clean Energy Incentive Program could provide the solar industry with longer-term policy certainty. The ITC extension could spur a 50 percent increase in cumulative installed capacity between 2016 and 2020 over the no-extension scenario ${ }^{492}$. Lawrence Berkeley National Laboratory (LBNL) estimates that existing RPS policies will require renewable generation to double from 215 TWh in 2015 to 431 TWh in 2030 for compliance for the entire United States $^{493}$. Specifically, LBNL estimates solar carve-outs (including for distributed PV) mean that an additional $2 \mathrm{GW}$ of capacity will be needed by 2020 and $5 \mathrm{GW}$ by 2030 relative to current amounts.

While, 1.3 GW of CSP capacity had been installed in the United States between 2010 and 2015, no CSP projects were projected for $2016^{494}$. The QER 1.2 Base Case projects over $300 \mathrm{TWh}$ of solar generation coming online by 2040 .

Table 11-2. QER 1.2 Base Case Projections for Solar Generation (TWh), 2014-2040

\begin{tabular}{|l|c|c|}
\hline & 2014 Actual & QER 1.2 Base Case \\
Solar Generation & 45 & 255 \\
\hline
\end{tabular}

The QER 1.2 projection calls for a seven-fold expansion in solar generation by 2040 compared to 2014 levels. Source: EPSA $2016^{495}$.

${ }^{\text {Ixiv }}$ Commercial projects placed in service after 2023 qualify for a 10 percent ITC. 
In its 450 Scenario, IEA projects that, globally, more than twice the amount of solar PV generation and over six times the amount of solar CSP generation will come online compared to the Current Policies Scenario (Table 11-3). In the 2040 time horizon, China and India are projected to lead global solar demand with the EU and North America following (Figure 11-10).

Table 11-3. Global Solar Generation Projections, 2013-2040

\begin{tabular}{|l|c|c|c|c|c|c|c|}
\hline IEA Scenario & & \multicolumn{2}{|c|}{ New Policies } & \multicolumn{2}{|c|}{ Current Policies } & \multicolumn{2}{|c|}{450} \\
\hline & $\mathbf{2 0 1 3}$ & $\mathbf{2 0 2 0}$ & $\mathbf{2 0 4 0}$ & $\mathbf{2 0 2 0}$ & $\mathbf{2 0 4 0}$ & $\mathbf{2 0 2 0}$ & $\mathbf{2 0 4 0}$ \\
\hline PV Generation (TWh) & 139 & 494 & 1,521 & 446 & 1,066 & 529 & 2,232 \\
\hline $\begin{array}{l}\text { CSP Generation } \\
\text { (TWh) }\end{array}$ & 5 & 27 & 262 & 25 & 147 & 32 & 937 \\
\hline $\begin{array}{l}\text { Percentage of Global } \\
\text { Total }\end{array}$ & 0.6 & 1.9 & 4.5 & 1.7 & 2.8 & 2.1 & 9.3 \\
\hline
\end{tabular}

In the 450 Scenario, more than twice the amount of solar PV generation and six times the amount of solar CSP generation are projected to come online compared to the Current Policies Scenario. Source: IEA $2015^{496}$.

Note: Solar PV includes both utility-scale and distributed capacity.

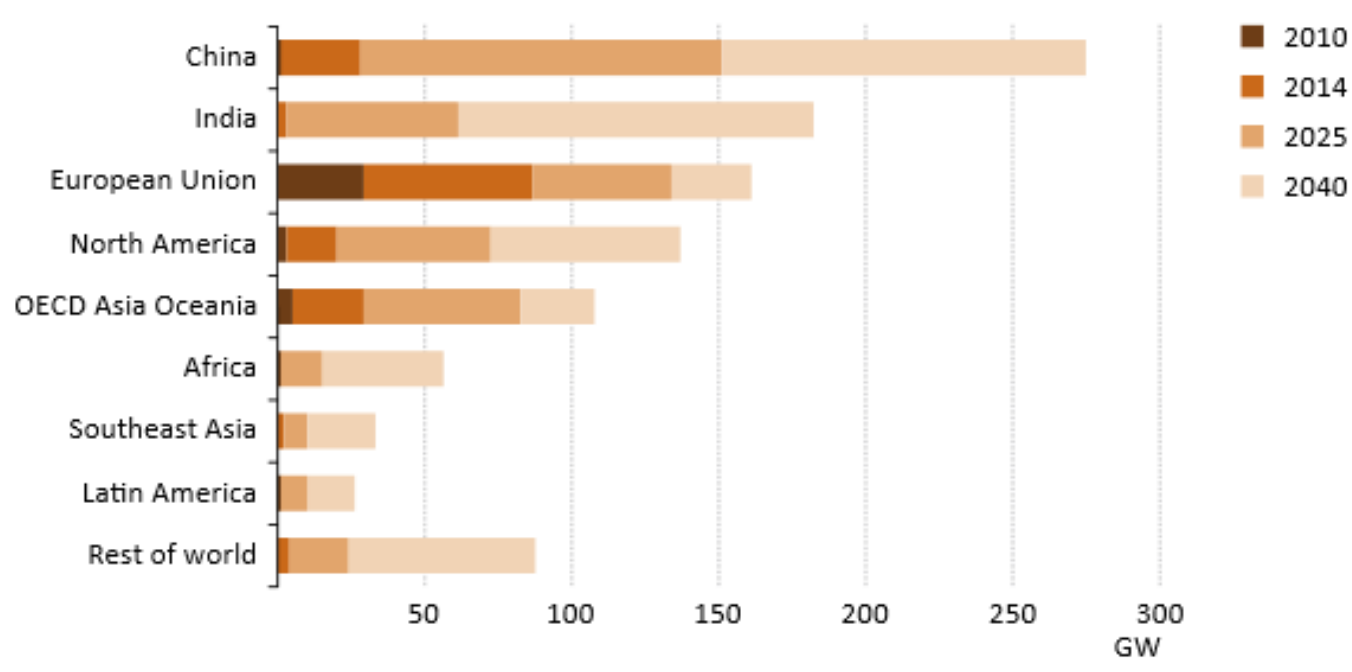

Figure 11-10. Solar PV installed capacity by region in the New Policies scenario

China is projected to lead global solar installed capacity. Source: IEA (2015) ${ }^{497}$.

Note: Includes both utility-scale and distributed solar PV capacity. 


\section{Geothermal}

\subsection{Technologies}

Geothermal power plants utilize turbine technology in a process similar to that used in fossil fuel and nuclear power plants, but geothermal plants capture heat from below the earth's surface to create steam or vapor. There are currently three main types of geothermal generation technology in the United States: dry steam plants, flash steam plants, and binary-cycle power plants. A fourth, enhanced geothermal systems (EGS), is not a generation technology per se, but a process to engineer the underground heat source so that it can provide usable energy ${ }^{498}$. To date, EGS is not commercially available.

Dry steam plants use steam piped directly from a geothermal reservoir to turn a generator. Flash steam plants use high-pressure, hot brine from deep reservoirs and convert it to steam to drive generator turbines. Binary cycle power plants transfer the heat from geothermal brine to a secondary working fluid with a lower boiling point, which is converted to vapor, again driving a turbine. Finally, EGS is a subsurface technology under development that could significantly expand the geothermal resource base as it relies on hot rock, but not necessarily the water content or permeability required in traditional hydrothermal resource sites ${ }^{499}$. EGS aims to engineer the subsurface to optimize the reservoir for sustained heat exchange. EGS can use any of the surface technologies noted above to generate electricity in an ST.

Geothermal plants range in size depending on the size of the geothermal reservoir that is available. Large-scale geothermal plants in the United States range from as small as $2 \mathrm{MW}$ up to 100MW, but other geothermal plants can be smaller size and distributed for certain applications $^{500}$. Geothermal plants are often composed of one or more generating units. One benefit of geothermal generation is that it can be easily ramped up and down through control systems. Geothermal power plants offer dispatchability, high physical inertia, low conventional air emissions, and firming capabilities ${ }^{501}$. Other geothermal power generation benefits include low life-cycle GHG emissions and baseload applications.

\subsection{0perational Attributes and Fleet Characteristics}

Geothermal power generation currently comprises less than 1 percent of the total electricity generation portfolio (17 TWh in 2015, Figure 12-1), with roughly $3.7 \mathrm{GW}$ installed capacity ${ }^{502}$. 


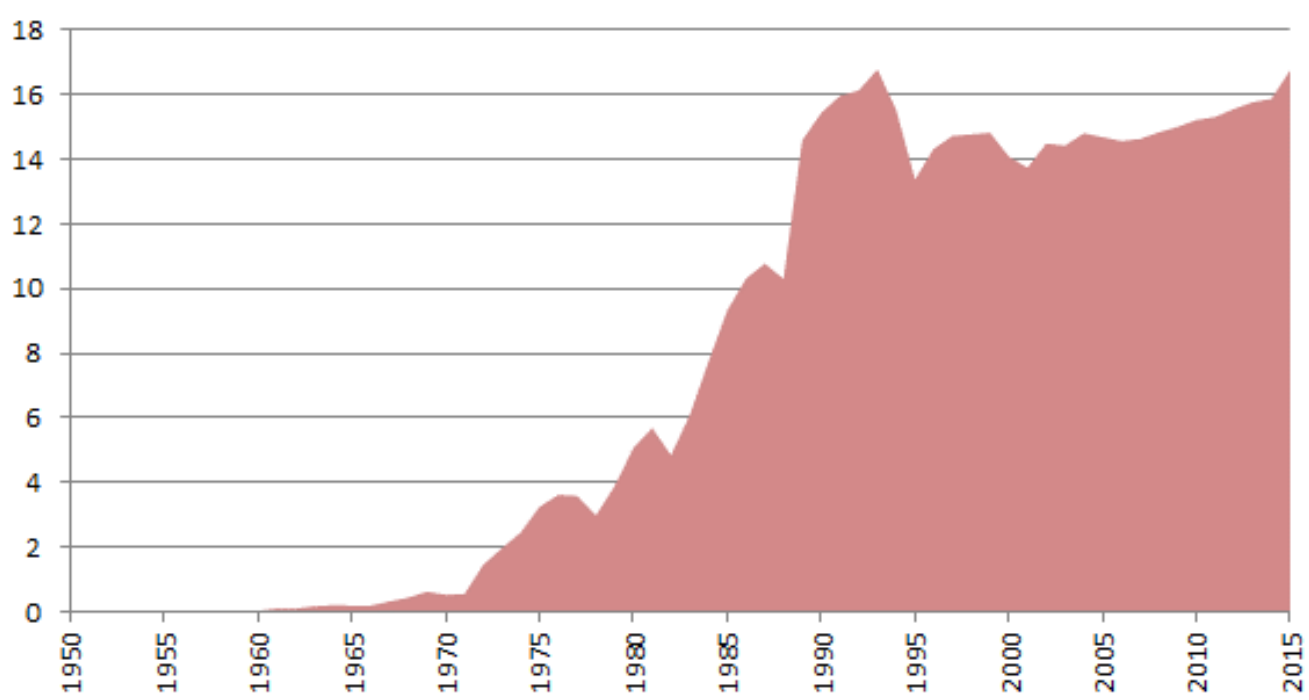

Figure 12-1. U.S. geothermal generation (TWh), 1950-2015

Geothermal generation expanded rapidly during the 1980s but has remained relatively constant since then. Source: EIA $2016^{503}$.

The capacity factor for geothermal plants was roughly 70 percent (based on installed nameplate capacity) between 2011 and 2015 (Figure 12-2) ${ }^{504}$. Plants require little downtime for maintenance, so the availability factor is in the range of 90 to 95 percent $^{505}$. However, over time there may be a reduction in availability as reservoirs decline in quality from ongoing extraction.

The majority of geothermal capacity and generation came from California in the 2010-2014 timeframe, followed by Nevada (Figure 12-3). Because of limited conventional resource availability, geothermal generation is confined to only a few additional states: Oregon, Idaho, Utah, New Mexico, and Hawaii.
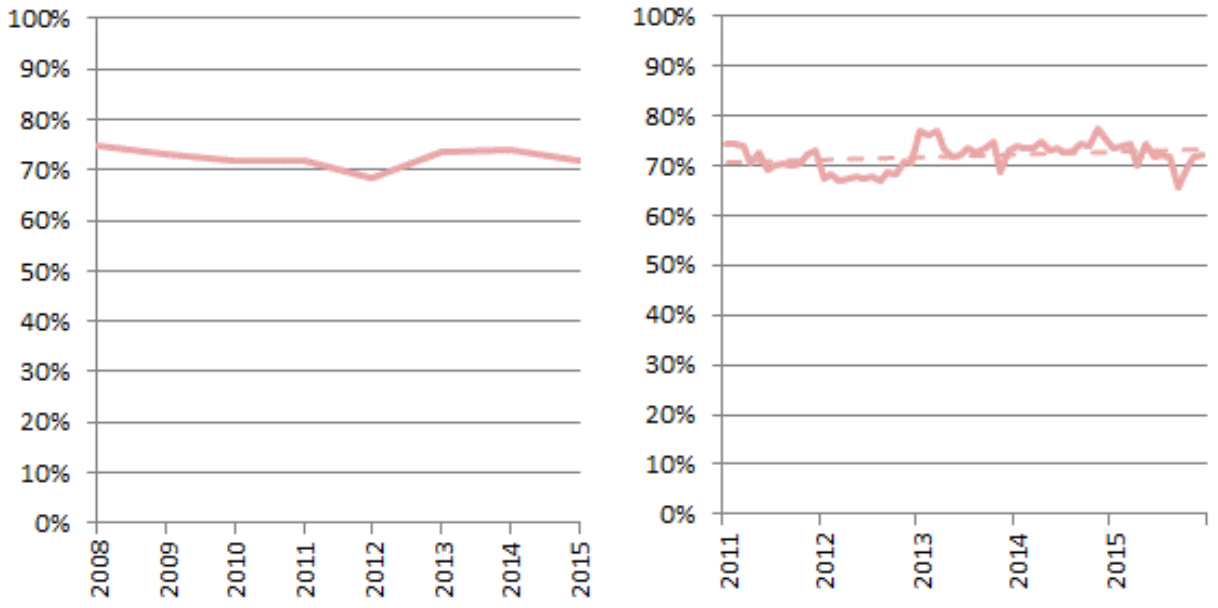

Figure 12-2. U.S. average annual and monthly geothermal generator capacity factors

Average annual capacity factors have declined slightly since 2008 , likely due to reduced availability from declining reservoir quality. Sources: SNL $2015^{506}$. 


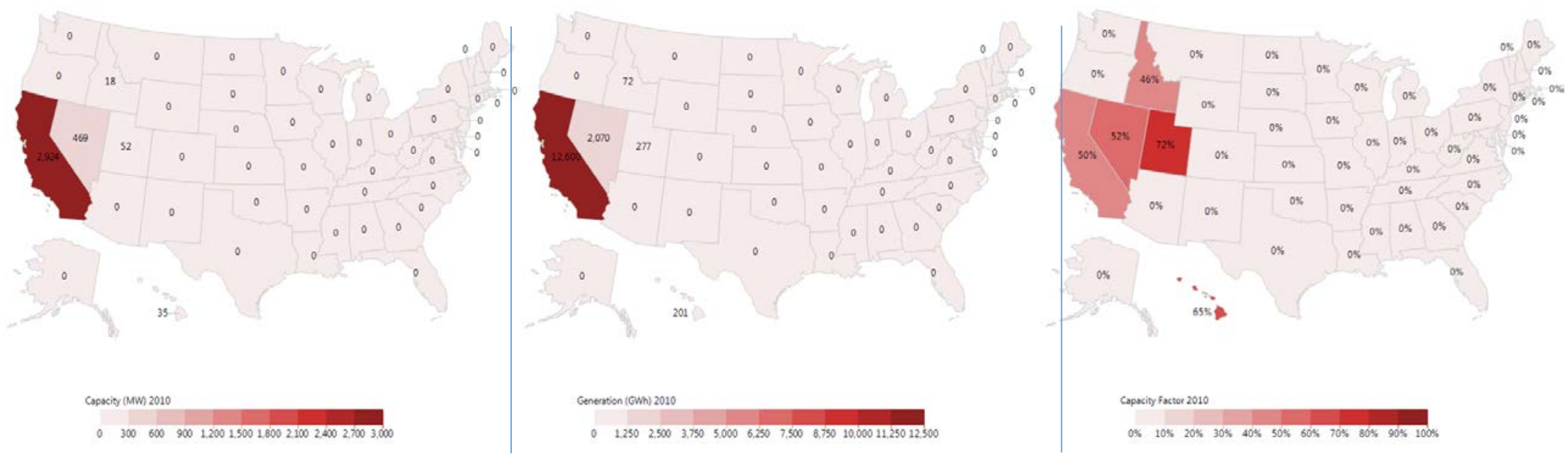

2014

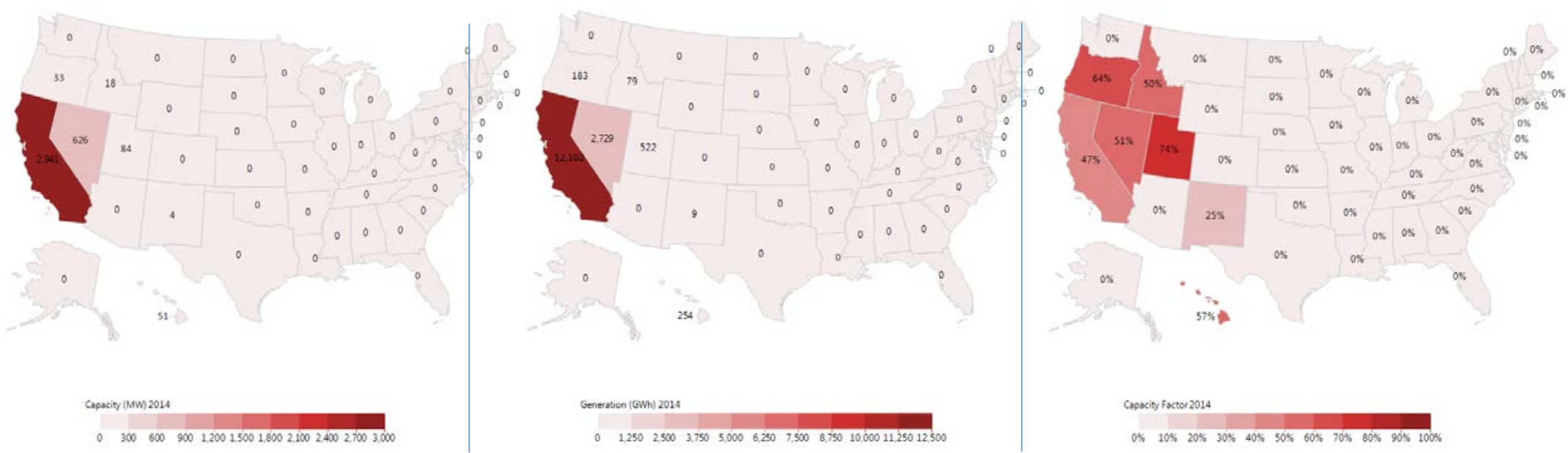

Figure 12-3. Geothermal capacity (left), generation (middle), and capacity factor (right) by state. Top: 2010; bottom: 2014.

The majority of geothermal capacity and generation came from California in the 2010-2014 timeframe, followed by Nevada. Geothermal generation is currently limited to only a few additional Western states: Oregon, Idaho, Utah, New Mexico, and Hawaii. Source: EIA $2016^{507}$. 
Geothermal systems vary in age, but roughly 70 percent of the existing generating capacity is over 20 years old yo8 $^{50}$

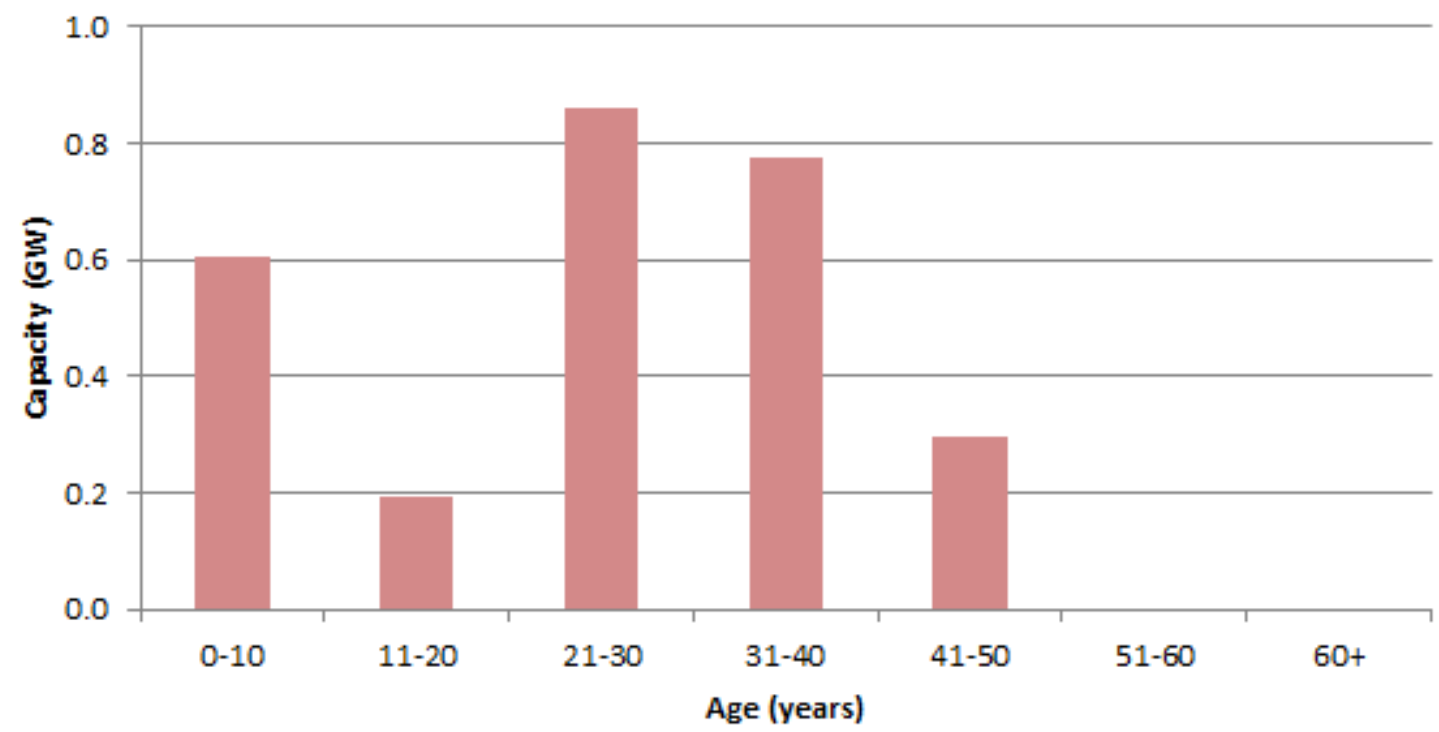

Figure 12-4. Age profile of U.S. geothermal generation fleet, 2014

Geothermal systems vary in age, but roughly 70 percent of the existing generating capacity is over 20 years old Source: SNL $2015^{509}$.

\subsection{Technology Costs}

The LCOE for geothermal generation is shown in Table 12-1. Looking at mean LCOE across sources, geothermal could provide low-LCOE, low-carbon baseload generation; however, the ranges of LCOEs is wide and depends on cost assumptions. For example, the high range given by NREL is due to the inclusion of near-field EGS resources in the cost assumptions, which are more expensive to develop than traditional hydrothermal resources. EIA and Lazard do not include EGS in their calculations. Similarly, the low end of the range for EIA represents expansion of an existing facility and is not representative of development of a new facility.

Table 12-1. LCOE for New Geothermal Generation (2013\$/MWh)

\begin{tabular}{|l|l|l|l|l|l|l|}
\hline & \multicolumn{3}{|l|}{ EIA } & \multicolumn{2}{l|}{ NREL } & \multicolumn{2}{l|}{ Lazard } \\
\hline & Low & High & Low & High & Low & High \\
\hline Geothermal & 37.44 & 54.10 & 24.08 & 453.26 & 66.25 & 124.88 \\
\hline
\end{tabular}

Current ranges of geothermal technology LCOEs using cost assumptions from three sources: NREL 2015; EIA 2015; Lazard $2015^{510}$. See Appendix B for more information on LCOE calculations.

\subsection{Fuel/Resource}

Most of the conventional U.S. geothermal resources are located in the western United States, although EGS could significantly expand the footprint, as shown in Figure 12-5. The United States Geological Survey estimates there are approximately $39 \mathrm{GW}$ of identified and undiscovered conventional geothermal resources and $517 \mathrm{GW}$ of mean estimated EGS resources $^{511}$. 


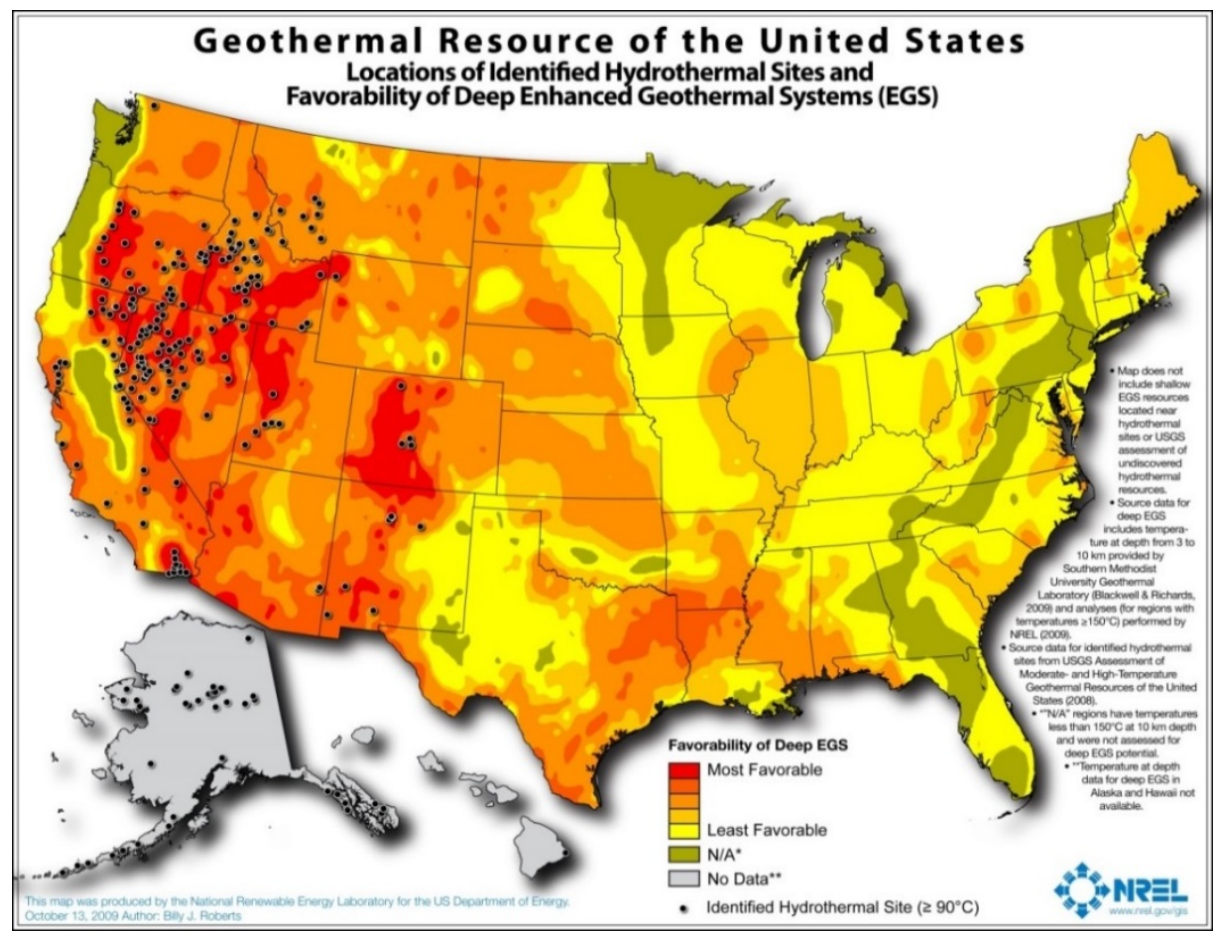

Figure 12-5. Geothermal resource of the United States

Most existing geothermal plants are located in the far western United States as the underground resource is best there. EGS have the potential to significantly expand the resource footprint for geothermal technologies. Source: Roberts $2009^{512}$.

\subsection{Environmental Impacts}

\subsubsection{Upstream}

Geothermal well drilling has similar environmental concerns to well drilling in the oil and gas industry. Drilling mud, used in the drilling process, and solid tailings must be disposed of properly to prevent contamination of the environment. There are also emissions from the diesel generators during the drilling process.

\subsubsection{Emissions and Environmental Impact}

Although geothermal plants emit no $\mathrm{CO}_{2}$ associated with combustion of a fuel, most plants release a small amount of $\mathrm{CO}_{2}$ that comes from dissolved gases found in the hot reservoir fluids, and this amount varies by technology and reservoir characteristics ${ }^{513}$. These $\mathrm{CO}_{2}$ emissions total less than 1 percent of the amount generated by an equivalent size fossil fuel-powered plant, roughly $0.1 \mathrm{lb} \mathrm{CO}_{2} / \mathrm{kWh}^{514}$. Some reservoirs may contain hydrogen sulfide, sodium chloride, and mercury in the water. These are extracted using scrubbing technology and emissions controls, which produce small amounts of solid waste. Open-loop systems can introduce hydrogen sulfide, $\mathrm{CO}_{2}$, ammonia, methane, and boron into the atmosphere ${ }^{515}$. Systems can use a closed-loop design to prevent produced water from contaminating the environment.

\subsection{Constraints}

Geothermal plant construction is similar to the supply chain for other steam power generation technologies such as coal, natural gas, and nuclear. Increased demand for metals and aggregates 
from other industries may adversely affect the construction cost and lead times since geothermal turbines are customized to the resource. Similarly, the cost and availability of drilling rigs may be a factor in the exploration phase of the construction.

Geothermal power siting is determined to a large extent by the location of available geothermal reservoirs. Since the plant sits near the reservoir, there are few options for alternative locations once a reservoir is identified. While some land is disrupted to construct the power plant facility and to drill the production wells, most of the surface area remains undisturbed.

There are some concerns about induced seismicity near new or expanded geothermal plants, as they are often located near fault lines, and water is being removed and reinjected into the earth for the purposes of enhancing the permeability or fluid content of an underground reservoir. However, induced seismicity is an issue that has been successfully managed in many different sectors, and it has been concluded that with proper protocol induced seismicity does not pose a threat to long-term geothermal development ${ }^{516}$.

Geothermal generators are baseload plants capable of providing valuable services to the grid, such as generation flexibility. As more VERs are integrated to the electric system, the flexibility of baseload capacity will grow in importance. The services a geothermal plant can provide include frequency and voltage regulation, load following, spinning reserve, nonspinning reserve, and replacement or supplemental reserve ${ }^{517}$. However, current ancillary service compensation models in areas with the most geothermal development do not provide sufficient revenue to warrant the increased operational and control retrofitting expenses ${ }^{518}$. Similarly, the dispatchability and baseload capabilities and characteristics may not be fully valued by utilities $^{519}$.

Deployment barriers include multijurisdictional permitting requirements, long development lead times, limited geographic availability (which increases grid interconnection costs), and a higher risk development profile. In 2015, 1,049 MW of geothermal capacity under development was stalled due to financing barriers, with $484 \mathrm{MW}$ stalled specifically due to the lack of funding for further exploration $^{520}$. The National Geothermal Data System and the Regulatory and Permitting Information Desktop Toolkit (RAPID) address exploration data availability and permitting barriers, which could lower the cost of development and shorten lead times.

Geothermal resources are often found in remote locations, requiring the construction of transmission infrastructure. The process of siting transmission lines can be costly and lengthy. Transmission costs are not necessarily proportional to plant capacity and can render projects economically unfeasible. Transmission costs include land use and rights-of-way fees. Additionally, visual impact mitigation requirements and local opposition can further increase costs and delay transmission construction ${ }^{521}$.

\subsection{Technical RDD\&D}

Developing EGS offers the potential to expand the geographic availability and capacity potential of geothermal resources for power production. EGS could expand the geothermal power potential more than tenfold compared with hydrothermal resources. Approximately 90 percent of the geothermal power resource potential in the United States is available only with EGS ${ }^{522}$. 
EGS differs from conventional geothermal systems in that suitable reservoir conditions must be created by increasing the permeability of a reservoir that contains enough heat to support sustained power production and by injecting fluid to convey the heat to a power plant located on the surface. Usually, EGS systems require drilling deeper-down to a depth of 2 to 6 kilometers - in harder rock than conventional geothermal development ${ }^{523}$. This deeper drilling increases the costs and risks of developing EGS plants, but it also increases access to otherwise unavailable geothermal resources.

The highest potential areas for reducing cost and lead time of geothermal plants are accurate resource characterizations and advances in well development. Improving characterization of the subsurface is critical to reduce development risks, secure financing, and lower development $\operatorname{costs}^{524}$. Advances in well drilling for hydrothermal reservoirs can reduce the large up-front capital costs that are currently a barrier for geothermal exploration.

The Frontier Observatory for Research in Geothermal Energy (FORGE) is a DOE-led initiative where the geothermal community will be able to test improved EGS technologies and techniques with the goal of accelerating the commercial deployment of EGS. FORGE focuses on methods to characterize, create, and sustain an EGS system ${ }^{525}$.

Other technologies that expand the capacity potential and geographic availability of geothermal resources include low-temperature power production and coproduction (with oil and gas) systems, hybrid systems (e.g., geothermal with solar), and the development of blind geothermal resources (i.e., geothermal resources that have no visible surface expressions).

\subsection{Development and Projected Future Deployment}

Prior to 1980, geothermal generation in the United States remained below 5 TWh annually. Then, between 1980 and 1989, generation tripled to 15 TWh as new facilities came online. Much of the early growth in geothermal power was driven by PURPA incentives, although this driving force has declined over time as the avoided costs of utility generation have fallen (Figure 12-6). Challenges in exploring new "blind" hydrothermal resources and long drilling times for production wells have led to increased uncertainty for investors in large geothermal projects. Additionally, industry analysts have asserted that expiration of tax credit horizons that do not allow enough time for project development (i.e., commence construction clauses that do not take into account the long lead time of geothermal project development), the scarcity of PPA opportunities, the need for transmission infrastructure, and low natural gas prices have likely contributed to modest growth in recent years ${ }^{526}$. In 2012, about $180 \mathrm{MW}$ of capacity was added to the U.S. geothermal fleet, which was the greatest annual growth in the last decade. In 2013 and 2014, $15 \mathrm{MW}$ or less of geothermal capacity was added, and in 2015, $32 \mathrm{MW}$ of geothermal capacity came online. Even with modest development in recent years, the United States is still the world leader in installed geothermal capacity. 


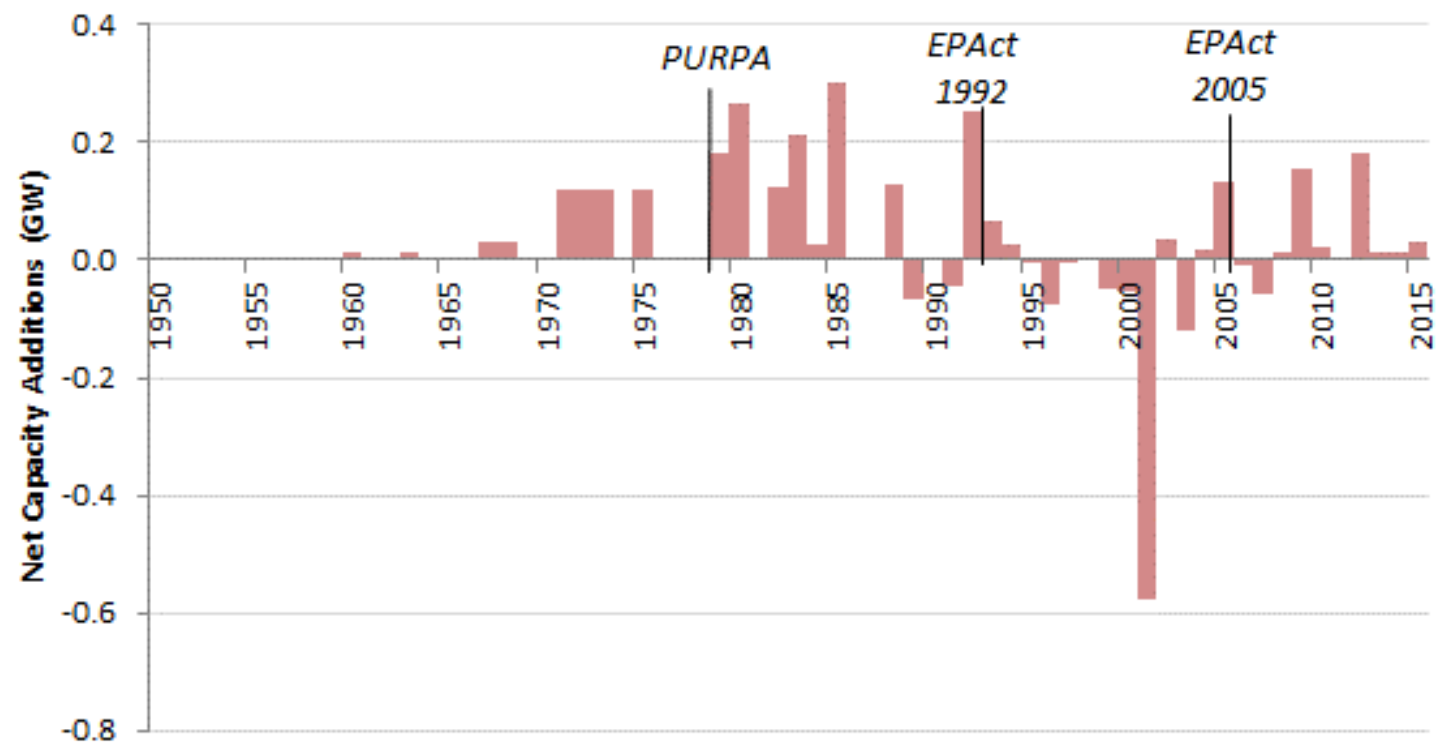

Figure 12-6. Historical annual geothermal capacity additions and retirements (GW), 1950-2015

The greatest growth for geothermal additions occurred in the 1980s. Many factors have contributed to geothermal's slowed growth since then, including challenges in exploring new 'blind' hydrothermal resources and long drilling times for production. Source: EIA 1990 and EIA $2016^{527}$.

Note: The large number of retirements in 2001 is due to a change in EIA's reporting; thus, total net capacity does not match actual installed capacity.

The 2015 omnibus spending bill extended PTC eligibility to geothermal projects that began construction before 2017 and included the option to elect a 30 percent ITC instead ${ }^{528}$. The 1-year extension and change in requirements - from "placed in service" to "begun construction"-may help geothermal projects that have at least completed the exploration phase but were not anticipated to spur greenfield development. RPS policies (especially the 50 percent target in California, where there is a large proven geothermal resource) could also spur geothermal development.

Incentives from the CPP starting in 2022, technological advances and other improvements that remove deployment barriers, and the commercialization of near-field EGS could further improve the outlook for geothermal. The QER1.2 Base Case projects U.S. geothermal generation to grow from $16 \mathrm{TWh}$ in 2014 to $57 \mathrm{TWh}$ in 2040.

Table 12-2. QER 1.2 Base Case Generation for Geothermal (TWh), 2014-2040

\begin{tabular}{|ccc|} 
& 2014 Actual & $\begin{array}{c}\text { QER 1.2 Base Case } \\
(2040)\end{array}$ \\
Geothermal Generation & 16 & 57 \\
\hline
\end{tabular}

The QER Base Case scenario projects that geothermal generation could expand nearly four-fold by 2040 Source: EPSA $2016^{529}$. 
Globally, geothermal has been growing more consistently, at a 4 to 5 percent annual rate ${ }^{530}$. IEA anticipates that by 2040, 299 TWh of generation will be online under current policies, with 541 TWh operating by 2040 under a 450 Scenario (Table 12-3).

Table 12-3. Global Geothermal Generation Projections

\begin{tabular}{|c|c|c|c|c|c|c|c|}
\hline IEA Scenario & & \multicolumn{2}{|c|}{ New Policies } & \multicolumn{2}{|c|}{ Current Policies } & \multicolumn{2}{|c|}{450} \\
\hline & 2013 & 2020 & 2040 & 2020 & 2040 & 2020 & 2040 \\
\hline $\begin{array}{l}\text { Geothermal } \\
\text { Generation (TWh) }\end{array}$ & 72 & 116 & 392 & 110 & 299 & 119 & 541 \\
\hline $\begin{array}{l}\text { Percentage of Global } \\
\text { Total }\end{array}$ & 0.3 & 0.4 & 1 & 0.4 & 0.7 & 0.5 & 1.6 \\
\hline
\end{tabular}

IEA projects that by 2040, 299 TWh of generation will be online under current policies, with 541 TWh operating by 2040 under a 450 Scenario. Source: IEA $2015^{531}$. 


\section{Petroleum}

\subsection{Technologies}

Petroleum is often combusted in STs, but a refined product can also be used in gas turbines or CC units. Sections 5 and 6, as well as Appendix A, discuss these technologies more in depth. Diesel generators, often using internal combustion or reciprocating engines, are used for off-grid or emergency power, and can usually be classified as distributed generation. Despite petroleum's significant decline as a generation fuel, from 17 percent of generation in 1978 to less than 1 percent in 2015, it remains an important fuel in some ISO/RTO markets, especially New England, during cold winter months (Figure 13-1). Many of the natural gas-fired CTs and CCs in these regions have dual fuel capability, meaning they can run on either natural gas or petroleum products with minor modifications. This is an important reliability option in New England, given that petroleum products are often easier to store at or near the generator, which can help alleviate issues that arise from gas supply disruptions.

\subsection{Operational Attributes and Fleet Characteristics}

In 2015, petroleum products generated approximately 28 TWh of electricity, or less than 1 percent of the nation's total. This is down from a peak of $365 \mathrm{TWh}$ in 1978, when it accounted for 17 percent of all U.S. generation (Figure 13-1).

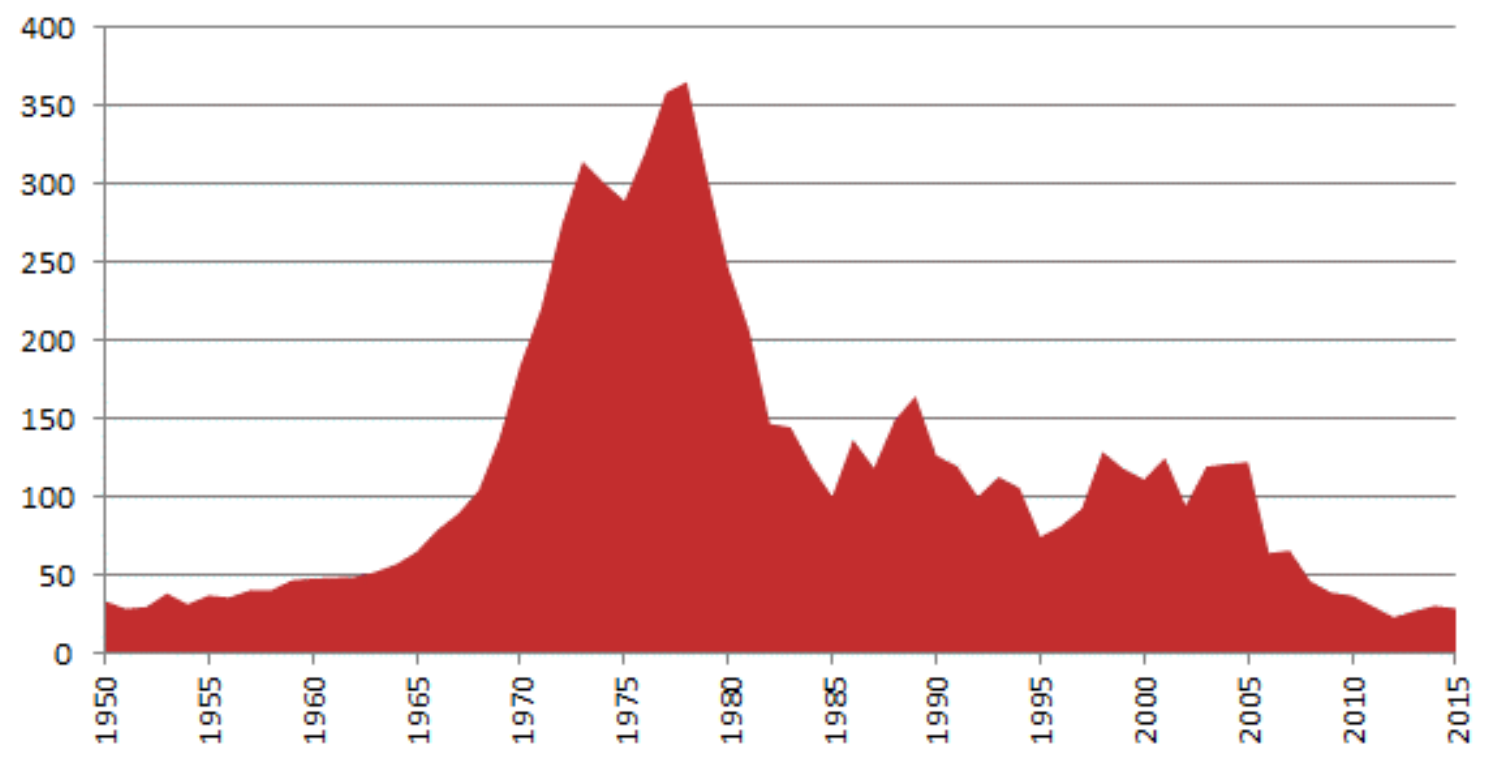

Figure 13-1. U.S petroleum generation (TWh), 1950-2015

Source: EIA $2016^{532}$.

Figure 13-2 shows that petroleum capacity by technology type was 44 percent ST, 40 percent CT, 13 percent internal combustion engine, and 4 percent CC in 2014. Due to their use in meeting peak demand, petroleum STs are dispatched first and therefore make up a larger percentage of generation at 71 percent. Petroleum-fired CC generators accounted for 18 percent of generation, while CT and internal combustion engine technologies accounted for 7 percent and 4 percent of generation, respectively, in 2014. 


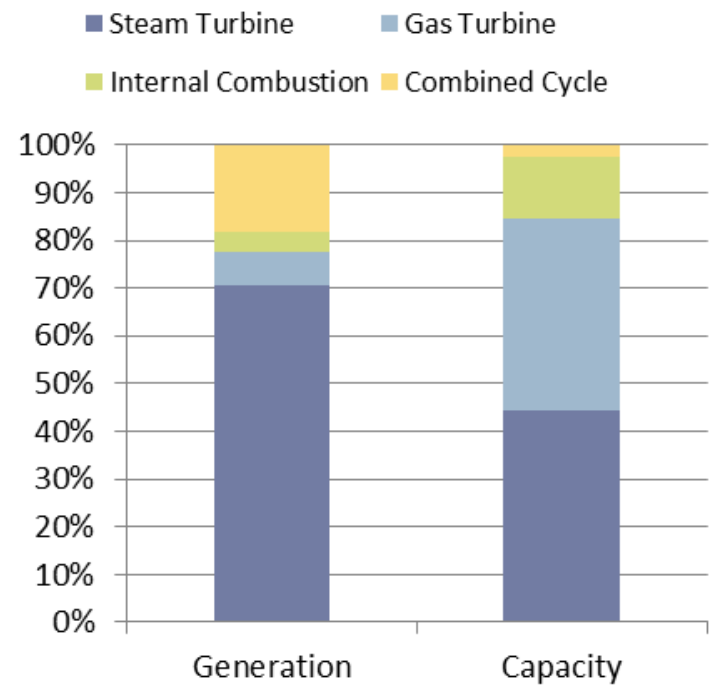

Figure 13-2. Share of U.S. operating petroleum capacity and generation by technology type, 2014 Source: EIA $2016^{533}$.

Due to their use primarily in meeting peak loads, capacity factors for petroleum generators are very low. As they are dispatched more frequently, petroleum STs have the highest capacity factor of any petroleum generator. The increased use of petroleum-fired STs in New England as back-up power during the Polar Vortex of 2014 and in 2015 is apparent in the second peak that appears at the beginning of those years in the monthly data below (Figure 13-3, right). Generation from internal combustion engines has also increased since 2014, but capacity factors still remain below 10 percent.

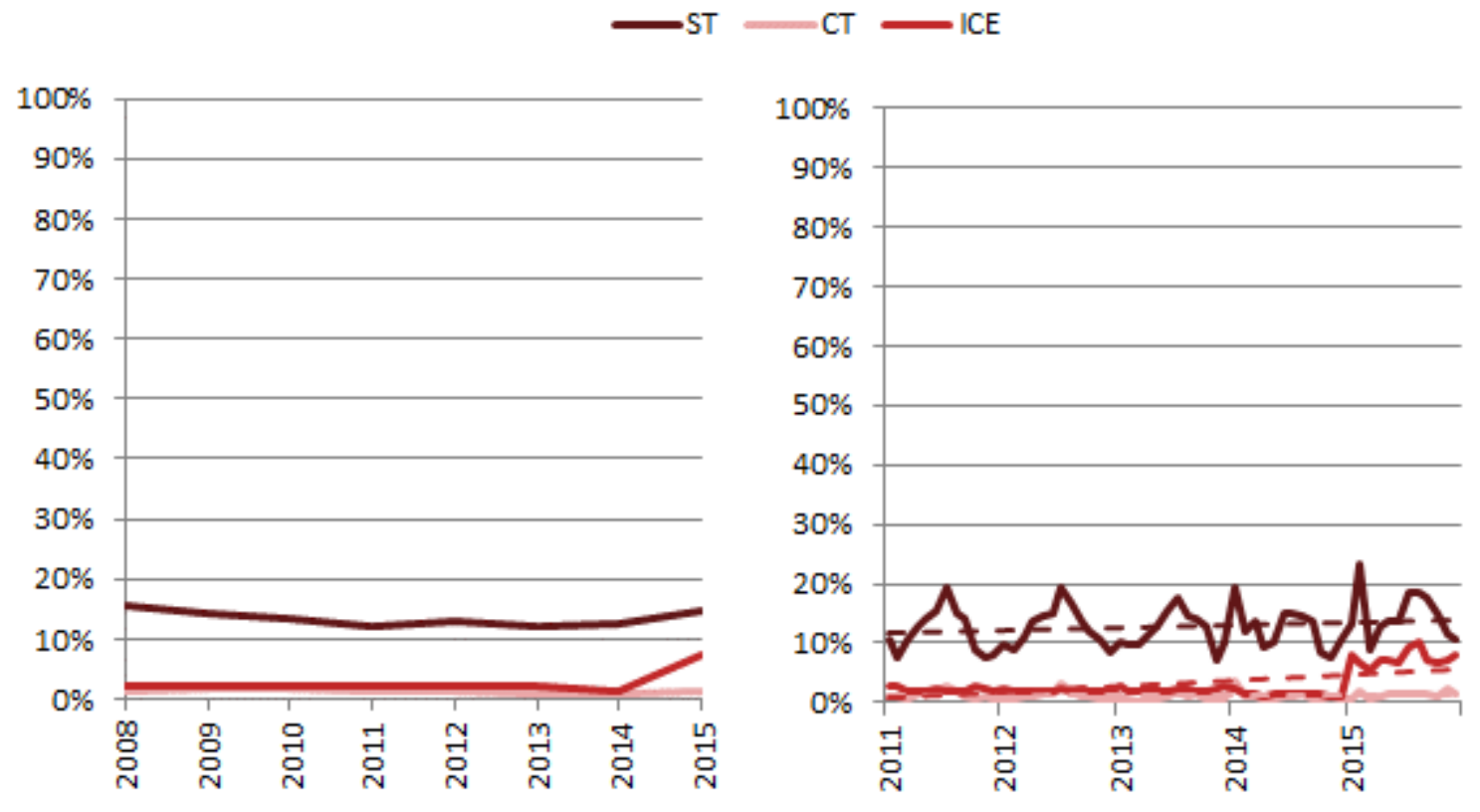

Figure 13-3. U.S. average annual and monthly petroleum generator capacity factors

Annual capacity factors have remained constant for STs and CTs, but jumped in 2013 for internal combustion engines (ICEs). Monthly capacity factors show the use of petroleum for meeting winter needs during shortages of other fuels (2014 and 2015). Sources: EIA $2016^{534}$. 
The majority of petroleum generation comes from only a few states and has generally been decreasing, as has capacity. Florida and New York lost the most petroleum-fired capacity in the 2010-2014 timeframe at 5,375 MW and 2,644 MW taken offline, respectively. Although most of the United States relies very little on petroleum generators with capacity factors for these plants at less than 10 percent, there are a few states that use these plants more frequently, such as Hawaii, Montana, Wyoming, and Louisiana ${ }^{535}$. 


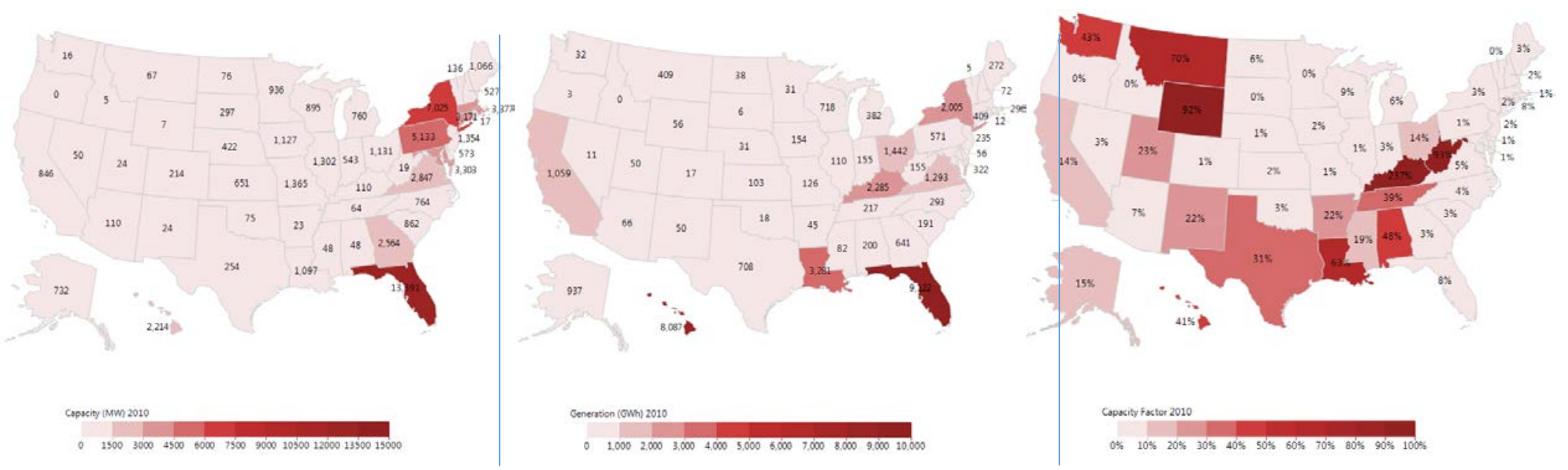

2014

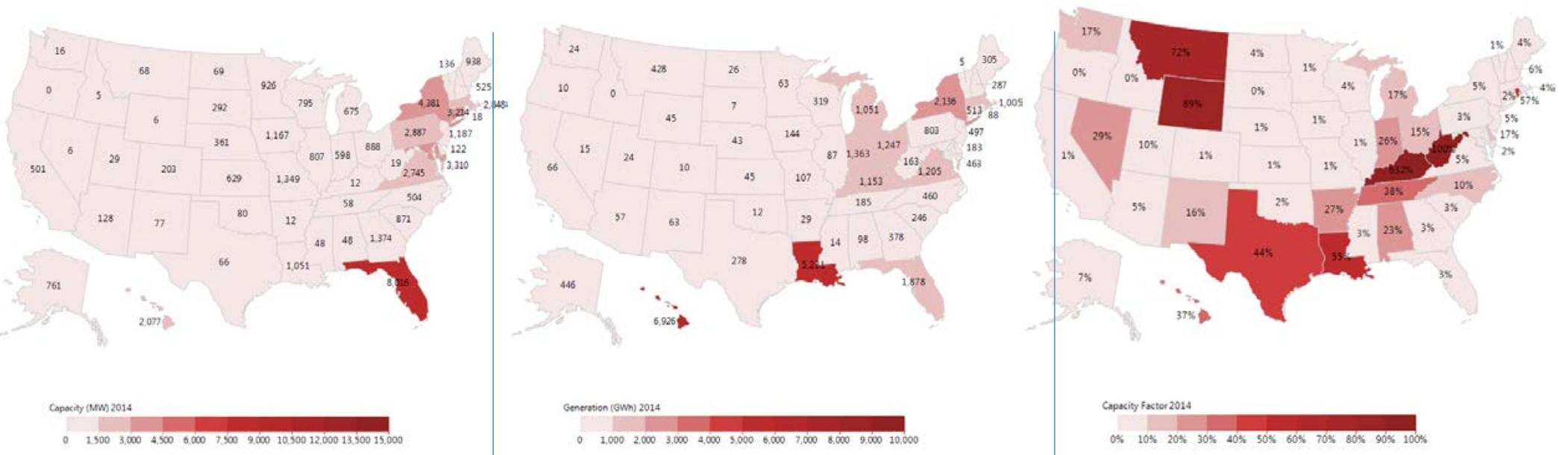

Figure 13-4. Petroleum capacity (left), generation (middle), and capacity factor (right) by state. Top: 2010; bottom: 2014.

Significant amounts of petroleum capacity came offline between 2010 and 2014, with Florida and New York losing the most at 5,375 MW and 2,644 MW, respectively. Most states generate very little electricity from petroleum, with state capacity factors less than 10 percent; however, a few states rely more heavily on their oil generators, such as Montana, Wyoming, and Louisiana. Source: EIA (2016f) ${ }^{536}$.

Note: Some capacity factors may be distorted. There is no way to separate the data to remove this distortion. 
Over half of the U.S. petroleum generation fleet is greater than 40 years old, corresponding to the sharp drop-off in new capacity additions following the oil crisis in the 1970s. With few capacity additions or retirements announced beyond 2016, the average fleet age will likely continue to increase (Figure 13-5).

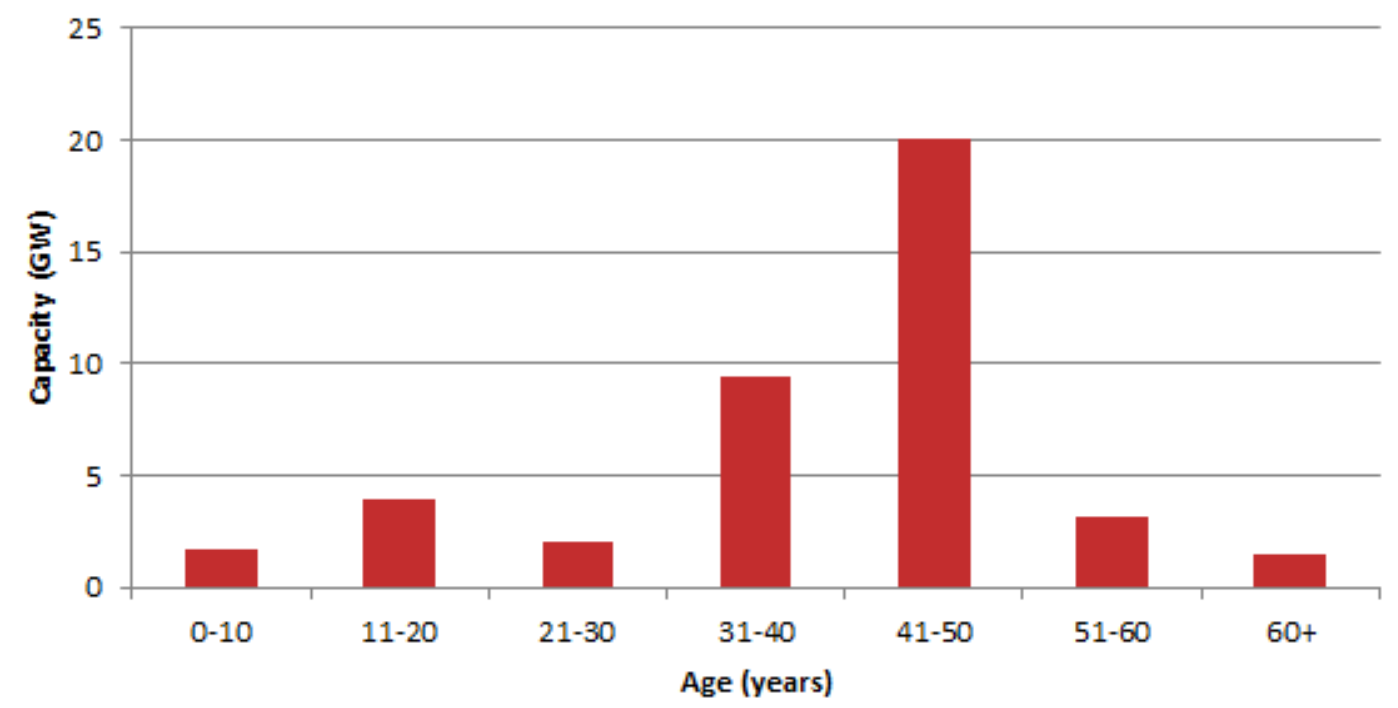

Figure 13-5. Age profile of U.S. petroleum generation fleet, 2014

Over half of the petroleum generating capacity is greater than 40 years old, corresponding to the sharp drop-off in new capacity additions in the 1970 s. Source: SNL $2015^{537}$.

Heat rates for the U.S. fleet of petroleum-fired generators, both STs and CTs, have remained relatively constant since 2007 (Figure 13-6). In comparing different fossil fuel and nuclear plants, petroleum CTs are the least efficient plant type. Without new additions to the petroleum fleet, it is unlikely that these heat rates will change significantly.

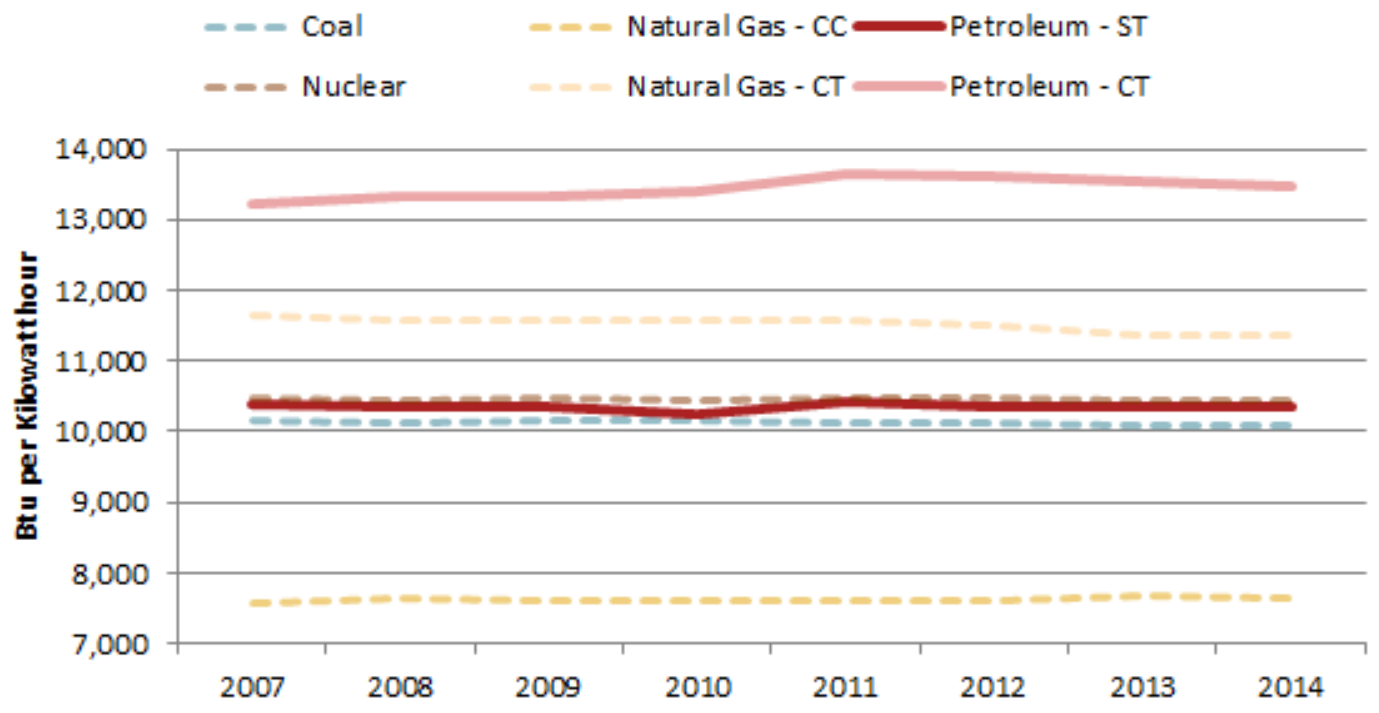

Figure 13-6. Heat rates for petroleum generators (BTU/kWh), 2007-2014

The heat rate for petroleum generators has remained relatively constant since 2007. Source: EIA $2015 \mathrm{a}^{538}$. 


\subsection{Technology Costs}

No LCOE was estimated for petroleum, as cost is not expected to play a significant role in the decision to build future petroleum-fired generation. Any future buildout will likely be made on a reliability basis, not a cost basis.

\subsection{Fuel}

U.S. oil production has increased due to the increased use of hydraulic fracturing and is currently about equal to the peak in production experienced in $1970^{539}$. The low crude oil pricing environment, however, may cause production to decrease in the near term. Onshore rig counts in the United States dropped from their peak in October 2014 at 1,596 rigs to 857 rigs in March $2015^{540}$.

In 2015, about 24 percent of the petroleum consumed by the United States was imported from foreign countries, the lowest percentage since $1970^{541,1 \mathrm{xv}}$. This translates to about 4.6 million barrels per day of petroleum from about 82 countries $^{\text {lxvi }}$. This decrease in imports is in part due to the increase in U.S. production resulting from the widespread adoption of hydraulic fracturing, as well as the decrease in petroleum demand observed since $2007^{542}$.

Petroleum is transported across the country in a complex network of pipelines, as well as by rail and by barge (Figure 13-7). In 2014, the U.S. liquid fuels system produced 8.8 million barrels of crude oil and imported 9.2 million barrels ${ }^{543}$ each day, and accounting for exports, imported a net of about 5.5 million barrels per day. Petroleum offers an advantage as a generation fuel because it can be stored onsite, which is generally not an option for natural gas.

\footnotetext{
${ }^{\mathrm{lxv}}$ This figure is based on net petroleum imports, where petroleum includes crude oil, natural gas plant liquids, liquefied refinery gases, refined petroleum products such as gasoline and diesel fuel, and biofuels including ethanol and biodiesel.

${ }^{1 x v i}$ This is the difference between the 9.4 million barrels per day of petroleum imported minus the 4.8 million barrels per day of petroleum exported.
} 


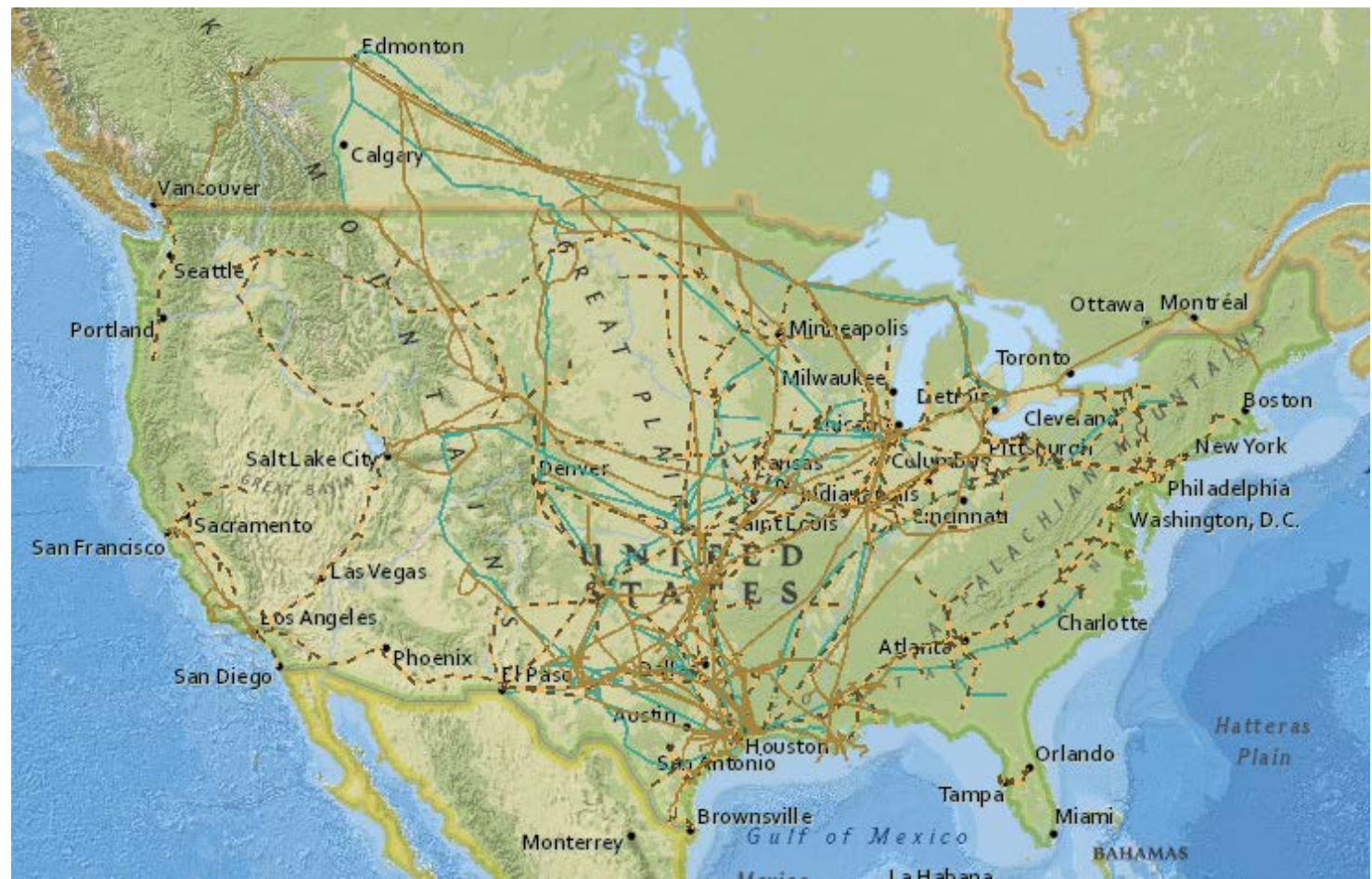

Figure 13-7. Pipelines in the U.S. and Canada that transport petroleum products

The solid orange lines show the crude oil pipelines in the lower 48 states of the United States and Canada. The dashed orange and black lines show the pipelines for petroleum products. The blue lines denote hydrocarbon liquids

pipelines, which are byproducts of both petroleum and gas production and refining. Source: EIA $2016^{544}$.

\subsubsection{Oil Price History}

Oil is traded on a global market with a partial cartel actively engaged in an effort to control prices and production, which makes its pricing particularly sensitive to external factors and, therefore, volatile. Increased U.S. production and decreased global demand for petroleum led to a sharp drop in prices in 2014, which have remained significantly lower than the 5-year average (Figure 13-8). It is likely that price volatility will be a continuing trait in oil prices, which makes the fuel component of petroleum generation cost particularly uncertain.

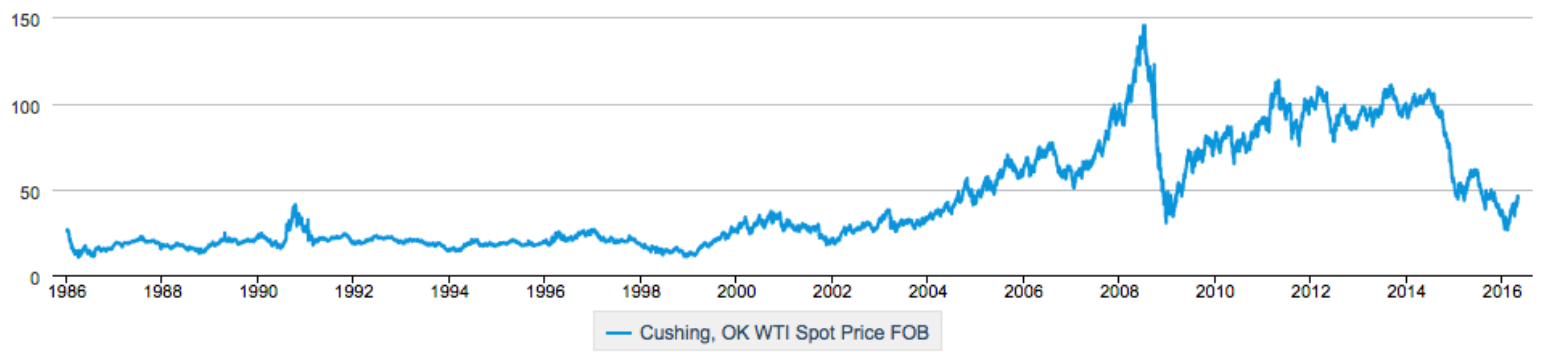

Figure 13-8. Spot prices of West Texas Intermediate crude oil at the Cushing, Oklahoma hub (\$/bbl), 1986-2016

Source: EIA $2016^{545}$. 


\subsection{Environmental Impacts}

\subsubsection{Upstream}

Similar to natural gas, petroleum is extracted from underground by drilling wells into subsurface reservoirs, which are often then hydraulically fractured to allow the oil to flow. These processes, especially hydraulic fracturing, have raised many public concerns, which are outlined in chapter 5 .

Once the oil has been extracted, it must be refined before use. Pollutants that result from the refining process include particulate matter, volatile organic compounds, $\mathrm{NO}_{\mathrm{x}}$ and $\mathrm{SO}_{\mathrm{x}}$, as well as wastewater. These hazards are regulated under statutes such as the Clean Air Act, the Clean Water Act, and the Safe Drinking Water Act, among many others ${ }^{546}$. The EPA recently issued their final rule adding more controls to prevent toxic air emissions ${ }^{547}$; the agency is currently considering whether there is a need to update their regulations regarding wastewater disposal at refineries ${ }^{548}$.

\subsubsection{Emissions}

In 2015, petroleum-fired generation only accounted for about 1 percent of total $\mathrm{CO}_{2}$ emissions in the U.S. electric power sector ${ }^{549}$. At around $70 \mathrm{~kg}$ of $\mathrm{CO}_{2}$ emitted per MMBtu, petroleum falls between coal and natural gas in terms of its emission coefficient ${ }^{550}$. Other air pollutants are a concern with petroleum, such as $\mathrm{SO}_{\mathrm{x}}, \mathrm{NO}_{\mathrm{x}}$, and NMVOCs, which can be greater than those for coal in some cases ${ }^{551}$.

\subsection{Constraints}

The petroleum infrastructure system is currently undergoing changes to accommodate the increase in U.S. production. Crude oil flow has generally reversed from the historical south-tonorth that took imported oil to inland refineries, resulting in pipeline reversals and new pipeline additions. There has also been an increase in the use of rail, barges, and trucks to move oil across the Nation. QER 1.1 addressed these changes in oil infrastructure in depth ${ }^{552}$.

\subsection{Technical RDD\&D}

Very little technical Federal RDD\&D is underway in regard to petroleum generation . The DOE programs regarding oil are focused on production, including enhanced oil recovery (EOR) and offshore drilling technologies ${ }^{553}$. EOR via gas injection is a process in which compressed gas, frequently $\mathrm{CO}_{2}$, is injected into an oil reservoir to push out more oil than could be captured by traditional pumps or injection techniques ${ }^{554}$. This form of EOR is particularly interesting to understand and harness as $\mathrm{CO}_{2}$ gathered from $\mathrm{CCS}$ technologies could be used in the process, with the oil well acting as a final storage place for the captured $\mathrm{CO}_{2}$. In 2010, DOE funded seven "next generation" EOR projects involving $\mathrm{CO}_{2}{ }^{555}$.

\subsection{Development and Projected Future Deployment}

Buildout of petroleum capacity peaked in 1974 and has steadily declined since then due to the oil crises of the 1970s, which caused oil price spikes and concerns over dependency on foreign supplies. Additionally, the Fuel Use Act restricted construction of new power plants using oil or natural gas between 1978 and $1987^{556}$. Since 1981, net retirements of oil plants have been much greater than deployments. 


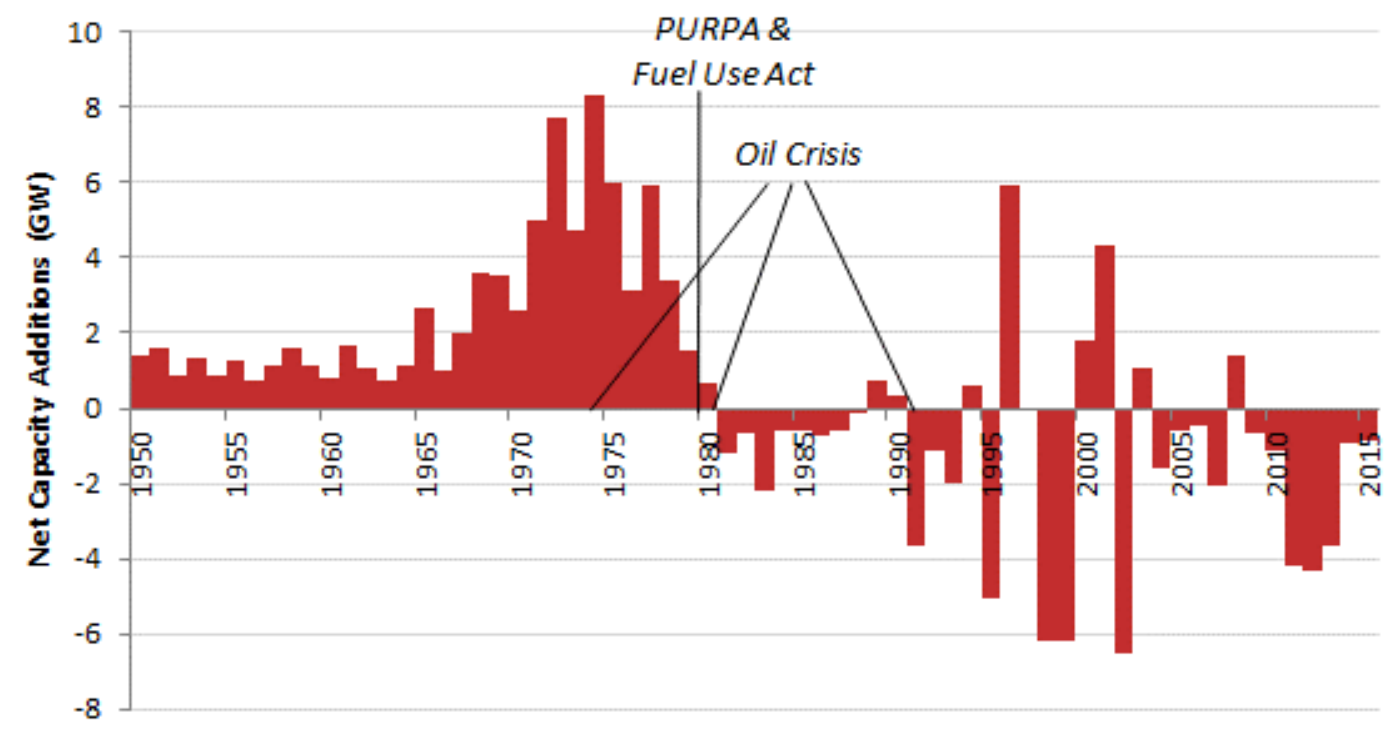

Figure 13-9. Historical annual petroleum capacity additions and retirements (GW), 1950-2015

Buildout of petroleum capacity peaked in 1974 and has steadily declined since then due to due to the oil crises of the 1970s. Source: EIA 1990 and EIA $2016^{557 .}$

In the QER 1.2 Base Case, petroleum generation is projected to continue to decline out to 2040 (Table 13-1). 
Table 13-1. QER 1.2 Base Case Projections for Petroleum (TWh), 2014-2040

\begin{tabular}{|l|c|c|}
\hline & 2014 Actual & QER 1.2 Base Case \\
& & $(2040)$ \\
Petroleum Generation & 30 & 11 \\
\hline
\end{tabular}

Source: EPSA $2016^{558}$.

IEA's projections in the WEO all show petroleum declining as a generation fuel. In every scenario, petroleum generation is at about 1 percent of total world generation by 2040 (Table 132).

Table 13-2. Global Petroleum Generation Projections, 2013-2040

\begin{tabular}{|l|c|c|c|c|c|c|c|}
\hline IEA Scenario & & \multicolumn{2}{|c|}{ New Policies } & \multicolumn{2}{|c|}{ Current Policies } & \multicolumn{2}{|c|}{450} \\
\hline & $\mathbf{2 0 1 3}$ & $\mathbf{2 0 2 0}$ & $\mathbf{2 0 4 0}$ & $\mathbf{2 0 2 0}$ & $\mathbf{2 0 4 0}$ & $\mathbf{2 0 2 0}$ & $\mathbf{2 0 4 0}$ \\
\hline $\begin{array}{l}\text { Petroleum } \\
\text { Generation (TWh) }\end{array}$ & 1,044 & 836 & 533 & 849 & 590 & 760 & 279 \\
\hline $\begin{array}{l}\text { Percentage of } \\
\text { Global Total }\end{array}$ & 4 & 3 & 1 & 3 & 1 & 3 & 1 \\
\hline
\end{tabular}

In all IEA scenarios, petroleum generation is projected to make up only 1 percent of total world generation by 2040 . Source: IEA $2015^{559}$. 


\section{References}

ABB Velocity Suite. "Generating Unit Capacity Database,” 2015.

AECOM Australia. "Energy Storage Study: Funding and Knowledge Sharing Priorities," July 13, 2015.

Apt, Jay, and Paulina Jaramillo. "Variable Renewable Energy and the Electricity Grid." Resources for the Future Press, Taylor \& Francis., n.d. http://samples.sainsburysebooks.co.uk/9781317907671_sample_838873.pdf.

Arent, Douglas, Jeffrey Logan, Jordan Macknick, William Boyd, Kenneth Medlock, Francis O'Sullivan, Jae Edmonds, Leon Clarke, Hillard Huntington, and Garvin Heath. "A Review of Water and Greenhouse Gas Impacts of Unconventional Natural Gas Development in the United States." MRS Energy \& Sustainability 2 (2015): E4. doi:10.1557/mre.2015.5.

Arora, Vipin, and Jozef Lieskovsky. "Electricity Use as an Indicator of U.S. Economic Activity." U.S. Energy Information Administration, 2014.

https://www.eia.gov/workingpapers/pdf/electricity_indicator.pdf.

Augustine, C, P Denholm, G Heath, T Mai, S Tegen, and K Young. "Geothermal Energy Technologies, Chapter 7.” National Renewable Energy Laboratory, 2012.

Augustine, Chad, Richard Bain, Jamie Chapman, Paul Denholm, Drury Easan, Douglas G. Hall, Eric Lantz, et al. "Renewable Electricity Futures Study. Volume 2: Renewable Electricity Generation and Storage Technologies." NREL, MIT, 2012.

AWEA. “American Wind Power Breezes Past 70-Gigawatt Milestone,” December 21, 2015. http://www.awea.org/MediaCenter/pressrelease.aspx?ItemNumber=8255.

“U.S. Wind Industry Fourth Quarter 2015 Market Report,” 2015. http://www.awea.org/4Q2015.

AWF. “Mine-Land Stewardship Initiative.” Appalachian Wildlife Foundation, 2015. http://www.appalachianwildlife.com/mlsi.html.

AWWI. "Wind Turbine Interactions with Wildlife and Their Habitats: A Summary of Research Results and Priority Questions." American Wind and Wildlife Institute, 2014.

https://awwi.org/wp-content/uploads/2014/05/AWWI-Wind-Wildlife-Interactions-Factsheet-0527-14.pdf.

Bain, Richard, Paul Denholm, Garvin Heath, Trieu Mai, and Suzanne Tegen. "Renewable Electricity Futures Study. Chapter 6: Biopower Technologies.” National Renewable Energy Laboratory, 2012. 
Balling, Lothar. "Fast Cycling and Rapid Start-Up: New Generation of Plants Achieves Impressive Results.” Siemens AG. Modern Power Systems (Reprint), 2011.

http://www.energy.siemens.com/us/pool/hq/power-generation/power-plants/gas-fired-powerplants/combined-cycle-powerplants/Fast_cycling_and_rapid_start-up_US.pdf.

Bandyk, Matthew. "Fitch: 'Failure' of New Nuke Construction Means Fewer Plants." SNL, 2015. https://www.snl.com/InteractiveX/articleabstract.aspx?ID=33617164\&KPLT=2.

Barbose, Galen. “U.S. Renewables Portfolio Standards 2016 Annual Status Report.” Lawrence Berkeley National Laboratory, 2016. https://emp.lbl.gov/sites/all/files/lbnl-1005057.pdf.

Barisano, D, G Canneto, F Nanna, E Alvino, G Pinto, A Villone, M Carnevale, V Valerio, A Battafarano, and G Braccio. "Steam/Oxygen Biomass Gasification at Pilot Scale in an Internally Circulating Bubbling Fluidized Bed Reactor." Fuel Processing Technology 141 (2016): 74-81. doi:10.1016/j.fuproc.2015.06.008.

Bassett, L, J Brodrick, S Capanna, J Castellano, C Cooper, P Donohoo-Vallet, and D Feldman. "Revolution Now: The Future Arrives for Five Clean Energy Technologies - 2015 Update." U.S. Department of Energy, 2015. http://www.energy.gov/sites/prod/files/2015/11/f27/RevolutionNow-11132015.pdf.

Beér, János M. "High Efficiency Electric Power Generation: The Environmental Role.” Progress in Energy and Combustion Science 33, no. 2 (2007): 107-34.

Beiter, Philipp. "2014 Renewable Energy Data Book.” NREL and DOE, November 1, 2015. http://www.osti.gov/scitech/biblio/1226242-renewable-energy-data-book.

Bell, Ron D., and Fred P. Buckingham. "An Overview of Technologies for Reduction of Oxides of Nitrogen from Combustion Furnaces.” MPR Associates, Inc., n.d. http://www.mpr.com/uploads/news/nox-reduction-coal-fired.pdf.

Bernhoft, S. "Program on Technology Innovation: Approach to Transition Nuclear Power Plants to Flexible Power Operations." Electric Power Research Institute, 2014.

http://www.epri.com/abstracts/Pages/ProductAbstract.aspx?ProductId=000000003002002612.

Bird, Lori, Jaquelin Cochran, and Xi Wang. "Wind and Solar Energy Curtailment: Experience and Practices in the United States." National Renewable Energy Laboratory, 2014. http://www.nrel.gov/docs/fy14osti/60983.pdf.

BLS. "Bureau of Labor Statistics Data," 2016. http://data.bls.gov/timeseries/CUUR0000SA0?output_view=pct_1mth.

BNEF. “New Energy Outlook 2015.” Bloomberg New Energy Finance, 2015. https://about.bnef.com/landing-pages/new-energy-outlook-2015-americas/. 
Bolinger, Mark, Samantha Weaver, and Jarett Zuboy. "Is \$50/MWh Solar for Real? Falling Project Prices and Rising Capacity Factors Drive Utility-Scale PV Toward Economic Competitiveness.” Lawrence Berkeley National Laboratory, 2015. https://emp.lbl.gov/sites/all/files/lbnl-183129_0.pdf.

Bömer, Jens, Karsten Burges, Pavel Zolotarev, and Joachim Lehner. "Impact of Large-Scale Distributed Generation on Network Stability during Over-Frequency Events \& Development of Mitigation Measures - Summary." Institute of Combustion and Power Plant Technology (IFK) and Ecofys Germany GmbH, 2011. http://www.vde.com/en/fnn/Documents/201109_Ecofys_IFK_50-2-Hz_Summary.pdf.

Bovarnick, Ben. "Integrated Energy Storage in the United States.” Center for American Progress, December 2015.

Bracmort, Kelsi. "Biopower: Background and Federal Support.” Congressional Research Service, 2015. http://nationalaglawcenter.org/wp-content/uploads/assets/crs/R41440.pdf.

_. "Is Biopower Carbon Neutral?" Congressional Research Service, 2015. https://www.fas.org/sgp/crs/misc/R41603.pdf.

Brandt, Adam R, GA Heath, EA Kort, F O’Sullivan, G Pétron, SM Jordaan, P Tans, J Wilcox, AM Gopstein, and D Arent. "Methane Leaks from North American Natural Gas Systems." Science 343, no. 6172 (2014): 733-35. doi:10.1126/science.1247045.

Brinkman, Greg, Debra Lew, and Paul Denholm. "Impacts of Renewable Generation on Fossil Fuel Unit Cycling: Costs and Emissions.” presented at the Clean Energy Regulatory Forum, 2012. http://www.nrel.gov/docs/fy12osti/55828.pdf.

C2ES. "Biopower." Center for Climate and Energy Solutions, 2016. http://www.c2es.org/technology/factsheet/Biopower.

—. "Enhanced Geothermal Systems." Center for Climate and Energy Solutions, 2015. http://www.c2es.org/technology/factsheet/EGS.

_. "Renewable Energy." Center for Climate and Energy Solutions, 2016. http://www.c2es.org/energy/source/renewables.

California Energy Comission. "Differences Between Publicly and Investor-Owned Utilities." California Energy Commission, 2016.

http://www.energy.ca.gov/pou_reporting/background/difference_pou_iou.html.

Cameco. "Uranium Price - Markets.” Cameco, 2015.

https://www.cameco.com/invest/markets/uranium-price.

CCSA. "What Is CCS?” Accessed December 4, 2015. http://www.ccsassociation.org/what-is$\operatorname{ccs} /$. 
Chapman, Jamie, Eric Lantz, Garvin Heath, Paul Denholm, Fort Felker, GA Heath, and Trieu Mai. "Renewable Electricity Futures Study. Chapter 11: Wind Energy Technologies." National Renewable Energy Laboratory, 2012. http://www.nrel.gov/docs/fy12osti/52409-2.pdf.

Chum, Hekena, Andre Faaij, Jose Moreia, Göran Berndes, Parveen Dhamijia, Hongmin Dong, Benoit Gabrielle, et al. "Bioenergy." IPCC Special Report on Renewable Enery Sources and Climate Change. Cambridge University Press, Cambridge, UK and New York, NY, USA, 2011. http://www.ipcc.ch/pdf/special-reports/srren/Chapter\%202\%20Bioenergy.pdf.

Clean Air Task Force. "Conversion and CO2 Capture.” Accessed December 4, 2015. http://www.catf.us/fossil/technology/conversion_and_capture/.

Cochran, Jaquelin, Lori Bird, Jenny Heeter, and Douglas Arent. "Integrating Variable Renewable Energy in Electric Power Markets.” National Renewable Energy Laboratory, 2012. http://www.nrel.gov/docs/fy12osti/53732.pdf.

Cochran, Jaquelin, Debra Lew, and Nikhil Kumarb. "Flexible Coal: Evolution from Baseload to Peaking Plant." National Renewable Energy Laboratory; 21st Century Power Partnership, 2013. http://www.nrel.gov/docs/fy14osti/60575.pdf.

Copping, Andrea, Luke Hanna, Johnathan Whiting, Simon Geerlofs, Molly Grear, Kara Blake, Anna Coffey, Meghan Massaua, Jocelyn Brown-Saracino, and Hoyt Battey. "Environmental Effects of Marine Energy Development around the World. Annex IV Final Report." Pacific Northwest National Laboratory, 2013. http://tethys.pnnl.gov/publications/environmental-effectsmarine-energy-development-around-world-annex-iv-final-report.

CPUC. “Aliso Canyon Risk Assessment Technical Report.” California Public Utilities Commission, 2016. http://www.energy.ca.gov/2016_energypolicy/documents/2016-0408 joint_agency_workshop/Aliso_Canyon_Risk_Assessment_Technical_Report.pdf.

Danko, Pete. "US Geothermal Stuck in the Mud, but 2014 Global Growth Boosts Industry." Breaking Energy, February 24, 2015. http://breakingenergy.com/2015/02/24/us-geothermalstuck-in-the-mud-but-2014-global-growth-boosts-industry/.

Dehamna, Alissa, and Mackinnon Lawrence. "Navigant Research Leaderboard Report: Li-Ion Grid Storage," 2015.

Denholm, Paul, Kara Clark, and Matthew O’Connell. 'On the Path to SunShot: Emerging Issues and Challenges in Integrating High Levels of Solar into the Electrical Generation and Transmission System," May 2016. www.nrel.gov/docs/fy16osti/65800.pdf.

Denholm, Paul, Maureen Hand, Maddalena Jackson, and Sean Ong. "Land-Use Requirements of Modern Wind Power Plants in the United States." National Renewable Energy Laboratory, 2009. http:/www.nrel.gov/docs/fy09osti/45834.pdf.

Denholm, Paul, Matthew O’Connell, Gregory Brinkman, and Jennie Jorgenson. "Overgeneration from Solar Energy in California: A Field Guide to the Duck Chart." National Renewable Energy Laboratory, 2015. http://www.nrel.gov/docs/fy16osti/65023.pdf. 
DOE. “2014 Distributed Wind Market Report.” U.S. Department of Energy, August 2015. http://energy.gov/eere/wind/downloads/2014-distributed-wind-market-report.

. “2014: The Year of Concentrating Solar Power,” May 2014.

"Advanced Manufacturing: Using Composites for Clean Energy." Department of Energy. Accessed September 28, 2016. http://www.energy.gov/eere/amo/advancedmanufacturing-using-composites-clean-energy.

—. "Atmosphere to Electrons : Enabling the Wind Plant of Tomorrow." Department of Energy, 2015. http://energy.gov/sites/prod/files/2016/01/f28/105197-

A2E\%20Fact\%20Sheet_v10.pdf.

—. "Biopower Fact Sheet," March 2010.

http:/www.energy.gov/sites/prod/files/2014/04/f14/biopower_factsheet.pdf.

_. "Biopower Technical Strategy Workshop Summary Report.” U.S. Department of Energy, 2010.

http://energy.gov/sites/prod/files/2014/04/f14/biopower_workshop_report_december_2010.pdf.

—. "Business Energy Investment Tax Credit (ITC).” Accessed September 28, 2016. http://energy.gov/savings/business-energy-investment-tax-credit-itc.

- "Chapter 4: Advancing Clean Electric Power Technologies, Technology Assessments Geothermal Power," 2015.

—. "Concentrating Solar Power." U.S. Department of Energy, 2016.

http://www.energy.gov/eere/sunshot/concentrating-solar-power.

—. "Critical Materials Technology Assessment (Draft).” Department of Energy, 2015. http://energy.gov/sites/prod/files/2015/02/f19/QTR\%20Ch8\%20\%20Critical\%20Materials\%20TA\%20Feb-13-2015.pdf.

—. "DOE Submits Its Defense-Related Uranium Mines Report to Congress." Department of Energy, August 2014. http://energy.gov/lm/articles/doe-submits-its-defense-related-uraniummines-report-congress.

—. "Effects of Climate Change on Federal Hydropower (Report to Congress)," 2013. http://www1.eere.energy.gov/water/pdfs/hydro_climate_change_report.pdf.

—. "Electricity Generation," 2016. http://energy.gov/eere/geothermal/electricity-generation.

__. "Enhanced Oil Recovery," 2016. http://energy.gov/fe/science-innovation/oil-gasresearch/enhanced-oil-recovery.

—. "FORGE Background and Updates," 2015. http://energy.gov/eere/forge/forgebackground-updates. 
_. "Get Pumped about Pumped Storage," April 27, 2015.

http://energy.gov/eere/articles/get-pumped-about-pumped-storage.

"How Gas Turbine Power Plants Work." Accessed December 2, 2015.

http://energy.gov/fe/how-gas-turbine-power-plants-work.

_ . "Hybrid Organic-Inorganic Halide Perovskite Solar Cells," 2016.

http://energy.gov/eere/sunshot/hybrid-organic-inorganic-halide-perovskite-solar-cells.

_ . "Hydropower Vision: A New Chapter for America's 1st Renewable Electricity Source," 2016. http://energy.gov/eere/water/articles/hydropower-vision-new-chapter-america-s-1strenewable-electricity-source.

_- "Increased Solar and Wind Electricity Generation in California Are Changing Net Load Shapes)." U.S. Energy Information Administration, December 9, 2014. https://www.eia.gov/todayinenergy/detail.cfm?id=19111.

_. "Multijunction III-V Photovoltaics Research.” Accessed January 13, 2016. http://energy.gov/eere/sunshot/multijunction-iii-v-photovoltaics-research.

_ . "Nuclear Energy Research and Development Roadmap." Department of Energy, April 2010. http://energy.gov/sites/prod/files/NuclearEnergy_Roadmap_Final.pdf.

__. "Offshore Wind Research and Development." Accessed September 28, 2016. http://energy.gov/eere/wind/offshore-wind-research-and-development.

__. "Oil \& Gas Research.” Accessed September 28, 2016. http://energy.gov/fe/scienceinnovation/oil-gas-research.

_. "Photovoltaics Research and Development," 2016.

http://energy.gov/eere/sunshot/photovoltaics-research-and-development.

_ . "Pre-Combustion Carbon Capture Research." Accessed January 5, 2016. http://energy.gov/fe/science-innovation/carbon-capture-and-storage-research/carbon-capture$\mathrm{rd} /$ pre-combustion-carbon.

—. "Quadrennial Energy Review First Installment: Transforming U.S. Energy Infrastructures in a Time of Rapid Change." U.S. Department of Energy, April 2016. http://energy.gov/epsa/downloads/quadrennial-energy-review-first-installment.

_. "Quadrennial Technology Review 2015.” U.S. Department of Energy, 2015. http://energy.gov/under-secretary-science-and-energy/quadrennial-technology-review-2015.

—. "Quadrennial Technology Review: An Assessment of Energy Technologies and Research Opportunities," September 2015. http://energy.gov/quadrennial-technology-review2015. 
—. "Renewable Electricity Production Tax Credit (PTC)." Accessed September 28, 2016. http://energy.gov/savings/renewable-electricity-production-tax-credit-ptc.

—. "Research, Development, and Demonstration." U.S. Department of Energy, 2016. http://www.energy.gov/eere/bioenergy/research-development-and-demonstration.

—. "Soft Costs," 2016. http://energy.gov/eere/sunshot/soft-costs.

—. "SunShot Vision Study.” U.S. Department of Energy, February 2012. http://energy.gov/sites/prod/files/2014/01/f7/47927.pdf.

- "SunShot Vision Study - Chapter 5: Concentrating Solar Power: Technologies, Cost, and Performance," February 2012.

—. "Systems Integration." U.S. Department of Energy, 2016.

http://energy.gov/eere/sunshot/systems-integration.

—. "Types of Fuel Cells," 2016. http://energy.gov/eere/fuelcells/types-fuelcells\#pem\%20fc.

_. "United States (48 Contiguous States) - Potential Wind Capacity Cumulative Area v. Gross Capacity Factor.” Department of Energy, 2014.

http://apps2.eere.energy.gov/wind/windexchange/windmaps/resource_potential.asp.

_. "Wind Vision: A New Era for Wind Power in the United States." U.S. Department of Energy, March 12, 2015.

DOE, NREL, and AWS Truepower. "WINDExchange: Potential Wind Capacity," September 9, 2015. http://apps2.eere.energy.gov/wind/windexchange/windmaps/resource_potential.asp\#states.

DOI. "Hydropower Program | Bureau of Reclamation." U.S. Department of the Interior, 2016. http://www.usbr.gov/power/edu/history.html.

_ . "Technical Position Paper: Potential of Impounded-Coal-Waste-Slurry Breakthroughs into Underground Mines; Issues and Answers.” U.S. Department of the Interior, 2011. http://www.arcc.osmre.gov/resources/pubs/2011-TechnicalPositionPaper-CoalWasteSlurry.pdf.

Döring, Michael. "Dealing with the 50.2 Hz Problem - Modern Power Systems." Modern Power Systems. Accessed September 28, 2016.

http://www.modernpowersystems.com/features/featuredealing-with-the-50.2-hz-problem/.

Duke Energy. "How Do Coal-Fired Plants Work?” Accessed December 3, 2015. https://www.duke-energy.com/about-energy/generating-electricity/coal-fired-how.asp.

—. "How IGCC Works." Accessed December 3, 2015. https://www.dukeenergy.com/about-us/how-igcc-works.asp. 
Dynamic Solar Tech. "How Solar Panels Work,” 2015. http://dynamicsolartech.com/aboutus/how-solar-panels-work/.

Edmunds, Thomas A, and Pedro Sotorrio. “Ancillary Service Revenue Potential for Geothermal Generators in California," 26-28, 2020.

https://pangea.stanford.edu/ERE/db/GeoConf/papers/SGW/2015/Edmunds.pdf.

EIA. “Annual Coal Report.” U.S. Energy Information Administration, March 23, 2016. http://www.eia.gov/coal/annual/.

_. "Annual Electric Generator Data - EIA-860 Data File.” U.S. Energy Information Administration, 2016. http://www.eia.gov/electricity/data/eia860/.

—. "Annual Electric Power Industry Report (EIA-861 Data File)." U.S. Energy Information Administration, 2016. http://www.eia.gov/electricity/data/eia861/.

—. "Annual Electric Utility Data - EIA-906/920/923 Data File." U.S. Energy Information Administration, 2016. https://www.eia.gov/electricity/data/eia923/.

. “Annual Energy Outlook 2016.” U.S. Energy Information Administration, 2016.

http://www.eia.gov/forecasts/aeo/.

—. 2015. “Annual Energy Outlook 2015.” http://www.eia.gov/forecasts/aeo/.

_. "Average Annual Natural Gas Spot Price in 2015 Was at Lowest Level since 1999 Today in Energy." U.S. Energy Information Administration, January 5, 2016. http://www.eia.gov/todayinenergy/detail.cfm?id=24412.

"Average Utilization for Natural Gas Combined-Cycle Plants Exceeded Coal Plants in 2015 - Today in Energy." U.S. Energy Information Administration, April 4, 2016. http://www.eia.gov/todayinenergy/detail.cfm?id=25652.

—. "California Has Nearly Half of the Nation's Solar Electricity Generating Capacity Today in Energy." U.S. Energy Information Administration, February 5, 2016.

https://www.eia.gov/todayinenergy/detail.cfm?id=24852.

"Coal Made up More than 80\% of Retired Electricity Generating Capacity in 2015 Today in Energy." U.S. Energy Information Administration, March 8, 2016. https://www.eia.gov/todayinenergy/detail.cfm?id=25272.

. "Coal Production Using Mountaintop Removal Mining Decreases by 62\% since 2008 Today in Energy," 2015. https://www.eia.gov/todayinenergy/detail.cfm?id=21952.

—. "Cushing, OK WTI Spot Price FOB (Dollars per Barrel)." U.S. Energy Information Administration, 2016.

http://www.eia.gov/dnav/pet/hist/LeafHandler.ashx?n=PET\&s=RWTC\&f=D. 
_. "Domestic Market for Distributed Wind Turbines Faces Several Challenges - Today in Energy," 2016. http://www.eia.gov/todayinenergy/detail.cfm?id=22692.

—. "EIA Electricity Data Now Include Estimated Small-Scale Solar PV Capacity and Generation - Today in Energy," 2015. https://www.eia.gov/todayinenergy/detail.cfm?id=23972.

—. "EIA's Energy in Brief: How Much U.S. Electricity Is Generated from Renewable Energy?" U.S. Energy Information Administration, 2016. http://www.eia.gov/energy_in_brief/article/renewable_electricity.cfm.

. "Electric Generator Dispatch Depends on System Demand and the Relative Cost of Operation - Today in Energy." U.S. Energy Information Administration, August 17, 2012. http://www.eia.gov/todayinenergy/detail.cfm?id=7590.

_. "Electric Power Annual," 2016. http://www.eia.gov/electricity/annual/.

—. "Electric Power Monthly," 2016. http://www.eia.gov/electricity/monthly/.

EIA. "Electricity Generating Capacity," January 3, 2013.

https://www.eia.gov/electricity/capacity/.

_. "Energy-Related Carbon Dioxide Emissions at the State Level, 2000-2013." U.S.

Energy Information Administration, 2015.

http://www.eia.gov/environment/emissions/state/analysis/pdf/stateanalysis.pdf.

- "Federal Power Marketing Administrations Operate across Much of the United States Today in Energy." U.S. Energy Information Administration, June 12, 2013.

http://205.254.135.7/todayinenergy/detail.php?id=11651.

—. "Fewer Wind Curtailments and Negative Power Prices Seen in Texas after Major Grid Expansion - Today in Energy." U.S. Energy Information Administration, 2014.

https://www.eia.gov/todayinenergy/detail.cfm?id=16831\#tabs_SpotPriceSlider-1.

_. "How Many Power Plants Are There in the United States?," 2015.

http://www.eia.gov/tools/faqs/faq.cfm? $\mathrm{id}=65 \& \mathrm{t}=2$.

"How Much of U.S. Carbon Dioxide Emissions Are Associated with Electricity

Generation? - FAQ." U.S. Energy Information Administration, April 1, 2016.

http://www.eia.gov/tools/faqs/faq.cfm?id=77\&t=11.

—. "How Much Oil Consumed by the United States Comes from Foreign Countries? FAQ." U.S. Energy Information Administration, March 8, 2016.

http://www.eia.gov/tools/faqs/faq.cfm?id=32\&t $=6$.

—. "Levelized Cost and Levelized Avoided Cost of New Generation Resources in the Annual Energy Outlook 2016," 2016.

https://www.eia.gov/forecasts/aeo/electricity_generation.cfm. 
_. "Many Newer Power Plants Have Cooling Systems That Reuse Water - Today in Energy - U.S. Energy Information Administration (EIA).” U.S. Energy Information Administration, 2014. https://www.eia.gov/todayinenergy/detail.cfm?id=14971.

. "Monthly Energy Review." U.S. Energy Information Administration, 2016. http://www.eia.gov/totalenergy/data/monthly/.

- "Natural Gas Expected to Surpass Coal in Mix of Fuel Used for U.S. Power Generation in 2016 - Today in Energy." U.S. Energy Information Administration, Match 2016. http://www.eia.gov/todayinenergy/detail.cfm?id=25392.

_. "Natural Gas Pipeline Network - Transportation Process \& Flow." U.S. Energy Information Administration, 2009.

http://www.eia.gov/pub/oil_gas/natural_gas/analysis_publications/ngpipeline/process.html.

_. "Natural Gas Pipeline Network - U.S. Natural Gas Pipeline Network Map." U.S. Energy Information Administration, 2009.

http://www.eia.gov/pub/oil_gas/natural_gas/analysis_publications/ngpipeline/ngpipelines_map.h tml.

_. "Shale in the Unites States," 2016.

http://www.eia.gov/energy_in_brief/article/shale_in_the_united_states.cfm.

_. "Short-Term Energy Outlook." U.S. Energy Information Administration, September 7, 2016. http://www.eia.gov/forecasts/steo/.

- "Southern States Lead Growth in Biomass Electricity Generation - Today in Energy." U.S. Energy Information Administration, May 25, 2016.

http://www.eia.gov/todayinenergy/detail.cfm?id=26392.

—. "State Nuclear Profiles - Arizona." U.S. Energy Information Administration, 2012. https://www.eia.gov/nuclear/state/arizona/.

. "The U.S. Surpassed Russia as World's Leading Producer of Dry Natural Gas in 2009 and 2010." U.S. Energy Information Administration, 2012.

http://www.eia.gov/todayinenergy/detail.cfm?id=5370.

- "Today in Energy: Warm Weather and Low Natural Gas Prices Dampen Spot Electricity Prices This Winter." U.S. Energy Information Administration, May 28, 2012.

http://www.eia.gov/todayinenergy/detail.cfm?id=6330.

"U.S. Crude Oil Rotary Rigs in Operation.” U.S. Energy Information Administration, 2016. http://www.eia.gov/dnav/ng/hist/e_ertrro_xr0_nus_cm.htm.

. "U.S. Economy and Electricity Demand Growth Are Linked, but Relationship Is Changing - Today in Energy." U.S. Energy Information Administration, March 22, 2013. http://www.eia.gov/todayinenergy/detail.cfm?id=10491. 
. "U.S. Energy Demand Slows except for Industrial, Commercial Sectors - Today in Energy." U.S. Energy Information Administration, April 29, 2015.

https://www.eia.gov/todayinenergy/detail.cfm?id=21012.

“U.S. Energy Mapping System.” U.S. Energy Information Administration, 2016. https://www.eia.gov/state/maps.cfm.

. "U.S. Field Production of Crude Oil, Monthly." U.S. Energy Information Administration, 2016. https://www.eia.gov/opendata/qb.cfm?sdid=PET.MCRFPUS1.M.

—. "U.S. Product Supplied of Crude Oil and Petroleum Products." U.S. Energy Information Administration, 2016.

http://www.eia.gov/dnav/pet/hist/LeafHandler.ashx?n=PET\&s=MTTUPUS1\&f=A.

_. "Waste-to-Energy (Municipal Solid Waste)," December 13, 2015. http://www.eia.gov/Energyexplained/?page=biomass_waste_to_energy.

. "Waste-to-Energy (Municipal Solid Waste)." U.S. Energy Information Administration, December 14, 2015. http://www.eia.gov/Energyexplained/?page=biomass_waste_to_energy.

"What Is the Efficiency of Different Types of Power Plants? - FAQ." U.S. Energy Information Administration, April 25, 2016. https:/www.eia.gov/tools/faqs/faq.cfm?id=107\&t=3.

. "Wholesale Power Prices Decrease across the Country in 2015 - Today in Energy." U.S. Energy Information Administration, January 11, 2016. http://www.eia.gov/todayinenergy/detail.cfm?id=24492.

. "Wind Adds the Most Electric Generation Capacity in 2015, Followed by Natural Gas and Solar - Today in Energy." U.S. Energy Information Administration, March 23, 2016. http://www.eia.gov/todayinenergy/detail.cfm?id=25492.

Ellis, Abraham, R Nelson, E Von Engeln, R Walling, J MacDowell, L Casey, E Seymour, W Peter, C Barker, and B Kirby. "Reactive Power Performance Requirements for Wind and Solar Plants," 1-8. IEEE, 2012. http://ieeexplore.ieee.org/xpls/abs_all.jsp?arnumber $=6345568$.

ENGO Network on CCS. "Closing the Gap on Climate-Why CCS Is a Vital Part of the Solution,” December 2015. http://www.engonetwork.org/ENGO_Report_FINAL.pdf.

EPA. “AP-42, CH 11.10: Coal Cleaning,” November 1995. http://www3.epa.gov/ttnchie1/ap42/ch11/final/c11s10.pdf.

"Basic Information about Energy Recovery from Waste | Municipal Solid Waste," April 14, 2014. http://www3.epa.gov/epawaste/nonhaz/municipal/wte/basic.htm. 
- "Carbon Pollution Standards for New, Modified and Reconstructed Power Plants." Policies and Guidance. U.S. Environmental Protection Agency, May 2, 2016.

https://www.epa.gov/cleanpowerplan/carbon-pollution-standards-new-modified-andreconstructed-power-plants.

—. "Catalog of CHP Technologies," 2008.

- "Chapter 11: Mineral Products Industry, AP 42." U.S. Environmental Protection Agency, 1995. https://www3.epa.gov/ttn/chief/ap42/ch11/index.html.

—. "Clean Air Interstate Rule (CAIR).” U.S. Environmental Protection Agency, 2016. https://archive.epa.gov/airmarkets/programs/cair/web/html/index.html.

_. "Clean Power Plan for Existing Power Plants." U.S. Environmental Protection Agency, 2015. https://www.epa.gov/cleanpowerplan/clean-power-plan-existing-power-plants.

—. "Climate Change Indicators: Drought." Reports and Assessments. U.S. Environmental Protection Agency, 2015. https://www.epa.gov/climate-indicators/climate-change-indicatorsdrought\#fragment-2.

- "Cross-State Air Pollution Rule (CSAPR)." U.S. Environmental Protection Agency, 2011. https://www3.epa.gov/airtransport/CSAPR/index.html.

—. "Energy Recovery from the Combustion of Municipal Solid Waste (MSW)." Overviews and Factsheets. U.S. Environmental Protection Agency, 2014. https://www.epa.gov/smm/energyrecovery-combustion-municipal-solid-waste-msw.

"EPA's Study of Hydraulic Fracturing for Oil and Gas and Its Potential Impact on Drinking Water Resources." Overviews and Factsheets. U.S. Environmental Protection Agency, 2015. https://www.epa.gov/hfstudy.

- "Fact Sheet: Final Petroleum Refinery Sector Risk and Technology Review and New Source Performance Standards Overview.” U.S. Environmental Protection Agency, 2016. https://www.epa.gov/sites/production/files/2016-06/documents/20100682_factsheet_overview.pdf.

_. "Final Rule: Disposal of Coal Combustion Residuals from Electric Utilities." U.S. Environmental Protection Agency, September 12, 2016. https://www.epa.gov/coalash/coal-ashrule.

__. "Landfill Gas Energy Basics.” U.S. Environmental Protection Agency, 2014.

. "Mercury and Air Toxics Standards (MATS)." Collections and Lists. U.S.

Environmental Protection Agency. Accessed September 29, 2016. https://www.epa.gov/mats.

_. "Petroleum Refining Effluent Guidelines." U.S. Environmental Protection Agency, 2016. https://www.epa.gov/eg/petroleum-refining-effluent-guidelines\#detailed. 
—_. "What Is Acid Mine Drainage.” U.S. Environmental Protection Agency, 2015.

—. "Wood Products Industry. Chapter 10.2, Chemical Wood Pulping." U.S. Environmental Protection Agency, 1990.

EPRI. "Program on Technology Innovation: Fossil Fleet Transition with Fuel hanges and Large Scale Variable Renewable Integration," n.d.

http://www.epri.com/abstracts/Pages/ProductAbstract.aspx?ProductId=000000003002006517.

EPSA. “QER 1.2 Base Case.” U.S. Department of Energy, 2016.

FERC. "Coordination of the Scheduling Processes of Interstate Natural Gas Pipelines and Public Utilities. Docket No. RM14-2-000; Order 809." Federal Energy Regulatory Commission, April 16, 2015. http://www.ferc.gov/whats-new/comm-meet/2015/041615/M-1.pdf.

_. "Essential Reliability Services and the Evolving Bulk-Power System—Primary Frequency Response." Federal Energy Regulatory Commission, February 18, 2016. https://www.ferc.gov/whats-new/comm-meet/2016/021816/E-2.pdf.

—. "Hydropower - Pumped Storage Projects." Federal Energy Regulatory Commission, 2015. http://www.ferc.gov/industries/hydropower/gen-info/licensing/pump-storage.asp.

_ . "Licensed Pumped Storage Projects," October 1, 2015.

http://www.ferc.gov/industries/hydropower/gen-info/licensing/pump-storage/licensedprojects.pdf.

_. "Pending Licenses and Relicenses for Pumped Storage Projects." Federal Energy Regulatory Commission, 2016. http://www.ferc.gov/industries/hydropower/geninfo/licensing/pump-storage/pending-licensed.pdf.

First Solar. "Manufacturing Process," 2016. http://www.firstsolar.com/en/Technologies-andCapabilities/PV-Modules/First-Solar-Series-3-Black-Module/Manufacturing-Process. aspx.

Flores-Espino, Francisco. "Compensation for Distributed Solar: A Survey of Options to Preserve Stakeholder Value.” NREL (National Renewable Energy Laboratory (NREL), 2015. http://www.nrel.gov/docs/fy15osti/62371.pdf.

Fraunhofer ISE. "Photovoltaics Report," November 17, 2015. https://www.ise.fraunhofer.de/en/downloads-englisch/pdf-files-englisch/photovoltaics-reportslides.pdf.

Fthenakis, Vasilis, and Hyung Chul Kim. "Land Use and Electricity Generation: A Life-Cycle Analysis." Renewable and Sustainable Energy Reviews 13, no. 6 (2009): 1465-74.

GAO. "Federal Power: The Evolution of Preference in Marketing Federal Power. Report to the Chairman, Committee on Resources, House of Representatives." GAO (Government Accountability Office), 2001. http://www.gao.gov/assets/240/231087.pdf. 
Office, 2015.

. "Key Issues: Disposal of High-Level Nuclear Waste." U.S. Government Accountability

http://www.gao.gov/key_issues/disposal_of_highlevel_nuclear_waste/issue_summary.

—. "Tennessee Valley Authority: Full Consideration of Energy Efficiency and Better Capital Expenditures Planning Are Needed." GAO (Government Accountability Office), 2011.

GCSSI. "Strategic Analysis of the Global Status of Carbon Capture and Storage. Report 4: Existing Carbon Capture and Storage Research and Development Networks around the World." Global CCS Institute, Electric Power Institute, Worley Parsons, 2009. http://www.globalccsinstitute.com/publications/strategic-analysis-global-status-carbon-capturestorage-Report-4.

—. "The Global Status of CCS: 2015 Summary Report.” GCSSI (Global CCS Institute), 2015. http://hub.globalccsinstitute.com/sites/default/files/publications/196843/global-status-ccs2015-summary.pdf.

GE. “7F.05 Heavy-Duty Gas Turbines | GE Power Generation.” Accessed September 29, 2016. https://powergen.gepower.com/products/heavy-duty-gas-turbines/7f-05-gas-turbine.html.

GEA. "Geothermal Energy Association Issue Brief: Firm and Flexible Power Services Available from Geothermal Facilities." Geothermal Energy Association, 2015. http://geoenergy.org/reports/2015/Firm\%20and\%20Flexible\%20Power\%20Services\%20from\%20Geother mal.pdf.

Gilman, Patrick, Lou Husser, Bryan Miller, and Lauren Peterson. "Federal Interagency Wind Turbine Radar Interference Mitigation Strategy - Federal-Interagency-Wind-Turbine-RadarInterference-Mitigation-Strategy-02092016rev.pdf.” Department of Energy, 2016. http://energy.gov/sites/prod/files/2016/06/f32/Federal-Interagency-Wind-Turbine-RadarInterference-Mitigation-Strategy-02092016rev.pdf.

GIZ. "Report on Forecasting, Concept of Renewable Energy Management Centres and Grid Balancing." Deutsche Gesellschaft für Internationale Zusammenarbeit, 2015.

http://mnre.gov.in/file-manager/UserFiles/draft-report-fscb-remcs.pdf.

Gonzalez-Longatt, Francisco M. "Activation Schemes of Synthetic Inertia Controller for Full Converter Wind Turbine Generators," 1-5. IEEE, 2015.

http://ieeexplore.ieee.org/xpls/abs_all.jsp?arnumber=7232292.

Goodrich, Alan C, Douglas M Powell, Ted L James, Michael Woodhouse, and Tonio Buonassisi. "Assessing the Drivers of Regional Trends in Solar Photovoltaic Manufacturing." Energy \& Environmental Science 6, no. 10 (2013): 2811-21.

Grace, Amy, Dan Shurey, Nathan Serota, and Madeline Yozwiak. "Impact of Tax Credit Extensions for Wind and Solar." Bloomberg New Energy Finance, 2015. http://www.bbhub.io/bnef/sites/4/2015/12/2015-12-16-BNEF-US-solar-and-wind-tax-creditimpact-analysis.pdf. 
GTM Research. "US Energy Storage Monitor: Q3 2015 Executive Summary,” December 2015.

Gupta, Sreenath B, Bipin Bihari, Munidhar Biruduganti, and Raj Sekar. Natural Gas Fired Reciprocating Engines for Power Generation: Concerns and Recent Advances. INTECH Open Access Publisher, 2012.

Hadjerioua, Boualem, Yaxing Wei, and Shih-Chieh Kao. "An Assessment of Energy Potential at Non-Powered Dams in the United States." U.S. Department of Energy, April 2012. http://nhaap.ornl.gov/sites/default/files/NHAAP_NPD_FY11_Final_Report.pdf.

Haque, Nawshad, Anthony Hughes, Seng Lim, and Chris Vernon. "Rare Earth Elements: Overview of Mining, Mineralogy, Uses, Sustainability and Environmental Impact." Resources 3, no. 4 (2014): 614-35.

Hayes, Jason. "Returning Mined Land to Productivity Through Reclamation." CORNERSTONE $M A G, 2015$. http://cornerstonemag.net/returning-mined-land-to-productivity-throughreclamation/.

Heikkila, Tanya, and Weible. "New York Fracking Ban Could Fuel Intensity of Debate in Colorado - The Denver Post." Denver Post, January 16, 2015.

http://www.denverpost.com/2015/01/16/new-york-fracking-ban-could-fuel-intensity-of-debatein-colorado/.

Holm, Alison, Dan Jennejohn, and Leslie Blodgett,. "Geothermal Resources and Climate Emissions." Geothermal Energy Association. Accessed September 29, 2016. http://geoenergy.org/reports/GeothermalGreenhouseEmissionsNov2012GEA_web.pdf.

Hornbach, Matthew J, Heather R DeShon, William L Ellsworth, Brian W Stump, Chris Hayward, Cliff Frohlich, Harrison R Oldham, Jon E Olson, M Beatrice Magnani, and Casey Brokaw. "Causal Factors for Seismicity near Azle, Texas." Nature Communications 6 (2015).

HSRC (Hazardous Substance Research Centers). "Environmental Impact of the Petroleum Industry.” Hazardous Substance Research Centers, 2003.

https://cfpub.epa.gov/ncer_abstracts/index.cfm/fuseaction/display.files/fileID/14522.

IAEA. "Nuclear Technology Review 2014." International Atomic Energy Agency. Accessed September 29, 2016. https://www.iaea.org/sites/default/files/ntr2014.pdf.

__. "Power Reactor Information System.” International Atomic Energy Agency, 2016. https://www.iaea.org/PRIS/home.aspx.

IEA. "Are We Entering a Golden Age of Gas?: Special Report of the World Energy Outlook 2011." International Energy Agency, 2011.

http://www.worldenergyoutlook.org/media/weowebsite/2011/WEO2011_GoldenAgeofGasRepor t.pdf.

. "Potential for Biomass and Carbon Dioxide Capture and Storage," 2011.

http://www.eenews.net/assets/2011/08/04/document_cw_01.pdf. 
_. "Re-Powering Markets: Market Design and Regulation During the Transition to LowCarbon Power Systems." International Energy Agency, Organization for Economic Co-operation and Development, 2016.

https:/www.iea.org/newsroomandevents/pressreleases/2016/february/how-to-reinventelectricity-markets-after-cop-21.html.

—. "World Energy Outlook 2015," 2015. http://www.worldenergyoutlook.org/weo2015/.

IPCC. "Special Report on Renewable Energy Sources and Climate Change Mitigation." Intergovernmental Panel on Climate Change, 2011. http:/www.ipcc.ch/report/srren/.

Italiana, Foster Wheeler. "Operating Flexibility of Power Plants with CCS.” GCSSI (Global CCS Institute), 2012.

http://hub.globalccsinstitute.com/sites/default/files/publications/104631/operating-flexibilitypower-plants-ccs.pdf.

Jordan, Dirk C, and Sarah R Kurtz. "Photovoltaic Degradation Rates - an Analytical Review." Progress in Photovoltaics: Research and Applications 21, no. 1 (2013): 12-29.

Kagel, Alyssa. "The State of Geothermal Technology Part II: Surface Technology." Geothermal Energy Association, 2008. http://www.geo-energy.org/reports/Geothermal\%20Technology\%20$\% 20$ Part $\% 20$ II $\% 20 \% 28$ Surface\%29.pdf.

Kao, Shih-Chieh, RA McManamay, KM Stewart, NM Samu, B Hadjerioua, ST DeNeale, D Yeasmin, MFK Pasha, AA Oubeidillah, and BT Smith. "New Stream-Reach Development: A Comprehensive Assessment of Hydropower Energy Potential in the United States." DOE, 2014. http://nhaap.ornl.gov/sites/default/files/ORNL_NSD_FY14_Final_Report.pdf.

Kaplan, Stan. Power Plants: Characteristics and Costs. DIANE Publishing, 2011.

Katz, Cheryl. "Will New Technologies Give Critical Boost to Solar Power?" e360, November 12, 2014.

http://e360.yale.edu/feature/will_new_technologies_give_critical_boost_to_solar_power/2832/.

Katz, Jessica, and Jaquelin Cochran. "Integrating Variable Renewable Energy into the Grid: Key Issues. Greening the Grid Initiative." National Renewable Energy Laboratory, 2015. http://www.nrel.gov/docs/fy15osti/63033.pdf.

Klass, Alexandra B. "The Electric Grid at a Crossroads: A Regional Approach to Siting Transmission Lines," 2014. http://lawreview.law.ucdavis.edu/issues/48/5/Articles/485_Klass.pdf.

Klinck, BA, M.P Hawkins, Y Moore, C Ngorima, U Kelm, B Palumbo, and J. S Lee. "The Environmental Impact of Metalliferous Mining: Korea, Chile and Zimbabwe Case Studies." U.K. Department for International Development, January 1, 2002. https://www.gov.uk/dfidresearch-outputs/the-environmental-impact-of-metalliferous-mining-korea-chile-and-zimbabwecase-studies-cr-02-190n. 
Koerth-Baker, Maggie. “Can America Turn Its Nuclear Power Back On?” Popular Mechanics, January 26, 2016. http://www.popularmechanics.com/science/energy/a18818/can-us-nuclearpower-get-un-stuck/.

Kueck, John D, D Tom Rizy, Fangxing Fran Li, Yan Xu, Huijuan Li, Sarina Adhikari, and Philip Irminger. "Local Dynamic Reactive Power for Correction of System Voltage Problems." Oak Ridge National Laboratory, 2008. http://info.ornl.gov/sites/publications/files/Pub12786.pdf.

Kuykendall, Taylor. "SNL: Did Natural Gas Topple King Coal in 2015? Race for Top Fuel Close at Year-End," January 7, 2016. https://www.snl.com/InteractiveX/article.aspx?CDID=A34983150-11059\&KPLT=4.

Lacey, Stephen. "Cheapest Solar Ever: Austin Energy Gets 1.2 Gigawatts of Solar Bids for Less Than 4 Cents," June 30, 2015. http://www.greentechmedia.com/articles/read/cheapest-solarever-austin-energy-gets-1.2-gigawatts-of-solar-bids-for-less.

Lantz, Eric, Daniel Steinberg, Michael Mendelsohn, Owen Zinaman, Ted James, Gian Porro, Maureen Hand, Trieu Mai, Jeffrey Logan, and Jenny Heeter. "Implications of a PTC Extension on US Wind Deployment.” National Renewable Energy Laboratory, 2014.

http:/www.nrel.gov/docs/fy14osti/61663.pdf.

Lawrence Berkeley National Lab. "Electricity End Uses, Energy Efficiency, and Distributed Energy Resources Baseline,” 2016. https://eetd.lbl.gov/publications/electricity-end-uses-energyefficienc.

Lazard. "Lazard's Levelized Cost of Energy Analysis - Version 9 and 10.0,” 2015, 2016. https://www.lazard.com/media/2390/lazards-levelized-cost-of-energy-analysis-90.pdf; https://www.lazard.com/perspective/levelized-cost-of-energy-analysis-100/.

Levitan \& Associates. "Gas-Electric System Interface Study, Target 2 Report, Evaluate the Capability of the Natural Gas Systems to Satisfy the Needs of the Electric Systems." DOE, 2015. http://nebula.wsimg.com/c1a27fe57283e35da35df90f71a63f7a?AccessKeyId=E28DFA42F06A3 AC21303\&disposition=0\&alloworigin $=1$.

Lew, Debra, Greg Brinkman, E Ibanez, BM Hodge, and J King. "The Western Wind and Solar Integration Study Phase 2." Contract 303 (2013): 275-3000.

Logan, Jeffery, and Stan Mark Kaplan. "Wind Power in the United States: Technology, Economic, and Policy Issues." Congressional Research Service, 2008. http://fas.org/sgp/crs/misc/RL34546.pdf.

Logan, Jeffrey, Garvin Heath, Jordan Macknick, Elizabeth Paranhos, William Boyd, and Ken Carlson. "Natural Gas and the Transformation of the US Energy Sector: Electricity." National Renewable Energy Laboratory, 2012. http://www.nrel.gov/docs/fy13osti/55538.pdf. 
Logan, Jeffrey, Kenneth Medlock, and William Boyd. "A Review of Sector and Regional Trends in US Electricity Markets: Focus on Natural Gas." Golden, CO: Joint Institute for Strategic Energy Analysis (JISEA); National Renewable Energy Laboratory (NREL), 2015. http://www.nrel.gov/docs/fy16osti/64652.pdf.

Longwell, John P, Edward S Rubin, and J Wilson. "Coal: Energy for the Future." Progress in Energy and Combustion Science 21, no. 4 (1995): 269-360.

Lono-Batura, Maile, Yinan Qi, and Ned Beecher. "Biogas Production And Potential From U.S. Wastewater Treatment," December 2012. http://www.biocycle.net/2012/12/18/biogasproduction-and-potential-from-u-s-wastewater-treatment/.

Macknick, Jordan, Robin Newmark, Garvin Heath, and KC Hallett. "A Review of Operational Water Consumption and Withdrawal Factors for Electricity Generating Technologies." Contract 303 (2011): 275-3000.

Mai, Trieu, Wesley Cole, Eric Lantz, Cara Marcy, and Benjamin Sigrin. "Impacts of Federal Tax Credit Extensions on Renewable Deployment and Power Sector Emissions." National Renewable Energy Laboratory. February, 2016.

Majer, Ernie, James Nelson, Ann Robertson-Tait, Jean Savy, and Ivan Wong. "Protocol for Addressing Induced Seismicity Associated with Enhanced Geothermal Systems." DOE, 2012. https://www1.eere.energy.gov/geothermal/pdfs/geothermal_seismicity_protocol_012012.pdf.

Marcy, Cara. "Nonhydro Electricity Storage Increasing as New Policies Are Implemented," April 3, 2015. https://www.eia.gov/todayinenergy/detail.cfm?id=20652.

Marron, Donald. “Oil And Natural Gas Prices Get Divorced.” Forbes, January 10, 2012. http://www.forbes.com/sites/energysource/2012/01/10/oil-and-natural-gas-prices-get-divorced/.

Matek, Benjamin. “2015 Annual U.S. \& Global Geothermal Power Production Report,” 2015. http://geo-

energy.org/reports/2015/2015\%20Annual\%20US\%20\%20Global\%20Geothermal\%20Power\%20 Production\%20Report\%20Draft\%20final.pdf.

_ . "Geothermal Energy Association Issue Brief: Firm and Flexible Power Services Available from Geothermal Facilities," 2015. http://geoenergy.org/reports/2015/Firm\%20and\%20Flexible\%20Power\%20Services\%20from\%20Geother mal.pdf.

Maurstad, Ola. "An Overview of Coal Based Integrated Gasification Combined Cycle (IGCC." Citeseer, 2005.

McDermott Will \& Emery. "Extension of Renewable Energy Tax Incentives." McDermott Will \& Emery Thought Leadership, November 22, 2015. https://www.mwe.com/en/thoughtleadership/publications/2015/12/extension-of-renewable-energy-tax-incentives. 
Meldrum, James, Syndi Nettles-Anderson, Garvin Heath, and Jordan Macknick. "Life Cycle Water Use for Electricity Generation: A Review and Harmonization of Literature Estimates." Environmental Research Letters 8, no. 1 (2013): 15031. doi:10.1088/1748-9326/8/1/015031.

Milligan, M, B Kirby, T Acker, M Alstrom, B Frew, M Goggin, W Lasher, M Marquis, and D Osborn. "Review and Status of Wind Integration and Transmission in the United States: Key Issues and Lessons Learned.” National Renewable Energy Laboratory, 2015. http://www.nrel.gov/docs/fy15osti/61911.pdf.

Mills, Andrew, and Ryan Wiser. "Changes in the Economic Value of Variable Generation at High Penetration Levels: A Pilot Case Study of California." Lawrence Berkeley National Laboratory, 2012. https://emp.lbl.gov/sites/all/files/lbnl-5445e.pdf.

Mints, Paula. "Photovoltaic Manufacturer Capacity, Shipments, Price \& Revenues 2014/2015," 2015.

https://library.thesource.nrel.gov/sites/default/files/pdf_files/SPV\%20Supply1\%20Manufacturer \%20Shipments\%20Capacity\%20Price\%20Revenue\%202014-2015.pdf.

Mintz, Marianne, Chris Saricks, and Anant Vyas. "Coal-by-Rail. A Business-as-Usual Reference Case." Argonne National Laboratory, 2015. http://energy.gov/sites/prod/files/2015/04/f22/QER\%20Analysis\%20-\%20Coal-byRail\%20Business-as-Usual\%20Reference\%20Case.pdf.

MIT. "The Future of Solar Energy.” MIT Energy Initiative, 2015. http://energy.mit.edu/publication/future-solar-energy/.

Moniz, Ernest J, Henry D Jacoby, AJM Meggs, RC Armtrong, DR Cohn, SR Connors, JM Deutch, QJ Ejaz, JS Hezir, and GM Kaufman. "The Future of Natural Gas.” MIT Energy Initiative, 2011. http://energy.mit.edu/publication/future-natural-gas/.

Moomaw, W, P Burgherr, G Heath, M Lenzen, J Nyboer, and A Verbruggen. "Special Report on Renewable Energy Sources and Climate Change Mitigation." Intergovernmental Panel on Climate Change, 2011.

Moretti, Albert L, Christopher S Jones, and Power-Gen Asia. "Advanced Emissions Control Technologies for Coal-Fired Power Plants.” Babcock \& Wilcox Power Generation Group, 2012.

Muljadi, Eduard, Vahan Gevorgian, Mohit Singh, and Surya Santoso. Understanding Inertial and Frequency Response of Wind Power Plants. IEEE, 2012.

$\mathrm{http}: / /$ ieeexplore.ieee.org/xpls/abs_all.jsp?arnumber $=6316361$.

Mulvaney, Dustin. "Hazardous Materials Used in Silicon PV Cell Production: A Primer." Process: Factory Environmental Management, 2013. http://www.solarindustrymag.com/online/issues/SI1309/index.htm. 
Munsell, Mike. "Investment Tax Credit Extension Would Increase US Solar Installations 54\% Through 2020." GTM Research, December 16, 2015.

http://www.greentechmedia.com/articles/read/investment-tax-credit-extension-will-increasesolar-installations-54-throug.

Namovicz, Chris. "Assessing the Economic Value of New Utility-Scale Renewable Generation Projects,” 2013. https://www.eia.gov/conference/2013/pdf/presentations/namovicz.pdf.

National Research Council. "Electricity from Renewable Resources: Status, Prospects, and Impediments," 2008. http://www.nap.edu/catalog/12619/electricity-from-renewable-resourcesstatus-prospects-and-impediments.

Nelson, RJ, H Ma, and NM Goldenbaum. "Fault Ride-through Capabilities of Siemens FullConverter Wind Turbines," 1-5. IEEE, 2011.

http://ieeexplore.ieee.org/xpls/abs_all.jsp?arnumber=6039729.

Nelson, Robert. "Active Power Control in Siemens Wind Turbines.” National Renewable Energy Laboratory, 2011.

NERC. "2015 Long-Term Reliability Assessment,” 2015.

http://www.nerc.com/pa/RAPA/ra/Reliability\%20Assessments\%20DL/2015LTRA\%20-

\%20Final\%20Report.pdf.

—. "Essential Reliability Services Task Force Measures Framework Report," 2015.

http://www.nerc.com/comm/Other/essntlrlbltysrvcstskfrcDL/ERSTF\%20Framework\%20Report $\% 20-\% 20$ Final.pdf.

—. "NERC Website," 2015. http://www.nerc.com/Pages/default.aspx.

NETL. "2014 Technology Readiness Assessment: A Checkpoint along a Challenging Journey," January 2015. https://www.netl.doe.gov/File\%20Library/Research/Coal/Reference\%20Shelf/DOE-NETL20151710-2014-Technology-Readiness-Assessment-Comprehensive.pdf.

_. "Black Liquor." Accessed December 7, 2015.

http://www.netl.doe.gov/research/coal/energy-systems/gasification/gasifipedia/blackliquor.

. 2015. "Cost and Performance Baseline for Fossil Energy Plants Volume 1a: Bituminous Coal (PC) and Natural Gas to Electricity Revision 3." http://www.netl.doe.gov/research/energyanalysis/baseline-studiesf.

. "Cost and Performance Baseline for Fossil Energy Plants Volume 1b: Bituminous Coal (IGCC) to Electricity," 2015. http://www.netl.doe.gov/energyanalyses/temp/CostandPerformanceBaselineforFEPlantsVollbBitCoalIGCCtoElecRev2bYearDo llarUpdate_073115.pdf. 
. 2015. "Cost and Performance Baseline for Fossil Energy Plants Volume 1b: Bituminous Coal (IGCC) to Electricity Revision 2b - Year Dollar Update."

http://www.netl.doe.gov/research/energy-analysis/baseline-studies.

. 2015. "Cost and Performance Baseline for Fossil Energy Plants Supplement: Sensitivity to CO2 Capture Rate in Coal-Fired Power Plants.” http://www.netl.doe.gov/research/energyanalysis/baseline-studies.

-. "Current and Future Technologies for Power Generation with Post-Combustion Carbon Capture." National Energy Technology Laboratory, 2012.

http://netl.doe.gov/File\%20Library/Research/Energy\%20Analysis/Publications/NETL-DOE2012-1557.pdf.

- "Impact of Load Following on Power Plant Cost and Performance: Literature Review and Industry Interviews," 2012.

http://netl.doe.gov/File\%20Library/Research/Energy\%20Analysis/Publications/NETL-DOE2013-1592-Rev1_20121010.pdf.

—. "NETL: Coal," 2016. http://www.netl.doe.gov/research/coal.

—. "Post-Combustion CO2 Control.” Accessed January 5, 2016. http://www.netl.doe.gov/research/coal/carbon-capture/post-combustion.

—. "Typical IGCC Configuration.” Accessed January 5, 2016.

http://www.netl.doe.gov/research/coal/energy-systems/gasification/gasifipedia/igcc-config.

"U.S. Department of Energy Oil \& Gas Technical Assistance Capabilities: Strategic Energy Analysis and Planning." presented at the Tribal Leader Forum Series, August 18, 2015. http://energy.gov/sites/prod/files/2015/09/f26/SEAP_TLF.pdf.

_. "Vanadium Redox Battery Demonstration Program," 2013.

http://energy.gov/sites/prod/files/2015/05/f22/VanadiumRedoxBattery-Aug2013.pdf.

NHA. "Challenges and Opportunities For New Pumped Storage Development.” National Hydropower Association, 2012. http://www.hydro.org/wpcontent/uploads/2014/01/NHA_PumpedStorage_071212b12.pdf.

- "House Passes Bill to Bring Hydropower Licensing Process into the 21 st Century," December 3, 2015. http://www.hydro.org/wp-content/uploads/2015/12/12.3.15-House-PassesHydro-Press-Release2.pdf.

NOAA. "What Is a Fish Ladder?" National Oceanic and Atmospheric Administration, 2014. http://oceanservice.noaa.gov/facts/fish-ladder.html.

NRC. "Status of License Renewal Applications and Industry Activities." U.S. Nuclear Regulatory Commission, 2016.

http://www.nrc.gov/reactors/operating/licensing/renewal/applications.html. 
—. "Subsequent License Renewal," 2016.

http://www.nrc.gov/reactors/operating/licensing/renewal/subsequent-license-renewal.html.

“The Boiling Water Reactor (BWR)," June 16, 2016. http://www.nrc.gov/reading$\mathrm{rm} /$ basic-ref/students/animated-bwr.html.

—. "The Pressurized Water Reactor (PWR)," June 16, 2016. http://www.nrc.gov/reading$\mathrm{rm} /$ basic-ref/students/animated-pwr.html.

__. "Uranium Enrichment.” U.S. Nuclear Regulatory Commission, July 16, 2016.

http://www.nrc.gov/materials/fuel-cycle-fac/ur-enrichment.html.

NREL. "Advanced Inverter Functions to Support High Levels of Distributed Solar: Policy and Regulatory Considerations (Brochure).” National Renewable Energy Laboratory, 2014. http:/www.nrel.gov/docs/fy15osti/62612.pdf.

—. "Annual Technology Baseline and Standard Scenarios," 2015. http://www.nrel.gov/analysis/data_tech_baseline.html.

. "Dynamic Maps, GIS Data, and Analysis Tools - Biomass Maps," 2015.

http://www.nrel.gov/gis/biomass.html.

—. "Life Cycle Greenhouse Gas Emissions from Electricity Generation (Fact Sheet)." National Renewable Energy Laboratory, January 2013. http://www.nrel.gov/docs/fy13osti/57187.pdf.

—. "New 100-Meter Map Keeps Pace with Growing Wind Technology." National Renewable Energy Laboratory, 2014.

. "NREL: Dynamic Maps, GIS Data, and Analysis Tools - Solar Maps," February 2, 2015. http://www.nrel.gov/gis/solar.html.

—. "NREL: Learning - Geothermal Electricity Production Basics," July 25, 2015. http://www.nrel.gov/learning/re_geo_elec_production.html.

—. "Wind Energy Resource Atlas of the United States," March 24, 2014.

http://rredc.nrel.gov/wind/pubs/atlas/tables/1-1T.html.

Nuclear Energy Institute. “Quick Facts: Nuclear Energy in America,” July 2015. http://www.nei.org/Master-Document-Folder/Backgrounders/Fact-Sheets/Quick-Facts-NuclearEnergy-in-America.

Overton, Thomas. "Even More Delays and Cost Overruns for Vogtle Expansion." Power Magazine, February 2, 2015. http:/www.powermag.com/even-more-delays-and-cost-overrunsfor-vogtle-expansion/.

—. "World's Largest Fuel Cell Plant Opens in South Korea." Power Magazine, February 25, 2014. http://www.powermag.com/worlds-largest-fuel-cell-plant-opens-in-south-korea/. 
Pauwels, Martine. "Nuclear Power as a Panacea for Climate Change? Experts Make Their Case on Each Side." www.ChinaPost.com.tw, December 6, 2015.

http:/www.chinapost.com.tw/commentary/afp/2015/12/06/452736/Nuclear-power.htm.

Petrova, Maria A. "NIMBYism Revisited: Public Acceptance of Wind Energy in the United States." Wiley Interdisciplinary Reviews: Climate Change 4, no. 6 (2013): 575-601.

doi:10.1002/wcc.250.

Pettyjohn, Luke. "The Opposition to Alternative Energy Progress: Why It Feels Like Running against the Wind," 2015. http://studentorgs.law.unc.edu/documents/elp/2014/pettyjohnelp.pdf.

Phillips, Benjamin R, John Ziagos, Hildigunnur Thorsteinsson, and Eric Hass. "A Roadmap for Strategic Development of Geothermal Exploration Technologies," 11-13, 2013.

http://energy.gov/sites/prod/files/2014/02/f7/exploration_technical_roadmap2013.pdf.

PJM Interconnection LLC. "Analysis of Operational Events and Market Impacts During the January 2014 Cold Weather Events," 2014.

https://www.pjm.com/ /media/documents/reports/20140509-analysis-of-operational-events-andmarket-impacts-during-the-jan-2014-cold-weather-events.ashx.

Powell, Neil. “America’s Aging Generation Fleet.” POWER, January 28, 2013.

http://www.powermag.com/americas-aging-generation-fleet/.

Power Electrical \& High Voltage Engineering. "Power Generation," 2009.

https://etrical.wordpress.com/power-generation/.

Ramireddy, Vinod. “An Overview of Combined Cycle Power Plant.” Electrical Engineering Portal, August 25, 2012. http://electrical-engineering-portal.com/an-overview-of-combinedcycle-power-plant.

Ranjan, S, S Balaji, Rocco A Panella, and B Erik Ydstie. "Silicon Solar Cell Production." Computers \& Chemical Engineering 35, no. 8 (2011): 1439-53.

Reilly, Amanda, and Brittany Patterson. "Biomass Amendment Reignites Clean Power Plan Debate," February 5, 2016. http://www.eenews.net/stories/1060031868.

Reiner, David M. "Learning through a Portfolio of Carbon Capture and Storage Demonstration Projects." Nature Energy 1 (January 11, 2016): 15011.

Reitenbach, Gail. "SaskPower Admits to Problems at First 'Full-Scale' Carbon Capture Project at Boundary Dam Plant." Power Magazine, October 30, 2015.

http://www.powermag.com/saskpower-admits-to-problems-at-first-full-scale-carbon-captureproject-at-boundary-dam-plant/.

Roberts, B. "Geothermal Resource of the United States," 2009.

http://www.nrel.gov/gis/images/geothermal_resource2009-final.jpg. 
Roselund, Christian. "Nevada Creates Separate Rate Class and Adds New Charges for Solar Owners.” Pv Magazine, 2015. http://www.pv-magazine.com/news/details/beitrag/nevadacreates-separate-rate-class-and-adds-new-charges-for-solar-owners_100022555/.

—. "The Disruptive Potential of Thin and Kerfless Wafers : Pv-Magazine," 2014.

http://www.pv-magazine.com/archive/articles/beitrag/the-disruptive-potential-of-thin-andkerfless-wafers100016427/86/?tx_ttnews\%5BbackCat\%5D=248\&cHash=4cb9a5153dd6d10526f35c9ff676c16 1\#axzz3tmtuAaFT.

Ruth, Mark. "Nuclear-Renewable Hybrid Energy System Market Analysis Plans," 2016. http://www.nrel.gov/docs/fy16osti/66603.pdf.

Samuelsohn, Darren. "Billions over Budget. Two Years after Deadline. What's Gone Wrong for the 'clean Coal' Project That's Supposed to Save an Industry?" Politico, May 26, 2015. http://www.politico.com/agenda/story/2015/05/billion-dollar-kemper-clean-coal-energy-project000015.

Sanchez, Daniel L, and Daniel M Kammen. "A Commercialization Strategy for Carbon-Negative Energy." Nature Energy 1 (2016): 15002.

Sathaye, Jayant, Oswaldo Lucon, Atiq Rahman, John Christensen, Fatima Denton, Junichi Fujino, Garvin Heath, Monirul Mirza, Hugh Rudnick, and August Schlaepfer. "Renewable Energy in the Context of Sustainable Development," 2011. http://www.ipcc.ch/pdf/specialreports/srren/Chapter\%209\%20Renewable\%20Energy $\% 20 \mathrm{in} \% 20$ the $\% 20$ Context $\% 20$ of $\% 20$ Sust ainable\%20Development.pdf.

Schaffer, Chris. "RE: Requesting Wind Turbine Qualification Criteria for On-Site Renewable Energy Scoring - Letter to U.S. Green Building Council.” Distributed Wind Energy Association, 2012. http://www.wind-

works.org/cms/fileadmin/user_upload/Files/Reports/DWEA_USGBC_8_20_12.pdf.

Schlissel, David, and Bruce Biewald. "Nuclear Power Plant Construction Costs," 2008. http://www.psr.org/nuclear-bailout/resources/nuclear-power-plant.pdf.

Schmalensee, Richard. "The Future of Solar Energy: A Personal Assessment.” Energy Economics 52 (2015): S142-48. doi::10.1016/j.eneco.2015.08.012.

SCHOTT North America. "Parabolic Trough Technology," 2015. http:/www.us.schott.com/csp/english/parabolic-through-technology.html.

SEIA. “Solar Market Insight 2015 Q3.” Solar Energy Industry Association, 2015. http://www.seia.org/research-resources/solar-market-insight-2015-q3.

SEIA, and GTM Research. "Solar Market Insight 2014 Year-in-Review." Solar Energy Industries Association, 2015. http://www.seia.org/research-resources/solar-market-insightreport-2014-q4. 
Senthilvel, Jack. "Rapid Start and Flexible Operation - Emerging Technologies in Advanced Gas Turbine Combined Cycle Plants," 2012.

http://pennwell.sds06.websds.net/2012/bangkok/pga/slideshows/T3S6O1-slides.pdf.

Short, Walter, Patrick Sullivan, Trieu Mai, Matthew Mowers, Caroline Uriarte, Nate Blair, Donna Heimiller, and Andrew Martinez. "Regional Energy Deployment System (ReEDS)." National Renewable Energy Laboratory, 2011. http://www.nrel.gov/docs/fy12osti/46534.pdf.

Shropshire, DE, KA Williams, EA Hoffman, JD Smith, DJ Hebditch, JJ Jacobson, JD Morton, AM Phillips, and JP Taylor. "Advanced Fuel Cycle Economic Analysis of Symbiotic LightWater Reactor and Fast Burner Reactor Systems.” Idaho National Laboratory, 2009.

Siedlecki, Marcin. "CFB Gasification of Biomass,” 2010.

https://cms.lnu.se/polopoly_fs/1.35422!CFB\%20Gasicication.pdf.

Sissine, Fred J. "Renewable Energy: Background and Issues for the 110th Congress." Congressional Research Service, Library of Congress, 2008. http://nationalaglawcenter.org/wpcontent/uploads/assets/crs/RL34162.pdf.

Sivaram, Varun, Samuel D Stranks, and Henry J Snaith. "Outshining Silicon." Scientific American 313, no. 1 (2015): 54-59. doi:10.1038/scientificamerican0715-54.

Sloss, Lesley. "Coal Mine Site Reclamation.” International Energy Agency's Clean Coal Centre, 2013.

https://www.usea.org/sites/default/files/022013_Coal\%20mine\%20site\%20reclamation_ccc216. pdf.

Snaith, Henry J. "Perovskite Solar Cells; Outshining Silicon." presented at the The 3rd Annual Sigma-Aldrich Distinguished Lecture, 2015. https://smartech.gatech.edu/handle/1853/54168.

SNL. "SNL Office with Excel Add-In. Subscription Service,” 2015. www.snl.com.

Staub, John. "The Growth of U.S. Natural Gas: An Uncertain Outlook for U.S. and World Supply." presented at the 2015 EIA Energy Conference, Washington, D.C., June 15, 2015. www.eia.gov/conference/2015/pdf/presentations/staub.pdf.

Stori, V. "Environmental Rules for Hydropower in State Renewable Portfolio Standards." Clean Energy States Alliance, 2013. http://www.cesa.org/assets/2013-Files/RPS/Environmental-Rulesfor-Hydropower-in-State-RPS-April-2013-final-v2.pdf.

Theodori, Gene L, AE Luloff, Fern K Willits, and David B Burnett. "Hydraulic Fracturing and the Management, Disposal, and Reuse of Frac Flowback Waters: Views from the Public in the Marcellus Shale," 2014.

Tidball, Rick, Joel Bluestein, Nick Rodriguez, and Stu Knoke. "Cost and Performance Assumptions for Modeling Electricity Generation Technologies." National Renewable Energy Laboratory, November 2010. www.nrel.gov/docs/fy1 1osti/48595.pdf. 
Tincher, Sarah. “Abandoned Mine Reclamation Could Renew WV Coalfields.” The State Journal, Jjuly 2015. http://www.statejournal.com/story/29617664/abandoned-mine-reclamationcould-renew-wv-coalfields.

Trabish, Herman. "Nuclear Industry Darkened by Delays, Cost Overruns at Vogtle \& Summer Facilities." Utility Dive, August 24, 2015. http://www.utilitydive.com/news/nuclear-industrydarkened-by-delays-cost-overruns-at-vogtle-summer-facil/404418/.

—. "NV Energy Buys Utility-Scale Solar at Record Low Price under 4 Cents/kWh." Utility Dive, July 9, 2015. http://www.utilitydive.com/news/nv-energy-buys-utility-scale-solar-atrecord-low-price-under-4-centskwh/401989/.

Trimble, David, and Frank Rusco. "Air Emissions and Electricity Generation at U.S. Power Plants," n.d. www.gao.gov/assets/600/590188.pdf.

Turconi, Roberto, Alessio Boldrin, and Thomas Astrup. "Life Cycle Assessment (LCA) of Electricity Generation Technologies: Overview, Comparability and Limitations.” Renewable and Sustainable Energy Reviews 28 (2013): 555-65.

TVA. “Coal-Fired Power Plant Schematic.” Tennessee Valley Authority, 2013. http://holbert.faculty.asu.edu/eee463/FOSSIL.HTML.

UCS. "Environmental Impacts of Geothermal Energy." Union of Concerned Scientists, 2015. http://www.ucsusa.org/clean_energy/our-energy-choices/renewable-energy/environmentalimpacts-geothermal-energy.html\#.V-2jbnovY4d.

Uria-Martinez, Rocio, Patrick O-Connor, Megan Johnson, and ORNL. "2014 Hydropower Market Report.” Department of Energy (DOE); Oak Ridge National Laboratory (ORNL), April 2015.

http://energy.gov/sites/prod/files/2015/05/f22/2014\%20Hydropower\%20Market\%20Report_201 50512_rev6.pdf.

U.S. DRIVE. "Hydrogen Production Technical Team Roadmap.” Driving Research and Innovation for Vehicle efficiency and Energy sustainability (U.S. DRIVE), 2013.

http://www1.eere.energy.gov/vehiclesandfuels/pdfs/program/hptt_roadmap_june2013.pdf.

USGS. “A Coal-Fired Thermoelectric Power Plant,” March 17, 2014.

http://water.usgs.gov/edu/wupt-coalplant-diagram.html.

Vaysman, Vladimir, Yuxin Lu, and Williams Summers. "Quality Guide Energy System Studies: Detailed Coal Specifications.” National Energy Technology Laboratory, January 1, 2012. http://www.netl.doe.gov/research/energy-analysis/search-publications/vuedetails?id=791.

Veil, John. "U.S. Produced Water Volumes and Management Practices in 2012." Ground Water Protection Council, April 2015.

Ventyx. "Monthly Plant Generation \& Consumption.," 2016. 
Virginia Uranium. “Uranium Market \& U.S. Uranium Sources.”Virginia Uranium, 2012. http://www.virginiauranium.com/uranium-101/uranium-market-u-s-uranium-sources/.

Wall, Anna, and Katherine Young. "Doubling Geothermal Generation Capacity by 2020: A Strategic Analysis.” National Renewable Energy Laboratory, 2016.

Walsh, F Rall, and Mark D Zoback. "Oklahoma’s Recent Earthquakes and Saltwater Disposal." Science Advances 1, no. 5 (2015): e1500195.

Walston, Leroy J, Katherine E Rollins, Karen P Smith, Kirk E LaGory, Karin Sinclair, Craig Turchi, Tim Wendelin, and Heidi Souder. "A Review of Avian Monitoring and Mitigation Information at Existing Utility-Scale Solar Facilities.” Argonne National Laboratory (ANL), 2015.

Wang, S.S. “Advanced Materials, Manufacturing and Design Integration for Large Offshore Wind Turbine Blades." University of Houston, Houston, TX, 2013.

Wärtsilä. “Combustion Engine vs Gas Turbine- Ramp Rate.” Wärtsilä, 2016.

http://www.wartsila.com/energy/learning-center/technical-comparisons/combustion-engine-vsgas-turbine-ramp-rate.

_. "Combustion Engine vs Gas Turbine- Startup Time.” Wärtsilä, 2016.

http://www.wartsila.com/energy/learning-center/technical-comparisons/combustion-engine-vsgas-turbine-startup-time.

Water Environment Federation. "Biogas Data," 2015.

http://www.resourcerecoverydata.org/biogasdata.php.

WHO. "Health Effects of Particulate Matter. Policy Implications for Countries in Eastern Europe, Caucasus and Central Asia." World Health Organization Regional Office for Europe, Copenhagen, 2013. http://www.euro.who.int/_data/assets/pdf_file/0006/189051/Health-effectsof-particulate-matter-final-Eng.pdf.

Williams, Colin F, Marshall J Reed, Robert H Mariner, Jacob DeAngelo, and S Peter Galanis. "Assessment of Moderate-and High-Temperature Geothermal Resources of the United States." USGS, 2008. http://pubs.usgs.gov/fs/2008/3082/pdf/fs2008-3082.pdf.

Williams, J.H., B Haley, F Kahrl, J Moore, A.D. Jones, M.S. Torn, and H McJeon. "Pathways to Deep Decarbonization in the United States." Sustainable Development Solutions Network and the Institute for Sustainable Development and International Relations, November 16, 2015. deepdecarbonization.org/wpcontent/uploads/2015/11/US_Deep_Decarbonization_Technical_Report.pdf.

Wiser, Ryan, and Mark Bolinger. "2014 Wind Technologies Market Report.” U.S. Department of Energy, August 2015.

WMA. "Mining Reclamation Practices.” Wyoming Mining Association, 2016. http://www.wyomingmining.org/reclamation. 
__. "Uranium Mining." Wyoming Mining Association, 2016.

http://www.wyomingmining.org/minerals/uranium/.

WNA. “Country Profiles.” World Nuclear Assoication. Accessed September 29, 2016. http://www.world-nuclear.org/information-library/country-profiles.aspx.

__. "Environmental Aspects of Uranium Mining." World Nuclear Assoication, June 2014. http://www.world-nuclear.org/information-library/nuclear-fuel-cycle/mining-ofuranium/environmental-aspects-of-uranium-mining.aspx.

_. "Nuclear Power Economics." World Nuclear Assoication, July 2016. http://www.worldnuclear.org/information-library/economic-aspects/economics-of-nuclear-power.aspx.

—. "Nuclear Power in the USA." World Nuclear Association, September 26, 2016. http://world-nuclear.org/information-library/country-profiles/countries-t-z/usa-nuclearpower.aspx.

__. "Nuclear Power Reactors." World Nuclear Assoication, September 2016.

http://www.world-nuclear.org/information-library/nuclear-fuel-cycle/nuclear-powerreactors/nuclear-power-reactors.aspx.

_ . "Nuclear Reactors," November 2015. http://www.world-nuclear.org/info/Nuclear-FuelCycle/Power-Reactors/Nuclear-Power-Reactors/.

__. "Renewable Energy and Electricity." World Nuclear Assoication, September 2016. http://www.world-nuclear.org/information-library/energy-and-the-environment/renewableenergy-and-electricity.aspx.

_ . "Uranium Enrichment." World Nuclear Assoication, 2016. http://www.worldnuclear.org/information-library/nuclear-fuel-cycle/conversion-enrichment-andfabrication/uranium-enrichment.aspx.

__. "Uranium Markets." World Nuclear Association, 2015. http://www.worldnuclear.org/information-library/nuclear-fuel-cycle/uranium-resources/uranium-markets.aspx.

Wu, Chenye, Gabriela Hug, and Soummya Kar. "Risk-Limiting Economic Dispatch for Electricity Markets with Flexible Ramping Products." IEEE Transactions on Power Systems 31, no. 3 (2016): 1990-2003.

Zayas, Jose, Michael Derby, Patrick Gilman, and Shreyas Ananthan. "Enabling Wind Power Nationwide." U.S. Department fo Energy, 2015.

Ziagos, John, Benjamin R Phillips, Lauren Boyd, Allan Jelacic, Greg Stillman, and Eric Hass. "A Technology Roadmap for Strategic Development of Enhanced Geothermal Systems," 11-13, 2013. http://www.osti.gov/servlets/purl/1219933/. 


\section{Appendix A: Supplementary Detail on Generating Technologies}

\section{Coal}

\section{Prime Mover Technology}

Conventional Pulverized Coal (PC) generators burn coal to create steam which drives a steam turbine tied to an electricity generator ${ }^{560}$. Coal is first pulverized into a powder before being sprayed into the boiler in this process. The coal-fired generating process is shown in Figure A-1. Most, if not all, coal plants operating in the U.S. today employ significant environmental technologies to control air emissions (not shown in Figure A-1).

The boiler is lined with miles of metal pipes carrying water at high pressure. The heat from combustion heats the water in the surrounding pipes until it becomes high pressure steam. The energy in the steam drives the turbines so that a significant portion of the internal energy in the steam is converted to mechanical energy. For large generating plants, there may be several turbines in succession, known as the high pressure (HP), intermediate pressure (IP) and low pressure (LP) turbines. The resulting low temperature and low pressure steam exiting the last turbine is condensed releasing a large amount of latent heat which is carried away by the cooling process. The water can now be pressurized and the cyclical process repeated.

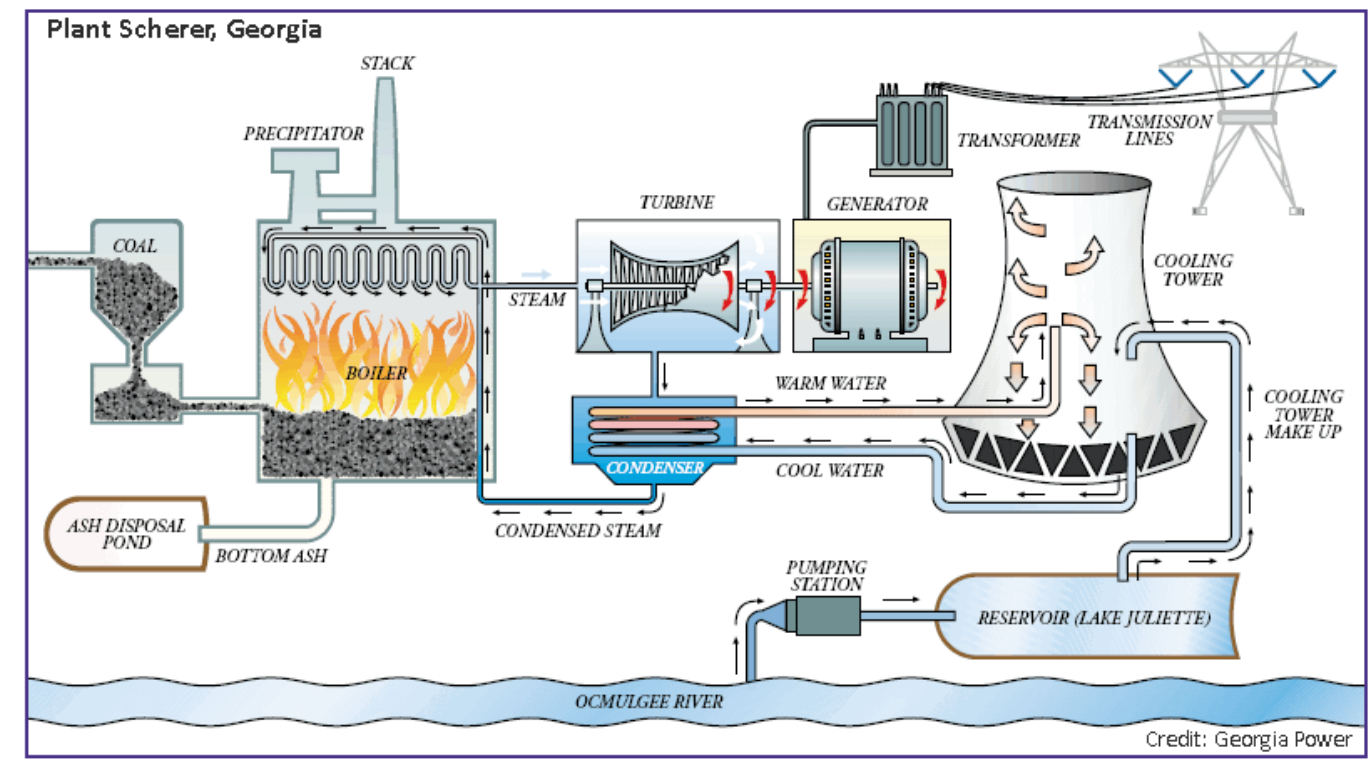

Figure A-1. Coal-fired power plant diagram ${ }^{561}$

Figure shows diagram of coal-fired steam turbine (needed pollution control technologies not shown in this figure). Coal plant shown utilizes a recirculating cooling tower for cooling needs.

Integrated Gasification Combined Cycle (IGCC) generators use a gasifier to create syngas from coal, which is cleaned and fired in a combustion turbine (Figure A-3). The exhaust heat from the combustion turbine is used to drive a secondary heat recovery system which uses the exhaust heat to generate steam to run a steam turbine and generator ${ }^{562}$. Any carbon-based feedstock can be used for IGCC generators, but the most common has been coal ${ }^{563}$. IGCC systems have similar 
operating parameters to $\mathrm{CC}$ plants, which will be further discussed in the natural gas section of this Appendix.

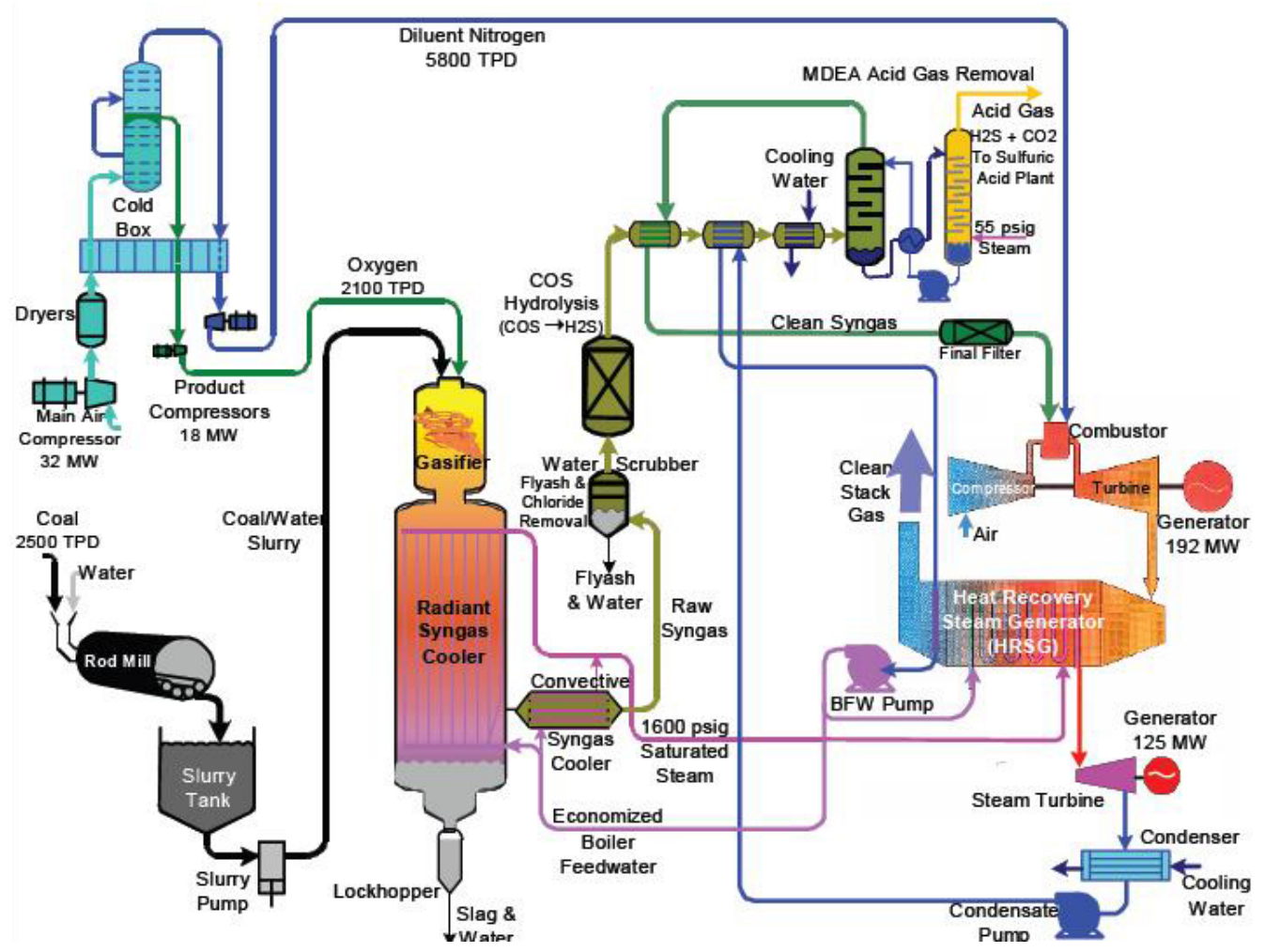

Figure A-2. Tampa electric IGCC process flow ${ }^{564}$

The IGCC process first gasifies coal into a syngas and then filters out unwanted contaminants (e.g., $\mathrm{CO}_{2}$ and $\mathrm{H}_{2} \mathrm{~S}$ ) before being burned in a combustion turbine. The process shown includes heat recovery (combined cycle) for greater efficiency.

\section{Carbon Capture and Storage}

The carbon capture and storage (CCS) process can reduce $\mathrm{CO}_{2}$ emissions of existing power plants by capturing $\mathrm{CO}_{2}$ before emission to the atmosphere. CCS is currently the only process available for decarbonizing high emission industries such as chemical, steel, and cement production $^{565}$. CCS can also be used with biopower (BECCS) and natural gas plants, but because of its importance for future coal plants it will be discussed in this section.

During $\mathrm{CCS}, \mathrm{CO}_{2}$ is captured either pre-combustion (with IGCC plants) or post-combustion (generally for PC units, but can be used with IGCC plants) as shown in Figure A-3. Precombustion capture of $\mathrm{CO}_{2}$ occurs after the feed stock is gasified into a syngas (mixture of $\mathrm{H}_{2}$, $\mathrm{CO}, \mathrm{CO}_{2}$, and methane). The $\mathrm{CO}$ can be reacted with water to produce $\mathrm{H}_{2}$ and $\mathrm{CO}_{2}$ which increases the $\mathrm{CO}_{2}$ concentration to $15-50 \%$ (higher concentrations enable easier separation). The $\mathrm{CO}_{2}$ is then separated from the syngas using physical or chemical adsorption processes and the $\mathrm{H}_{2}$-rich fuel is combusted ${ }^{566}$. Post-combustion capture uses a solvent, a sorbent, or a membrane to absorb $\mathrm{CO}_{2}{ }^{567}$. 
After capture, $\mathrm{CO}_{2}$ is then compressed and transported by pipeline, barge, or truck to a processing facility. $\mathrm{CO}_{2}$ is then compressed (again, if needed), injected, and stored in underground reservoirs for permanent storage or used elsewhere. Compressed $\mathrm{CO}_{2}$ is often be used for enhanced oil recovery (EOR) purposes in the oil and gas industry ${ }^{568}$, but other uses of $\mathrm{CO}_{2}$ exist.

IGCC plants with CCS have an advantage in that $\mathrm{CO}_{2}$ can be separated before combustion. In contrast, any CCS system for pulverized coal plants has to remove the $\mathrm{CO}_{2}$ from the flue gas where it is more diluted (5-15\%) and mixed with more impurities, therefore requiring more volume and energy to separate ${ }^{569}$.

Plants with CCS will have lower efficiencies than plants without CCS due to parasitic load from equipment in the CCS process. There is also energy needed to heat up the $\mathrm{CO}_{2}$ solvent solution to remove $\mathrm{CO}_{2}$ and recycle the solvent.

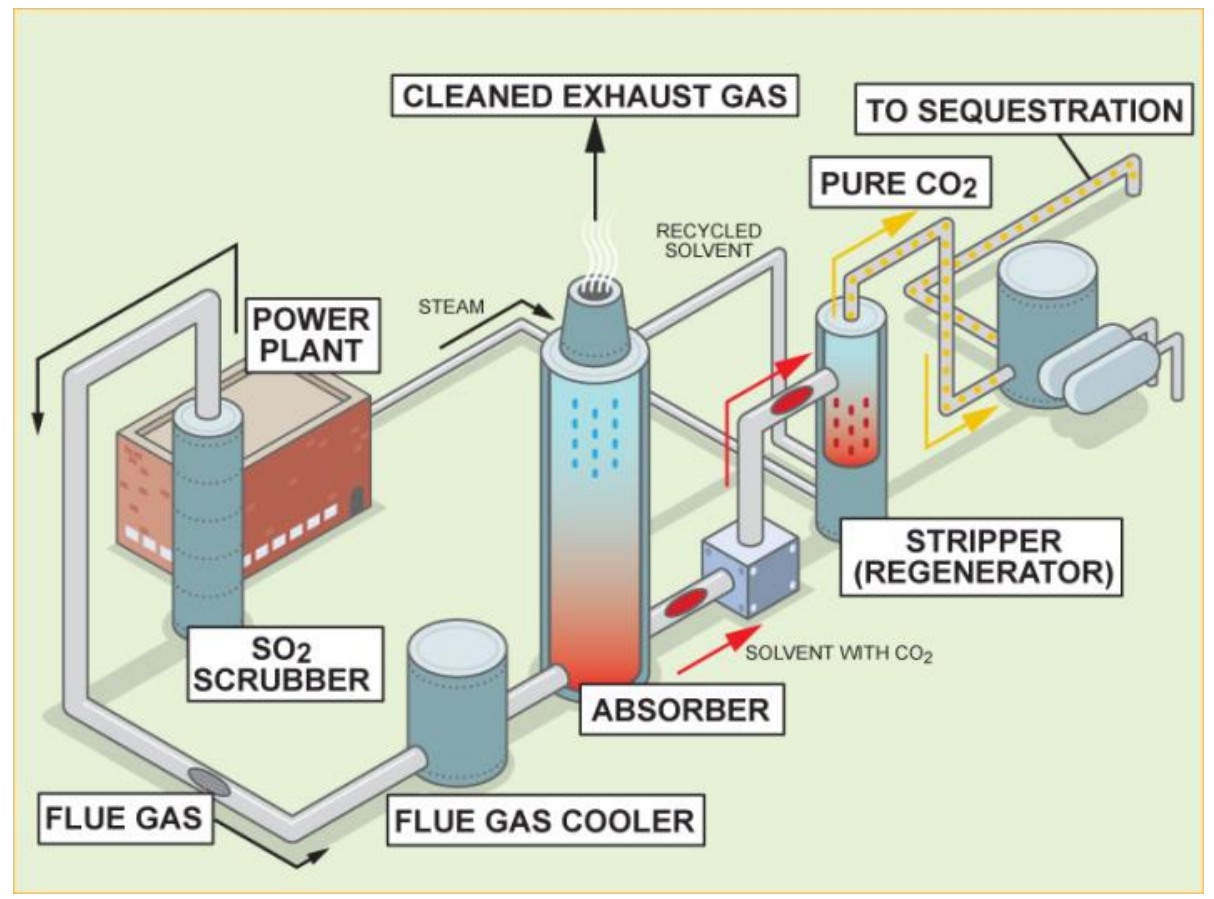

Figure A-3. Diagram of post-combustion CCS plant ${ }^{570}$

Note: Graphic does not include compression, which is needed before transport or underground injection.

\section{Physical Attributes}

With a steam turbine and generator there is often a large rotating mass that must be spun up at plant start. It often takes hours for coal plants to build pressure and temperature high enough to achieve operating efficiencies. Coal plants only operate at these high efficiencies during high output conditions so ramping up and down can be costly, but is becoming more common with technology upgrades. Because of these attributes, coal is often used to provide base load for the power system. Coal plants can also maintain steam pressure and not have the steam turbine connected to the generator, which can provide spinning reserves. 
PC plants can have different operating conditions depending on the design and materials used for the boiler. Higher temperature and pressure operating conditions can increase plant efficiency and reduce emissions (on a per energy unit basis).

- $\quad$ Subcritical - Operating conditions are generally around 2400 psi and $1000^{\circ} \mathrm{F}$. Plant efficiencies are in the range of $37 \%\left(\mathrm{LHV}^{571}\right)^{572}$.

- Supercritical - Operating conditions are generally around $3550 \mathrm{psi}$ and $1050^{\circ} \mathrm{F}$. Plant efficiencies are in the range of $40 \%(\mathrm{LHV})^{573}$.

- Ultra-supercritical - Operating conditions are generally around $4350 \mathrm{psi}$ and $1100^{\circ} \mathrm{F}$. Plant efficiencies are in the range of $42 \%(\mathrm{LHV})^{574}$.

IGCC plants have operating efficiencies around $40 \%$, but otherwise similar operating characteristics to combined cycle combustion turbines. The lower efficiency of IGCC plants compared to CC plants (60\%) results from the energy needed during the gasification process ${ }^{575}$.

\section{Scale Efficiencies}

As of 2013, the average net summer capacity of conventional coal-fired units was $230 \mathrm{MW}^{576}$. The largest coal unit reported was $1300 \mathrm{MW}^{577}$. Most utility-scale plants try to take advantage of economies of scale and deploy multiple units per site due to the large supply chain needed for coal deliveries and expensive retrofits needed to meet air quality standards.

\section{Natural Gas}

\section{Prime Mover Technology}

Natural gas steam turbines also play a role in the U.S. power sector, but like coal, plants have been retiring over recent years; we do not describe natural gas steam turbines in this Appendix, but the technology is the same as coal steam turbines.

A CT first compresses air in the turbine and the air feeds into the combustion chamber, as shown in Figure A-4. This process increases the temperature a few hundred degrees due to work done (adiabatically) by the compressor. Then, natural gas (or another fuel) is injected into the combustion chamber and combusted so that temperature of the air and fuel combustion products increases to roughly $2000{ }^{\circ} \mathrm{F}$ to produce a high temperature and pressure gas stream. This gas stream is then expanded through a rotary turbine that is linked to a generator to produce electricity $^{578}$.

Combined cycle generators (Figure A-5) use exhaust heat from a CT to run a secondary Rankine cycle steam generator. After the air has expanded through the turbine the air is still quite hot $\left(750-930^{\circ} \mathrm{F}\right)$. This waste heat can be captured to power a secondary steam turbine that increases the overall efficiency of the process to around $60 \%$. Use of a regenerator is another option where the still hot exhaust gas is used to partly pre-heat the compressed gas before it enters to the combustor. 


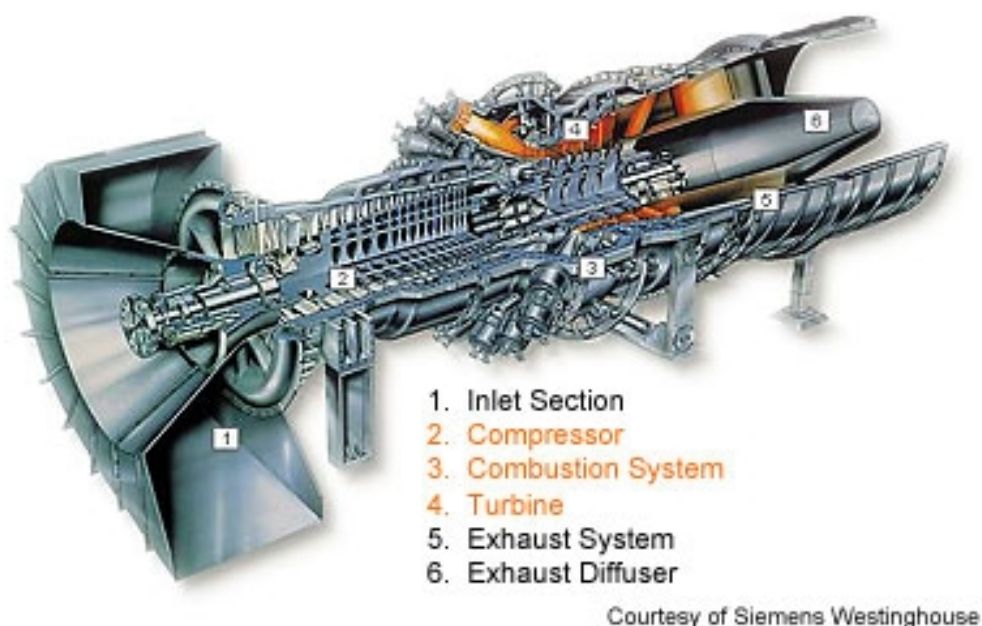

Figure A-4. Combustion turbine diagram ${ }^{579}$

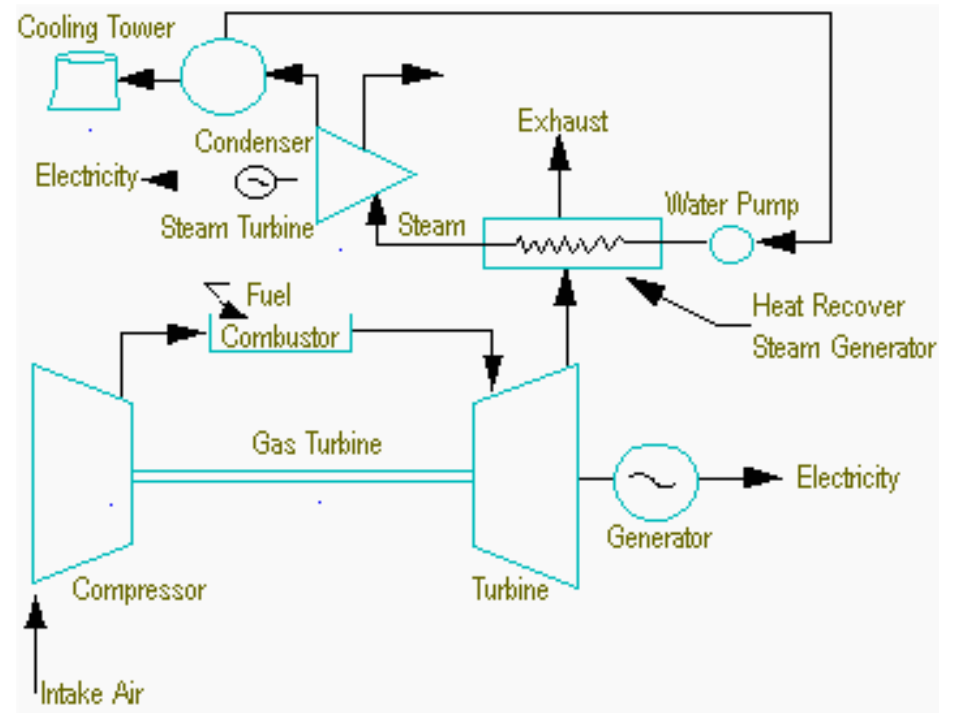

Figure A-5. Combined cycle generation process flow diagram ${ }^{580}$

Natural gas can also be used as a feedstock for use in fuel cells. In some fuel cell technologies methane is steam reformed to produce hydrogen which is used in the fuel cell (as shown in Figure A-6). Other fuel cell technologies use methanol, which is produced from methane by creating a syngas made of $\mathrm{CO}$ and $\mathrm{H}_{2}$ and then reacting this syngas into methanol.

Natural gas power plants can also be combined with the CCS process to reduce $\mathrm{CO}_{2}$ emissions of generation, as described in the carbon capture and storage part of the coal section of this Appendix. The differences between CCS used in natural gas plants and coal plants is beyond the scope of this Appendix. 


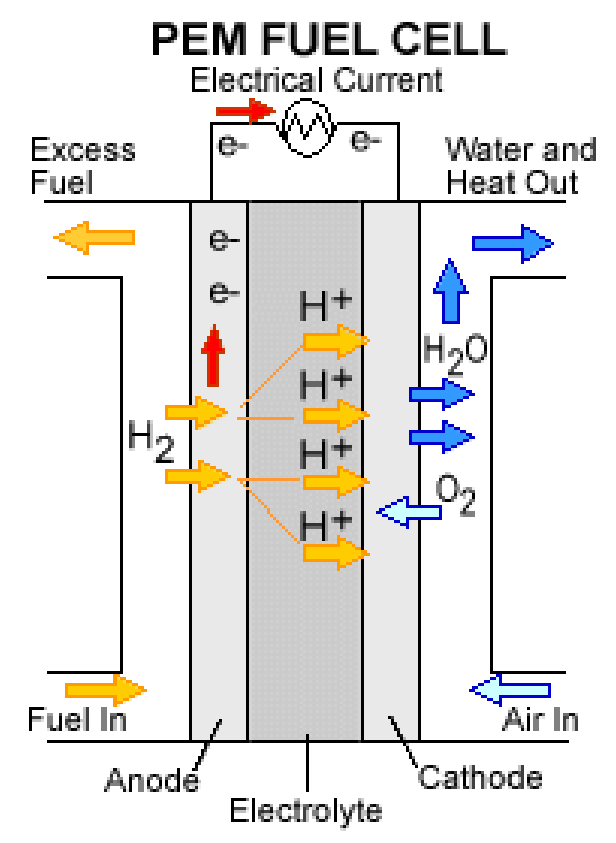

Figure A-6. Hydrogen fuel cell diagram ${ }^{581}$

For centralized power generation, large gas turbines are preferred as they offer very low maintenance. These turbines tend to be $>20 \mathrm{MW}$ in size and are typically about $30 \%$ efficient. For distributed power generation applications, prime mover requirements are smaller than 20 MW and the preferred generating technologies are reciprocating engines, fuel cells and microturbines $^{582}$. Fuel cells are low-polluting, and highly efficient (about $60 \%$ ), but often require very high capital costs. Microturbines, on the other hand, are low polluting but have very low efficiencies (around 30\%). Reciprocating engines offer very low capital costs and further have very high efficiencies (about $42 \%$ ) but NOx emissions are a concern. Also, the maintenance requirements are higher as compared to the other two prime movers ${ }^{583}$.

\section{Physical Attributes}

CTs can be started and ramped up quickly due to the nature of the combustion cycle. They are generally used for peaking purposes due to this ability, but are inefficient generators in comparison to other technologies ${ }^{584}$. Combustion turbines come in units from $30 \mathrm{~kW}$ (microturbines) to $400 \mathrm{MW}$ and have lower installation costs ${ }^{585}$. Advanced turbines have emerged that can take turbine operating conditions up to $2600^{\circ} \mathrm{F}$, which increases turbine efficiency.

CCs are more efficient than CTs, but take longer to reach those efficiencies due to the time it takes to make steam from a cold start. CTs can ramp at $4.5 \%$ of capacity/min while CCs are $0.9 \%$ of capacity $/ \mathrm{min}^{\text {lxvii, } 586}$. CCs still maintain the ability of CTs to ramp up and down once temperature and pressure are built up, so they are preferred for intermediate and sometimes peaking load applications ${ }^{587}$. New CCs have the ability to start up more quickly and can ramp up

\footnotetext{
lxvii Note: This is an average of generating units in WECC and may be conservative, as the numbers are representative of the allowable ramping rates over an hour time period. Individual generators may be able to ramp more over a 5 minute period.
} 
or down with more agility. This can be an important asset in grids that have high proportions of variable generation.

\section{Scale Efficiencies}

New CTs have an efficiency of 20 to $35 \%$ of conversion of heat to electricity. Most of the efficiency loss comes from the initial compression needed for the Brayton cycle. Efficiencies increase to up to $60 \%$ for the best in class CC units ${ }^{588}$.

\section{Nuclear}

\section{Prime Mover Technology}

As of mid-2016, there were 64 pressurized water reactors (PWR) and 35 boiling water reactors (BWR) operating in the U.S. with 64 GWe and 34 GWe in combined capacity, respectively ${ }^{589}$. Most modern reactors were originally adapted from designs for naval use.

Nuclear reactors use two separate systems to produce electricity. In PWRs, water is heated by nuclear fission within the reactor, but not able to boil due to the pressurized system. This water is then run through a heat exchanger, which indirectly produces steam to drive a turbine under a traditional steam cycle. A BWR, on the other hand, contains only a single closed system and water in the reactor is heated to form steam, which drives a turbine before being condensed, pressurized, and reheated. These processes are shown in Figure A-7and Figure A-8.

PWRs are able to operate at a higher temperature and pressure leading to higher turbine efficiencies and are able to separate radiation contamination from the generating equipment. BWRs, on the other hand, are able to achieve higher thermal efficiencies with direct contact and output is easier to control by adjusting the amount of water entering the reactor.

The fuel rods produce heat primarily from the fission of U-235. A neutron absorbed by U-235 causing fission into two roughly equal fragments which produces 2 to 3 neutrons. This process releases a large amount of energy (about $200 \mathrm{MeV}$ ) that heats the fuel rod and surrounding water, as the neutron is small enough to escape the rod and pass through water surrounding the rods. For the reaction to be sustainable each fission process must lead to one neutron being captured and enough energy remaining to promote fission. 


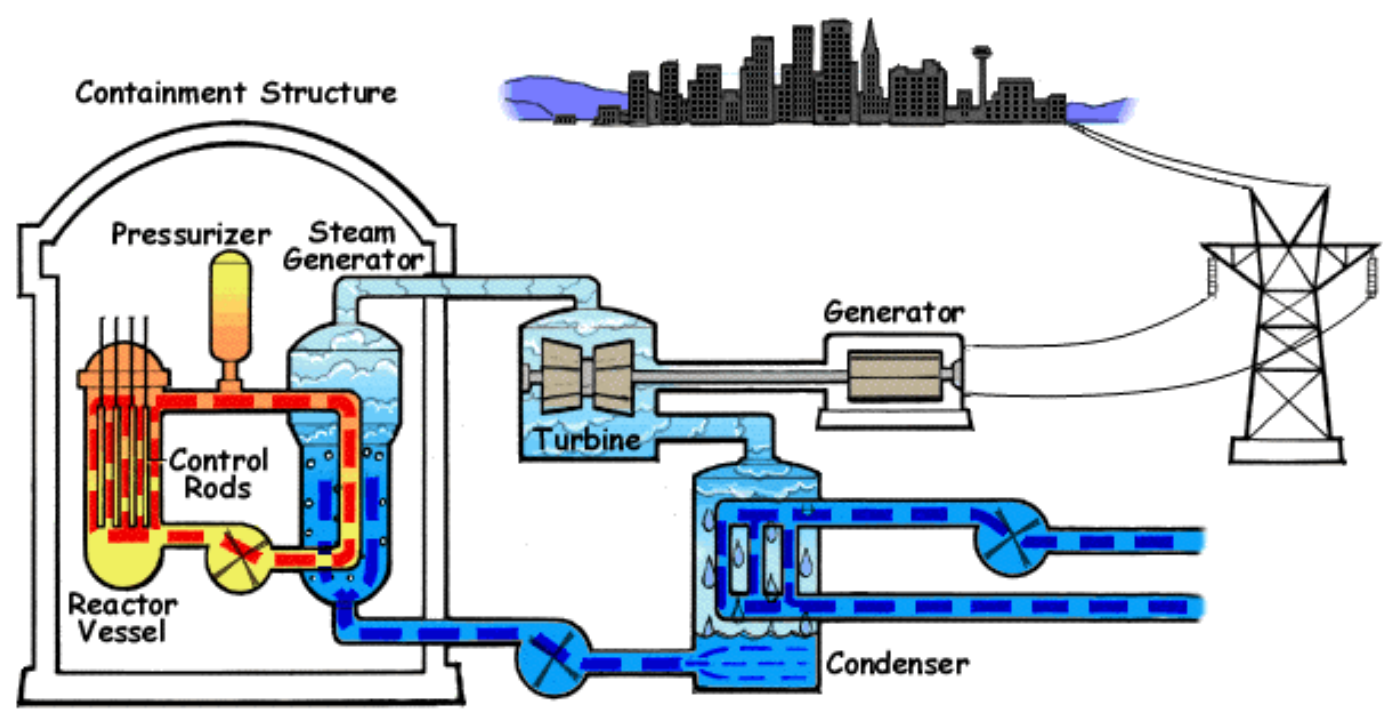

Figure A-7. PWR process diagram ${ }^{590}$

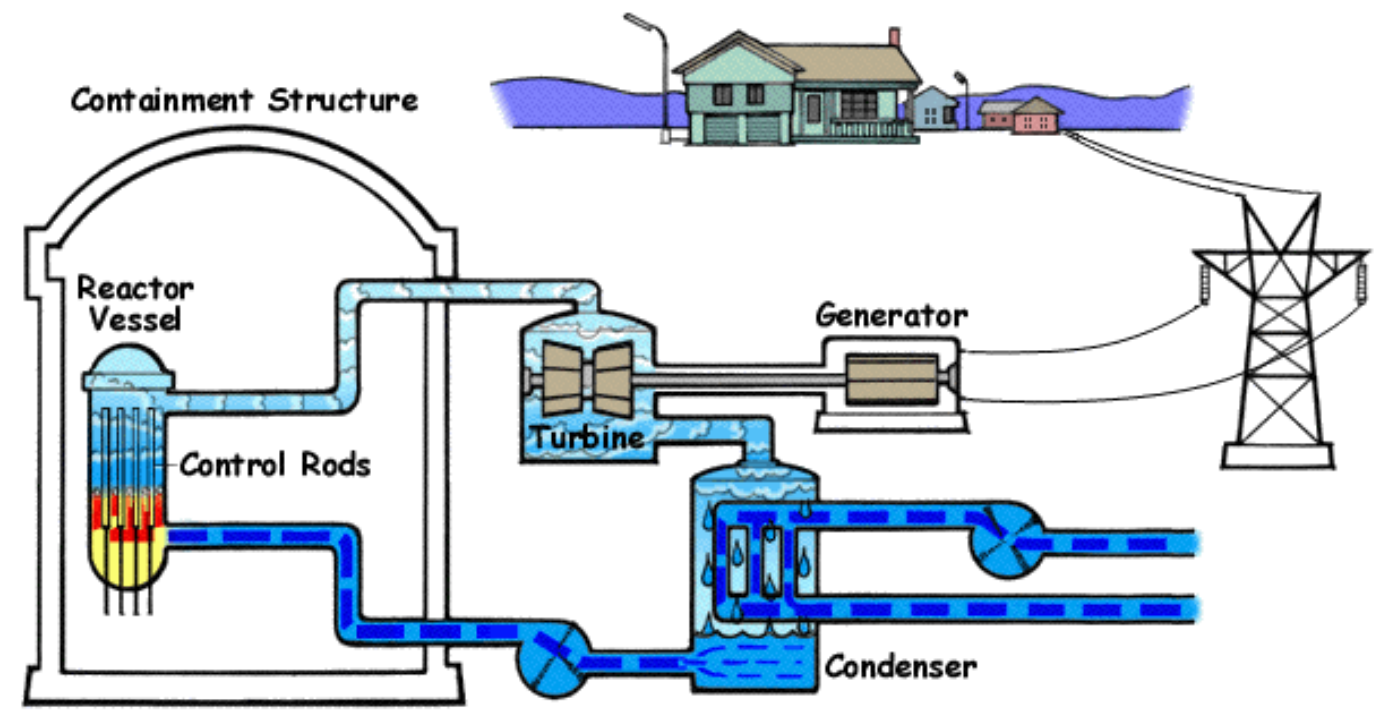

Figure A-8. BWR process diagram ${ }^{591}$

\section{Physical Attributes}

PWRs operate around $610^{\circ} \mathrm{F}$ and 2175 psi while BWRs operate around $545^{\circ} \mathrm{F}$ and $1090 \mathrm{psi}^{592}$. PWRs generally contain roughly 80-100 tons of uranium, while BWRs contain up 140 tons $^{593}$.

Nuclear power plants are considered base load generators and are not generally ramped up and down, as it is expensive to run nuclear plants at less than full capacity ${ }^{594}$. Power output is also affected by the re-fueling cycle of rods, which occurs every 18-24 months in PWRs ${ }^{595}$. Not all fuel is replaced at the same time in the reactor depending on plant operating procedures.

It often takes one to two days to reach max output of a nuclear plant from a cold start due to the time to build up steam pressure and temperature (the fission reaction can be started quickly), and 
shutting down the reactor can take the same amount of time. Because of this, nuclear plants prefer to operate at a high capacity factor and often are only shut down for routine or emergency maintenance.

\section{Scale Efficiencies}

Nuclear plants are large scale facilities with large capital investments that can take as much as a decade to build. The large investment requires the plants to be run continuously over long periods of time to be able to produce electricity at low cost. Nuclear reactor units are typically 1 GW or more in generating capacity to achieve efficiencies of scale, but there are some reactors in operation that are smaller. There are 61 nuclear sites in the U.S. and many contain multiple reactors and associated turbine and generator sets at each plant to share infrastructure.

\section{Water}

\section{Prime Mover Technology}

Hydroelectric plants capture the potential energy in water due to elevation differences above the turbine. The pressure due to weight of the water is used to drive a hydro turbine and generate electricity as shown in Figure A-9.

Conventional hydroelectric plants consist of large dams, normally located along rivers. By damming the river a large reservoir is created upstream from the dam. This large reservoir functions as storage allowing the plant operators to capture varying seasonal precipitation throughout the year and store the water until needed. A few hydroelectric dams are operated primarily as agricultural water reservoirs and generate electricity only when it coincides with water releases for irrigation of agricultural lands.

Rather than have a large damn, generators can rely on simple "run of the river" systems that may only be available during certain months of the year when water is flowing. Most of the large hydroelectric generators in the United States were built decades ago and most new hydro capacity today relies on re-powering existing plants with newer, larger, and more efficient turbines.

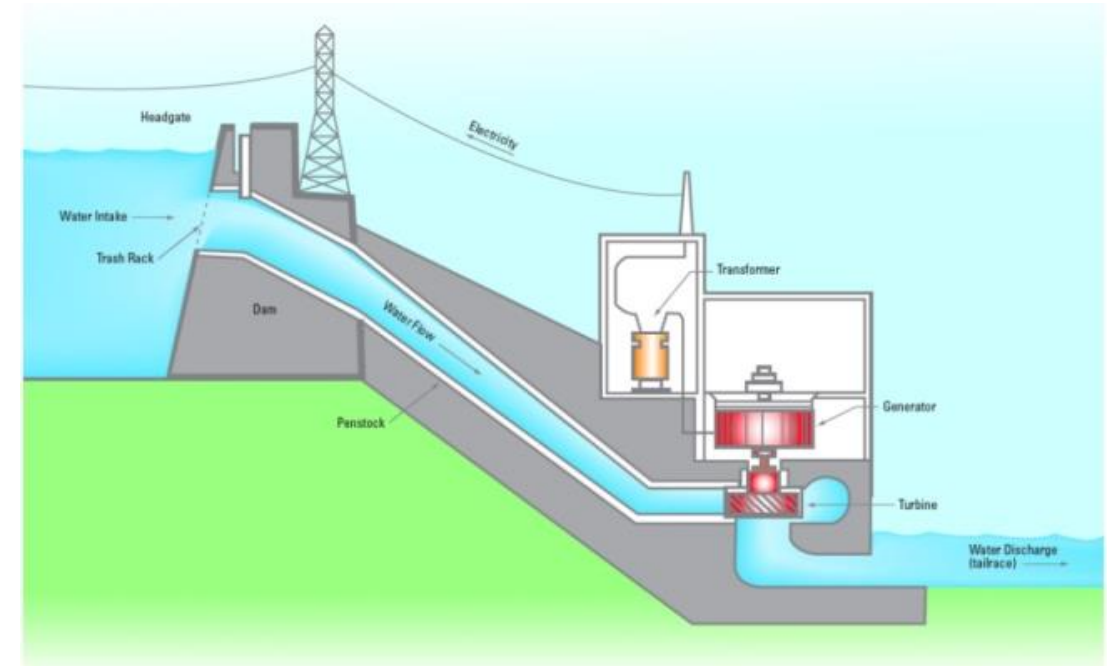

Figure A-9. Hydroelectric power generator diagram ${ }^{596}$ 
Currently, pumped storage hydro (PSH) is the most deployed electricity storage technology. PSH acts like a giant battery, using electricity to pump water uphill into a storage reservoir during times of low electricity demand (night) when wholesale prices are lower and releasing it through a turbine during times of higher demand (day), when electricity are higher, as illustrated in Figure A-10. PSH can be dispatched almost immediately after water is released from the reservoir allowing for services to meet peak demand. The amount of electricity that can be generated per day is limited by the size of the reservoir, though these can be very large. For example, Raccoon Mountain in Tennessee has $1.5 \mathrm{GW}$ capacity and can discharge at this capacity for $20 \mathrm{hrs}$ when the reservoir is full.

PSH can also provide substantial reserves for the electricity system, and because of its ability to ramp up and down, it can be used to balance the variable generation of solar and wind resources ${ }^{597}$. The distribution of PSH projects in the United States is illustrated in Figure A-11. Further information on PSH can be found in the storage section of this Appendix.

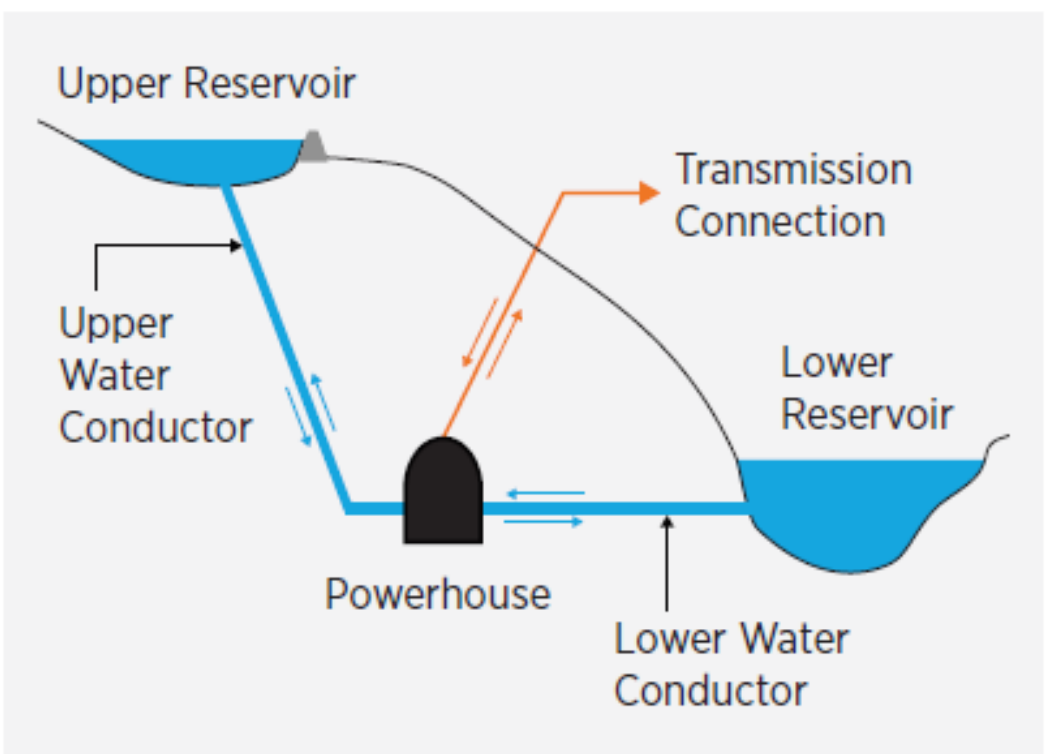

Figure A-10. Pumped storage hydro diagram ${ }^{598}$ 


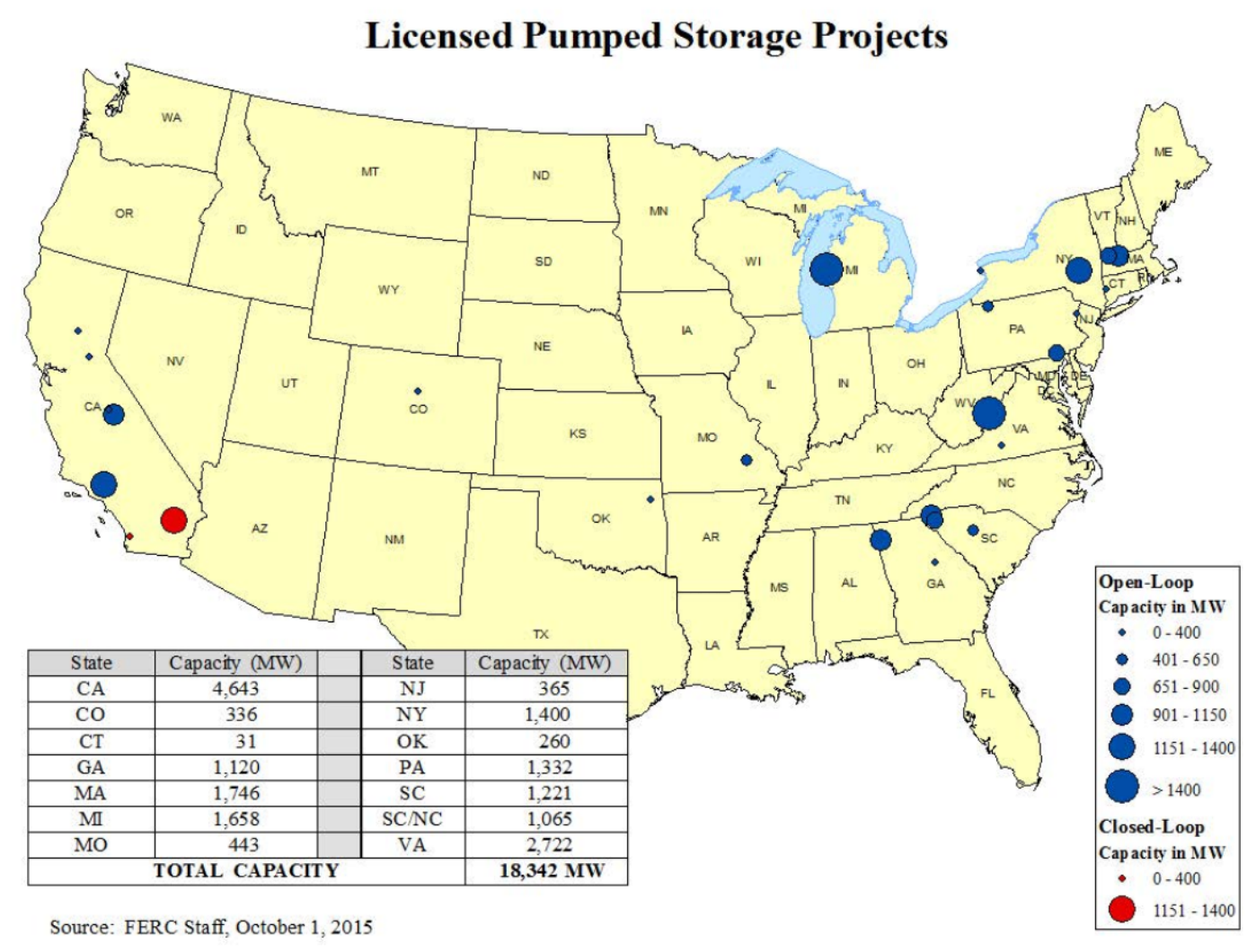

Figure A-11. Licensed PSH projects ${ }^{599}$

\section{Physical Attributes}

Hydroelectric generators have a large turbine, but these turbines use water pressure to drive the turbine which can be ramped up and down by limiting water flow.

\section{Wind}

\section{Prime Mover Technology}

Wind turbines utilize the kinetic energy contained in the wind to turn an electric generator. Wind power generators consist of components as shown in Figure A-12. The nacelle on top of the tower can rotate 360 degrees to position the blades in the optimal location to harness wind energy. 


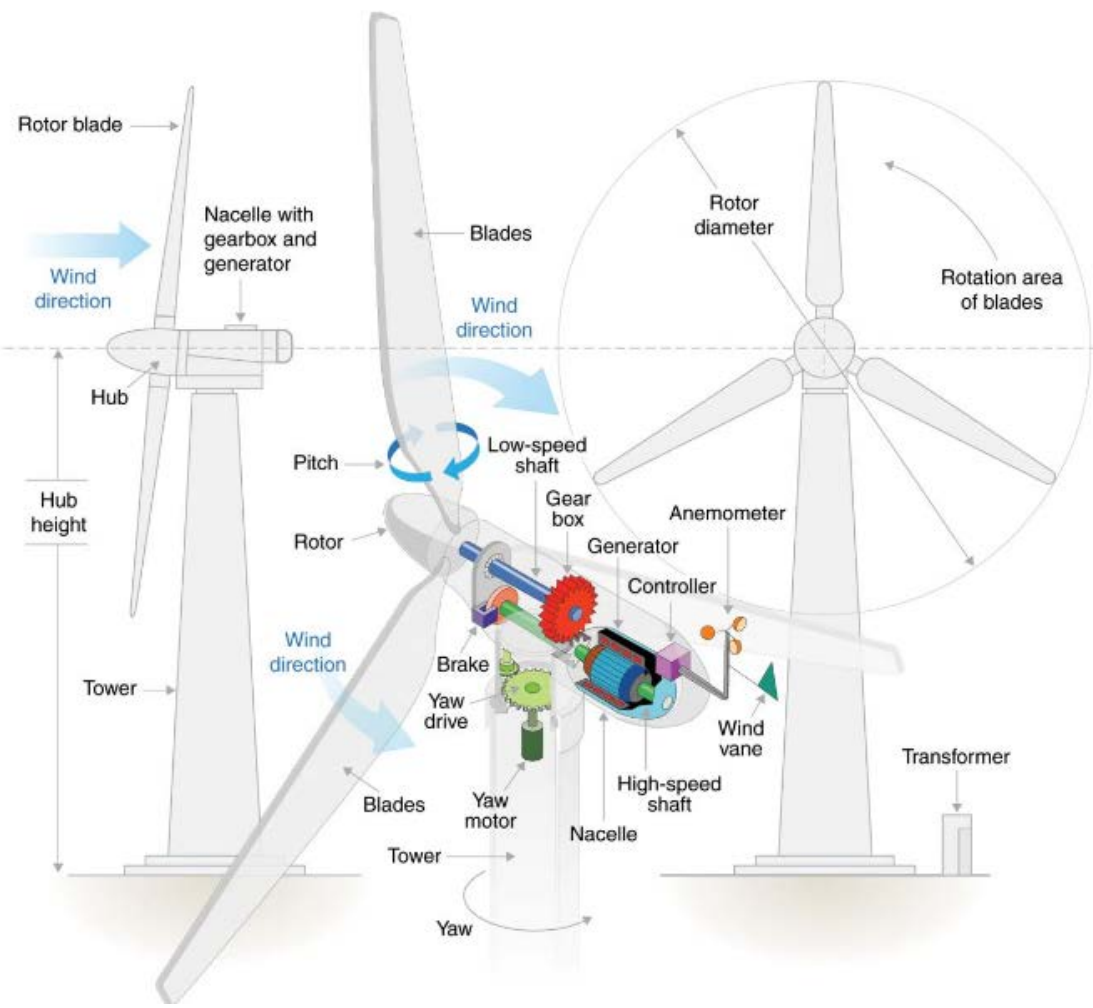

Figure A-12. Wind turbine diagram ${ }^{600}$

Given sufficient wind speed, the turbine blades will rotate up to a maximum speed, beyond which the blades are furled and the turbine stops rotating to avoid excessive wear and damage to the interior gear system and other components.

Figure A-13 shows the conceptual power curve for wind turbines. In wind Region $\mathrm{I}^{601}$ there is not enough power to spin the turbine until it reaches the cut-in speed of the turbine. Power production occurs in wind Regions II \& III up to the rated power of the turbine. When the wind speed reaches Region IV the turbine stops producing power and allows wind to pass through the blades to protect turbine integrity. 


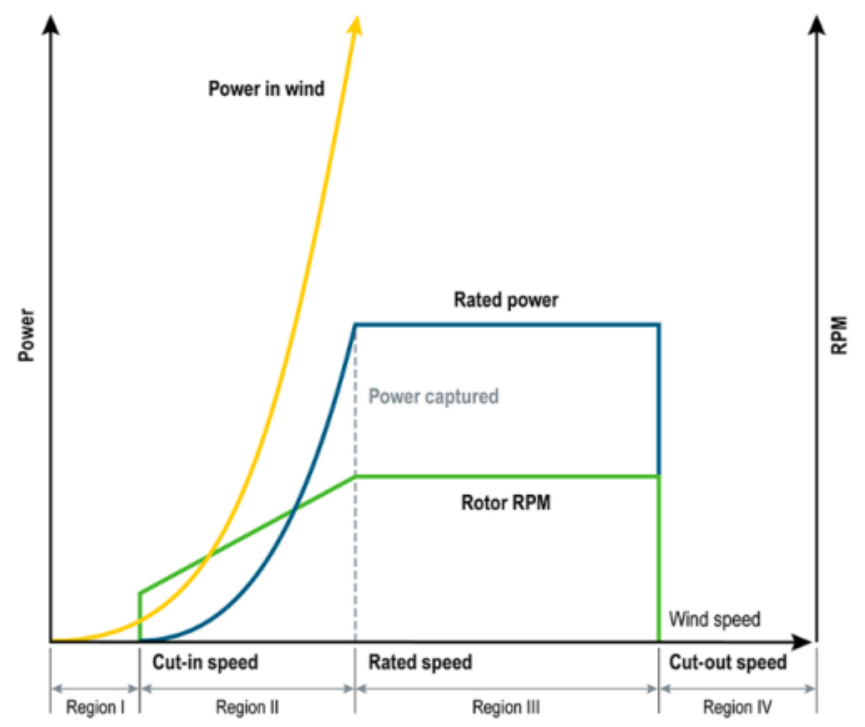

Figure A-13. Conceptual power curve for wind turbines ${ }^{602}$

\section{Physical Attributes}

The generating capacity of a single wind turbine can range anywhere from $2 \mathrm{~kW}$ to $8 \mathrm{MW}$, depending on application, hub height and blade length. Variable generator output of the rotating blades is converted by power control equipment at the base of each tower to match power output with the frequency of the electrical grid.

\section{Scale Efficiencies}

Over time, hub heights and blade lengths have grown to increase total generating capacity of each turbine. Higher hub heights allow for access to faster and more consistent wind speeds, which can increase the capacity factor and lower the LCOE for wind turbines. Changes to wind turbine characteristics over time are shown in Figure A-14.

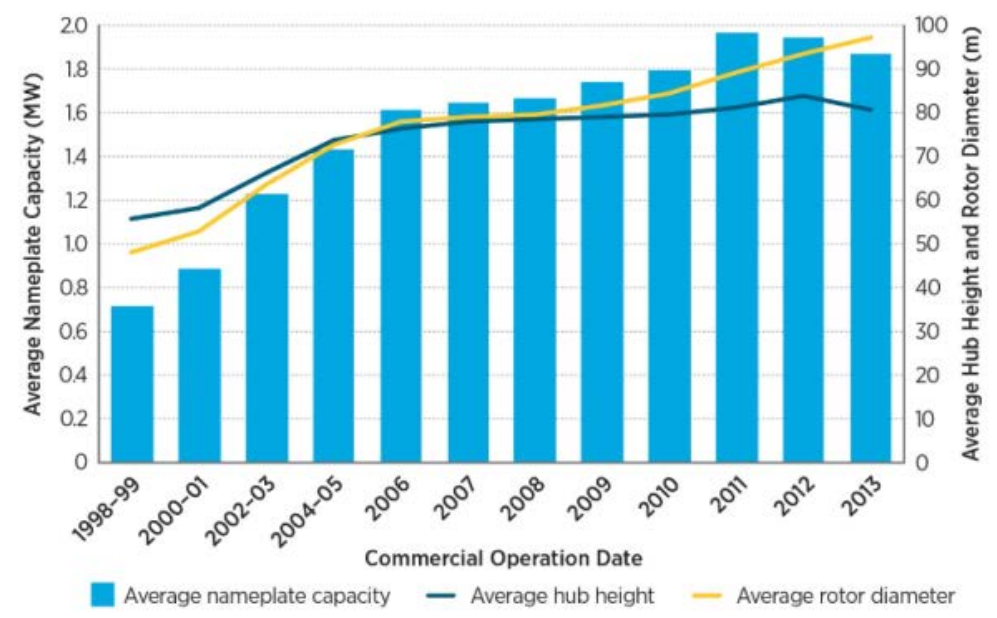

Figure A-14. Wind turbine capacity, hub height, and rotor diameter over time ${ }^{603}$ 


\section{Biopower}

\section{Prime Mover Technology}

There are three main processes for producing electricity from biopower ${ }^{604}$ :

1. Direct-fired: Biomass is burned directly in a boiler to produce steam. This steam in turn drives a steam turbine generator. Direct-fired power plants are the most common technology of biopower in the United States ${ }^{605}$. MSW plants are included in this category and the waste to energy process is shown in Figure A-15.

2. Co-fired: Biomass is burned along with coal in a coal plant that has been modified to cofire. Biomass has been shown to replace up to $15 \%$ of coal in boilers ${ }^{606}$. Further use of biomass in co-firing plants is available with boiler modifications.

3. Gasification: Biomass is heated and processed to produce a syngas and then burned in an internal combustion engine, combustion turbine (with or without combined heat recovery), microturbine, or fuel cell ${ }^{607}$. Methane created from landfills and WWTPs is utilized in the same manner. Further information on combustion turbines can be found in the natural gas section of this Appendix.

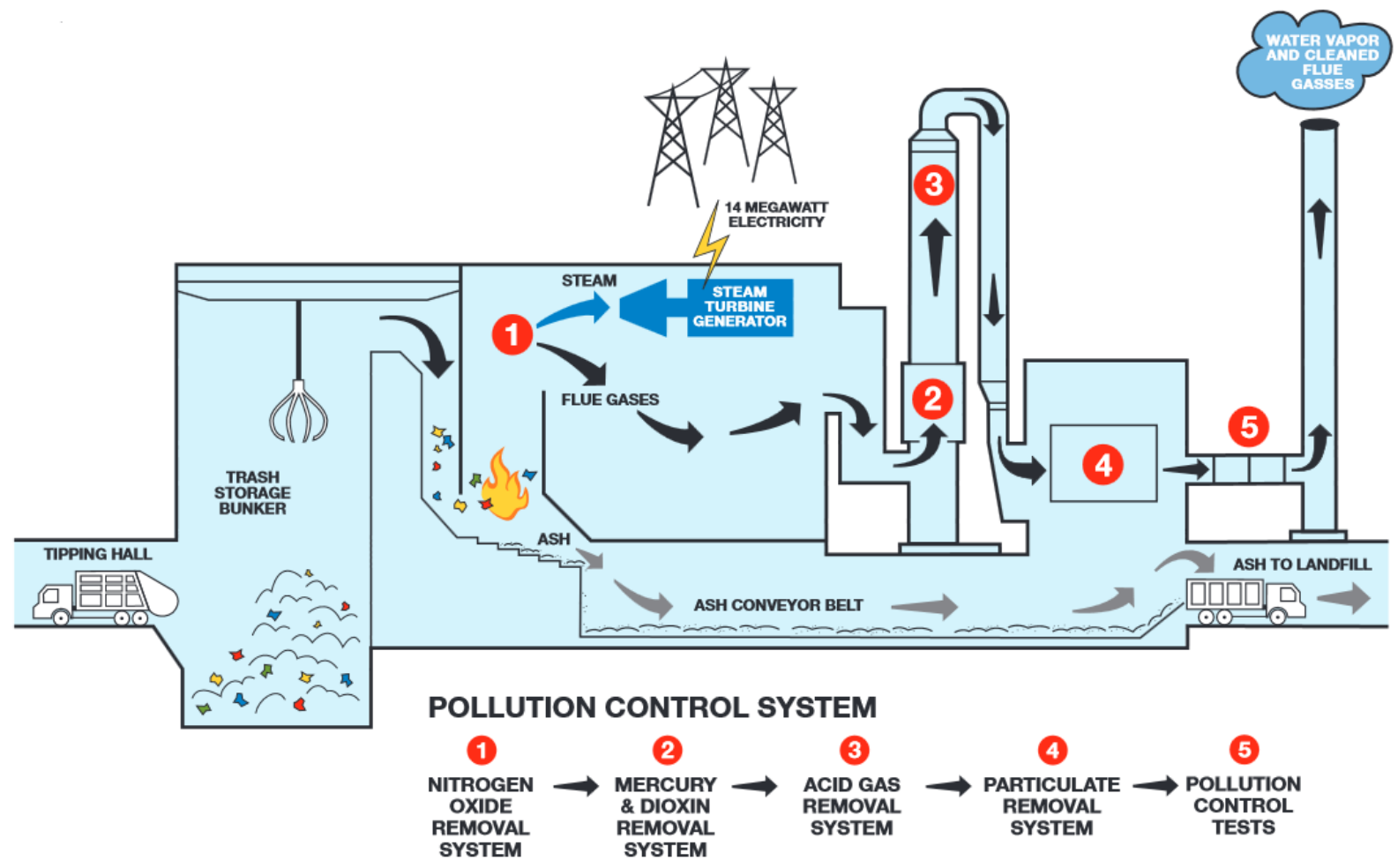

Figure A-15. Waste to energy process diagram with pollution controls ${ }^{608}$

This figure details MSW direct-fired generating technology, sometimes called the waste to energy process. A typical MSW plant generates about $550 \mathrm{kWh}$ per ton of waste ${ }^{609}$.

\section{Physical Attributes}

Physical attributes depend on the firing technology. Direct-fired systems operate similar to coal fired power plants, except that the lower energy content of biomass leads to a decrease in 
operating conditions (operating conditions for direct-fired biopower plants are $1250 \mathrm{psig}$ and $950^{\circ} \mathrm{F}$ compared to 2400 psig and $1000^{\circ} \mathrm{F}$ for subcritical pulverized coal plants $)^{610}$. Co-fired systems operate similar to coal plants as biomass is being substituted for coal which leads to a higher heat rate (roughly 1.5 to $10 \%)^{611}$. Gasification plants operate similar to combustion turbines or combined cycle plants, and can also be used in combined heat and power (CHP) applications.

\section{Scale Efficiencies}

Biopower can be used for both centralized and distributed generation. Centralized direct-fired and gasification plants are generally small in size due to limited availability of local fuel resources and range from $2-100 \mathrm{MW}$ in capacity ${ }^{612}$. Co-fired plants are the same size as coal plants, but do not add any capacity as the biomass is substituted for coal.

Biogas from landfills and WWTPs can be burned in microturbines and internal combustion engines to provide distributed and on-site generation.

\section{Solar}

\section{Prime Mover Technology}

PV modules use semiconductors with the right bandgap characteristics to convert sunlight directly to electricity. A photon strikes the solar cell and the energy of this photon excites an electron within the cell, causing the electron to jump from an energy level occupied by many electrons to one that is unoccupied, as shown in Figure A-16. The result is a "hole" in the occupied level, which has a positive charge. The materials in the solar panel are designed to isolate the excited electron from the hole, which creates and electron-hole pair. Just as positive and negative charges on magnets attract, the hole and electron are drawn to reconnect, but they must travel through separate layers of the cell and, eventually, an external circuit to recombine. The travelling of the electron through the circuit is electricity.

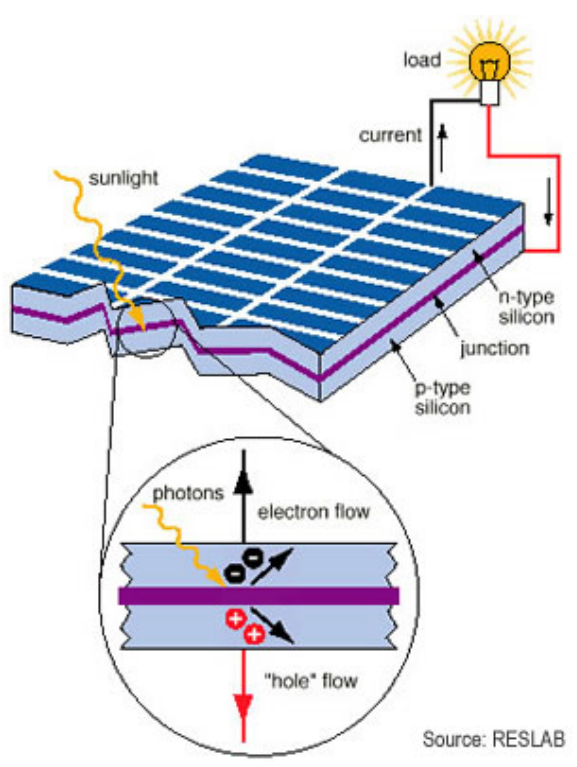

Figure A-16. Diagram of solar module electricity generation ${ }^{613}$ 
There are numerous materials and configurations that are employed for PV modules. In 2014, crystalline silicon (c-Si) modules represented 94\% of all global PV module shipments ${ }^{614}$.

Modules are made of 32-64 C-Si cells connected in parallel and series. C-Si solar cells are made by first heating silicon dioxide $\left(\mathrm{SiO}_{2}\right)$ to remove oxygen, resulting in near pure $\mathrm{Si}$. These $\mathrm{Si}$ crystals are then used to grow a cylindrical ingot. This ingot is then cut using a saw to create $\mathrm{Si}$ wafers $(.5 \mathrm{~mm}$ thick) and the abrasions from sawing are polished off. The cells are then doped using boron and phosphorous (creating the p-n junction within the material). Then the cells are arranged in a module and connected with electrical contacts, coated with an anti-reflective material, and encapsulated $^{615}$. The theoretical efficiency of c-Si cells is $34 \%$ and the manufacturing process is energy-intensive. C-Si modules are common due to low cost and availability of $\mathrm{Si}$ (sand).

Thin film solar modules are created through vapor deposition of semiconductors onto a backing sheet (often glass). The semiconductors are generally nanometers thick, reducing overall material needs $^{616}$. Common materials for thin films are CdTe (cadmium telluride) and CIGS (copperindium-gallium-sulfide). Thin film modules are cheaper than C-Si modules, but were less efficient, until very recently. Thin films can be deposited onto flexible materials making them usable for various applications (building integrated solar, solar fabrics, etc.).

Multi-junction solar cells are made of different semiconducting materials that are stacked together to take advantage of bandgap characteristics and allows for greater wavelength absorption. There are created through vapor epitaxy, a process which vaporizes a material and deposits it in one atomically-thin layer at a time ${ }^{617}$. Currently, cost is a barrier to use, but multijunction cells hold promise as their theoretical efficiency is around $85 \%$. Global production of the different PV technologies over time is shown in Figure A-17.

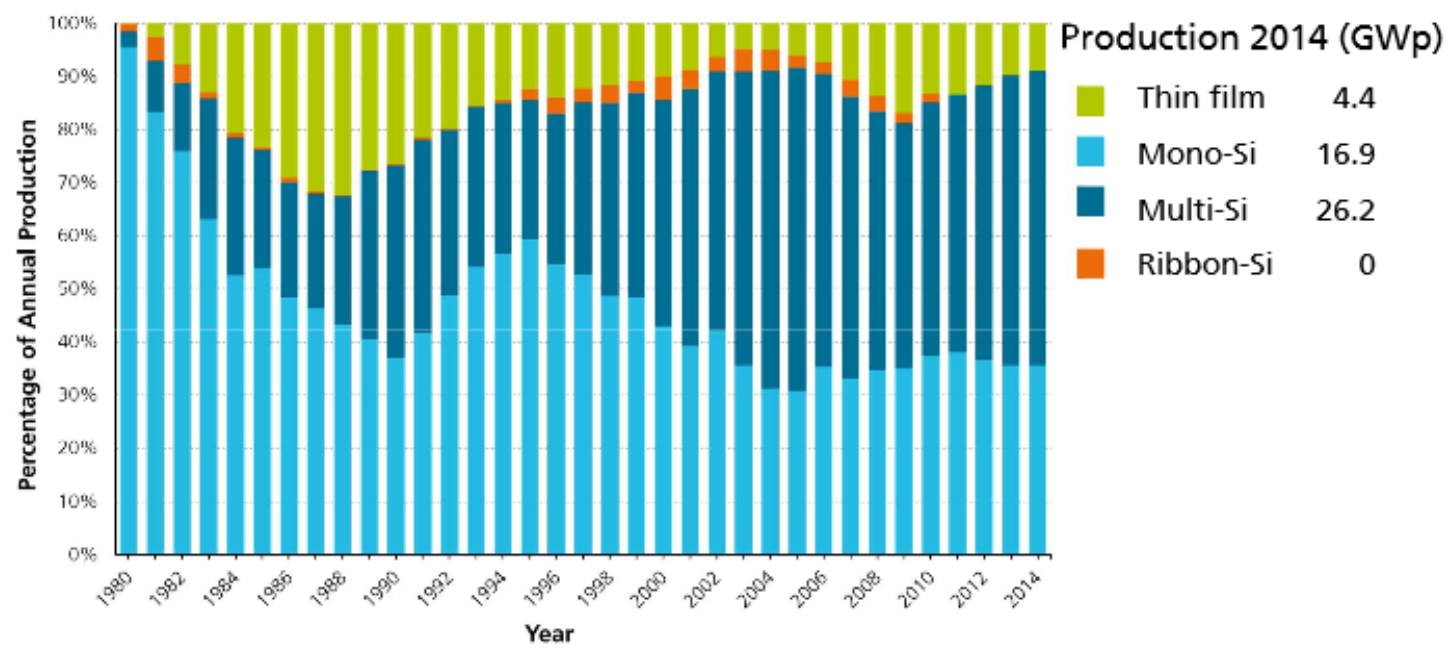

Figure A-17. Total global PV production by technology ${ }^{618}$

Perovskites have the potential to replace Si for solar PV cell materials. Perovskites are generally made of lead or tin-halides and are cheap to produce ${ }^{619}$. One of the advantages of perovskite as compared with crystalline silicon is that it enables the use of much lower temperatures in PV cell manufacturing. For comparison, silicon cells are heated to $900^{\circ} \mathrm{C}$ to remove defects, whereas perovskite can be processed at temperatures of around $100^{\circ} \mathrm{C}$. Lab-based perovskite cell 
efficiency has increased from $4 \%$ to $20 \%$ in just a few years ${ }^{620}$. The material also can support multi-junction cells, which could deliver much higher efficiency than single junction silicon.

CSP is similar to coal and nuclear technologies in that it uses a steam cycle generator. However, in this case the heat source is solar radiation rather than combustion of fossil fuels or heat from fuel rods. To capture and transfer this heat from the solar radiation CSP often uses a liquid medium (such as mineral oil or molten salts). This thermal energy is focused on a central point to create steam via a heat exchanger to drive a steam turbine generator. There are two main designs currently used for CSP:

1. Solar troughs (Figure A-18) feature large troughs of mirrored surfaces that concentrate the heat from the sun into a tube running along the trough. Efficiency ranges from 14$20 \%{ }^{621}$.

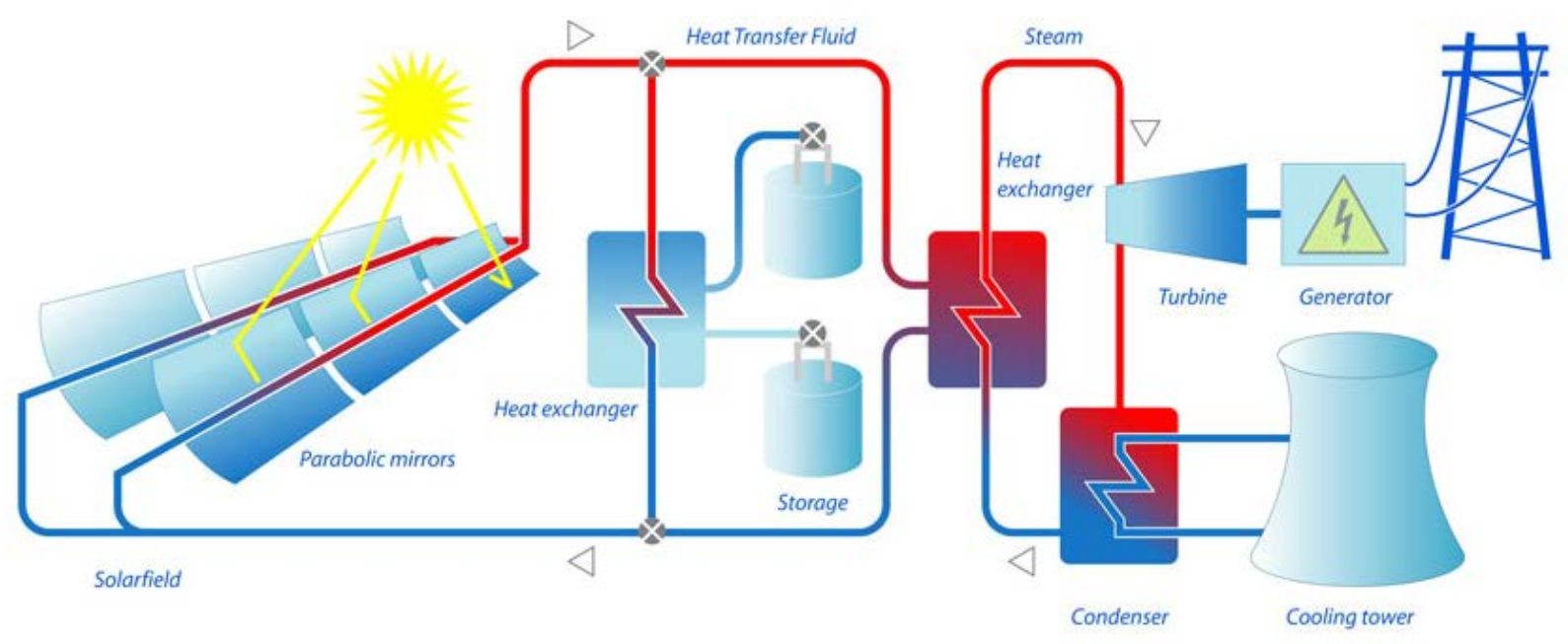

Figure A-18. Solar trough plant diagram ${ }^{622}$

2. Power towers (Figure A-19) feature a large central tower surrounded by a large array of mirrors called heliostats that reflect solar radiation into a receiver and track the sun throughout the day to optimize thermal capture, as shown in Figure A-19. The working fluid can be either a mineral oil derivative or molten salt (often used for thermal storage applications). The working fluid is then heated to roughly $750^{\circ} \mathrm{F}$ and used to create steam in a heat exchanger. Efficiencies range from $23-35 \%{ }^{623}$. 


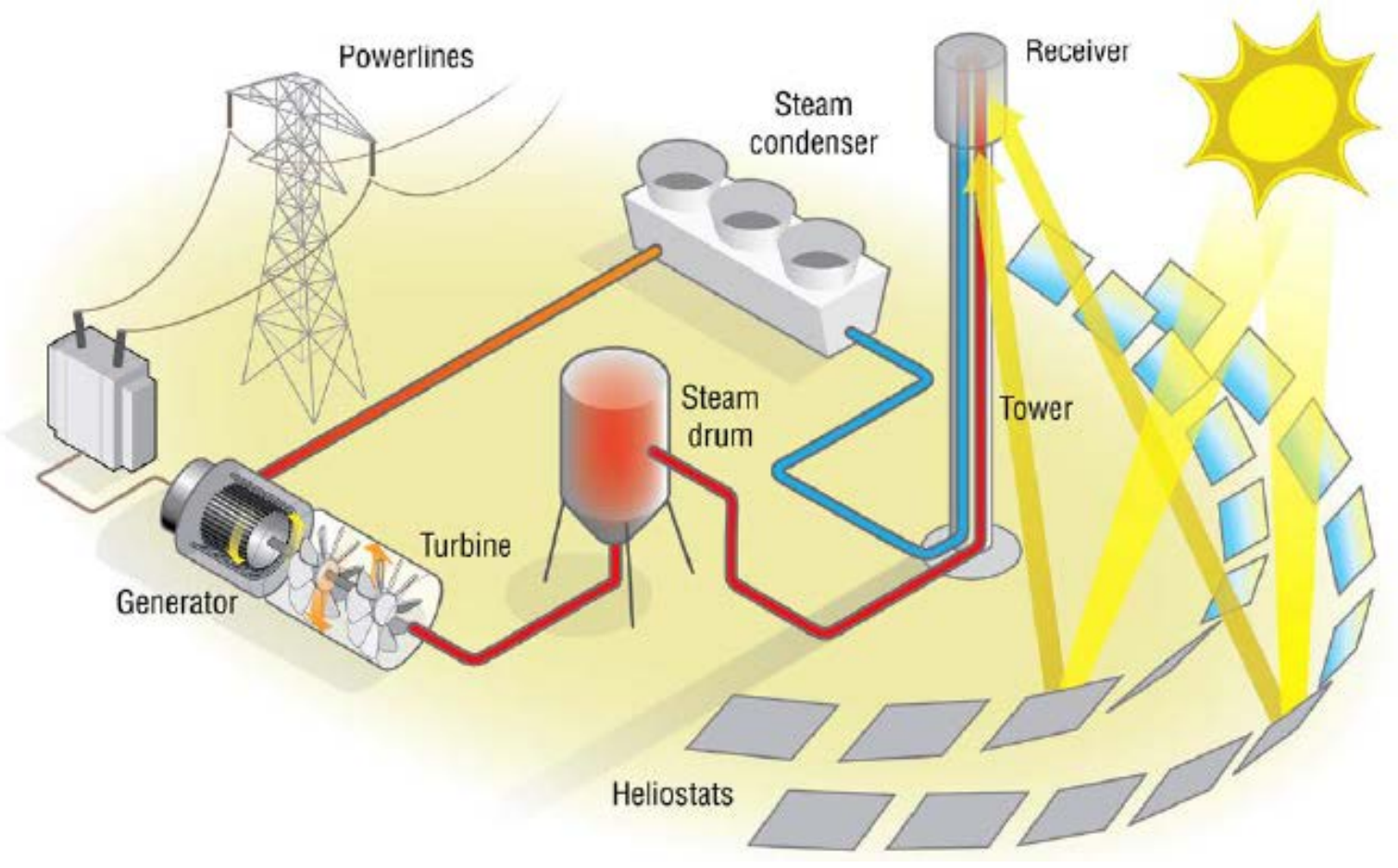

Figure A-19. Solar power tower plant diagram ${ }^{624}$

\section{Physical Attributes}

PV systems feature modules and inverters that have no moving parts; however, some panels are mounted on one or two axis rotating platforms that move throughout the day to track the sun and maximize power production (generally for utility scale PV projects). Tracking increases the power output of modules, but also requires increased capital and O\&M costs. PV modules generate electricity the instant solar radiation is absorbed by the panel (high angles of incidence cause photons to reflect off the surface). Generation from PV is therefore limited to daylight hours, with the peak amount generated at solar noon. Solar cells can also be combined with concentrating technologies, which can improve the efficiency, but increase cost.

CSP is similar to other thermal generators in that it takes time to build up heat and steam for the plant to operate at full efficiency. Both trough and towers require direct sunlight so there is some delay between sun-rise and when power production starts. CSP is currently one of the only renewable generating technologies that allows for energy storage. In thermal storage applications, molten salt is used as the working fluid which has a high heat capacity and allows CSP plants to produce electricity for hours after the sun sets.

\section{Scale Efficiencies}

PV plants can range in size from a few $\mathrm{kW}$ (distributed) to hundreds of MW (utility-scale). Utility-scale projects tend to be large in size as per unit soft costs (non-hardware costs) do not increase as rapidly as capacity costs, leading to larger projects with lower LCOE. 
CSP plants are generally large in size in order to create enough steam to power a turbine. Plant capacities are generally 10-300 MW in size.

\section{Geothermal}

\section{Prime Mover Technology}

There are three main types of geothermal generating systems ${ }^{625}$ :

1. Dry steam plants, as shown in Figure A-20, use steam at high temperature and pressure piped directly from a geothermal reservoir to drive generator turbines. This steam is then condensed and re-injected back into the reservoir. The first dry steam power plants in the U.S. were built in the 1960s at Geysers in California. The Geysers plant is currently the only dry steam plant in operation in the U.S. and one of the largest geothermal plants in the world. Dry steam plants require a reservoir with temperatures of greater than $500^{\circ} \mathrm{F}$.

2. Flash steam plants (Figure A-21) take high-pressure hot water from deep inside the earth and convert it by 'flashing' part of the water to steam using a pressure drop. Again, the steam is then used to drive generator turbines. When the steam cools, it condenses to water and is then injected back into the ground to be used again. Most existing geothermal power plants in the U.S. are flash steam plants. Flash steam plants are well suited for reservoirs with temperatures greater than $360^{\circ} \mathrm{F}$

3. Binary cycle power plants (Figure A-22) operate at lower temperatures and transfer heat from geothermal hot water to another liquid that has a lower boiling point than water (for a given pressure). The heat causes the second liquid to turn to vapor, which is then used to drive a generator turbine. Binary cycle plants are best suited for reservoirs with lower temperatures in the range of $225-360^{\circ} \mathrm{F}$.

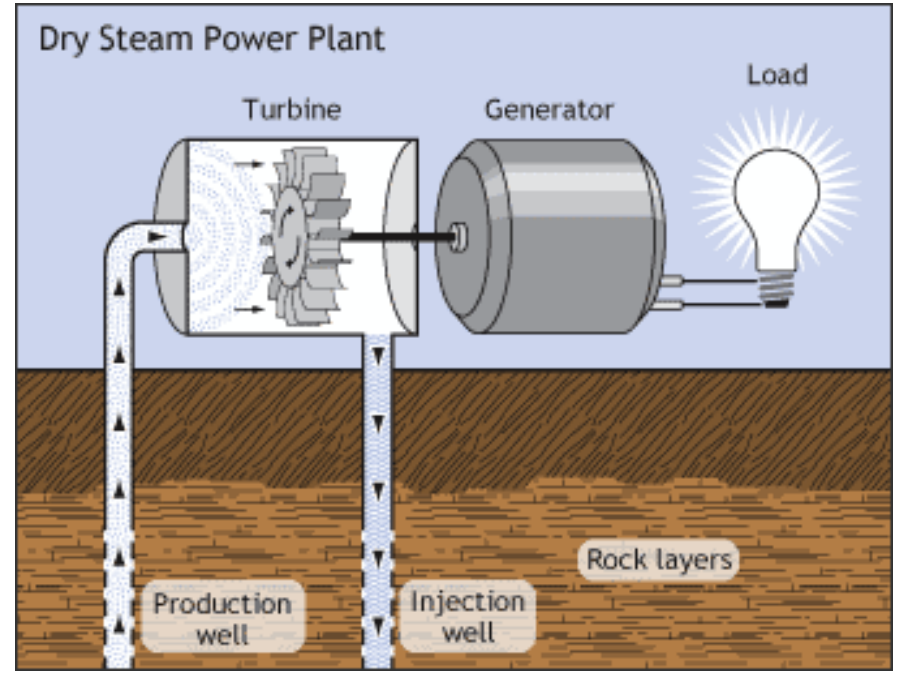

Figure A-20. Dry steam geothermal power plant diagram ${ }^{626}$ 


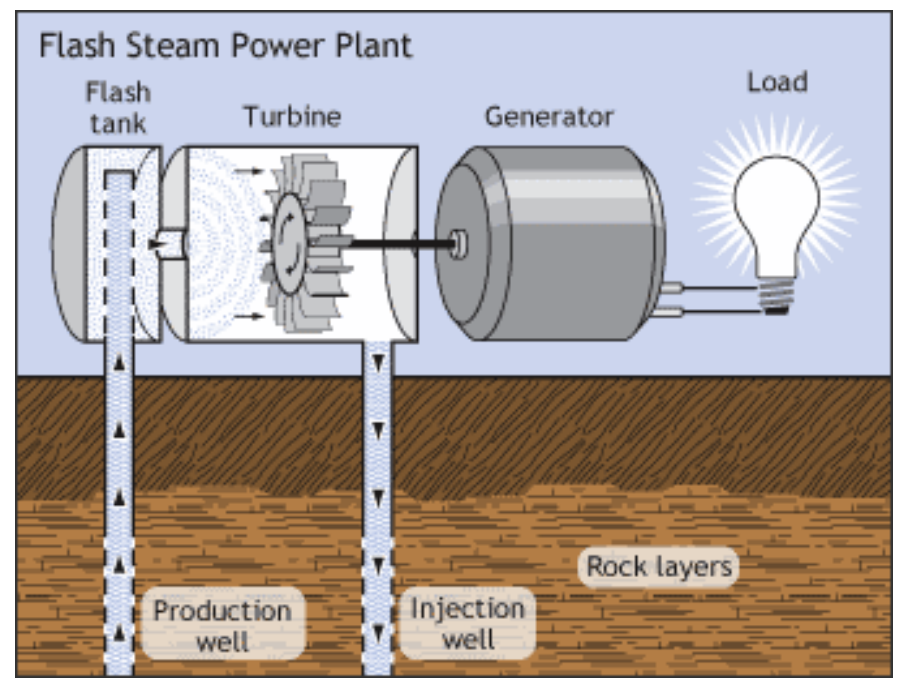

Figure A-21. Flash steam geothermal power plant diagram ${ }^{627}$

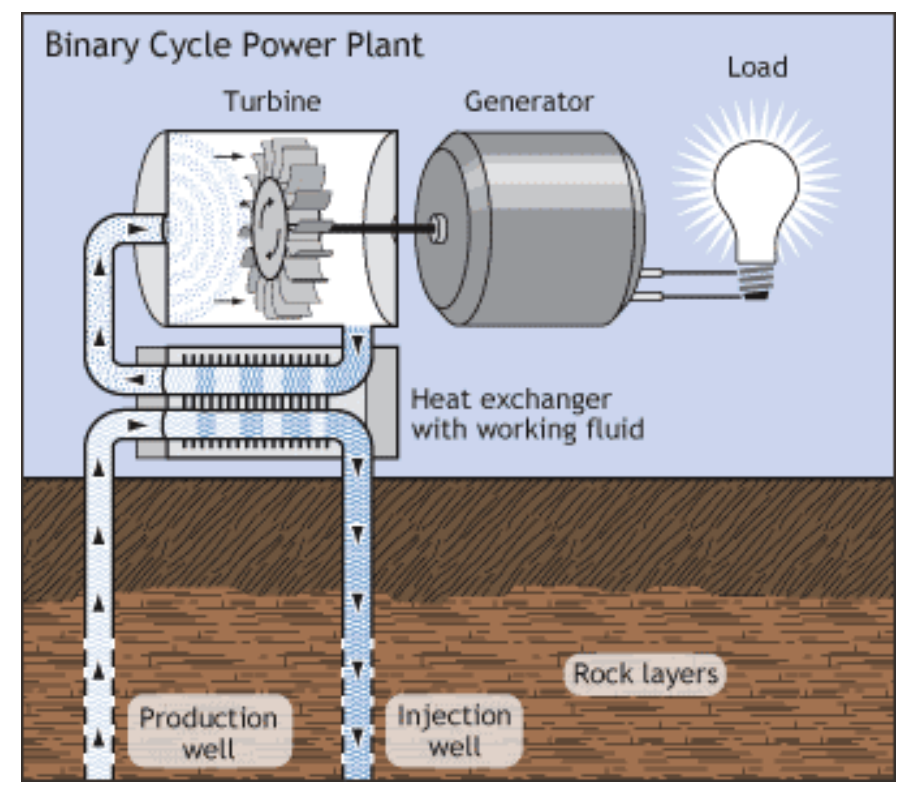

Figure A-22. Geothermal binary power plant ${ }^{628}$

Additionally, there are four main resource types of geothermal energy ${ }^{629}$ :

1. Hydrothermal - Conventional and commercially available technology responsible for most of the geothermal generating capacity in the U.S. The resource is often site-specific. The majority of current production from this resource is in California and Nevada. Hydrothermal generating technologies include dry steam, flash steam, and binary power plants.

2. Enhanced Geothermal Systems (EGS) - only in the research and development and demonstration stage, but offer the potential for greatly expanding geothermal resources in the U.S. by creating a suitable geothermal resource in currently uneconomic reservoirs. EGS resources are hot dry rock reservoirs that do not have enough water or permeability 
to support power production. These resources can be 6 miles deep in order to achieve sufficient temperature. When sufficient water is not available in the reservoir, water from the surface can be pumped down through the rock to extract heat. If the reservoir does not have sufficient permeability, water and chemicals can be injected at high pressure to enable fluid to flow ${ }^{630}$.

3. Co-Production with O\&G wells - This technology uses thermal energy from O\&G production. Due to the distributed nature of wells and the resource, these systems are often small in nature $(<1 \mathrm{MW})$.

4. Geopressured - This resource comes from high pressure reservoirs that contain high temperature in situ brines and methane. This resource is thought to be greatest in the Gulf Coast region.

\section{Physical Attributes}

Geothermal generators are comprised of a rotary steam turbine, which drives a generator. The wells are cased with large pipes that channel the steam and hot water from the wellhead to the power plant. Geothermal energy can be easily ramped up and down through control systems ${ }^{631}$.

\section{Scale Efficiencies}

Geothermal plants range in size depending on the size of the geothermal reservoir that is available. Large scale geothermal plants in the U.S. range from as small as $2 \mathrm{MW}$ up to $100 \mathrm{MW}$, but can be smaller size and distributed for certain applications ${ }^{632}$. Geothermal plants are often comprised of one or more generating units.

\section{Storage}

Energy storage is a complex and dynamic alternative to the generation options discussed in this Appendix. While not an electricity generating technology, storage resources can allow for greater flexibility and dispatchability of the U.S. electricity system. The battery storage sector is growing at a rapid rate, although starting from low levels. There are potentially transformative changes that could occur in the electric power sector if storage costs continue to decline as projected.

\section{Prime Mover Technology}

The main storage technologies are ${ }^{633}$ :

1. Pumped Storage Hydro (PSH) - Utilizes two reservoirs at different elevations connected via turbines. In practice the lower reservoir may be associated with a river, while the upper reservoir may be artificially created (e.g. excavation at the top of a mountain, as practiced at the Raccoon Mountain project). At night when demand is low and electricity rates are lower, the turbine is used to pump water to the upper reservoir. During the day when electricity demand is higher causing electricity rates to rise, the water is run through a turbine to produce electricity. Considered the most mature storage technology. Efficiencies range between $70-85 \%{ }^{634}$. Further information on PSH can be found in the water section of this Appendix.

2. Compressed Air Energy Storage (CAES) - Off-peak electricity is used to compress air, which is stored in underground caverns or tanks. This air is then released into a 
combustor of a natural gas turbine during peak demand periods. This reduces the need for air compression before injection into the combustor, saving energy as compression is the largest parasitic load for CT units. Efficiencies range between $40-75 \%{ }^{635}$.

3. Lead Acid Batteries - Lead acid batteries are currently the most commonly used electrochemical battery technology. They are made of a lead and lead oxide electrode in an acid electrolyte. Efficiencies range between $70-90 \%{ }^{636}$.

4. Lithium-ion Batteries - Lithium ion batteries are rapidly replacing lead acid batteries for energy storage applications and are considered flexible for a wide range of applications ${ }^{637}$. Efficiencies range between $85-98 \%{ }^{638}$.

5. Flywheels - A flywheel is a heavy mass that stores electricity as rotational energy and is primarily used for short bursts of energy (quick discharge) ${ }^{639}$.

6. High Temperature NaS Batteries - NaS batteries are made up of molten sulfur at the cathode and sodium at the anode, which are separated by an electrolyte. Operating temperatures are between $570-660^{\circ} \mathrm{F}^{640}$. Benefits of NaS batteries are high round trip efficiencies.

7. Flow Batteries - Similar to conventional batteries, but contain two independent electrolyte solution systems separated by a membrane. Efficiencies range between $65-$ $80 \%{ }^{641}$. A vanadium flow battery is illustrated in Figure A-23.

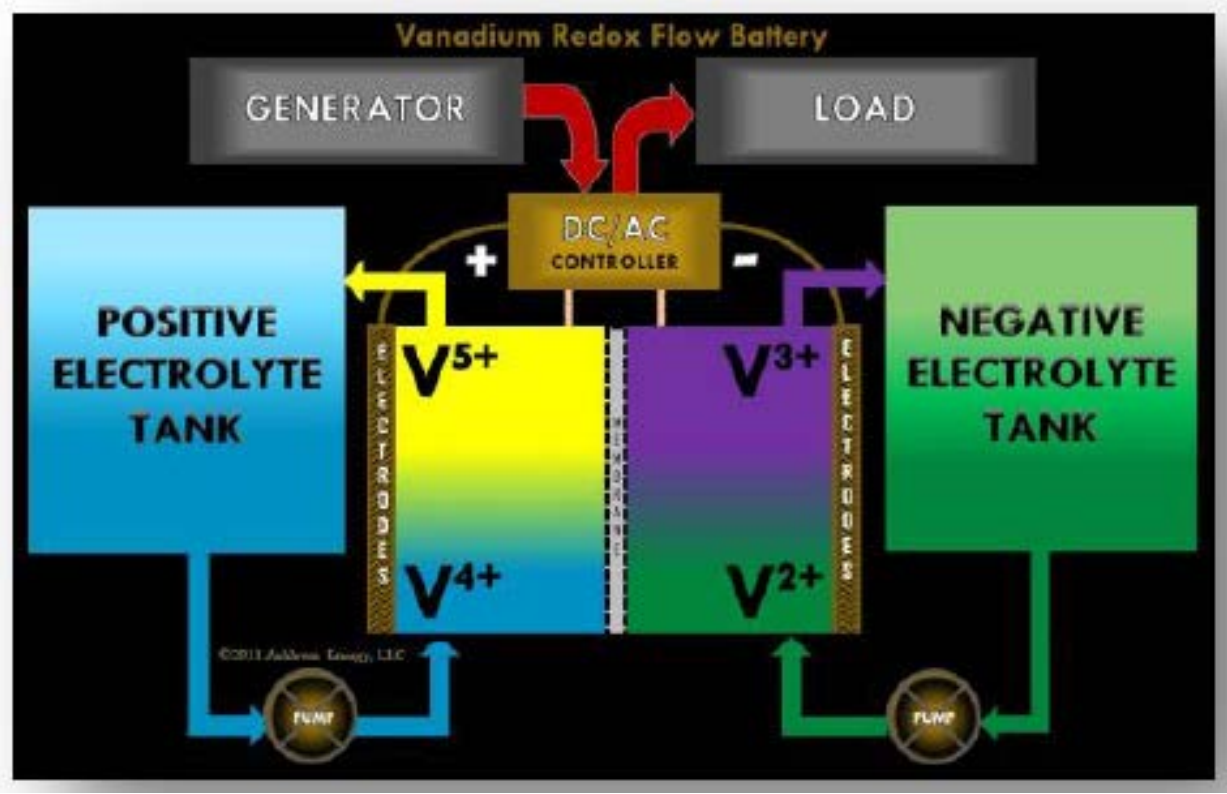

Figure A-23. Vanadium redox flow battery diagram ${ }^{642}$

Other examples of storage technologies are thermal, hydrogen, and electrical. Thermal storage can store thermal energy for use in steam turbines either in molten salt or as chilled load in chiller technologies. Hydrogen can be separated from water through hydrolysis with excess electricity for use in fuel cells or injected directly into the natural gas pipeline system. Super or ultra-capacitors can store energy in electrical field between two plates while superconducting magnetic energy storage can store energy in a magnetic field ${ }^{643}$. 
Distributed storage resources can provide off-grid services for solar customers, bill reductions in time-of-use (TOU) pricing markets, and potential ancillary services to the grid (electric vehicles and behind the meter storage systems).

PSH makes up roughly $98 \%$ of deployed storage in the U.S. as shown in Figure A-24, but costs for batteries are declining and some market analysts expect continued strong growth in nonhydro storage development ${ }^{644}$. As of November 2015 , approximately $3.5 \mathrm{GW}$ of battery, flywheel and CAES projects were under development.

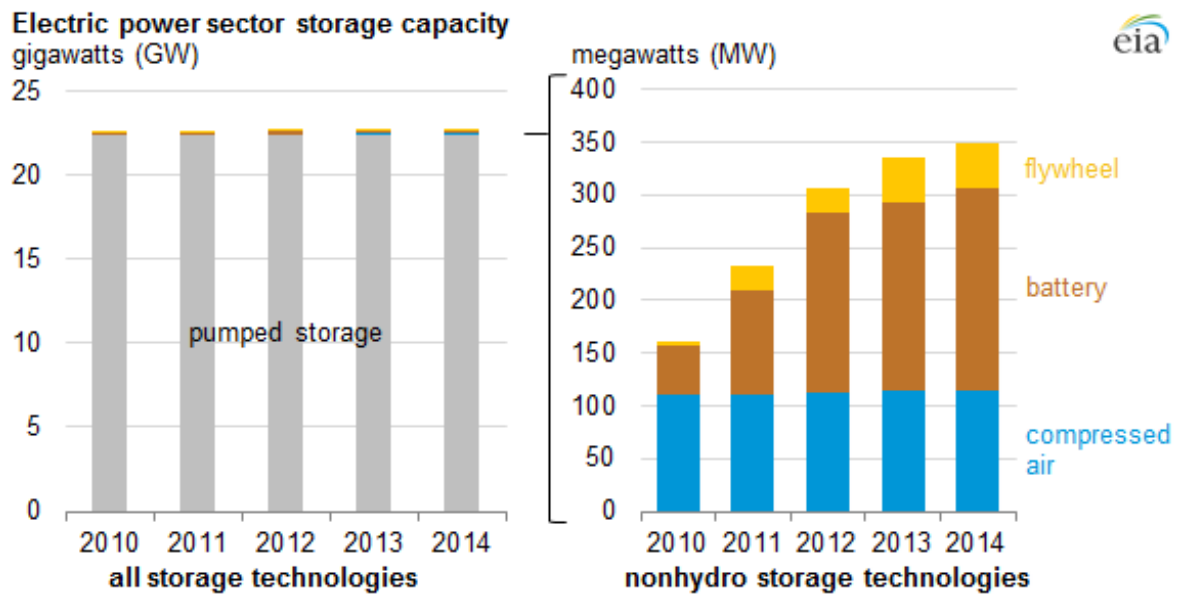

Figure A-24. Electric power sector storage capacity ${ }^{645}$

California hosts more energy storage projects than any other state by a wide margin, followed by Texas, Pennsylvania and Hawaii. The distribution of energy storage projects is shown in Figure A-25.

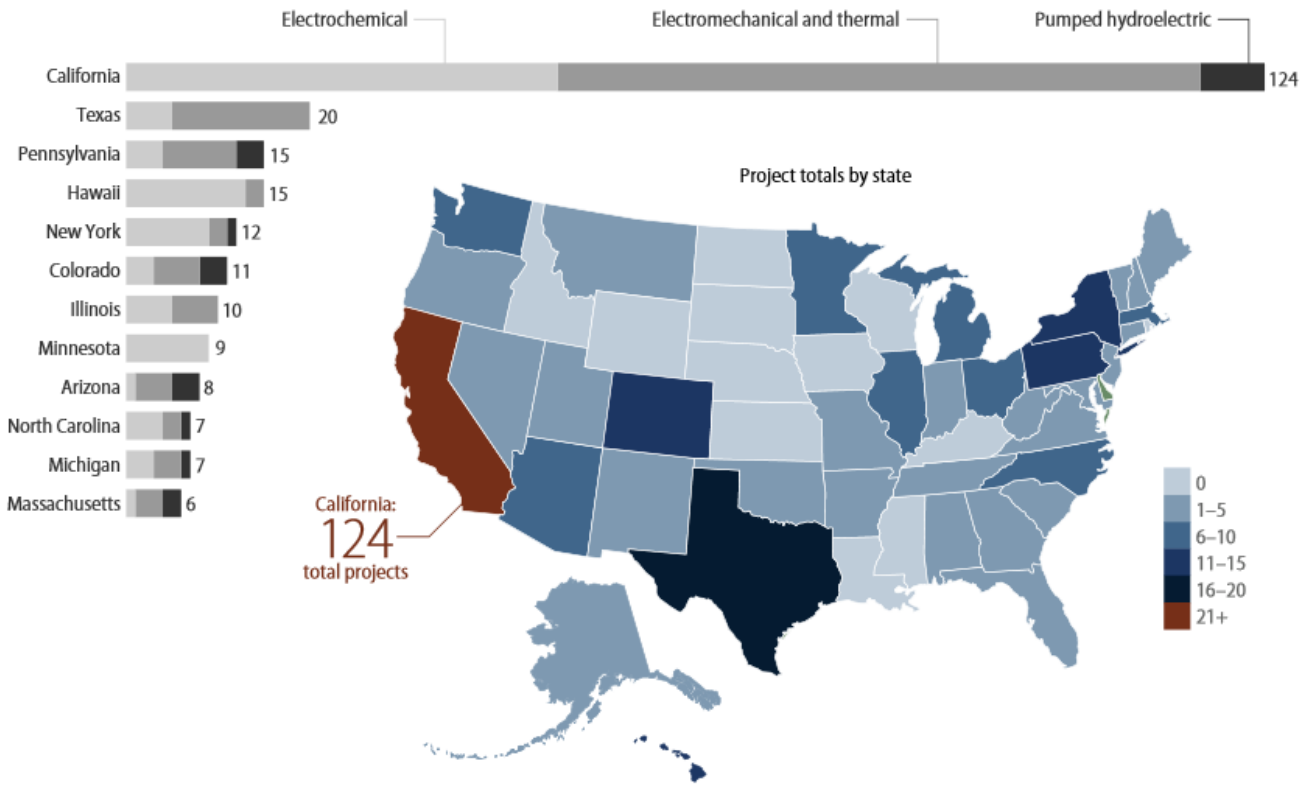

Figure A-25. Energy storage projects in the United States $2015^{646}$ 


\section{Physical Attributes}

Battery technologies have a variety of applications depending on the technology as shown in Figure A-26.

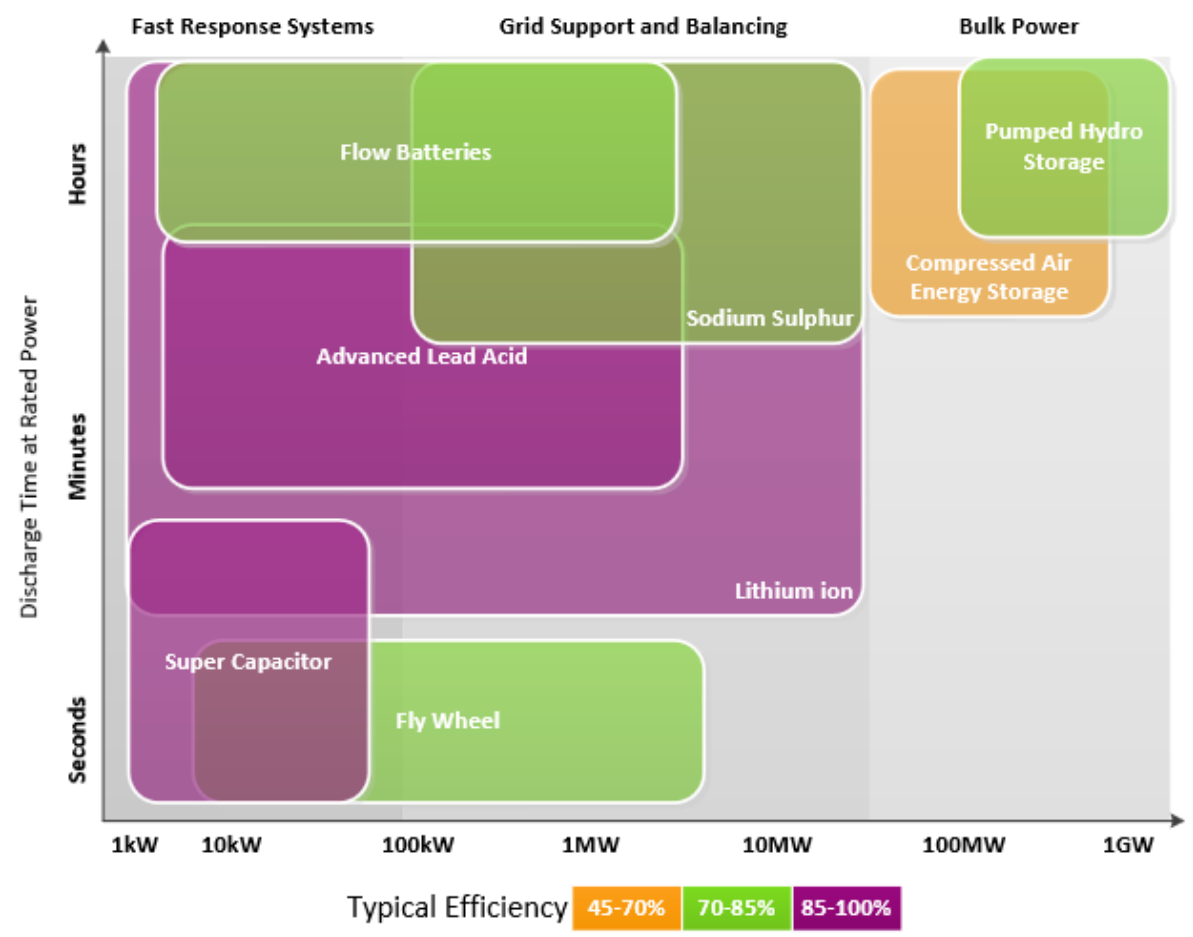

Figure A-26. Storage technologies and service characterization ${ }^{647}$

\section{Scale Efficiencies}

There are no scale efficiencies for storage technologies and each application will be dependent on storage needs and the ancillary services provided. 


\section{Appendix B: Levelized Cost of Electricity (LCOE) Methodology and Assumptions}

An LCOE calculation takes input assumptions about costs, operational characteristics, and financing options to determine the cost in current dollars per megawatt-hour of electricity generation for the financial lifetime of a plant, as illustrated in the Equation 1.

$$
\begin{gathered}
\text { LCOE }=\frac{\text { Overnight Capital Cost } \times \text { Financial Factor }+ \text { Fixed } 0 \& M}{8760 \times \text { Capacity Factor }} \\
+ \text { Variable O\&M+Fuel Cost } \times \text { Heat Rate }
\end{gathered}
$$

Note: The financial factor is the product of the construction finance factor, the project finance factor, and the capital recovery factor. Equations for these factors are included at the end of this Appendix.

Sometimes it is difficult to compare LCOE values drawn from different reports because of the different assumptions involved in estimating these values. This report tries to eliminate some confusion in comparing LCOE across sources by controlling for financial and other nontechnology (e.g. operational) factors. As a result, LCOE's are re-estimated from their primary sources to reflect the key differences in technology cost assumptions among the different sources. For this report, three primary LCOE study assumptions are compared: EIA, NREL, and Lazard. Note that the referenced NETL reports are primary sources for coal and natural gas combined cycle plant costs, whereas NREL is not; consequently, NETL operating assumptions and costs are used in lieu of the NREL values for those plants.

Low and high estimates for LCOEs are generated using the lowest and highest financial and operating input assumptions reported across the EIA, NREL, and Lazard primary sources (Table B-1). These financial assumptions, along with construction times and schedules from NREL's Annual Technology Baseline ${ }^{\text {lxviii }}$, were used to generate the Financial Factor, which is largely dependent on the weighted average cost of capital (WACC). Specifically, the Financial Factor is the product of the construction finance factor, the project finance factor, and the capital recovery factor, for which equations are shown at the end of this Appendix.

\footnotetext{
lxviii Construction times and schedules (i.e. profiles) are by technology and come from NREL's Annual Technology Baseline (NREL 2015), as these profiles were generally between those from EIA and Lazard.
} 
Table B-1. Finance Assumptions for LCOE Calculation

\begin{tabular}{lrrrrrr} 
& EIA & NREL & \multicolumn{1}{c}{ Lazard } & $\begin{array}{c}\text { Low LCOE } \\
\text { Inputs }\end{array}$ & $\begin{array}{c}\text { High LCOE } \\
\text { Inputs }\end{array}$ \\
\hline Debt & $45.0 \%$ & $50.0 \%$ & $60.0 \%$ & NA & NA \\
\hline Cost of Equity & $11.5 \%$ & $13.0 \%$ & $12.0 \%$ & $\mathbf{3 8 . 0 \%}$ & $\mathbf{4 0 . 0 \%}$ \\
\hline Tax Rate & $38.0 \%$ & $40.0 \%$ & $40.0 \%$ & $\mathbf{6 . 3} \%$ & $\mathbf{8 . 0 \%}$ \\
\hline Interest & $6.3 \%$ & $8.0 \%$ & $8.0 \%$ & $\mathbf{5 . 1 \%}$ & $\mathbf{6 . 2 \%}$ \\
\hline WACC & $5.4 \%$ & $6.2 \%$ & $5.1 \%$ & $\mathbf{3 0}$ years & $\mathbf{2 0}$ years \\
\hline $\begin{array}{l}\text { Financial } \\
\text { Lifetime }\end{array}$ & 30 year & 20 year & $\begin{array}{r}20-40 \\
\text { years }\end{array}$ & &
\end{tabular}

Note: Real (not nominal) WACC values presented. Debt/Equity and Cost of Equity values were only used in calculating the WACC for each source. The minimum and maximum WACC from the sources were then used as LCOE inputs (i.e. High/Low WACC inputs were not calculated from the range of inputs.) Sources: (NREL 2015; EIA 2015; Lazard 2015)

The financial assumptions used to generate the WACC ranges (Table B-1) include the debt to equity ratio, the cost of equity, tax rate, interest, and the financial lifetime. It is important to note that the financial lifetime differs from a plant's physical lifetime. For example, a new gas plant may have a planned physical lifetime of 50 years or more, but when making investment decisions, equity investors may expect to recover their investment over a much shorter timeframe of perhaps 20 or 30 years. An inflation rate of $2.5 \%$ was assumed for all technologies and both the high and low LCOE estimates.

While the same financial characteristics were applied across all technologies, different operating characteristics, such as fuel costs and capacity factors, were used for each technology. The maximum and minimum value from all four sources, as summarized in Table B-2, was applied to each technology when generating the LCOE values for this report.

Cost components, summarized in Table B-3 (dispatchable technologies) and Table B-4 (nondispatchable technologies) of this Appendix, include overnight capital costs, variable and fixed operation and maintenance costs (O\&M), as well as heat rate assumptions by technology. The resulting LCOE values are also reported in Tables B-3 and B-4.

Lazard's cost ranges for utility-scale solar directly correlate to improved capacity factors. In Table B-4, Lazard's utility PV capital costs are higher for the low LCOE estimate because they assume that the higher cost pays for improvements in the capacity factor (e.g. fixed-tilt vs. single axis tracking), while NREL and EIA's values only represent single axis tracking and ranges are due to variations in regional resources. The result is a tighter range for Lazard for utility-scale solar. 
Table B-2. Technology Operational Assumptions for LCOE Calculation, 2015

\begin{tabular}{|c|c|c|c|c|c|c|c|c|c|c|c|}
\hline \multirow{2}{*}{ Technology } & \multirow{2}{*}{ Category } & \multicolumn{2}{|c|}{ EIA } & \multicolumn{2}{|c|}{ NREL } & \multicolumn{2}{|c|}{ NETL } & \multicolumn{2}{|c|}{ Lazard } & \multicolumn{2}{|c|}{ LCOE Inputs } \\
\hline & & Low & High & Low & High & Low & High & Low & High & Low & High \\
\hline \multirow{2}{*}{$\begin{array}{l}\text { Coal- } \\
\text { Pulverized }\end{array}$} & Fuel Cost (\$/MMBtu) & 2.39 & 2.81 & $\mathrm{~N} / \mathrm{A}$ & N/A & 2.82 & 2.82 & 1.93 & 1.93 & 1.93 & 2.82 \\
\hline & Net Capacity Factor & $85 \%$ & $85 \%$ & $\mathrm{~N} / \mathrm{A}$ & $\mathrm{N} / \mathrm{A}$ & $85 \%$ & $85 \%$ & $93 \%$ & $93 \%$ & $93 \%$ & $85 \%$ \\
\hline \multirow{2}{*}{$\begin{array}{l}\text { Coal- } \\
\text { Pulverized- } \\
\text { CCS }\end{array}$} & Fuel Cost (\$/MMBtu) & N/A & N/A & $\mathrm{N} / \mathrm{A}$ & N/A & 2.82 & 2.82 & $\mathrm{~N} / \mathrm{A}$ & $\mathrm{N} / \mathrm{A}$ & $1.93^{*}$ & 2.82 \\
\hline & Net Capacity Factor & $\mathrm{N} / \mathrm{A}$ & $\mathrm{N} / \mathrm{A}$ & $\mathrm{N} / \mathrm{A}$ & $\mathrm{N} / \mathrm{A}$ & $85 \%$ & $85 \%$ & $\mathrm{~N} / \mathrm{A}$ & $\mathrm{N} / \mathrm{A}$ & $85 \%$ & $85 \%$ \\
\hline \multirow{2}{*}{$\begin{array}{l}\text { Coal- } \\
\text { Pulverized- } \\
\text { Partial (22\%) } \\
\text { CCS } \\
\end{array}$} & Fuel Cost (\$/MMBtu) & $\mathrm{N} / \mathrm{A}$ & N/A & $\mathrm{N} / \mathrm{A}$ & $\mathrm{N} / \mathrm{A}$ & 2.82 & 2.82 & $\mathrm{~N} / \mathrm{A}$ & $\mathrm{N} / \mathrm{A}$ & $1.93^{*}$ & 2.82 \\
\hline & Net Capacity Factor & $\mathrm{N} / \mathrm{A}$ & $\mathrm{N} / \mathrm{A}$ & $\mathrm{N} / \mathrm{A}$ & $\mathrm{N} / \mathrm{A}$ & $85 \%$ & $85 \%$ & $\mathrm{~N} / \mathrm{A}$ & $\mathrm{N} / \mathrm{A}$ & $85 \%$ & $85 \%$ \\
\hline \multirow{2}{*}{$\begin{array}{l}\text { Coal- } \\
\text { IGCC }\end{array}$} & Fuel Cost (\$/MMBtu) & 2.39 & 2.81 & $N / A$ & $\mathrm{~N} / \mathrm{A}$ & 2.82 & 2.82 & 1.93 & 1.93 & 1.93 & 2.82 \\
\hline & Net Capacity Factor & $85 \%$ & $85 \%$ & $\mathrm{~N} / \mathrm{A}$ & $\mathrm{N} / \mathrm{A}$ & $80 \%$ & $80 \%$ & $93 \%$ & $93 \%$ & $93 \%$ & $80 \%$ \\
\hline \multirow{2}{*}{$\begin{array}{l}\text { Coal- } \\
\text { IGCC-CCS }\end{array}$} & Fuel Cost (\$/MMBtu) & 2.39 & 2.81 & N/A & N/A & 2.82 & 2.82 & 1.93 & 1.93 & 1.93 & 2.82 \\
\hline & Net Capacity Factor & $85 \%$ & $85 \%$ & $\mathrm{~N} / \mathrm{A}$ & N/A & $80 \%$ & $80 \%$ & $93 \%$ & $93 \%$ & $93 \%$ & $80 \%$ \\
\hline \multirow{2}{*}{$\begin{array}{l}\text { Gas- } \\
\text { CC }\end{array}$} & Fuel Cost (\$/MMBtu) & 4.26 & 5.44 & $N / A$ & $\mathrm{~N} / \mathrm{A}$ & 5.17 & 5.17 & 3.39 & 3.39 & 3.39 & 5.44 \\
\hline & Net Capacity Factor & $87 \%$ & $87 \%$ & $\mathrm{~N} / \mathrm{A}$ & N/A & $85 \%$ & $85 \%$ & $70 \%$ & $40 \%$ & $87 \%$ & $40 \%$ \\
\hline \multirow{2}{*}{$\begin{array}{l}\text { Gas- } \\
\text { CC-CCS }\end{array}$} & Fuel Cost (\$/MMBtu) & 4.26 & 5.44 & $\mathrm{~N} / \mathrm{A}$ & $\mathrm{N} / \mathrm{A}$ & 5.17 & 5.17 & 3.39 & 3.39 & 3.39 & 5.44 \\
\hline & Net Capacity Factor & $87 \%$ & $87 \%$ & N/A & N/A & $85 \%$ & $85 \%$ & $70 \%$ & $40 \%$ & $87 \%$ & $40 \%$ \\
\hline \multirow{2}{*}{$\begin{array}{l}\text { Gas- } \\
\text { CT }\end{array}$} & Fuel Cost (\$/MMBtu) & 4.26 & 5.44 & $\mathrm{~N} / \mathrm{A}$ & $\mathrm{N} / \mathrm{A}$ & $\mathrm{N} / \mathrm{A}$ & $\mathrm{N} / \mathrm{A}$ & 3.39 & 3.39 & 3.39 & 5.44 \\
\hline & Net Capacity Factor & $30 \%$ & $30 \%$ & N/A & N/A & $\mathrm{N} / \mathrm{A}$ & $\mathrm{N} / \mathrm{A}$ & $10 \%$ & $10 \%$ & $30 \%$ & $10 \%$ \\
\hline \multirow{2}{*}{ Nuclear } & Fuel Cost (\$/MMBtu) & 0.85 & 0.85 & $N / A$ & N/A & $\mathrm{N} / \mathrm{A}$ & $\mathrm{N} / \mathrm{A}$ & 0.84 & 0.84 & 0.84 & 0.85 \\
\hline & Net Capacity Factor & $90 \%$ & $90 \%$ & $\mathrm{~N} / \mathrm{A}$ & $\mathrm{N} / \mathrm{A}$ & $\mathrm{N} / \mathrm{A}$ & $\mathrm{N} / \mathrm{A}$ & $90 \%$ & $90 \%$ & $90 \%$ & $90 \%$ \\
\hline \multirow{2}{*}{$\begin{array}{l}\text { Biomass } \\
\text { Direct }\end{array}$} & Fuel Cost (\$/MMBtu) & 1.81 & 2.94 & 2.90 & 2.90 & $\mathrm{~N} / \mathrm{A}$ & $\mathrm{N} / \mathrm{A}$ & 0.98 & 1.97 & 0.98 & 2.94 \\
\hline & Net Capacity Factor & $83 \%$ & $83 \%$ & $51 \%$ & $51 \%$ & $\mathrm{~N} / \mathrm{A}$ & $\mathrm{N} / \mathrm{A}$ & $85 \%$ & $85 \%$ & $85 \%$ & $51 \%$ \\
\hline \multirow{2}{*}{ Geothermal } & Fuel Cost (\$/MMBtu) & 0 & 0 & 0 & 0 & $\mathrm{~N} / \mathrm{A}$ & $\mathrm{N} / \mathrm{A}$ & 0 & 0 & 0 & 0 \\
\hline & Net Capacity Factor & $92 \%$ & $92 \%$ & $90 \%$ & $80 \%$ & $\mathrm{~N} / \mathrm{A}$ & $\mathrm{N} / \mathrm{A}$ & $90 \%$ & $85 \%$ & $92 \%$ & $80 \%$ \\
\hline \multirow{2}{*}{ Hydropower } & Fuel Cost (\$/MMBtu) & 0 & 0 & 0 & 0 & $\mathrm{~N} / \mathrm{A}$ & $\mathrm{N} / \mathrm{A}$ & NA & NA & 0 & 0 \\
\hline & Net Capacity Factor & $54 \%$ & $54 \%$ & $68 \%$ & $58 \%$ & $\mathrm{~N} / \mathrm{A}$ & $\mathrm{N} / \mathrm{A}$ & NA & NA & $68 \%$ & $54 \%$ \\
\hline \multirow{2}{*}{$\begin{array}{l}\text { Wind, } \\
\text { Onshore }\end{array}$} & Fuel Cost (\$/MMBtu) & 0 & 0 & 0 & 0 & $\mathrm{~N} / \mathrm{A}$ & $\mathrm{N} / \mathrm{A}$ & 0 & 0 & 0 & 0 \\
\hline & Net Capacity Factor & $31 \%$ & $40 \%$ & $53 \%$ & $34 \%$ & $\mathrm{~N} / \mathrm{A}$ & $\mathrm{N} / \mathrm{A}$ & $55 \%$ & $30 \%$ & $55 \%$ & $30 \%$ \\
\hline \multirow{2}{*}{$\begin{array}{l}\text { Wind, } \\
\text { Offshore }\end{array}$} & Fuel Cost (\$/MMBtu) & 0 & 0 & 0 & 0 & $\mathrm{~N} / \mathrm{A}$ & $\mathrm{N} / \mathrm{A}$ & 0 & 0 & 0 & 0 \\
\hline & Net Capacity Factor & $38 \%$ & $38 \%$ & $48 \%$ & $44 \%$ & $\mathrm{~N} / \mathrm{A}$ & $\mathrm{N} / \mathrm{A}$ & $45 \%$ & $40 \%$ & $48 \%$ & $38 \%$ \\
\hline \multirow{2}{*}{ Utility PV } & Fuel Cost (\$/MMBtu) & 0 & 0 & 0 & 0 & $\mathrm{~N} / \mathrm{A}$ & $\mathrm{N} / \mathrm{A}$ & 0 & 0 & 0 & 0 \\
\hline & Net Capacity Factor & $22 \%$ & $32 \%$ & $28 \%$ & $14 \%$ & $\mathrm{~N} / \mathrm{A}$ & $\mathrm{N} / \mathrm{A}$ & $32 \%$ & $21 \%$ & $32 \%$ & $14 \%$ \\
\hline \multirow{2}{*}{$\begin{array}{l}\text { CSP- } \\
\text { EIA, no storage } \\
\text { NREL \& Lazard, } \\
\text { with storage }\end{array}$} & Fuel Cost (\$/MMBtu) & 0 & 0 & 0 & 0 & $\mathrm{~N} / \mathrm{A}$ & $N / A$ & 0 & 0 & 0 & 0 \\
\hline & Net Capacity Factor & $26 \%$ & $5 \%$ & $62 \%$ & $45 \%$ & $\mathrm{~N} / \mathrm{A}$ & $\mathrm{N} / \mathrm{A}$ & $85 \%$ & $52 \%$ & $85 \%$ & $45 \%$ \\
\hline
\end{tabular}

Notes: Fuel cost values are in 2013\$. Coal and natural gas fuel costs for EIA were taken from AEO2014 rather than AEO2015 because AEO2014 included more side cases and a greater range of fuel costs. Fuel costs for coal came from AEO high and low coal cost side cases; fuel costs for natural gas came from AEO high and low oil and natural gas resource cases. EIA Solar CSP values do not include storage, NREL and Lazard estimates include storage.

*Low coal price used from Lazard

Sources: (NETL 2015; NREL 2015; EIA 2015; Lazard 2015) 
Table B-3. Range of Cost and Heat Rate Assumptions and LCOE for Dispatchable Technologies

\begin{tabular}{|c|c|c|c|c|c|c|c|c|c|}
\hline \multirow[b]{2}{*}{ Technology } & \multirow[b]{2}{*}{ Category } & \multicolumn{2}{|c|}{ EIA } & \multicolumn{2}{|c|}{ NREL } & \multicolumn{2}{|c|}{ NETL } & \multicolumn{2}{|c|}{ Lazard } \\
\hline & & Low & High & Low & High & Low & High & Low & High \\
\hline \multirow{5}{*}{$\begin{array}{l}\text { Coal- } \\
\text { Pulverized }\end{array}$} & $\begin{array}{l}\text { Overnight Capital Cost } \\
(\$ / \mathrm{kW})\end{array}$ & 2596 & 3355 & $\mathrm{~N} / \mathrm{A}$ & $\mathrm{N} / \mathrm{A}$ & 2593 & 2593 & 2460 & 2460 \\
\hline & Variable O\&M (\$/MWh) & 3.98 & 5.14 & $\mathrm{~N} / \mathrm{A}$ & $\mathrm{N} / \mathrm{A}$ & 9.36 & 9.36 & 1.97 & 1.97 \\
\hline & Fixed O\&M (\$/kW-yr) & 27.73 & 35.85 & $\mathrm{~N} / \mathrm{A}$ & $\mathrm{N} / \mathrm{A}$ & 73.92 & 73.92 & 39.36 & 39.36 \\
\hline & $\begin{array}{l}\text { Heat Rate } \\
\text { (MMBtu/MWh) }\end{array}$ & 8.80 & 8.80 & $\mathrm{~N} / \mathrm{A}$ & $\mathrm{N} / \mathrm{A}$ & 8.38 & 8.38 & 8.75 & 8.75 \\
\hline & LCOE (\$/MWh) & 54.81 & 97.53 & N/A & N/A & 65.01 & 91.43 & 52.53 & 77.95 \\
\hline \multirow{5}{*}{$\begin{array}{l}\text { Coal- } \\
\text { Pulverized- } \\
\text { CCS }\end{array}$} & $\begin{array}{l}\text { Overnight Capital Cost } \\
(\$ / \mathrm{kW})\end{array}$ & $\mathrm{N} / \mathrm{A}$ & N/A & $\mathrm{N} / \mathrm{A}$ & $\mathrm{N} / \mathrm{A}$ & 4482 & 4482 & $\mathrm{~N} / \mathrm{A}$ & $\mathrm{N} / \mathrm{A}$ \\
\hline & Variable O\&M (\$/MWh) & $\mathrm{N} / \mathrm{A}$ & $\mathrm{N} / \mathrm{A}$ & $\mathrm{N} / \mathrm{A}$ & $\mathrm{N} / \mathrm{A}$ & 15.24 & 15.24 & $\mathrm{~N} / \mathrm{A}$ & $\mathrm{N} / \mathrm{A}$ \\
\hline & Fixed O\&M (\$/kW-yr) & $\mathrm{N} / \mathrm{A}$ & $\mathrm{N} / \mathrm{A}$ & $\mathrm{N} / \mathrm{A}$ & $\mathrm{N} / \mathrm{A}$ & 118.63 & 118.63 & $\mathrm{~N} / \mathrm{A}$ & $\mathrm{N} / \mathrm{A}$ \\
\hline & $\begin{array}{l}\text { Heat Rate } \\
\text { (MMBtu/MWh) }\end{array}$ & N/A & $\mathrm{N} / \mathrm{A}$ & $\mathrm{N} / \mathrm{A}$ & $\mathrm{N} / \mathrm{A}$ & 10.51 & 10.51 & $\mathrm{~N} / \mathrm{A}$ & $\mathrm{N} / \mathrm{A}$ \\
\hline & LCOE (\$/MWh) & N/A & N/A & N/A & N/A & 108.96 & 144.66 & N/A & N/A \\
\hline \multirow{5}{*}{$\begin{array}{l}\text { Coal- } \\
\text { Pulverized- } \\
\text { Partial (22\%) } \\
\text { CCS }\end{array}$} & $\begin{array}{l}\text { Overnight Capital Cost } \\
(\$ / \mathrm{kW})\end{array}$ & $\mathrm{N} / \mathrm{A}$ & $\mathrm{N} / \mathrm{A}$ & $\mathrm{N} / \mathrm{A}$ & $\mathrm{N} / \mathrm{A}$ & 3297 & 3297 & $\mathrm{~N} / \mathrm{A}$ & $\mathrm{N} / \mathrm{A}$ \\
\hline & Variable O\&M (\$/MWh) & $\mathrm{N} / \mathrm{A}$ & $\mathrm{N} / \mathrm{A}$ & $\mathrm{N} / \mathrm{A}$ & $\mathrm{N} / \mathrm{A}$ & 10.83 & 10.83 & $\mathrm{~N} / \mathrm{A}$ & $\mathrm{N} / \mathrm{A}$ \\
\hline & Fixed O\&M (\$/kW-yr) & $\mathrm{N} / \mathrm{A}$ & $\mathrm{N} / \mathrm{A}$ & $\mathrm{N} / \mathrm{A}$ & $\mathrm{N} / \mathrm{A}$ & 91.67 & 91.67 & $\mathrm{~N} / \mathrm{A}$ & $\mathrm{N} / \mathrm{A}$ \\
\hline & $\begin{array}{l}\text { Heat Rate } \\
\text { (MMBtu/MWh) }\end{array}$ & $\mathrm{N} / \mathrm{A}$ & $\mathrm{N} / \mathrm{A}$ & $\mathrm{N} / \mathrm{A}$ & $\mathrm{N} / \mathrm{A}$ & 8.85 & 8.85 & $\mathrm{~N} / \mathrm{A}$ & $\mathrm{N} / \mathrm{A}$ \\
\hline & LCOE (\$/MWh) & N/A & N/A & N/A & N/A & 88.33 & 110.58 & N/A & N/A \\
\hline \multirow{5}{*}{$\begin{array}{l}\text { Coal- } \\
\text { IGCC }\end{array}$} & $\begin{array}{l}\text { Overnight Capital Cost } \\
(\$ / \mathrm{kW})\end{array}$ & 3392 & 4249 & $\mathrm{~N} / \mathrm{A}$ & $\mathrm{N} / \mathrm{A}$ & 3141 & 3141 & 3247 & 5461 \\
\hline & Variable O\&M (\$/MWh) & 6.57 & 8.23 & $\mathrm{~N} / \mathrm{A}$ & $\mathrm{N} / \mathrm{A}$ & 9.73 & 9.73 & 6.89 & 6.89 \\
\hline & Fixed O\&M (\$/kW-yr) & 46.75 & 58.56 & $\mathrm{~N} / \mathrm{A}$ & $\mathrm{N} / \mathrm{A}$ & 99.46 & 99.46 & 61.25 & 61.25 \\
\hline & $\begin{array}{l}\text { Heat Rate } \\
\text { (MMBtu/MWh) }\end{array}$ & 8.70 & 8.70 & $\mathrm{~N} / \mathrm{A}$ & $\mathrm{N} / \mathrm{A}$ & 8.76 & 8.76 & 8.80 & 8.80 \\
\hline & LCOE (\$/MWh) & 68.87 & 125.49 & N/A & N/A & 75.68 & 111.06 & 69.47 & 148.99 \\
\hline \multirow{5}{*}{$\begin{array}{l}\text { Coal- } \\
\text { IGCC-CCS }\end{array}$} & $\begin{array}{l}\text { Overnight Capital Cost } \\
(\$ / \mathrm{kW})\end{array}$ & 5908 & 7271 & N/A & $\mathrm{N} / \mathrm{A}$ & 4340 & 4340 & 5461 & 7675 \\
\hline & Variable O\&M (\$/MWh) & 7.68 & 9.45 & $\mathrm{~N} / \mathrm{A}$ & $\mathrm{N} / \mathrm{A}$ & 12.66 & 12.66 & 8.36 & 8.36 \\
\hline & Fixed O\&M (\$/kW-yr) & 66.25 & 81.54 & $\mathrm{~N} / \mathrm{A}$ & $\mathrm{N} / \mathrm{A}$ & 132.16 & 132.16 & 71.83 & 71.83 \\
\hline & $\begin{array}{l}\text { Heat Rate } \\
\text { (MMBtu/MWh) }\end{array}$ & 10.70 & 10.70 & $\mathrm{~N} / \mathrm{A}$ & $\mathrm{N} / \mathrm{A}$ & 10.46 & 10.46 & 11.70 & 11.70 \\
\hline & LCOE (\$/MWh) & 105.74 & 195.68 & N/A & N/A & 99.97 & 147.28 & 103.80 & 204.16 \\
\hline \multirow{5}{*}{ Gas-CC } & $\begin{array}{l}\text { Overnight Capital Cost } \\
(\$ / \mathrm{kW})\end{array}$ & 905 & 1688 & $\mathrm{~N} / \mathrm{A}$ & $\mathrm{N} / \mathrm{A}$ & 867 & 867 & 886 & 1181 \\
\hline & Variable O\&M (\$/MWh) & 2.91 & 5.43 & $\mathrm{~N} / \mathrm{A}$ & $\mathrm{N} / \mathrm{A}$ & 1.72 & 1.72 & 3.44 & 1.97 \\
\hline & Fixed O\&M (\$/kW-yr) & 13.67 & 25.50 & $\mathrm{~N} / \mathrm{A}$ & $\mathrm{N} / \mathrm{A}$ & 26.10 & 26.10 & 6.10 & 5.41 \\
\hline & $\begin{array}{l}\text { Heat Rate } \\
\text { (MMBtu/MWh) }\end{array}$ & 6.43 & 6.43 & $\mathrm{~N} / \mathrm{A}$ & $\mathrm{N} / \mathrm{A}$ & 6.63 & 6.63 & 6.90 & 6.70 \\
\hline & LCOE (\$/MWh) & 36.53 & 105.54 & N/A & N/A & 37.23 & 74.95 & 36.77 & 81.51 \\
\hline \multirow{5}{*}{$\begin{array}{l}\text { Gas- } \\
\text { CC-CCS }\end{array}$} & $\begin{array}{l}\text { Overnight Capital Cost } \\
(\$ / k W)\end{array}$ & 1823 & 3108 & $\mathrm{~N} / \mathrm{A}$ & $\mathrm{N} / \mathrm{A}$ & 1866 & 1866 & NA & NA \\
\hline & Variable O\&M (\$/MWh) & 5.97 & 10.17 & $\mathrm{~N} / \mathrm{A}$ & $\mathrm{N} / \mathrm{A}$ & 4.10 & 4.10 & NA & NA \\
\hline & Fixed O\&M (\$/kW-yr) & 27.96 & 47.66 & $\mathrm{~N} / \mathrm{A}$ & $\mathrm{N} / \mathrm{A}$ & 50.65 & 50.65 & NA & NA \\
\hline & $\begin{array}{l}\text { Heat Rate } \\
\text { (MMBtu/MWh) }\end{array}$ & 7.53 & 7.53 & $\mathrm{~N} / \mathrm{A}$ & $\mathrm{N} / \mathrm{A}$ & 7.47 & 7.47 & NA & NA \\
\hline & LCOE (\$/MWh) & 55.34 & 171.21 & N/A & N/A & 56.74 & 123.14 & NA & NA \\
\hline
\end{tabular}




\begin{tabular}{|c|c|c|c|c|c|c|c|c|c|}
\hline \multirow[b]{2}{*}{ Technology } & \multirow[b]{2}{*}{ Category } & \multicolumn{2}{|c|}{ EIA } & \multicolumn{2}{|c|}{ NREL } & \multicolumn{2}{|c|}{ NETL } & \multicolumn{2}{|c|}{ Lazard } \\
\hline & & Low & High & Low & High & Low & High & Low & High \\
\hline \multirow{5}{*}{ Gas-CT } & $\begin{array}{l}\text { Overnight Capital Cost } \\
(\$ / \mathrm{kW})\end{array}$ & 624 & 1127 & $\mathrm{~N} / \mathrm{A}$ & $\mathrm{N} / \mathrm{A}$ & $\mathrm{N} / \mathrm{A}$ & $\mathrm{N} / \mathrm{A}$ & 787 & 984 \\
\hline & Variable O\&M (\$/MWh) & 9.64 & 17.42 & $\mathrm{~N} / \mathrm{A}$ & $\mathrm{N} / \mathrm{A}$ & $\mathrm{N} / \mathrm{A}$ & $\mathrm{N} / \mathrm{A}$ & 4.62 & 7.38 \\
\hline & Fixed O\&M (\$/kW-yr) & 6.55 & 11.83 & $\mathrm{~N} / \mathrm{A}$ & $\mathrm{N} / \mathrm{A}$ & N/A & $\mathrm{N} / \mathrm{A}$ & 4.92 & 24.60 \\
\hline & $\begin{array}{l}\text { Heat Rate } \\
\text { (MMBtu/MWh) }\end{array}$ & 9.75 & 9.75 & $\mathrm{~N} / \mathrm{A}$ & $\mathrm{N} / \mathrm{A}$ & $\mathrm{N} / \mathrm{A}$ & $\mathrm{N} / \mathrm{A}$ & 10.30 & 9.0 \\
\hline & LCOE (\$/MWh) & 65.24 & 238.49 & N/A & N/A & N/A & N/A & 66.70 & 219.30 \\
\hline \multirow{5}{*}{ Nuclear } & $\begin{array}{l}\text { Overnight Capital Cost } \\
(\$ / k W)\end{array}$ & 5098 & 5795 & $\mathrm{~N} / \mathrm{A}$ & $\mathrm{N} / \mathrm{A}$ & $\mathrm{N} / \mathrm{A}$ & N/A & 4329 & 6593 \\
\hline & Variable O\&M (\$/MWh) & 2.03 & 2.31 & $\mathrm{~N} / \mathrm{A}$ & $\mathrm{N} / \mathrm{A}$ & $\mathrm{N} / \mathrm{A}$ & $\mathrm{N} / \mathrm{A}$ & 0.49 & 0.74 \\
\hline & Fixed O\&M (\$/kW-yr) & 88.57 & 100.69 & $\mathrm{~N} / \mathrm{A}$ & $\mathrm{N} / \mathrm{A}$ & $N / A$ & N/A & 132.83 & 132.83 \\
\hline & $\begin{array}{l}\text { Heat Rate } \\
\text { (MMBtu/MWh) }\end{array}$ & 10.48 & 10.48 & $\mathrm{~N} / \mathrm{A}$ & $\mathrm{N} / \mathrm{A}$ & $\mathrm{N} / \mathrm{A}$ & N/A & 10.45 & 10.45 \\
\hline & LCOE (\$/MWh) & 81.71 & 122.62 & N/A & N/A & N/A & N/A & 76.77 & 138.67 \\
\hline
\end{tabular}

Table B-3. Range of Cost and Heat Rate Assumptions and LCOE for Dispatchable Technologies (Continued)

\begin{tabular}{llrrrrrr} 
& & \multicolumn{2}{c}{ EIA } & \multicolumn{2}{c}{ NREL } & \multicolumn{2}{c}{ Lazard } \\
Technology & Category & Low & High & Low & High & Low & High \\
\hline & Overnight Capital Cost $(\$ / \mathrm{kW})$ & 3330 & 4610 & 3679 & 3679 & 2558 & 3444 \\
& Variable O\&M $(\$ / \mathrm{MWh})$ & 4.79 & 6.63 & 5.34 & 5.34 & 14.76 & 14.76 \\
Biomass & Fixed O\&M $(\$ / \mathrm{kW}-\mathrm{yr})$ & 96.08 & 133.03 & 107.22 & 107.22 & 93.48 & 93.48 \\
& Heat Rate $(\mathrm{MMBtu} / \mathrm{MWh})$ & 13.50 & 13.50 & 13.5 & 13.5 & 14.50 & 14.50 \\
& LCOE $(\$ / M W h)$ & $\mathbf{6 5 . 4 2}$ & $\mathbf{1 8 8 . 3 4}$ & $\mathbf{7 1 . 0 9}$ & $\mathbf{1 5 8 . 6 1}$ & $\mathbf{6 8 . 0 3}$ & $\mathbf{1 6 2 . 1 6}$ \\
\hline \multirow{3}{*}{ Geothermal } & Overnight Capital Cost $(\$ / \mathrm{kW})$ & 2448 & 2448 & 1750 & 24250 & 3837 & 5510 \\
& Variable O\&M $(\$ / \mathrm{MWh})$ & 0.00 & 0.00 & 0.01 & 0.1 & 29.52 & 39.36 \\
& Fixed O\&M $(\$ / \mathrm{kW}-\mathrm{yr})$ & 112.85 & 112.85 & 59.00 & 538.00 & 0 & 0 \\
& Heat Rate $(\mathrm{MMBtu} / \mathrm{MWh})$ & 0 & 0 & 0 & 0 & 0 & 0
\end{tabular}


Table B-4. Range of Cost and Heat Rate Assumptions and LCOE for Non-Dispatchable Technologies

\begin{tabular}{|c|c|c|c|c|c|c|c|}
\hline \multirow[b]{2}{*}{ Technology } & \multirow[b]{2}{*}{ Category } & \multicolumn{2}{|c|}{ EIA } & \multicolumn{2}{|c|}{ NREL } & \multicolumn{2}{|c|}{ Lazard } \\
\hline & & Low & High & Low & High & Low & High \\
\hline \multirow{5}{*}{ Hydropower } & Overnight Capital Cost $(\$ / k W)$ & 2651 & 2651 & 1369 & 9099 & N/A & $\mathrm{N} / \mathrm{A}$ \\
\hline & Variable O\&M (\$/MWh) & 5.76 & 5.76 & 2.69 & 2.69 & N/A & $\mathrm{N} / \mathrm{A}$ \\
\hline & Fixed O\&M (\$/kW-yr) & 15.15 & 15.15 & 15.05 & 15.05 & N/A & $\mathrm{N} / \mathrm{A}$ \\
\hline & Heat Rate (MMBtu/MWh) & 0 & 0 & 0 & 0 & 0 & 0 \\
\hline & LCOE (\$/MWh) & 47.22 & 78.83 & 25.31 & 245.68 & N/A & N/A \\
\hline \multirow{5}{*}{$\begin{array}{l}\text { Wind, } \\
\text { Land-based }\end{array}$} & Overnight Capital Cost $(\$ / k W)$ & 1881 & 2475 & 1605 & 1748 & 1230 & 1673 \\
\hline & Variable O\&M (\$/MWh) & 0.00 & 0.00 & 0 & 0 & 0 & 0 \\
\hline & Fixed O\&M (\$/kW-yr) & 37.55 & 49.41 & 49.90 & 49.90 & 34.44 & 39.36 \\
\hline & Heat Rate (MMBtu/MWh) & 0 & 0 & 0 & 0 & 0 & 0 \\
\hline & LCOE (\$/MWh) & 37.09 & 117.76 & 35.36 & 88.87 & 26.30 & 81.86 \\
\hline \multirow{5}{*}{$\begin{array}{l}\text { Wind, } \\
\text { Offshore }\end{array}$} & Overnight Capital Cost $(\$ / k W)$ & 5662 & 7939 & 4804 & 6209 & 3050 & 5412 \\
\hline & Variable O\&M (\$/MWh) & 0.00 & 0.00 & 0 & 0 & 12.79 & 17.71 \\
\hline & Fixed O\&M (\$/kW-yr) & 68.04 & 95.41 & 122.01 & 150.17 & 59.04 & 98.40 \\
\hline & Heat Rate (MMBtu/MWh) & 0 & 0 & 0 & 0 & 0 & 0 \\
\hline & LCOE (\$/MWh) & 117.22 & 279.25 & 114.75 & 241.09 & 81.27 & 218.10 \\
\hline \multirow{5}{*}{ Utility PV } & Overnight Capital Cost $(\$ / k W)$ & 2754 & 4755 & 1881 & 1881 & 1574 & 1476 \\
\hline & Variable O\&M (\$/MWh) & 0.00 & 0.00 & 0 & 0 & 0 & 0 \\
\hline & Fixed O\&M (\$/kW-yr) & 20.73 & 35.79 & 15.00 & 15.00 & 12.79 & 9.84 \\
\hline & Heat Rate (MMBtu/MWh) & 0 & 0 & 0 & 0 & 0 & 0 \\
\hline & LCOE (\$/MWh) & 80.00 & 430.52 & 54.94 & 171.03 & 46.06 & 132.61 \\
\hline \multirow{5}{*}{ CSP } & Overnight Capital Cost $(\$ / k W)$ & 3485 & 4579 & 7086 & 7086 & 8856 & 8610 \\
\hline & Variable O\&M (\$/MWh) & 0.00 & 0.00 & 3 & 3 & 0 & 0 \\
\hline & Fixed O\&M (\$/kW-yr) & 57.82 & 75.97 & 61.00 & 61.00 & 113.16 & 78.72 \\
\hline & Heat Rate (MMBtu/MWh) & 0 & 0 & 0 & 0 & 0 & 0 \\
\hline & LCOE (\$/MWh) & 140.20 & 1271.89 & 82.61 & 207.35 & 104.44 & 249.46 \\
\hline
\end{tabular}




\section{Financial Factor Input Calculations}

The Construction Finance Factor is calculated with Equation 2:

$$
\sum_{i=0}^{N}(\text { Capital Fraction })_{i} \times(\text { Accumulated Interest })_{i}
$$

Where $i$ indicates the construction year, and $N$ is the total number of years of construction. The annual Capital Fraction for each technology is given in NREL's Annual Technology Baseline. The annual Accumulated Interest is calculated with Equation 3:

$$
1+(1-\text { Tax Rate }) \times\left[\left(1+\text { Interest }^{i+0.5}\right)-1\right]
$$

The Project Finance Factor is calculated with Equation 4:

$$
\frac{[1-(\text { Tax Rate } \times \text { Present Value of Depreciation })]}{(1-\text { Tax Rate })}
$$

Where Present Value of Depreciation can be found using Equation 5:

$$
\sum_{j=1}^{N}(\text { Depreciation Fraction })_{j} \times(\text { Depreciation Factor })_{j}
$$

Where $j$ indicates the number of years in depreciation, and $N$ is the total number of years in depreciation determined by the Modified Accelerated Cost Recovery System (MACRS). The depreciation period is 5 years for non-hydro renewables, 15 years for nuclear generation and combustion turbines, and 20 years for other fossil, hydropower, and storage. The annual Depreciation Fraction for each technology is determined by MACRS. The annual Depreciation Factor can be calculated with Equation 6:

$$
\frac{1}{[(1+W A C C) \times(1+\text { inflation })]^{j}}
$$

Where the WACC real, not nominal.

The Capital Recovery Factor (real) is calculated with Equation 7:

$$
\frac{\text { WACC }}{\left[1-\left(\frac{1}{1+W A C C}\right)^{\text {Economic Life }}\right]}
$$

Where the WACC is real, not nominal.

The resulting Financial Factors for each technology are given in Table B-5. 
Table B-5. Maximum and Minimum Financial Factors by Technology Used for LCOE Calculations

\begin{tabular}{ccc} 
& \multicolumn{2}{c}{ Financial Factor } \\
Technology & Min & Max \\
\hline Coal-Pulverized & 0.09554 & 0.13930 \\
Coal-Pulverized-CCS & 0.09554 & 0.13930 \\
Coal-Pulverized-Partial (22\%) CCS & 0.09554 & 0.13930 \\
Coal-IGCC & 0.09554 & 0.13930 \\
Coal-IGCC-CCS & 0.09554 & 0.13930 \\
Gas-CC & 0.08443 & 0.12008 \\
Gas-CC-CCS & 0.08443 & 0.12008 \\
Gas-CT & 0.08443 & 0.12008 \\
Nuclear & 0.09224 & 0.13418 \\
Biomass Direct & 0.07715 & 0.10877 \\
Geothermal & 0.07715 & 0.10877 \\
Hydropower & 0.08745 & 0.12466 \\
Wind, Land-based & 0.07504 & 0.10508 \\
Wind, Offshore & 0.07504 & 0.10508 \\
Utility PV & 0.07415 & 0.10352 \\
CSP & 0.07504 & 0.10508
\end{tabular}




\section{Endnotes}

${ }^{1}$ EIA, "Electric Power Monthly," 2016, http://www.eia.gov/electricity/monthly/.

2 DOE, “Quadrennial Technology Review 2015," U.S. Department of Energy, 2015, http://energy.gov/under-secretary-scienceand-energy/quadrennial-technology-review-2015.

${ }^{3}$ DOE, "Quadrennial Energy Review First Installment: Transforming U.S. Energy Infrastructures in a Time of Rapid Change," U.S. Department of Energy, April 2016, http://energy.gov/epsa/downloads/quadrennial-energy-review-first-installment.

${ }^{4}$ EIA, "Electric Power Monthly."

${ }^{5}$ Ibid.

${ }^{6}$ EIA, “Annual Electric Power Industry Report (EIA-861 Data File),” U.S. Energy Information Administration, 2016, http://www.eia.gov/electricity/data/eia861/; BLS, "Bureau of Labor Statistics Data," 2016,

http://data.bls.gov/timeseries/CUUR0000SA0?output_view=pct_1mth.

${ }^{7}$ SNL, "SNL Office with Excel Add-In. Subscription Service," 2015, www.snl.com.

${ }^{8}$ Ibid.

${ }^{9}$ Ibid.

${ }^{10}$ Ibid.

${ }^{11}$ EIA, "Electric Power Monthly."

${ }^{12}$ EIA, "Coal Made up More than $80 \%$ of Retired Electricity Generating Capacity in 2015 - Today in Energy," U.S. Energy Information Administration, March 8, 2016, https://www.eia.gov/todayinenergy/detail.cfm?id=25272.

${ }^{13}$ See for example, NREL, "Western Wind and Solar Integration Study: Phase 2," September 2013.

http://www.nrel.gov/docs/fy13osti/55588.pdf.

${ }^{14}$ EIA, “Annual Electric Generator Data - EIA-860 Data File,” U.S. Energy Information Administration, 2016, http://www.eia.gov/electricity/data/eia860/.

${ }^{15}$ Trieu Mai et al., "Impacts of Federal Tax Credit Extensions on Renewable Deployment and Power Sector Emissions," National Renewable Energy Laboratory. February, 2016.

${ }^{16}$ EIA, "EIA Electricity Data Now Include Estimated Small-Scale Solar PV Capacity and Generation - Today in Energy," 2015, https://www.eia.gov/todayinenergy/detail.cfm?id=23972.

${ }_{17}^{17}$ EIA, “Annual Electric Power Industry Report (EIA-861 Data File)."

${ }^{18}$ See, for example, Lori Bird and Debbie Lew, "Integrating Wind and Solar Energy in the Bulk U.S. Power System: Lessons from Regional Integration Studies,” Joint Institute for Strategic Energy Analysis, National Renewable Energy Laboratory. http://www.nrel.gov/docs/fy12osti/55830.pdf.

${ }^{19}$ Lazard, "Lazard's Levelized Cost of Energy Analysis - Version 10.0," 2016, https://www.lazard.com/media/438038/levelizedcost-of-energy-v100.pdf.

${ }^{20}$ Uria-Martinez et al., "2014 Hydropower Market Report."

${ }^{21}$ EPSA, “QER 1.2 Base Case.” (U.S. Department of Energy, 2016); IEA, “World Energy Outlook 2015,” 2015, http://www.worldenergyoutlook.org/weo2015/.

22 Jeffrey Logan, Kenneth Medlock, and William Boyd, “A Review of Sector and Regional Trends in US Electricity Markets: Focus on Natural Gas" (Golden, CO: Joint Institute for Strategic Energy Analysis (JISEA); National Renewable Energy Laboratory (NREL), 2015), http://www.nrel.gov/docs/fy16osti/64652.pdf.

${ }^{23}$ EIA, "Electric Power Monthly."

${ }^{24}$ EIA, “Annual Energy Outlook 2016," U.S. Energy Information Administration, 2016, http://www.eia.gov/forecasts/aeo/.

${ }^{25}$ Ernest J Moniz et al., "The Future of Natural Gas" (MIT Energy Initiative, 2011), http://energy.mit.edu/publication/futurenatural-gas/; EIA, "Shale in the Unites States," 2016, http://www.eia.gov/energy_in_brief/article/shale_in_the_united_states.cfm. ${ }^{26}$ Moniz et al., "The Future of Natural Gas."

${ }^{27}$ IEA, “Are We Entering a Golden Age of Gas?: Special Report of the World Energy Outlook 2011" (International Energy Agency, 2011), http://www.worldenergyoutlook.org/media/weowebsite/2011/WEO2011_GoldenAgeofGasReport.pdf.

${ }^{28}$ EIA, "Shale in the Unites States."

${ }^{29}$ EIA, "The U.S. Surpassed Russia as World's Leading Producer of Dry Natural Gas in 2009 and 2010," U.S. Energy Information Administration, 2012, http://www.eia.gov/todayinenergy/detail.cfm?id=5370.

${ }^{30}$ EIA, "Monthly Energy Review," U.S. Energy Information Administration, 2016, http://www.eia.gov/totalenergy/data/monthly/.

31 John Staub, "The Growth of U.S. Natural Gas: An Uncertain Outlook for U.S. and World Supply" (2015 EIA Energy

Conference, Washington, D.C., June 15, 2015), www.eia.gov/conference/2015/pdf/presentations/staub.pdf.

${ }^{32}$ EIA, "Short-Term Energy Outlook" (U.S. Energy Information Administration, September 7, 2016), http://www.eia.gov/forecasts/steo/.

${ }^{33}$ EIA, "Today in Energy: Warm Weather and Low Natural Gas Prices Dampen Spot Electricity Prices This Winter," U.S.

Energy Information Administration, May 28, 2012, http:/www.eia.gov/todayinenergy/detail.cfm?id=6330.

${ }^{34}$ EIA, "Monthly Energy Review."

${ }^{35}$ EIA, "Electric Power Monthly."

${ }^{36}$ Ibid. 
${ }^{37}$ EIA, "EIA's Energy in Brief: How Much U.S. Electricity Is Generated from Renewable Energy?," U.S. Energy Information Administration, 2016, http://www.eia.gov/energy_in_brief/article/renewable_electricity.cfm.

${ }^{38}$ Ibid.

${ }^{39}$ L Bassett et al., "Revolution Now: The Future Arrives for Five Clean Energy Technologies - 2015 Update" (U.S. Department of Energy, 2015), http://www.energy.gov/sites/prod/files/2015/11/f27/Revolution-Now-11132015.pdf.

${ }^{40}$ Lazard, "Lazard's Levelized Cost of Energy Analysis - Version 9.0."

${ }^{41}$ Alan C Goodrich et al., "Assessing the Drivers of Regional Trends in Solar Photovoltaic Manufacturing," Energy \& Environmental Science 6, no. 10 (2013): 2811-21.

${ }^{42}$ Herman Trabish, "NV Energy Buys Utility-Scale Solar at Record Low Price under 4 Cents/kWh," Utility Dive, July 9, 2015, http://www.utilitydive.com/news/nv-energy-buys-utility-scale-solar-at-record-low-price-under-4-centskwh/401989/; Stephen Lacey, "Cheapest Solar Ever: Austin Energy Gets 1.2 Gigawatts of Solar Bids for Less Than 4 Cents,” June 30, 2015,

http://www.greentechmedia.com/articles/read/cheapest-solar-ever-austin-energy-gets-1.2-gigawatts-of-solar-bids-for-less; Mark Bolinger, Samantha Weaver, and Jarett Zuboy, "Is \$50/MWh Solar for Real? Falling Project Prices and Rising Capacity Factors Drive Utility-Scale PV Toward Economic Competitiveness" (Lawrence Berkeley National Laboratory, 2015),

https://emp.lbl.gov/sites/all/files/lbnl-183129_0.pdf.

${ }^{43}$ Ryan Wiser and Mark Bolinger, "2014 Wind Technologies Market Report” (U.S. Department of Energy, August 2015).

${ }^{44}$ Lazard, "Lazard's Levelized Cost of Energy Analysis - Version 10.0."

${ }^{45}$ EIA, "Domestic Market for Distributed Wind Turbines Faces Several Challenges - Today in Energy,” 2016, http://www.eia.gov/todayinenergy/detail.cfm?id=22692.

${ }^{46}$ Lawrence Berkeley National Lab, "Electricity End Uses, Energy Efficiency, and Distributed Energy Resources Baseline," 2017.

${ }^{47}$ EIA, “EIA's Energy in Brief: How Much U.S. Electricity Is Generated from Renewable Energy?"

${ }^{48}$ BNEF, "New Energy Outlook 2015" (Bloomberg New Energy Finance, 2015), https://about.bnef.com/landing-pages/newenergy-outlook-2015-americas/; SEIA, “Solar Market Insight 2015 Q3,” Solar Energy Industry Association, 2015,

http://www.seia.org/research-resources/solar-market-insight-2015-q3.

${ }^{49}$ Lazard, "Lazard's Levelized Cost of Energy Analysis - Version 10.0."

${ }^{50}$ Bassett et al., "Revolution Now: The Future Arrives for Five Clean Energy Technologies - 2015 Update."

${ }^{51}$ DOE, "Wind Vision: A New Era for Wind Power in the United States" (U.S. Department of Energy, March 12, 2015); Wiser and Bolinger, "2014 Wind Technologies Market Report."

52 Eric Lantz et al., "Implications of a PTC Extension on US Wind Deployment" (National Renewable Energy Laboratory, 2014), http://www.nrel.gov/docs/fy14osti/61663.pdf; Wiser and Bolinger, "2014 Wind Technologies Market Report."

${ }^{53}$ M Milligan et al., "Review and Status of Wind Integration and Transmission in the United States: Key Issues and Lessons Learned” (National Renewable Energy Laboratory, 2015), http://www.nrel.gov/docs/fy15osti/61911.pdf.

${ }^{54}$ Jessica Katz and Jaquelin Cochran, "Integrating Variable Renewable Energy into the Grid: Key Issues. Greening the Grid Initiative" (National Renewable Energy Laboratory, 2015), http://www.nrel.gov/docs/fy15osti/63033.pdf.

${ }_{55}$ Andrew Mills and Ryan Wiser, "Changes in the Economic Value of Variable Generation at High Penetration Levels: A Pilot Case Study of California” (Lawrence Berkeley National Laboratory, 2012), https://emp.lbl.gov/sites/all/files/lbnl-5445e.pdf.

${ }_{57}^{56}$ Katz and Cochran, "Integrating Variable Renewable Energy into the Grid: Key Issues. Greening the Grid Initiative."

${ }^{57}$ NERC, "Essential Reliability Services Task Force Measures Framework Report,” 2015, http://www.nerc.com/comm/Other/essntlrlbltysrvcstskfrcDL/ERSTF\%20Framework\%20Report\%20-\%20Final.pdf.

${ }^{58}$ FERC, "Essential Reliability Services and the Evolving Bulk-Power System-Primary Frequency Response" (Federal Energy Regulatory Commission, February 18, 2016), https://www.ferc.gov/whats-new/comm-meet/2016/021816/E-2.pdf.

59 Jay Apt and Paulina Jaramillo, "Variable Renewable Energy and the Electricity Grid" (Resources for the Future Press, Taylor \& Francis., n.d.), http://samples.sainsburysebooks.co.uk/9781317907671_sample_838873.pdf; EPRI, "Program on Technology Innovation: Fossil Fleet Transition with Fuel hanges and Large Scale Variable Renewable Integration," n.d., http://www.epri.com/abstracts/Pages/ProductAbstract.aspx?ProductId=000000003002006517; Chenye Wu, Gabriela Hug, and Soummya Kar, "Risk-Limiting Economic Dispatch for Electricity Markets with Flexible Ramping Products," IEEE Transactions on Power Systems 31, no. 3 (2016): 1990-2003.

${ }^{60}$ SNL, "SNL Office with Excel Add-In. Subscription Service."

${ }^{61}$ EIA, "Coal Made up More than 80\% of Retired Electricity Generating Capacity in 2015 - Today in Energy."

62 EPA, "Clean Power Plan for Existing Power Plants," U.S. Environmental Protection Agency, 2015,

https://www.epa.gov/cleanpowerplan/clean-power-plan-existing-power-plants.

${ }^{63}$ EPSA, "QER 1.2 Base Case."

${ }^{64}$ Ibid.

65 Ibid.

${ }^{66}$ Vipin Arora and Jozef Lieskovsky, "Electricity Use as an Indicator of U.S. Economic Activity" (U.S. Energy Information Administration, 2014), https://www.eia.gov/workingpapers/pdf/electricity_indicator.pdf.

${ }^{67}$ DOE, "Quadrennial Technology Review 2015," 2015.

${ }^{68}$ EIA, "U.S. Economy and Electricity Demand Growth Are Linked, but Relationship Is Changing - Today in Energy," U.S.

Energy Information Administration, March 22, 2013, http://www.eia.gov/todayinenergy/detail.cfm?id=10491.

${ }^{69}$ EIA, "Electric Power Monthly." 
${ }^{70}$ DOE, “Quadrennial Technology Review 2015,” 2015.

${ }^{71}$ EIA, "Monthly Energy Review."

${ }^{72}$ EIA, "Short-Term Energy Outlook."

${ }^{73}$ EIA, "U.S. Energy Demand Slows except for Industrial, Commercial Sectors - Today in Energy," U.S. Energy Information Administration, April 29, 2015, https://www.eia.gov/todayinenergy/detail.cfm?id=21012.

${ }^{74}$ EIA, "Electric Power Monthly."

${ }^{75}$ Bassett et al., "Revolution Now: The Future Arrives for Five Clean Energy Technologies - 2015 Update."

${ }^{76}$ EIA, “Annual Energy Outlook 2016."

${ }^{77}$ Ibid.

${ }^{78}$ J.H. Williams et al., "Pathways to Deep Decarbonization in the United States" (Sustainable Development Solutions Network and the Institute for Sustainable Development and International Relations, November 16, 2015), deepdecarbonization.org/wpcontent/uploads/2015/11/US_Deep_Decarbonization_Technical_Report.pdf.

${ }^{79}$ EIA, "Monthly Energy Review"; BLS, "Bureau of Labor Statistics Data."

${ }^{80}$ EIA, "How Many Power Plants Are There in the United States?," 2015, http://www.eia.gov/tools/faqs/faq.cfm?id=65\&t=2.

${ }^{81}$ TVA, "Coal-Fired Power Plant Schematic" (Tennessee Valley Authority, 2013),

http://holbert.faculty.asu.edu/eee463/FOSSIL.HTML.

${ }^{82}$ WNA, "Renewable Energy and Electricity," World Nuclear Assoication, September 2016, http://www.worldnuclear.org/information-library/energy-and-the-environment/renewable-energy-and-electricity.aspx.

${ }^{83}$ Jaquelin Cochran et al., "Integrating Variable Renewable Energy in Electric Power Markets" (National Renewable Energy Laboratory, 2012), http://www.nrel.gov/docs/fy12osti/53732.pdf; Lori Bird, Jaquelin Cochran, and Xi Wang, "Wind and Solar Energy Curtailment: Experience and Practices in the United States" (National Renewable Energy Laboratory, 2014),

http://www.nrel.gov/docs/fy14osti/60983.pdf; M Milligan et al., "Review and Status of Wind Integration and Transmission in the United States: Key Issues and Lessons Learned" (National Renewable Energy Laboratory, 2015),

http://www.nrel.gov/docs/fy15osti/61911.pdf.

${ }^{84}$ DOE, "Quadrennial Energy Review First Installment: Transforming U.S. Energy Infrastructures in a Time of Rapid Change," U.S. Department of Energy, April 2016, http://energy.gov/epsa/downloads/quadrennial-energy-review-first-installment.

${ }^{85}$ SNL, "SNL Office with Excel Add-In. Subscription Service," 2015, www.snl.com.

${ }^{86}$ Greg Brinkman, Debra Lew, and Paul Denholm, "Impacts of Renewable Generation on Fossil Fuel Unit Cycling: Costs and Emissions," 2012, http://www.nrel.gov/docs/fy12osti/55828.pdf; NETL, "Impact of Load Following on Power Plant Cost and Performance: Literature Review and Industry Interviews," 2012,

http://netl.doe.gov/File\%20Library/Research/Energy\%20Analysis/Publications/NETL-DOE-2013-1592-Rev1_20121010.pdf.

${ }^{87}$ EPRI, "Program on Technology Innovation: Fossil Fleet Transition with Fuel Changes and Large Scale Variable Renewable Integration," n.d., http://www.epri.com/abstracts/Pages/ProductAbstract.aspx?ProductId=000000003002006517; Lothar Balling, "Fast Cycling and Rapid Start-Up: New Generation of Plants Achieves Impressive Results" (Siemens AG. Modern Power Systems (Reprint), 2011), http:/www.energy.siemens.com/us/pool/hq/power-generation/power-plants/gas-fired-powerplants/combined-cycle-powerplants/Fast_cycling_and_rapid_start-up_US.pdf; GCSSI, "The Global Status of CCS: 2015 Summary Report." (GCSSI (Global CCS Institute), 2015),

http://hub.globalccsinstitute.com/sites/default/files/publications/196843/global-status-ccs-2015-summary.pdf.

${ }_{88}$ Jack Senthilvel, "Rapid Start and Flexible Operation - Emerging Technologies in Advanced Gas Turbine Combined Cycle Plants," 2012, http://pennwell.sds06.websds.net/2012/bangkok/pga/slideshows/T3S6O1-slides.pdf.

${ }^{89}$ EIA, “Average Utilization for Natural Gas Combined-Cycle Plants Exceeded Coal Plants in 2015 - Today in Energy,” U.S. Energy Information Administration, April 4, 2016, http://www.eia.gov/todayinenergy/detail.cfm?id=25652.

${ }^{90}$ DOE, “Quadrennial Technology Review 2015,” U.S. Department of Energy, 2015, http://energy.gov/under-secretary-scienceand-energy/quadrennial-technology-review-2015.

${ }_{91}$ EIA, "What Is the Efficiency of Different Types of Power Plants? - FAQ," U.S. Energy Information Administration, April 25, 2016, https://www.eia.gov/tools/faqs/faq.cfm?id=107\&t=3.

${ }^{92}$ EIA, “Annual Electric Utility Data - EIA-906/920/923 Data File,” U.S. Energy Information Administration, 2016, https://www.eia.gov/electricity/data/eia923/.

93 EIA, "Levelized Cost and Levelized Avoided Cost of New Generation Resources in the Annual Energy Outlook 2016," 2016, https://www.eia.gov/forecasts/aeo/electricity_generation.cfm.

${ }^{94}$ NREL, “Annual Technology Baseline and Standard Scenarios," 2015, http://www.nrel.gov/analysis/data_tech_baseline.html; EIA, "Levelized Cost and Levelized Avoided Cost of New Generation Resources in the Annual Energy Outlook 2016"; Lazard, "Lazard's Levelized Cost of Energy Analysis - Version 9.0," 2015, https:/www.lazard.com/media/2390/lazards-levelized-costof-energy-analysis-90.pdf.

95 EIA, "Wind Adds the Most Electric Generation Capacity in 2015, Followed by Natural Gas and Solar - Today in Energy," U.S. Energy Information Administration, March 23, 2016, http://www.eia.gov/todayinenergy/detail.cfm?id=25492.

${ }^{96}$ EIA, "Levelized Cost and Levelized Avoided Cost of New Generation Resources in the Annual Energy Outlook 2016"; Chris Namovicz, "Assessing the Economic Value of New Utility-Scale Renewable Generation Projects," 2013, https://www.eia.gov/conference/2013/pdf/presentations/namovicz.pdf.

${ }^{97}$ BNEF, "New Energy Outlook 2015" (Bloomberg New Energy Finance, 2015), https://about.bnef.com/landing-pages/newenergy-outlook-2015-americas/; Lazard, "Lazard's Levelized Cost of Energy Analysis - Version 9.0.” 
${ }_{98}^{98}$ EIA, "Levelized Cost and Levelized Avoided Cost of New Generation Resources in the Annual Energy Outlook 2016."

${ }^{99}$ Jayant Sathaye et al., "Renewable Energy in the Context of Sustainable Development," 2011, http://www.ipcc.ch/pdf/specialreports/srren/Chapter\%209\%20Renewable\%20Energy\%20in\%20the\%20Context\%20of\%20Sustainable\%20Development.pdf.

${ }^{100}$ Kelsi Bracmort, "Is Biopower Carbon Neutral?" (Congressional Research Service, 2015),

https://www.fas.org/sgp/crs/misc/R41603.pdf.

${ }^{101}$ Sathaye et al., "Renewable Energy in the Context of Sustainable Development."

102 WHO, "Health Effects of Particulate Matter. Policy Implications for Countries in Eastern Europe, Caucasus and Central Asia," World Health Organization Regional Office for Europe, Copenhagen, 2013,

http://www.euro.who.int/_data/assets/pdf_file/0006/189051/Health-effects-of-particulate-matter-final-Eng.pdf.

${ }^{103}$ Sathaye et al., "Renewable Energy in the Context of Sustainable Development."

${ }^{104}$ Jordan Macknick et al., "A Review of Operational Water Consumption and Withdrawal Factors for Electricity Generating Technologies," Contract 303 (2011): 275-3000; James Meldrum et al., "Life Cycle Water Use for Electricity Generation: A Review and Harmonization of Literature Estimates," Environmental Research Letters 8, no. 1 (2013): 15031, doi:10.1088/17489326/8/1/015031.

${ }^{105}$ Meldrum et al., "Life Cycle Water Use for Electricity Generation: A Review and Harmonization of Literature Estimates."

${ }^{106}$ DOE, "SunShot Vision Study” (U.S. Department of Energy, February 2012), http://energy.gov/sites/prod/files/2014/01/f7/47927.pdf.

${ }^{107}$ EIA, "Many Newer Power Plants Have Cooling Systems That Reuse Water - Today in Energy - U.S. Energy Information Administration (EIA)," U.S. Energy Information Administration, 2014, https://www.eia.gov/todayinenergy/detail.cfm?id=14971.

${ }^{108}$ Meldrum et al., "Life Cycle Water Use for Electricity Generation: A Review and Harmonization of Literature Estimates."

${ }^{109}$ Vasilis Fthenakis and Hyung Chul Kim, "Land Use and Electricity Generation: A Life-Cycle Analysis," Renewable and Sustainable Energy Reviews 13, no. 6 (2009): 1465-74.

${ }^{110}$ Sathaye et al., "Renewable Energy in the Context of Sustainable Development."

${ }^{111}$ Paul Denholm et al., "Land-Use Requirements of Modern Wind Power Plants in the United States" (National Renewable Energy Laboratory, 2009), http://www.nrel.gov/docs/fy09osti/45834.pdf; DOE, "Wind Vision: A New Era for Wind Power in the United States" (U.S. Department of Energy, March 12, 2015).

${ }^{112}$ Richard Schmalensee, “The Future of Solar Energy: A Personal Assessment," Energy Economics 52 (2015): S142-48, doi::10.1016/j.eneco.2015.08.012.

${ }^{113}$ GAO, "Tennessee Valley Authority: Full Consideration of Energy Efficiency and Better Capital Expenditures Planning Are Needed." (GAO (Government Accountability Office), 2011).

${ }^{114}$ EIA, "Federal Power Marketing Administrations Operate across Much of the United States - Today in Energy," U.S. Energy Information Administration, June 12, 2013, http://205.254.135.7/todayinenergy/detail.php?id=11651.

${ }^{115}$ EIA, “Annual Electric Power Industry Report (EIA-861 Data File)," U.S. Energy Information Administration, 2016, http://www.eia.gov/electricity/data/eia861/.

${ }^{116}$ ABB Velocity Suite, "Generating Unit Capacity Database," 2015.

${ }^{117}$ Rocio Uria-Martinez et al., "2014 Hydropower Market Report” (Department of Energy (DOE); Oak Ridge National Laboratory (ORNL), April 2015),

http://energy.gov/sites/prod/files/2015/05/f22/2014\%20Hydropower\%20Market\%20Report_20150512_rev6.pdf.

${ }_{118}^{11}$ Ibid.

${ }^{119}$ California Energy Comission, "Differences Between Publicly and Investor-Owned Utilities," California Energy Commission, 2016, http://www.energy.ca.gov/pou_reporting/background/difference_pou_iou.html.

${ }^{120}$ DOI, "Hydropower Program | Bureau of Reclamation," U.S. Department of the Interior, 2016, http://www.usbr.gov/power/edu/history.html.

${ }^{121}$ GAO, "Federal Power: The Evolution of Preference in Marketing Federal Power. Report to the Chairman, Committee on Resources, House of Representatives." (GAO (Government Accountability Office), 2001),

http://www.gao.gov/assets/240/231087.pdf.

${ }^{122}$ DOI, "Hydropower Program | Bureau of Reclamation."

${ }^{123}$ EIA, "Electric Power Monthly."

${ }^{124}$ EIA, "Short-Term Energy Outlook" (U.S. Energy Information Administration, September 7, 2016), http://www.eia.gov/forecasts/steo/.

${ }^{125}$ EIA, "Coal Made up More than 80\% of Retired Electricity Generating Capacity in 2015 - Today in Energy," U.S. Energy Information Administration, March 8, 2016, https://www.eia.gov/todayinenergy/detail.cfm?id=25272.

${ }^{126}$ EIA, "Natural Gas Expected to Surpass Coal in Mix of Fuel Used for U.S. Power Generation in 2016 - Today in Energy," U.S. Energy Information Administration, Match 2016, http://www.eia.gov/todayinenergy/detail.cfm?id=25392.

${ }^{127}$ Jeffery Logan and Stan Mark Kaplan, "Wind Power in the United States: Technology, Economic, and Policy Issues" (Congressional Research Service, 2008), http://fas.org/sgp/crs/misc/RL34546.pdf; Galen Barbose, "U.S. Renewables Portfolio Standards 2016 Annual Status Report” (Lawrence Berkeley National Laboratory, 2016), https://emp.lbl.gov/sites/all/files/lbnl1005057.pdf; C2ES, "Renewable Energy," Center for Climate and Energy Solutions, 2016, http://www.c2es.org/energy/source/renewables.

${ }^{128}$ DOE, "Renewable Electricity Production Tax Credit (PTC)," accessed September 28, 2016, http://energy.gov/savings/renewable-electricity-production-tax-credit-ptc. 
${ }^{129}$ Fred J Sissine, "Renewable Energy: Background and Issues for the 110th Congress" (Congressional Research Service, Library of Congress, 2008), http://nationalaglawcenter.org/wp-content/uploads/assets/crs/RL34162.pdf.

${ }^{130}$ DOE, "Business Energy Investment Tax Credit (ITC)," accessed September 28, 2016, http://energy.gov/savings/businessenergy-investment-tax-credit-itc.

${ }^{131}$ EIA, "Electric Power Monthly."

132 Ibid.

133 Ibid.

${ }^{134}$ Ibid.

${ }^{135}$ SNL, "SNL Office with Excel Add-In. Subscription Service."

${ }^{136}$ EIA, "Energy-Related Carbon Dioxide Emissions at the State Level, 2000-2013" (U.S. Energy Information Administration, 2015), http://www.eia.gov/environment/emissions/state/analysis/pdf/stateanalysis.pdf.

${ }^{137}$ EIA, "Electric Power Monthly."

${ }^{138}$ Ibid.

139 Ibid.

140 Ibid.

141 Ibid.

142 Ibid.

${ }^{143}$ EIA, "Electric Power Annual," 2016, http://www.eia.gov/electricity/annual/; EIA, "Electric Power Monthly."

144 EIA, "Electric Power Monthly."

${ }^{145}$ SNL, "SNL Office with Excel Add-In. Subscription Service."

${ }^{146}$ NERC, "NERC Website,” 2015, http://www.nerc.com/Pages/default.aspx.

${ }^{147}$ SNL, "SNL Office with Excel Add-In. Subscription Service."

148 Ibid.

149 Ibid.

${ }^{150}$ Ibid.

151 Ibid.

152 Ibid.

153 Ibid.

${ }^{154}$ Ibid.

155 Ibid.

156 Ibid.

157 Ibid.

158 Ibid.

159 Ibid.

160 Ibid.

${ }^{161}$ DOE, “Quadrennial Technology Review 2015,” 2015; NETL, “2014 Technology Readiness Assessment: A Checkpoint along a Challenging Journey," January 2015, https://www.netl.doe.gov/File\%20Library/Research/Coal/Reference\%20Shelf/DOE-

NETL-20151710-2014-Technology-Readiness-Assessment-Comprehensive.pdf; GCSSI, "Strategic Analysis of the Global Status of Carbon Capture and Storage. Report 4: Existing Carbon Capture and Storage Research and Development Networks around the World." (Global CCS Institute, Electric Power Institute, Worley Parsons, 2009),

http://www.globalccsinstitute.com/publications/strategic-analysis-global-status-carbon-capture-storage-Report-4; NETL, "NETL: Coal," 2016, http://www.netl.doe.gov/research/coal.

162 GCSSI, "The Global Status of CCS: 2015 Summary Report."

${ }^{163}$ EIA, "Electric Power Monthly."

${ }^{164}$ SNL, "SNL Office with Excel Add-In. Subscription Service."

${ }^{165}$ EIA, "Electric Power Monthly."

${ }^{166}$ SNL, "SNL Office with Excel Add-In. Subscription Service."

${ }^{167}$ Ventyx, "Monthly Plant Generation \& Consumption.," 2016.

${ }^{168}$ SNL, "SNL Office with Excel Add-In. Subscription Service."

${ }^{169}$ EIA, “Annual Electric Generator Data - EIA-860 Data File," U.S. Energy Information Administration, 2016, http://www.eia.gov/electricity/data/eia860/.

${ }^{170}$ EIA, "Levelized Cost and Levelized Avoided Cost of New Generation Resources in the Annual Energy Outlook 2016"; NETL, "Cost and Performance Baseline for Fossil Energy Plants Volume 1b: Bituminous Coal (IGCC) to Electricity," 2015, http://www.netl.doe.gov/energy-

analyses/temp/CostandPerformanceBaselineforFEPlantsVol1bBitCoalIGCCtoElecRev2bYearDollarUpdate_073115.pdf; Lazard, "Lazard's Levelized Cost of Energy Analysis - Version 9.0."

${ }^{171}$ NETL, "Current and Future Technologies for Power Generation with Post-Combustion Carbon Capture" (National Energy Technology Laboratory, 2012), http://netl.doe.gov/File\%20Library/Research/Energy\%20Analysis/Publications/NETL-DOE2012-1557.pdf; Vladimir Vaysman, Yuxin Lu, and Williams Summers, "Quality Guide Energy System Studies: Detailed Coal Specifications" (National Energy Technology Laboratory, January 1, 2012), http://www.netl.doe.gov/research/energyanalysis/search-publications/vuedetails?id=791. 
${ }^{172}$ EIA, "Coal Production Using Mountaintop Removal Mining Decreases by 62\% since 2008 - Today in Energy,” 2015, https://www.eia.gov/todayinenergy/detail.cfm?id=21952.

${ }^{173}$ EIA, “Annual Coal Report” (U.S. Energy Information Administration, March 23, 2016), http://www.eia.gov/coal/annual/.

${ }^{174}$ EIA, “Annual Energy Outlook 2016,” U.S. Energy Information Administration, 2016, http://www.eia.gov/forecasts/aeo/.

${ }^{175}$ Marianne Mintz, Chris Saricks, and Anant Vyas, "Coal-by-Rail. A Business-as-Usual Reference Case" (Argonne National Laboratory, 2015), http://energy.gov/sites/prod/files/2015/04/f22/QER\%20Analysis\%20-\%20Coal-by-Rail\%20Business-as-

Usual\%20Reference\%20Case.pdf.

${ }^{176}$ Ibid.

${ }^{177}$ Ibid.

${ }^{178}$ EPA, "What Is Acid Mine Drainage" (U.S. Environmental Protection Agency, 2015).

${ }^{179}$ Ibid.

${ }^{180}$ Lesley Sloss, “Coal Mine Site Reclamation” (International Energy Agency’s Clean Coal Centre, 2013),

https://www.usea.org/sites/default/files/022013_Coal\%20mine\%20site\%20reclamation_ccc216.pdf.

${ }^{181}$ WMA, "Mining Reclamation Practices," Wyoming Mining Association, 2016, http://www.wyomingmining.org/reclamation; AWF, "Mine-Land Stewardship Initiative," Appalachian Wildlife Foundation, 2015,

http://www.appalachianwildlife.com/mlsi.html; Sloss, "Coal Mine Site Reclamation"; Jason Hayes, "Returning Mined Land to Productivity Through Reclamation," CORNERSTONE MAG, 2015, http://cornerstonemag.net/returning-mined-land-toproductivity-through-reclamation/; Sarah Tincher, "Abandoned Mine Reclamation Could Renew WV Coalfields," The State Journal, Jjuly 2015, http:/www.statejournal.com/story/29617664/abandoned-mine-reclamation-could-renew-wv-coalfields.

${ }^{182}$ EIA, "Coal Production Using Mountaintop Removal Mining Decreases by $62 \%$ since 2008 - Today in Energy."

${ }^{183}$ EPA, “AP-42, CH 11.10: Coal Cleaning,” November 1995, http://www3.epa.gov/ttnchie1/ap42/ch11/final/c11s10.pdf.

${ }^{184}$ DOI, "Technical Position Paper: Potential of Impounded-Coal-Waste-Slurry Breakthroughs into Underground Mines; Issues and Answers" (U.S. Department of the Interior, 2011), http://www.arcc.osmre.gov/resources/pubs/2011-TechnicalPositionPaperCoalWasteSlurry.pdf.

${ }^{185}$ Eli Kintisch, "Was the Clean Air Act Intended to Cover CO2?" Science, http://www.sciencemag.org/news/2011/02/was-cleanair-act-intended-cover-co2.

${ }^{186}$ Ron D. Bell and Fred P. Buckingham, “An Overview of Technologies for Reduction of Oxides of Nitrogen from Combustion Furnaces” (MPR Associates, Inc., n.d.), http://www.mpr.com/uploads/news/nox-reduction-coal-fired.pdf.

${ }^{187}$ Ibid.

${ }^{188}$ NETL, "Cost and Performance Baseline for Fossil Energy Plants Volume 1b: Bituminous Coal (IGCC) to Electricity."

${ }^{189}$ EPA, "Cross-State Air Pollution Rule (CSAPR)," U.S. Environmental Protection Agency, 2011, https://www3.epa.gov/airtransport/CSAPR/index.html.

${ }^{190}$ EPA, "Clean Air Interstate Rule (CAIR)," U.S. Environmental Protection Agency, 2016,

https://archive.epa.gov/airmarkets/programs/cair/web/html/index.html.

${ }^{191}$ Albert L Moretti, Christopher S Jones, and Power-Gen Asia, “Advanced Emissions Control Technologies for Coal-Fired Power Plants" (Babcock \& Wilcox Power Generation Group, 2012).

${ }^{192}$ EPA, "Mercury and Air Toxics Standards (MATS)," Collections and Lists, U.S. Environmental Protection Agency, accessed September 29, 2016, https://www.epa.gov/mats.

${ }^{193}$ EPA, "Carbon Pollution Standards for New, Modified and Reconstructed Power Plants," Policies and Guidance, U.S.

Environmental Protection Agency, (May 2, 2016), https://www.epa.gov/cleanpowerplan/carbon-pollution-standards-newmodified-and-reconstructed-power-plants.

${ }^{194}$ EPA, "Clean Power Plan for Existing Power Plants," U.S. Environmental Protection Agency, 2015,

https://www.epa.gov/cleanpowerplan/clean-power-plan-existing-power-plants; NETL, "Cost and Performance Baseline for Fossil Energy Plants Volume 1b: Bituminous Coal (IGCC) to Electricity."

195 NETL, "Cost and Performance Baseline for Fossil Energy Plants Volume 1b: Bituminous Coal (IGCC) to Electricity."

${ }^{196}$ EPA, "Carbon Pollution Standards for New, Modified and Reconstructed Power Plants."

${ }^{197}$ EPA, "Final Rule: Disposal of Coal Combustion Residuals from Electric Utilities," U.S. Environmental Protection Agency, September 12, 2016, https://www.epa.gov/coalash/coal-ash-rule.

${ }^{198}$ EPA, "Carbon Pollution Standards for New, Modified and Reconstructed Power Plants."

199 EPA, "Clean Power Plan for Existing Power Plants."

${ }^{200}$ EIA, "Electric Power Annual."

${ }^{201}$ EIA, “Annual Energy Outlook 2016."

${ }^{202}$ EPSA, "QER 1.2 Base Case.” (U.S. Department of Energy, 2015).

${ }^{203}$ IEA, "World Energy Outlook 2015,” 2015, http://www.worldenergyoutlook.org/weo2015/.

${ }^{204}$ Ibid.

205 Ibid.

${ }^{206}$ DOE, "How Gas Turbine Power Plants Work," accessed December 2, 2015, http://energy.gov/fe/how-gas-turbine-powerplants-work.

${ }^{207}$ Thomas Overton, “World's Largest Fuel Cell Plant Opens in South Korea,” Power Magazine, February 25, 2014, http://www.powermag.com/worlds-largest-fuel-cell-plant-opens-in-south-korea/. 
${ }^{208}$ Taylor Kuykendall, "SNL: Did Natural Gas Topple King Coal in 2015? Race for Top Fuel Close at Year-End,” January 7, 2016, https://www.snl.com/InteractiveX/article.aspx?CDID=A-34983150-11059\&KPLT=4.

${ }^{209}$ EIA, "Electric Power Monthly."

${ }^{210}$ EIA, “Annual Electric Generator Data - EIA-860 Data File”; EIA, “Annual Electric Power Industry Report (EIA-861 Data File)."

${ }^{211}$ Balling, "Fast Cycling and Rapid Start-Up: New Generation of Plants Achieves Impressive Results"; Foster Wheeler Italiana, "Operating Flexibility of Power Plants with CCS" (GCSSI (Global CCS Institute), 2012),

http://hub.globalccsinstitute.com/sites/default/files/publications/104631/operating-flexibility-power-plants-ccs.pdf; EPRI,

"Program on Technology Innovation: Fossil Fleet Transition with Fuel hanges and Large Scale Variable Renewable Integration."

${ }^{212}$ Senthilvel, "Rapid Start and Flexible Operation - Emerging Technologies in Advanced Gas Turbine Combined Cycle Plants."

${ }^{213}$ GE, "7F.05 Heavy-Duty Gas Turbines | GE Power Generation," accessed September 29, 2016,

https://powergen.gepower.com/products/heavy-duty-gas-turbines/7f-05-gas-turbine.html.

${ }^{214}$ Wärtsilä, "Combustion Engine vs Gas Turbine- Startup Time," Wärtsilä, 2016, http://www.wartsila.com/energy/learningcenter/technical-comparisons/combustion-engine-vs-gas-turbine-startup-time; Wärtsilä, "Combustion Engine vs Gas Turbine-

Ramp Rate," Wärtsilä, 2016, http://www.wartsila.com/energy/learning-center/technical-comparisons/combustion-engine-vs-gasturbine-ramp-rate.

${ }^{215}$ SNL, "SNL Office with Excel Add-In. Subscription Service."

${ }^{216}$ EIA, "Electric Power Monthly."

${ }^{217}$ Neil Powell, “America’s Aging Generation Fleet,” POWER, January 28, 2013, http://www.powermag.com/americas-aginggeneration-fleet/.

${ }_{218}$ Ventyx, "Monthly Plant Generation \& Consumption."

${ }^{219}$ SNL, "SNL Office with Excel Add-In. Subscription Service."

${ }^{220}$ EIA, "Annual Electric Generator Data - EIA-860 Data File."

${ }^{221}$ EIA, "Levelized Cost and Levelized Avoided Cost of New Generation Resources in the Annual Energy Outlook 2016";

NETL, "Cost and Performance Baseline for Fossil Energy Plants Volume 1b: Bituminous Coal (IGCC) to Electricity"; Lazard, "Lazard's Levelized Cost of Energy Analysis - Version 9.0."

${ }^{222}$ EIA, "Natural Gas Pipeline Network - Transportation Process \& Flow," U.S. Energy Information Administration, 2009, http://www.eia.gov/pub/oil_gas/natural_gas/analysis_publications/ngpipeline/process.html.

${ }^{223}$ EIA, "Natural Gas Pipeline Network - U.S. Natural Gas Pipeline Network Map," U.S. Energy Information Administration, 2009, http://www.eia.gov/pub/oil_gas/natural_gas/analysis_publications/ngpipeline/ngpipelines_map.html.

${ }^{224}$ Donald Marron, "Oil And Natural Gas Prices Get Divorced," Forbes, January 10, 2012,

http://www.forbes.com/sites/energysource/2012/01/10/oil-and-natural-gas-prices-get-divorced/.

${ }^{225}$ EIA, “Average Annual Natural Gas Spot Price in 2015 Was at Lowest Level since 1999 - Today in Energy,” U.S. Energy Information Administration, January 5, 2016, http://www.eia.gov/todayinenergy/detail.cfm?id=24412.

${ }^{226}$ Gene L Theodori et al., "Hydraulic Fracturing and the Management, Disposal, and Reuse of Frac Flowback Waters: Views from the Public in the Marcellus Shale," 2014.

${ }^{227}$ Jeffrey Logan et al., "Natural Gas and the Transformation of the US Energy Sector: Electricity" (National Renewable Energy Laboratory, 2012), http://www.nrel.gov/docs/fy13osti/55538.pdf.

${ }^{228}$ John Veil, "U.S. Produced Water Volumes and Management Practices in 2012" (Ground Water Protection Council, April 2015).

${ }^{229}$ F Rall Walsh and Mark D Zoback, “Oklahoma's Recent Earthquakes and Saltwater Disposal," Science Advances 1, no. 5 (2015): e1500195.

${ }^{230}$ NETL, "2014 Technology Readiness Assessment: A Checkpoint along a Challenging Journey."

${ }^{231}$ Ibid.

${ }^{232}$ Adam R Brandt et al., "Methane Leaks from North American Natural Gas Systems," Science 343, no. 6172 (2014): 733-35, doi:10.1126/science.1247045; Douglas Arent et al., "A Review of Water and Greenhouse Gas Impacts of Unconventional Natural Gas Development in the United States," MRS Energy \& Sustainability 2 (2015): E4, doi:10.1557/mre.2015.5.

${ }^{233}$ Sathaye et al., "Renewable Energy in the Context of Sustainable Development"; Roberto Turconi, Alessio Boldrin, and Thomas Astrup, "Life Cycle Assessment (LCA) of Electricity Generation Technologies: Overview, Comparability and Limitations," Renewable and Sustainable Energy Reviews 28 (2013): 555-65.

${ }^{234}$ Arent et al., "A Review of Water and Greenhouse Gas Impacts of Unconventional Natural Gas Development in the United States."

${ }^{235}$ EIA, "Monthly Energy Review," U.S. Energy Information Administration, 2016, http://www.eia.gov/totalenergy/data/monthly/.

${ }^{236}$ Tanya Heikkila and Weible, "New York Fracking Ban Could Fuel Intensity of Debate in Colorado - The Denver Post," Denver Post, January 16, 2015, http://www.denverpost.com/2015/01/16/new-york-fracking-ban-could-fuel-intensity-of-debatein-colorado/.

${ }^{237}$ EPA, "EPA's Study of Hydraulic Fracturing for Oil and Gas and Its Potential Impact on Drinking Water Resources," Overviews and Factsheets, U.S. Environmental Protection Agency, (2015), https://www.epa.gov/hfstudy.

${ }^{238}$ Walsh and Zoback, "Oklahoma's Recent Earthquakes and Saltwater Disposal." 
${ }^{239}$ Matthew J Hornbach et al., "Causal Factors for Seismicity near Azle, Texas,” Nature Communications 6 (2015); Walsh and Zoback, "Oklahoma's Recent Earthquakes and Saltwater Disposal."

${ }^{240}$ Logan, Medlock, and Boyd, "A Review of Sector and Regional Trends in US Electricity Markets: Focus on Natural Gas."

${ }^{241}$ CPUC, "Aliso Canyon Risk Assessment Technical Report” (California Public Utilities Commission, 2016),

http://www.energy.ca.gov/2016 energypolicy/documents/2016-04-

08_joint_agency_workshop/Aliso_Canyon_Risk_Assessment_Technical_Report.pdf.

${ }^{242}$ Levitan \& Associates, "Gas-Electric System Interface Study, Target 2 Report, Evaluate the Capability of the Natural Gas

Systems to Satisfy the Needs of the Electric Systems" (DOE, 2015),

http://nebula.wsimg.com/c1a27fe57283e35da35df90f71a63f7a?AccessKeyId=E28DFA42F06A3AC21303\&disposition=0\&allo worigin $=1$.

${ }^{243}$ PJM Interconnection LLC, "Analysis of Operational Events and Market Impacts During the January 2014 Cold Weather Events," 2014, https://www.pjm.com/ /media/documents/reports/20140509-analysis-of-operational-events-and-market-impactsduring-the-jan-2014-cold-weather-events.ashx.

${ }^{244}$ FERC, "Coordination of the Scheduling Processes of Interstate Natural Gas Pipelines and Public Utilities. Docket No. RM142-000; Order 809” (Federal Energy Regulatory Commission, April 16, 2015), http://www.ferc.gov/whats-new/commmeet/2015/041615/M-1.pdf.

${ }^{245}$ EIA, "Monthly Energy Review."

${ }^{246}$ NETL, "U.S. Department of Energy Oil \& Gas Technical Assistance Capabilities: Strategic Energy Analysis and Planning," August 18, 2015, http://energy.gov/sites/prod/files/2015/09/f26/SEAP_TLF.pdf.

${ }^{247}$ NETL, "2014 Technology Readiness Assessment: A Checkpoint along a Challenging Journey."

${ }^{248}$ EPSA, "QER 1.2 Base Case."

${ }^{249}$ IEA, "World Energy Outlook 2015."

${ }^{250}$ EIA, "Electric Power Monthly."

${ }^{251}$ WNA, "Nuclear Power Reactors," World Nuclear Assoication, September 2016, http://www.world-nuclear.org/informationlibrary/nuclear-fuel-cycle/nuclear-power-reactors/nuclear-power-reactors.aspx.

${ }^{252}$ S. Bernhoft, "Program on Technology Innovation: Approach to Transition Nuclear Power Plants to Flexible Power Operations" (Electric Power Research Institute, 2014),

http://www.epri.com/abstracts/Pages/ProductAbstract.aspx?ProductId=000000003002002612; Mark Ruth, "Nuclear-Renewable Hybrid Energy System Market Analysis Plans,” 2016, http://www.nrel.gov/docs/fy16osti/66603.pdf.

${ }^{253}$ EIA, "Electric Power Monthly."

${ }^{254}$ Rick Tidball et al., "Cost and Performance Assumptions for Modeling Electricity Generation Technologies" (National

Renewable Energy Laboratory, November 2010), www.nrel.gov/docs/fy11 osti/48595.pdf.

${ }^{255}$ EIA, "Electric Power Monthly."

${ }^{256}$ Ibid.

${ }^{257}$ NRC, "Status of License Renewal Applications and Industry Activities," U.S. Nuclear Regulatory Commission, 2016, http://www.nrc.gov/reactors/operating/licensing/renewal/applications.html.

${ }^{258}$ NRC, "Subsequent License Renewal," 2016, http://www.nrc.gov/reactors/operating/licensing/renewal/subsequent-licenserenewal.html.

${ }^{259}$ EIA, "Wholesale Power Prices Decrease across the Country in 2015 - Today in Energy," U.S. Energy Information Administration, January 11, 2016, http://www.eia.gov/todayinenergy/detail.cfm?id=24492.

${ }^{260}$ SNL, "SNL Office with Excel Add-In. Subscription Service."

${ }^{261}$ EIA, "Annual Electric Generator Data - EIA-860 Data File."

${ }^{262}$ EIA, "Levelized Cost and Levelized Avoided Cost of New Generation Resources in the Annual Energy Outlook 2016"; NETL, "Cost and Performance Baseline for Fossil Energy Plants Volume 1b: Bituminous Coal (IGCC) to Electricity"; Lazard, "Lazard's Levelized Cost of Energy Analysis - Version 9.0."

${ }^{263}$ WNA, "Uranium Markets," World Nuclear Association, 2015, http://www.world-nuclear.org/information-library/nuclear-fuelcycle/uranium-resources/uranium-markets.aspx.

${ }^{264}$ DOE, "DOE Submits Its Defense-Related Uranium Mines Report to Congress," Department of Energy, August 2014, http://energy.gov/lm/articles/doe-submits-its-defense-related-uranium-mines-report-congress.

${ }^{265}$ Virginia Uranium, "Uranium Market \& U.S. Uranium Sources,” Virginia Uranium, 2012, http://www.virginiauranium.com/uranium-101/uranium-market-u-s-uranium-sources/.

${ }^{266}$ Cameco, “Uranium Price - Markets," Cameco, 2015, https://www.cameco.com/invest/markets/uranium-price.

${ }^{267}$ Ibid.

${ }^{268}$ WNA, "Environmental Aspects of Uranium Mining," World Nuclear Assoication, June 2014, http://www.worldnuclear.org/information-library/nuclear-fuel-cycle/mining-of-uranium/environmental-aspects-of-uranium-mining.aspx.

${ }^{269}$ BA Klinck et al., "The Environmental Impact of Metalliferous Mining: Korea, Chile and Zimbabwe Case Studies" (U.K. Department for International Development, January 1, 2002), https://www.gov.uk/dfid-research-outputs/the-environmentalimpact-of-metalliferous-mining-korea-chile-and-zimbabwe-case-studies-cr-02-190n.

${ }^{270}$ NRC, “Uranium Enrichment," U.S. Nuclear Regulatory Commission, July 16, 2016, http://www.nrc.gov/materials/fuel-cyclefac/ur-enrichment.html.

${ }^{271}$ Ibid. 
272 Ibid.

${ }^{273}$ WNA, "Environmental Aspects of Uranium Mining."

${ }^{274}$ NRC, "Uranium Enrichment."

275 Ibid.

${ }^{276}$ WNA, "Uranium Enrichment," World Nuclear Assoication, 2016, http://www.world-nuclear.org/information-library/nuclearfuel-cycle/conversion-enrichment-and-fabrication/uranium-enrichment.aspx.

${ }^{277}$ Martine Pauwels, "Nuclear Power as a Panacea for Climate Change? Experts Make Their Case on Each Side,"

www.ChinaPost.com.tw, December 6, 2015, http://www.chinapost.com.tw/commentary/afp/2015/12/06/452736/Nuclear-

power.htm.

${ }_{278}$ GAO, "Key Issues: Disposal of High-Level Nuclear Waste," U.S. Government Accountability Office, 2015,

http://www.gao.gov/key_issues/disposal_of_highlevel_nuclear_waste/issue_summary.

${ }^{279}$ EIA, "State Nuclear Profiles - Arizona,"

https://www.eia.gov/nuclear/state/arizona/.

${ }^{280}$ WNA, "Nuclear Power Economics," World Nuclear Assoication, July 2016, http://www.world-nuclear.org/informationlibrary/economic-aspects/economics-of-nuclear-power.aspx; Maggie Koerth-Baker, "Can America Turn Its Nuclear Power Back On?,” Popular Mechanics, January 26, 2016, http://www.popularmechanics.com/science/energy/a18818/can-us-nuclear-powerget-un-stuck/.

${ }^{281}$ David Schlissel and Bruce Biewald, "Nuclear Power Plant Construction Costs," 2008, http://www.psr.org/nuclearbailout/resources/nuclear-power-plant.pdf; Thomas Overton, "Even More Delays and Cost Overruns for Vogtle Expansion," Power Magazine, February 2, 2015, http:/www.powermag.com/even-more-delays-and-cost-overruns-for-vogtle-expansion/.

${ }^{282}$ Matthew Bandyk, "Fitch: 'Failure' of New Nuke Construction Means Fewer Plants" (SNL, 2015),

https://www.snl.com/InteractiveX/articleabstract.aspx?ID=33617164\&KPLT=2; Herman Trabish, "Nuclear Industry Darkened by Delays, Cost Overruns at Vogtle \& Summer Facilities," Utility Dive, August 24, 2015 ,

http://www.utilitydive.com/news/nuclear-industry-darkened-by-delays-cost-overruns-at-vogtle-summer-facil/404418/.

${ }^{283}$ DE Shropshire et al., "Advanced Fuel Cycle Economic Analysis of Symbiotic Light-Water Reactor and Fast Burner Reactor Systems" (Idaho National Laboratory, 2009).

${ }^{284}$ WNA, "Uranium Markets."

${ }^{285}$ WMA, "Uranium Mining," Wyoming Mining Association, 2016, http://www.wyomingmining.org/minerals/uranium/.

${ }^{286}$ Nuclear Energy Institute, "Quick Facts: Nuclear Energy in America," July 2015, http://www.nei.org/Master-DocumentFolder/Backgrounders/Fact-Sheets/Quick-Facts-Nuclear-Energy-in-America.

${ }^{287}$ DOE, "Nuclear Energy Research and Development Roadmap" (Department of Energy, April 2010), http://energy.gov/sites/prod/files/NuclearEnergy_Roadmap_Final.pdf.

${ }^{288}$ IAEA, "Nuclear Technology Review 2014” (International Atomic Energy Agency), accessed September 29, 2016, https://www.iaea.org/sites/default/files/ntr2014.pdf.

${ }^{289}$ WNA, "Nuclear Power Reactors"; DOE, "Quadrennial Technology Review 2015," 2015.

${ }^{290}$ WNA, "Nuclear Power in the USA," World Nuclear Association, September 26, 2016, http://world-nuclear.org/informationlibrary/country-profiles/countries-t-z/usa-nuclear-power.aspx.

${ }^{291}$ EIA, "Electric Power Annual."

${ }^{292}$ EPSA, "QER 1.2 Base Case."

${ }^{293}$ WNA, "Country Profiles," World Nuclear Assoication, accessed September 29, 2016, http://www.world-

nuclear.org/information-library/country-profiles.aspx; IAEA, "Power Reactor Information System," International Atomic Energy Agency, 2016, https://www.iaea.org/PRIS/home.aspx.

${ }^{294}$ IEA, "World Energy Outlook 2015."

${ }^{295}$ DOE, "Wind Vision: A New Era for Wind Power in the United States."

${ }^{296}$ EIA, "Electric Generator Dispatch Depends on System Demand and the Relative Cost of Operation - Today in Energy," U.S.

Energy Information Administration, August 17, 2012, http://www.eia.gov/todayinenergy/detail.cfm?id=7590.

${ }^{297}$ EIA, "Electric Power Monthly."

298 Ibid.

${ }^{299}$ Uria-Martinez et al., "2014 Hydropower Market Report."

${ }^{300}$ SNL, "SNL Office with Excel Add-In. Subscription Service."

${ }^{301}$ EIA, "Electric Power Monthly."

${ }^{302}$ SNL, "SNL Office with Excel Add-In. Subscription Service."

${ }^{303}$ Ibid.

${ }^{304}$ Uria-Martinez et al., "2014 Hydropower Market Report."

${ }^{305}$ EIA, "Levelized Cost and Levelized Avoided Cost of New Generation Resources in the Annual Energy Outlook 2016"; NETL, "Cost and Performance Baseline for Fossil Energy Plants Volume 1b: Bituminous Coal (IGCC) to Electricity"; Lazard, "Lazard's Levelized Cost of Energy Analysis - Version 9.0."

${ }^{306}$ Shih-Chieh Kao et al., "New Stream-Reach Development: A Comprehensive Assessment of Hydropower Energy Potential in the United States" (DOE, 2014), http://nhaap.ornl.gov/sites/default/files/ORNL_NSD_FY14_Final_Report.pdf. 
${ }^{307}$ Boualem Hadjerioua, Yaxing Wei, and Shih-Chieh Kao, “An Assessment of Energy Potential at Non-Powered Dams in the United States" (U.S. Department of Energy, April 2012),

http://nhaap.ornl.gov/sites/default/files/NHAAP_NPD_FY11_Final_Report.pdf.

${ }^{308}$ Sathaye et al., "Renewable Energy in the Context of Sustainable Development."

${ }^{309}$ NOAA, "What Is a Fish Ladder?" (National Oceanic and Atmospheric Administration, 2014), http://oceanservice.noaa.gov/facts/fish-ladder.html.

${ }^{310}$ FERC, "Pending Licenses and Relicenses for Pumped Storage Projects," Federal Energy Regulatory Commission, 2016, http://www.ferc.gov/industries/hydropower/gen-info/licensing/pump-storage/pending-licensed.pdf; NHA, "Challenges and Opportunities For New Pumped Storage Development” (National Hydropower Association, 2012), http://www.hydro.org/wpcontent/uploads/2014/01/NHA_PumpedStorage_071212b12.pdf.

${ }^{311}$ Andrea Copping et al., "Environmental Effects of Marine Energy Development around the World. Annex IV Final Report" (Pacific Northwest National Laboratory, 2013), http://tethys.pnnl.gov/publications/environmental-effects-marine-energydevelopment-around-world-annex-iv-final-report.

${ }^{312}$ Uria-Martinez et al., "2014 Hydropower Market Report."

${ }^{313}$ DOE, "Effects of Climate Change on Federal Hydropower (Report to Congress)," 2013, http://www1.eere.energy.gov/water/pdfs/hydro_climate_change_report.pdf.

${ }^{314}$ DOE, "Quadrennial Technology Review 2015,” $201 \overline{5}$.

${ }^{315}$ Ibid.

${ }^{316}$ Chad Augustine et al., "Renewable Electricity Futures Study. Volume 2: Renewable Electricity Generation and Storage Technologies" (NREL, MIT, 2012).

${ }^{317}$ DOE, "Quadrennial Technology Review 2015,” 2015.

${ }^{318}$ Ibid.

${ }^{319}$ Ibid.

${ }^{320}$ Uria-Martinez et al., "2014 Hydropower Market Report.”

${ }^{321}$ Ibid.

322 Ibid.

${ }^{323}$ V Stori, "Environmental Rules for Hydropower in State Renewable Portfolio Standards" (Clean Energy States Alliance, 2013), http://www.cesa.org/assets/2013-Files/RPS/Environmental-Rules-for-Hydropower-in-State-RPS-April-2013-final-v2.pdf.

${ }^{324}$ FERC, "Hydropower - Pumped Storage Projects," Federal Energy Regulatory Commission, 2015, http://www.ferc.gov/industries/hydropower/gen-info/licensing/pump-storage.asp.

${ }^{325}$ FERC, "Pending Licenses and Relicenses for Pumped Storage Projects."

${ }^{326}$ EIA, "Electric Power Annual."

${ }^{327}$ Uria-Martinez et al., "2014 Hydropower Market Report."

${ }^{328}$ EPSA, "QER 1.2 Base Case."

${ }^{329}$ IEA, "World Energy Outlook 2015."

${ }^{330}$ Ibid.

${ }^{331}$ Ryan Wiser and Mark Bolinger, “2014 Wind Technologies Market Report” (U.S. Department of Energy, August 2015).

${ }^{332}$ Chris Schaffer, "RE: Requesting Wind Turbine Qualification Criteria for On-Site Renewable Energy Scoring - Letter to U.S. Green Building Council" (Distributed Wind Energy Association, 2012), http://www.wind-

works.org/cms/fileadmin/user_upload/Files/Reports/DWEA_USGBC_8_20_12.pdf.

${ }^{333}$ Jose Zayas et al., "Enabling Wind Power Nationwide" (US Department fo Energy, 2015).

${ }^{334}$ Wiser and Bolinger, "2014 Wind Technologies Market Report."

${ }^{335}$ EIA, "Electric Power Monthly."

${ }^{336}$ AWEA, “American Wind Power Breezes Past 70-Gigawatt Milestone,” December 21, 2015, http://www.awea.org/MediaCenter/pressrelease.aspx?ItemNumber=8255.

${ }^{337}$ AWEA, “U.S. Wind Industry Fourth Quarter 2015 Market Report,” 2015, http://www.awea.org/4Q2015.

${ }^{338}$ DOE, "2014 Distributed Wind Market Report," U.S. Department of Energy, August 2015, http://energy.gov/eere/wind/downloads/2014-distributed-wind-market-report.

${ }^{339}$ EIA, "Electric Power Monthly."

${ }^{340}$ SNL, "SNL Office with Excel Add-In. Subscription Service."

${ }^{341}$ EIA, "Electric Power Monthly."

${ }^{342}$ SNL, "SNL Office with Excel Add-In. Subscription Service."

${ }^{343}$ Tidball et al., "NREL/SR-6A20-48595."

${ }^{344}$ SNL, "SNL Office with Excel Add-In. Subscription Service."

${ }^{345}$ EIA, "Levelized Cost and Levelized Avoided Cost of New Generation Resources in the Annual Energy Outlook 2016"; NETL, "Cost and Performance Baseline for Fossil Energy Plants Volume 1b: Bituminous Coal (IGCC) to Electricity"; Lazard, "Lazard's Levelized Cost of Energy Analysis - Version 9.0."

${ }^{346}$ Anthony Lopez, Billy Roberts, Donna Heimiller, Nate Blair and Gian Porro. "U.S. Renewable Energy Technical Potentials: A GIS-Based Analysis. NREL. 2012. http://www.nrel.gov/docs/fy12osti/51946.pdf

${ }^{347}$ NREL, "New 100-Meter Map Keeps Pace with Growing Wind Technology" (National Renewable Energy Laboratory, 2014). 
${ }^{348}$ Nawshad Haque et al., "Rare Earth Elements: Overview of Mining, Mineralogy, Uses, Sustainability and Environmental Impact," Resources 3, no. 4 (2014): 614-35.

${ }^{349}$ DOE, "Critical Materials Technology Assessment (Draft)" (Department of Energy, 2015), http://energy.gov/sites/prod/files/2015/02/f19/QTR\%20Ch8\%20-\%20Critical\%20Materials\%20TA\%20Feb-13-2015.pdf.

${ }^{350}$ EPA, “Chapter 11: Mineral Products Industry, AP 42," U.S. Environmental Protection Agency, 1995, https://www3.epa.gov/ttn/chief/ap42/ch11/index.html.

${ }^{351}$ NREL, "Life Cycle Greenhouse Gas Emissions from Electricity Generation (Fact Sheet)" (National Renewable Energy Laboratory, January 2013), http://www.nrel.gov/docs/fy13osti/57187.pdf.

352 Jamie Chapman et al., "Renewable Electricity Futures Study. Chapter 11: Wind Energy Technologies" (National Renewable Energy Laboratory, 2012), http://www.nrel.gov/docs/fy12osti/52409-2.pdf.

${ }^{353}$ GIZ, "Report on Forecasting, Concept of Renewable Energy Management Centres and Grid Balancing" (Deutsche Gesellschaft für Internationale Zusammenarbeit, 2015), http://mnre.gov.in/file-manager/UserFiles/draft-report-fscb-remcs.pdf.

${ }^{354}$ Milligan et al., "NREL/TP-5D00-61911."

${ }^{355}$ IEA, "Re-Powering Markets: Market Design and Regulation During the Transition to Low-Carbon Power Systems" (International Energy Agency, Organization for Economic Co-operation and Development, 2016), https://www.iea.org/newsroomandevents/pressreleases/2016/february/how-to-reinvent-electricity-markets-after-cop-21.html.

${ }^{356}$ Milligan et al., "NREL/TP-5D00-61911."

${ }^{357}$ Alexandra B Klass, "The Electric Grid at a Crossroads: A Regional Approach to Siting Transmission Lines," 2014, http://lawreview.law.ucdavis.edu/issues/48/5/Articles/48-5_Klass.pdf.

${ }^{358}$ Ibid.

${ }^{359}$ EIA, "Fewer Wind Curtailments and Negative Power Prices Seen in Texas after Major Grid Expansion - Today in Energy," U.S. Energy Information Administration, 2014, https://www.eia.gov/todayinenergy/detail.cfm?id=16831\#tabs SpotPriceSlider-1.

${ }^{360}$ Maria A Petrova, "NIMBYism Revisited: Public Acceptance of Wind Energy in the United States," Wiley Interdisciplinary Reviews: Climate Change 4, no. 6 (2013): 575-601, doi:10.1002/wcc.250.

${ }^{361}$ AWWI, "Wind Turbine Interactions with Wildlife and Their Habitats: A Summary of Research Results and Priority Questions." (American Wind and Wildlife Institute, 2014), https://awwi.org/wp-content/uploads/2014/05/AWWI-Wind-WildlifeInteractions-Factsheet-05-27-14.pdf.

362 AWEA, "U.S. Wind Industry Fourth Quarter 2015 Market Report”; Patrick Gilman et al., "Federal Interagency Wind Turbine Radar Interference Mitigation Strategy - Federal-Interagency-Wind-Turbine-Radar-Interference-Mitigation-Strategy02092016rev.pdf" (Department of Energy, 2016), http://energy.gov/sites/prod/files/2016/06/f32/Federal-Interagency-WindTurbine-Radar-Interference-Mitigation-Strategy-02092016rev.pdf.

363 Zayas et al., "Enabling Wind Power Nationwide."

${ }^{364}$ AWEA, "U.S. Wind Industry Fourth Quarter 2015 Market Report."

${ }^{365}$ Chapman et al., "Renewable Electricity Futures Study. Chapter 11: Wind Energy Technologies."

${ }^{366}$ Ibid.

${ }^{367}$ Milligan et al., "NREL/TP-5D00-61911."

${ }^{368}$ Abraham Ellis et al., "Reactive Power Performance Requirements for Wind and Solar Plants" (2012 IEEE Power and Energy Society General Meeting, IEEE, 2012), 1-8, http://ieeexplore.ieee.org/xpls/abs_all.jsp?arnumber=6345568; Robert Nelson,

"Active Power Control in Siemens Wind Turbines" (National Renewable Energy Laboratory, 2011); RJ Nelson, H Ma, and NM

Goldenbaum, "Fault Ride-through Capabilities of Siemens Full-Converter Wind Turbines" (2011 IEEE Power and Energy Society General Meeting, IEEE, 2011), 1-5, http://ieexplore.ieee.org/xpls/abs_all.jsp?arnumber=6039729; NREL, "Advanced Inverter Functions to Support High Levels of Distributed Solar: Policy and Regulatory Considerations (Brochure)" (National Renewable Energy Laboratory, 2014), http://www.nrel.gov/docs/fy15osti/62612.pdf; DOE, “Quadrennial Technology Review $2015, " 2015$.

${ }^{369}$ Eduard Muljadi et al., Understanding Inertial and Frequency Response of Wind Power Plants (IEEE, 2012),

http://ieeexplore.ieee.org/xpls/abs_all.jsp?arnumber=6316361; Francisco M Gonzalez-Longatt, "Activation Schemes of Synthetic Inertia Controller for Full Converter Wind Turbine Generators” (PowerTech, 2015 IEEE Eindhoven, IEEE, 2015), 1-5, http://ieeexplore.ieee.org/xpls/abs_all.jsp?arnumber=7232292.

${ }^{370}$ Zayas et al., "Enabling Wind Power Nationwide."

${ }^{371}$ Wiser and Bolinger, "2014 Wind Technologies Market Report."

372 DOE, NREL, and AWS Truepower, "WINDExchange: Potential Wind Capacity," September 9, 2015, http://apps2.eere.energy.gov/wind/windexchange/windmaps/resource_potential.asp\#states; DOE, "United States (48 Contiguous States) - Potential Wind Capacity Cumulative Area v. Gross Capacity Factor," Department of Energy, 2014, http://apps2.eere.energy.gov/wind/windexchange/windmaps/resource_potential.asp.

${ }^{373}$ DOE, “Advanced Manufacturing: Using Composites for Clean Energy,” Department of Energy, accessed September 28, 2016, http://www.energy.gov/eere/amo/advanced-manufacturing-using-composites-clean-energy.

${ }^{374}$ S.S. Wang, "Advanced Materials, Manufacturing and Design Integration for Large Offshore Wind Turbine Blades" (Applied \& Computational Mathematics Division Seminar Series, University of Houston, Houston, TX, 2013); Zayas et al., "Enabling Wind Power Nationwide."

${ }^{375}$ DOE, “Atmosphere to Electrons : Enabling the Wind Plant of Tomorrow" (Department of Energy, 2015), http://energy.gov/sites/prod/files/2016/01/f28/105197-A2E\%20Fact\%20Sheet_v10.pdf. 
${ }^{376}$ DOE, “Offshore Wind Research and Development," accessed September 28, 2016, http://energy.gov/eere/wind/offshorewind-research-and-development.

${ }^{377}$ DOE, "Renewable Electricity Production Tax Credit (PTC)."

${ }^{378}$ EIA, "Electric Power Annual."

${ }^{379}$ Wiser and Bolinger, "2014 Wind Technologies Market Report."

${ }^{380}$ Ibid.

${ }^{381}$ Ibid.

382 Zayas et al., "Enabling Wind Power Nationwide."

${ }^{383}$ Amy Grace et al., "Impact of Tax Credit Extensions for Wind and Solar" (Bloomberg New Energy Finance, 2015),

http://www.bbhub.io/bnef/sites/4/2015/12/2015-12-16-BNEF-US-solar-and-wind-tax-credit-impact-analysis.pdf.

${ }^{384}$ EPSA, "QER 1.2 Base Case."

${ }^{385}$ IEA, "World Energy Outlook 2015."

${ }^{386}$ Ibid.

${ }^{387}$ DOE, “Quadrennial Technology Review 2015,” 2015.

${ }^{388}$ Richard Bain et al., "Renewable Electricity Futures Study. Chapter 6: Biopower Technologies" (National Renewable Energy Laboratory, 2012).

${ }^{389}$ Ibid.

${ }^{390}$ DOE, "Biopower Technical Strategy Workshop Summary Report” (U.S. Department of Energy, 2010), http://energy.gov/sites/prod/files/2014/04/f14/biopower_workshop_report_december_2010.pdf.

${ }^{391}$ Amanda Reilly and Brittany Patterson, “Biomass Amendment Reignites Clean Power Plan Debate,” February 5, 2016, http://www.eenews.net/stories/1060031868.

${ }^{392}$ Kelsi Bracmort, "Biopower: Background and Federal Support" (Congressional Research Service, 2015),

http://nationalaglawcenter.org/wp-content/uploads/assets/crs/R41440.pdf; Bracmort, "CRS Report No. R41603."

${ }^{393}$ Daniel L Sanchez and Daniel M Kammen, “A Commercialization Strategy for Carbon-Negative Energy,” Nature Energy 1 (2016): 15002.

${ }^{394}$ DOE, "Quadrennial Technology Review 2015," 2015.

395 EIA, "Electric Power Monthly."

${ }^{396}$ EIA, "EIA's Energy in Brief: How Much U.S. Electricity Is Generated from Renewable Energy?," U.S. Energy Information Administration, 2016, http://www.eia.gov/energy_in_brief/article/renewable_electricity.cfm.

${ }^{397}$ EIA, "Electric Power Monthly."

${ }^{398}$ DOE, "Quadrennial Technology Review 2015," 2015.

${ }^{399}$ EIA, "Electric Power Annual."

400 Tidball et al., "NREL/SR-6A20-48595."

${ }^{401}$ SNL, "SNL Office with Excel Add-In. Subscription Service."

${ }^{402}$ EIA, "Electric Power Monthly."

${ }^{403}$ Walter Short et al., "Regional Energy Deployment System (ReEDS)" (National Renewable Energy Laboratory, 2011), http://www.nrel.gov/docs/fy12osti/46534.pdf.

${ }^{404}$ SNL, "SNL Office with Excel Add-In. Subscription Service."

405 Ibid.

${ }^{406}$ EIA, "Levelized Cost and Levelized Avoided Cost of New Generation Resources in the Annual Energy Outlook 2016";

NETL, "Cost and Performance Baseline for Fossil Energy Plants Volume 1b: Bituminous Coal (IGCC) to Electricity"; Lazard, "Lazard's Levelized Cost of Energy Analysis - Version 9.0."

${ }^{407}$ EIA, "Electric Power Monthly."

${ }^{408}$ EPA, "Wood Products Industry. Chapter 10.2, Chemical Wood Pulping” (U.S. Environmental Protection Agency, 1990).

${ }^{409}$ NETL, "Black Liquor," accessed December 7, 2015, http://www.netl.doe.gov/research/coal/energysystems/gasification/gasifipedia/blackliquor.

${ }^{410}$ NREL, "Dynamic Maps, GIS Data, and Analysis Tools - Biomass Maps,” 2015, http://www.nrel.gov/gis/biomass.html.

${ }^{411}$ EPA, "Energy Recovery from the Combustion of Municipal Solid Waste (MSW)," Overviews and Factsheets, U.S.

Environmental Protection Agency, (2014), https://www.epa.gov/smm/energy-recovery-combustion-municipal-solid-waste-msw.

${ }^{412}$ EIA, "Waste-to-Energy (Municipal Solid Waste),” December 13, 2015,

http://www.eia.gov/Energyexplained/?page=biomass_waste_to_energy.

${ }^{413}$ EIA, "Waste-to-Energy (Municipal Solid Waste)," U.S. Energy Information Administration, December 14, 2015, http://www.eia.gov/Energyexplained/?page=biomass_waste_to_energy.

${ }^{414}$ EPA, "Landfill Gas Energy Basics" (U.S. Environmental Protection Agency, 2014).

${ }^{415}$ Ibid.

${ }^{416}$ Ibid.

${ }^{417}$ Ibid.

${ }^{418}$ Water Environment Federation, "Biogas Data,” 2015, http://www.resourcerecoverydata.org/biogasdata.php.

${ }^{419}$ NREL, "Dynamic Maps, GIS Data, and Analysis Tools - Biomass Maps."

${ }^{420}$ National Research Council, "Electricity from Renewable Resources: Status, Prospects, and Impediments," 2008, http://www.nap.edu/catalog/12619/electricity-from-renewable-resources-status-prospects-and-impediments. 
${ }^{421}$ C2ES, "Biopower," Center for Climate and Energy Solutions, 2016, http://www.c2es.org/technology/factsheet/Biopower.

422 Ibid.

423 DOE, “Quadrennial Technology Review 2015,” 2015.

${ }^{424}$ Bracmort, "CRS Report No. R41603."

${ }^{425}$ DOE, "Quadrennial Technology Review 2015," 2015.

${ }^{426}$ DOE, "DOE-EE-0276"; Bain et al., "Renewable Electricity Futures Study. Chapter 6: Biopower Technologies."

${ }^{427}$ Bracmort, "CRS Report No. R41603."

${ }^{428}$ Ibid.

${ }^{429}$ IPCC, "Special Report on Renewable Energy Sources and Climate Change Mitigation" (Intergovernmental Panel on Climate Change, 2011), http://www.ipcc.ch/report/srren/; DOE, “Quadrennial Technology Review 2015,” 2015; ENGO Network on CCS, "Closing the Gap on Climate-Why CCS Is a Vital Part of the Solution"; Sanchez and Kammen, "A Commercialization Strategy for Carbon-Negative Energy."

${ }^{430}$ EPA, "Climate Change Indicators: Drought," Reports and Assessments, U.S. Environmental Protection Agency, (2015), https://www.epa.gov/climate-indicators/climate-change-indicators-drought\#fragment-2.

${ }^{431}$ Hekena Chum et al., "Bioenergy," IPCC Special Report on Renewable Enery Sources and Climate Change. Cambridge University Press, Cambridge, UK and New York, NY, USA, 2011, http://www.ipcc.ch/pdf/specialreports/srren/Chapter\%202\%20Bioenergy.pdf.

${ }^{432}$ Bain et al., "Renewable Electricity Futures Study. Chapter 6: Biopower Technologies."

${ }^{433}$ Bracmort, "CRS Report No. R41440."

${ }^{434}$ Bracmort, "CRS Report No. R41603”; IEA, "Potential for Biomass and Carbon Dioxide Capture and Storage,” 2011, http://www.eenews.net/assets/2011/08/04/document_cw_01.pdf.

${ }^{435}$ DOE, "DOE-EE-0276."

${ }^{436}$ DOE, "Research, Development, and Demonstration," U.S. Department of Energy, 2016, http://www.energy.gov/eere/bioenergy/research-development-and-demonstration.

${ }^{437}$ Bain et al., "Renewable Electricity Futures Study. Chapter 6: Biopower Technologies."

${ }^{438}$ Marcin Siedlecki, “CFB Gasification of Biomass,” 2010, https://cms.lnu.se/polopoly_fs/1.35422!CFB\%20Gasicication.pdf; D Barisano et al., "Steam/Oxygen Biomass Gasification at Pilot Scale in an Internally Circulating Bubbling Fluidized Bed Reactor," Fuel Processing Technology 141 (2016): 74-81, doi:10.1016/j.fuproc.2015.06.008.

${ }^{439}$ U.S. DRIVE, "Hydrogen Production Technical Team Roadmap" (Driving Research and Innovation for Vehicle efficiency and Energy sustainability (U.S. DRIVE), 2013),

http://www1.eere.energy.gov/vehiclesandfuels/pdfs/program/hptt_roadmap_june2013.pdf.

${ }^{440}$ EIA, "Southern States Lead Growth in Biomass Electricity Generation - Today in Energy," U.S. Energy Information Administration, May 25, 2016, http://www.eia.gov/todayinenergy/detail.cfm?id=26392.

${ }^{441}$ Bracmort, "CRS Report No. R41440."

${ }^{442}$ Bracmort, "CRS Report No. R41603."

${ }^{443}$ DOE, "DOE-EE-0276."

${ }^{444}$ Grace et al., "Impact of Tax Credit Extensions for Wind and Solar."

${ }^{445}$ EIA, "Electric Power Annual."

${ }^{446}$ EPSA, "QER 1.2 Base Case."

${ }^{447}$ IEA, "World Energy Outlook 2015."

448 Ibid.

${ }^{449}$ DOE, "Increased Solar and Wind Electricity Generation in California Are Changing Net Load Shapes)," U.S. Energy

Information Administration, December 9, 2014, https://www.eia.gov/todayinenergy/detail.cfm?id=19111.

${ }^{450}$ EIA, "Electric Power Monthly."

${ }^{451}$ EIA, "EIA Electricity Data Now Include Estimated Small-Scale Solar PV Capacity and Generation - Today in Energy," 2015, https://www.eia.gov/todayinenergy/detail.cfm?id=23972.

${ }^{452}$ EIA, "Electric Power Monthly."

453 Ibid.

${ }^{454}$ EIA, "California Has Nearly Half of the Nation's Solar Electricity Generating Capacity - Today in Energy," U.S. Energy Information Administration, February 5, 2016, https://www.eia.gov/todayinenergy/detail.cfm?id=24852.

${ }_{455}$ EIA, "Annual Electric Generator Data - EIA-860 Data File”; EIA, “Annual Electric Power Industry Report (EIA-861 Data File)."

${ }^{456}$ EIA, "Electric Power Annual."

${ }^{457}$ Dirk C Jordan and Sarah R Kurtz, "Photovoltaic Degradation Rates—an Analytical Review," Progress in Photovoltaics:

Research and Applications 21, no. 1 (2013): 12-29.

${ }^{458}$ SNL, "SNL Office with Excel Add-In. Subscription Service."

${ }^{459}$ EIA, "Electric Power Monthly."

460 Tidball et al., "NREL/SR-6A20-48595."

${ }^{461}$ EIA, "Electric Power Annual."

${ }^{462}$ Short et al., "NREL/TP-6A20-46534."

${ }^{463}$ SNL, "SNL Office with Excel Add-In. Subscription Service." 
${ }^{464}$ EIA, "Levelized Cost and Levelized Avoided Cost of New Generation Resources in the Annual Energy Outlook 2016"; NETL, "Cost and Performance Baseline for Fossil Energy Plants Volume 1b: Bituminous Coal (IGCC) to Electricity"; Lazard, "Lazard's Levelized Cost of Energy Analysis - Version 9.0."

${ }^{465}$ NREL, "NREL: Dynamic Maps, GIS Data, and Analysis Tools - Solar Maps," February 2, 2015, http://www.nrel.gov/gis/solar.html.

${ }^{466}$ Ibid.

${ }^{467}$ Dustin Mulvaney, "Hazardous Materials Used in Silicon PV Cell Production: A Primer," Process: Factory Environmental Management, 2013, http://www.solarindustrymag.com/online/issues/SI1309/index.htm.

${ }^{468}$ NREL, "Life Cycle Greenhouse Gas Emissions from Electricity Generation (Fact Sheet)."

${ }^{469}$ Ibid.

${ }^{470}$ MIT, “The Future of Solar Energy” (MIT Energy Initiative, 2015), http://energy.mit.edu/publication/future-solar-energy/.

${ }^{471}$ DOE, "SunShot Vision Study."

${ }^{472}$ Leroy J Walston et al., "A Review of Avian Monitoring and Mitigation Information at Existing Utility-Scale Solar Facilities" (Argonne National Laboratory (ANL), 2015).

${ }^{473}$ Ellis et al., "Reactive Power Performance Requirements for Wind and Solar Plants"; Nelson, "Active Power Control in Siemens Wind Turbines"; Nelson, Ma, and Goldenbaum, "Fault Ride-through Capabilities of Siemens Full-Converter Wind Turbines"; NREL, "Advanced Inverter Functions to Support High Levels of Distributed Solar: Policy and Regulatory Considerations (Brochure)."

${ }^{474}$ John D Kueck et al., "Local Dynamic Reactive Power for Correction of System Voltage Problems" (Oak Ridge National Laboratory, 2008), http://info.ornl.gov/sites/publications/files/Pub12786.pdf.

${ }^{475}$ Michael Döring, "Dealing with the $50.2 \mathrm{~Hz}$ Problem - Modern Power Systems," Modern Power Systems, accessed September 28, 2016, http://www.modernpowersystems.com/features/featuredealing-with-the-50.2-hz-problem/.

${ }^{476}$ Jens Bömer et al., "Impact of Large-Scale Distributed Generation on Network Stability during Over-Frequency Events \& Development of Mitigation Measures - Summary" (Institute of Combustion and Power Plant Technology (IFK) and Ecofys Germany GmbH, 2011), http://www.vde.com/en/fnn/Documents/2011-09 Ecofys IFK 50-2-Hz Summary.pdf.

${ }^{477}$ Jaquelin Cochran, Debra Lew, and Nikhil Kumarb, "Flexible Coal: Evolution from Baseload to Peaking Plant" (National Renewable Energy Laboratory; 21st Century Power Partnership, 2013), http://www.nrel.gov/docs/fy14osti/60575.pdf.

${ }^{478}$ Ibid.; Paul Denholm et al., "Overgeneration from Solar Energy in California: A Field Guide to the Duck Chart" (National Renewable Energy Laboratory, 2015), http://www.nrel.gov/docs/fy16osti/65023.pdf.

${ }^{479}$ Francisco Flores-Espino, "Compensation for Distributed Solar: A Survey of Options to Preserve Stakeholder Value" (NREL (National Renewable Energy Laboratory (NREL), 2015), http://www.nrel.gov/docs/fy15osti/62371.pdf; Christian Roselund, "Nevada Creates Separate Rate Class and Adds New Charges for Solar Owners," Pv Magazine, 2015, http://www.pvmagazine.com/news/details/beitrag/nevada-creates-separate-rate-class-and-adds-new-charges-for-solar-owners_100022555/.

${ }^{480}$ DOE, "Photovoltaics Research and Development," 2016, http://energy.gov/eere/sunshot/photovoltaics-research-anddevelopment.

${ }^{481}$ Ibid.

482 Ibid.; Christian Roselund, “The Disruptive Potential of Thin and Kerfless Wafers : Pv-Magazine,” 2014, http://www.pvmagazine.com/archive/articles/beitrag/the-disruptive-potential-of-thin-and-kerfless-wafers100016427/86/?tx_ttnews\%5BbackCat\%5D=248\&cHash=4cb9a5153dd6d10526f35c9ff676c161\#axzz3tmtuAaFT.

${ }^{\overline{483}}$ Paula Mints, "Photovoltaic Manufacturer Capacity, Shipments, Price \& Revenues 2014/2015," 2015, https://library.thesource.nrel.gov/sites/default/files/pdf_files/SPV\%20Supply1\%20Manufacturer\%20Shipments\%20Capacity\%20 Price\%20Revenue\%202014-2015.pdf.

${ }^{484}$ Cheryl Katz, "Will New Technologies Give Critical Boost to Solar Power?," e360, November 12, 2014, http://e360.yale.edu/feature/will_new_technologies_give_critical_boost_to_solar_power/2832/.

${ }^{485}$ Henry J Snaith, "Perovskite Solar Cells; Outshining Silicon,” 2015 , https://smartech.gatech.edu/handle/1853/54168; Varun Sivaram, Samuel D Stranks, and Henry J Snaith, “Outshining Silicon," Scientific American 313, no. 1 (2015): 54-59, doi:10.1038/scientificamerican0715-54.

${ }^{486}$ DOE, "Soft Costs," 2016, http://energy.gov/eere/sunshot/soft-costs.

${ }^{487}$ DOE, "Quadrennial Technology Review 2015," 2015.

${ }^{488}$ DOE, "Systems Integration," U.S. Department of Energy, 2016, http://energy.gov/eere/sunshot/systems-integration.

${ }^{489}$ DOE, "Concentrating Solar Power," U.S. Department of Energy, 2016, http://www.energy.gov/eere/sunshot/concentratingsolar-power.

${ }^{490}$ Philipp Beiter, "2014 Renewable Energy Data Book” (NREL and DOE, November 1, 2015), http://www.osti.gov/scitech/biblio/1226242-renewable-energy-data-book.

491 EIA, "Electric Power Annual."

${ }^{492}$ Grace et al., "Impact of Tax Credit Extensions for Wind and Solar"; Mike Munsell, "Investment Tax Credit Extension Would Increase US Solar Installations 54\% Through 2020," GTM Research, December 16, 2015, http://www.greentechmedia.com/articles/read/investment-tax-credit-extension-will-increase-solar-installations-54-throug. ${ }^{493}$ Barbose, "LBNL-1005057."

${ }^{494}$ SEIA and GTM Research, "Solar Market Insight 2014 Year-in-Review” (Solar Energy Industries Association, 2015), http://www.seia.org/research-resources/solar-market-insight-report-2014-q4. 
${ }^{495}$ EPSA, "QER 1.2 Base Case."

${ }^{496}$ IEA, "World Energy Outlook 2015."

${ }^{497}$ Ibid.

${ }^{498}$ Augustine et al., "Renewable Electricity Futures Study. Volume 2: Renewable Electricity Generation and Storage Technologies."

${ }^{499}$ DOE, "Quadrennial Technology Review 2015,” 2015.

${ }^{500}$ Augustine et al., "Renewable Electricity Futures Study. Volume 2: Renewable Electricity Generation and Storage Technologies."

${ }^{501}$ Pete Danko, "US Geothermal Stuck in the Mud, but 2014 Global Growth Boosts Industry," Breaking Energy, February 24, 2015, http://breakingenergy.com/2015/02/24/us-geothermal-stuck-in-the-mud-but-2014-global-growth-boosts-industry/.

${ }^{502}$ EIA, "Electric Power Annual."

${ }^{503}$ EIA, "Electric Power Monthly."

${ }^{504}$ EIA, "Electric Power Annual."

${ }^{505}$ DOE, "FORGE Background and Updates," 2015, http://energy.gov/eere/forge/forge-background-updates.

${ }^{506}$ SNL, "SNL Office with Excel Add-In. Subscription Service."

${ }^{507}$ EIA, "Electric Power Monthly."

${ }^{508}$ SNL, "SNL Office with Excel Add-In. Subscription Service."

${ }^{509}$ Ibid.

${ }^{510}$ EIA, "Levelized Cost and Levelized Avoided Cost of New Generation Resources in the Annual Energy Outlook 2016";

NETL, "Cost and Performance Baseline for Fossil Energy Plants Volume 1b: Bituminous Coal (IGCC) to Electricity"; Lazard, "Lazard's Levelized Cost of Energy Analysis - Version 9.0."

${ }^{511}$ DOE, "Chapter 4: Advancing Clean Electric Power Technologies, Technology Assessments - Geothermal Power," 2015; Colin F Williams et al., "Assessment of Moderate-and High-Temperature Geothermal Resources of the United States" (USGS, 2008), http://pubs.usgs.gov/fs/2008/3082/pdf/fs2008-3082.pdf.

${ }^{512}$ B Roberts, "Geothermal Resource of the United States,”2009, http://www.nrel.gov/gis/images/geothermal_resource2009final.jpg.

${ }^{513}$ Alison Holm, Dan Jennejohn, and Leslie Blodgett, "Geothermal Resources and Climate Emissions" (Geothermal Energy Association), accessed September 29, 2016, http://geo-

energy.org/reports/GeothermalGreenhouseEmissionsNov2012GEA_web.pdf.

${ }^{514}$ UCS, "Environmental Impacts of Geothermal Energy," Union of Concerned Scientists, 2015,

http://www.ucsusa.org/clean_energy/our-energy-choices/renewable-energy/environmental-impacts-geothermal-energy.html\#.V-

2 jbnovY4d.

${ }^{515}$ Ibid.

${ }^{516}$ Ernie Majer et al., "Protocol for Addressing Induced Seismicity Associated with Enhanced Geothermal Systems" (DOE, 2012), https://www1.eere.energy.gov/geothermal/pdfs/geothermal_seismicity_protocol_012012.pdf.

${ }^{517}$ Benjamin Matek, "Geothermal Energy Association Issue Brief: Firm and Flexible Power Services Available from Geothermal Facilities," 2015, http://geo-

energy.org/reports/2015/Firm\%20and\%20Flexible\%20Power\%20Services\%20from\%20Geothermal.pdf.

518 Thomas A Edmunds and Pedro Sotorrio, "Ancillary Service Revenue Potential for Geothermal Generators in California," 2020, 26-28, https://pangea.stanford.edu/ERE/db/GeoConf/papers/SGW/2015/Edmunds.pdf.

${ }^{519}$ Benjamin Matek, "2015 Annual U.S. \& Global Geothermal Power Production Report,” 2015, http://geo-

energy.org/reports/2015/2015\%20Annual\%20US\%20\%20Global\%20Geothermal\%20Power\%20Production\%20Report\%20Draft \%20final.pdf; Danko, "US Geothermal Stuck in the Mud, but 2014 Global Growth Boosts Industry"; GEA, "Geothermal Energy Association Issue Brief: Firm and Flexible Power Services Available from Geothermal Facilities" (Geothermal Energy Association, 2015), http://geoenergy.org/reports/2015/Firm\%20and\%20Flexible\%20Power\%20Services\%20from\%20Geothermal.pdf.

${ }^{520}$ Anna Wall and Katherine Young, "Doubling Geothermal Generation Capacity by 2020: A Strategic Analysis," National Renewable Energy Laboratory, 2016.

${ }^{521}$ Luke Pettyjohn, "The Opposition to Alternative Energy Progress: Why It Feels Like Running against the Wind," 2015, http://studentorgs.law.unc.edu/documents/elp/2014/pettyjohnelp.pdf; Alyssa Kagel, "The State of Geothermal Technology Part II: Surface Technology” (Geothermal Energy Association, 2008), http://www.geoenergy.org/reports/Geothermal\%20Technology\%20-\%20Part\%20II\%20\%28Surface\%29.pdf.

${ }^{522}$ John Ziagos et al., "A Technology Roadmap for Strategic Development of Enhanced Geothermal Systems," 2013, 11-13, http://www.osti.gov/servlets/purl/1219933/.

${ }^{523}$ C2ES, "Enhanced Geothermal Systems," Center for Climate and Energy Solutions, 2015, http://www.c2es.org/technology/factsheet/EGS.

${ }^{524}$ Ziagos et al., "A Technology Roadmap for Strategic Development of Enhanced Geothermal Systems"; Benjamin R Phillips et al., "A Roadmap for Strategic Development of Geothermal Exploration Technologies," 2013, 11-13, http://energy.gov/sites/prod/files/2014/02/f7/exploration_technical_roadmap2013.pdf.

${ }^{525}$ DOE, "FORGE Background and Updates." 
${ }^{526}$ See, for example, Geothermal Energy Association, "Statement of the Geothermal Energy Association to the House Ways and Means Committee,” 2012, https://waysandmeans.house.gov/UploadedFiles/Geothermal_Energy_Assoc. FC42612.pdf, and Geothermal Energy Association, "2016 Annual U.S. and Global Geothermal Power Production Report," 2016, http://geoenergy.org/reports/2016/2016\%20Annual\%20US\%20Global\%20Geothermal\%20Power\%20Production.pdf.

${ }^{527}$ EIA, "Electric Power Annual."

${ }^{528}$ McDermott Will \& Emery, "Extension of Renewable Energy Tax Incentives" (McDermott Will \& Emery Thought Leadership, November 22, 2015), https:/www.mwe.com/en/thought-leadership/publications/2015/12/extension-of-renewableenergy-tax-incentives.

${ }^{529}$ EPSA, "QER 1.2 Base Case."

${ }^{530}$ Danko, "US Geothermal Stuck in the Mud, but 2014 Global Growth Boosts Industry."

${ }^{531}$ IEA, "World Energy Outlook 2015."

${ }^{532}$ EIA, "Electric Power Monthly."

${ }^{533}$ EIA, "Annual Electric Generator Data - EIA-860 Data File”; EIA, “Annual Electric Power Industry Report (EIA-861 Data File)."

${ }^{534}$ EIA, "Electric Power Monthly."

535 Ibid.

${ }^{536}$ Ibid.

${ }^{537}$ SNL, "SNL Office with Excel Add-In. Subscription Service."

${ }^{538}$ EIA, "Annual Electric Generator Data - EIA-860 Data File."

${ }^{539}$ EIA, "U.S. Field Production of Crude Oil, Monthly," U.S. Energy Information Administration, 2016, https://www.eia.gov/opendata/qb.cfm?sdid=PET.MCRFPUS1.M.

${ }^{540}$ EIA, “U.S. Crude Oil Rotary Rigs in Operation," U.S. Energy Information Administration, 2016, http://www.eia.gov/dnav/ng/hist/e_ertrro_xr0_nus_cm.htm.

${ }^{541}$ EIA, "How Much Oil Consumed by the United States Comes from Foreign Countries? - FAQ," U.S. Energy Information Administration, March 8, 2016, http://www.eia.gov/tools/faqs/faq.cfm?id=32\&t=6.

${ }^{542}$ EIA, "U.S. Product Supplied of Crude Oil and Petroleum Products," U.S. Energy Information Administration, 2016, http://www.eia.gov/dnav/pet/hist/LeafHandler.ashx?n=PET\&s=MTTUPUS1\&f=A.

${ }^{543}$ EIA, "U.S. Imports by Country of Origin," http://www.eia.gov/dnav/pet/pet move impcus a2 nus ep00 im0 mbblpd a.htm and EIA, "Petroleum and Other Liquids," http://www.eia.gov/dnav/pet/hist/LeafHandler.ashx?n=PET\&s=WTTNTUS2\&f=4.

${ }_{544}^{5}$ EIA, “U.S. Energy Mapping System," U.S. Energy Information Administration, 2016, https://www.eia.gov/state/maps.cfm.

${ }^{545}$ EIA, "Cushing, OK WTI Spot Price FOB (Dollars per Barrel)," U.S. Energy Information Administration, 2016, http://www.eia.gov/dnav/pet/hist/LeafHandler.ashx?n=PET\&s=RWTC\&f=D.

${ }^{546}$ HSRC (Hazardous Substance Research Centers), "Environmental Impact of the Petroleum Industry" (Hazardous Substance Research Centers, 2003), https://cfpub.epa.gov/ncer_abstracts/index.cfm/fuseaction/display.files/fileID/14522.

${ }^{547}$ EPA, "Fact Sheet: Final Petroleum Refinery Sector Risk and Technology Review and New Source Performance Standards Overview" (U.S. Environmental Protection Agency, 2016), https:/www.epa.gov/sites/production/files/2016-06/documents/20100682_factsheet_overview.pdf.

${ }^{548}$ EPA, "Petroleum Refining Effluent Guidelines," U.S. Environmental Protection Agency, 2016, https://www.epa.gov/eg/petroleum-refining-effluent-guidelines\#detailed.

${ }^{549}$ EIA, "How Much of U.S. Carbon Dioxide Emissions Are Associated with Electricity Generation? - FAQ," U.S. Energy

Information Administration, April 1, 2016, http://www.eia.gov/tools/faqs/faq.cfm?id=77\&t=11.

${ }^{550}$ Ibid.

${ }^{551}$ W Moomaw et al., "Special Report on Renewable Energy Sources and Climate Change Mitigation” (Intergovernmental Panel on Climate Change, 2011).

${ }_{552}$ DOE, "Quadrennial Energy Review First Installment: Transforming U.S. Energy Infrastructures in a Time of Rapid Change."

${ }^{553}$ DOE, "Oil \& Gas Research," accessed September 28, 2016, http://energy.gov/fe/science-innovation/oil-gas-research.

${ }_{555}^{55}$ DOE, "Enhanced Oil Recovery,” 2016, http://energy.gov/fe/science-innovation/oil-gas-research/enhanced-oil-recovery.

${ }^{555}$ Ibid.

${ }^{556}$ David Trimble and Frank Rusco, “Air Emissions and Electricity Generation at U.S. Power Plants,” n.d., www.gao.gov/assets/600/590188.pdf.

557 EIA, "Electric Power Annual."

${ }^{558}$ EPSA, "QER 1.2 Base Case."

${ }^{559}$ IEA, "World Energy Outlook 2015."

${ }^{560}$ Duke Energy, "How Do Coal-Fired Plants Work?," accessed December 3, 2015, https://www.duke-energy.com/aboutenergy/generating-electricity/coal-fired-how.asp.

${ }^{561}$ USGS, “A Coal-Fired Thermoelectric Power Plant,” March 17, 2014, http://water.usgs.gov/edu/wupt-coalplant-diagram.html.

${ }^{562}$ Duke Energy, "How IGCC Works," accessed December 3, 2015, https://www.duke-energy.com/about-us/how-igccworks.asp.

${ }^{563}$ NETL, “Typical IGCC Configuration,” accessed January 5, 2016, http://www.netl.doe.gov/research/coal/energysystems/gasification/gasifipedia/igcc-config.

${ }^{564}$ Ibid. 
${ }^{565}$ David M. Reiner, "Learning through a Portfolio of Carbon Capture and Storage Demonstration Projects," Nature Energy 1 (January 11, 2016): 15011.

${ }^{566}$ DOE, "Pre-Combustion Carbon Capture Research," accessed January 5, 2016, http://energy.gov/fe/science-innovation/carboncapture-and-storage-research/carbon-capture-rd/pre-combustion-carbon.

${ }^{567}$ NETL, "Post-Combustion CO2 Control," accessed January 5, 2016, http://www.netl.doe.gov/research/coal/carboncapture/post-combustion.

${ }_{568}$ CCSA, "What Is CCS?," accessed December 4, 2015, http://www.ccsassociation.org/what-is-ccs/.

${ }^{569}$ NETL, "Post-Combustion CO2 Control."

${ }^{570}$ Clean Air Task Force, "Conversion and CO2 Capture," accessed December 4, 2015,

http://www.catf.us/fossil/technology/conversion_and_capture/.

${ }^{571}$ Lower heating value (LHV) represents the thermal efficiency of combustion where water formed during combustion stays in a vapor state and does not include energy needed to condense it back to liquid water. Higher heating value (HHV) differs by assuming that water is in liquid form when it leaves the combustion phase and includes the heat of vaporization of water. LHV assumes that the fuel delivers less energy input than HHV, resulting in higher thermal efficiencies. In the United States, coal plant efficiencies are commonly reported using HHV and natural gas plants are reported using LHV metrics, making comparisons between the two complicated John P Longwell, Edward S Rubin, and J Wilson, "Coal: Energy for the Future," Progress in Energy and Combustion Science 21, no. 4 (1995): 269-360..

572 Beér, "High Efficiency Electric Power Generation: The Environmental Role."

573 Ibid.

574 Ibid.

${ }^{575}$ Ola Maurstad, "An Overview of Coal Based Integrated Gasification Combined Cycle (IGCC” (Technology; MIT LFEE 2005002 WP; Laboratory for Energy and the Environment, Massachusetts Institute of Technology, Citeseer, 2005).

${ }^{576}$ EIA, "Electricity Generating Capacity,” January 3, 2013, https://www.eia.gov/electricity/capacity/.

${ }^{577}$ Ibid.

${ }^{578}$ DOE, "Quadrennial Technology Review 2015."

${ }^{579}$ DOE, "How Gas Turbine Power Plants Work," accessed December 2, 2015, http://energy.gov/fe/how-gas-turbine-powerplants-work.

${ }_{580}$ Vinod Ramireddy, “An Overview of Combined Cycle Power Plant,” Electrical Engineering Portal, August 25, 2012, http://electrical-engineering-portal.com/an-overview-of-combined-cycle-power-plant.

${ }^{581}$ DOE, "Types of Fuel Cells," 2016, http://energy.gov/eere/fuelcells/types-fuel-cells\#pem\%20fc.

${ }^{582}$ Sreenath B Gupta et al., Natural Gas Fired Reciprocating Engines for Power Generation: Concerns and Recent Advances (INTECH Open Access Publisher, 2012).

583 Ibid.

${ }^{584}$ Stan Kaplan, Power Plants: Characteristics and Costs (DIANE Publishing, 2011).

${ }^{585}$ EPA, "Catalog of CHP Technologies," 2008.

${ }^{586}$ Debra Lew et al., "The Western Wind and Solar Integration Study Phase 2,” Contract 303 (2013): 275-3000.

${ }^{587}$ Kaplan, Power Plants: Characteristics and Costs.

${ }^{588}$ DOE, "How Gas Turbine Power Plants Work."

${ }^{589}$ World Nuclear Association, "Nuclear Power in the USA," November 2015, http://world-nuclear.org/info/CountryProfiles/Countries-T-Z/USA--Nuclear-Power/.

${ }^{590}$ NRC, “The Pressurized Water Reactor (PWR)," June 16, 2016, http://www.nrc.gov/reading-rm/basic-ref/students/animatedpwr.html.

${ }^{591}$ NRC, “The Boiling Water Reactor (BWR),” June 16, 2016, http://www.nrc.gov/reading-rm/basic-ref/students/animatedbwr.html.

${ }_{592}$ World Nuclear Association, "Nuclear Reactors,” November 2015, http://www.world-nuclear.org/info/Nuclear-FuelCycle/Power-Reactors/Nuclear-Power-Reactors/.

${ }^{593}$ Ibid.

594 Ibid.

${ }^{595}$ Ibid.

${ }^{596}$ Power Electrical \& High Voltage Engineering, "Power Generation," 2009, https://etrical.wordpress.com/power-generation/.

${ }^{597}$ DOE, "Get Pumped about Pumped Storage," April 27, 2015, http://energy.gov/eere/articles/get-pumped-about-pumpedstorage.

${ }^{598}$ DOE, "Hydropower Vision: A New Chapter for America's 1st Renewable Electricity Source," 2016,

http://energy.gov/eere/water/articles/hydropower-vision-new-chapter-america-s-1 st-renewable-electricity-source.

${ }^{599}$ FERC, "Licensed Pumped Storage Projects," October 1, 2015, http://www.ferc.gov/industries/hydropower/geninfo/licensing/pump-storage/licensed-projects.pdf.

${ }^{600}$ J Chapman et al., "Chapter 11: Wind Energy Technologies" (National Renewable Energy Laboratory, 2012).

${ }^{601}$ Wind regions are based dependent on the hub height and all speeds presented are based on $50 \mathrm{~m}$ hub height. Region I: $0.0-$ 5.6 m/s, Region II: $5.6-6.4$ m/s, Region III: $6.4-7.0$ m/s, Region IV: $7.0-7.5$ m/s NREL, "Wind Energy Resource Atlas of the United States," March 24, 2014, http://rredc.nrel.gov/wind/pubs/atlas/tables/1-1T.html.

${ }^{602}$ Chapman et al., "Renewable Electricity Futures Study." 
${ }^{603}$ Jose Zayas et al., "Enabling Wind Power Nationwide" (DOE, May 2015).

${ }^{604}$ DOE, "Biopower Fact Sheet," March 2010, http://www.energy.gov/sites/prod/files/2014/04/f14/biopower factsheet.pdf.

${ }^{605}$ R Bain et al., “"Biopower Technologies,' Chapter 6” (National Renewable Energy Laboratory, 2012).

${ }^{606}$ Ibid.

${ }^{607}$ Maile Lono-Batura, Yinan Qi, and Ned Beecher, "Biogas Production And Potential From U.S. Wastewater Treatment," December 2012, http://www.biocycle.net/2012/12/18/biogas-production-and-potential-from-u-s-wastewater-treatment/.

${ }^{608}$ EPA, "Basic Information about Energy Recovery from Waste | Municipal Solid Waste," April 14, 2014, http://www3.epa.gov/epawaste/nonhaz/municipal/wte/basic.htm.

${ }^{609}$ Ibid.

${ }^{610}$ Bain et al., "Renewable Electricity Futures Study, Vol. 2"; János M Beér, "High Efficiency Electric Power Generation: The

Environmental Role," Progress in Energy and Combustion Science 33, no. 2 (2007): 107-34.

${ }^{611}$ Bain et al., "Renewable Electricity Futures Study, Vol. 2."

${ }^{612}$ DOE, "Quadrennial Technology Review: An Assessment of Energy Technologies and Research Opportunities," September 2015, http://energy.gov/quadrennial-technology-review-2015.

${ }^{613}$ Dynamic Solar Tech, "How Solar Panels Work," 2015, http://dynamicsolartech.com/about-us/how-solar-panels-work/.

${ }^{614}$ Paula Mints, "Photovoltaic Manufacturer Capacity, Shipments, Price \& Revenues 2014/2015," 2015,

https://library.thesource.nrel.gov/sites/default/files/pdf_files/SPV\%20Supply $1 \% 20$ Manufacturer\%20Shipments\%20Capacity $\% 20$ Price\%20Revenue\%202014-2015.pdf.

${ }^{615}$ S Ranjan et al., "Silicon Solar Cell Production," Computers \& Chemical Engineering 35, no. 8 (2011): $1439-53$.

${ }^{616}$ First Solar, "Manufacturing Process," 2016, http://www.firstsolar.com/en/Technologies-and-Capabilities/PV-Modules/FirstSolar-Series-3-Black-Module/Manufacturing-Process.aspx.

${ }^{617}$ DOE, “Multijunction III-V Photovoltaics Research,” accessed January 13, 2016, http://energy.gov/eere/sunshot/multijunctioniii-v-photovoltaics-research.

${ }^{618}$ Fraunhofer ISE, "Photovoltaics Report,” November 17, 2015, https://www.ise.fraunhofer.de/en/downloads-englisch/pdf-filesenglisch/photovoltaics-report-slides.pdf.

${ }^{619}$ DOE, "Hybrid Organic-Inorganic Halide Perovskite Solar Cells," 2016, http://energy.gov/eere/sunshot/hybrid-organicinorganic-halide-perovskite-solar-cells.

${ }^{620}$ Henry J. Snaith, "Perovskite Solar Cells; Outshining Silicon,” Presentation, (November 10, 2015), https://smartech.gatech.edu/handle/1853/54168.

${ }^{621}$ DOE, "SunShot Vision Study - Chapter 5: Concentrating Solar Power: Technologies, Cost, and Performance," February 2012.

${ }^{622}$ SCHOTT North America, "Parabolic Trough Technology," 2015, http://www.us.schott.com/csp/english/parabolic-through-

technology.html.

${ }^{623}$ DOE, "SunShot Vision Study - Chapter 5: Concentrating Solar Power: Technologies, Cost, and Performance."

${ }^{624}$ DOE, "2014: The Year of Concentrating Solar Power,” May 2014.

${ }^{625}$ NREL, "NREL: Learning - Geothermal Electricity Production Basics,” July 25, 2015, http://www.nrel.gov/learning/re_geo_elec_production.html.

${ }^{626}$ DOE, "Electricity Generation," 2016, http://energy.gov/eere/geothermal/electricity-generation.

${ }^{627}$ Ibid.

${ }^{628}$ Ibid.

${ }^{629}$ C Augustine et al., "Geothermal Energy Technologies, Chapter 7" (National Renewable Energy Laboratory, 2012).

${ }^{630}$ DOE, "Quadrennial Technology Review: An Assessment of Energy Technologies and Research Opportunities."

${ }^{631}$ DOE, "Chapter 4: Advancing Clean Electric Power Technologies, Technology Assessments - Geothermal Power," 2015.

${ }^{632}$ Augustine et al., "Renewable Energy Futures Study, Vol. 2."

${ }^{633}$ Lazard, "Levelized Cost of Storage Analysis - Version 1.0," November 2015.

${ }^{634}$ AECOM Australia, "Energy Storage Study: Funding and Knowledge Sharing Priorities,” July 13, 2015.

${ }^{635}$ Ibid.

${ }^{636}$ Ibid.

${ }^{637}$ Lazard, "Levelized Cost of Storage Analysis - Version 1.0."

${ }^{638}$ AECOM Australia, "Energy Storage Study: Funding and Knowledge Sharing Priorities."

${ }^{639}$ Ibid.

${ }^{640}$ Ibid.

${ }^{641}$ Ibid.

${ }^{642}$ NETL, "Vanadium Redox Battery Demonstration Program," 2013, http://energy.gov/sites/prod/files/2015/05/f22/VanadiumRedoxBattery-Aug2013.pdf.

${ }^{643}$ AECOM Australia, "Energy Storage Study: Funding and Knowledge Sharing Priorities."

${ }^{644}$ Alissa Dehamna and Mackinnon Lawrence, "Navigant Research Leaderboard Report: Li-Ion Grid Storage," 2015; GTM Research, "US Energy Storage Monitor: Q3 2015 Executive Summary,” December 2015.

${ }^{645}$ Cara Marcy, "Nonhydro Electricity Storage Increasing as New Policies Are Implemented," April 3, 2015, https://www.eia.gov/todayinenergy/detail.cfm?id=20652.

${ }^{646}$ Ben Bovarnick, "Integrated Energy Storage in the United States" (Center for American Progress, December 2015).

${ }^{647}$ AECOM Australia, "Energy Storage Study: Funding and Knowledge Sharing Priorities." 